\title{
TEORIA DO FLUXO DA ÁGUA EM SOLOS NÃO SATURADOS: NOVOS CONCEITOS E APLICAÇÕES
}

\author{
CELSO LUIZ PREVEDELLO
}

Orientador: Prof. Dr. PAULO LEONEL LIBARDI

Tese apresentada à Escola Superior de Agricultura "Luiz de Queiroz", da Universidade de São Paulo, para obtenção do título de Doutor em Agronomia, Área de Concentração: Solos $\theta$ Nutrição de Plantas.

PIRACICABA

Estado de São Paulo - Brasil

Fevereiro - 1987 
Aos meus pais e irmãos;

A minha esposa, Beatriz, e aos nossos filthos:

Daniel, Luciano, Endrigo e Juliana,

D E D I C 


\section{AGRADECIMENTOS}

Meus agradecimentos às pessoas e às instituições que tornaram possível a realização deste trabalho, especialmente:

- Ao Prof. Dr. Paulo Leonel Libardi, pela orientação e amizade.

- Ao Prof. Dr. KZaus Reichardt, pela amizade e apoio.

- Aos amigos Sergio Oliveira Moraes, João Eduardo Pilotto, Sebastião Alberto de Oliveira, Jorge Kazuo Yomomoto, Reynaldo Luiz Victória, Luiz Antonio Martinelzi, Alvaro Pires da Silva, Rivaiz Salvador Lourenço, José Ademir Rodrigues e outros que, de alguma forma, colaboraram na realização deste trabalho.

- Aos Professores do Curso de Pós-Graduação em Solos e Nutrifão de Plantas da ESALQ/USP, pelos ensinamentos recebidos.

- Aos funcionārios Luiz Angelezi e Manoel Israel, pela ajuda no experimento de campo.

- A Universidade Federal do Paraná (Setor de Ciências Agrärias, Departamento de Engenharia e Tecnologia Rurais), e à Escola Superior de Agricultura "Luiz de Queiroz", pela oportunidade de realização do Curso.

- Ao Plano Institucional de Capacitacão de Docentes da CAPES, pela Bolsa de Estudos. 


\section{CONTEODO}

\section{pägina}

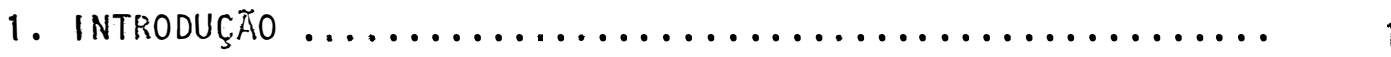

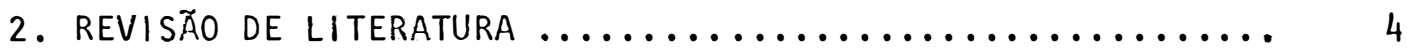

2. 1. Resumo da evolução histórica da teoria do fluxo de àgua em solos não saturados ................. 4

2.2. Principais métodos de determinação das funções condutividade e difusividade hidráulicas dos solos não saturados

2.2.1. Métodos baseados na condição de regime de flu-

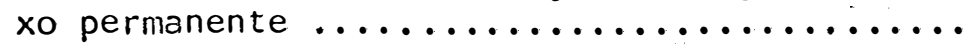

2.2.2. Métodos baseados na condição de regime de flu-

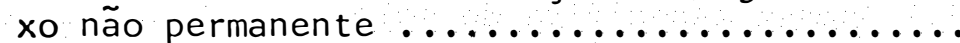

2.2.2.1. Utilizando a técnica da entrada ou

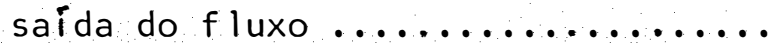

2.2.2.2. Utilizando a técnica do perfil ins-

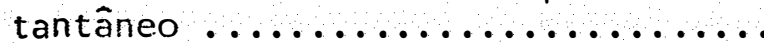

3. CONSIDERAÇð̋ES TEORICAS

3.1. Derivação da equação diferencial geral que governa o fluxo de àgua em solos não saturados ............. 14

3.2. Base teórica para a hipótese formulada ........... 18

3.3. Mêtodo proposto para a determinação da função difusividade hidrāulica global, $D_{g}(\Theta) \ldots \ldots \ldots \ldots \ldots \ldots$

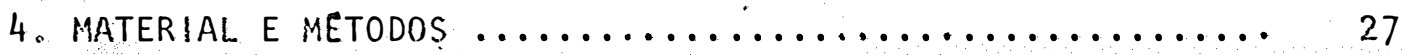

4.1. Considerações gerais ................... 27

4.2. Experimento en Terra Roxa Estruturada .......... 28

4.2.1. Local do experimento e caracteristicas do clima e solo ......................... 28

4.2.2. Instalação do experimento ............ 30

4.2.3. Saturação do solo na parcela experimental ... 37

4.2.4. Curvas de calibração da sonda de neutrons e perfis de umidade em função do tempo ........ 
4.2.5. Perfis de potencial matricial em função do

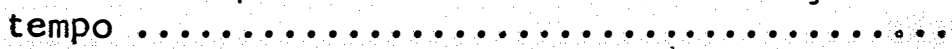

4.2.6. Uso da função "Spl ine" cúbica na obtenção dos perfis de umidade e de potencial matricial em função da profundidade, e nos cälculos das armazenagens e fluxos da àgua no solo ........ 43

4.2.7. Difusividades global, matricial e gravitacional, e condutividade hidráulica ...........

4.3. Experimento em Duna de Areia (dados fornecidos por CHO et alii, 1977)

5. RESULTADOS E DISCUSSÃO

5.1. Experimento em Terra Roxa Estruturada........... 51

5.1.1. Massa especifica do solo ............. 51

5.1.2. Curvas de calibração da sonda de neutrons ... 51

5.1.3. Perfis de umidade em função do tempo ....... 56

51.4. Perfis de potencial matricial em função do tempo .......................... 56

5.1.5. Perfis de umidade e de potencial matricial em função da profundidade ................. 108

5.1.6. Difusividades global, matricial, gravitacional, e condutividade hidräulica ........... 109

5.2. Experimento em Duna de Areia ................. 158

5.3. Roteiro para determinação da função $D_{g}(\Theta) \ldots \ldots \ldots \ldots 162$

6. CONCLUSÕES

APENDICE A

APENDICE B 


\section{RESUMO}

PREVEDELLO, C.L. Teoria do fluxo da ăgua em solos não saturados: novos conceitos e aplicações. 264 p. (Doutorado - Escola Superior de Agricultura "Luiz de Queiroz" da Universidade de São Paulo). Professor Orientador: Prof. Dr. Paulo Leonel Libardi.

A partir de duas funções matemāticas que expressani as dependências dos potenciais matricial e gravitacional (energia/peso) com a umidade e coordenada de posição vertical, são propostas novas equações para a quantificação e descrição do fluxo vertical da água em solos não saturados, em termos de novos conceitos de difusividades hidräulicas: matricial $\left(D_{m}\right)$, gravitacional $\left(D_{z}\right)$ e global $\left(D_{g}\right)$. Eproposto também um mētodo de determinação da difusividade hidrāulica global em função do conteūdo de āgua, em qualquer camada de um perfil de solo, desde que cada camada do perfil possa ser considerada hidraulicamente homogênea. 0 método de HILLEL et alii (Soil Sci., 114:395-400, 1972), foi utilizado para comprovar a validade da teoria proposta em dois solos distintos, um deles classificado como Terra Roxa Estruturada (Paleudalf óxico), localizado no campus de Piracicaba da Universidade de São Paulo (latitude $20^{\circ} 42^{\prime} 30^{\prime \prime} \mathrm{S}$; longitude $47^{\circ} 38^{\prime} 00^{\prime \prime} 0$ ), e o outro, como Duna de Areia (provavelmente Quartzipsamment), localizado dentro do Instituto de Pesquisas de Dunas de Areia, Fa- 
culdade de Agricultura da Universidade de Tottori, Japão (latitude $35^{\circ} 32^{\prime} \mathrm{N}$; longidude $\left.134^{\circ} 12^{\prime} \mathrm{L}\right)$. A teoria proposta é válida para meios porosos hidraulicamente homogêneos, podendo também, para propósitos prāticos, ser aplicada em meios aproximadamente homogêneos do ponto de vista hidrāulico. São analisados três critérios para identificação de meios porosos hidraulicamente homogêneos, e dos três: (a) morfolögico, (b) através da função $F$ (proposta no trabalho), e (c) da familia de curvas características, o primeiro nem sempre conduz a resultados satisfatórios, o segundo é o mais apropriado, e o terceiro é de interesse prātico, preferível ao primeiro, porém, menos preciso que o segundo. 


\section{SUMMARY}

PREVEDELLO, C.L. Theory of the water flow in unsaturated soils: New concepts and uses. 264 p. (Ph.D. - Escola Superior de Agricultura "Luiz de Queiroz", University of São Paulo, Piracicaba, SP, Brazil). Adviser professor: Paulo Leonel Libardi

From two mathematical functions of matric and gravitational potentials as a function of soil-water content and soil depth, new equations are proposed to quantify and to describe the vertical water flux in unsaturated soil, in terms of new concepts of matric, gravitational and global diffusivities. Amethod to determine the global water diffusivity as a function of soil-water content in any soil layer of a soil profile, provided that the layer can be considered homogeneous from the hydraulic point of view, is also proposed. The HILLEL et ali $i$ (Soil Sci., 114: 395-400, 1972) procedure was utilized to confirm the validity of the proposed theory in two different soils, one classified as Oxic Paleudalf, located in the campus of the University of São Paulo, in Piracicaba, SP, Brazil (2042'30"'s; $47^{\circ} 38^{\prime} 00^{\prime \prime} \mathrm{W} ; 580 \mathrm{~m}$ above sea level) and the other as a Quartzipsamment, located in Japan, Research Institute of Sand Dunes, College of Agriculture of the University of Tottori $\left(35^{\circ} 32^{\prime} \mathrm{N}, 13^{\circ} 12^{\prime} \mathrm{E}\right)$. The proposed theory is valid to homogeneous porous media from the hydraulic point of view 
but, to practical purposes, it can also be applied to approximately homogeneous porous media from that point of view. Three criteria to identify homogeneous porous media from the hydraulic point of view are analysed: (a) morphologic, (b) through the $F$ function (proposed in the work), and (c) from the family of characteristic curves. The first one not always lead to satisfactory results; the second is the more appropriated one; and the third one is of practical interest, preferable to the first, but less precise than the second. 


\section{INTRODUÇÃO}

DARCY (1856) foi o primeiro a estabelecer uma equação que possibilitasse a quantificação do fluxo de água em solos saturados. Ele verificou que a densidade de fluxo é igual ao produto do gradiente de potencial hidráulico dentro do solo, pela sua condutividade hidrāulica. Por outro lado, embora o fluxo de água em solos saturados seja importante, os solos geralmente não se encontram neste estado, mas mesmo assim, àrmazenam considerável quiantidade de agua, parte da qual deve ser utilizada pelas plantas. Os processos de fluxo de àgua em solos não saturados fażem parte de assuntos científicos terrestres do ciclo hidrolögico e de problemas relacionados com irrigação, ecologia de plantas, e com a biologia da fauna e flora do so10. Processos especificos de grande interesse e importância incluem: infiltração, redistribuição, evaporação e retenção de ãgua pelos solos, e a extração de água pelas plantas. Contudo, nas aplicações quantitativas da teoria do fluxo em tais processos, quando se visa entendê-los com profundidade e obter uma maior eficiência no uso da àgua e dos insumos na agricultura, há necessidade do conhecimento das características hidráulicas dos solos envolvidos.

Em condições de não saturação, a primeira modificação na équação de DARCY (1856), envolve o reconhecimento de que os poros ocupados por ar reduzem a àrea efetiva ao fluxo, aumentando a tortuosidade do fluxo remanescente. Assim, a condutividade hidráulica em 
fluxos nao saturados, è menor que para fluxos saturados, e dependente do conteúdo de água ou potencial matricial do meio Argumentos desse tipo foram primeiramente considerados por BUCKINGHAM (1907), com base na analogia com fluxos de calor e elētrico, sem menção à equação de DARCY (1856). A conexão com a equação de DARCY (1856) foi notada posteriormente por ISRAELSEN (1927); e RICHARDS (1961), bem como SWARTZENDRUBER $(1966,1969)$, têm chamado esta equação de fluxo de água em solos não saturados como "equação de Buckingham-Darcy". BUCKINGHAM (1907) introduziu ainda uma nova função na teoria do fluxo de āgua em solos não saturados (embora sem dar nome a ela), definida como a razão entre a condutividade hidräulica e a capacidade específica de àgua, essa obtida pela tangente na curva de retenção para um dado valor de umidade ou potencial matricial. Mais tarde, essa função foi chamada de difusividade da água, por CHILDS \& COLLIS-GEORGE (1948).

RICHARDS (1931) combinou a equação de Buckingham-Darcy com a equação da continuidade e obteve a equação diferencial geral que governa o fluxo de água em solos não saturados, explicita e implicitamente em termos das funções condutividade e difusividade, respectivamente.

Todavia, se por um lado o conceito de difusividade trouxe vantagens, por outro trouxe tambëm desvantagens. Vantagens na quantificação do fluxo dos processos na direção horizontal (definido simplesmente como o produto da difusividade pelo gradiente de umidade, dispensando o uso de instrumentos de recursos limitados, como os tensiômetros), e no tratamento matemático analítico e experimental desses processos, onde a equação diferencial geral do fluxo expressa em termos da difusividade, encontra muitas soluções jā disponíveis (por exemplo, CARSLAW \& JAEGER, 1976; CRANK, 1975), quando envolvem 
condições iniciais e de contorno aplicáveis aos processos de fluxo de ägua. Desvantagens na quantificação do fluxo dos processos na direção vertical (sendo função de ambas: condutividade e difusividade), e no tratamento matemātico analítico desses processos, onde a equação diferencial geral do fluxo resulta em soluções altamente complexas.

Assim, embora o conceito de difusividade como originalmente proposto por BUCKINGHAM (1907) tenha trazido grandes contribuições à teoria do fluxo não saturado de āgua na direção horizontal, este conceito parece merecer ainda novos estudos, devendo ser revisto e ampliado, visando os mesmos objetivos para a direção vertical. Esta situação é altamente desejāvel, porquanto a maioria dos processos de fluxo no solo sob condições principalmente de campo, realizam-se na presença do potencial gravitacional.

Dessa forma, a partir da definição de duas funções matemäticas que expressam as dependências dos potenciais matricial e gravitacional coma umidade e coordenadas de posição vertical e, admitindo a validade da equação de Buckingham-Darcy para a quant if icação do fluxo de āgua em solos não saturados, este trabalho teve por objetivos:

i) propor a introdução de novos conceitos de difusividades hidrāulicas na teoria do fluxo de āgua em solos não saturados;

ii) propor uma nova equação para a quantificação e para a descrição do fluxo vertical da āgua em solos não saturados, em termos de um novo conceito de difusividade hidräulica global;

i ii) propor um método de determinação da difusividade hidrāulica global em função do conteúdo de āgua, em qualquer camada de um perfil de solo, desde que cada camada do perfil possa ser considerada hidraulicamente homogênea; e

iv) comprovar a validade da teoria proposta. 


\section{REV ISÃO DE LITERATURA}

Neste capítulo é apresentado primeiramente um resumo dos principais trabalhos científjcos que marcaram a evolução histórica da teoria do fluxo de āgua em solos não saturados, cujas contribuições foram decisivas para o estabelecimento das bases teóricas gerais. Posteriormente, é apresentado um levantamento dos värios métodos disponíveis para a determinação das funções condutividade e difusividade da água nos solos não saturados, identificando-se os princípios, vantagens e desvantagens dos mesmos.

2.1. Resumo da evolução histórica da teoria do fluxo de ägua em solos. - não saturados

DARCY (1856), trabalhando com colunas de areia saturada de água, foi o primeiro a estabelecer uma equação que possibi litasse a quantificação do fluxo de água em solos saturados. Ele estabeleceu que a quantidade de água que passa por unidade de tempo e de área através de um solo, é igual ao produto do gradiente de potencial hidráulico dentro do solo, pela sua condutividade hidráulica.

SLICHTER (1898) combinou a equação de OARCY (1856) com a equação da continuidade e obteve a equação diferencial geral que governa o fluxo de àgua em solos saturados. 
Em condições de não saturação, a primeira modificação na equação de DARCY (1856) envolve o reconhecimento de que os poros ocupados por ar reduzem a ärea efetiva ao fluxo, aumentando a tortuosidade do fluxo remanescente. Assim, a condutividade hidrāulica em fluxos não saturados, è menor que para fluxos saturados, e dependente do conteüdo de àgua ou potencial matricial do meio. Argumentos desse tipo foram primeiramente considerados por BUCKINGHAM (1907), com base na analogia com fluxos de calor e elētrico, sem menção à equação de DARCY (1856).

ISRAELSEN (1927) notou a semel hança da equação de DARCY (1856) com a de BUCKINGHAM (1907) para solos não saturados, e RICHARDS (1961), bem como SWARTZENDRUBER $(1966,1969)$, em reconhecimento ao trabalho de BUCKINGHAM (1907), têm chamado estaa equação de fluxo de ãgua em solos não saturados, como "equação de Buckingham-Darcy".

BUCKINGHAM (1907) introduziu ainda uma nova função na teoria do fluxo de àgua em solos não saturados (embora sem dar nome a ela), definida como a razão entre a condutividade hidráulica e a capacidade específica de àgua, essa obtida pela tangente na curva de retenção para um dado valor de umidade ou potencial matricial. Mais tarde, essa função foi chamada de difusividade da āgua, por CHILDS \& COLLIS-GEORGE (1948). Por este conceito, basta possuir a curva de retenção e a função condutividade para que a função difusividade seja conhecida, ou vice-versa. Isto promoveu, até certo ponto, um grande avanço na obtenção de metodologias destinadas à determinação dessas funções, particularmente em experimentos onde o potencial gravitacional pode ser negligenciado, pois dessa forma, as equaçöes que as regem são mais facilmente solüveis do que quando o potencial gravitacional deve ser considerado. Promoveu ainda vantagens no tratamento 
experimental dos ensaios, onde as condições iniciais e de contorno podem ser propostas em termos de umidade, dispensando assim o uso de instrumentos de recursos limitados, como os tensiômetros.

Finalmente, RICHARDS (1931) combinou a equação de Buckingham-Darcy com a equação da continuidade e obteve a equação diferencial geral que governa o fluxo de ägua em solos não saturados. Embora RICHARDS (1931) não apresente a mesma equação diferencial posta em termos da função difusividade, ele reconheceu explicitamente que o uso da condutividade em função da umidade ou do potencial matricial, era estritamente uma questão de notação matemātica. Por esta razão, SWARTZENDRUBER (1969) sugere que ambas as formas da equação diferencial geral, possam ser apropriadamente referidas como "equações de Richards".

2.2. Principais métodos de determinação das funções condutividade $\underline{e}$ difusividade hidräulicas dos solos não saturados.

A rigor, de acordo com o regime de fluxo que se estabelece no solo, pode-se dividir os métodos de determinação das funções condutividade e difusividade, em dois grandes grupos: i) métodos baseados na condição de regime de fluxo permanente, e i i) métodos baseados na condição de regime de fluxo não permanente. No primeiro caso, - fluxo volumétrico e o gradiente de potencial hidráulico são medidos em um sistema de fluxo unidirecional, onde a umidade não varia com o tempo. Neste caso, a equação de Buckingham-Darcy é usada diretamente para determinar a condutividade, sendo que ela é associada com o potencial matricial ou umidade na posição e tempo nos quais o fluxo e o 
gradiente são medidos. No segundo caso, a dependência temporal de alguns aspectos do comportamento do sistema de fluxo é usado para a determinação da função condutividade ou difusividade. Este grupo compreende os métodos que se utilizam de uma das seguintes técnicas: i) técnica da entrada ou saída do fluxo, e i i) técnica do perfil instantâneo.

\subsubsection{Métodos baseados na condição de regime de fluxo permanente.}

RICHARDS (1931) provavelmente foi o primeiro a apresentar um método de determinação da condutividade hidráulica. Ele utilizou uma pequena coluna de solo entre duas placas porosas de cerâmica, mantendo um regime de fluxo constante entre ambas. Quando esta condição era atingida, a condutividade era então facilmente determinada pela aplicação direta da equação de Buckingham-Darcy.

Outra versão dos métodós baseados na condição de regime de fluxo permanente, é apresentada por CHILDS \& COLLIS-GEORGE (1950) que utilizaram uma coluna relativamente grande de solo, submetendo-a a um suprimento de fluxo constante na superfície e mantendo um lençol freātico na base. Nestas condições, haverā um fluxo descendente e, sob condições de regime permanente, se a coluna for uniforme, a parte superior tenderá a a.tingir uma condição de umidade e potencial matricial constantes, sendo a condutividade hidráulica do solo nesta zona igual ao fluxo de àgua. Iniciando com a saturação e depois através de uma série de fluxos progressivamente decrescentes, pode-se determinar a condutividade como uma função do potencial matricial ou umidade. YOUNGS (1964) descreve um método baseado neste princípio, mudando apenas as condições de contorno e utilizando uma placa porosa no 
topo da coluna, para controle do potencial matricial. Mais tarde, HILLEL \& BENYAMINI (1973) adaptaram este método para condições de campo.

Em geral, os métodos baseados na condição de regime de fluxo permanente apresentam a desvantagem de requererem longos períodos de tempo para estabelecer o fluxo constante, sendo caracterizados primariamente como mētodos de laboratōrio (KLUTE, 1972).

\subsubsection{Métodos baseados na condição de rẹgime de fluxo não permanente}

\subsubsection{Utilizando a técnica da entrada ou saida do fluxo}

GARDNER (1956), através da utilização do aparelho de câmara de pressão, cuja descrição. detalhada pode ser encontrada em RICHARDS (1965), desenvolveu um método inerentemente de laboratório para a determinação tanto da função condutividade como da difusividade, atravēs de simplificações que linearizam a equação diferencial geral do fluxo não saturado, tornando-a mäis facilmente solúvel. Ele assumiu neglegível a componente gravitacional do fluxo, porquanto a altura da amostra era de alguns centímetros, e que para pequenos incrementos de pressão dentro da câmara, a condutividade e a difusividade podiam ser consideradas constantes durante o processo, e a curva de retenção linear. MILLER \& ELRICK (1958), PECK (1966), KUNZE \& KIRKHAM (1962) e outros, refinaram o mētodo de GARDNER (1956) no sentido de evitar o problema da resistência da placa porosa, enquanto que JACKSON et ali i (1963) e DAVIDSON et alii (1966) examinaram o método e concluiram que ele não é prätico o suficiente para se usar pequenos incrementos de pressão e validar a suposição da condutividade e difusividade constantes, além de apresentar extrema dificuldade na obtenção 
de repetições.

Um outro método, também de laboratörio, comumente conhecido como "one-step method", foi descrito por DOERING (1965), com base em algumas anālises prévias de GARDNER (1962) sobre a técnica de separação de variáveis e solução da equação diferencial geral do fluxo não saturado, escrita em termos da difusividade. GARDNER (1962) assumiu que a função difusividade podia ser representada como um produto de uma função do tempo, e que durante a saída do fluxo da amostra previamente saturada, o conteūdo de āgua era aproximadamente uniforme com respeito à posição. Desde que neste mētodo somente um incremento de pressão é necessário, maior rapidez na determinação podia ser obtido, comparado com o método de GARDNER (1956). De qualquer forma, DOERING (1965) não previu a resistência da membrana, embora tenha concluido que os valores da difusividade eram mais compativeis do que aqueles produzidos pelo método de GARDNER (1956).

BRUCE \& KLUTE (1956) descrevem um outro método, tambēm de natureza laboratorial, para determinar a função difusividade com base na distribuição espacial do conteūdo de āgua para um tempo fixado num sistema de fluxo de infiltração horizontal. Eles utilizaram a técnica da transformação de Boltzmann para a solução da equação diferencial geral do fluxo não saturado, por separação de variáveis,transformando-a numa equação diferencial ordinäria. WHISLER et alii (1968), utilizando a mesma técnica, desenvolveram um método para determinação da função difusividade com base na distribuição temporal do conteúdo de àgua para uma posição fixada. Segundo KLUTE (1972), este método è mais conveniente para ser usado com a técnica de atenuaçãogama, enquanto que o método de BRUCE \& KLUTE (1956) por amostragem gravimétrica da umidade. Ambos os métodos são laboratoriais. 
Os métodos atē agora citados se destinam à obtenção da função difusividade para relativamente àltos valores de umidade. Para solos relativamente secos, JACKSON (1964a e 1964b) apresenta métodos de determinação da difusão do vapor de água baseados nas isotermas de adsorção e desorção dos conteúdos de ãgua entre 0 e $0,07 \mathrm{~cm}^{3} / \mathrm{cm}^{3}$. Já CASSEL et alii (1968), para valores intermediärios de umidade, todavia com a técnica do perfil instantâneo, que se descreve a seguir.

\subsubsection{Utilizando a técnica do perfil instantâneo}

Quando se integra a equação da continuidade para uma direção, com relação à distância, obtēm-se que a diferença entre os fluxos nas distâncias correspondentes aos limites de integração, equivale à integral das variações da umidade com o tempo dentro dos mesmos limites de integração. Se se conhece a variaçãoda umidade com a profundidade e com o tempo, então esta integral pode seravaliada e, se um dos fluxos è conhecido, o outro pode ser estimado. Esta técnica, que como se nota, se aplica em condições de regime de fluxo não permanente, è conhecida com o nome de "perfil instantâneo", largamente uti lizada tanto em experimentos de campo como de laboratório, todavia com muitas variações nas análises dos dados, uma vez que as condições de contorno não necessitam serem constantes, ou conhecidas em detaIhes (KLUTE, 1972).

RICHARDS \& WEEKS (1953) foram provavelmente os primeiros a utilizarem esta técnica em experimentos de colunas, e RICHARDS et alii (1956), os primeiros em experimentos de campo. Os primeiros mediram o fluxo de drenagem de uma coluna posicionada horizontalmente e fechada numa de suas extremidades, medindo os potenciais matricial ao longo da mesma em função do tempo, atravēs de leituras em tensiô- 
metros munidos com manômetros de mercūrio; as variações de umidade com a distância e com o tempo eram obtidas a partir da curva de retenção. Os segundos, após saturarem um perfil de solo, permitiram que este sofresse evaporação e drenagem; atravēs de medidas simultâneas de potencial matricial por meio de tensiômetros com manômetros de mercúrio instalados a diversas profundidades e amostragem do solo nas mesmas profundidades para medida da umidade, estimaram o gradiente de potencial e o fluxo de drenagem (ou evaporação) procurando ao longo do perfil as posições nas quais o fluxo se tornava nulo.

OGATA \& RICHARDS (1957) simplificaram bastante o procedimento de RICHARDS et alii (1956) eliminando o fluxo na superficie com a cobertura de uma lona plästica, de modo que somente o processo de drenagem ocorresse. Este mesmo procedimento foi também utilizado posteriormente por NIELSEN et alii (1962), HILLEL et alii (1972), Van BAVEL et alii (1968), CHO et alii (1977) e outros, com a diferença de que a umidade do solo em função da profundidade e do tempo de redistribuição era medida com auxílio da técnica de moderação de nêutrons e não gravimetricamente como originalmente utilizada por OGATA \& RICHARDS (1957). Atualmente, a utilização da sonda de nêutrons está sendo bastante empregada em condições de campo, principalmente pela vantagem que apresenta com relação ao método gravimétrico em não ser destrutiva. Em nosso meio, trabalhos desta natureza utilizando sonda de nêutrons foram realizados por REICHARDT \& LIBARDI (1974), GROHMANN et alii. (1976), SAUNDERS et alii (1978), e outros.

LIBARDI (1978) destaca o trabalho de HILLEL et alii (1972) pelo fato de apresentar um roteiro simples e completo para a determinação da função condutividade em condições de campo. PREVEDELLO et alii (1981) simplificaram o método de HILLEL (1972), com re- 
sultados satisfatórios.

Como se verifica, embora todos estes mëtodos tenham em comum a técnica do perfil instantâneo, esta teoria não exige uniformidade das propriedades hidráulicas do sistema de fluxo e nem que as condições de contorno sejam necessariamente constantes ou conhecidas em detalhes. Como consequência, as variações na anālise dos dados são muitas. ROSE et alii (1965), por exemplo, determinaram a função condutividade em diversas profundidades de um solo estratificado sob condições de evaporação e redistribúição simultaneamente, sendo que o fluxo de evaporação foi estimado assumindo ser igual ao fluxo de evaporação potencial e calculado pela equação de Penman. 0 objetivo era mostrar como a função condutividade podia ser determinada em condições de campo para uma ampla variação nos conteúdos de água no solo.

GARDNER (1970), assumindo a umidade do solo como função do tempo mas não função da profundidade durante o processo de redistribuição, transformou a equação de Richards num método para determinação da difusividade em função do potencial matricial. Este método foi utilizado por NIELSEN et alii (1972), que concluiram ser perfeitamente adequado para os propósitos präticos, particularmente durante os estágios iniciais da redistribuição.

A técnica do perfil instantâneo pode ser aplicada tambēm em colunas de solo, estratificados ou não, sob condições de laboratōrio. Muitos métodos são disponíveis, todos variando em detalhes, mas com o mesmo princípio em comum. WATSON (1966) e WEEKS \& RICHARDS (1967), por exemplo, determinaram a função condutividade de maneira idêntica a de RICHARDS \& WEEKS (1953), sendo que o primeiro utilizou a técnica da atenuação de radiação gama para medir a umidade, tensiômetros com transdutor de pressão para medir o potencial matricial e o 
fluxo era vertical; os segundos, alēm de usarem o solo homogeneamente acondicionado em colunas, utilizaram também colunas de solocomestrutura não deformada.

WIND (1966) utilizou colunas de solo com estrutura não deformada fechadas na base e posicionadas verticalmente, e mediu o fluxo de evaporação a partir dos valores de umidade obtidos das curvas de retenção atravēs de leituras de tensiômetros e elementos de resistência de "nyion". Semelhantemente, FLOCKER et alii (1968) procederam da mesma forma, porēm com a diferença de utilizarem a técnica da atenuação de radiação gama para medida da umidade do solo.

VACHAUD \& THONY (1971) utilizaram coluna de solo homogêneo fechada na base, e determinaram a função condutividade em expe-rimento que envolvia infilttração no solo previamente seco ao ar, drenagem e redistribuição, atravēs da técnica de atenuação de radiação gama para medida da umidade do solo e tensiômetros com transdutor de pressão para medida do potencial matricial, procurando ao longo da coluna as posições nas quais o fluxo se tornava nulo. Este procedimento é semelhante ao utilizado por RICHARDS et alii (1956) em condições de campo.

Finalmente, uma variante da técnica do perfil instantāneo è aquela de se considerar gradiente de potencial hidráulico unitário, uma aproximação que tem sido explorada por BLACK et alii (1969), DAVIDSON et alii (1969) e LIBARDI et alii (1980), os quais recomendam em solos identificados como homogēneos. Neste aspecto, LIBARDI et ali i. (1980) apresentam uma metodologia simplificada para determinação da função condutividade, atravēs apenas de medidas de umidade do solo em função da profundidade e tempo de redistribuição, quando se previne a infiltração e evaporação atravēs da superfície do solo. 


\section{CONSIDERAÇÕES TEORICAS}

\subsection{Derivação da equaçao diferencial geral que governa o fluxo de á-} gua em solos não saturados.

A primeira equaçao que possibilitou a quantificação do fluxo de água num solo saturado foi desenvolvida por DARCY (1856), que escrita na forma diferencial é:

$$
q_{0}=-K_{0} \frac{d \psi_{h}}{d s}
$$

onde $\mathrm{q}_{0}$ é o fluxo de ägua em solo saturado ao longo de um segmento dirigido ds, isto é, o volume de água que flui por unidade de área e de tempo; $K_{0}$ é a condutividade hidrāulica do solo saturado; $\psi_{h}$ é o potencial hidráulico da água no solo (igual à soma dos potenciais de pressão e gravitacional); e s é uma coordenada qualquer de posição.

Para fluxo em solo saturado, a condutividade hidráulica da equação (1) é uma constante e representa uma característica do solo em transmitir água. Para fluxo em solo não saturado, esta característica se torna função da umidade do solo $(\theta)$ ou do potencial matricial $\left(\psi_{m}\right)$, de tal maneira que a equação (1) se converte na equação de Buckigham-Darcy, ou seja:

$$
q=-k(\theta) \frac{d \psi_{h}}{d s}
$$


onde q è o fluxo não saturado de água; $K(\theta)$ è a condutividadehidrāulica do solo não saturado; $\psi_{h}$ é o potencial hidräulico da água no solo (agora igual à soma dos potenciais matricial e gravitacional).

os fluxos $q$ ou $q_{0}$ das equações anteriores, por se tratar de uma grandeza vetorial, podem ser escritos para qualquer direção. Nesse caso, a coordenada s pode assumir, no sistema cartesiano, os valores $x, y$ ou $z$, conforme o fluxo seja horizontal ( $x$ e $y$ ) ou vertical (z). A mesma observação è välida para $K(\theta)$ e $K_{0}$.

Reescrevendo a equação (2) para as direções $x, y$ e $z$, resulta, respectivamente:

$$
\begin{aligned}
& q_{x}=-k_{x}(\theta) \frac{\partial \psi_{h}}{\partial x} \\
& q_{y}=-k_{y}(\theta) \frac{\partial \psi_{h}}{\partial y} \\
& q_{z}=-k_{z}(\theta) \frac{\partial \psi_{h}}{\partial z}
\end{aligned}
$$

Nas equações (3), (4) e (5) foi usada a derivada parcial no lugar da derivada total para mostrar que y e z são mantidos constantes, enquanto $\psi_{h}$ varia com $x$; similarmente para $q_{y}$ e $q_{z}$.

Se a equação de Buckingham-Darcy for admitida como välida para a quantificação do fluxo em solos, não saturados, então a descrição desse fluxo deve obedecer ainda à lei da conservação da massa, a qual, em três dimensões $(x, y$ e $z)$, è expressa por:

$$
\frac{\partial \theta}{\partial t}=-\left(\frac{\partial q_{x}}{\partial x}+\frac{\partial q_{y}}{\partial y}+\frac{\partial q_{z}}{\partial z}\right)
$$


Assim, se na equação (6) os fluxos $q_{x}, q_{y}$ e $q_{z}$ forem substituidos pela equação de Buckingham-Darcy para as respectivas direções, obtēm-se a seguinte equação:

$$
\frac{\partial \theta}{\partial t}=\frac{\partial}{\partial x}\left[k_{x}(\theta) \frac{\partial \psi_{h}}{\partial x}\right]+\frac{\partial}{\partial y}\left[k_{y}(\theta) \frac{\partial \psi_{h}}{\partial y}\right]+\frac{\partial}{\partial z}\left[k_{z}(\theta) \frac{\partial \psi_{h}}{\partial z}\right]
$$

conhecida como equação diferencial geral que governa o fluxo de água em solos não saturados, ou equaçãó de Richards, escrita em termos da função condutividade.

Lembrando que o potencial hidráulico $\psi_{\mathrm{h}}$ é igual à soma dos potenciais matricial $\psi_{m}$ e gravitacional $\psi_{g}$, então a equação (7a) pode ser reescrita como:

$\frac{\partial \theta}{\partial t}=\frac{\partial}{\partial x}\left[k_{x}(\theta)-\frac{\partial \psi_{m}}{\partial x}\right]+\frac{\partial}{\partial y}\left[k_{y}(\theta) \frac{\partial \psi_{m}}{\partial y}\right]+\frac{\partial}{\partial z}\left[k_{z}(\theta)\left(\frac{\partial \psi_{m}}{\partial z}+\frac{\partial \psi_{g}}{\partial z}\right)\right](7 b)$ ou

$\frac{\partial \theta}{\partial t}=\frac{\partial}{\partial x}\left[k_{x}(\theta) \frac{\partial \psi_{m}}{\partial x}\right]+\frac{\partial}{\partial y}\left[k_{y}(\theta) \frac{\partial \psi_{m}}{\partial y}\right]+\frac{\partial}{\partial z}\left[k_{z}(\theta)\left(\frac{\partial \psi_{m}}{\partial z}+1\right)\right](7 c)$

para o caso particular em que $\psi_{\mathrm{m}}$ e $\psi_{\mathrm{g}}$ são expressos em termos de energia por uriáade de peso de água (carga hidráulica).

BUCKINGHAM (1907) a inda definiu uma nova função na teoria do fluxo de àgua em solos não saturados, mais tarde chamada de difusividade hidräulica por CHILDS \& COLLIS-GEORGE (1948), ou seja:

$$
D(\theta)=\frac{K(\theta)}{c(\theta)}=K(\theta) \frac{d \psi_{m}}{d \theta}
$$


onde $c(\theta)$ é a capacidade específica de água, obtida pela tangente na curva de retenção para um determinado valor de $\theta$ ou $\psi_{m}$.

Substituindo a equação (8) na equação (7c), esta fica:

$\frac{\partial \theta}{\partial t}-\frac{\partial}{\partial x}\left[D_{x}(\theta)\left(\frac{d \theta}{d \psi_{m}}\right)_{x} \frac{\partial \psi_{m}}{\partial x}\right]+\frac{\partial}{\partial y}\left[D_{y}(\theta)\left(\frac{d \theta}{d \psi_{m}}\right) \frac{\partial \psi_{m}}{\partial y}\right]+$

$\frac{\partial}{\partial z}\left[D_{z}(\theta)\left(\frac{d \theta}{d \psi_{m}}\right)_{z} \frac{\partial \psi_{m}}{\partial z}+k_{z}(\theta)\right]$

Se o solo for homogêneo e isotröpico, então os gradientes de potencial matricial podem ser expandidos pela regra da cadeia (HILLEL, 1971), e a equação (9) fica:

$\frac{\partial \theta}{\partial t}=\frac{\partial}{\partial x}\left[D(\theta) \frac{\partial \theta}{\partial x}\right]+\frac{\partial}{\partial y}\left[D(\theta) \frac{\partial \theta}{\partial y}\right]+\frac{\partial}{\partial z}\left[D(\theta) \frac{\partial \theta}{\partial z}+K(\theta)\right]$

que é a equação diferencial geral que governa o fluxo de ägua em solos não saturados homogêneos.

Comparando agora as equações (6) e (10), resulta:

$$
\begin{aligned}
& q_{x}=-D(\theta) \frac{\partial \theta}{\partial x} \\
& q_{y}=-D(\theta) \frac{\partial \theta}{\partial y} \\
& q_{z}=-\left[D(\theta) \frac{\partial \theta}{\partial z}+K(\theta)\right]
\end{aligned}
$$




\subsection{Base teörica para a hipótese formulada.}

A introdução do conceito de difusividade hidräulica, assim chamada por CHILDS \& COLLIS-GEORGE (1948) e originalmente proposto por BUCKINGHAM (1907), até certo ponto contribuiu em muito na teoria do fluxo de água em solos homogêneos não saturados. Como se pode observar pelas equações (11) e (12), a quantificação do fluxo na direção horizontal, portanto, fica simplesmente definida através desta função e do gradiente de umidade, dispensando-se, com isso, o uso de tensiômetros, um instrumento de recursos relativamente limitados. Do mesmo modo, a equação diferencial (equação 10) para a mesma direção, por se apresentar de forma anāloga à equação de condução de calor em sōlidos, simplifica o tratamento matemático analítico e também experimental dos processos de fluxo, uma vez que muitas soluções podem ser disponíveis (por exemplo, CARSLAW \& JAEGER, 1976; CRANK, 1975), quando envolvem condições iniciais e de contorno aplicáveis aos processos de fluxo de água (HILLEL, 1971). Por outro lado, o mesmo não se verifica para a direção vertical, onde a equação (13) mostra que o fluxo é função de ambas: difusividade e condutividade. Além disso, a equação diferencial (equação 10) nessa direção, resulta num tratamento matemático analítico altamente complexo. Evidentemente, essa situação é indesejável, porquanto a maioria dos processos de fluxo no solo sob condições principalmente de campo, realizam-se em presença do potencial gravitacional, isto é, quando esta componente não pode ser desprezada. Isso, entretanto, pode mudar com a introdução de novos conceitos, a exemplo de BUCKINGHAM (1907). Assim, expressemos inicialmente o fato de que o potencial matricial $\psi_{m}$ é uma função da umidade $\Theta$ que, por sua vez, no sistema cartesiano, é uma função das 
coordenadas de posição $x, y$ e $z$, e do tempo $t$, ou seja:

$$
\psi_{m}=f[\dot{[}(x, y, z, t)]
$$

onde $f[\theta(x, y, z, t)]$ denota uma função de $\theta$ a qual é função de $x, y$, $z e t$.

Analogamente, para o potencial gravitacional, se este for expresso em termos de energia por unidade de peso, isto é, carga hidräulica, então pode-se escrever:

$$
\psi_{g} \equiv z=f[\theta(z, t)]
$$

que diz que $\psi_{g}$ (carga hidráulica) è numericamente igual à coordenada de posição $z$, a qual è uma função de $\theta$, que por sua vez, è tambēm uma função da coordenada de posição $z$, e do tempo t; uma função de função implícita, portanto.

Com isso, se as funções $\psi_{m}$ e $z$ versus $\Theta$ foremunivocas, contínuas e deriváveis, então os gradientes de potencial matricial e gravitacional da equação (7b) podem ser expandidos pela regra da cadeia atravēs das equações (14) e (15), respectivamente. Assim, para t constante, derivando-se ambos os membros da equação (14) com relação a $x, y$ e $z$, e ambos os membros da equação (15) com relação a $z$, obtém-se, respectivamente:

$$
\begin{aligned}
& \frac{\partial \psi_{m}}{\partial x}=\frac{d \psi_{m}}{d \Theta} \frac{\partial \Theta}{\partial x} \\
& \frac{\partial \psi_{m}}{\partial y}=\frac{d \psi_{m}}{d \Theta} \frac{\partial \Theta}{\partial y}
\end{aligned}
$$




$$
\begin{aligned}
& \frac{\partial \psi_{m}}{\partial z}=\frac{d \psi_{m}}{d \Theta} \frac{\partial \Theta}{\partial z} \\
& \frac{\partial \psi_{g}}{\partial z}=\frac{\partial z}{\partial z}=1=\frac{d z}{d \theta} \frac{\partial \theta}{\partial z}
\end{aligned}
$$

Substi tuindo as equações (16), (17), (18) e (19), respectivamente, na equação (7b), resul ta:

$$
\begin{aligned}
& \frac{\partial \theta}{\partial t}=\frac{\partial}{\partial x}\left[K(\Theta) \frac{d \psi_{m}}{d \theta} \frac{\partial \theta}{\partial x}\right]+\frac{\partial}{\partial y}\left[K(\Theta) \frac{d \psi_{m}}{d \theta} \frac{\partial \theta}{\partial y}\right]+\frac{\partial}{\partial z}[K(\Theta) \\
& \left.\left(\frac{d \psi_{m}}{d \theta} \frac{\partial \theta}{\partial z}+\frac{d z}{d \theta} \frac{\partial \theta}{\partial z}\right)\right]
\end{aligned}
$$

Definindo as funções

$$
\begin{aligned}
& D_{m}(\theta)=K(\theta)^{d \psi_{m}}=\frac{\text { difusividade hidräul ica }}{\text { matricial }} \\
& D_{z}(\theta)=K(\theta) \frac{d z}{d \theta}=\frac{\text { difusividade hidräul ica }}{\text { gravitacional }}
\end{aligned}
$$

então, a equação (20) pode ser escrita como:

$$
\frac{\partial \theta}{\partial t}=\frac{\partial}{\partial x}\left[D_{m}(\Theta) \frac{\partial \Theta}{\partial x}\right]+\frac{\partial}{\partial y}\left[D_{m}(\Theta) \frac{\partial \theta}{\partial y}\right]+\frac{\partial}{\partial z}\left[D_{m}(\theta) \frac{\partial \theta}{\partial z}+D_{z}(\Theta) \frac{\partial \theta}{\partial z}\right]
$$

Definindo ainda mais uma função:

$$
D_{g}(\theta)=D_{m}(\Theta)+D_{z}(\Theta)=\frac{\text { difusividade hidrāulica }}{\text { global }}
$$

então, a equação (23) pode ainda ser simplificada para: 
$\frac{\partial \Theta}{\partial t}=\frac{\partial}{\partial x}\left[D_{m}(\Theta) \frac{\partial \Theta}{\partial x}\right]+\frac{\partial}{\partial y}\left[D_{m}(\Theta) \frac{\partial \Theta}{\partial y}\right]+\frac{\partial}{\partial z}\left[D_{g}(\Theta) \frac{\partial \Theta}{\partial z}\right]$

onde

$D_{g}(\theta)=D_{m}(\theta)+D_{z}(\theta)=k(\theta)\left[\frac{d \psi_{m}}{d \theta}+\frac{d z}{d \theta}\right] \equiv k(\theta) \frac{d \psi_{h}}{d \theta}$

uma vez que $z \equiv \psi_{g}$ (posto em termos de carga hidräulica).

Como se verifica, a equação (21), com exceção da nova nomenclatura adotada, em nada difere da equação (\&) originalmente proposta por BUCKINGHAM (1907). Por outro lado, as equações (22), (24) e, consequentemente, (25), para a direção vertical, constituem-se em novidades na teoria do fluxo de āgua em solos não saturados, comotambém a equação (27), que se obtém comparando-se a equação (25) para a direção vertical, com a equação (6) para a mesma direção, ou seja:

$$
q_{z}=-D_{g}(\theta) \frac{\partial \theta}{\partial z}
$$

Desse modo, as equações (27) e (25) para a direção vertical, substituem com vantagens as respectivas equações (13) e (10) para a mesma direção. Isto porque pela equação (27), o fluxo na direção vertical è quantificado somente em função do gradiente de umidade e da difusividade, da mesma forma que na direção horizontal $x$ ou y advinda da teoria clässica, inicialmente proposta por BUCKINGHAM (1907). Consequentemente, a equação diferencial geral, equação (25), para a direção vertical, ao contrārio da equação (10), poderá receber o mesmo tratamento matemätico analitico que se verifica para a direção horizontal, podendo até mesmo encontrar muitas soluções jä disponiveis (por exemplo, CARSLAW \& JAEGER, 1976; CRANK, 1975), quando en- 
volver condições iniciais e de contorno aplicáveis aos processos de fluxo de água. Para isso, basta que se disponha de uma metodologia adequada para obtenção da função difusividade hidrāulica global $D_{g}(\theta)$, que será a seguir considerada.

3.3. Método proposto para a determinação da função difusividade hidrāulica global, $\underset{g}{D}(\Theta)$

Com base na técnica do perfil instantâneo, procuraremos uma solução para a equação (25) escrita para a direção vertical, visando a obtenção da função difusividade hidrāulica global $D_{g}(\Theta)$. Antes porém, algumas observações importantes sobre a função difusividade hidrāulica, devem ser consideradas. Nas definições das equações (21) e (22), implicitamente ficou assumido que $K, D, d \psi_{m} / d \theta$ e $d z / d \theta$ são funções unicamente de $\Theta$. Isto, entretanto, pode não ser rigorosamente verdadeiro, uma vez que estas funções podem ser afetadas pelo fenômeno da histerese, o que dificulta sobremaneira a descrição matemática do fluxo de água em solos não saturados. Este problema, por outro lado, pode ser parcialmente contornado utilizando-se as funções $K, D, d \psi_{m} / d \theta$ e $d z / d \theta$ de molhamento quando se descrevem processos de molhamento, e de secamento em processos de secamento. Quando os dois processos ocorrem simultaneamente, o problema torna-se muito complexo necessitando, na maioria das vezes, ser desconsiderado (REICHARDT, 1985). Assumindo a unicidade da função difusividade hidräulica, provavelmente a mais simples interpretação dessa função é encontrada nas equações (11) e (12) para a di reção horizontal, e pela equação proposta para a direção vertical, que dizem que a difusividade hidráu- 
lica è uma medida do fluxo de água sob um gradiente de umidade. Isto indica que a difusividade hidrāulica tem um significado físico. Por outro lado, esta função deve ser usada com critērios. Em outras palavras, quando se define a difusividade hidräulica como um fator de proporcionalidade entre o fluxo e o gradiente de umidade, tacitamente estā se assumindo que o solo é homogêneo; e isto torna claro que o principal interesse em se introduzir a função difusividade hidrāulica na teoria do fluxo de àgua em solos não saturados, é para facilitar a resolução de problemas prōprios dos meios porosos hidraulicamente homogêneos, isto è, aqueles que satisfazem as igualdades das e-quações (16), (17) e (18). Neste caso, a equação (25) não deve sofrer nenhuma restrição de aplicação. Contudo, quando se observam os perfis de solo sob condições de campo, verifica-se que, na grandemaioria das vezes, não exibem morfologia homogênea; são os horizontes ou camadas, cujos graus de diferenciação variam desde abrupta até difusa, passando pelas transições intermediārias clara e gradual. Mas mesmo assim, de acordo com as proposições levantadas no item 3.2., pode-se af irmar:

\footnotetext{
"Se cada horizonte ou camada

de um perfil de solo for

considerado hidraulicamente

homogêneo, então a função

difusividade hidrāulica global,

$D_{g}(\Theta)$ da equação (25), para cada

horizonte ou camada do perfil,

pode ser obtida."
}

Para tanto, após a saturação de um perfil de solo (homogêneo ou não) e prevenida a infiltração e evaporação atravēs de sua 
superfície, as seguintes condiçōes inicial e de contorno podem ser utilizadas durante o processo de redistribuição:

$$
\begin{aligned}
& \theta=\theta(z) ; \quad t=0, ; z>0 \\
& \theta=\theta_{i} ; \quad t>0, \quad z=0 \\
& q=0 ; \quad t>0 ; \quad z=0
\end{aligned}
$$

onde $\theta_{i}$ é a umidade inicial do solo.

Sendo assim, integrando-se a equação (25) para a direção vertical com relação à coordenada de posição $z$, desde a superfície do solo até a profundidade de interesse $z$, obtém-se:

$$
\int_{0}^{z} \frac{\partial \theta}{\partial t} d z=\int_{0}^{z} \frac{\partial}{\partial z}\left[D_{g}(\theta) \frac{\partial \theta}{\partial z}\right] d z
$$

ou

$$
\int_{0}^{z} \frac{\partial \theta}{\partial t} d z=\left.D_{g}(\theta) \frac{\partial \theta}{\partial z}\right|_{z}-\left.D_{g}(\theta) \frac{\partial \theta}{\partial z}\right|_{0}
$$

Em princípio, a equação (31b) se aplica para casos de drenagem e evaporação sịmultaneamente. Entretanto, para se evitar modificaçöes desfavoráveis no regime hidríco do perfil de solo, após este ter sido saturado, a superfície do solo é coberta para previnir a evaporação e infiltração (condição 30 ), e somente a redistribuição ocorre. Neste caso, o termo $\left.D_{g}(\theta) \frac{\partial \theta}{\partial z}\right|_{0}$ é nulo, e a equação (31b) fica:

$$
\int_{0}^{z} \frac{\partial \theta}{\partial t} d z=\left.D_{g}(\theta) \frac{\partial \theta}{\partial z}\right|_{z}
$$


ou, explicitando $D_{g}(\theta)$ :

$$
D_{g}(\theta)=\frac{\int_{0}^{z} \frac{\partial \theta}{\partial t} d z}{\left.\frac{\partial \theta}{\partial z}\right|_{z}}
$$

onde a função $D_{g}(\theta)$ e o gradiente de umidade são avaliados na profundidade de interesse $z$.

$$
\text { A equação (32b) permite a obtenção da função } D_{g}(\theta) \text { pa- }
$$
ra qualquer profundidade, $z$, desde que o gradiente de umidade, $\partial \theta / \partial z$, possa ser medido dentro de uma camada hidraulicamente homogênea.

Assim, através de medidas de umidade do solo durante um certo período de redistribuição, determinam-se a integral da equação (32b), que corresponde ao fluxo (q) de ägua na profundidade z, e o gradiente de umidade na mesma profundidade. Um procedimento simplificado que se sugere para a determinação da função $D_{g}(\theta)$ nas diversas profundidades do solo a partir da equação (32b), consiste na elaboração de duas tabelas: uma para determinação da densidade de fluxo da água no solo nas diversas profundidades e para diversos tempos a partir da integral da equação (32b); è a outra para o cálculo da difusividade hidräulica global, $D_{9}$, em cada profundidade e para diferentes umidades, dividindo os fluxos apresentados na primeira tabela pelos gradientes de umidade nos respectivos tempos, todavia dentro da camada considerada hidraulicamente homogênea.

A hipötese fundamental do presente trabalho, portanto, é a de verificar a validade da equação (25) proposta para a direção vertical do fluxo, em camadas hidraulicamente homogêneas do perfil de 
solo, o que é imposto pela equação (18). O capítulo seguinte detalha a metodologia empregada nesse sentido. 


\section{MATERIAL E METODOS}

\subsection{Considerações gerais}

Para comprovar a validade da equação (25) proposta para a direção vertical do fluxo, a equação (18) impõe a necessidade de que as camadas de interesse do perfil de solo sejam hidraulicamente homogêneas. Se isso se verifica, então pelo enunciado no item 3.3., a relação funcional $D_{g}(\Theta)$ pode ser obtida pela metodologia proposta naquele item, que envolve experimento de redistribuição de ägua no perfil de solo, após ele ter sido previamente saturado e prevenida a evaporação e infiltração de água na sua superfície. Uma vez conhecida a função $D_{g}(\Theta)$, e desde que se disponha também dos valores de $d \psi_{m}$ ' $d \Theta$ e $d z / d \Theta$, fica fäcil então se obter a relação funcional $k(\theta)$, pela equação (26), que por sua vez, possibilita o conhecimento das funções $D_{m}(\theta)$ e $D_{z}(\theta)$, pela equações $(21)$ e (22), respectivamente.

Desse modo, se se dispõe de uma outra metodologia, reconhecidamente aceita como padrão para obtenção das relações funcionais $K(\theta)$ e $D_{m}(\theta)$, como a proposta por HILLEL et alii (1972), por exemplo, então uma relação estreita entre essas duas funções assim obtidas, com as mesmas respectivas funções obtidas pela teoria proposta, validarão a hipótese fundamental do trabalho e, consequentemente, os conceitos emitidos, notadamente o cumprimento da condição de homogeneidade hidrắulica (equação 18). 
Dois solos distintos sob o ponto de vista físico-químico foram estudados. Um deles é de natureza argilosa e classificado como Terra Roxa Estruturada, localizado no Brasil; e outro è de natureza arenosa e classificado como duna de areia, localizado no Japão, cujos dados são fornecidos por CHO et alii (1977).

\subsection{Experimento em Terra Roxa Estruturada.}

\subsubsection{Local do experimento e características do clima e solo}

A área experimental utilizada nesse solo localiza-se dentro do campus da Escola Superior de Agricultura "Luiz de Queiroz", Universidade de São Paulo, Piracicaba, prōximo ao Posto AgrometeoroIógico do Departamento de Física e Meteorologia, cujas coordenadas geogrä́ficas são: $20^{\circ} 42^{\prime} 30^{\prime \prime}$ de latitude sul, $47^{\circ} 38^{\prime} 00^{\prime \prime}$ de longitude 0 este, a $580 \mathrm{~m}$ de altitude. A Figura 1 mostra o local onde foi instalada a parcela experimental.

Os dados meteorológicos coletados no postopróximo ( $F$ igura 1) mostram, em termos médios anuais, que a precipitação pluvial. é de $1247,1 \mathrm{~mm}$, ocorrendo, a maior parte, no verão (de novembro a fevereiro), principalmente como chuvas de alta intensidade e curta duração; a temperatura do ar é de $20,8^{\circ} \mathrm{C}$, sendo a mínima da ordem de $10^{\circ} \mathrm{C}$ em julho, e a máxima da ordem de $30^{\circ} \mathrm{C}$ em janeiro; a umidade relativa é de $69 \%$; a velocidade do vento é de $2,5 \mathrm{~m} / \mathrm{s}$; e o período de britho solar é de $6 \mathrm{~h} / \mathrm{dia}$ (CERVELLINI et alii, 1973).

o clima da região é denominado de tropical de altitude por CAMARGO et ali i (1974), com estiagem no inverno, com temperatura média do mês mais frio superior a $18^{\circ} \mathrm{C}$ e do mês mais quente superior 


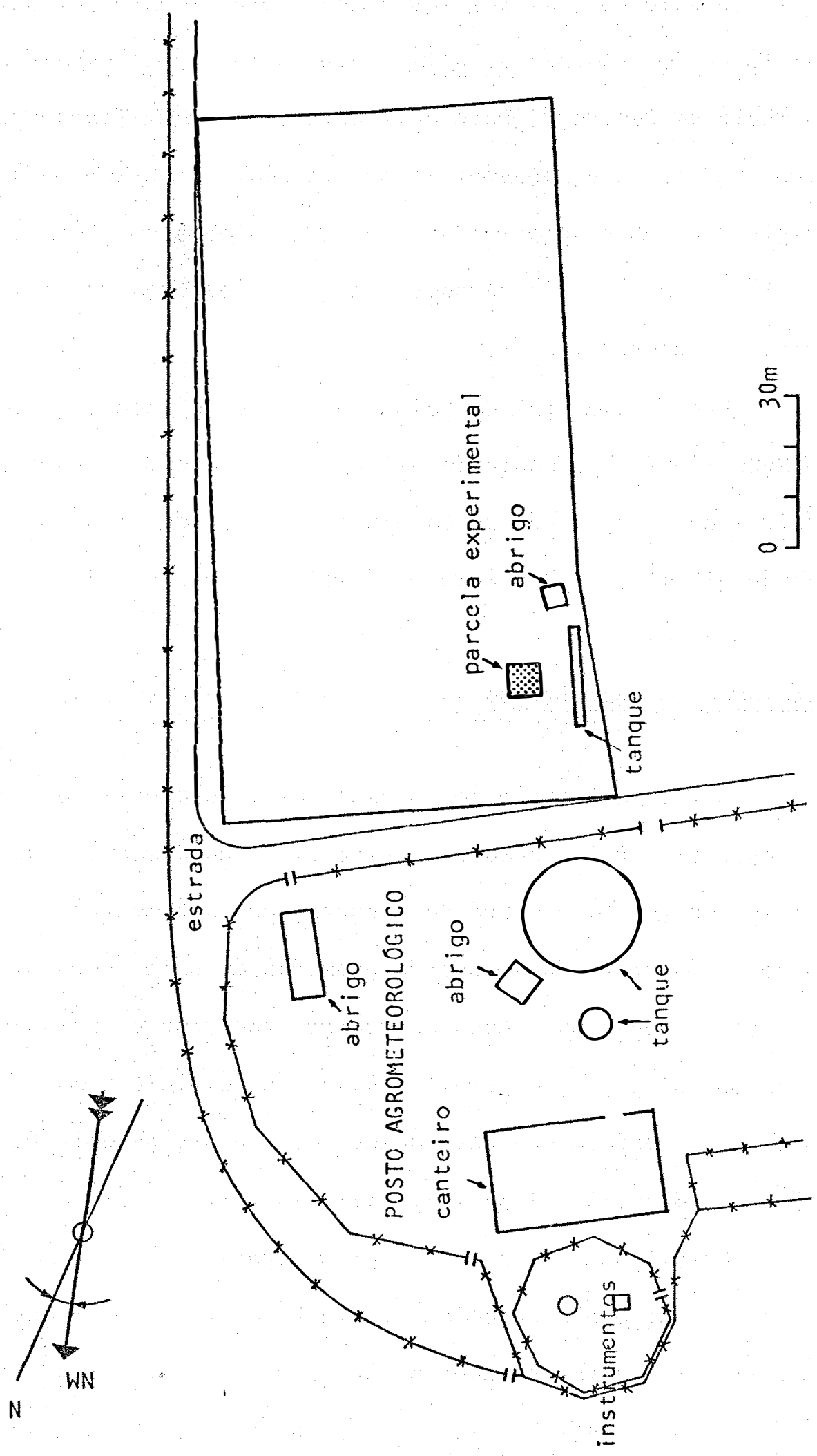

a 
a $22^{\circ} \mathrm{C}$.

o solo no qual foi instalado o experimento foi descrito e classificado por RANZANI et alii (1966) como Terra Roxa Estruturada sërie "Luiz de Queiroz" (Paleudalf óxico, pela Soil Taxonomy, ESTADOS UNIDOS, 1979). Ele apresenta como material de origem rochas eruptivas básicas e cobre aproximadamente $1,0 \%$ da área do Estado de São Paulo. São solos muito profundos, com o lençol freático a vărios metros abaixo da superfície.

Este mesmo tipo de solo, mas de outro local, segundo MONIZ \& JACKSON (1967), do ponto de vista mineralógico, apresenta: $15,3 \%$ de óxidos de ferro; $48 \%$ de caolinita; $10,7 \%$ de mica + vermiculita; $4,3 \%$ de gibsita; e $31,7 \%$ de material amorfo.

\subsubsection{Instal ação do experimento}

Antes da instalação do experimento e prōximo a parcela destinada a esse fim, foi aberta uma trincheira com dimensões de 2,0 metros de comprimento, 1,0 metro de largura, por 2,6 metros de profundidade, com o objetivo de separar as camadas de solo consideradas morfologicamente homogêneas. Após cuidadoso exame das principais características morfológicas, o perfil foi, então, dividido em seis camadas consideradas morfologicamente homogêneas, quais sejam: $0-15$, $15-1: 9, \quad 49-83,83-113,113-173,173-233 \mathrm{~cm}$.

Resumidamente, as principais caracteristicas morfologicas desse solo são: presença de horizonte Ap de 0-15 cm, franco-argiloso com estrutura forte, pequena a média, blocos subangulares assentados sobre um horizonte $B$ textural $\left(B_{t}\right)$ de $83-113 \mathrm{~cm}$, argilo- limoso com estrutura moderada, grande, prismáțica, que se rompe em blo- 
cos subangulares, forte, pequena a média, que, por sua vez, num $1 \mathrm{i}$ mite ondulado e difuso tem abaixo um horizonte B latossölico $\left(B_{S q}\right)$ argilo-limoso com estrutura muito fraca, pequena a média, blocos subangulares.

Com a definição dessas camadas ${ }^{(1)}$ e com a decisão de que cada uma delas, com exceção da primeira, receberia três tensiômetros verticalmente equidistantes, 15 cápsulas porosas de alto fluxo, de procedência americana, foram então selecionadas de um total de 30 . Essa seleção levou em conta as características de pressão de borbuIhamento e condutância hidräulica das cāpsulas (LIBARDI, 1984), a fim de que os tensiômetros destinados a cada camada fossem dotados de cápsulas hidraulicamente homogêneas. A Tabela 1 mostra os valores de condutância hidrāulica e pressão de borbulhamento das cápsulas ensaiadas, bem como a profundidade em que foram instaladas no perfil, após a confecção dos tensiômetros.

Os tensiômetros foram construidos artesanalmente, e consistem essencialmente de um tubo de PVC de $1 / 2$ polegada de diâmetro e comprimento variävel de acordo com a profundidade para a qual se deseja obter o valor do potencial matricial; uma cápsula porosa colada numa das extremidades do tubo e uma rolha de borracha ajustada na outra (protegida por tampa rosqueável); e um tubo de "nylor" de $2 \mathrm{~mm}$ de diâmetro interno e comprimento variāvel, conectado numa das extremidades ao tubo de PVC e a outra imersa numa cuba de mercürio. Um procedimento usual que facilita bastante o manejo

(1) Embora os termos camada e horizonte encerrem conceitos pedologicamente distintos, neste trabalho, por simplicidade, eles serão utilizados indistintamente. 
TABELA 1 - Características hidrăulicas das cāpsulas selecionadas para confecção dos tensiômetros e profundidade de instalação nas respectivas camadas morfologicamente homogêneas do solo Terra Roxa Estruturada.

\begin{tabular}{|c|c|c|c|c|}
\hline $\begin{array}{l}\text { espessura } \\
\text { da camada } \\
\quad(\mathrm{cm})\end{array}$ & $\begin{array}{c}n e \text { da } \\
\text { cápsula }\end{array}$ & $\begin{array}{l}\text { prof. de } \\
\text { instalaçãa } \\
\text { no solo }(\mathrm{cm})\end{array}$ & $\begin{array}{c}\text { condutânciaa } \\
\text { hidrāulica }\left(10^{-4}\right) \\
\left(\mathrm{cm}^{2} / \mathrm{s}\right)\end{array}$ & $\begin{array}{l}\text { pressao de } \\
\text { borbulhamento } \\
\left(\mathrm{cm} \mathrm{H}_{2} \mathrm{O}\right)\end{array}$ \\
\hline & 23 & 23,5 & 7,4 & $>1000$ \\
\hline \multirow[t]{3}{*}{$15-49$} & 28 & 32 & 7,4 & $>1000$ \\
\hline & 16 & 40,5 & 7,4 & $>1000$ \\
\hline & 8 & 57,5 & 7,3 & $>1000$ \\
\hline \multirow[t]{3}{*}{$49-83$} & 12 & 66 & 7,3 & $>1000$ \\
\hline & 19 & 74,5 & 7,3 & $>1000$ \\
\hline & 6 & 90,5 & 7,0 & $>1000$ \\
\hline \multirow[t]{3}{*}{$83-113$} & 21 & 98 & 7,0 & $>1000$ \\
\hline & 29 & 105,5 & 7,0 & $>1000$ \\
\hline & 4 & 128 & 6,9 & $>1000$ \\
\hline \multirow[t]{3}{*}{$113-173$} & 18 & 143 & 6,9 & $>1000$ \\
\hline & 22 & 158 & 6,9 & $>1000$ \\
\hline & 10 & 188 & 6,7 & $>1000$ \\
\hline \multirow[t]{2}{*}{$173-233$} & 11 & 203 & 6,7 & $>1000$ \\
\hline & 7 & 218 & 6,7 & $>1000$ \\
\hline
\end{tabular}


operacional desses instrumentos no campo, principalmente quando é necessário uma bateria deles, é confeccionar um suporte de madeira com $2,5 \mathrm{~cm}$ de espessura, por $200 \mathrm{~cm}$ de comprimento, e fazer tantas canaletas no sentido do maior comprimento quanto for o nümero de tensiômetros necessärios. A abertura dessas canaletas deve ser igual ao diâmetro externo do tubo de "nylon", para permitir sua fixação. Além disso, na parte superior do suporte de madeira, são feitos orifícios inclinados por onde os tubos de "nylon" passam e se inserem nas respectivas canaletas, sendo que sua porção terminal livre é inserida na cuba, que por sua vez, pode ser comum a todos os tensiômetros ou individual; normalmente são placas de lucite de comprimento igual à largura do suporte, altura de $7 \mathrm{~cm}$ e espessura de $2 \mathrm{~cm}$, com orifícios de $1,4 \mathrm{~cm}$ e $5 \mathrm{~cm}$ de profundidade para receber o mercūrio, e espaçados igualmente às canaletas. A Figura 2 mostra com detalhes o esquema de um tensiômetro instalado no campo, apontando os materiais acima discriminados .

Com base no esquema mostrado na Figura 2 , è fäcil demonstrar que:

$$
\psi_{m}=-12,6 h+H_{c}+z
$$

onde $\psi_{m}$ è o potencial matricial $\left(\mathrm{cm} \mathrm{H}_{2} \mathrm{O}\right)$; h é a altura da coluna de mercūrio $(\mathrm{cm})$, medida com auxílio de uma rēgua graduada; $H_{c}$ è a distância $(\mathrm{cm})$ entre a superfície do solo e a superfície do mercūrio na cuba; e z è a distância $(\mathrm{cm})$ entre a superfície do solo e a metade do comprimento da cápsula porosa.

No caso deste experimento, à semelhança do que fez PAULETTO (1986), a equação (33) foi um pouco modificada, a fim de considerar a distância $H_{c}$ fixa, uma vez que esta varia à medida quea al- 


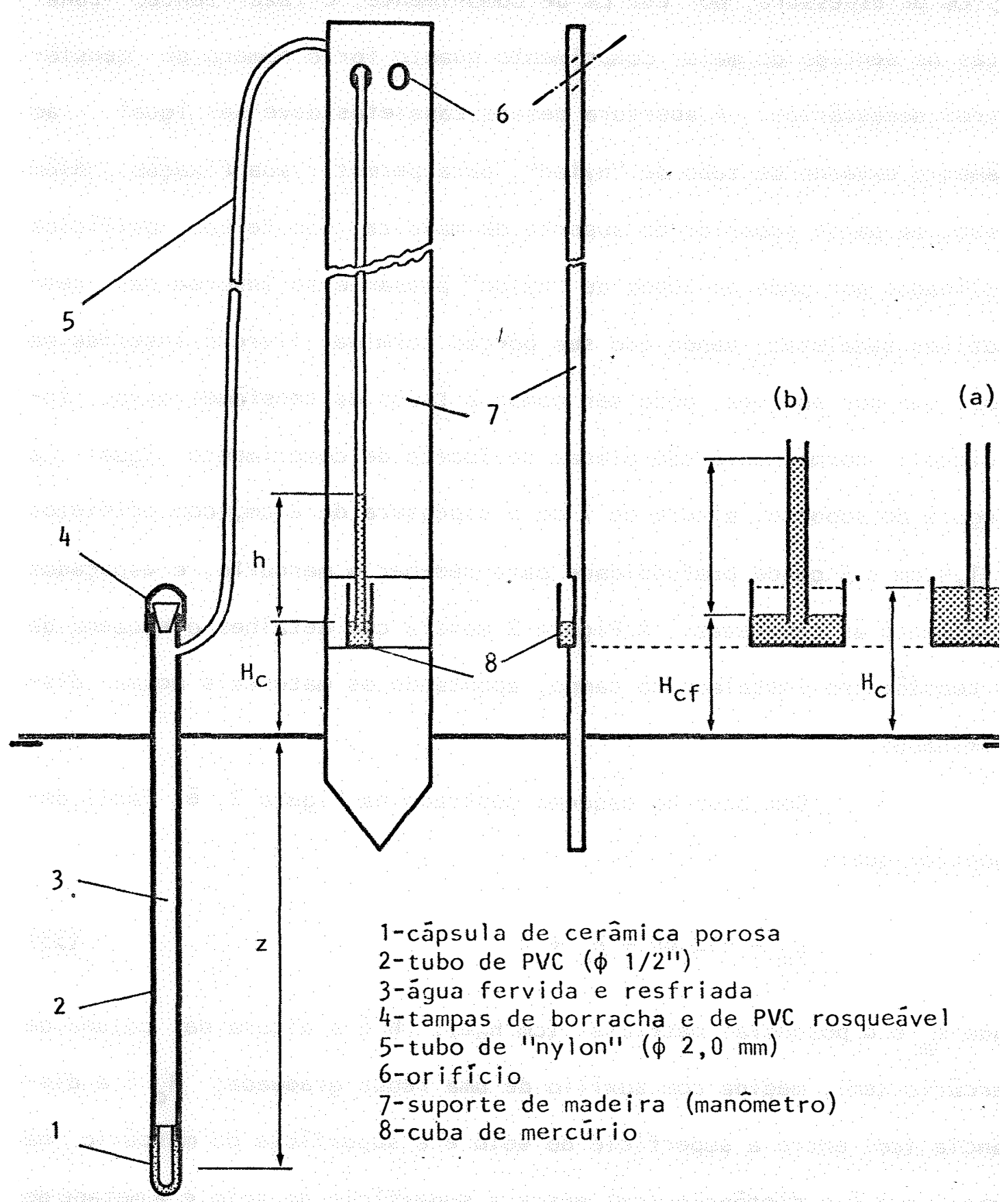

FIGURA 2 - Esquema de um tensiômetro instalado no campo. As letras (a) e (b) referem-se a leituras antes e após o tensiômetro ter sido ativado, respectivamente. 
tura h também varia. Para que isso possa ser feito, hä que se levar em conta o diâmetro da cuba de mercūrio e o diâmetro interno do tubo de "nylon". Assim, uma vez instalados os tensiômetros e colocado o mercūrio em suas cubas correspondentes, marca-se a posição do nível de mercūrio na cuba de cada um deles, de tal maneira que a distância a partir dessa marca (feita antes dos tensiômetros serem ativados) até a superficie do solo, vale $\mathrm{H}_{\mathrm{c}}$.

Quando os tensiômetros são ativados, a coluna $h$ aumenta e, consequentemente, $H_{c}$ decresce (passa de $H_{c}$ para $H_{c f}$, na Figura 2). Para proceder a correção na equação (33), mantendo $H_{c} f i x o$, basta igualar o volume de mercúrio que desaparece na cuba com aquele que vai para o tubo de "nylon", determinar a variação do nível de mercūrio com relação à superfície do solo e descontā-la na equação (33), ou seja:

$$
\frac{\pi D^{2}}{4} \cdot\left(H_{C}-H_{C f}\right)=\frac{\pi d^{2}}{4} \cdot h
$$

ou, explicitando $\mathrm{H}_{\mathrm{c}}-\mathrm{H}_{\mathrm{cf}}$ :

$$
H_{C}-H_{c f}=\left(\frac{d}{D}\right)^{2} h
$$

que, descontada na equação (33), resulta:

$$
\psi_{m}=-\left[12,6+\left(\frac{d}{D}\right)^{2}\right] h+H_{c}+z
$$

onde $\psi_{m}$ é o potencial matricial da ägua no solo $\left(\mathrm{cm} \mathrm{H}_{2} \mathrm{O}\right)$; d é o diâmetro interno $(\mathrm{cm})$ do tubo de "nylon"; e D é o diâmetro (cm) da cuba de mercūrio.

Definidas as profundidades de instalação dos tensiôme- 
tros e os mesmos tendo sido confeccionados, a parcela

experimental

previamente livre de vegetação e de dimensões $5,5 \times 5,5 \mathrm{~m}$, foi nivelada e cercada com tábuas de $30 \mathrm{~cm}$ de largura, as sentadas numa pequena vala de $15 \mathrm{~cm}$ de profundidade, sendo que o solo ao seu redor foi bem compactado para evitar vazamentos durante a saturação.

No centro da parcela foi instalado um tubo de alumínio (selado com uma rolha de borracha numa de suas extremidades), de 4,1 $\mathrm{cm}$ de diâmetro interno e $4,5 \mathrm{~cm}$ de diâmetro externo atē a profundidade de $2,4 \mathrm{~m}$ para acesso da sonda de nêutrons. Para isso, foi utilizado um trado tipo holandês, de diâmetro pouco maior ao tubo.

Para a instalação dos 15 tensiômetros, foram abertos orifícios no solo, dispostos em duas linhas paralelas e distantes $20 \mathrm{~cm}$ um do outro, com ajuda de um trado helicoidal, de diâmetro igual ao do tensiômetro $\left(1 / 2^{\prime \prime}\right)$. Antes da introdução do tensiômetro, o orifício era alargado um pouco com um trado do tipo pistão, de diâmetro pouco maior ao da cápsula porosa. Esse trado era sempre introduzido até uma profundidade $5 \mathrm{~cm}$ menor do que a profundidade alcançada pela ponta da cápsula do tensiômetro, a fim de que, quando este fosse introduzido no orifício, pudesse ser obtido um contato perfeito entre a cápsula e o solo, na profundidade desejada.

Para minimizar os efeitos da ação direta da luz do sol no regime térmico do solo e para prevenir a incidência de chuvas dentro da parcela durante o experimento, a mesma foi coberta por uma tenda de lona plástica. As figuras 3 e 4 mostram o esquema de duas vistas da parcela, vertical e horizontal, respectivamente, com a distribuição dos instrumentos utilizados; o suporte de madeira contendo os manômetros de mercúrio foi instalado fora da parcela, mas sob o abrigo da tenda, e o feixe de tubos de "nylon" que ligam os tensiómetros 
aos respectivos manômetros no suporte de madeira, foi conduzido subterraneamente sob o cercado da parcela por meio de uma mangueira flexivel de 2 polegadas. A distância $H_{C}$ indicada na Figura 3 e definida anteriormente, foi medida com auxilio de um nivel de água.

\subsubsection{Saturação do solo na parcela experimental}

A infiltração foi iniciada colocando-se água na parcela por meio de uma mangueira, a partir de um reservatório de água existente próximo à parcela (Figura 1), até que se estabelecesse a condição de regime de fluxo constante em todas as profundidades, até $218 \mathrm{~cm}$. A parcela foi inundada por quatro vezes consecutivas com uma lâmina de água que totalizou aproximadamente $92 \mathrm{~cm}$.

A confirmação de que se havia atingida a condição de equilíbrio dinâmico foi obtida por meio das colunas de mercúrio nos tensiômetros, isto é, quando estas permaneceram constantes; nesse caso, a umidade do solo não estava mais variando e, consequentemente, o fluxo devia ser constante.

Terminada esta operação, o excesso de água na parcela foi drenado, e a superfície do solo foi coberta com uma lona plástica preta de $48 \mathrm{~m}^{2}$ para evitar qualquer fluxo através da superficie (evaporação ou infiltração). 


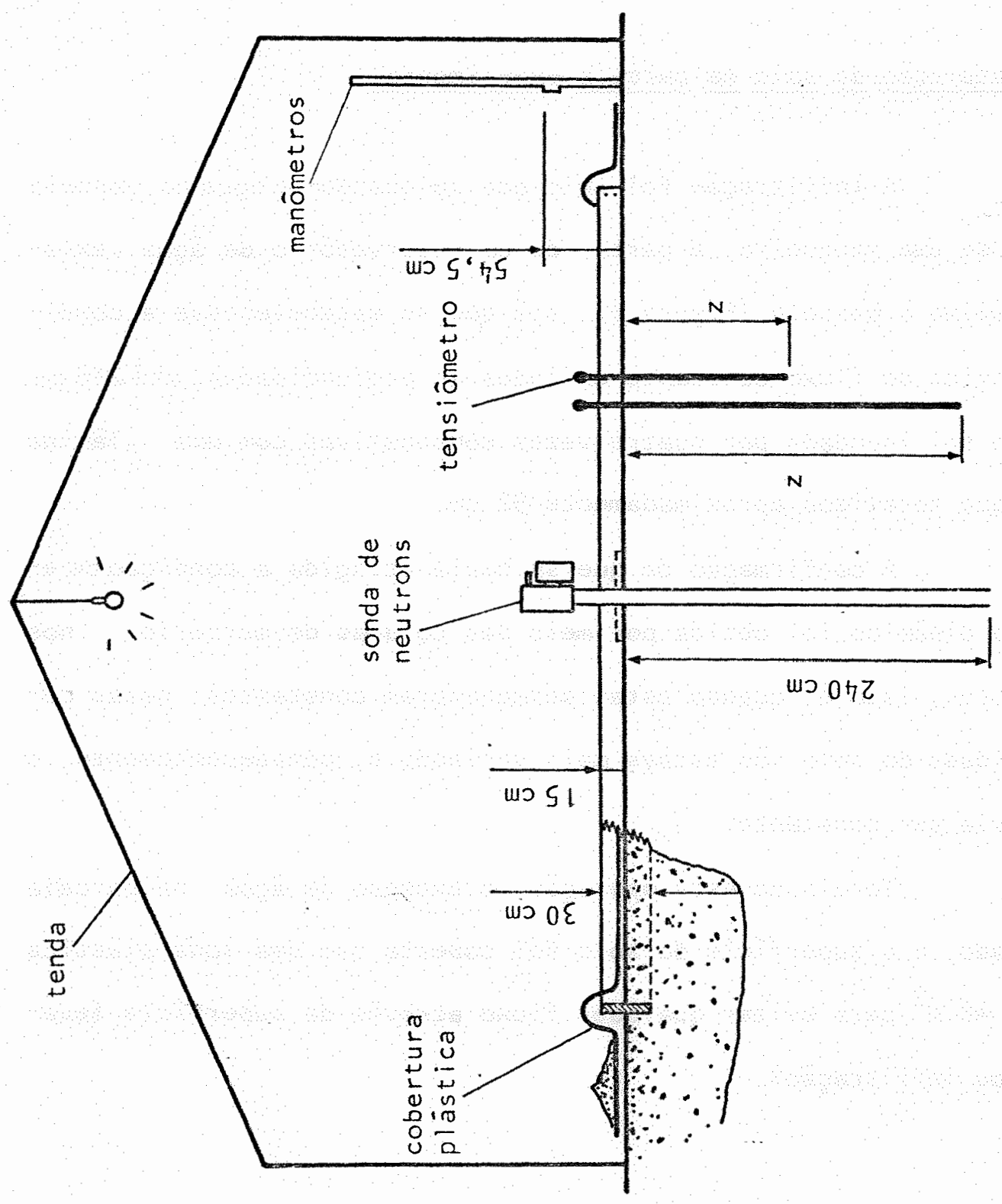

ह.

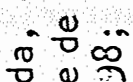

0 0

ป ำ

गे वे

w 40 in

m ta

$\times$ 年

\& 0

ช

L.

in

$5 N$

E 1 in

- 19

$\stackrel{0}{\circ} \div$

Q

ㄴ $\dot{\sim} \ddot{m}$

용 in.

(1) 约

$\sigma=m_{\infty}$

$\overline{0} \pm \bar{N}$

$\checkmark \supset \stackrel{0}{0} 0$

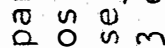

o $\stackrel{\sim}{c} \mathrm{O}$

0 Ð 0 ..

- E

잉

- n

1.0 i

$>$ ni

m 윰

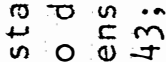

$-100 \pm$

o 3 n

$0.0 \mathrm{~N}$

만.

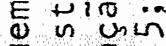

चु $\frac{\pi}{0}$ ก

.

$m$

禾 

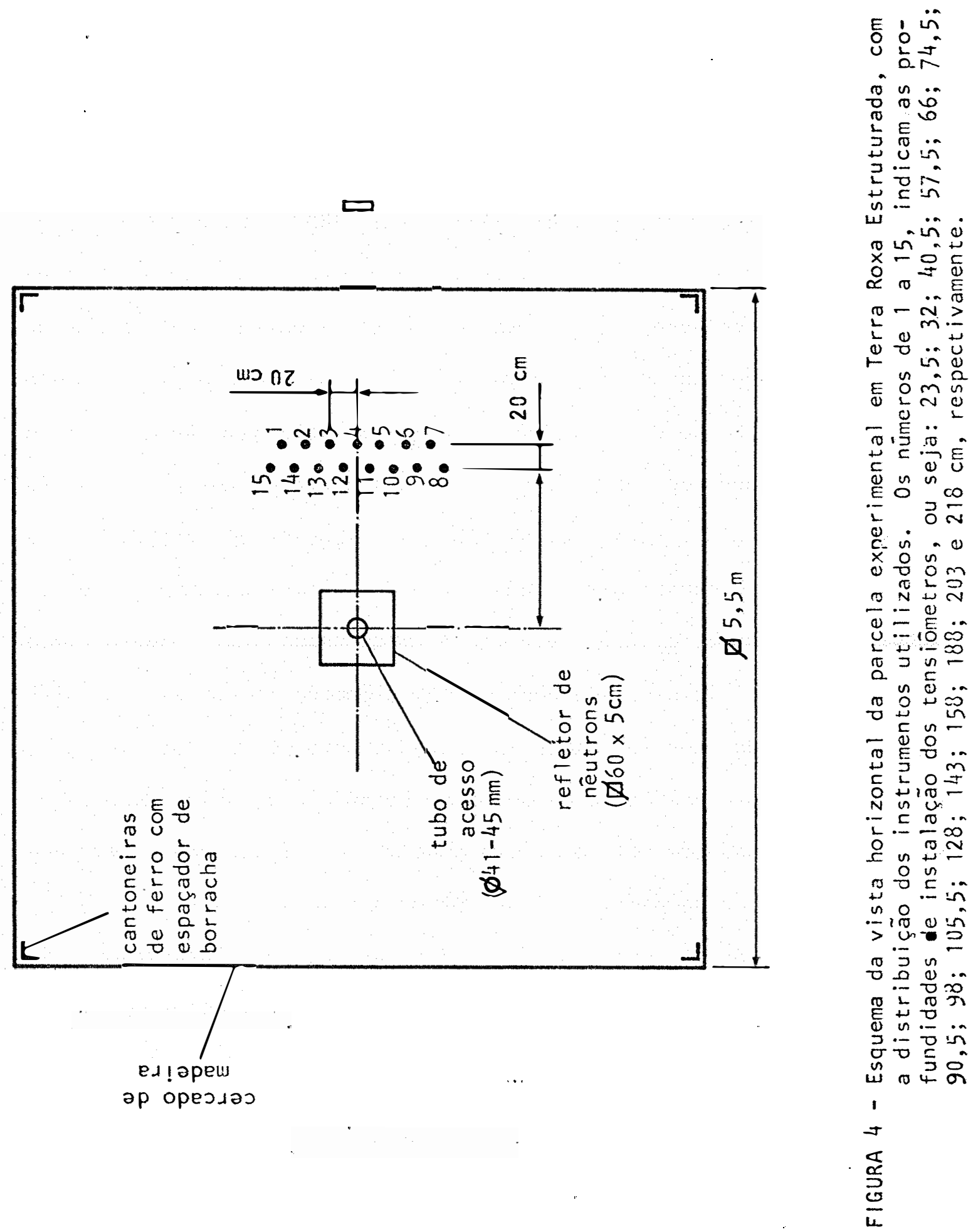
4.2.4. Curvas de calibração da sonda de nêutrons e perfis de umidade em função do tempo

As medidas de umidade ao longo do tempo de redistribuição da água no solo, foram realizadas nas mesmas profundidades de instalação dos tensiômetros, isto é, 23,$5 ; 32 ; 40,5 ; 57,5 ; \quad 66$; 74,$5 ; 90,5 ; 98 ; 105,5 ; 128 ; 143 ; 158 ; 188 ; 203$ e $218 \mathrm{~cm}$, além de mais uma a $7,5 \mathrm{~cm}$, que foi feita visando maior precisão nos cálculos dos fluxos de ägua. Essas medidas foram executadas comauxíliode uma sonda de nêutrons de fabricação francesa, marca Nardeux, modelo Solo-25. Ela contém uma fonte de ${ }^{241} \mathrm{Am}-$ Be de atividade $40 \mathrm{mCi}$, e um cristal cintilador de ${ }^{3}$ He para detecção dos nêutrons termalizados. As medidas superficiais foram feitas sob a proteção de um refletor de nêutrons, que se constituiu de uma placa de polietileno de alta densidade, com dimensões de $0,6 \times 0,6 \mathrm{~m}$ e $5 \mathrm{~cm}$ de espessura. Nessa placa foi feito um orifício no seu centro, com diâmetro pouco maior ao diâmetro do tubo de acesso. Antes do processamento de qualquer leitura, a placa refletora era colocada sobre a superfície do solo, tendo o tubo de acesso passando pelo orifício central, e somente era retirada apos a integração do perfil com as leituras desejadas.

As leituras com a sonda foram feitas a intervalos de minutos no início logo após a cobertura da superfície com a lona plástica, passando a intervalos progressivamente maiores com o tempo de redistribuição da água, durante um período de 27 dias, perfazendo um total de 14 médias de leituras por profundidade. 0 número de leituras para fazer a média por profundidade, no entanto, variou de 3 no início do processo de redistribuição, e foi aumentado para até 12 leituras, à medida que a redistribuição se tornava mais lenta. Esse pro- 
cedimento visou a obtenção de médias bem mais representativas do que evidentemente se obteria com menor nūmero de leituras. Para cada mëdia de leituras, o tempo de redistribuição acumulado considerado (a partir do momento em que a superfície do solo foi coberta, tempo zero), foi aquele no qual era iniciada a primeira leitura na respectiva profundidade. Toda vez, antes de se introduzir a sonda no tubo de acesso, anotava-se a média de 6 a 8 leituras padrões que, neste experimento, foram tomadas quando a fonte radioativa se encontrava dentro da blindagem.

Paralelamente a algumas leituras no solo, amostras com até 3 a 4 repetições eram tradadas para determinação da umidade gravimétrica nas profundidades de leituras com a sonda. Esse procedimento visou obter as curvas de calibração para coñversão da contagem relativa (contagem no solo/contagem padrão), em valores de umidade.

Transcorridos os 27 dias de redistribuição interna da ăgua, a superfície do solo na parcela foi descoberta, todavia mantendo-se a cobertura da tenda de lona plástica. Isso possibilitou uma secagem mais rápida da ăgua no solo e a garantia de obtenção das curvas de calibração mais bem elaboradas, porque as leituras padrões no solo, e as tradagens nas respectivas profundidades, continuaram a ser realizadas de tempo em tempo durante esse processo de evaporação por 30 dias. Após esse período, foi aberta uma trincheira dentro da parcela, com dimensões de 2,0 m de comprimento, 1,0 m de largura, por 2,6 $\mathrm{m}$ de profundidade, de tal modo que uma de suas faces maior tangenciasse o tubo de acesso para a sonda de nêutrons; dessa face, e nas mesmas profundidades de leituras da sonda de nêutrons, foram coletadas 7 amostras de solo não deformado, por profundidade, para determinação da massa específica média do solo, a fim de transformar os 
valores de umidade gravimétrica do experimento em umidade volumétrica. Dessa forma, pôde-se obter as curvas de calibrações com cerca de 22 a 27 pares de pontos, por profundidade, dentro de uma variação de umidade relativamente ampla, sendo que a contagem padrão da sonda foi considerada como a média de todas as médias das leituras padrões realizadas.

Com a obtenção das curvas de calibração por profundidade, as relações entre os valores médios das contagens no solo pela contagem padrão (contagens relativas) foram convertidas em valores de umidade, os quais, por sua vez, foram ajustados com os respectivos tempos de redistribuição interna, pela equação (36), adaptada de van GENUCHTEN (1980):

$$
\theta=\beta+\frac{(\gamma-\beta)}{\left[1+(\alpha t)^{n}\right]^{1-1 / n}}
$$

onde $\alpha, \beta, \gamma$ e n são parâmetros independentes; $t$ é o tempo acumulado de redistribuição da água no solo (a partir da cobertura da superfície do solo, tempo zero de redistribuição); e $\Theta$ a umidade $\left(\mathrm{cm}^{3} / \mathrm{cm}^{3}\right)$.

4.2.5. Perfis de potencial matricial em função do tempo

Os valores de potencial matricial da água no solo, nas diversas profundidades, como uma função do tempo de redistribui ção, foram obtidos com os tensiômetros instalados às profundidades correspondentes.

As leituras dos tensiómetros foram feitas a intervalos de horas, após a cobertura da superfície com a lona plástica, passando a intervalos progressivamente maiores com o tempo de redistribui- 
ção da água, durante o mesmo período de 27 dias, perfazendo um total de 23 leituras por profundidade!

Para um dado tempo qualquer, as leituras das colunas de mercúrio (h) dos tensiōmetros foram realizadas de modo praticamente simultâneo por meio de uma rëgua, uma vez que o conjunto de tubos de "nylon"-cubas de mercúrio foi fixado no suporte de madeira instalado à margem da percela experimental (ver item 4.2.3.), facilitando bastante essa operação. Esses valores medidos juntamente com as distâncias $H_{c}$ e $z$, ambas previamente conhecidas (ver item 4.2.3.), foram utilizados na equação (35) para o cálculo do potencial matricial, $\psi_{m}$. 0 ajuste dos valores de $\psi_{m}$, por profundidade, com 0 tempo de redistribuição, foi feito pela equação:

$$
\psi_{m}=e^{\alpha+\beta \ln (1+t)}
$$

onde $\alpha$ e $\beta$ são parâmetros independentes; e é a base do logaritmo neperiano; e t é o tempo acumulado de redistribuição da água no solo.

4.2.6. Uso da função "SPLINE" cübica na obtenção dos perfis de umidade e de potencial matricial em função da profundidade, e nos cälculos das armazenagens e fluxos da água no solo

Com o auxilio das equações (36) e (37), correspondentes a cada profundidade ( $z$ ) no solo, foram elaboradas duas tabelas $\left(\Theta=\Theta(z, t)\right.$ e $\psi_{m}=\psi_{m}(z, t)$, respectivamente), ambas para uma série de valores de tempos ( $t$ ) em comum, que variaram arbitrariamente desde zero hora até $672 \mathrm{~h}$ de redistribuição, com intervalos de 6 e 6 horas para as primeiras 48 horas, e de 24 em 24 horas para o restante. De 
cada tabela correspondente, para cada tempo fixo, foram obtidos os perfis de umidade e de potencial matricial $\left(\theta=\theta(z)\right.$ e $\left.\psi_{\mathrm{m}}=\psi_{\mathrm{m}}(z)\right)$, res pectivamente, usando uma função "spline"cúbica. Essa função, que em estudos dessa natureza é provavelmente a primeira vez que se utiliza em nosso meio, é um processo analítico de interpolação que promove uma contínua e suave curva a partir dos pares de pontos observados, a qual è diferenciável bem como integrável para um domínio de interesse. E, portanto, um instrumento de auxílio muito importante, principalmente nos estudos quantitativos da dinâmica da água em solos, uma vez que muitos dos processos envolvidos são tratados empiricamente devido à prōpria complexidade que o sistema solo apresenta. Nesses estudos são frequentes as necessidades de se avaliar como a umidade, ou o potencial matricial, ou o potencial hidráulico, se distribuemcomo tempo ou profundidade; da armazenagem da água em função do tempo, etc., e suas derivadas ou integrais são tediosas e sujeitas a erros quando avaliadas manualmente. A função "spline" cúbica usa um processo polinomial de 3 : grau para interpolação de valores entre cada par de pontos observados. Uma polinomial diferente é usada para cada intervalo, e cada um è construido para passar sempre pelos dados originais e apresentar uma derivada contínua nas funções entre cada intervalo. A curva definida por uma polinomial cúbica pode passar exatamente por 4 pontos; mas no caso de uma longa sequência de pontos, é necessário usar uma sucessão de intervalos polinomiais. Por isso, para assegurar que não haja mudanças sübitas nas inclinações ou curvaturas entre os intervalos sucessivos, a função polinomial não é ajustada para quatro pontos, mas somente para dois.

A função "spline" cúbica foi primeiramente desenvolvida por SCHOENBERG (1946) e posteriormente aperfeiçoada por WALSH et 
alii (1962). NIELSEN et alii (1973) foram os primeiros a utilizarem essa função em estudos da dinâmica da água no solo. ERH (1972) mostra algumas aplicações da função "spline" cúbica na ciência do solo, e DAVIS (1986), um exemplo de sua obtenção.

No Apêndice $A$ é apresentado um programa para computar a armazenagem de água (por camada e acumulada), e as tangentes $\left(\frac{\partial \Theta}{\partial z}\right)_{t}$ nos $n$ pares de pontos observados, a partir de um perfil de umidade que se obtēm, por interpolação "spline" cúbica, dos n pares de pontos (umidade versus profundidade). Nește programa, as inclinações são computadas pela obtenção da inclinação da parábola que passa em cada ponto dado e seus dois vizinhos próximos. 0 mesmo programa foi aplicado também para obtenção das tangentes $\left(d \psi_{m} / d \theta\right)_{z},\left(\partial \psi_{m} / \partial z\right)_{t}$ e dos fluxos. de água $(q)_{z}$; bastou apenas organizar as entradas dos dados $x, y$, de acordo com o interesse.

Nesse solo, a umidade entre a superfície do solo e à profundidade de $7,5 \mathrm{~cm}$, foi assumida ser idêntica àquela a $7,5 \mathrm{~cm}$, e a ägua armazenada nessa camada $(0-7,5 \mathrm{~cm})$, foi 7,5 vezes o conteúdo de água na profundidade de $7,5 \mathrm{~cm}$. Para as demais profundidades no perfil, em qualquer tempo, a umidade e a armazenagem foram obtidas a partir de interpolações dos valores de umidade para 23,$5 ; 32 ; 40,5$; 57,$5 ; 66 ; 74,5 ; 90,5 ; 105,5 ; 128 ; 143 ; 158 ; 188 ; 203$ e 218 cm, atravēs da função "spline" cübica, com auxílio do programa dado no Apêndice A. Com os valores de umidade interpolados, a função $\Theta=\Theta(z, t)$ foi então integrada (no programa) de $z=7,5$ até $z$ para obter a armazenagem de água no perfil no tempo $t$ apös o término da infiltração. Assim, a quantidade de água armazenada $A_{z}(\mathrm{~cm})$ no tempo $t$, foi:

$$
A_{z}(t)=7,5 \Theta(7,5 ; t)+\int_{7,5}^{z} \theta(z, t) d z
$$


com incrementos $\mathrm{d} z=0,5 \mathrm{~cm}$.

Para os cálculos do fluxo de āgua $q$, que é a quantidade de água que passa por unidade de tempo e de área numa profundidade de interesse, o programa dado no Apêndice A também foi utilizado. os valores dos fluxos na profundidade $z$ foram calculados pelas razões das variações da quantidade de āgua armazenada no perfil desde a superfície até a profundidade $z$, com o tempo; seus valores são simplesmente:

$$
(q)_{z}=d A_{z}(t) / d t
$$

a qual é a derivada da equação (38) para $A_{z}$.

4.2.7. Difusividades global, matricial, gravitacional e condutividade hidrāulica.

Os experimentos e cálculos descritos nos itens anteriores deste capitulo, foram realizados para que se pudesse calcular as funções difusividades global $\left(D_{g}\right)$, matricial $\left(D_{m}\right)$, gravitacional $\left(D_{z}\right)$, e condutividade hidrāulica $(K)$, todas como uma função da umidade, a partir das teorias desenvolvidas nos itens 3.2. e 3.3.

E fácil perceber que, uma vez conhecida a função $D_{g}(\theta)$ pelo método proposto no item 3.3., e desde que se disponha também as funções $\psi_{m}=\psi_{m}(\theta)$ (curva característica) e $\theta=\theta(z)$ (perfil de umidade), então pode-se obter a relação funcional $K(\theta)$ pela equação (26), que por sua vez, possibilita o conhecimento das funções $D_{m}(\theta)$ e $D_{z}(\theta)$, pelas equações (21) e (22), respectivamente. Além disso, para comprovar a validade da equação (25), deve-se dispor ainda de uma outra metodologia, reconhecidamente aceita como padrão para obtenção das relações funcionais $K(\Theta)$ e $D_{m}(\theta)$. Com esse propósito, a metodologia 
adotada neste trabalho, foi a proposta por HILLEL et alii. (1972), por apresentar um roteiro simples e completo. Dessa forma, se existir uma relação estreita entre essas duas funções assim obtidas, com as mesmas respectivas funções obtidas pela teoria proposta, então a hipótese fundamental do trabalho será aceita, notadamente os conceitos emitidos e o cumprimento da condição de homogeneidade hidrāulica imposta pela equação (18), para cada camada de solo considerada. Para isso, foi utilizado um procedimento simplificado, que consiste na elaboração de duas tabelas: uma para determinação dos fluxos de ãgua no solo nas diversas profundidades e para diversos tempos, que $\vec{e}$ comum tanto parao método de HILLEL et alii (1972), como para a teoria proposta; e a outra para cálculo das funções $D_{g}(\theta), D_{z}(\theta), D_{m}(\theta)$ e $K(\theta)$ pela teoria proposta, e $K(\Theta)$ e $D_{m}(\Theta)$ pelo método de HILLEL et alii (1972), doravante simbolizadas, respectivamente, por $K_{H}(\Theta)$ e $D_{m H}(\theta)$.

Essas funções foram calculadas em cada profundidade de interesse e para diferentes umidades, da seguinte forma:

(i) $D_{g}(\Theta)$ : pela teoria proposta no item 3.3., equação (32b), isto é, dividindo os fluxos apresentados na primeira tabela pelos gradientes de umidade $\partial \Theta / \partial z$ obtidos pela função "spline" cúbica (Apêndice A);

(ii) $K(\theta)$ : pela teoria proposta, equação (26), isto é, dividindo os valores de $D_{g}(\Theta)$ pela soma das tangentes $d \psi_{\mathrm{m}} / \mathrm{d} \theta$ e $\mathrm{dz} / \mathrm{d} \theta$, respectivamente obtidas a partir da curva caracteristica e perfil de umidade pela função "spline" cübica (Apêndice A);

(i i i) $D_{m}(\Theta)$ : pela teoria proposta, equação (21), isto ē, multiplicando os valores de $K(\Theta)$ pelas tangentes $d \psi_{m} / d \theta$;

(iv) $D_{z}(\Theta)$ : pela teoria proposta, equação (22), isto é, multiplicando os valores de $K(\Theta)$ pelas tangentes $d z / d \theta$; 
(v) $K_{H}(\Theta)$ : pela teoria proposta por HILLEL et alii (1972), isto é, dividindo os fluxos apresentados na primeira tabela pelos gradientes de potencial hidräulico, $\partial \psi_{h} / \partial z$, que por sua vez, foram calculados somando uma unidade aos gradientes de potencial matricial, $\partial \psi_{m} / \partial z$, esses obtidos pela função "spline" cúbica (Apêndice A); e, finalmente,

(vi) $\mathrm{D}_{\mathrm{mH}}(\theta)$ : pela teoria proposta por HILLEL et al ii (1972), isto é, multiplicando os valores de $K_{H}(\theta)$ pelas tangentes $d \psi_{m}$ ' $d \Theta$.

4.3. Experimento em duna de areia. (dados fornecidos por CHO et alii, 1977)

Todos os detalhes da instalação e desenvolvimento experimental nesse solo são apresentados por CHO et alii (1977), de maneira que aqui somente serão fornecidas algumas informações julgadas indispensāveis.

A ärea experimental utilizada nesse solo localiza-se dentro do Instituto de Pesquisas de Dunas de Areia, Faculdade de Agricultura, Universidade de Tottori, Tottori, Japão, próximo a um Posto Meteorológico, cujas coordenadas geogrä́icas são $35^{\circ} 32 !$ de latitude Norte, $134^{\circ} 12^{\prime}$ de longitude Leste, a $23 \mathrm{~m}$ de altitude.

Os dados meteorológicos coletados no posto próximo mostram, em termos médios anuais, que a precipitação para 20 anos (19511970) foi $2009 \mathrm{~mm}$, e a evaporação (evaporímetro de $20 \mathrm{~cm}$ de diâmetro), $1251 \mathrm{~mm}$. O clima da região é úmido. 
A distribuição do tamanho de partículas numa amostra típica da duna, revelou que $10 \%$ do material é constituído de partículas com diâmetro menor que $0,22 \mathrm{~mm} ; 20 \%$ com diâmetromenor que 0,28; $60 \%$ com diâmetro menor que 0,33 ; e $100 \%$ com diâmetro menor que 0,9 mm. Com base nas classes texturais do método internacional, o solo é classificado como areia no triângulo textural, com massa especificade partículas em torno de $2,7 \mathrm{~g} / \mathrm{cm}^{3}$ e massa específica do solo em torno de $1,5 \mathrm{~g} / \mathrm{cm}^{3}$ (provavelmente Quartzipsamment, pela Soil Taxonomy, ESTADOS UNIDOS, 1979).

A taxa de infiltração bäsica medida com cilindros infiltrômetros foi de $1300 \mathrm{~mm} / \mathrm{h}$; a capacidade de campo na ordem de 7\% em volume, e a máxima capacidade de retenção, na ordem de 35\% (tambēm em volume). 0 lençol freático nesse solo se encontra a cerca de 30 m de profundidade.

Nesse solo, uma parcela com dimensões $5 \times 5 \mathrm{~m}$ foi instalada e coberta com uma tenda, no sentido de possibilitar a obtenção da relação $K(\theta)$, pelo método de HILLEL et alii (i972). Para isso, foi instalado um tubo de alumínio para acesso da sonda de nêutrons, e tambēm uma bateria de 12 tensiômetros nas profundidades de 5, 10, $15,20,30,40,50,60,70,80,90$ e $100 \mathrm{~cm}$. Para as primeiras 4 profundidades, as curvas de calibração foram obtidas por meio de uma sonda de nêutrons de superficie, e para as demais com uma sonda de nêutrons de profundidade. Após o solo ter sido previamente 'saturado e coberta sua superfície com uma lona plästica (tempo zero de redistribuição), as leituras com as sondas e tensiômetros foram processadas por um período de 7 dias, em intervalos de minutos no início do processo, passando a intervalos de horas apös a primeira hora, e de dias após o primeiro dia de leituras. 
Os dados sumarizados por CHO et alii (1977), da umidade e do potencial matricial em função da prófundidade e do tempo de redistribuição da água, encontram-se respectivamente nas Tabelas 1 e 2 do Apêndice B, e foram utilizados neste trabalho tambēm com o propósi to de aplicação e verificação da validade da teoria proposta.

Presumivelmente, por se tratar de um solo de morfologia homogênea, a teoria foi aplicada para as profundidades de 10,15 , $20,30,40,50,60,70,80$ e $90 \mathrm{~cm}$, e os dados utilizados foram os originalmente apresentados por CHO et alii (1977), Tabelas 1 e 2 do Apêndice $B$, sem ajustes dos perfis de umidade e de potencial matricial em função do tempo, já que o número de dados nessas tabelas é suficientemente grande.

Aqui, a função "spline" cūbica (Apêndice A) também foi utilizada na obtenção dos perfis de umidade e de potencial matricial em função da profundidade. A quantidade de ägua a rmazenada $A_{z}(\mathrm{~cm})$ no tempo t foi calculada pela equação:

$$
A_{z}(t)=5,0 \Theta(5,0 ; t)+\int_{5,0}^{z} \theta(z, t) d z
$$

com incrementos $\mathrm{dz}=0,5 \mathrm{~cm}$; e os valores dos fluxos na profundidade z foram calculados pela equação (39).

Finalmente, para a obtenção das funções $D_{g}(\Theta), D_{m}(\Theta)$, $D_{Z}(\theta), D_{m H}(\theta), K(\theta)$ e $K_{H}(\theta)$, seguiu-se exatamente o descrito no item 4.2.7., do experimento em Terra Roxa Estruturada. 


\section{RESULTADOS E DISCUSSÃO}

\subsection{Experimento em Terra Roxa Estruturada}

5.1.1. Massa especifica do solo.

A Tabela 2 mostra os valores médios da massa específica do solo e seus desvios padrões respectivos, obtidos nas várias pro-. fundidades estudadas nessẹ solo; são mostradas tạmbém as umidades médias correspondentes por ocasião da coleta dessas amostras no final do experimento, bem como seus respectivos desvios padrões

Esses dados revelam que o solo é mais compacto na superficie $(23,5$ e $32 \mathrm{~cm})$, com os valores da massa especifica decrescendo gradualmente com a profundidade; a variabilidade dos dados pode ser considerada baixa (WARRICK E NIELSEN, 1980).

\subsubsection{Curvas de calibração da sonda de nêutrons.}

o valor médio (contagem ou leitura padrão) das médias de leituras realizadas durante todo o experimento com a sonda de nêutrons dentro de seu corpo de blindagem, é mostrado na Figura 5 . Esse valor foi de $164,985 \mathrm{cpm}$, com um desvio padrão, para os 20 valores mostrados na Figura 5 , de apenas $1,45 \mathrm{cpm}$. Como o corpo de blindagem da sonda é de polietileno, procedimento dessa natureza para determinação da contagem padrão, pode não ser o mais adequado, se com- 
TABELA 2 - Massa específica do solo, $\rho_{s}$, umidade de coleta, $\theta$, e seus respectivos desvios padrões, $s$, em função da profundidade do solo Terra Roxa Estruturada. Mëdia de 7 repetições por profundidade.

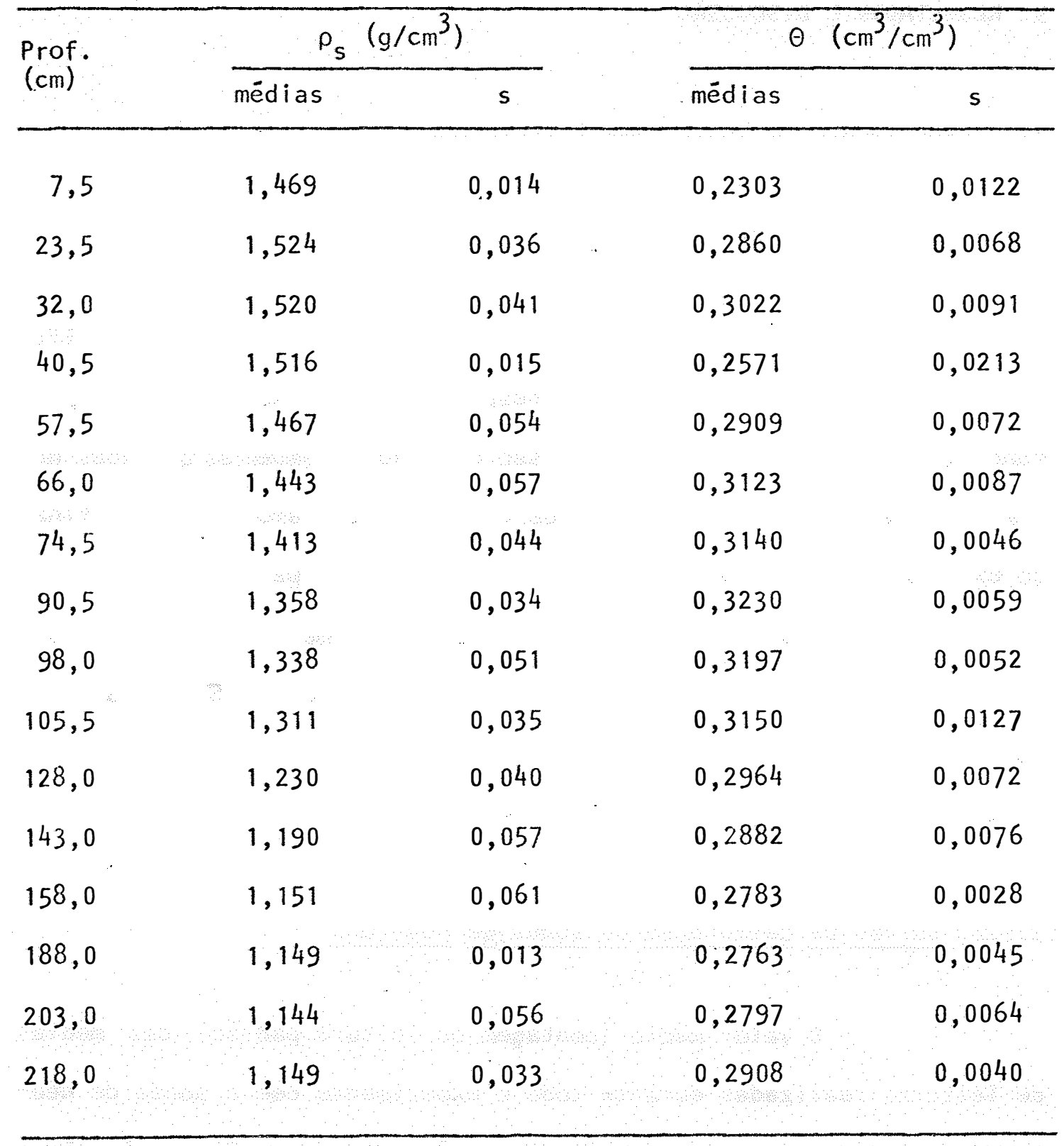


parado com a àgua que è um ótimo térmalizador. Mesmo assim, os dados obtidos revelam a boa performance da sonda empregada, embora o período do experimento sob condições de campo tenha sido relativamente curto (57 dias), e não sujeito a grandes oscilações térmicas.

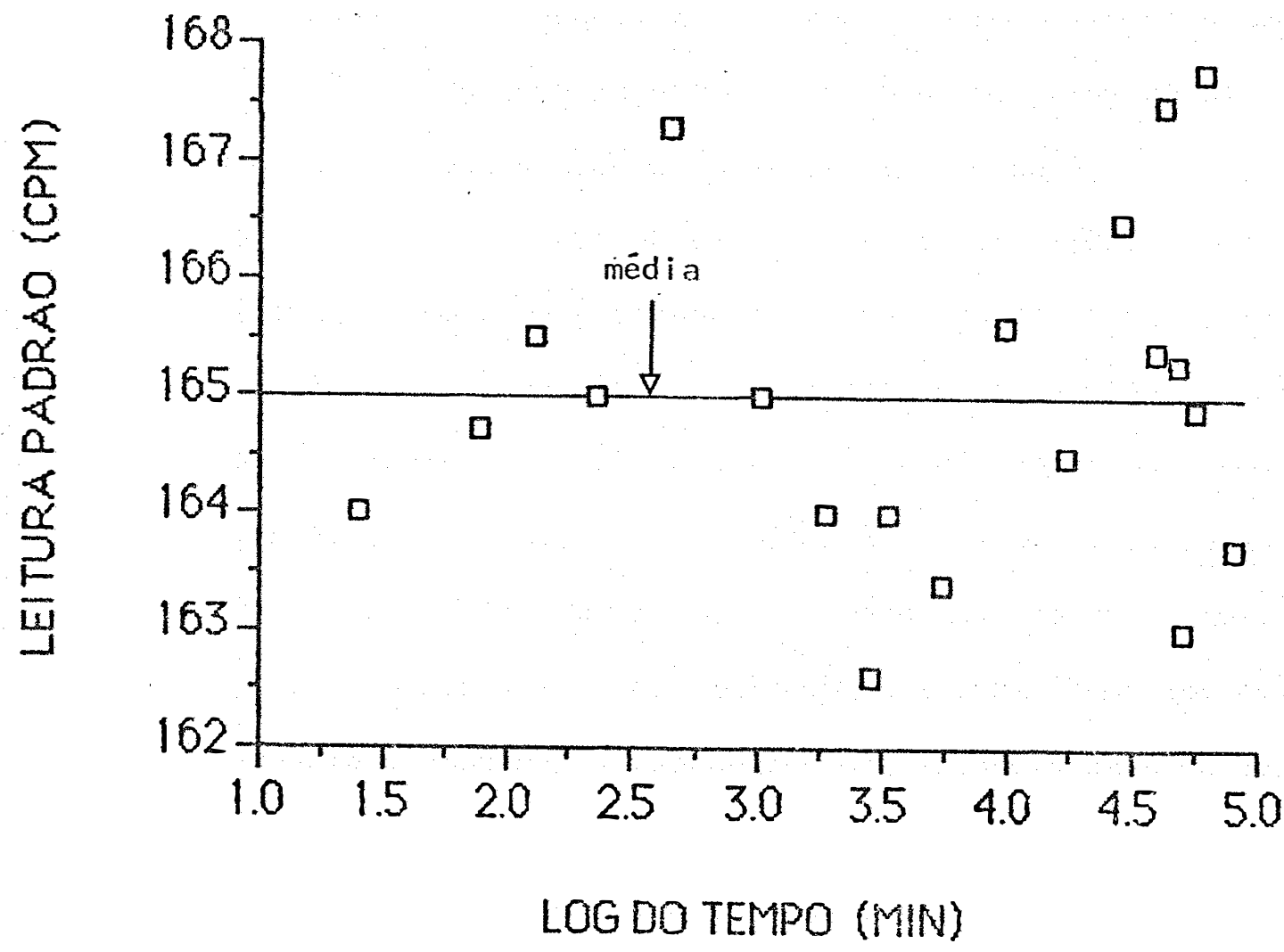

FIGURA 5 - Leitura padrão para a sonda de nêutrons empregada no experimento em Terra Roxa Estruturada, sob condições de campo.

A Tabela 1 do Apêndice $C$ mostra os valores médios das contagens padrões e das contagens no solo realizadas com a sonda de nêutrons nas profundidades estudadas, em diferentes tempos. Como descrito no item 4.2.4., essas leituras foram processadas em duas fases: a primeira, durante o período de redistribuição da àgua no solo da parcela previamente saturada e prevenida a evaporação e infiltra- 
ção (27 dias de duração); e a segunda, durante o período de redistribuição e evaporação da água, após a remoção da lona plástica que cobria a superficie do solo (30 dias de duração).

No mesmo Apêndice, a Tabela 2 mostra os valores de $u$ midade obtidos através de amostras que foram coletadas por tradagens, nas mesmas profundidades e nos mesmos tempos em que se processaramalgumas das leituras no solo com a sonda de nêutrons.

A partir desses dados e dos valores da massa especifica do solo (Tabela 1), foram construidos os gräficos de calibração da sonda, por profundidade, relacionando a umidade volumétrica em função da contagem relativa (contagem no solo/contagem padrão). Esses gräficos encontram-se nas figuras 6 a 21 , e as curvas que se ajustam aos pontos experimentais foram obtidas através de regressão, cujos coeficientes de determinação $\left(r^{2}\right)$ variaram entre 0,505 e 0,993 . 0s valores dos coeficientes de determinação e as equações de regressão obtidos para as diversas profundidades, encontram-se dispostos na Tabela 3. Para esses ajustes, foi estudada uma família de 13 equações diferentes, e o critērio adotado para sua escolha foi o maior coeficiente de determinação. Isso resultou na equação da reta para a maioria das profundidades, com exceção das profundidades 23,5 e $32 \mathrm{~cm}$, cujas equações são do tipo polinomial de 2 a. ordem inversa. Fatos como esse são comuns de serem observados sob condições de campo (cHo et alii, 1977; BELTRAME \& TAYLOR, 1980), principalmente nas profundidades mais superficiais do perfil, onde os outros constituintes do solo, a lém da água, podem não ser desprezíveis na moderação dos nêutrons rápidos. De qualquer forma, desde que a precisão do método da moderação de nêutrons depende da derivação de uma regressão onde as contagens possam ser satisfatoriamente convertidas em umidade no solo, as 
calibrações para essas duas profundidades, 23,5 e $32 \mathrm{~cm}$, careceram de um maior nümero de pontos experimentais, principalmente entre os limites de contagem relativa $2,6-2,9$ e $2,95-3,15$, respectivamente. E esse não parece ser o caso da calibração na profundidade de $40,5 \mathrm{~cm}$ onde os limites de contagem relativa (Figura 9) estão bem representados pelos pontos experimentais, mas com baixo coeficiente de determinação devido a um problema de variabilidade natural do solo nessa profundidade; isso pode ser observado na Tabela 2 do Apêndice C, que mostra valores de umidades até bem distintos para uma mesma contagem no solo.

Quanto às demais 13 profundidades do perfil, a Tabela 3 e as figuras correspondentes, mostram que as calibrações foram muito boas, melhorando sensivelmente com o aumento da profundidade, provavelmente decorrente de uma maior homogeneidade do solo.

Finalmente, os coeficientes angulares das equações da reta mostrados na Tabela 3, revelam uma particularidade importante, do ponto de vista de ćbtenção experimental dessas calibrações. Como se observa, os valores numéricos dos coeficientes angulares apresentam-se levemente decrescentes com o aumento da profundidade, com um mäximo de 0,159 e um mínimo de 0,118. Essa é uma variação muito pequena, pois os arcos tangentes desses valores resultam nos ângulos de 9 e $6,7^{\circ}$, respectivamente e, portanto, muito pröximos. Com isso, para propōsitos präticos, desde que se disponha de uma ünica calibração,adequadamente elaborada para qualquer profundidade no perfil, então a calibração para qualquer outra profundidade de interesse (com exceção, ao que parece, daquelas mais superficiais), pode ser facilmente obtida, bastando para isso proceder simultaneamente uma leitura com a sonda e uma tradagem cuidadosa, e a partir desses valores, traçar uma pa- 
ralela ao ajuste previamente obtido.

\subsubsection{Perfis de umidade em função do tempo}

Os dados de umidade para as diversas profundidades como uma função do tempo de redistribuição da āgua, foram obtidos pela conversão dos valores de leituras no solo com a sonda de nêutrons (Tabela 1 do Apêndice $($ ), nas profundidades e tempos respectivos, atravēs das equações de calibração (Tabela 3 ).

A partir desses dados, foram feitos os gráficos de umidade em função do tempo de redistribuição da água no solo, para cada profundidade, os quais se encontram nas Figuras 22 a 37 . Nesses gráficos, as linhas que se ajustam aos pontos experimentais foram obtidas por meio da equação (36) através de regressão não-linear (BORAT0, 1984), com al tos coeficientes de determinação $\left(r^{2}\right)$, para todas as profundidades, mostrando a adequação da equação (36) em descrever o fenômeno. Essa equação constitui-se numa novidade no emprego de representações dessa natureza e foi adaptada de Van GENUCHTEN (1980), que a utiliza para ajustes em curvas características, simplesmente substituindo o termo $\psi_{m}$ (potencial matricial) por $t$ (tempode redistribuição da água), na equação (36). Os valores dos coeficientes de determinação e dos parâmetros de ajuste da equação (36) obtidos para as diversas profundidades, encontram-se dispostos na Tabela 4.

\subsubsection{Perfis de potencial matricial em função do tempo}

A Tabela 3 do Apêndice $C$ mostra os dados de potencial matricial para os diferentes tempos de redistribuição da água nas di - 
versas profundidades estudadas, ou seja: 23,$5 ; 32 ; 40,5 ; 57,5 ; 66$; 74,$5 ; 90,5 ; 98 ; 105,5 ; 128 ; 143 ; 158 ; 188 ; 203$ e $218 \mathrm{~cm}$. Atravës desses valores e da utilização da equação (37), foram construídos os gräficos de potencial matricial em função do tempo de redistribuição da ägua no solo, para cada profundidade, os quais se encontram nas Figuras 38 a 52.

Aqui, os ajustes dos pontos experimentais à equação (37), obtidos atravēs de regressão não linear (BORATO, 1984), foram muito bons, visto que os' coeficientes de determinação superam a 0,975 para todas as profundidades, mostrando a adequação da equação, que tambëm se constitui numa novidade no emprego de representações dessa natureza. Ela foi adaptada a partir de uma conhecida equação exponencial do tipo $y=e^{\alpha+\beta x}$ (que resulta na equação dá reta, quando logaritmizada), e das condições teóricas desenvolvidas por LIBARDI (i978). Os valores dos coeficientes de determinação e dos parâmetros de ajuste da equação (37) obtidos para as diversas profundidades, encontramse dispostos na Tabela 5 . 


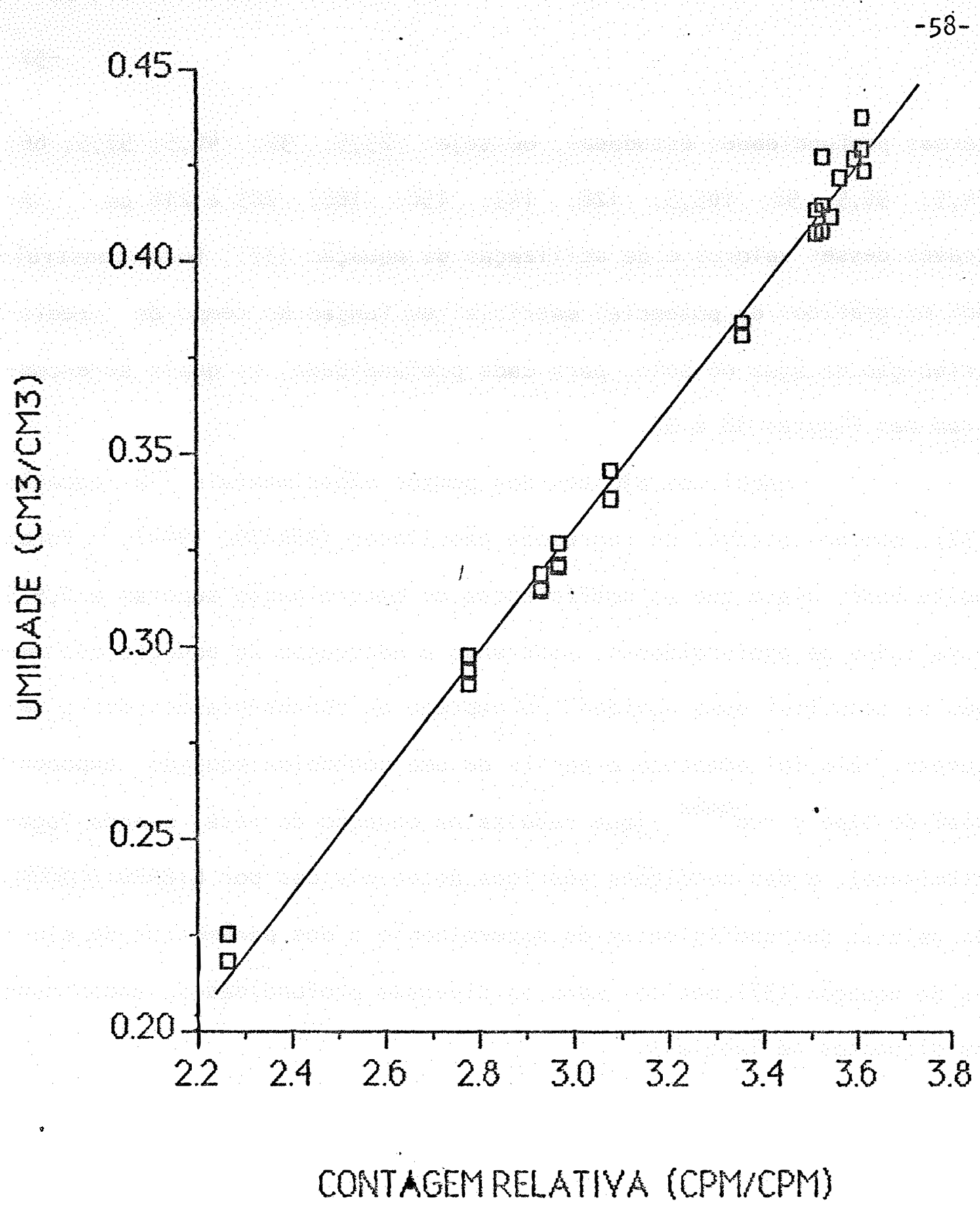

FIGURA 6 - Calibração da sonda de nêutrons para a profundidade de $7,5 \mathrm{~cm}$ do solo Terra Roxa Estruturada. 


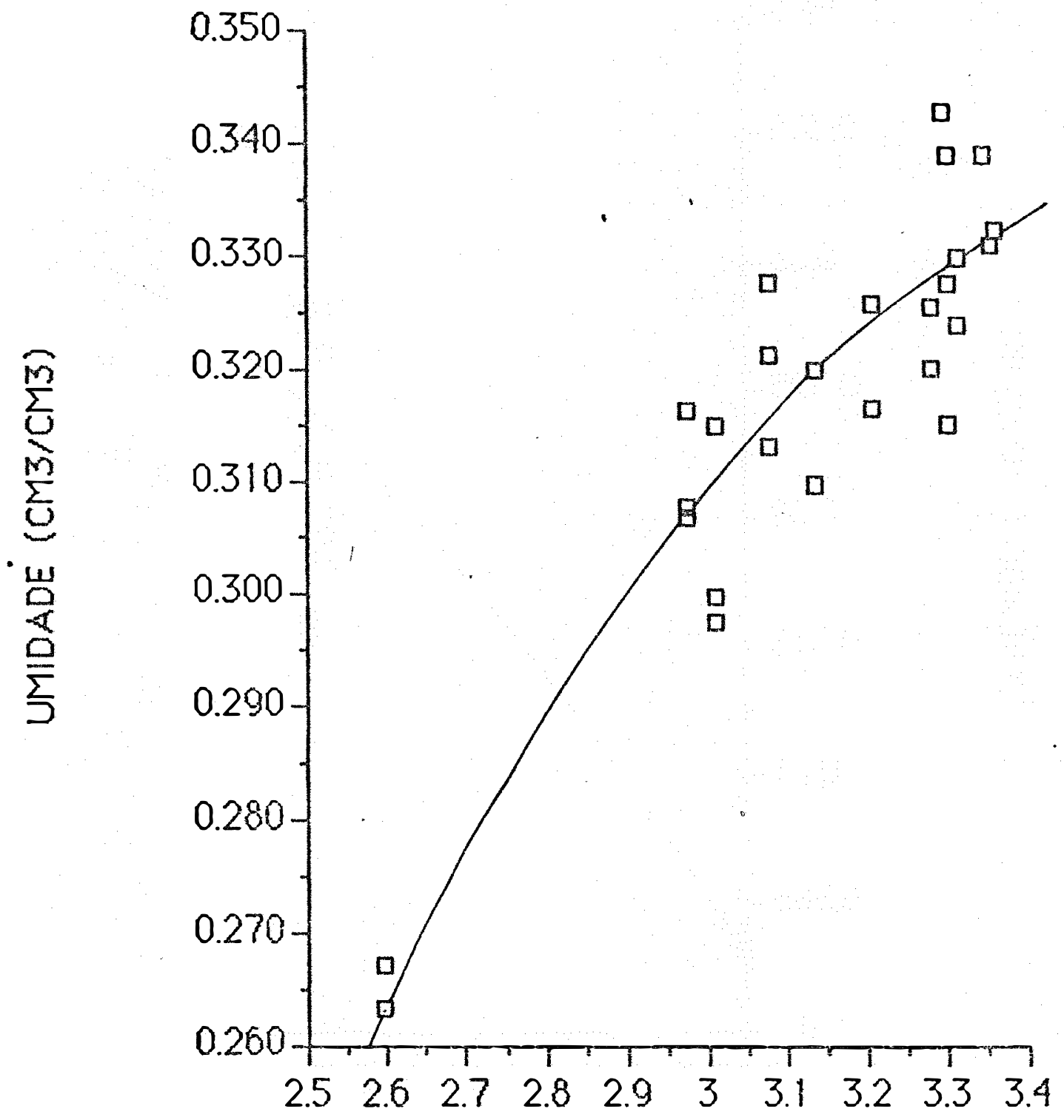

CONTAGEMRELATIVA (CPMICPM)

FIGURA 7 - Calibração de sonda de nêutrons para a profundidade de $23,5 \mathrm{~cm}$ do solo Terra Roxa Estruturada. 


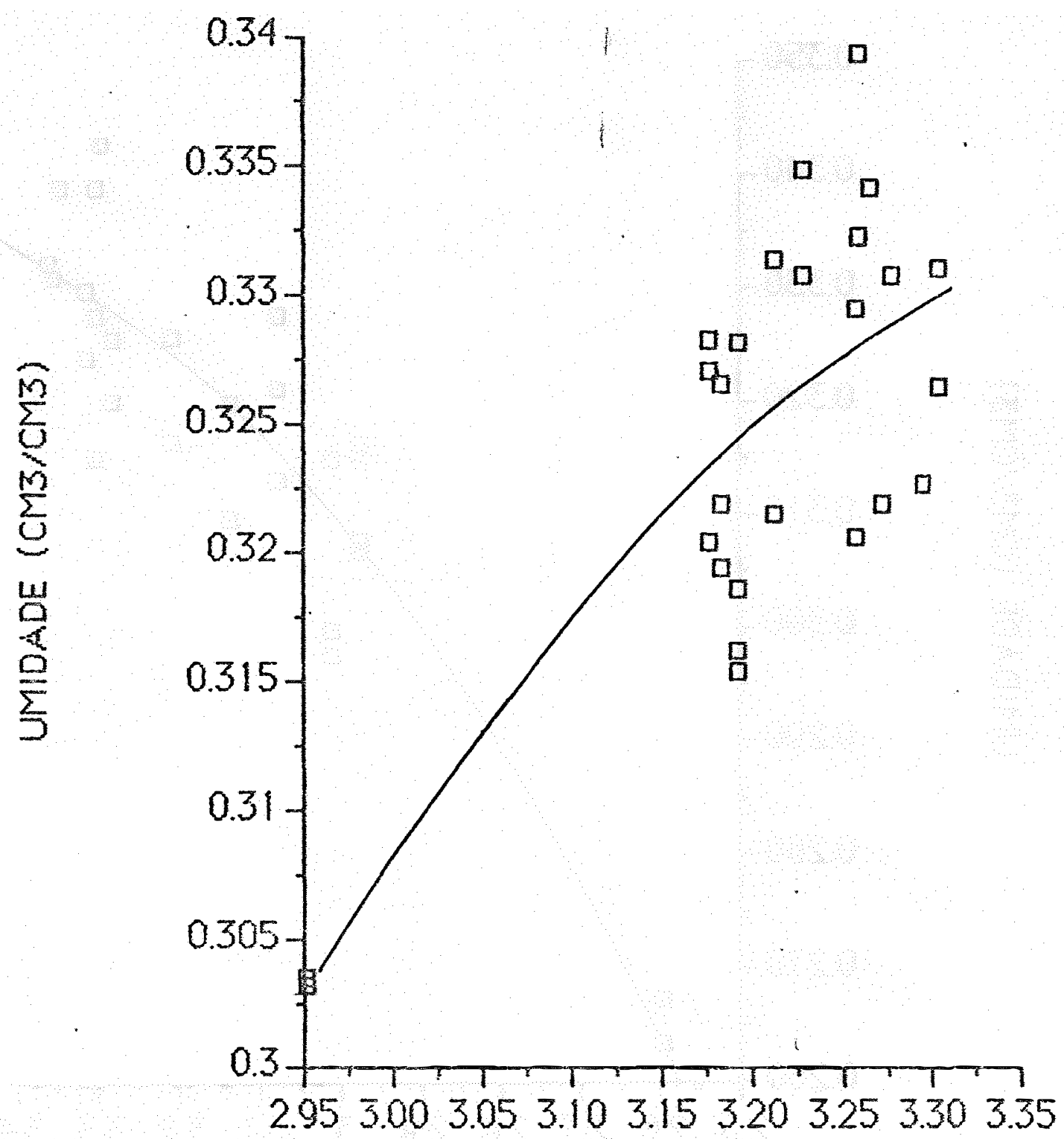

CONTAGEMRELATIVA (CPM/CPM)

FIGURA 8 - Calibração da sonda de néutrons para a profundidade de $32 \mathrm{~cm}$ do solo Terra Roxa Estruturada. 


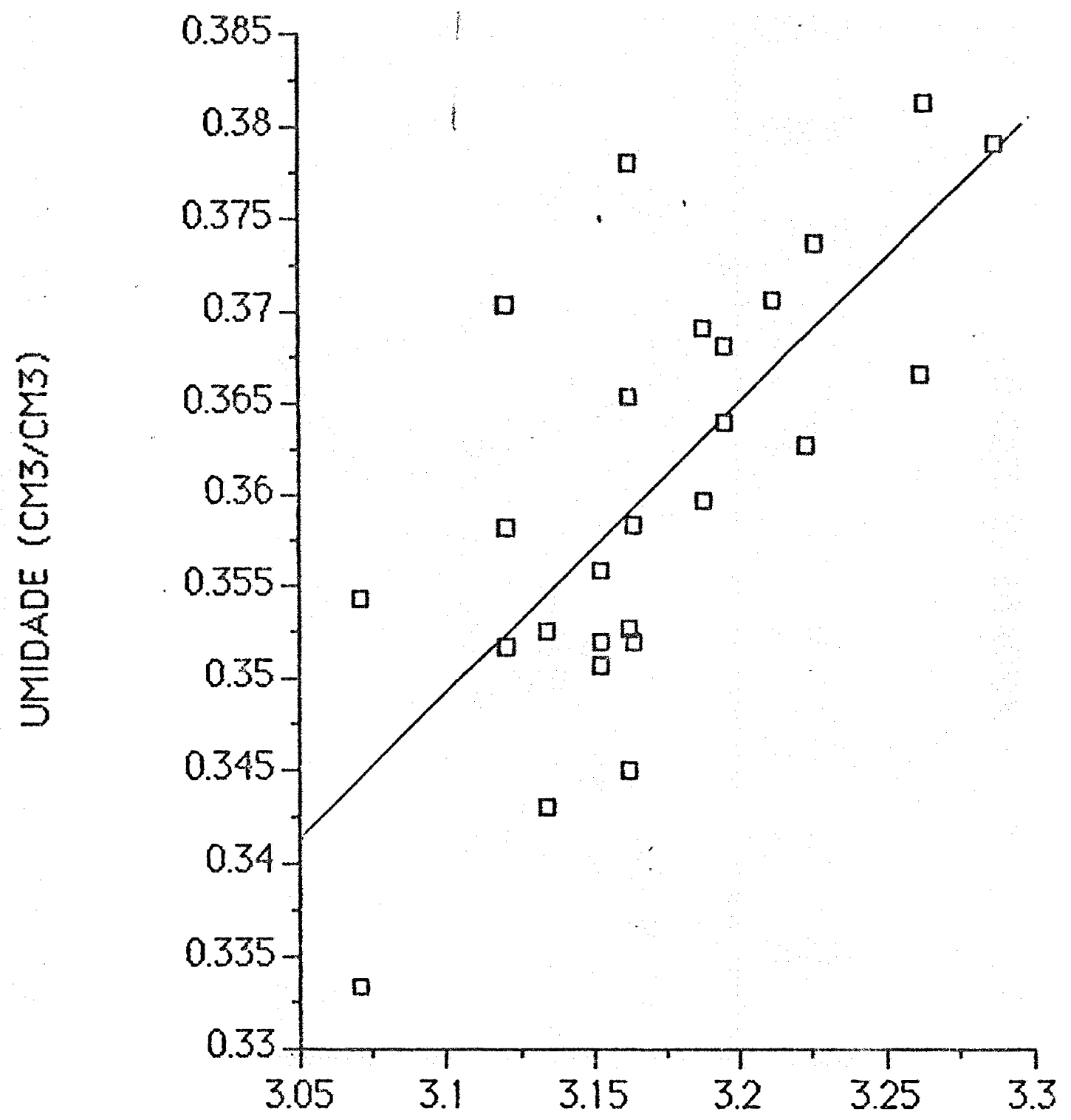

CONTAGEMRELATIVA (CPM/CPM)

FIGURA 9 - Calibração da sonda de nêutrons para a profundidade de $40,5 \mathrm{~cm}$ do solo Terra Roxa Estruturada. 


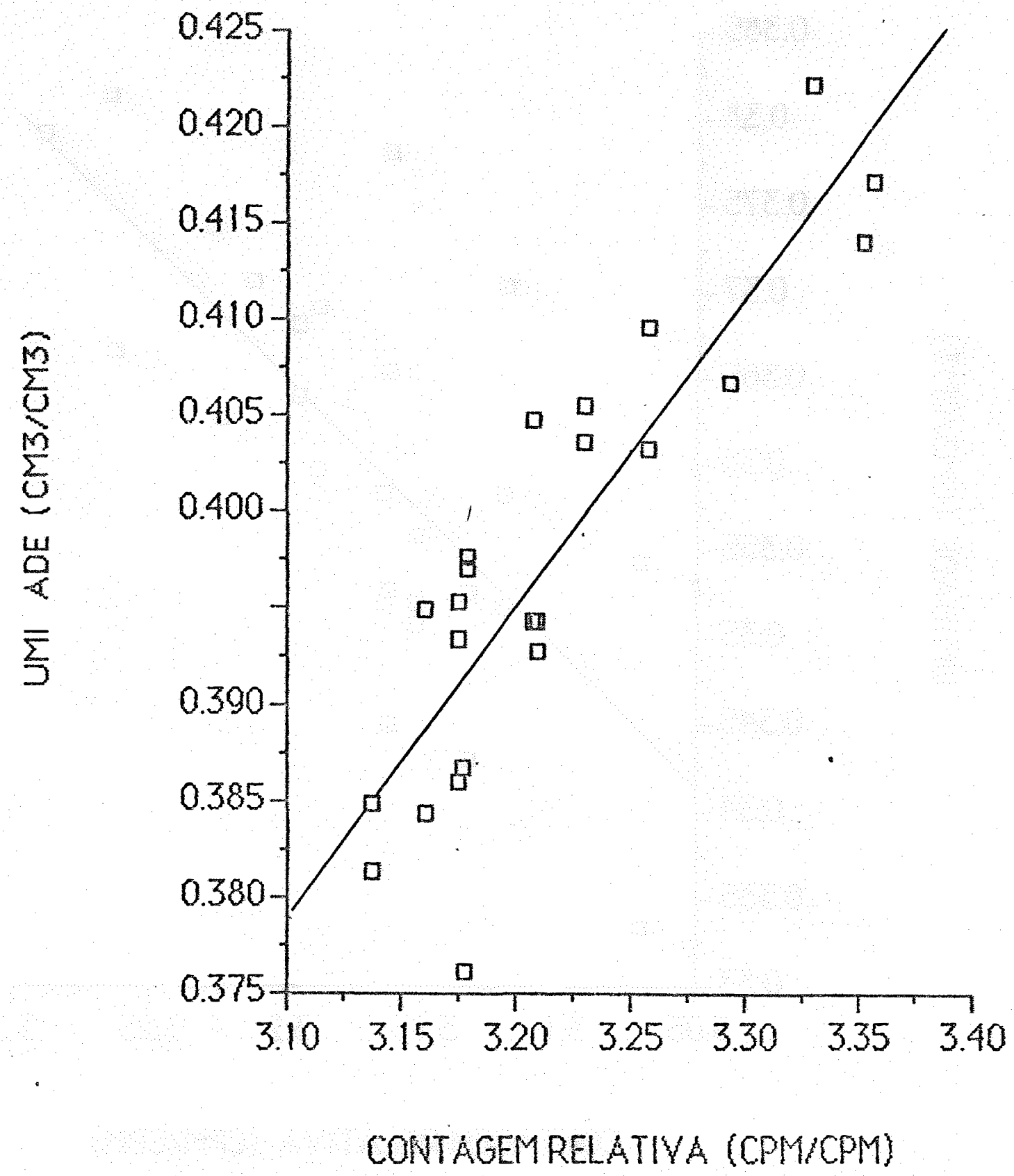

FIGURA 10 - Calibração da sonda de nêutrons para a profundidade de $57,5 \mathrm{~cm}$ do solo Terra Roxa Estruturada. 


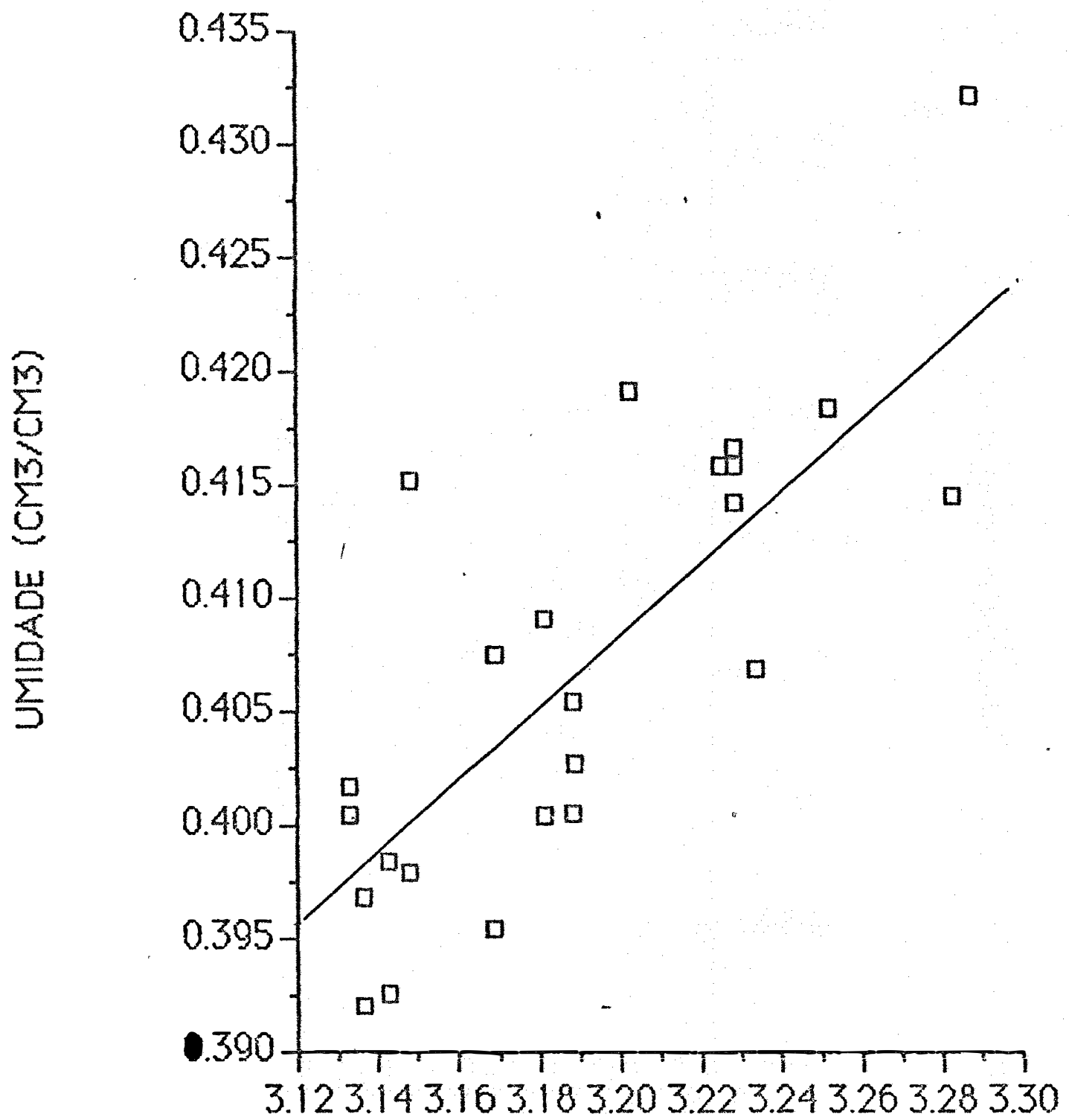

CONTAGEMRELATIVA (CPM/CPM)

FIGURA 11 - Calibração da sonda de nêutrons para a profundidade de $66 \mathrm{~cm}$ do solo Terra Roxa Estruturada. 


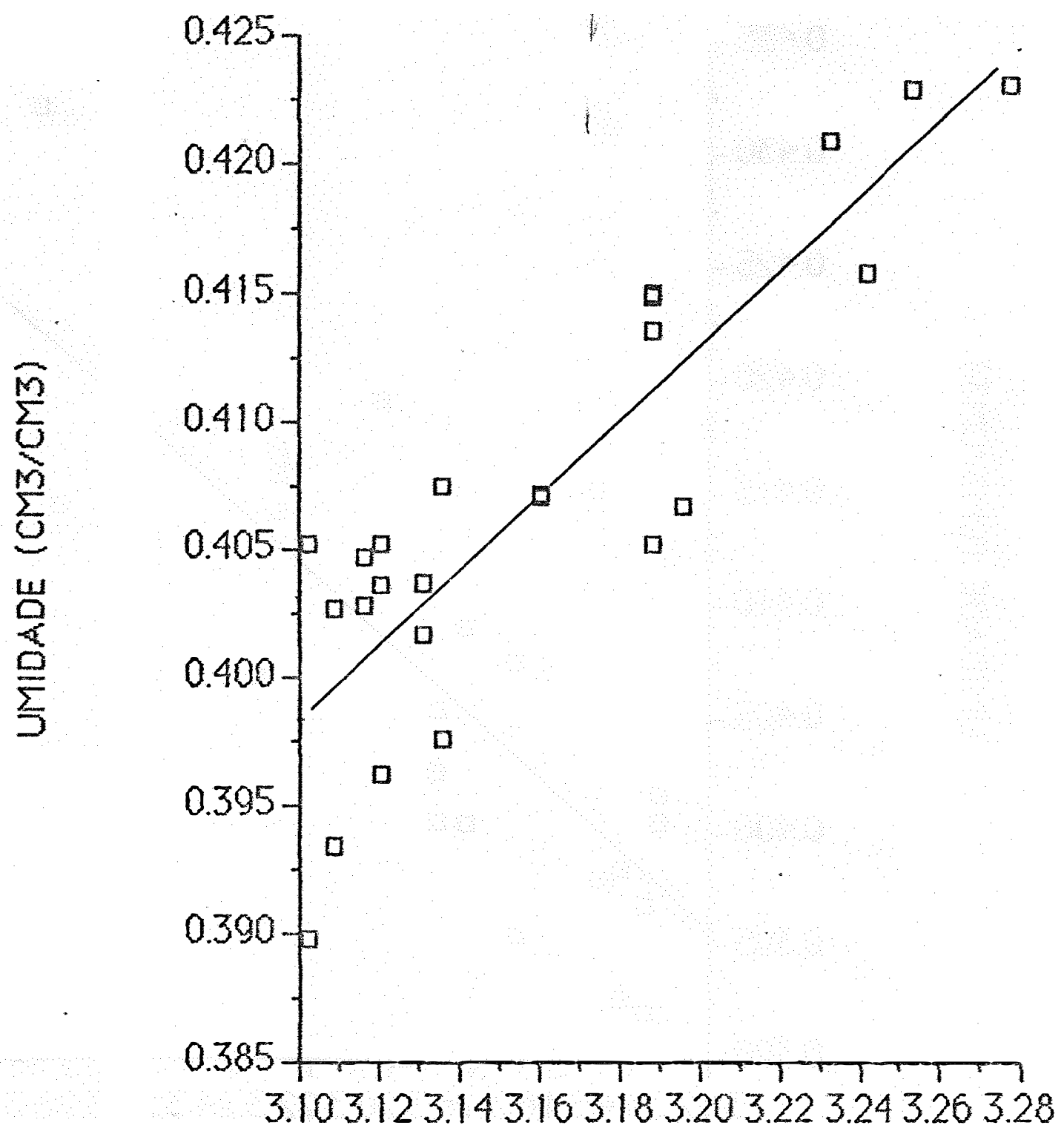

CONTAGEMRELATIVA (CPM/CPM)

FIGURA 12 - Calibração da sonda de nẹutrons para a profundidade de $74,5 \mathrm{~cm}$ do solo Terra Roxa Estruturada. 


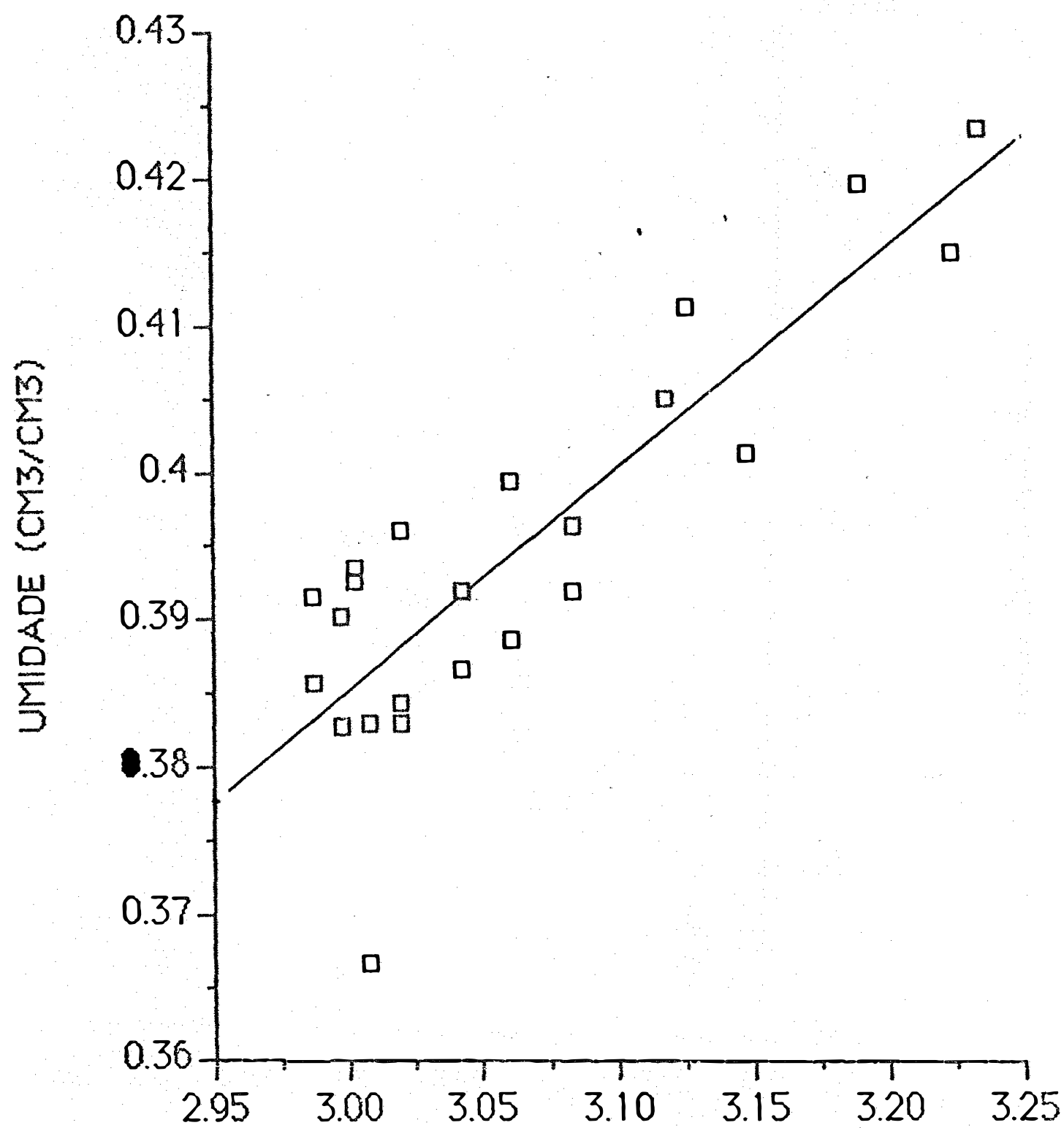

CONTAGEMRELATIVA (CPM/CPM)

FIGURA 13 - Calibração da sonda de nêutrons para a profundidade de $90,5 \mathrm{~cm}$ do solo Terra Roxa Estruturada. 


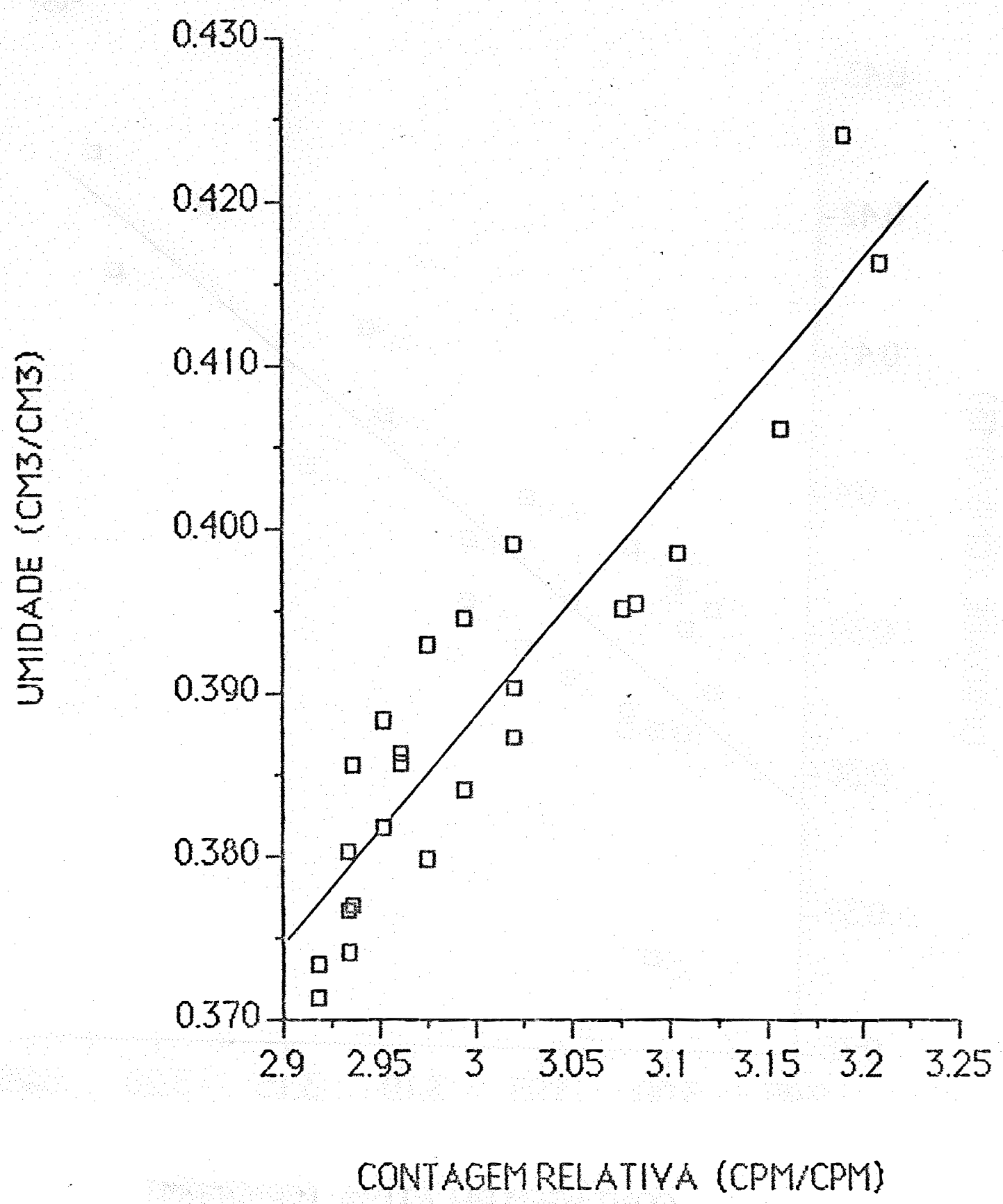

FIGURA 14 - Calibração da sonda de nêutrons para a profundidade de $98 \mathrm{~cm}$ do solo Terra Roxa Estruturada. 


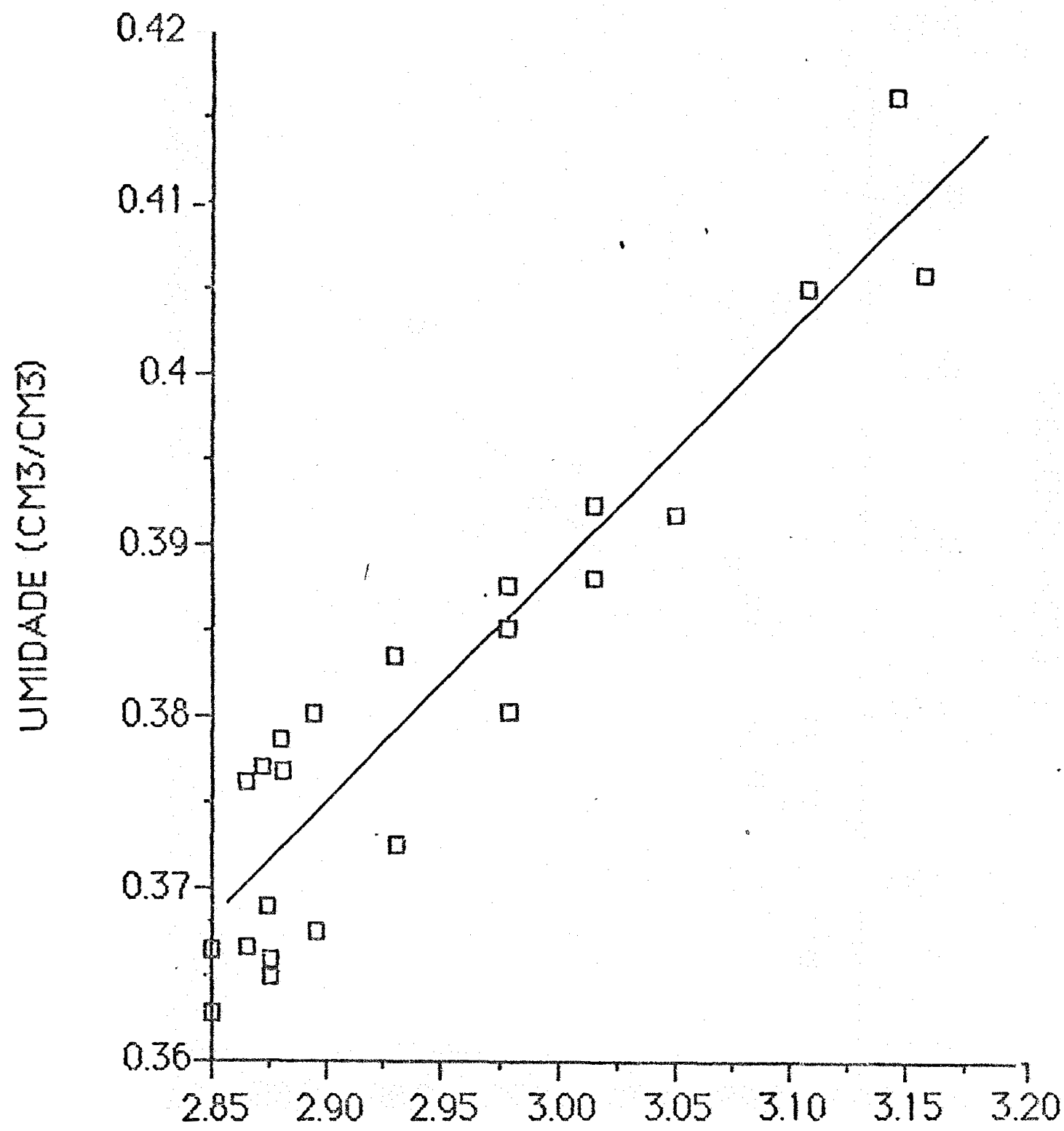

CONTAGEMRELATIVA (CPMICPM)

FIGURA 15 - Calibração da sonda de nêutrons para a profundidade de $105,5 \mathrm{~cm}$ do solo Terra Roxa Estruturada. 


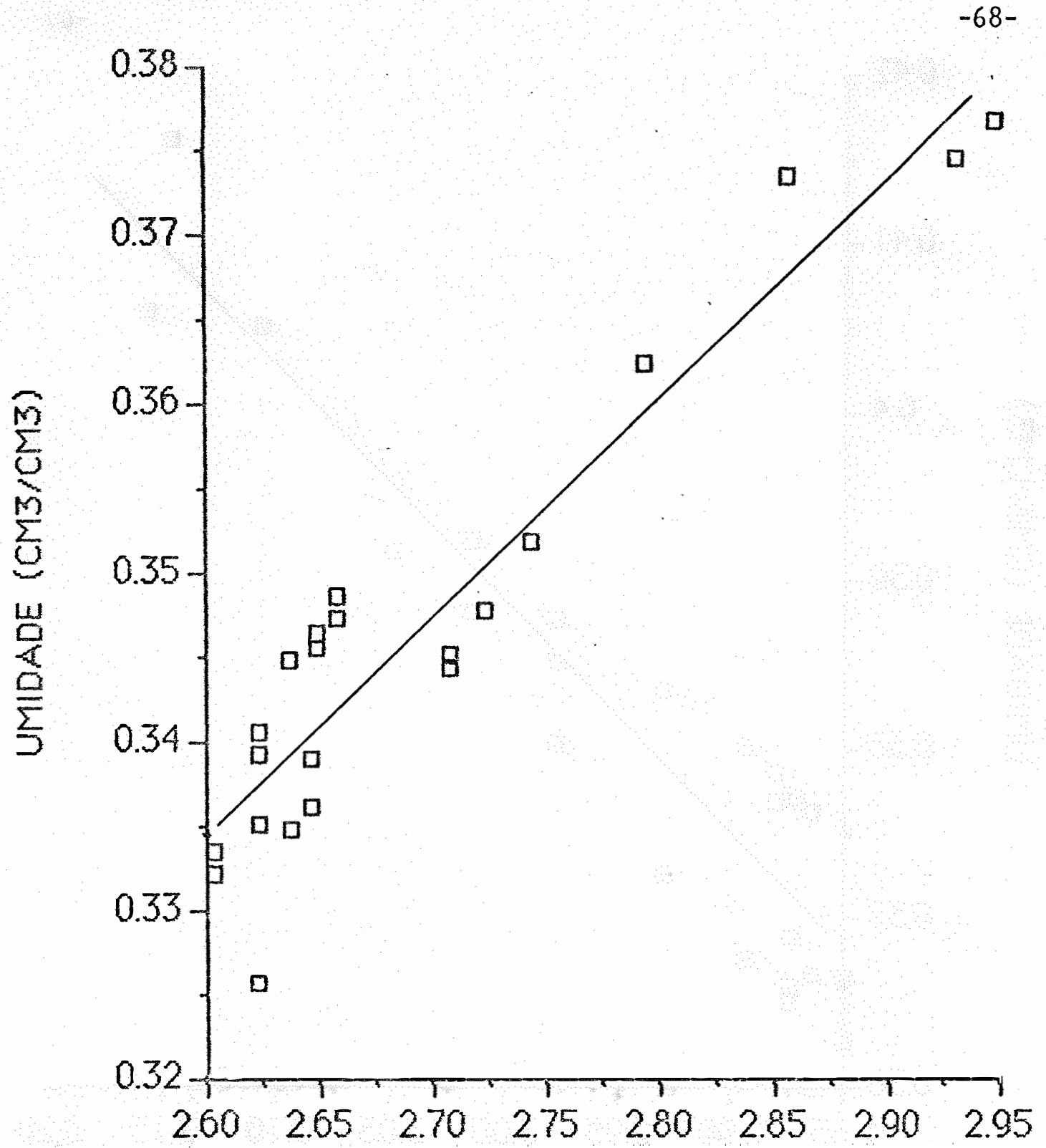

CONTAGEMRELATIVA (CPM/CPM)

FIGURA 16 - Calibração da sonda de nêutrons para a profundidade de $128 \mathrm{~cm}$ do solo Terra Roxa Estruturada. 


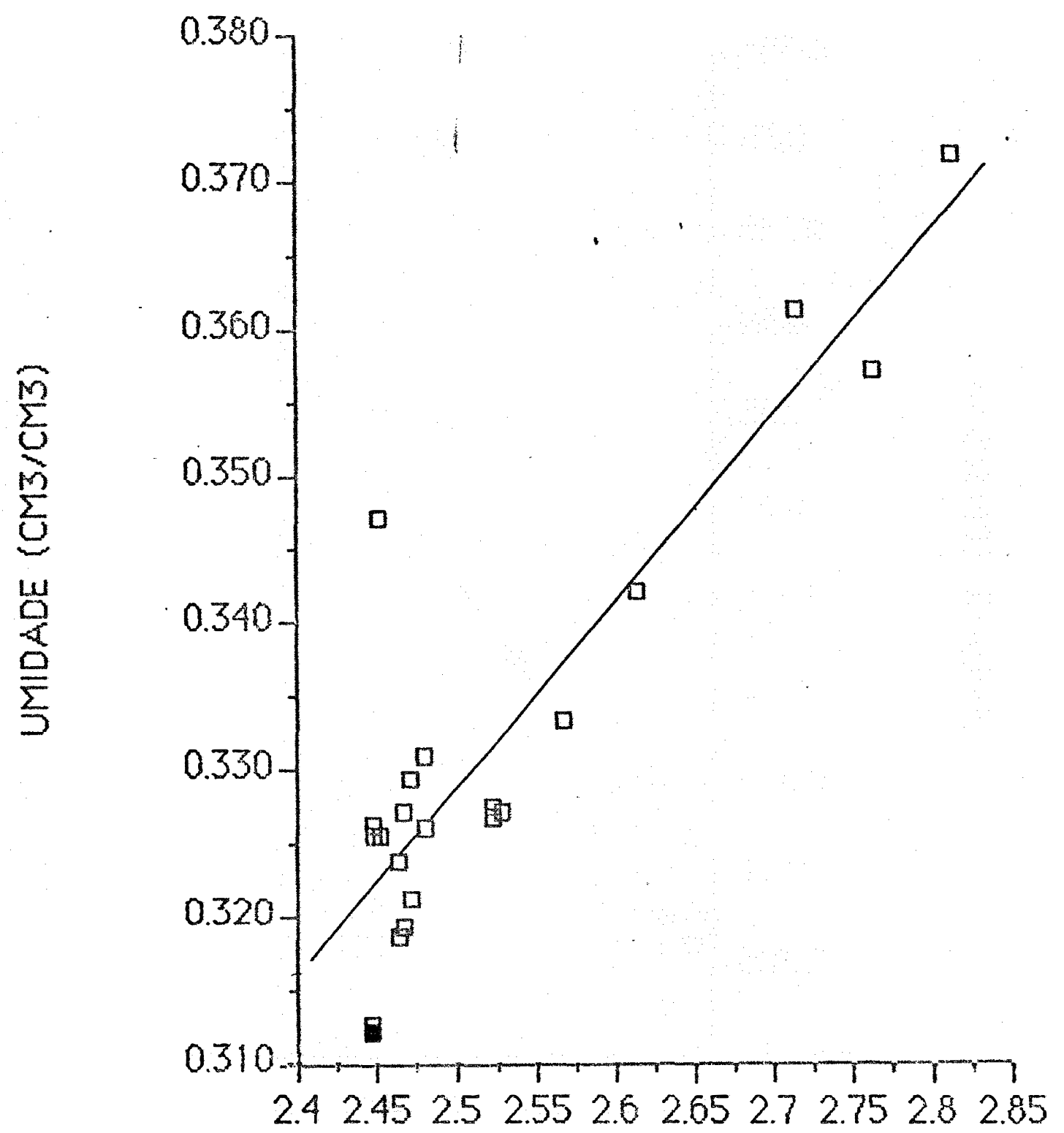

CONTAGEMRELATIVA (CPM/CPM)

FIGURA 17 - Calibração da sonda de nêutrons para a profundidade de $143 \mathrm{~cm}$ do solo Terra Roxa Estruturada. 


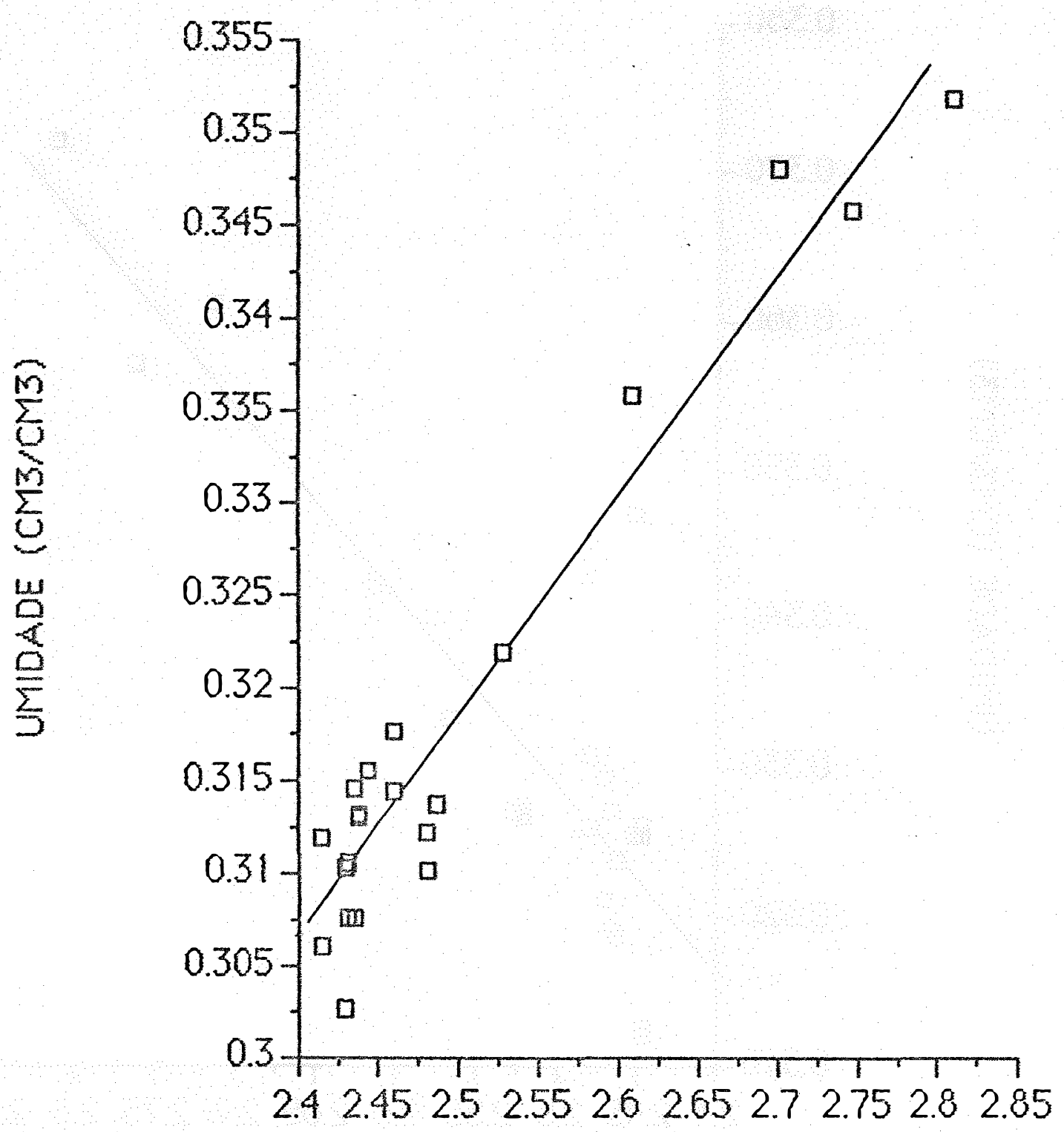

CONTAGEMRELATIUA (CPM/CPM)

FIGURA 18 - Calibração da sonda de nêutrons para a profundidade de $158 \mathrm{~cm}$ do solo Terra Roxa Estruturada. 


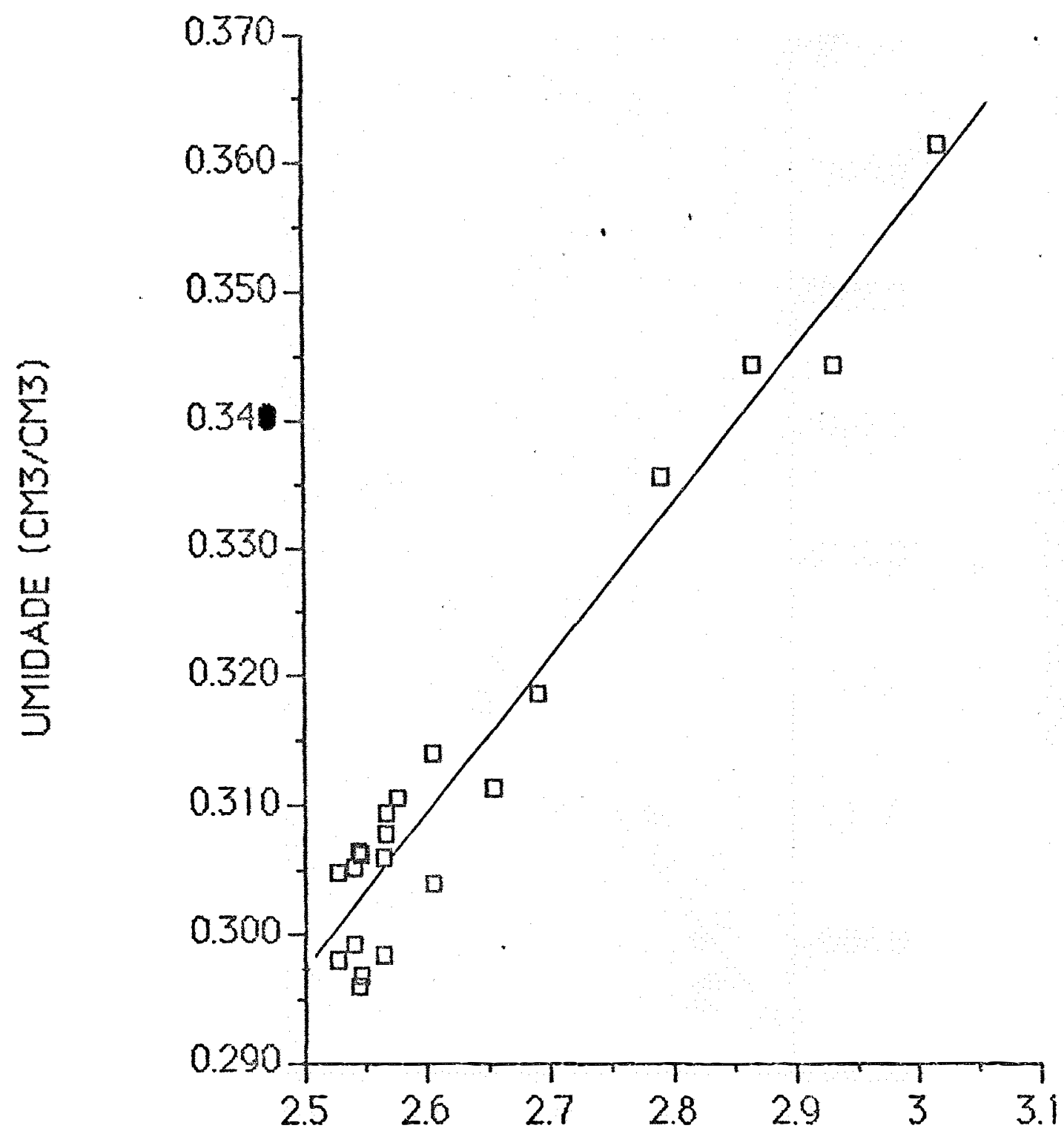

CONTAGEMRELATIVA (CPM/CPM)

FIguRa 19 - Calibração da sonda de nêutrons para a profundidade de $188 \mathrm{~cm}$ do solo Terra Roxa Estruturada. 


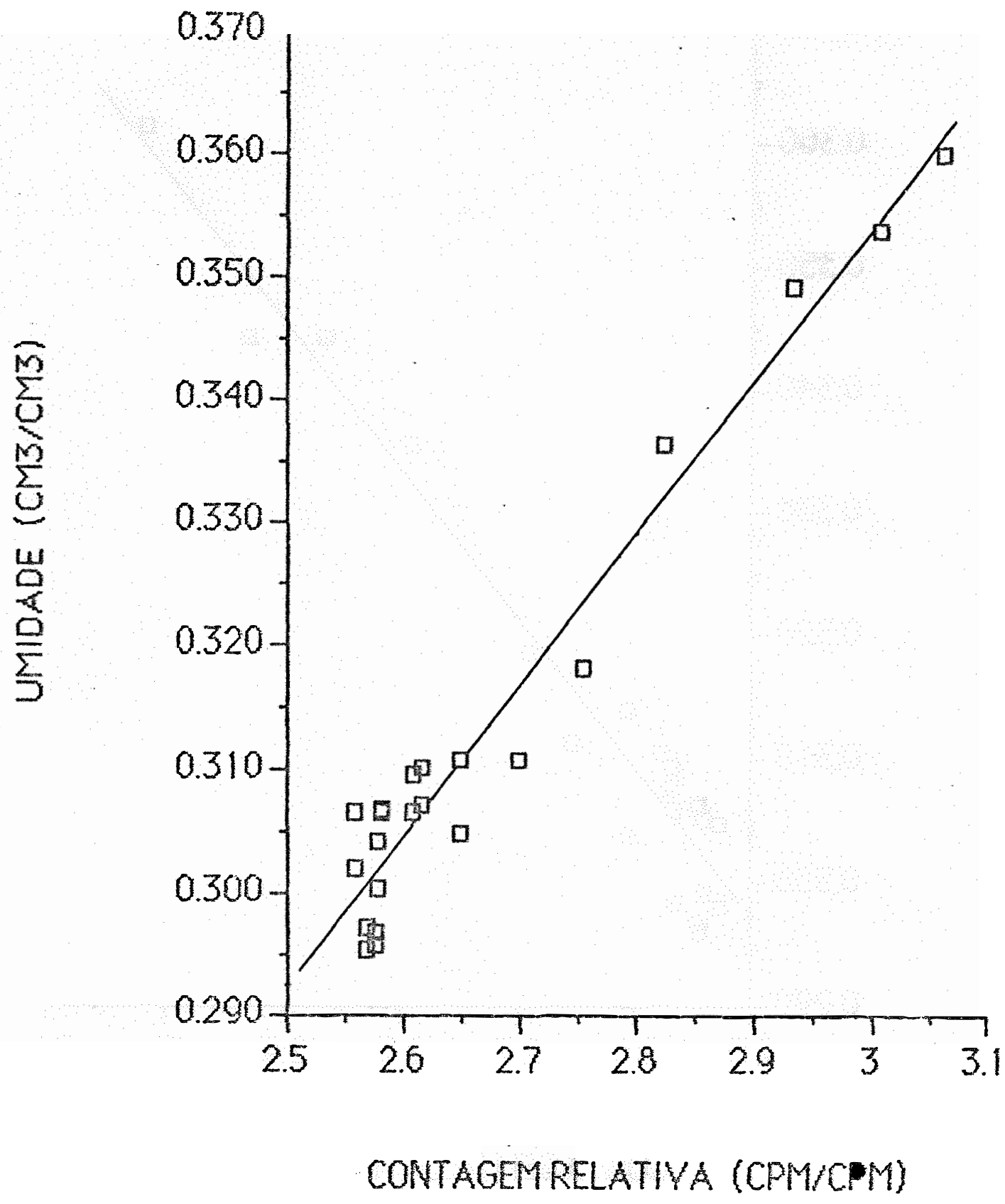

FIGURA 20 - Calibração da sonda de nêutrons para a profundidade de $203 \mathrm{~cm}$ do solo Terra Roxa Estruturada. 


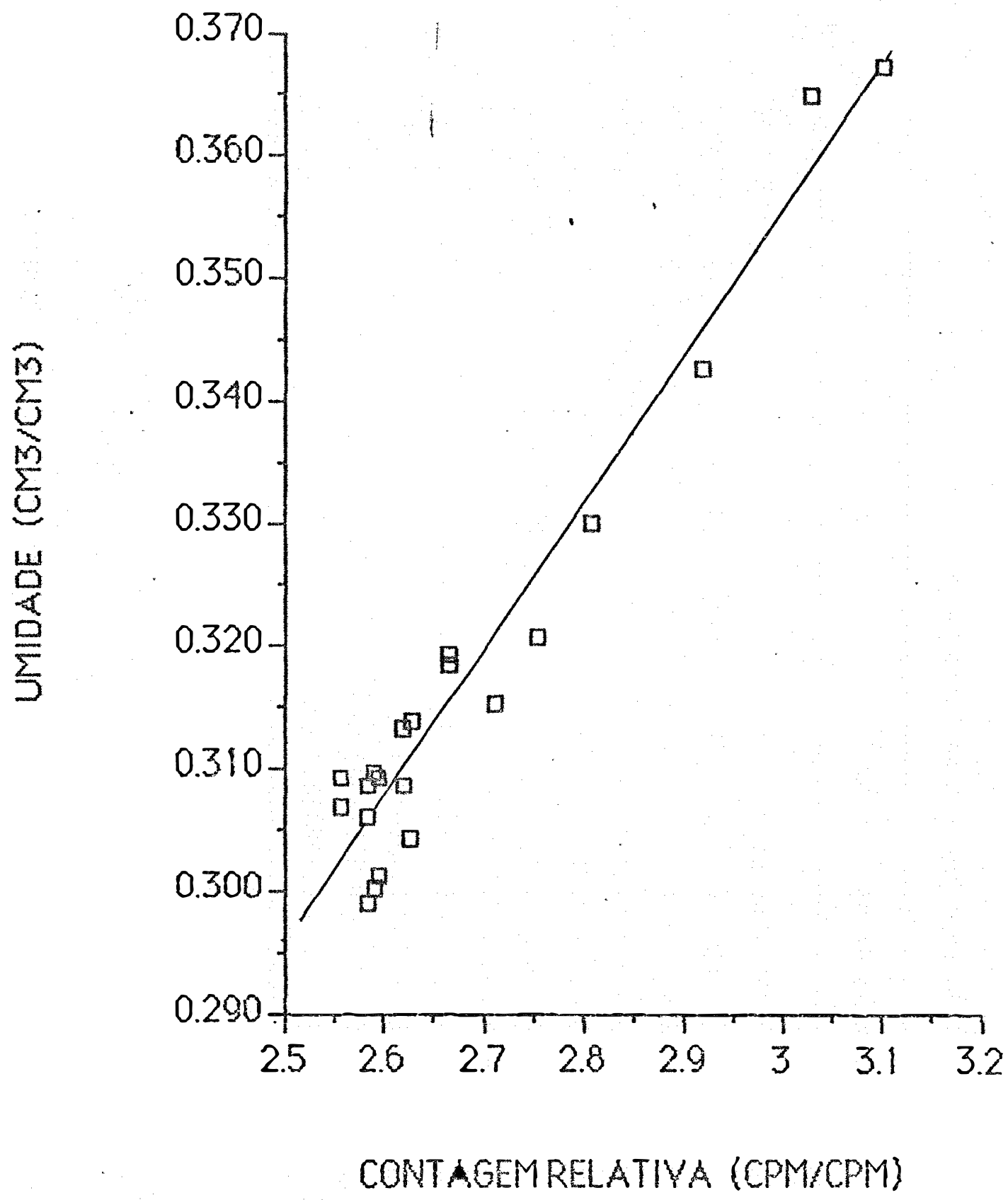

FIGURA 21 - Calibração da sonda de nêutrons para a profundidade de $218 \mathrm{~cm}$ do solo Terra Róxa Estruturada. 


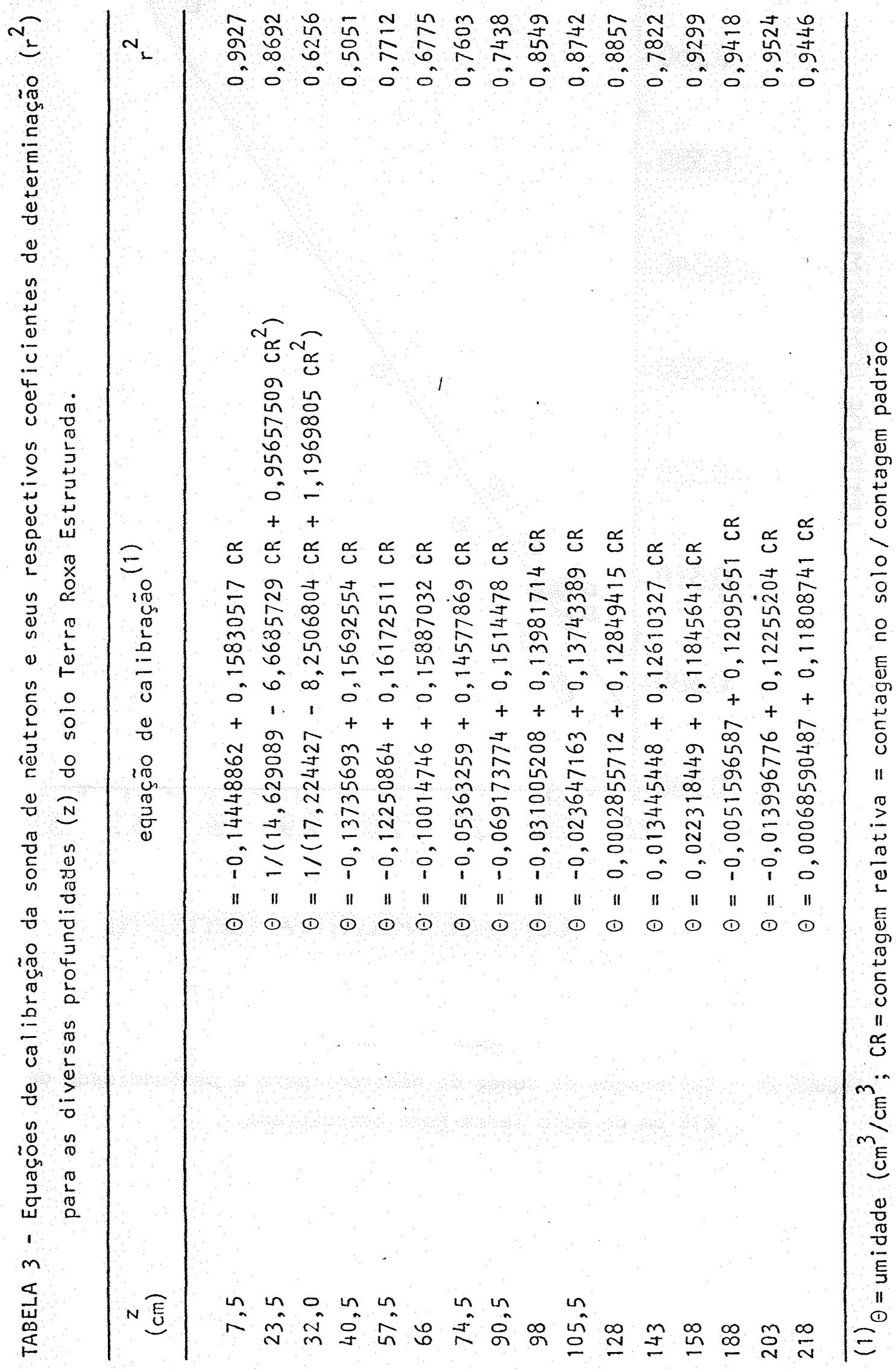




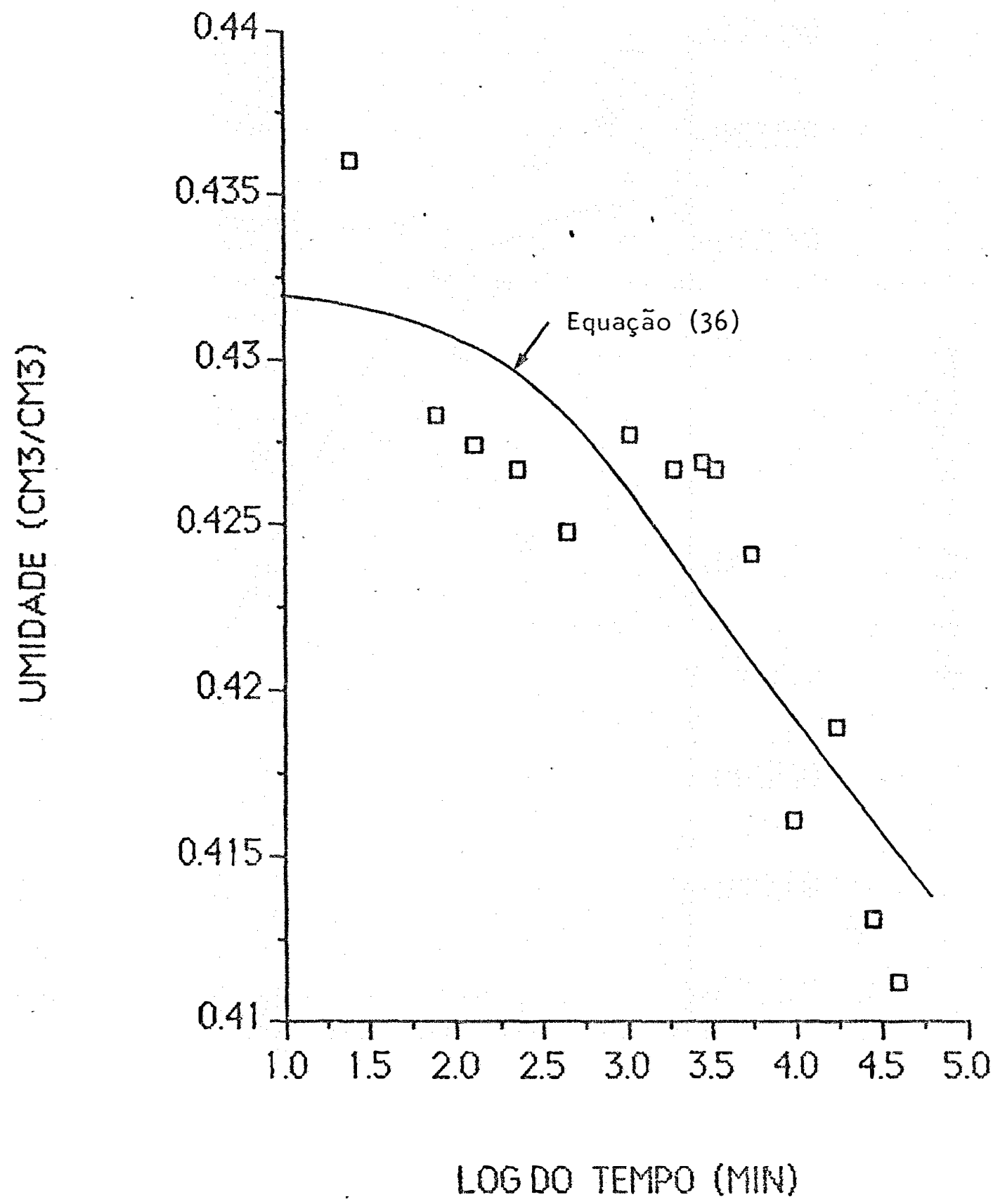

FIGURA 22 - Umidade em função do tempo de redistribuição da ăgua na profundidade de $7,5 \mathrm{~cm}$ do solo Terra Roxa Estruturada. 


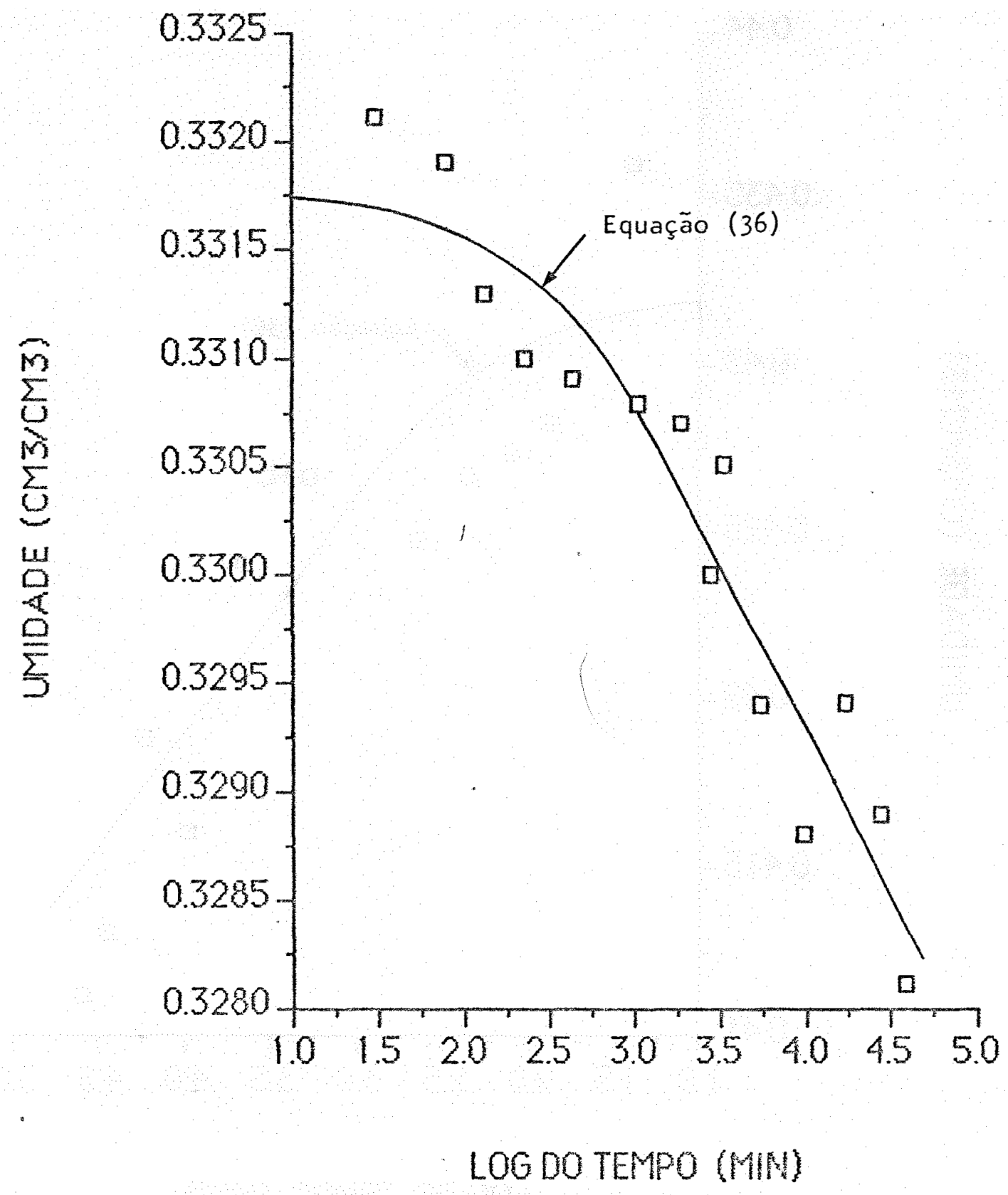

FIGURA 23 - Umidade em função do tempo de redistribuição da água na profundidade de $23,5 \mathrm{~cm}$ do solo Terra Roxa Estruturada. 


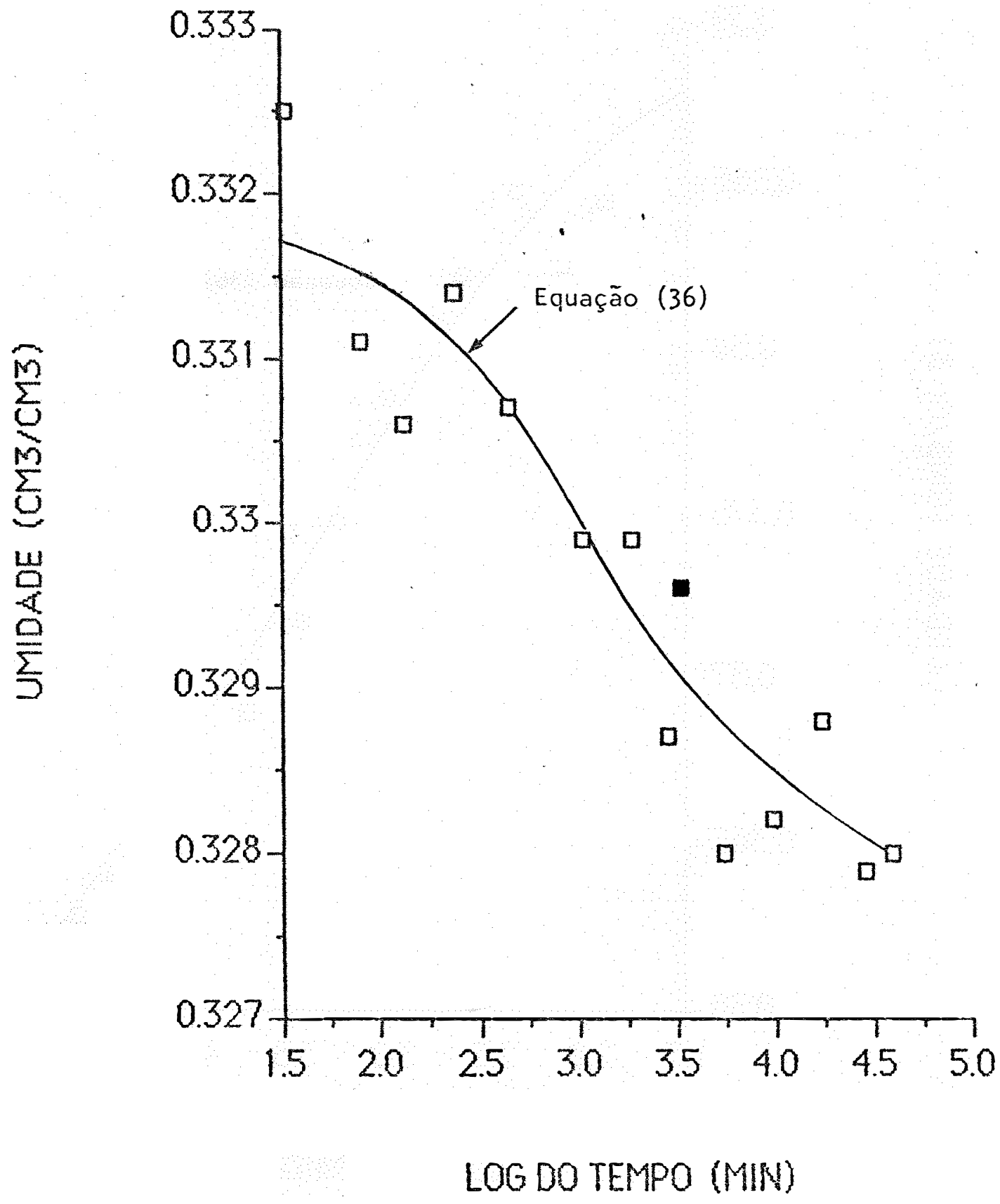

FIGURA 24 - Umidade em função do tempo de redistribuição da ägua na profundidade de $32 \mathrm{~cm}$ do solo Terra Roxa Estruturada. 


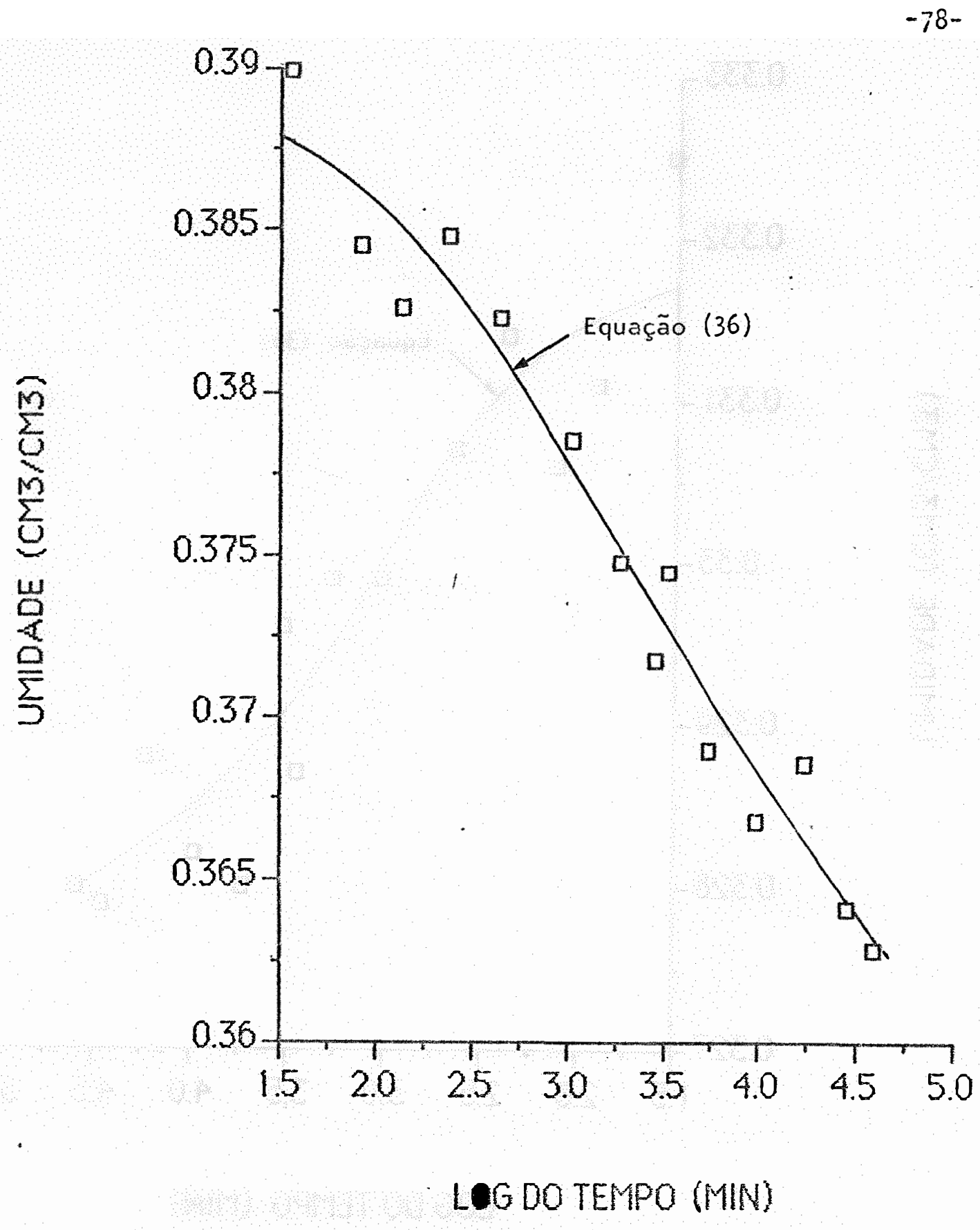

FIGURA 25 - Umidade em função do tempo de redistribuição da água na profundidade de $40,5 \mathrm{~cm}$ do solo Terra Roxa Estruturada. 


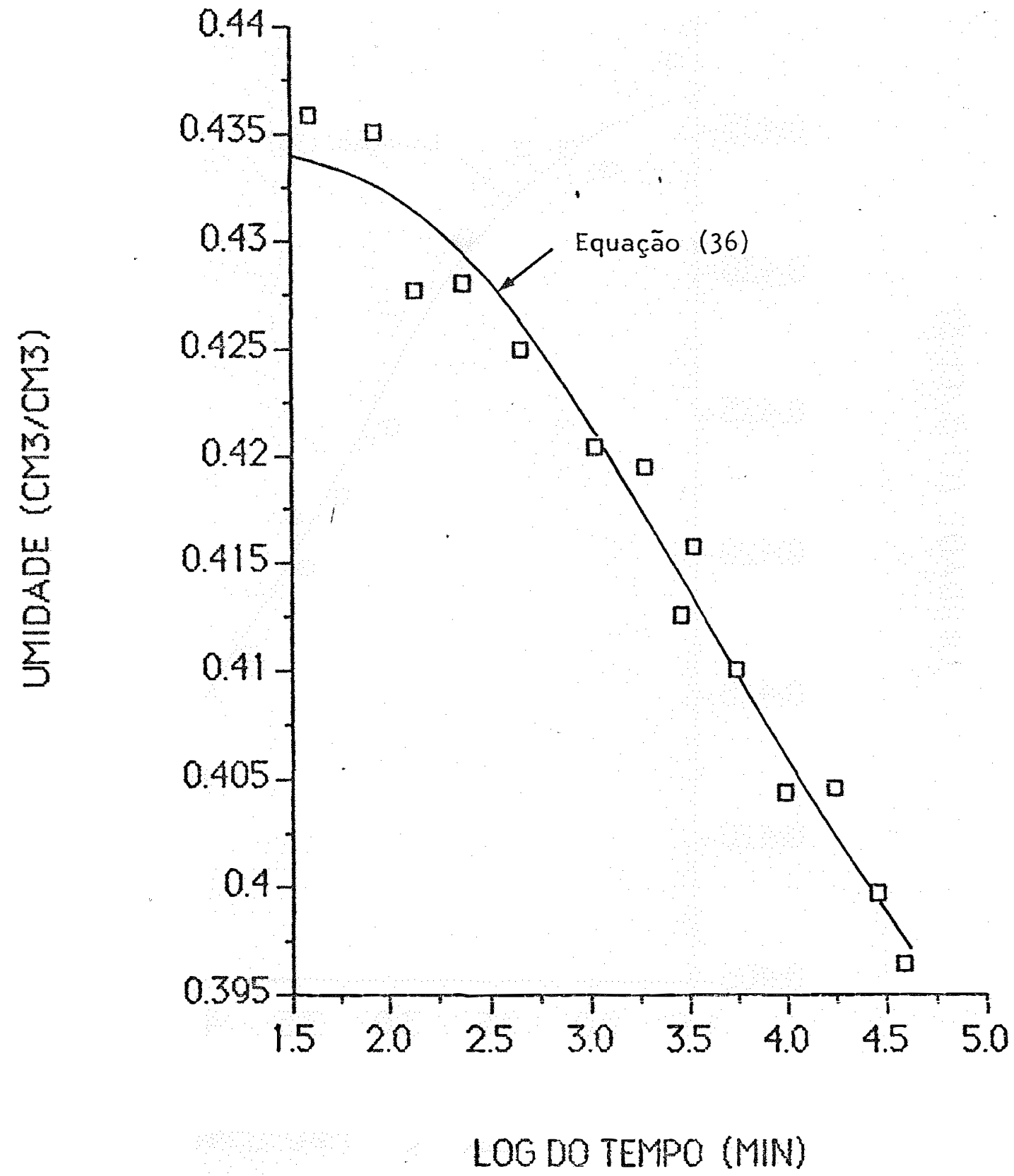

FIGURA 26 - Umidade em função do tempo de redistribuição da água na profundidade de $57,5 \mathrm{~cm}$ do solo Terra Roxa Estruturada. 


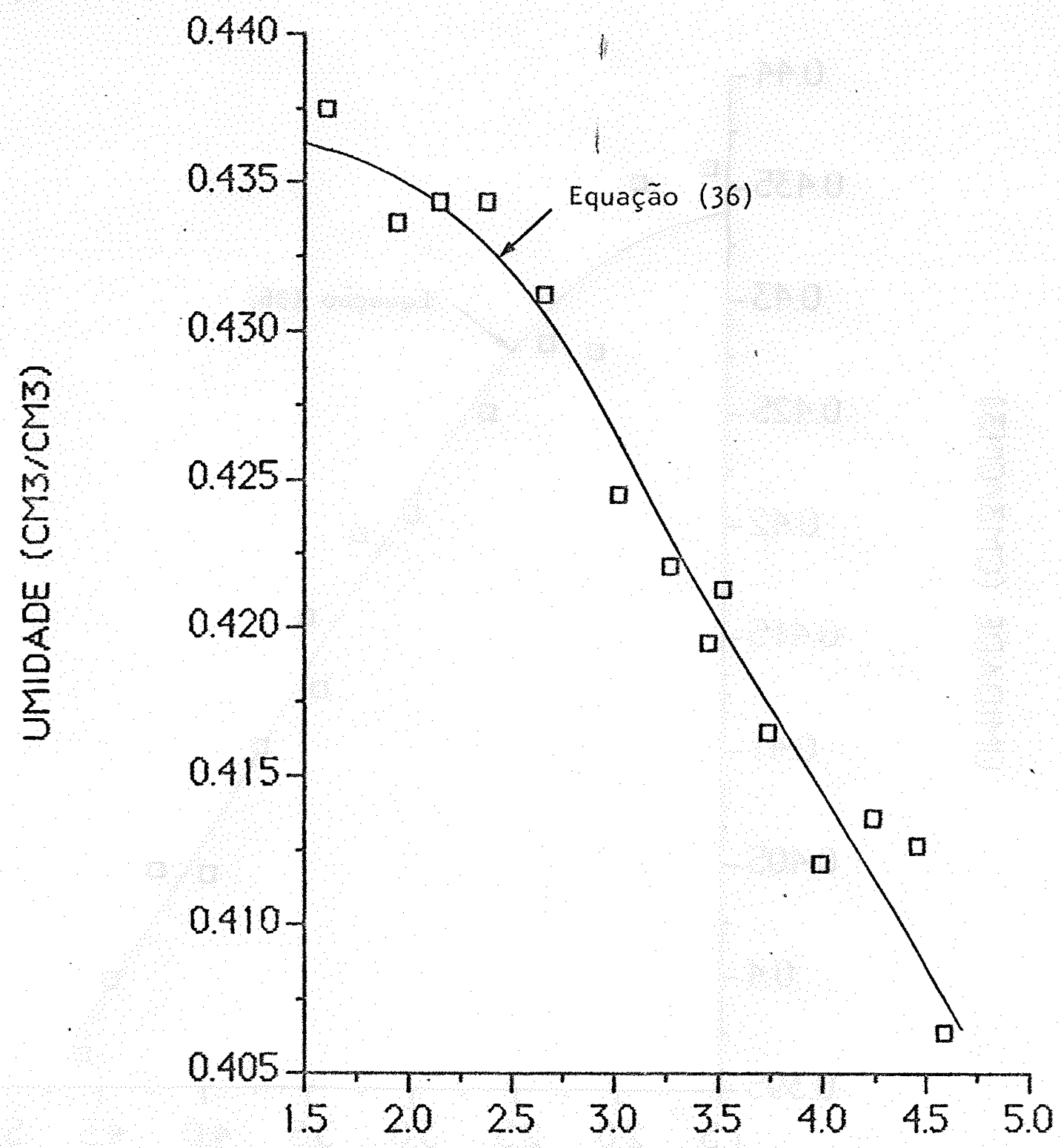

LOG DO TEMPO (MIN)

FIGURA 27 - Umidade em função do tempo de redistribuição da água na profundidade de $66 \mathrm{~cm}$ do solo Terra Roxa Estruturada. 


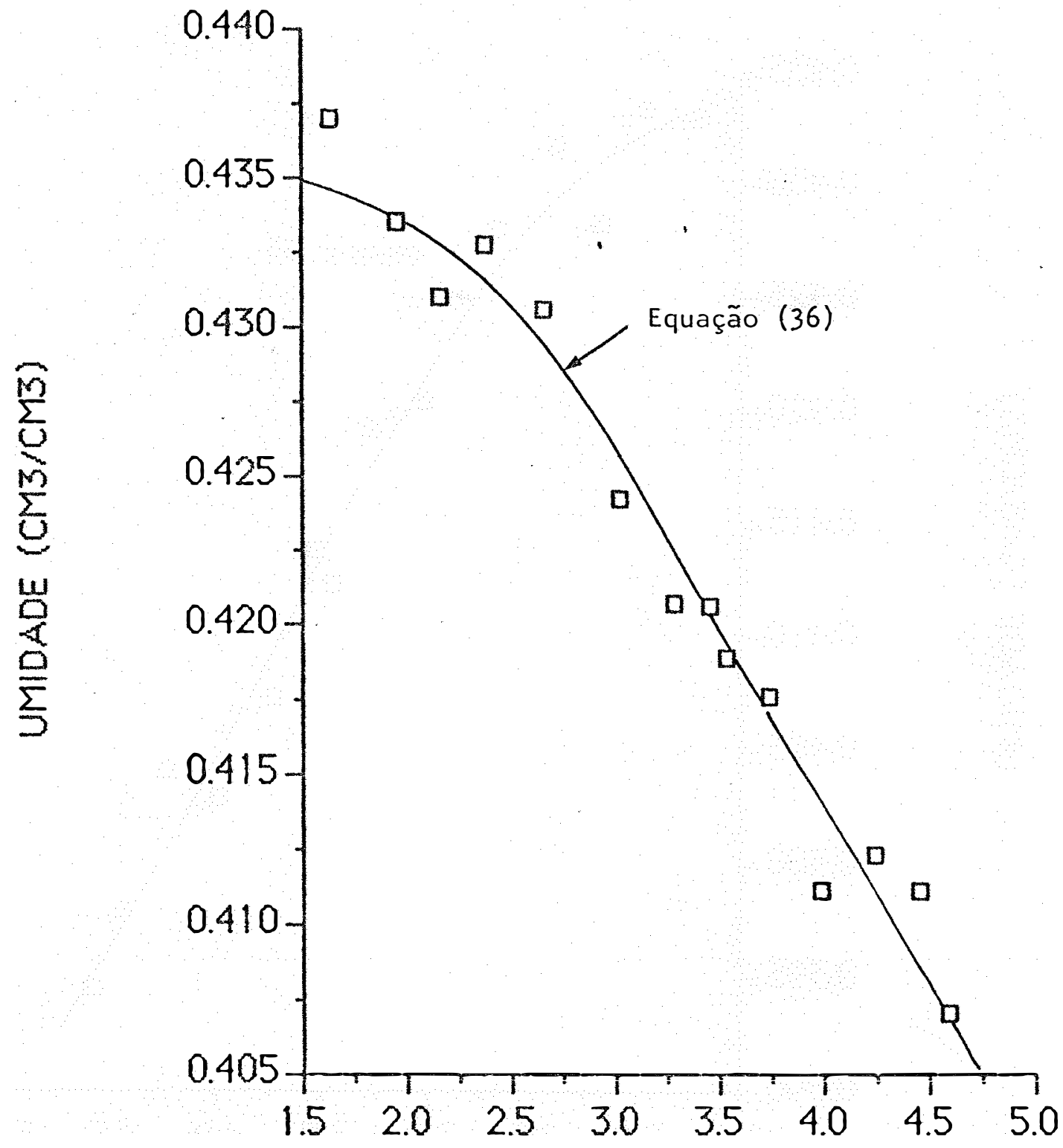

LOG DO TEMPO (MIN)

FIGURA 28 - Umidade em função do tempo de redistribuição da água na profundidade de $74,5 \mathrm{~cm}$ do solo Terra Roxa Estruturada. 


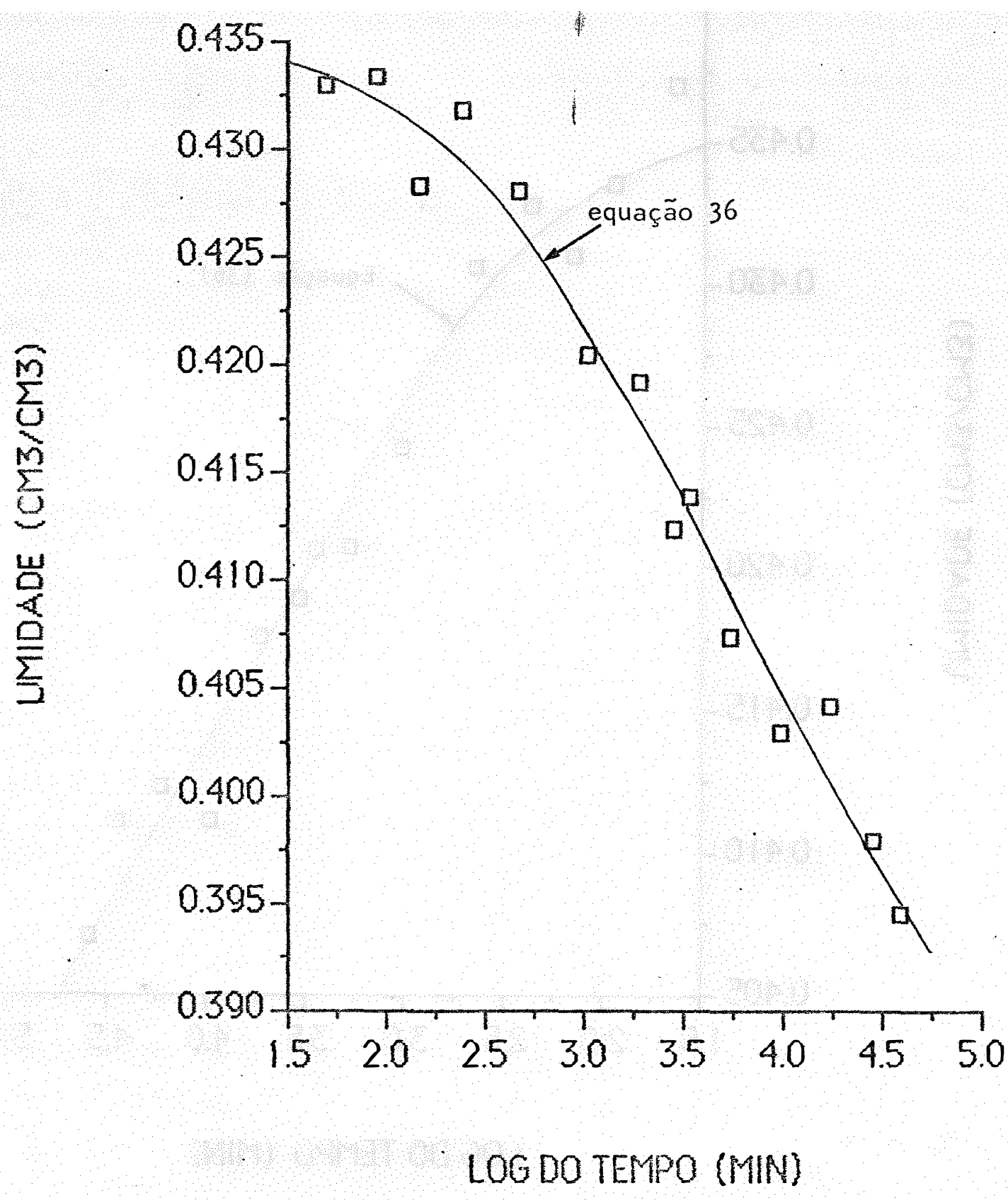

FIGURA 29 - Umidade em função do tempo de redistribuição da água na profundidade de $90,5 \mathrm{~cm}$ do solo Terra Roxa Estruturada. 


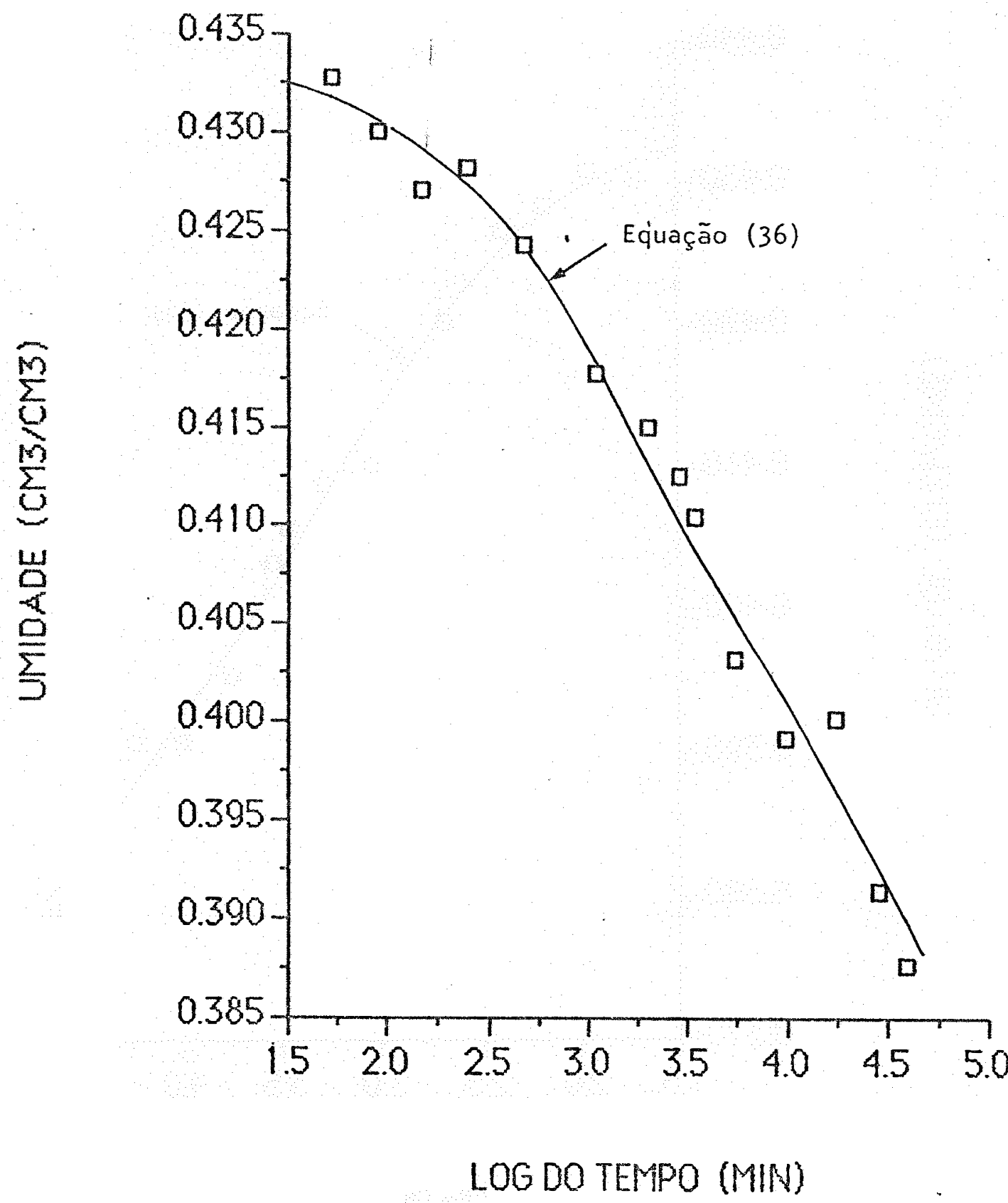

FIGURA 30 - Umidade em função do tempo de redistribuição da água na profundidade de $98 \mathrm{~cm}$ do solo Terra Roxa Estruturada. 


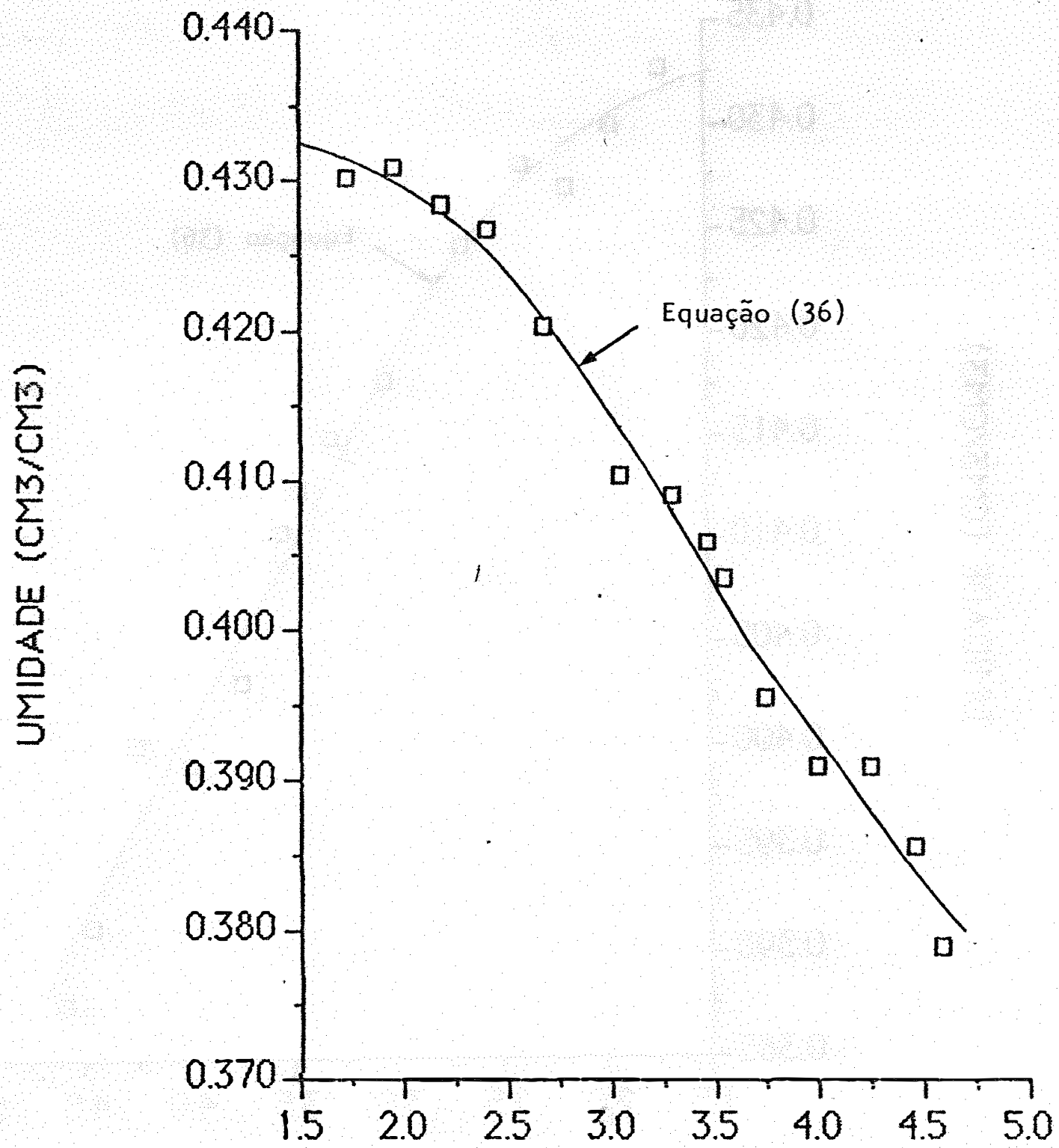

\section{LOG DO TEMPO (MIN)}

FIGURA 31 - Umidade em função do tempo de redistribuição da água na. profundidade de $105,5 \mathrm{~cm}$ do solo Terra Roxa Estruturada. 


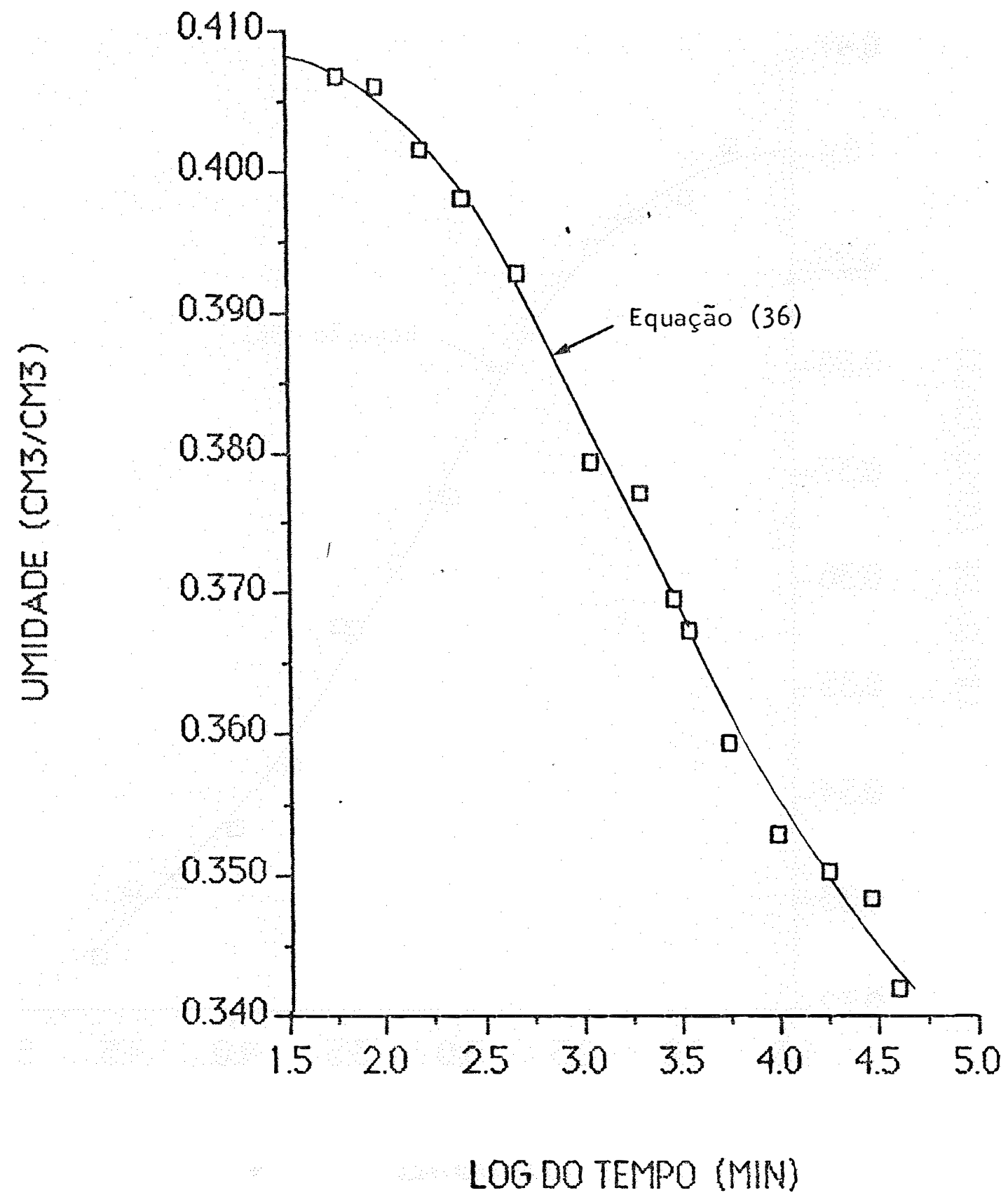

FIGURA 32 - Umidade em função do tempo de redistribuição da água na profundidade de $128 \mathrm{~cm}$ do solo Terra Roxa Estruturada. 


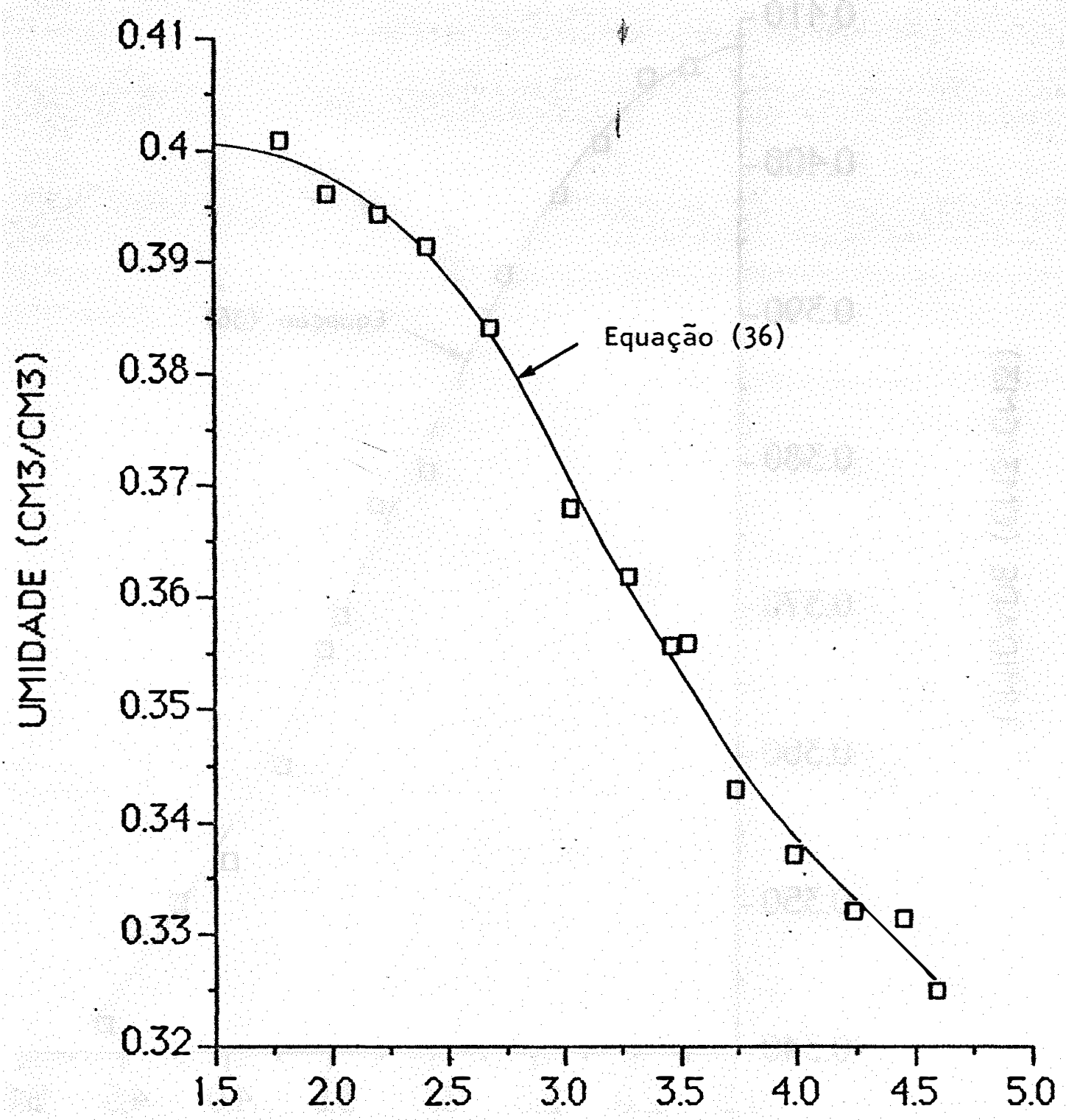

LOG DO TEMPO (MIN)

FIGURA 33 - Umidade em função do tempo de redistribuição da ăgua na profundidade de $143 \mathrm{~cm}$ do solo Terra Roxa Estruturada. 


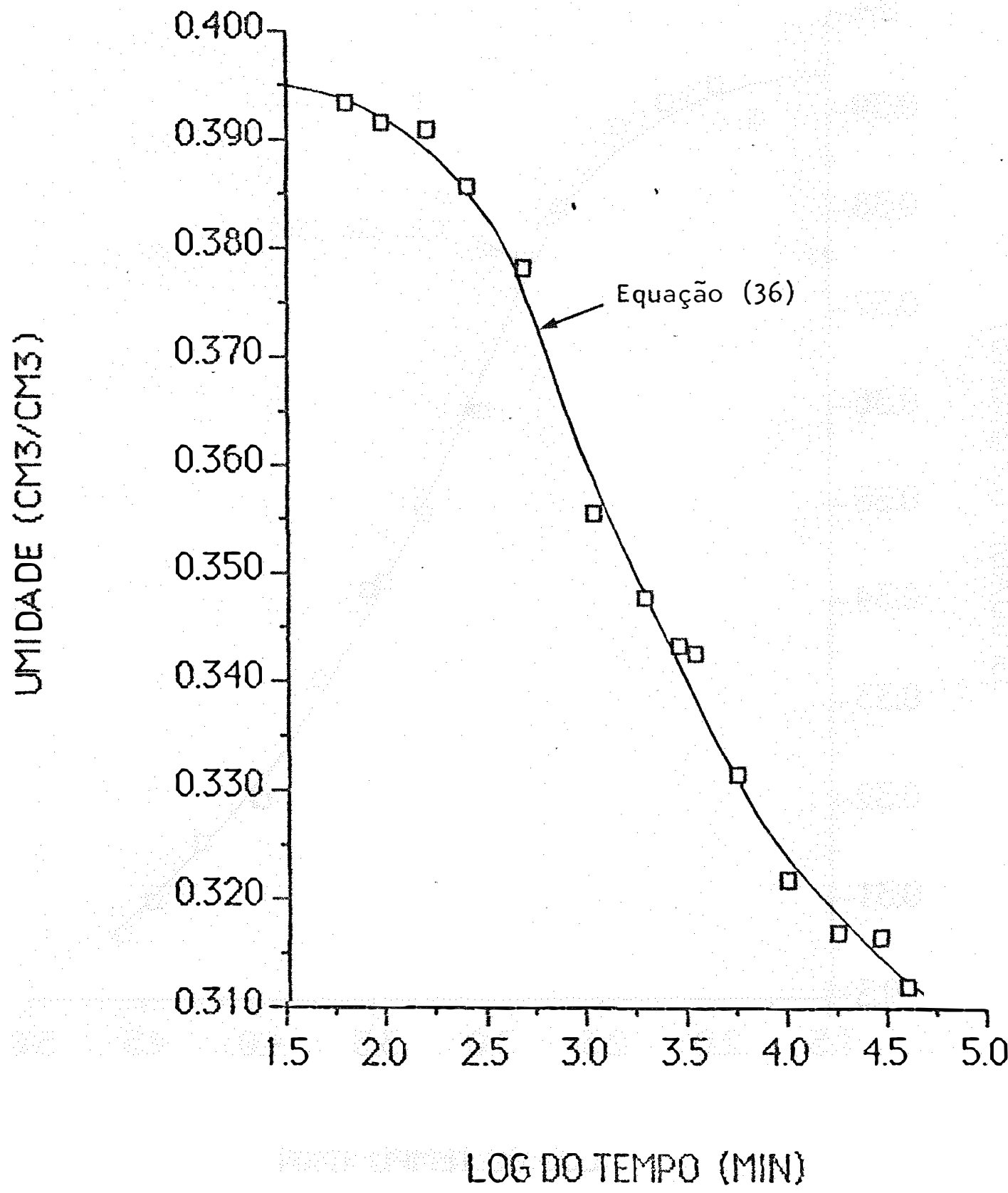

FIGURA 34 - Umidade em função do tempo de redistribuição da āgua na profundidade de $158 \mathrm{~cm}$ do solo Terra Roxa Estruturada. 


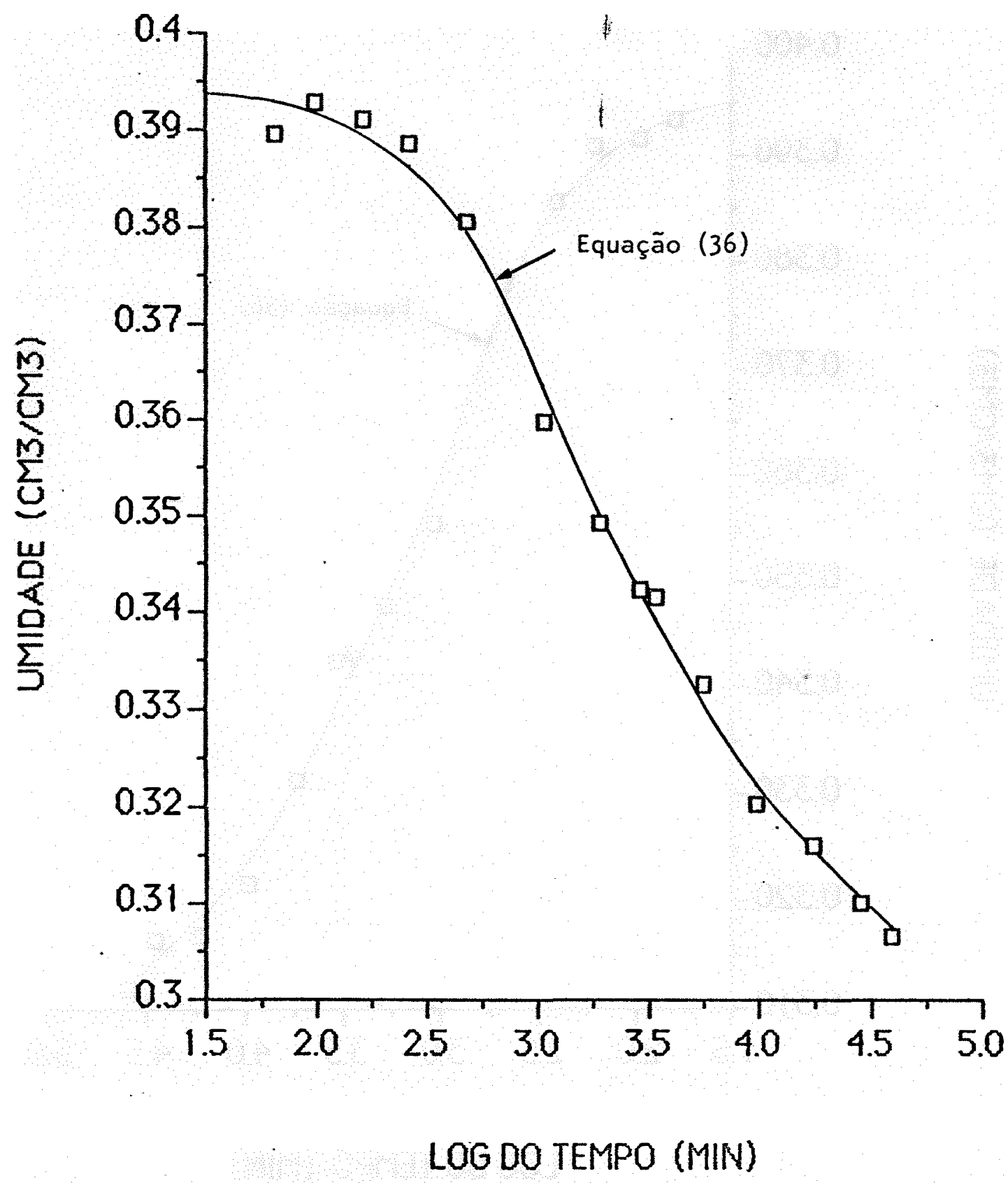

FIGURA 35 - Umidade em função do tempo de redistribuição da água na profundidade de $188 \mathrm{~cm}$ do solo Terra Roxa Estruturada. 


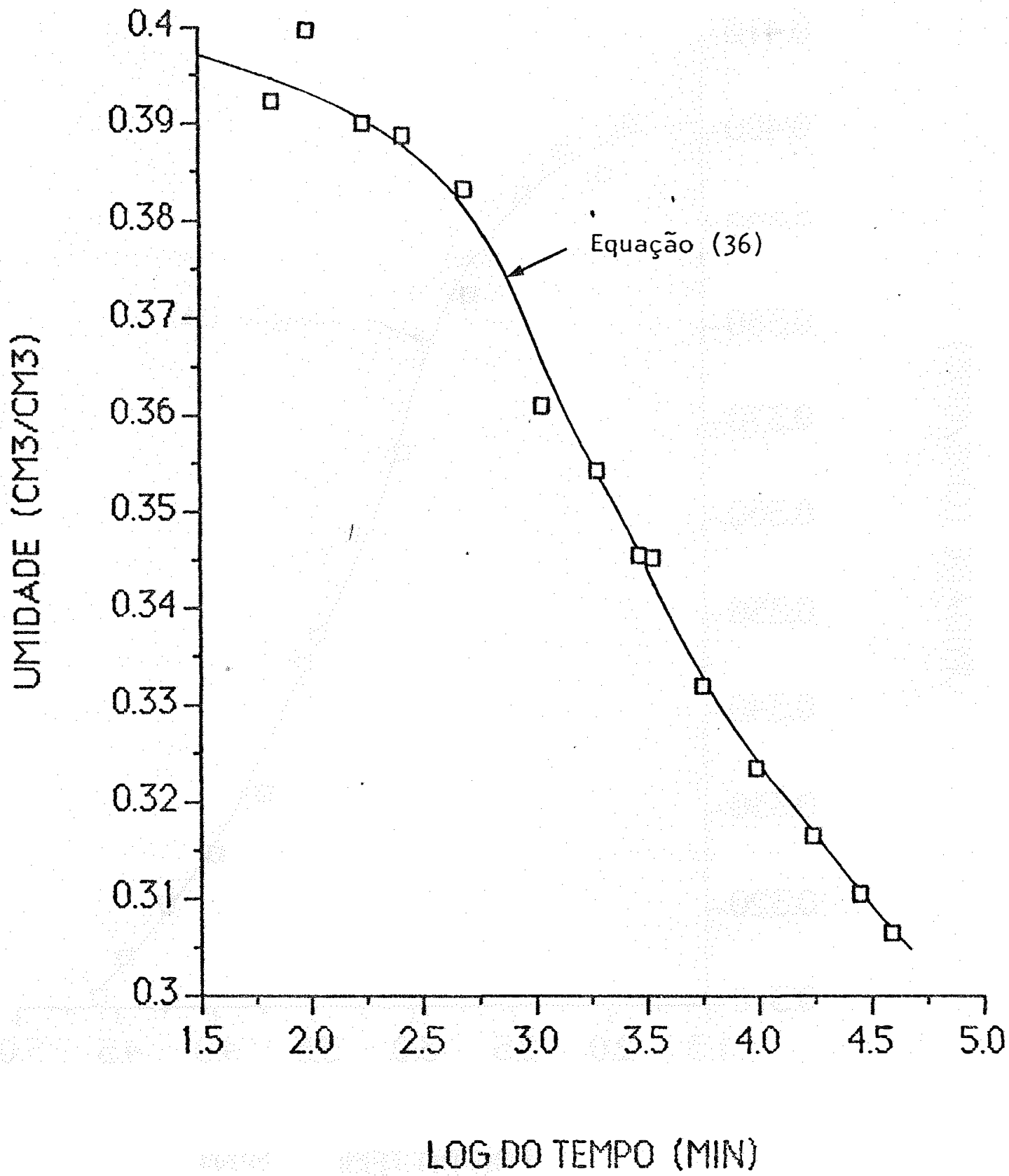

FIGURA 36 - Umidade em função do tempo de redistribuição da água na profundidade de $203 \mathrm{~cm}$ do solo Terra Roxa Estruturada. 


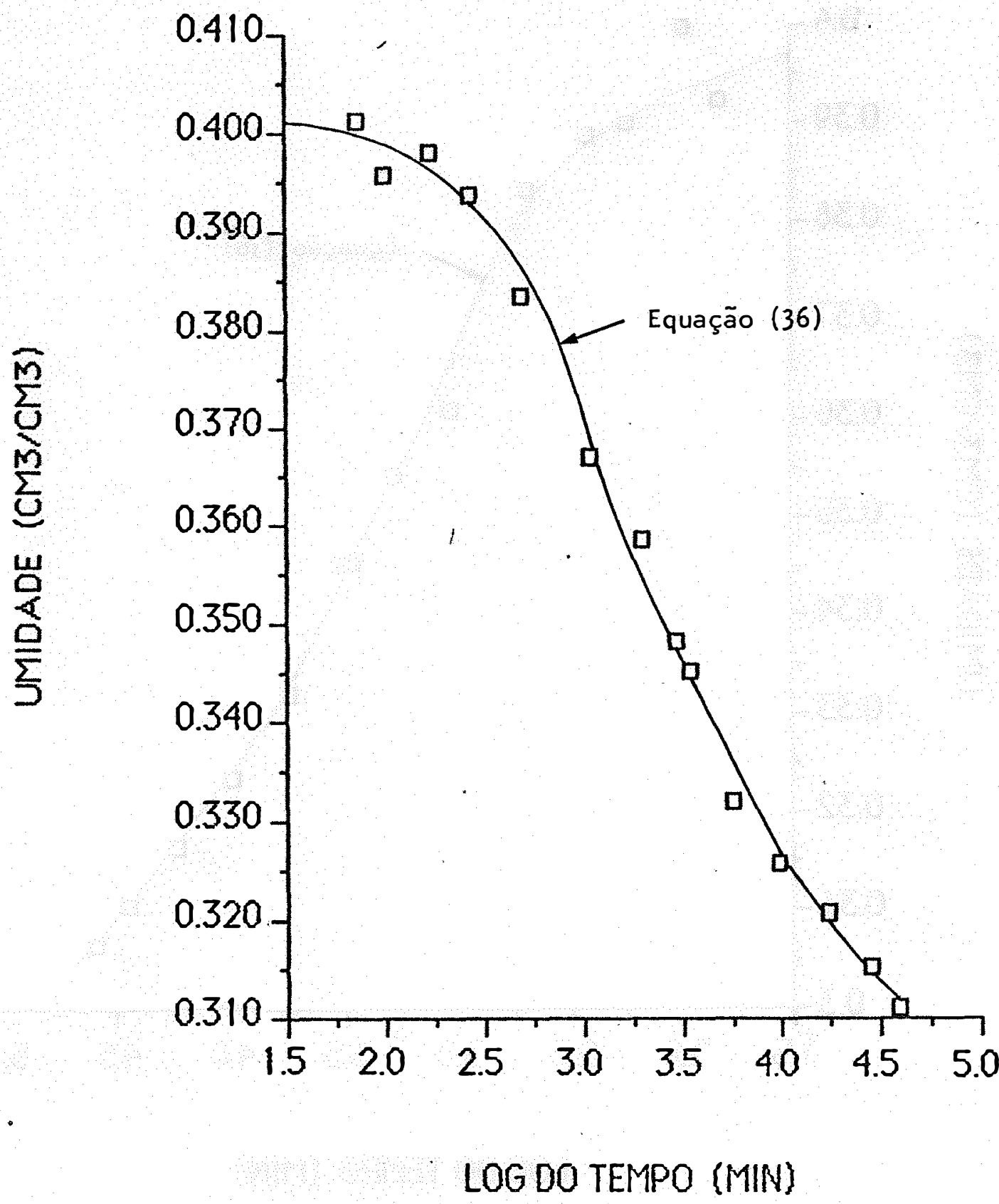

FIGURA 37 - Umidade em função do tempo de redistribuição da ăgua na profundidade de $218 \mathrm{~cm}$ do solo Terra Roxa Estruturada. 


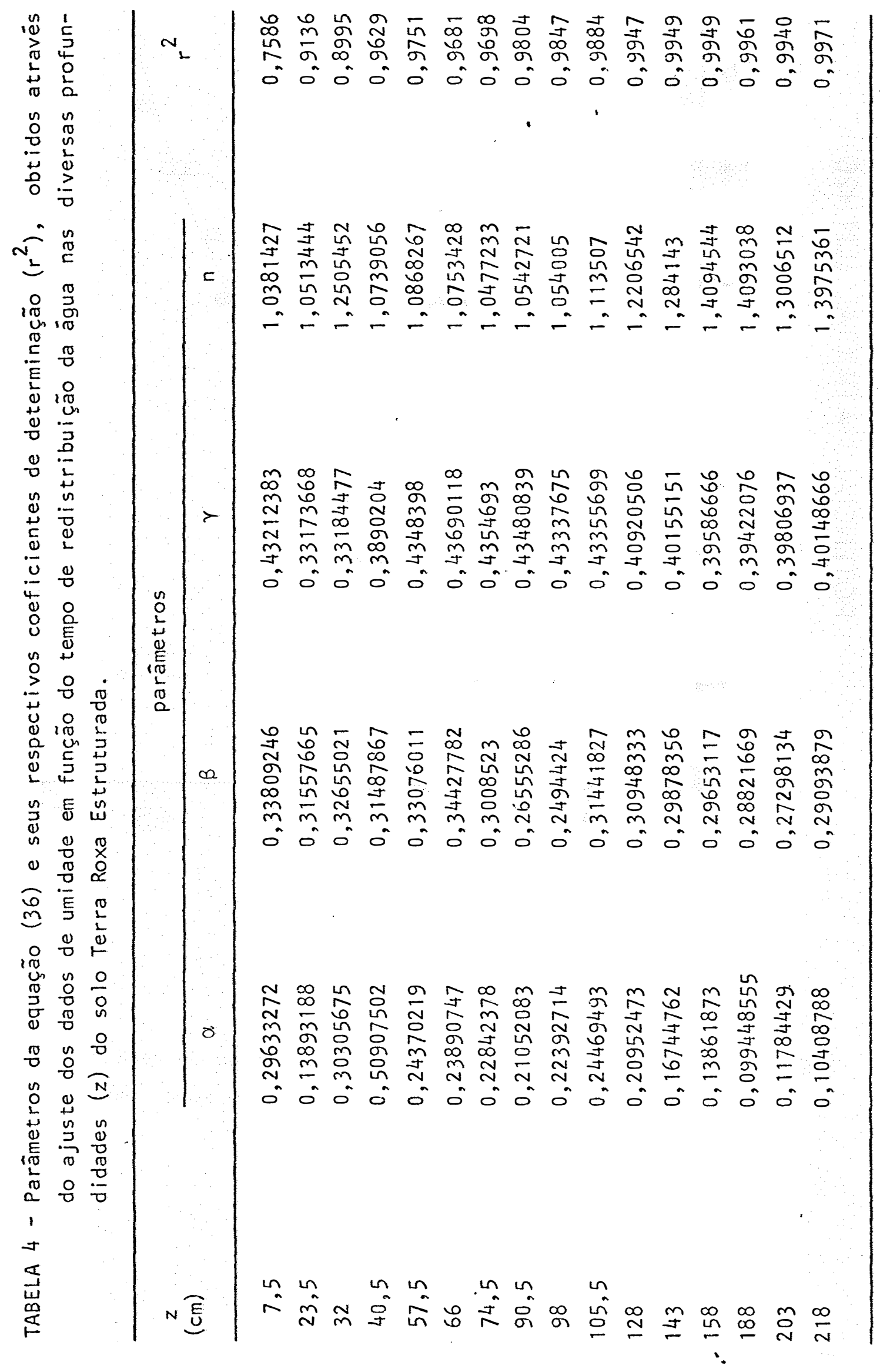




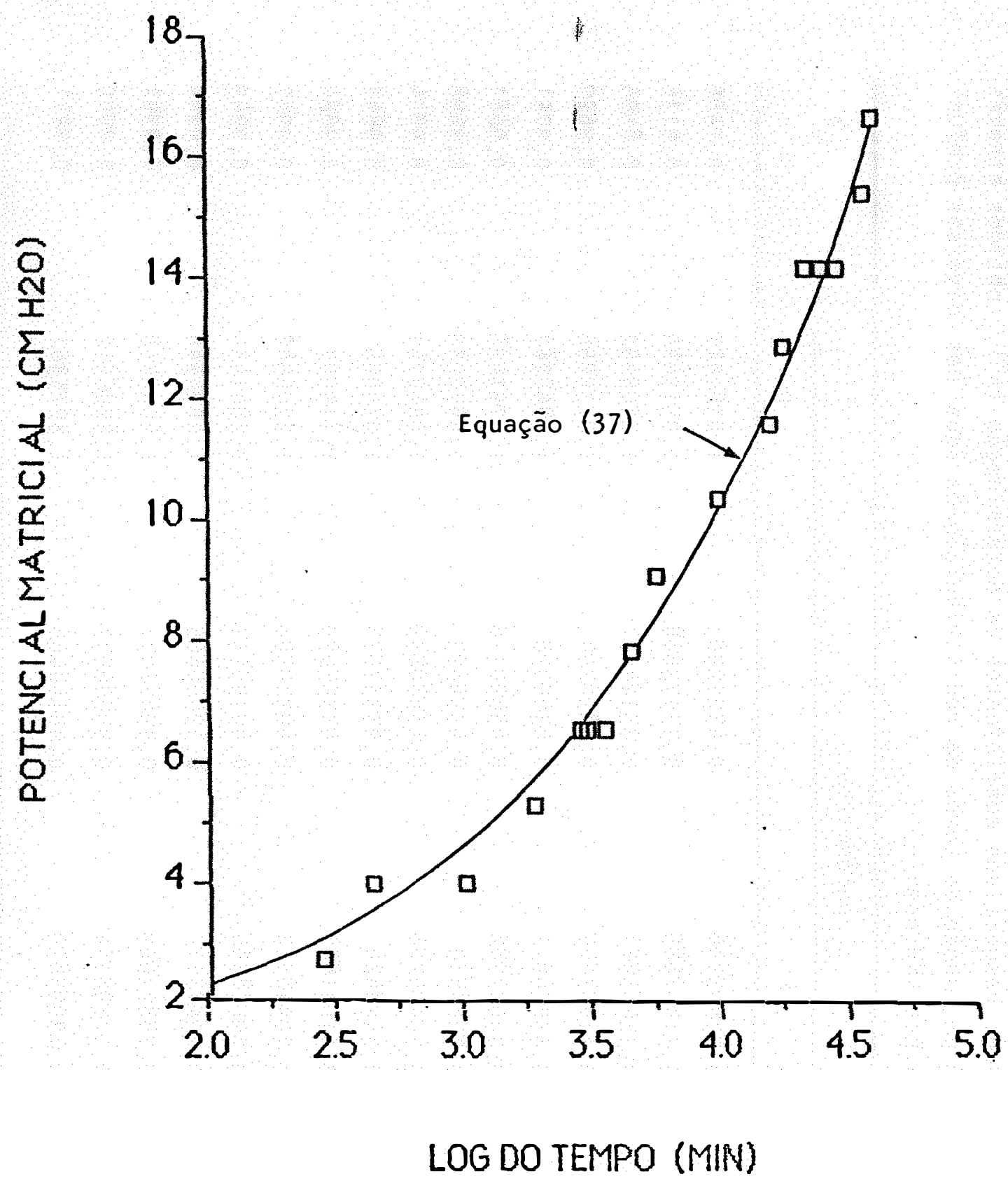

FIGURA 38 - Potencial matricial em função do tempo de redistribuição da ägua na profundidade de $23,5 \mathrm{~cm}$ do solo. Terra Roxa Estruturada. 


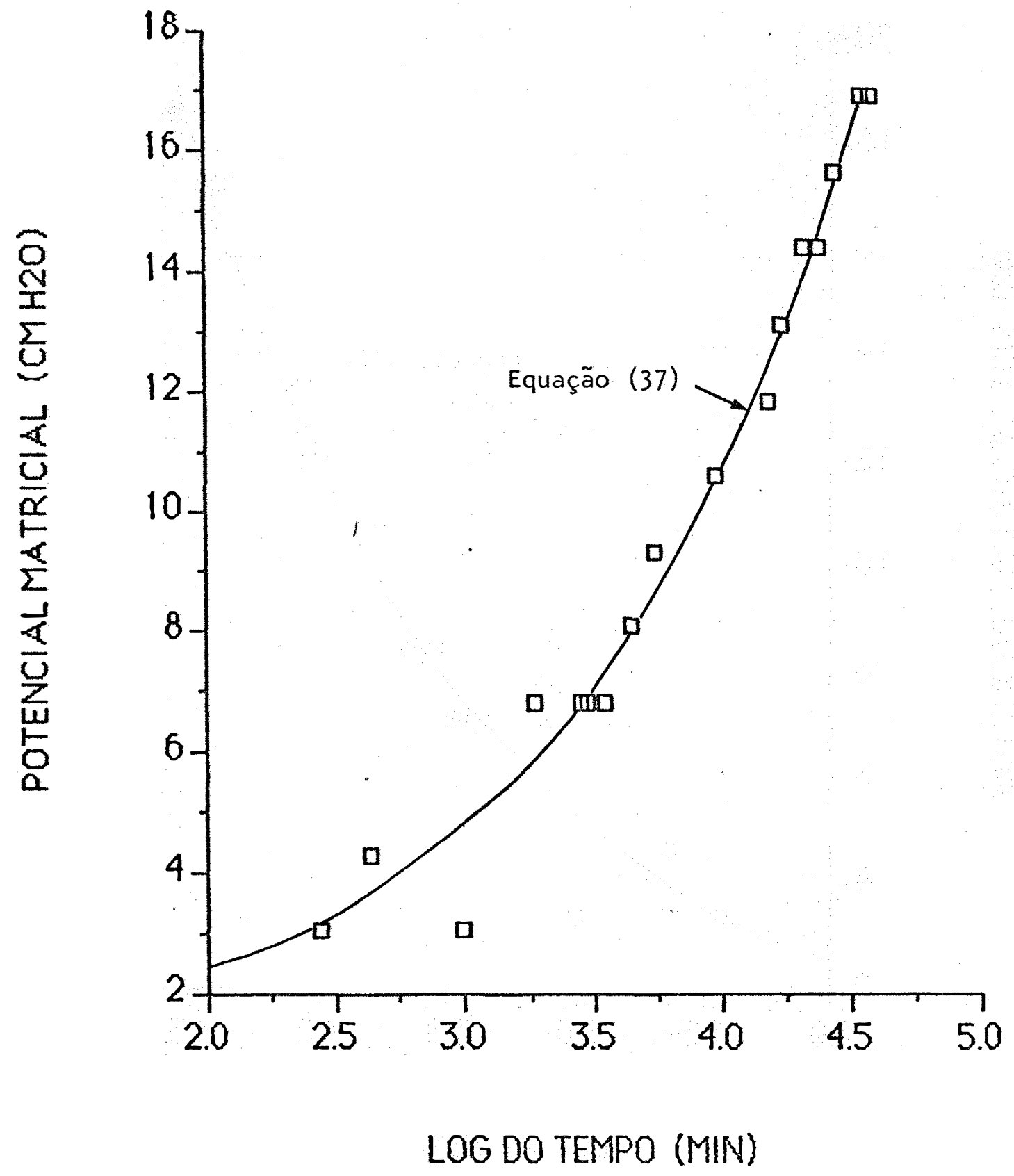

FIGURA 39 - Potencial matricial em função do tempo de redistribuição da ägua na profundidade de $32 \mathrm{~cm}$ do solo Terra Roxa E truturada. 


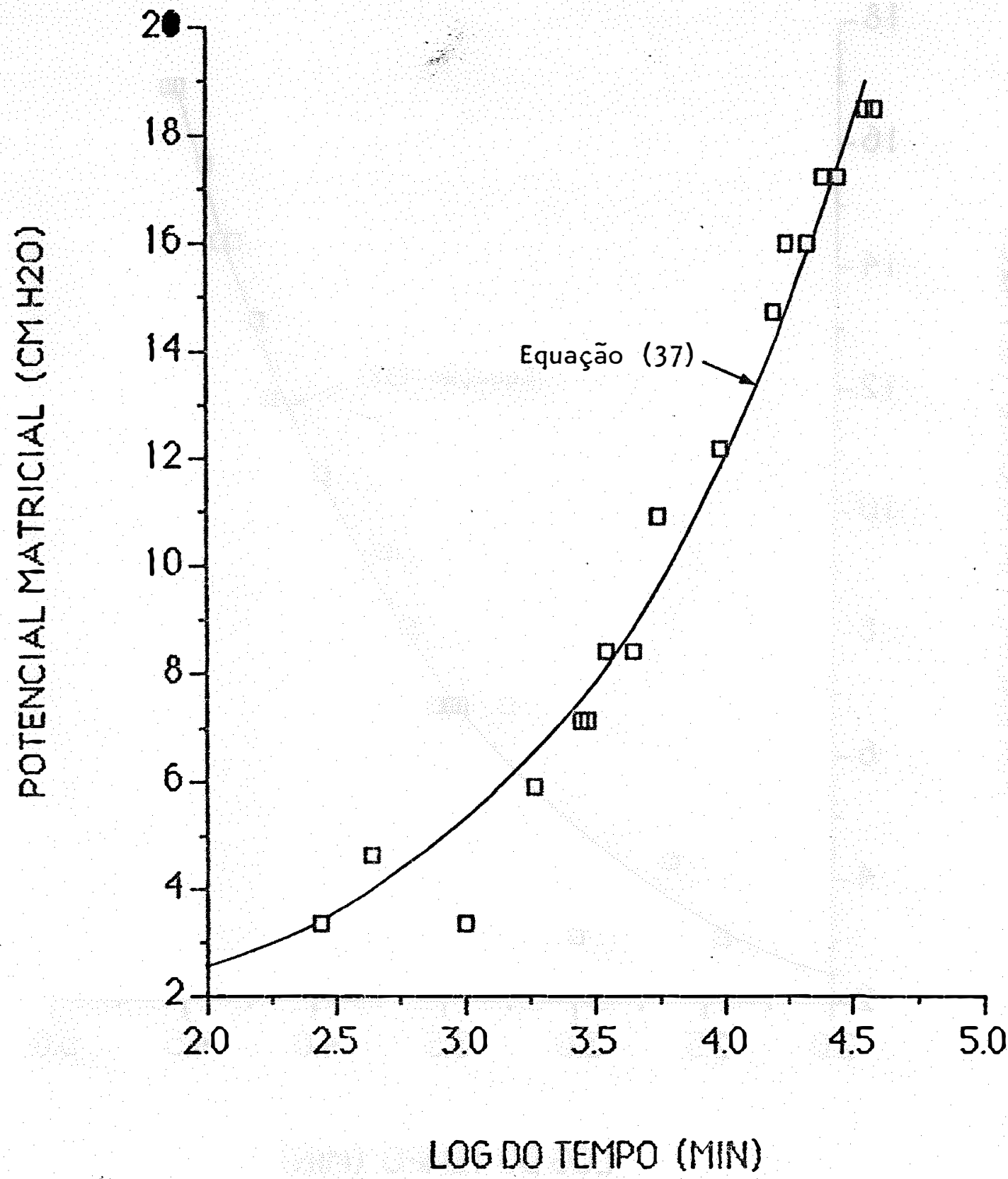

FIGURA 40 - Potencial matricial em função do tempo de redistribuição da ägua na profundidade de $40,5 \mathrm{~cm}$ do solo Terra Roxa Es truturada. 


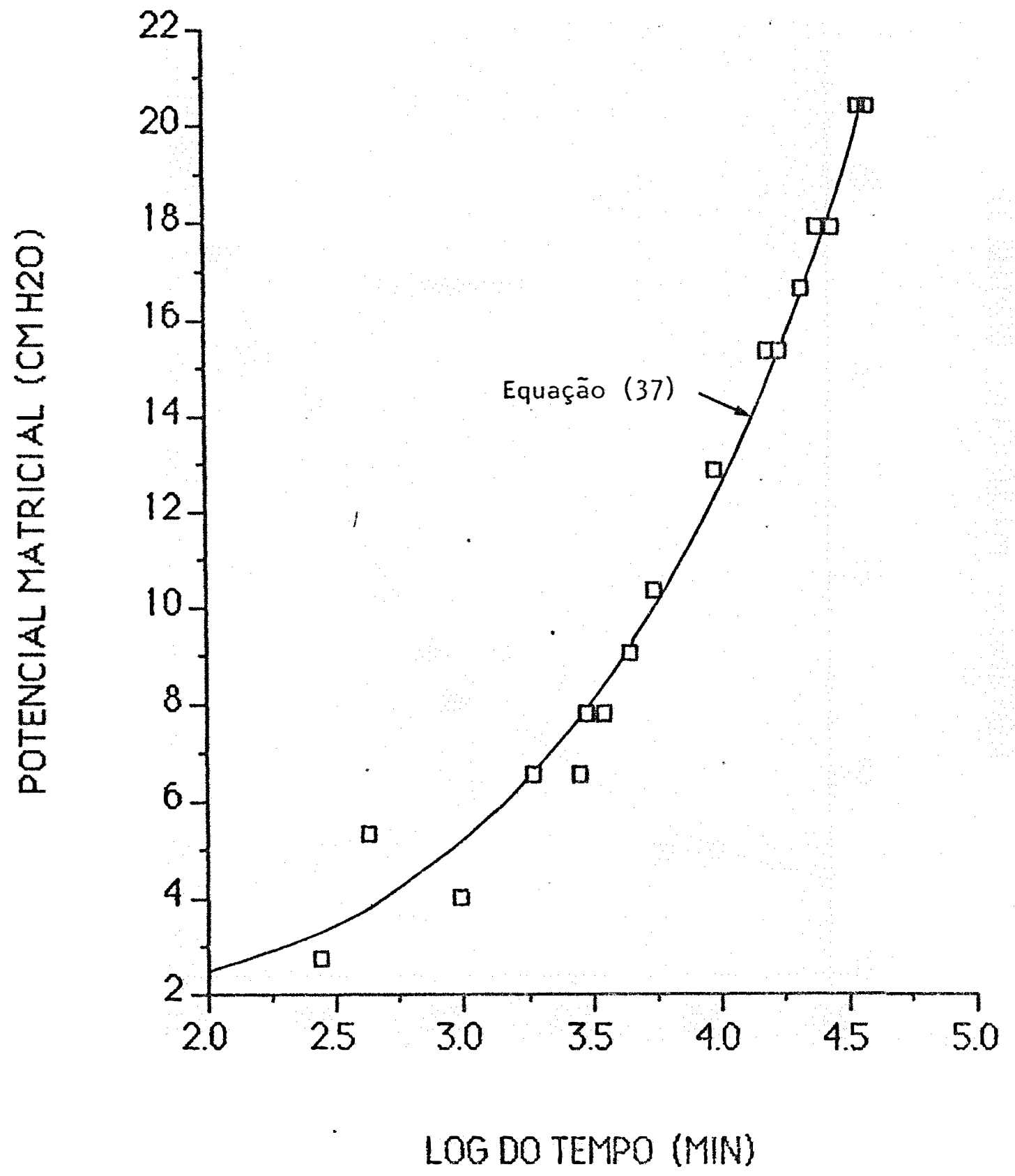

FIGURA 41 - Potencial matricial em função do tempo de redistribuição da àgua na profundidade de $57,5 \mathrm{~cm}$ do solo Terra Roxa Es truturada. 


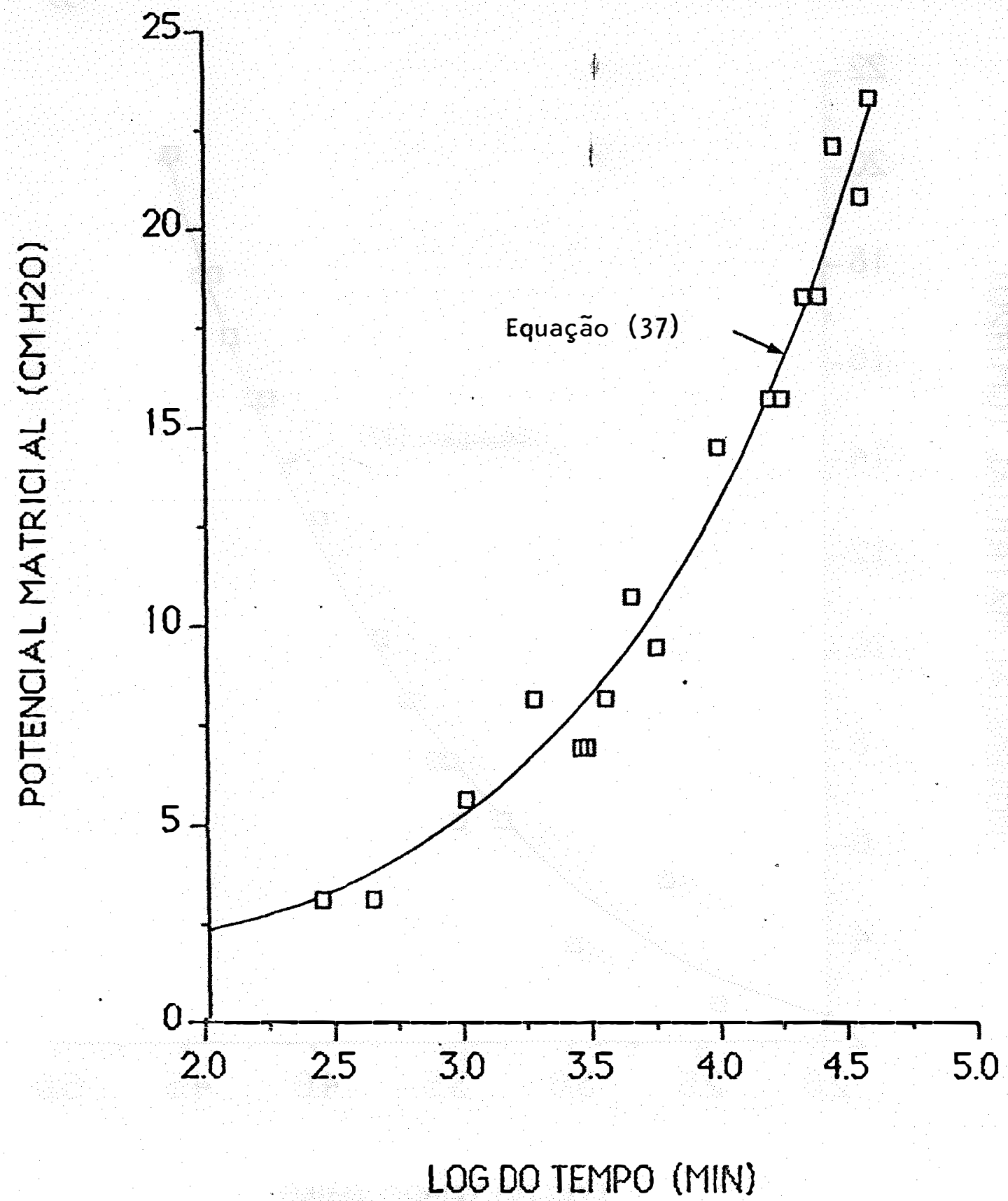

FIGURA 42 - Potencial matricial em função do tempo de redistribuição da água na profundidade de $66 \mathrm{~cm}$ de solo Terra Roxa Es truturada. 


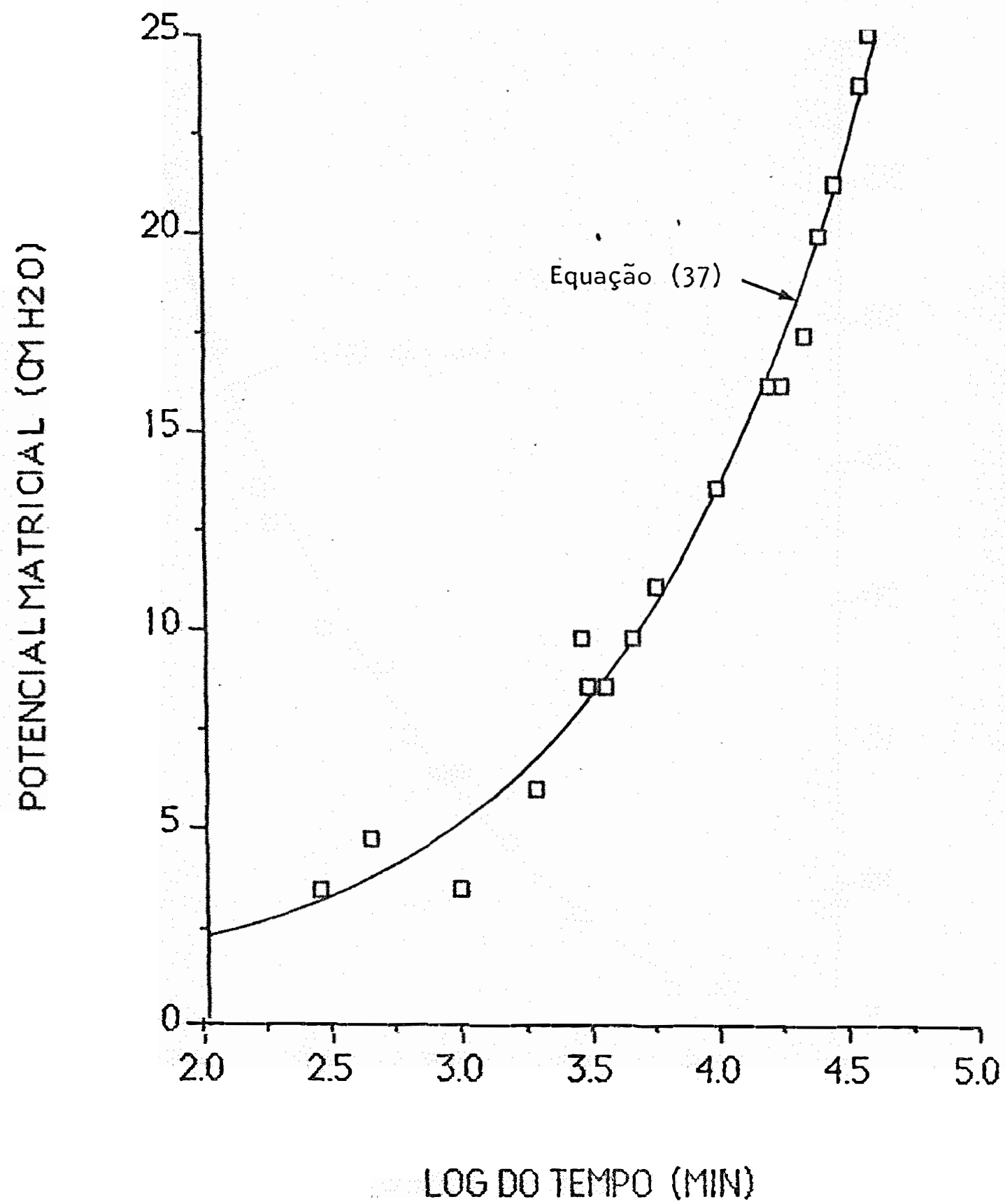

FIGURA 43 - Potencial matricial em função do tempo de redistribuição da água na profundidade de $74,5 \mathrm{~cm}$ do solo Terra Roxa Es truturada. 


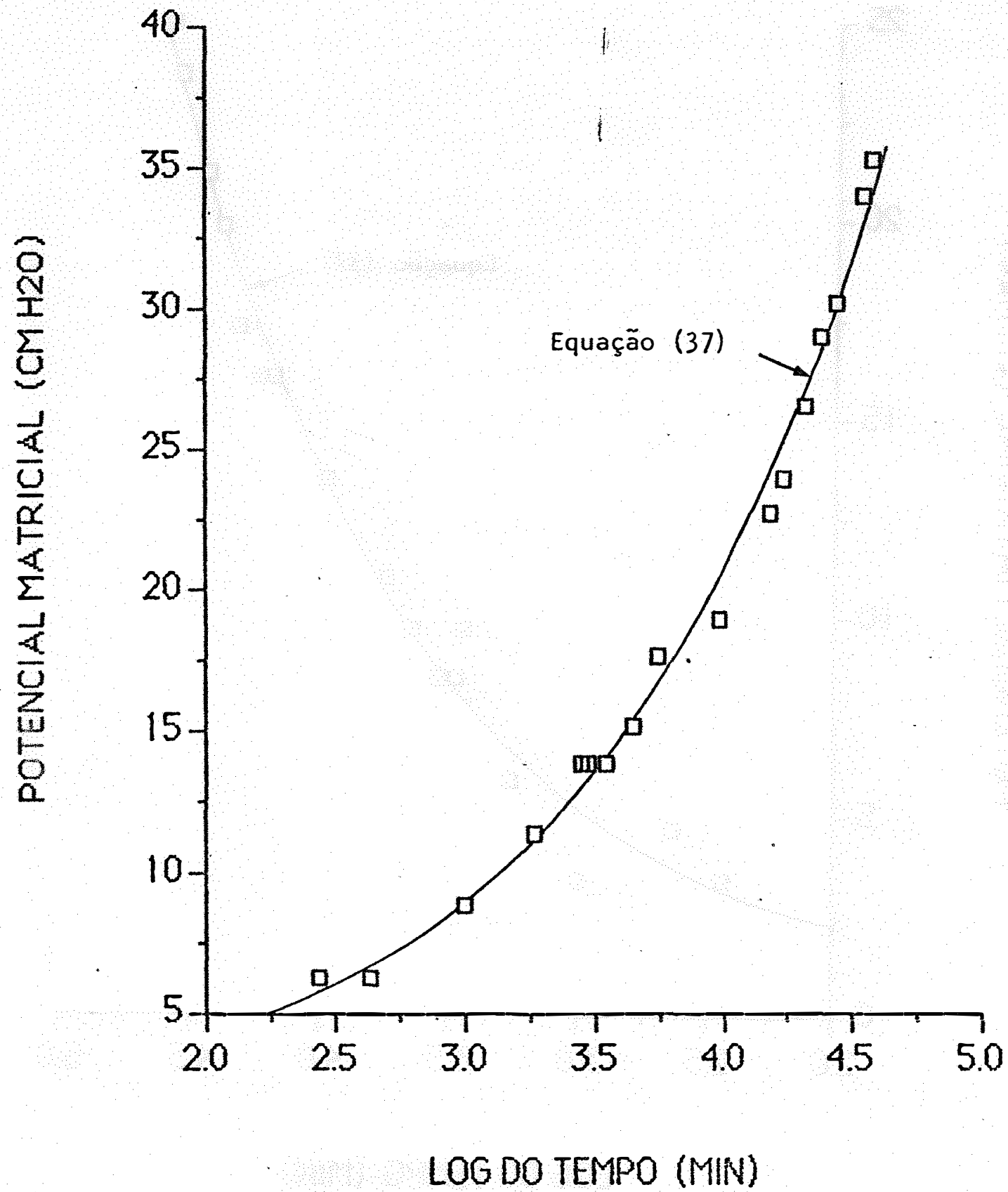

FIGURA 44 - Potencial matricial em função do tempo de redistribuição da ägua na profundidade de $90,5 \mathrm{~cm}$ do solo Terra Roxa Es truturada. 


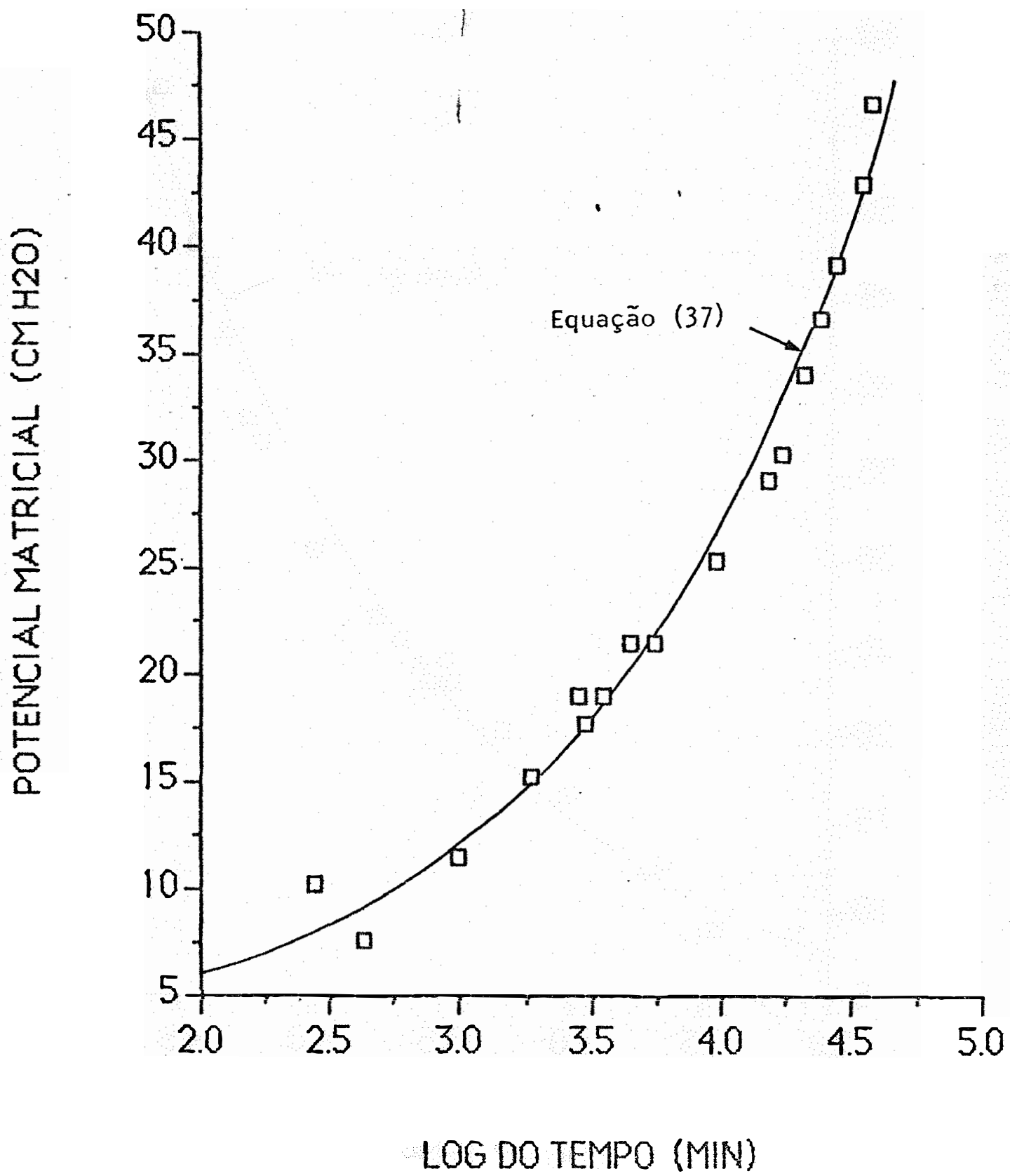

FIGUR 45 - Potencial matricial em função do tempo de redistribuição da água na profundidade de $98 \mathrm{~cm}$ do solo Terra Roxa Es truturada. 


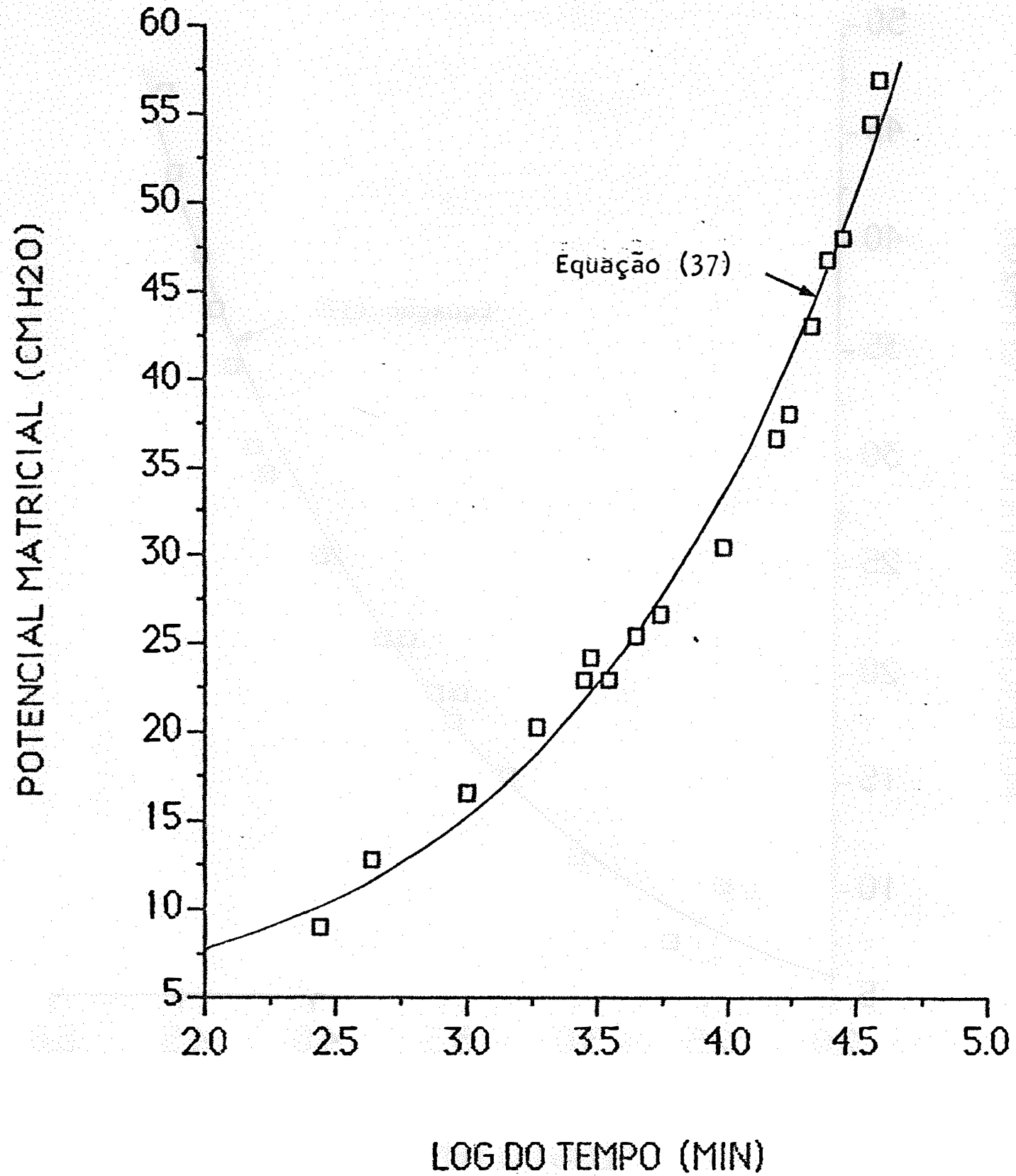

FIGURA 46 - Potencial matricial em função do tempo de redistribuição da ägua na profundidade de $105,5 \mathrm{~cm}$ do solo Terra Roxa Estruturada. 


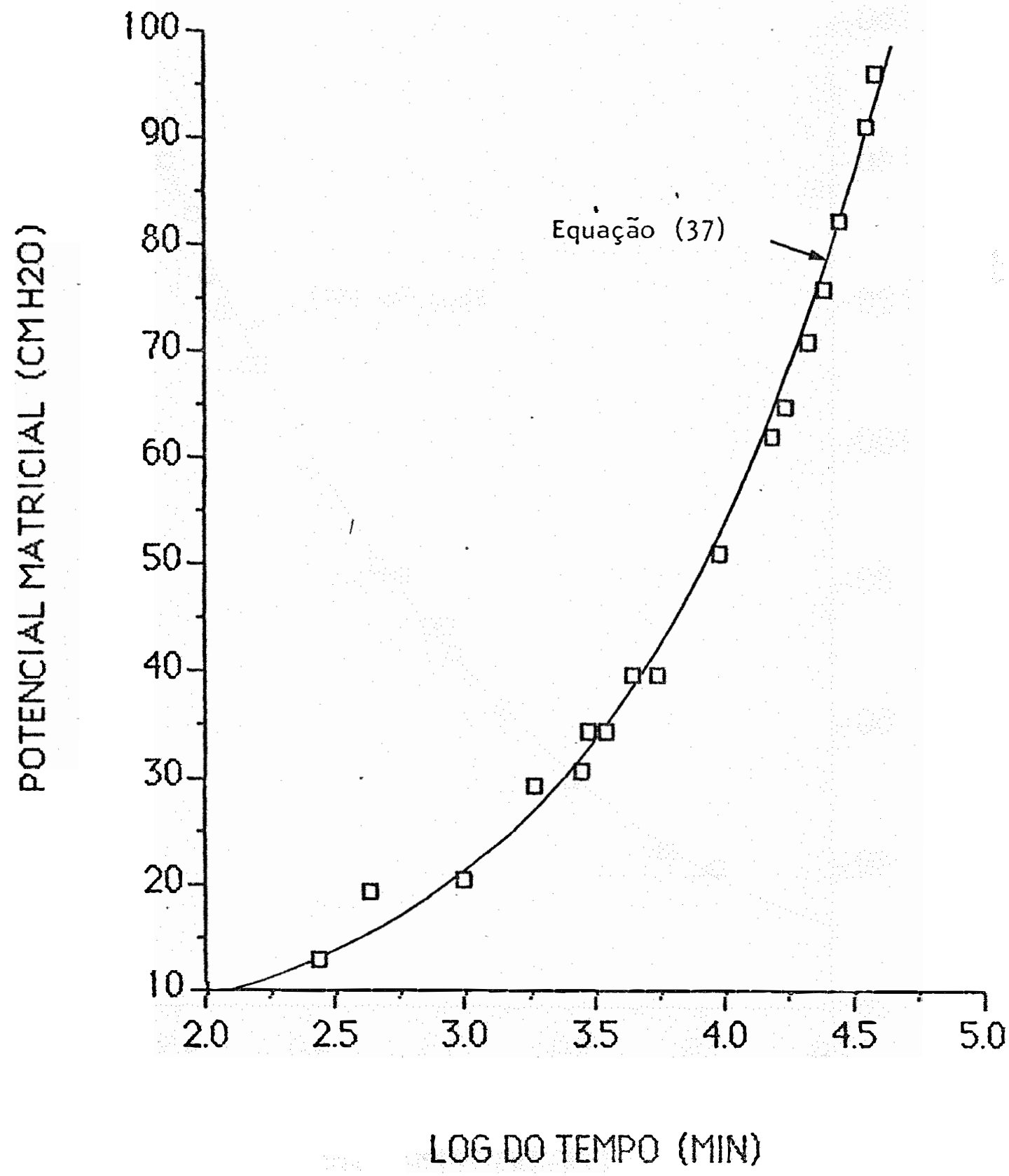

FIGURA 47 - Potencial matricial em função do tempo de redistribuição da água na profundidade de $128 \mathrm{~cm}$ do solo Terra Roxa Es truturada. 


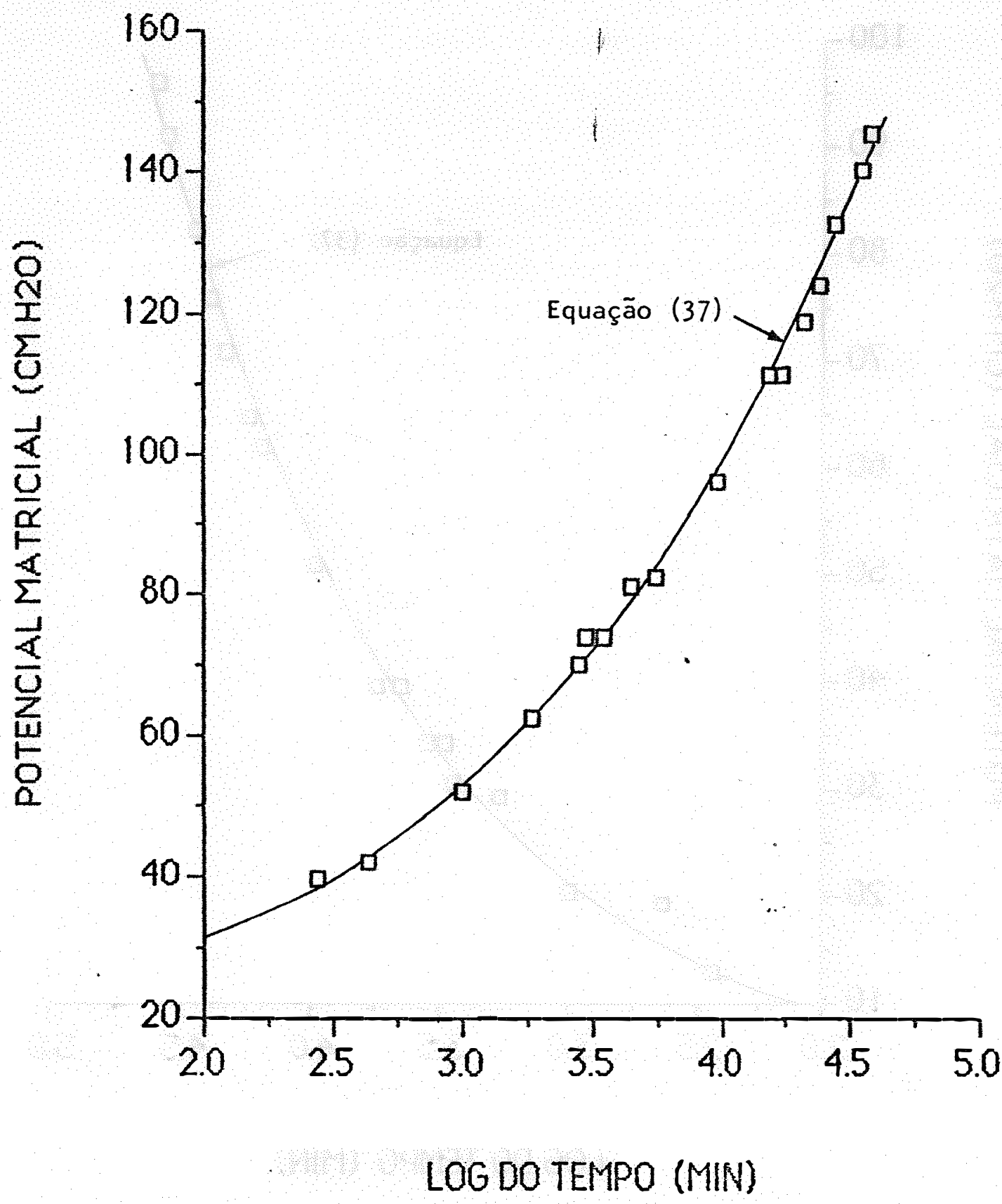

FIGURA 48 - Potencial matricial em função do tempo de redistribuição da água na profundidade de $143 \mathrm{~cm}$ do solo Terra Roxa Es truturada. 


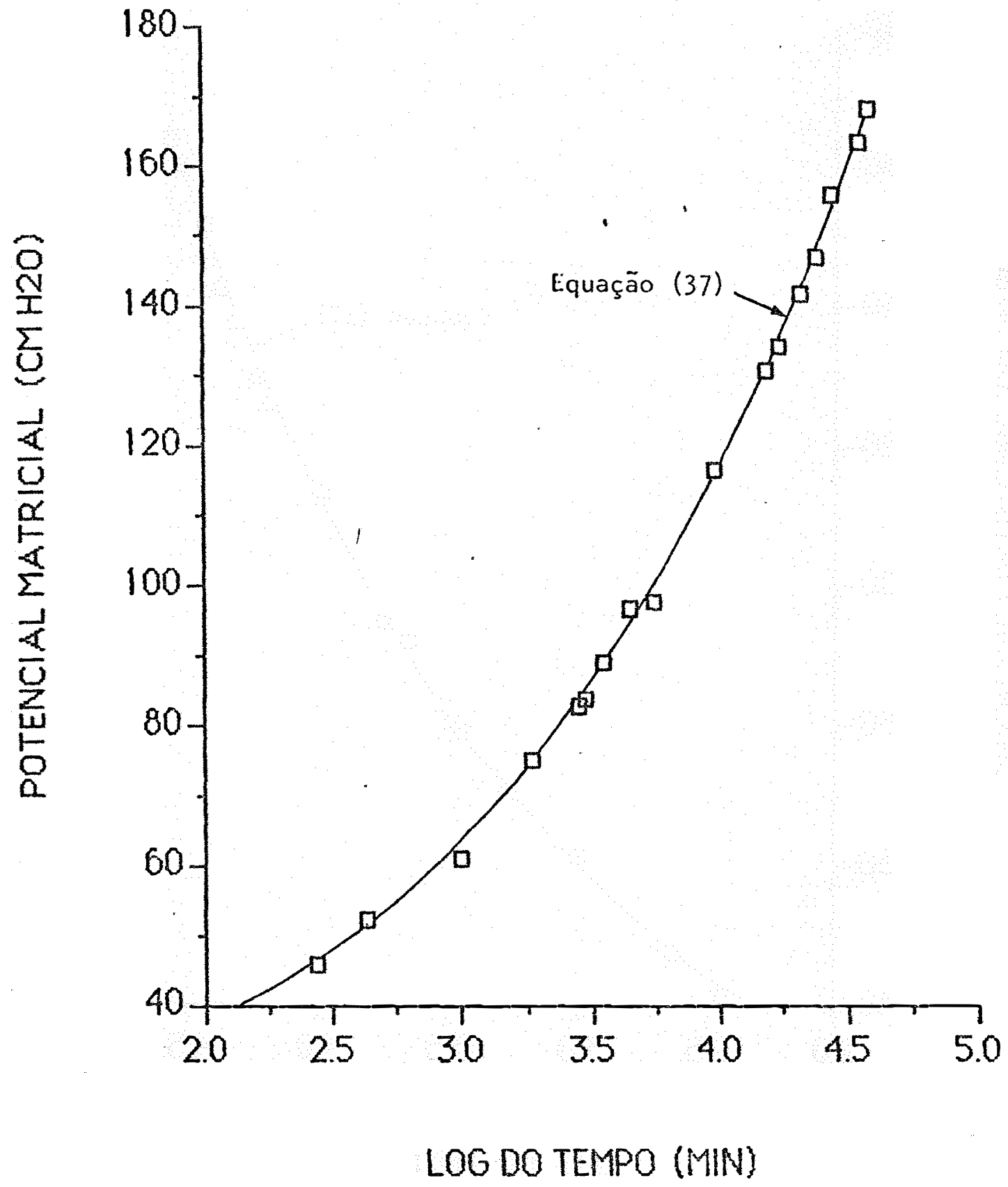

FIGURA 49 - Potencial matricial em função do tempo de redistribuição da āgua na profunfidade de $158 \mathrm{~cm}$ do solo Terra Roxa Es truturada. 


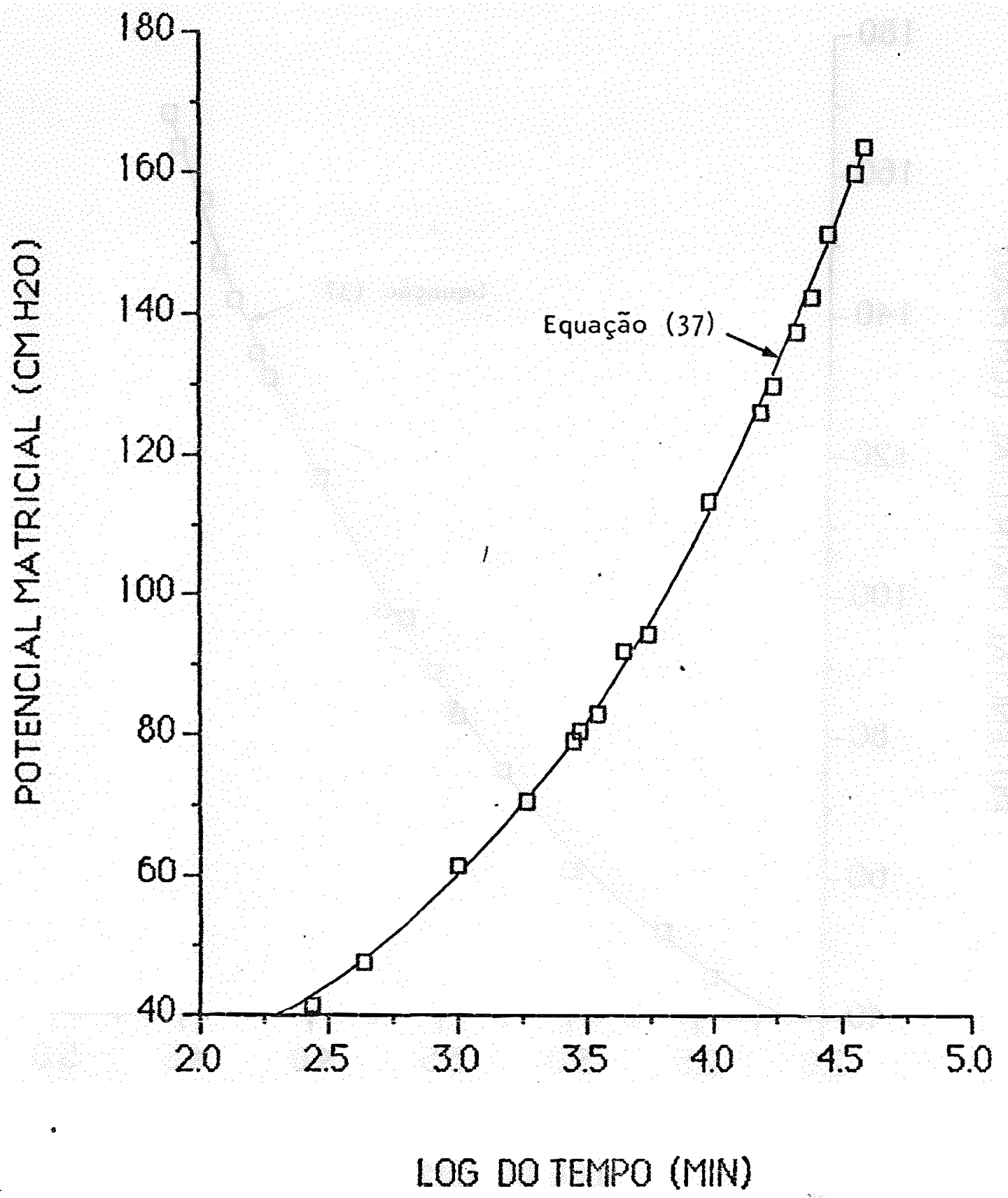

FIGURA 50 - Potencial matricial em função do tempo de redistribuição da água na profundidade de $188 \mathrm{~cm}$ do solo Terra Roxa Es truturada. 


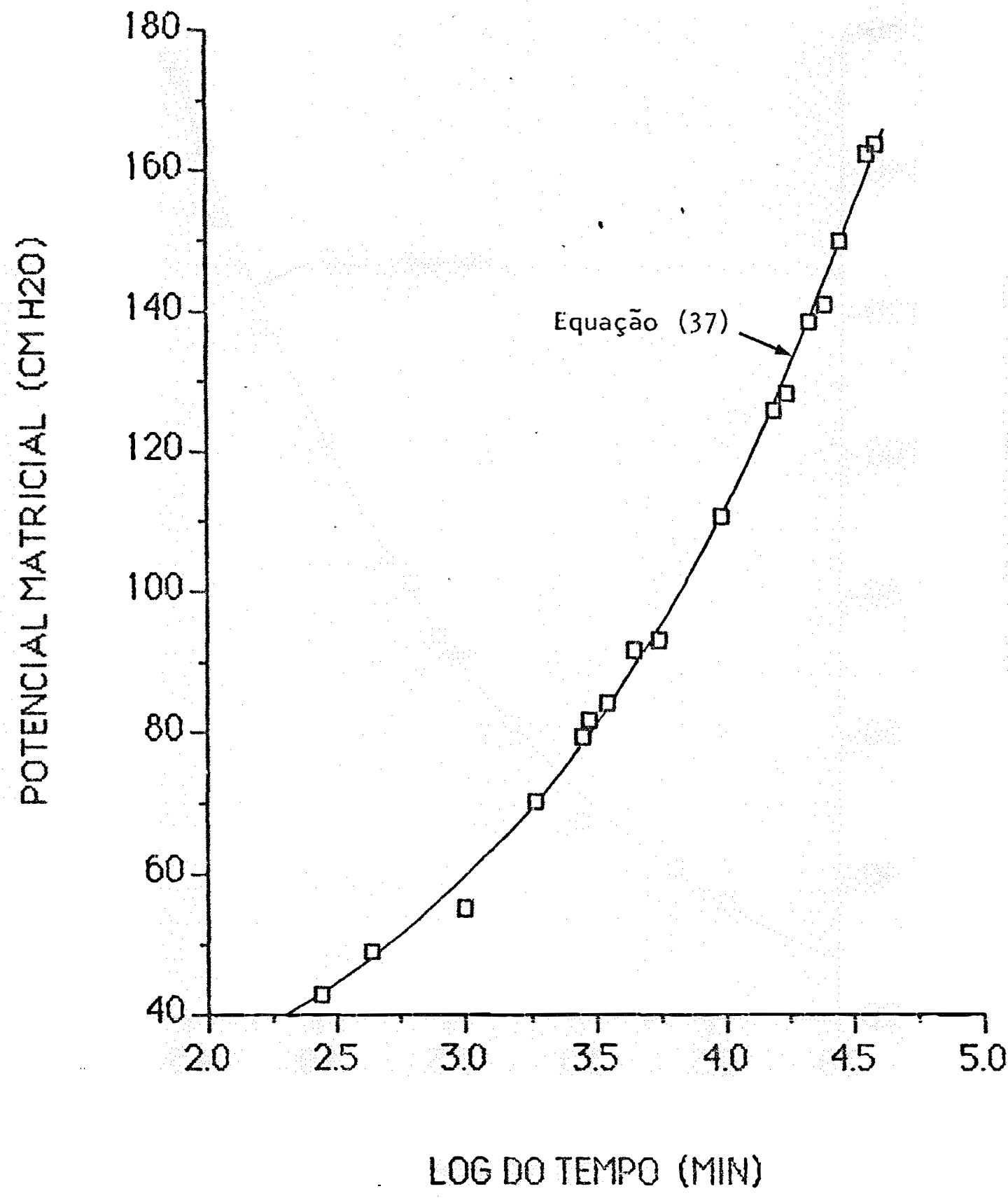

FIGURA 51 - Potencial matricial em função do tempo de redistribuição

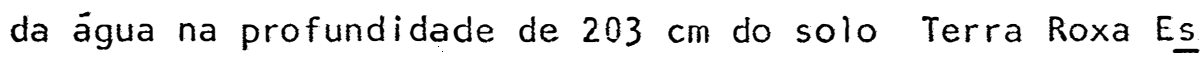
truturada. 


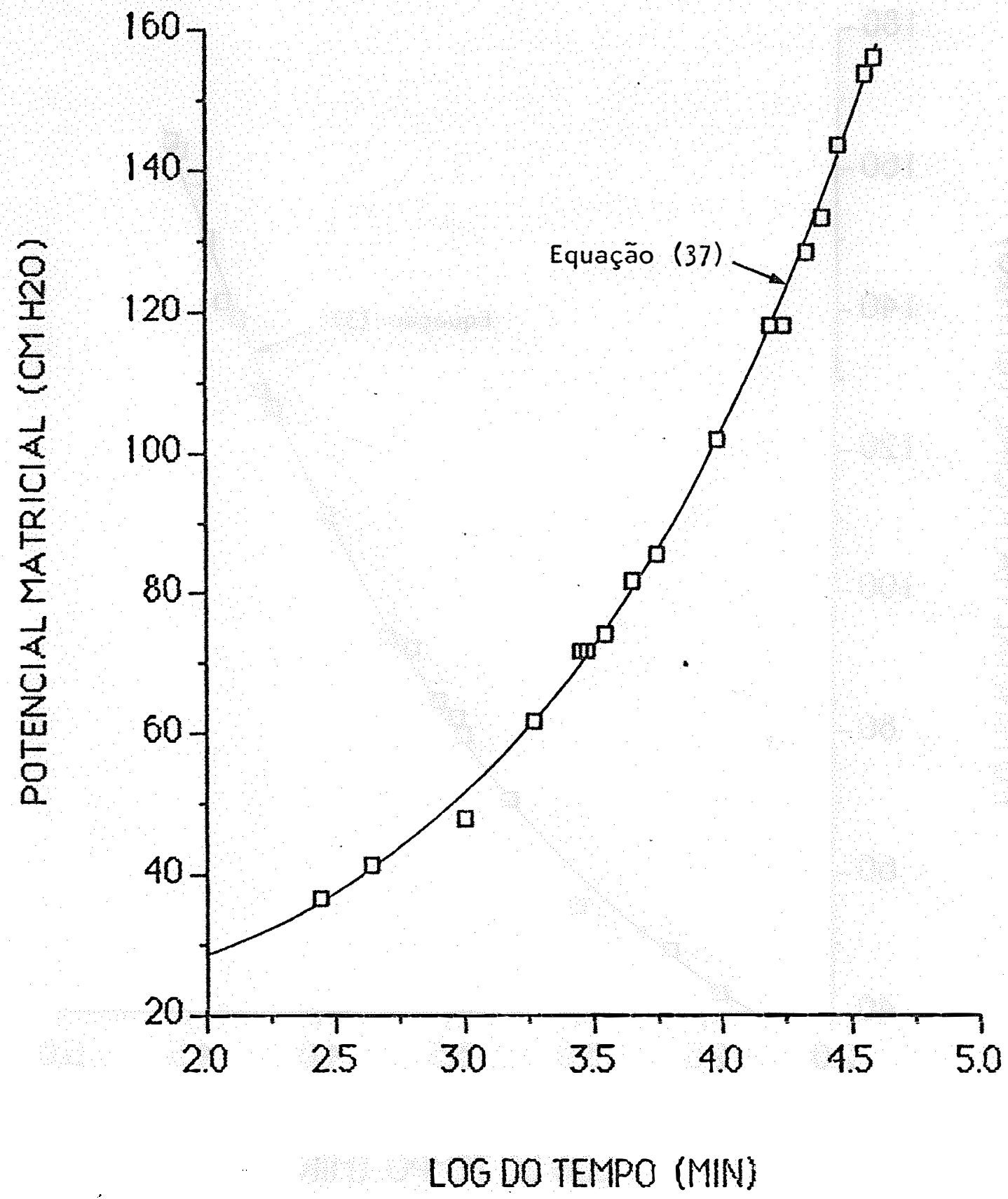

FIGURA 52 - Potencial matricial em função do tempo de redistribuição da ägua na profundidade de $218 \mathrm{~cm}$ do solo Terra Roxa Es truturada. 


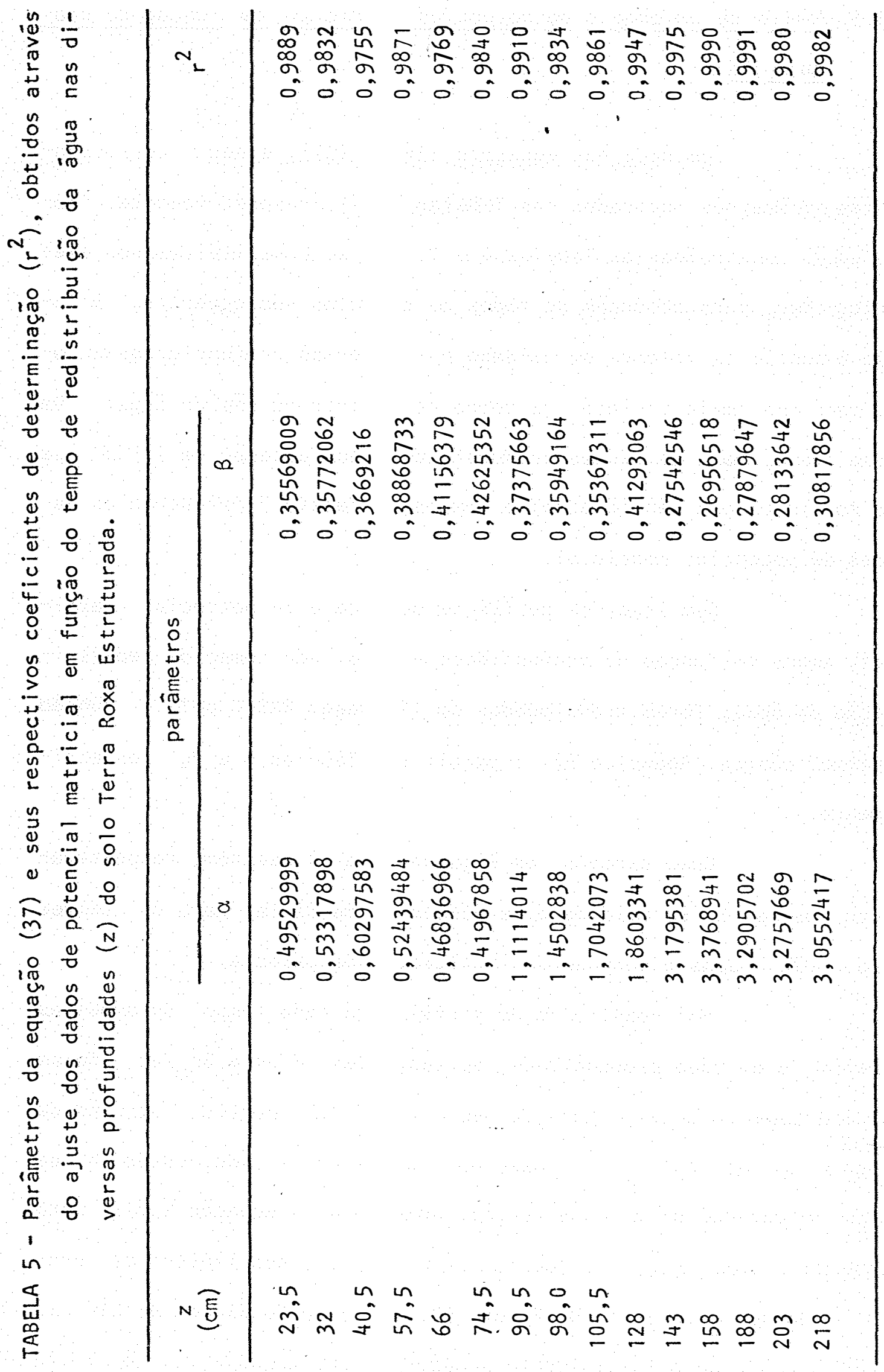


5.1.5. Perfis de umidade e de potencial matricial em função da profundidade

Com base nas equações (36) e (37), e seus correspondentes parâmetros mostrados nas Tabelas 4 e 5 , respectivamente, foram então construídas as Tabelas 6 e 7 , que se constituiram nos elementos-chave para obtenção de todos os cälculos subsequentes. A Tabela 6 contēm os valores de umidade nas diversas profundidades do solo, para uma ampla variação no tempo de redistribuição da ägua. Da mesma forma, para as mesmas profundidades (com exceção de $7,5 \mathrm{~cm}$, que não foi instalado tensiômetro) e tempos, a Tabela 7 apresenta os valores de potencial matricial.

Com isso, os perfis de umidade e de potencial matricial, ambos em função da profundidade e para cada tempo de redistribuição da água, foram transladados em linguagem BASIC pela função "Spline" cúbica (Apêndice A), a partir das Tabelas 6 e 7 , respectivamente.

Como exemplo, as Figuras 53 e 54 mostram, respectivamente, os perfis de umidade e de potencial matricial para os tempos zero e 672 h após o término da infiltração na parcela.

Foi construido um perfil para cada tempo de ambas as tabelas, e em cada profundidade, as tangentes $\partial \Theta / \partial z$ e $\partial \psi_{m} / \partial z$ foram automaticamente determinadas de seus respectivos perfis, através da função "Spline" cúbica. No caso dos perfis de umidade, esses ainda foram integrados pela mesma função, obedecendo à equação (38), para fornecer a armazenagem de água em cada tempo, e nos limites de profundidade de interesse. Na Figura 53, até a profundidade de $218 \mathrm{~cm}$, os $88,3 \mathrm{~cm}$ de água inicialmente armazenados no tempo zero, diminuiu 
para $76,6 \mathrm{~cm}$ apōs $672 \mathrm{~h}$ de drenagem e redistribuição. Comparativamente, nos primeiros $40,5 \mathrm{~cm}$ de profundidade, esse decréscimo foi de $15,0 \mathrm{~cm}$ para $14,6 \mathrm{~cm}$ de àgua, no mesmo pẹíodo.

5.1.6. Difusividades global, matricial, gravitacional. e condutividade hidräulica

Atravēs do procedimento apresentado no item 4.2.7. para determinação das funções ${ }^{\prime} D_{g}(\theta), K(\theta), D_{m}(\theta), D_{z}(\theta), K_{H}(\theta)$ e $D_{m H}(\theta)$, foram construídas as Tabelas 8 e 9 , que fornecem, alēm desses parâmetros hidráulicos, todos aqueles outros necessärios às suas determinações, tambëm descritos no i tem 4.2.7. Todos os cälculos foram realizados visando a determinação dessas funções para as profundidades de $32,66,98,143$ e $203 \mathrm{~cm}$, que são exatamente as profundidades médias das camadas $15-49,49-83,83-113,113-173$ e $173-233 \mathrm{~cm}$, consideradas morfologicamente homogêneas (ver item 4.2.1.).

A terceira coluna da Tabela 8 foi obtida pela equação (39) atravēs da função "Spline" cūbica (Apêndice A), entrando-se no programa com os dados de armazenagens previamente obtidos (coluna 2) e dos tempos respectivos, para cada profundidade de interesse. De modo semelhante foram obtidas as tangentes nas curvas características $d \psi_{m} / d \Theta$ (quinta coluna da Tabela 9); neste caso, foram utilizados tambēm, para cada profundidade de interesse, os dados de umidade e de potencial matricial das Tabelas 6 e 7 , uma vez que eles são comuns com o tempo de redistribuição. A obtenção detalhada dos demais parâmetros hidräulicos da Tabela 9, é descrita no item 4.2.7.

$$
\text { Observando-se os valores de } K(\Theta) \text { e } K_{H}(\Theta) \text { da Tabela } 9 \text {, }
$$
verifica-se, de modo geral, que eles são bastante diferentes na pro- 
fundidade de $32 \mathrm{~cm}$ e também a $66 \mathrm{~cm}$ para os menores valores de umidade, passando a melhorar sensivelmente, principalmente para as profundidades de 98,143 e $203 \mathrm{~cm}$. A mesma observação é válida para as funções $D_{m}(\theta)$ e $D_{m H}(\theta)$, uma vez que essas são obtidas pelo produto das respectivas condutividades hidráulica $\left(K(\theta)\right.$ e $\left.K_{H}(\theta)\right)$, com as tangentes $d \psi_{\mathrm{m}} / \mathrm{d} \Theta$, para um mesmo valor de umidade. Para melhor visualizar o comportamento dessas funções e facilitar a comparação entre elas, foram construidas, a partir da Tabela 9, as Figuras 55 a 59, que mostram graficamente os valores das condutividades hidráulicas determinadas pela teoria proposta, K, e pelo método de HILLEL et alii (1972), K , ambos em função da umidade, para cada uma das profundidades estudadas. Da mesma forma, os valores das difusividades hidráulicas determinadas pela teoria proposta: global $\left(D_{g}\right)$, gravitacional $\left(D_{z}\right)$ e matricial $\left(D_{m}\right)$, bem como a determinada pelo método de HILLEL et alii (1972), e neste trabalho simbolizada por $D_{m H}$, também foram graficadas em função da umidade, e são mostradas nas Figuras 60 a 64 , para cada profundidade.

Como se pode notar, há uma defasagem bastante pronunciada entre os valores de condutividades hidräulicas ( $K$ e $K_{H}$ ) para a profundidade de $32 \mathrm{~cm}$, e também para os menores valores de umidade na profundidade de $66 \mathrm{~cm}$. Isso não ocorreu para as demais profundidades, podendo-se até dizer que essas funções se ajustam razoavelmente bem entre si, principalmente na profundidade de $98 \mathrm{~cm}$. Essas mesmas observações também se aplicam para as funções $D_{m}$ e $D_{m H}$, das Figuras 60 a 64 .

Tudo isso mostra, como será comprovado a seguir, que as três ültimas camadas, isto é, $83-113,113-173$ e $173-233 \mathrm{~cm}$, são suficientemente homogêneas do ponto de vista hidráulico, embora não o bastante em duas delas para indicar corretamente o sentido vertical do 
fluxo. E o caso das camadas 83-113 e 113-173 cm, onde os valores de gradiente de umidade $(\partial \Theta / \partial z)$ foram negativos. Se tais camadas fossem rigorosamente homogêneas, esses valores seriam'positivos, indicando, pela equação (27), o movimento descendente da água no perfil de solo. Mesmo assim, os resultados nelas obtidos ainda validam e tornam possível a aplicação do método proposto no item 3.3. para fins práticos, porquanto que para esses propósitos, o sentido do fluxo serā respeitado se os sinais das funções $D_{g}(\theta)$ forem observados.

Desse modo, as funções $D_{g}(\theta)$, tal como foram obtidas nas profundidades de 98, 143 e $203 \mathrm{~cm}$, são de grande importância prática, uma vez que através delas pode-se estimar razoavelmente bem o fluxo de água pela equação (27), com algumas vantagens sobre a equação de Buckingham-Darcy, equação (5). Essas funções sãomostradas nas Figuras 62 a 64 , onde se pode notar que todas apresentam comportamento exponencial e com uma distribuição dos pontos experimentais muito bem definida em cada profundidade. Isso também se observa para as demais funções $D_{m}(\theta)$ e $D_{z}(\Theta)$, e serve para mostrar a coerência na definição desses conceitos, equações 21 e 22, especialmente da segunda, que se constitui numa novidade no campo da física da água em meios porosos não saturados. Ambas as funções estão relacionadas com a propriedade do meio em conduzir água, seja pela presença da matriz $\left(D_{m}(\Theta)\right)$, ou pela ação do campo gravitacional terrestre $\left(D_{z}(\Theta)\right)$. Por isso, como é de se esperar e mostrado nas Figuras 62 a 64 , a função $D_{\mathbf{z}}(\Theta)$ assume maior importância para altos valores de umidade, próximo à saturação, tendendo a decrescer mais pronunciadamente do que a função $D_{m}(\Theta)$, à medida que as forças matriciais mais intensamente se evidenciam com a secagem do solo.

Com relação às profundidades de 32 e 66 cm, embora as 
funções $D_{g}(\Theta)$ se apresentem bem definidas, Figuras 60 e 61 , respectivamente, elas não encerram nenhum fundamento físico que justifique aplicabilidade. Pelo conträrio, as defasagens entre as funções $k(\theta)$ e $K_{H}(\theta)$, e $D_{m}(\theta)$ e $D_{m H}(\theta)$ nessas profundidades, mostram que ambas as camadas não são hidraulicamente homogêneas e, portanto, o método proposto não pode ser aplicado em nenhuma delas.

Para comprovar essas afirmações de uma forma mais adequada e fisicamente embasada, retornemos à equação (18). Como descrito no item 3.2 , essa equação foi obtida admitindo-se a hipótese de solo (camada de solo no caso em questão) hidraulicamente homogêneo, todavia sem impor restrições quanto ao regime do fluxo de água que nele se processa (evaporação, redistribuição, infiltração, etc). Ela diz que se um solo é rigorosamente homogêneo do ponto de vista hidráulico, então para qualquer tempo dentro do regime de fluxo envolvido, - produto das tangentes $\partial \theta / \partial z$ e $d \psi_{m} / d \theta$, deve ser exatamente igual ao gradiente de potencial matricial $\left(\partial \psi_{m} / \partial z\right)$. E lógico admitir, por outro lado, que a imposição dessa condição seja difícil de ser satisfeita, principalmente sob condições de campo. Daí, a pergunta que surge de imediato, é a seguinte: como se pode avaliar o afastamento que uma camada qualquer de solo apresenta, com relação a uma condição padrão de homogeneidade hidráulica?

A equação (18) pode ser utilizada para responder a esta pergunta, se através dela puder ser definida a condição padrão de Wric yeneiaje hidrāulica. Para isso, se considerarmos a equação

$$
F(\Theta)=\frac{\partial \psi_{m}}{\partial z}-\frac{d \psi_{m}}{d \theta} \cdot \frac{\partial \theta}{\partial z}
$$

então a condição padrão será satisfeita, quando o valor de $F$ for nulo 
para qualquer valor de umidade. Portanto, se para qualquer valor de umidade o valor de $F$ for diferente de zero na equação (41), esta será uma medida do afastamento da condição padrão de homogeneidade hidrāulica, para aquele valor de umidade. Assim, se todos os parâmetros hidrāulicos da equação (41) são conhecidos para uma ampla variação de umidade na camada de interesse, então o comportamentodessa camada pode ser analisado dentro dessa variação de umidade, com respeito à condição padrão de homogeneidade hidráulica.

Os valorés de F da equação (41), em função da umidade, foram calculados para todas as camadas consideradas, a partir dos dados da Tabela 9. Esses valores se encontram graficados nas Figuras 65 a 69. Como pode ser notado, hã, sem exceção, uma correlação muito estreita entre os valores de $F$ com as respectivas diferenças entre as funções $K(\theta)$ e $K_{H}(\theta)$, e $D_{m}(\theta)$ e $D_{m H}(\theta)$ nas profundidades correspondentes (Figuras 55 a 64), e isso mostra que essas diferenças também podem ser utilizadas como critērio interpretativo para análise de homogeneidade hidráulica dentro da camada de interesse. Deve ser notado, tambēm, que as funções $F(\theta)$ de camadas distintas, não podem ser utilizadas para comparação entre si, a menos que essa comparação seja referida a valores de umidades comuns para ambas as camadas. Isso é fäcil de compreender, porque somente assim os parâmetros hidräulicos da equação (41) serão afins para esse propósito.

Diante de tudo isso, e como ficou demonstrado, se conclui que toda a teoria formulada nos itens 3.2. e 3.3. deste trabalho, pode ser aplicada para propósitos práticos, em meios porosos aproximadamente homogêneos hidraulicamente, mas que o critério morfológico para identificação das camadas hidraulicamente homomogêneas, nem sempre conduz a resultados satisfatōrios. 
Infelizmente, essa conclusão se traduz desfavoravelmente na aplicação da teoria proposta em solos dessa natureza, uma vez que a descrição morfologica é um processo relativamente rápido e simples no campo. Por outro lado, o critērio da função $F(\theta)$, equação (41), que embora se constitua numa maneira segura para identificação das camadas hidraulicamente homogêneas, tem como implicação o conhecimento prévio de um volume de informações adicionais, que provavelmente não justifique a aplicação do método proposto no item 3.3 ., comparativamente ao de HILLEL et alii (1972), por exemplo.

Para que essa situação se inverta, é necessário adotar um novo critério para identificação das camadas hidraulicamente homogêneas, e que seja relátivamente seguro e rápido. Ao que parece, uma maneira atrativa de se conseguir isso, e que tem muito a ver com a equação (41), é a de se utilizar o confrontamento das curvas características respectivas a cada profundidade dentro da camada de interesse. Evidentemente, quanto mais pröximas se apresentarem as curvas, mais forte será a indicação de se tratar de uma camada hidraulicamente homogênea.

As Figuras 70 a 74 mostram as famílias de curvas características das camadas de solo consideradas, obtidas a partir das Tabelas 6 e 7. Como se pode observar, embora esse critério seja menos preciso do que a equação $(41)$, já que as curvas características são independentes do tempo, mesmo assim ele oferece uma boa idéia, pelo menos para efeitos práticos, da condição de homogeneidade hidráulica de cada uma das camadas. Há, em outras palavras, uma boa aproximação das curvas para as três ültimas camadas, enquanto que para aquelas mais superficiais, pelo menos uma delas se apresenta diferentemente disposta com relação às outras, o que permite inferir as mesmas 
TABELA 6 - Valores de umidade $\left(\mathrm{cm}^{3} / \mathrm{cm}^{3}\right)$ em função da profundidade e do tempo de redistribuição da āgua, do experimento em Terra Roxa Estruturada, obtidos pela equação (36) e parâmetros da Tabela 4.

\begin{tabular}{|c|c|c|c|c|c|c|c|c|}
\hline \multirow{2}{*}{$\begin{array}{c}t \\
\text { (hora) }\end{array}$} & \multicolumn{8}{|c|}{ profundidade $(\mathrm{cm})$} \\
\hline & $z=7,5$ & $z=23,5$ & $z=32$ & $z=40,5$ & $z=57,5$ & $z=66$ & $z=75,5$ & $z=90,5$ \\
\hline 0 & 0,4321 & 0,3317 & 0,3316 & 0,389 & 0,4348 & 0,4369 & 0,4355 & 0,4348 \\
\hline 6 & 4286 & 0,3313 & 0,3308 & 0,3819 & 0,4275 & 0,4312 & 0,4302 & 0,4278 \\
\hline 12 & 4269 & 0,3 & 0,3302 & 0,3791 & 0,4235 & 0,4282 & 0,4274 & 0,4239 \\
\hline 18 &, 4258 & 0,3 & 299 & 774 & 0,421 &, 4262 & 0,4255 & 0,4212 \\
\hline 24 & 425 & 0, & 97 & 62 & 0,4191 & 0,4247 & 0,4241 & 92 \\
\hline 30 & 4243 & 0 , & 96 & 53 & 0,4176 & 0,4235 & 0,423 & 76 \\
\hline 36 & 237 & 0 , & 94 & 45 & 0,4163 & 0,4225 & 0,4 & 63 \\
\hline 42 & 233 & 0 , & 93 & 739 & 0,4153 & 0,4217 & 0,4212 & 52 \\
\hline 48 & 29 & 0, & 92 & 33 & 0,4144 & 0,421 & 0,4205 & 0,4142 \\
\hline 72 &, 4216 & 0,3 & 0 , & 16 & 0,4116 & 0,4188 &, 4184 &, 4112 \\
\hline 96 & 4208 & 0 , & 88 & 0 , & 0,4097 & 0,4173 & 58 & 0 , \\
\hline 120 & 4201 & 0 & 0 , & 0 , & 0,4082 & 0,4 & 6 & 74 \\
\hline 144 & 4195 & 0 , & 86 & 688 & 0,4071 & 0,4 & 7 & 6 \\
\hline 168 & 191 & 0 , & 85 & 0,3682 & 0,4061 & 0, & 39 & 49 \\
\hline 192 & 4186 & & 85 & 677 & 0,4052 & 0, & 0 , & 0,4039 \\
\hline 216 & 0,4183 & 0 , & 84 & 0,3672 & 0,4045 & 0,4 & 0, & 0,403 \\
\hline 240 & 0,418 & 0 , & 84 & 668 & 0,4036 & 0,4125 & $0, L$ & 0,4022 \\
\hline 264 &, 4177 & & 33 & 0 , & 0,4032 & 0,412 & 0 , & 015 \\
\hline 288 & 0,4 & & 3 & 361 & 0,4027 & 0,4116 & 0 , & 0,4009 \\
\hline 312 & 0,4172 & & 2 & 0,3 & 0,4022 & 0,4112 & 0 , & 0,4003 \\
\hline 336 & 0,417 & & 0 , & 0 & 0,4017 & 0,4108 & 0,1 & 998 \\
\hline 360 & 0,4168 & & 0 , & 0 , & 0,4013 & 0,4105 & $0, L$ & 0,3993 \\
\hline 384 & 0,4166 & & 2 & 0 , & 0,4009 & 0,4101 & $0, !$ & 0,3988 \\
\hline 408 & 0,4164 & & 0 , & 0 , & 0,4005 & 0,4098 & 0,4092 & 0,3984 \\
\hline 432 & 0,4162 & & 1 & 0 & 0,4002 & 0,4096 & 0,4089 & 0,398 \\
\hline 456 & 0,4161 & 0 , & 0, & 0 , & 0,3999 & 0,4093 & 0,4087 & 0,3976 \\
\hline 480 & 0,4159 & 0 & 0,3 & 0 , & 0,3996 & 0,409 & 0,4084 & 0,3973 \\
\hline 504 & 0,4153 & 6 & 0,3281 & 0 , & 0,3993 & 0,4088 & 0,4082 & 0,3969 \\
\hline 528 & 0,4156 & 0,3 & 0,3 & 0,3 & 0,399 & 0,4086 & 0,4079 & 0,3966 \\
\hline 552 & 0,4155 & 0,3 & 0,328 & 0 , & 0,3987 & 0,4084 & 0,4077 & 0,3963 \\
\hline 576 & 0,4154 & 0,3 & 0,328 & 0,3 & 0,3985 & 0,4082 & 0,4075 & 0,396 \\
\hline 60 & 0,4153 & 0,3284 & 0,328 & 0,3 & 0,3982 & 0,408 & 0,4073 & 0,3957 \\
\hline & 0,4 & 0,3 & 0,3 & 0 , & 0,398 & 0,4078 & 0,4071 & 0,3954 \\
\hline & & 0,3 & 0,3 & 0 , & 0,3978 & 0,4076 & 0,4069 & 0,3951 \\
\hline 672 & 0 , & 0,3284 & 0,3279 & 0, & 0,3976 & 0,4074 & 0,4067 & 0,394 \\
\hline
\end{tabular}

(continua) 
TABELA 6 - Valores de umidade $\left(\mathrm{cm}^{3} / \mathrm{cm}^{3}\right)$ em função da profundidade e do tempo de redistribuição da àgua, do experimento em Terra Roxa Estruturada, obtidos pela equação (36) e parâmetros da Tabela 4.

\begin{tabular}{|c|c|c|c|c|c|c|c|c|}
\hline \multirow{2}{*}{$\stackrel{t}{\text { (hora) }}$} & \multicolumn{8}{|c|}{ profundidade $(\mathrm{cm})$} \\
\hline & $z=98$ & $z=105,5$ & $z=128$ & $z=143$ & $z=158$ & $z=188$ & $z=203$ & $z=218$ \\
\hline 0 & 0,4334 & 0,4336 & 0,4092 & 0,4016 & 0,3959 & 0,3942 & 0,3981 & 0,4015 \\
\hline 6 & 0,4254 & 0,4228 & 0,3951 & 0,3869 & 0,3807 & 0,3828 & 0,3846 & 0,3891 \\
\hline 12 & 0,4211 & 0,4171 & 0,3868 & 0,3769 & 0,3684 & 0,3716 & 0,3736 & 0,3775 \\
\hline 18 & 0,4182 & 0,4233 & 0,3815 & 0,3704 & 0,3602 & 0,3633 & 0,3657 & 0,369 \\
\hline 24 & 0,4161 & 0,4106 & 0,3777 & 0,3657 & 0,3544 & 0,3571 & 0,3598 & 0,3626 \\
\hline 30 & 0,4143 & 0,4084 & 0,3748 & 0,3621 & 0,35 & 0,3523 & 0,3551 & 0,3576 \\
\hline 36 & 0,4129 & 0,4067 & 0,3724 & 0,3592 & 0,3465 & 0,3484 & 0,3514 & 0,3537 \\
\hline 42 & 0,4117 & 0,4052 & 0,3704 & 0,3568 & 0,3437 & 0,3452 & 0,3482 & 0,3504 \\
\hline 48 & 0,4106 & 0,4039 & 0,3688 & 0,3548 & $0,3414^{\circ}$ & 0,3424 & 0,3456 & 0,3476 \\
\hline 72 & 0,4073 & 0,4001 & 0,3639 & 0,349 & 0,3348 & 0,3347 & 0,3378 & 0,3398 \\
\hline 96 & 0,405 & 0,3974 & 0,3607 & 0,3452 & 0,3307 & 0,3 & 327 & 0,3347 \\
\hline 120 & 0,4032 & 0,3954 & 0,3583 & 0,3424 & 0,3278 & 0 , & 0 , & 311 \\
\hline 144 & 0,4017 & $0,3 y 38$ & 0,3564 & 102 & 0,32 & 0 , & 61 & 264 \\
\hline 168 & 0,4005 & 0,3924 & 0,3548 & 385 & 0 & 0 , & 0 , & 262 \\
\hline 192 & 0,3994 & 0,3913 & 0,3535 & 0 , & 0 , & & 8 & 244 \\
\hline 216 & 0,3985 & 0,3903 & 0,3524 & 0,3358 & 0,3 & 0 , & 0 , & 229 \\
\hline 240 & 0,3977 & 0,3894 & 0,3514 & 0,3347 & 0,3 & & 86 & 216 \\
\hline 264 & 0,3969 & 0,3886 & 0,3506 & 337 & 0 , & 0 , & 74 & 205 \\
\hline 288 & 0,3962 & 0,3879 & 0,3498 & 0,3329 & 0,3 & & 62 & 95 \\
\hline 312 & 0,3956 & 0,3872 & 0,3491 & 0,3321 & 0,3177 & 41 & 52 & 0,3186 \\
\hline 336 & 0,395 & 0,3860 & 0,3484 & 0,3314 & 0, & 0 & 43 & 0,3178 \\
\hline 360 & 0,3945 & 0,386 & 0,3479 & 0,3308 & 0,3165 & 0 & 34 & 0,3171 \\
\hline 384 & 0,394 & 0,3855 & 0,3473 & 0,3302 & 0,316 & 0 , & 27 & 0,3164 \\
\hline 408 & 0,3935 & 0,385 & 0,3468 & 0,3297 & 0,3155 & 115 & 0 , & 0,3158 \\
\hline 432 & 0,3931 & 0,3846 & 0,3464 & 292 & 0,3151 & 0 , & 13 & 0,3153 \\
\hline 456 & 0,3927 & 0,3841 & 0,3459 & 287 & 0,3147 & 04 & 07 & 0,3147 \\
\hline 480 & 0,3923 & 0,3837 & 0,3455 & 0,3283 & 0,3143 & 0 , & 0,3101 & 0,3143 \\
\hline 504 & 0,3919 & 0,3834 & 0,3451 & 279 & 0,314 & 095 & 0,3096 & 0,3138 \\
\hline 528 & 0,3915 & 0,383 & 0,3448 & 275 & 0,3136 & 0 , & 0,3091 & 0,3134 \\
\hline 552 & 0,3912 & 0,3827 & 0,3444 & 272 & 0,3133 & 0 , & 0,3086 & 0,313 \\
\hline 576 & 0,3909 & 0,3823 & 0,3441 & 0,3268 & 0,313 & 0,3 & 0,3081 & 0,3126 \\
\hline 600 & 0,3906 & 0,382 & 0,3438 & 0,3265 & 0,3128 & 0,3 & 0,3077 & 0,3123 \\
\hline 624 & 0,3903 & 0,3817 & 0,3435 & 0,3262 & 0,3125 & 0,3 & 0,3073 & 0,312 \\
\hline 648 & 0,39 & 0,3814 & 0,3432 & 0,3259 & 0,3123 & 0,3075 & 0,3069 & 0,3116 \\
\hline 672 & 0,3897 & 0,3812 & 0,3429 & 0,3256 & 0,312 & 0,3072 & 0,3066 & 0,3113 \\
\hline
\end{tabular}


TABELA 7 - Valores de potencial matricial em função da profundidade e do tempo de redistribuição da água, do experimento em Terra Roxa Estruturada, obtidos pela equação (37) e parâmetros da Tabela 5 .

\begin{tabular}{|c|c|c|c|c|c|c|c|c|}
\hline \multirow{2}{*}{$\begin{array}{c}t \\
\text { (hora) }\end{array}$} & \multicolumn{8}{|c|}{ profundidade $(\mathrm{cm})$} \\
\hline & $z=23,5$ & $=32$ & $z=40,5$ & $z=57,5$ & $z=66$ & $z=74,5$ & $z=90,5$ & $z=98$ \\
\hline $\begin{array}{l}0 \\
6 \\
12 \\
18 \\
24 \\
30 \\
36 \\
42 \\
48 \\
72 \\
96 \\
120 \\
144 \\
168 \\
192 \\
216 \\
240 \\
264 \\
288 \\
312 \\
336 \\
360 \\
384 \\
408 \\
432 \\
456 \\
480 \\
504 \\
528 \\
552 \\
576 \\
600 \\
624 \\
648 \\
672\end{array}$ & $\begin{array}{l}1,64 \\
3,28 \\
4,09 \\
4,68 \\
5,16 \\
5,57 \\
5,93 \\
6,25 \\
6,55 \\
7,55 \\
8,35 \\
9,04 \\
9,64 \\
10,18 \\
10,67 \\
11,12 \\
11,54 \\
11,94 \\
12,31 \\
12,67 \\
13,01 \\
13,33 \\
13,64 \\
13,93 \\
14,22 \\
14,49 \\
14,76 \\
15,02 \\
15,27 \\
15,51 \\
15,75 \\
15,98 \\
16,2 \\
16,42 \\
16,63\end{array}$ & $\begin{array}{l}1,7 \\
3,42 \\
4,27 \\
4,89 \\
5,39 \\
5,82 \\
6,2 \\
6,54 \\
6,86 \\
7,91 \\
8,76 \\
9,48 \\
10,11 \\
10,68 \\
11,2 \\
11,68 \\
12,12 \\
12,54 \\
12,94 \\
13,31 \\
13,67 \\
14,01 \\
14,34 \\
14,65 \\
14,95 \\
15,24 \\
15,52 \\
15,8 \\
16,06 \\
16,32 \\
16,57 \\
16,81 \\
17,05 \\
17,28 \\
17,51\end{array}$ & $\begin{array}{l}1,83 \\
3,73 \\
4,68 \\
5,38 \\
5,95 \\
6,44 \\
6,88 \\
7,26 \\
7,62 \\
8,82 \\
9,79 \\
10,62 \\
11,35 \\
12 \\
12,6 \\
13,16 \\
13,67 \\
14,16 \\
14,62 \\
15,05 \\
15,46 \\
15,86 \\
16,24 \\
16,6 \\
16,95 \\
17,29 \\
17,62 \\
17,94 \\
18,25 \\
18,55 \\
18,84 \\
19,12 \\
19,4 \\
19,67 \\
19,93\end{array}$ & $\begin{array}{l}1,69 \\
3,6 \\
4,58 \\
5,31 \\
5,9 \\
6,42 \\
6,88 \\
7,29 \\
7,67 \\
8,95 \\
10 \\
10,9 \\
11,69 \\
12,41 \\
13,06 \\
13,67 \\
14,24 \\
14,78 \\
15,28 \\
15,77 \\
16,23 \\
16,67 \\
17,09 \\
17,49 \\
17,89 \\
18,26 \\
18,63 \\
18,99 \\
19,33 \\
19,67 \\
20 \\
20,32 \\
20,63 \\
20,93 \\
21,23\end{array}$ & $\begin{array}{l}1,6 \\
3,56 \\
4,59 \\
5,37 \\
6,01 \\
6,56 \\
7,06 \\
7,51 \\
7,93 \\
9,34 \\
10,5 \\
11,5 \\
12,39 \\
13,19 \\
13,93 \\
14,62 \\
15,27 \\
15,88 \\
16,45 \\
17 \\
17,53 \\
18,03 \\
18,51 \\
18,98 \\
19,43 \\
19,87 \\
20,29 \\
20,7 \\
21,1 \\
21,49 \\
21,87 \\
22,24 \\
22,6 \\
22,95 \\
23,3\end{array}$ & $\begin{array}{l}1,52 \\
3,49 \\
4,54 \\
5,34 \\
6 \\
6,58 \\
7,09 \\
7,56 \\
7,99 \\
9,47 \\
10,69 \\
11,75 \\
12,69 \\
13,55 \\
14,34 \\
15,07 \\
15,76 \\
16,41 \\
17,03 \\
17,62 \\
18,18 \\
18,72 \\
19,25 \\
19,75 \\
20,23 \\
20,7 \\
21,16 \\
21,6 \\
22,04 \\
22,46 \\
22,87 \\
23,27 \\
23,66 \\
24,04 \\
24,42\end{array}$ & $\begin{array}{l}3,04 \\
6,29 \\
7,93 \\
9,13 \\
10,12 \\
10,97 \\
11,72 \\
12,39 \\
13,01 \\
15,1 \\
16,8 \\
18,24 \\
19,52 \\
20,67 \\
21,72 \\
22,7 \\
23,6 \\
24,46 \\
25,26 \\
26,03 \\
26,75 \\
27,45 \\
28,112 \\
28,76 \\
29,38 \\
29,98 \\
30,56 \\
31,12 \\
31,67 \\
32,119 \\
32,71 \\
33,21 \\
33,7 \\
34,18 \\
34,65\end{array}$ & $\begin{array}{c}4,26 \\
8,56 \\
10,72 \\
12,29 \\
13,56 \\
14,65 \\
15,62 \\
16,48 \\
17,28 \\
19,94 \\
22,08 \\
23,91 \\
25,52 \\
26,96 \\
28,28 \\
29,5 \\
30,63 \\
31,69 \\
32,7 \\
33,65 \\
34,56 \\
35,42 \\
36,25 \\
37,05 \\
37,81 \\
38,55 \\
39,27 \\
39,96 \\
40,64 \\
41,29 \\
41,92 \\
42,54 \\
43,15 \\
43,73 \\
44,31\end{array}$ \\
\hline
\end{tabular}


TABELA 7 - Valores de potencial matricial em função da profundidade e do tempo de redistribuição da āgua, do experimento em Terra Roxa Estruturada, obtidos pela equação (37) e parâmetros da Tabela 5 .

\begin{tabular}{|c|c|c|c|c|c|c|c|}
\hline \multirow{2}{*}{ (hora) } & \multicolumn{6}{|c|}{ profundidade $(\mathrm{cm})$} & \multirow[b]{2}{*}{$z=218$} \\
\hline & $z=105,5$ & $z=128$ & $z=143$ & $z=158$ & $z=188$ & $z=203$ & \\
\hline 0 & 5,5 & 6,43 & 24,04 & 29,28 & 26,86 & 26,46 & 21,23 \\
\hline 6 & 10,94 & 14,35 & 41,08 & 49,47 & 46,2 & 45,75 & 38,66 \\
\hline 12 & 13,62 & 18,53 & 48,72 & 58,46 & 54,91 & 54,46 & 46,79 \\
\hline 18 & 15,57 & 21,68 & 54,08 & 64,76 & 61,04 & 60,59 & 52,6 \\
\hline 24 & 17,16 & 24,28 & $58,33 t$ & 69,73 & 65,89 & 65,45 & 57,24 \\
\hline 30 & 18,52 & 26,53 & 61,89 & 73,89 & 69,96 & 69,54 & 61,16 \\
\hline 36 & 19,71 & 28,54 & 64,98 & 77,5 & 73,5 & 73,09 & 64,59 \\
\hline 42 & 20,79 & 30,37 & 67,73 & 80,7 & 76,64 & 76,24 & 67,65 \\
\hline 48 & 21,77 & 32,05 & 70,21 & 83,6 & 79,49 & 79,1 & 70,43 \\
\hline 72 & 25,07 & 37,79 & 78,35 & 93,08 & 88,83 & 88,48 & 79,64 \\
\hline 96 & 27,72 & 42,49 & 84,74 & 100,49 & 96,16 & 95,85 & 86,93 \\
\hline 120 & 29,97 & 46,56 & 90,06 & 106,66 & 102,27 & 102 & 93,06 \\
\hline 144 & 31,96 & 50,17 & 94,66 & 111,99 & 107,56 & 107,33 & 98,39 \\
\hline 168 & 33,73 & 53,44 & 98,74 & 116,72 & 112,25 & 112,05 & 103,15 \\
\hline 192 & 35,36 & 56,46 & 102,41 & 120,97 & 116,49 & 116,32 & 107,46 \\
\hline 216 & 36,85 & 59,26 & 105,77 & 124,85 & 120,36 & 120,22 & 111,41 \\
\hline 240 & 38,25 & 61,88 & 108,67 & 128,43 & 123,93 & 123,82 & 115,07 \\
\hline 264 & 39,55 & 64,35 & 111,76 & 131,76 & 127,25 & 127,17 & 118,49 \\
\hline 288 & 40,78 & 66,7 & 114,46 & 134,88 & 130,37 & 130,31 & 121,69 \\
\hline 312 & 41,95 & 68,93 & 117 & 137,81 & 138,3 & 133,27 & 124,72 \\
\hline 336 & 43,06 & 71,07 & 119,41 & 140,58 & 136,07 & 136,07 & 127,6 \\
\hline 360 & 44,12 & 73,11 & 121,69 & 143,21 & 138,71 & 138,73 & 130,33 \\
\hline 384 & 45,14 & 75,03 & 123,87 & 145,72 & 141,22 & 141,26 & 132,94 \\
\hline 408 & 46,11 & 76,98 & 125,95 & 148,11 & 143,62 & 143,69 & 135,44 \\
\hline 432 & 47,05 & 78,82 & 127,94 & 150,41 & 145,92 & 146,01 & 137,84 \\
\hline 456 & 47,96 & 80,59 & 129,86 & 152,61 & 148,13 & 148,24 & 140,15 \\
\hline 480 & 48,83 & 82,31 & 131,7 & 154,73 & 150,26 & 150,39 & 142,38 \\
\hline 504 & 49,68 & 83,99 & 133,48 & 156,78 & 152,32 & 152,47 & 144,53 \\
\hline 528 & 50,51 & 85,61 & 135,2 & 158,75 & 154,3 & 154,47 & 146,62 \\
\hline 552 & 51,3 & 87,19 & 136,86 & 160,66 & 156,22 & 156,41 & 148,64 \\
\hline 576 & 52,08 & 88,74 & 138,47 & 162,51 & 158,08 & 158,29 & 150,59 \\
\hline 600 & 52,84 & 90,24 & 140,03 & 164,31 & 159,89 & 160,12 & 152,5 \\
\hline 624 & 53,57 & 91,71 & 141,55 & 166,05 & 161,64 & 161,89 & 154,35 \\
\hline 648 & 54,29 & 93,15 & 143,03 & 167,75 & 163,35 & 163,62 & 156,15 \\
\hline 672 & 54,99 & 94,58 & 144,47 & 169,4 & 165,01 & 165,3 & 157,91 \\
\hline
\end{tabular}




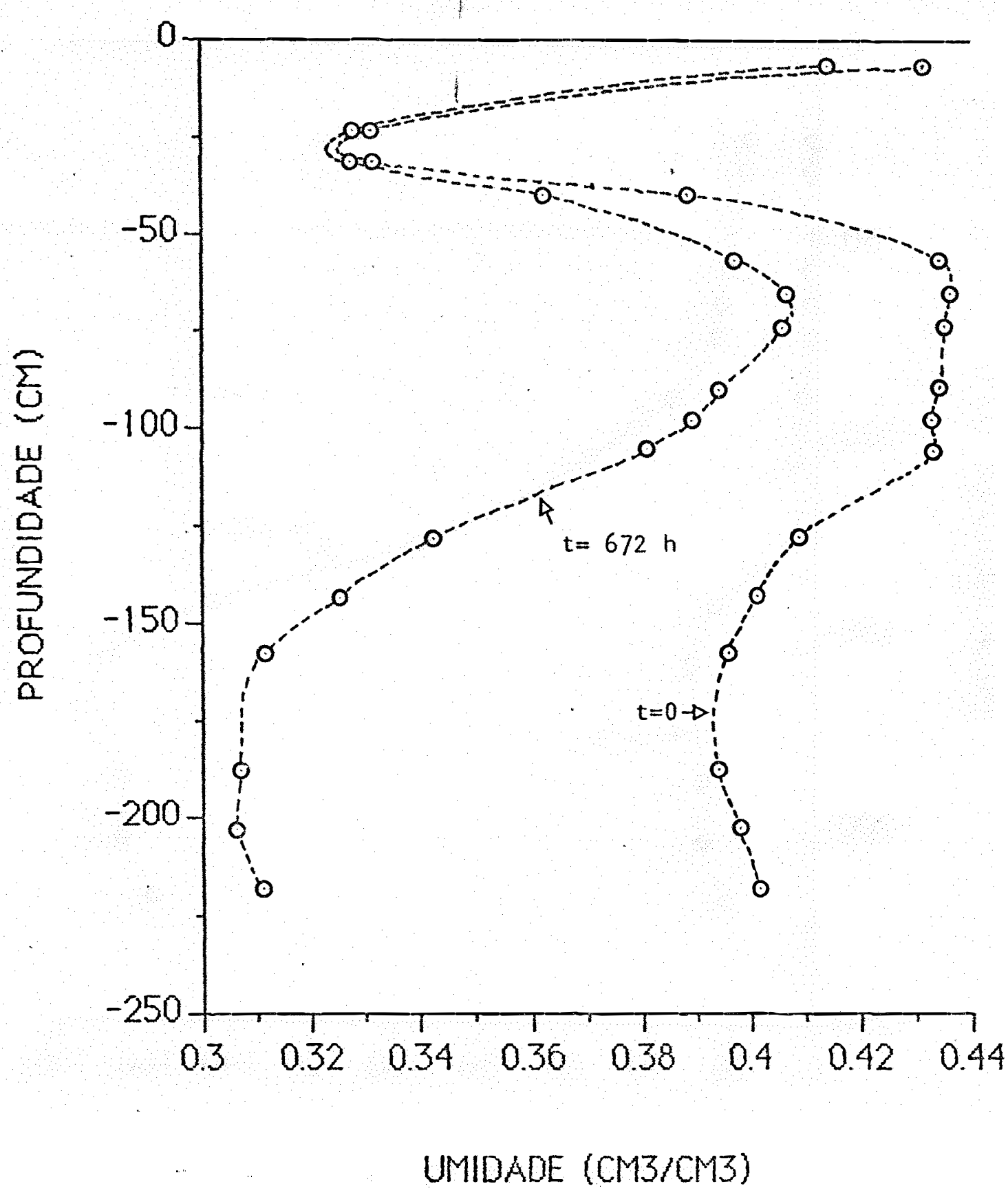

FIGURA 53 - Perfis de umidade em função da profundidade para os tempos zero e $672 \mathrm{~h}$ de redistribuição de ăgua no solo Terra Roxa Estruturada. 


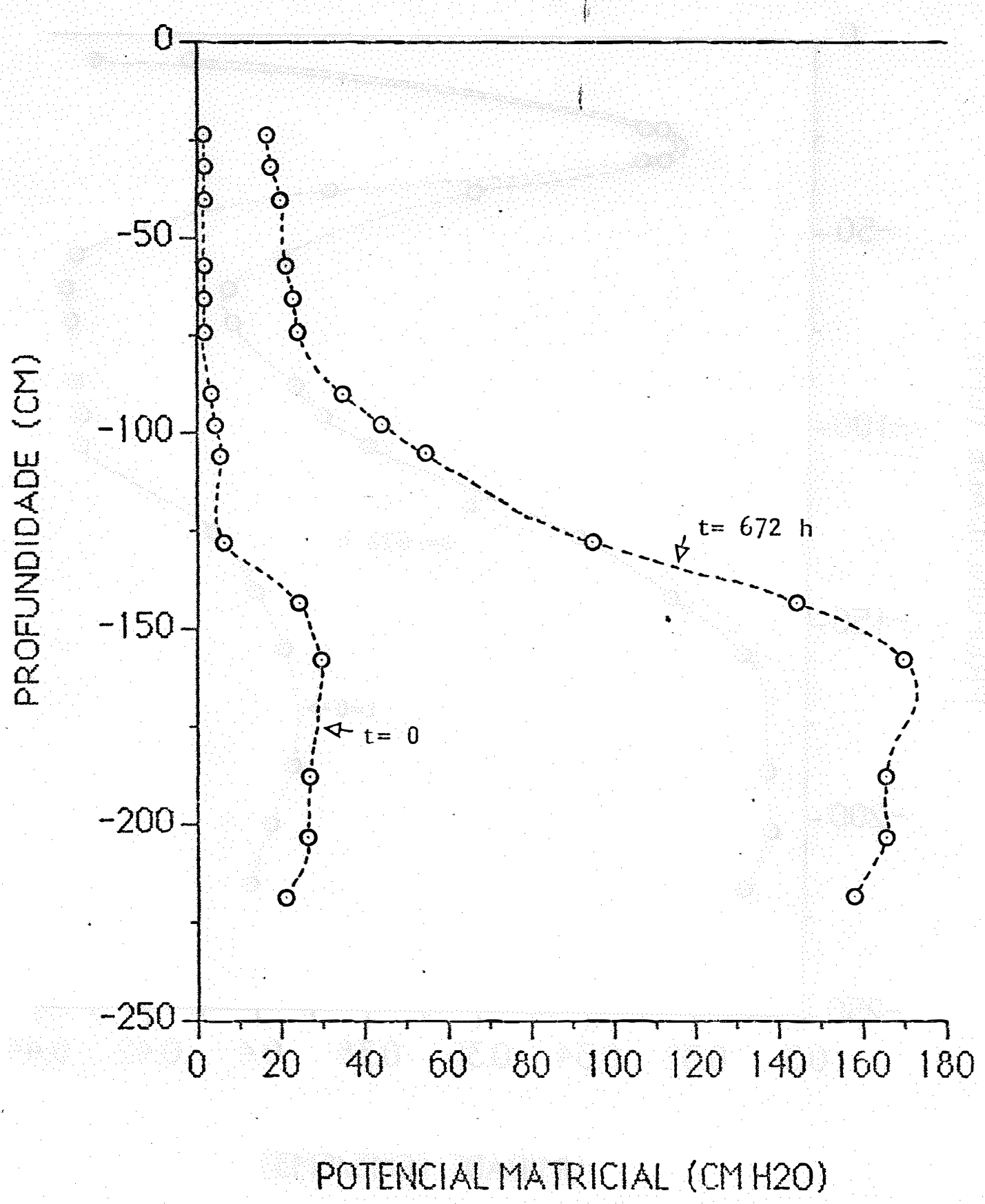

FIGURA 54 - Perfis de potencial matricial em função da profundidade para os tempos zero e 672 h de redistribuição da ăgua no solo Terra Roxa Estruturada. 
TABELA 8 - Cálculo dos fluxos de água no solo nas diversas profundidades $(z)$ e diversos tempos de redistribuição $(t)$, para o solo Terra Rexa Estruturada.

\begin{tabular}{cccc}
\hline$t$ & $z$ & $A z(t)$ & $-(q)_{2} \cdot 10^{4}$ \\
(hora) & $(\mathrm{cm})$ & $(\mathrm{cm})$ & $(\mathrm{cm} /$ hora $)$ \\
\hline
\end{tabular}

6

32

66

98

143

203

12

32

66

98

143

203

32

66

18

98

143

203

32

66

24

98

143

203
11,88

25,55

39,28

57,52

80,45

11,86

25,42

39,04

56,94

79,18

11,84

25,33

38,88

56,56

78,32

11,82

25,67

38,76

56,29

77,69
67,42

347,08

601,75

1363,58

2614,25

38,42

184,75

335,58

796,5

1781,25

26,75

124,08

230,83

542,08

1242,83

22,25

95,58

177,17

408,50

931,00

(continua) 
TABELA 8 - Cálculo dos fluxos de ägua no solonas diversas profundidades $(z)$ e diversos tempos de redistribuição $(t)$, para o solo Terra Roxa Estruturada.

\begin{tabular}{|c|c|c|c|}
\hline $\begin{array}{c}t \\
\text { (hora) }\end{array}$ & $\begin{array}{l}z \\
(\mathrm{~cm})\end{array}$ & $\begin{array}{c}\mathrm{Az}(\mathrm{t}) \\
(\mathrm{cm})\end{array}$ & $\begin{array}{l}-(\mathrm{q}) / 2 \cdot 10^{4} \\
(\mathrm{~cm} / \text { hora })\end{array}$ \\
\hline & 32 & 11,81 & 18,75 \\
\hline & 66 & 25,22 & 78,83 \\
\hline \multirow[t]{5}{*}{30} & 98 & 38,66 & 145,67 \\
\hline & 143 & 56,08 & $328 ; 67$ \\
\hline & 203 & 77,20 & 738,33 \\
\hline & 32 & 11,80 & 14,08 \\
\hline & 66 & 25,17 & 63,42 \\
\hline \multirow[t]{5}{*}{36} & 98 & 38,58 & 119,5 \\
\hline & 143 & 55,90 & 270,42 \\
\hline & 203 & 76,80 & 601,58 \\
\hline & 32 & 11,80 & 11,75 \\
\hline & 66 & 25,14 & 53,00 \\
\hline \multirow[t]{5}{*}{42} & 98 & 38,52 & 101,00 \\
\hline & 143 & 35,75 & 227,75 \\
\hline & 203 & 76,48 & 502,50 \\
\hline & 32 & 11,79 & 11,05 \\
\hline & 66 & 25,11 & 49,03 \\
\hline \multirow[t]{5}{*}{98} & 98 & 38,46 & 91,99 \\
\hline & 143 & 55,63 & 200,99 \\
\hline & 203 & 76,20 & 438,18 \\
\hline & 32 & 11,77 & 7,23 \\
\hline & 66 & 25,02 & 32,5 \\
\hline \multirow[t]{3}{*}{72} & 98 & 38,29 & 62,15 \\
\hline & 143 & 55,25 & 133,83 \\
\hline & 203 & 75,39 & 279,08 \\
\hline
\end{tabular}


TABELA 8 - Cälculo dos fluxos de água no solo nas diversas profundidades $(z)$ e diversos tempos de redistribuição $(t)$, para o solo Terra Roxa Estruturada.

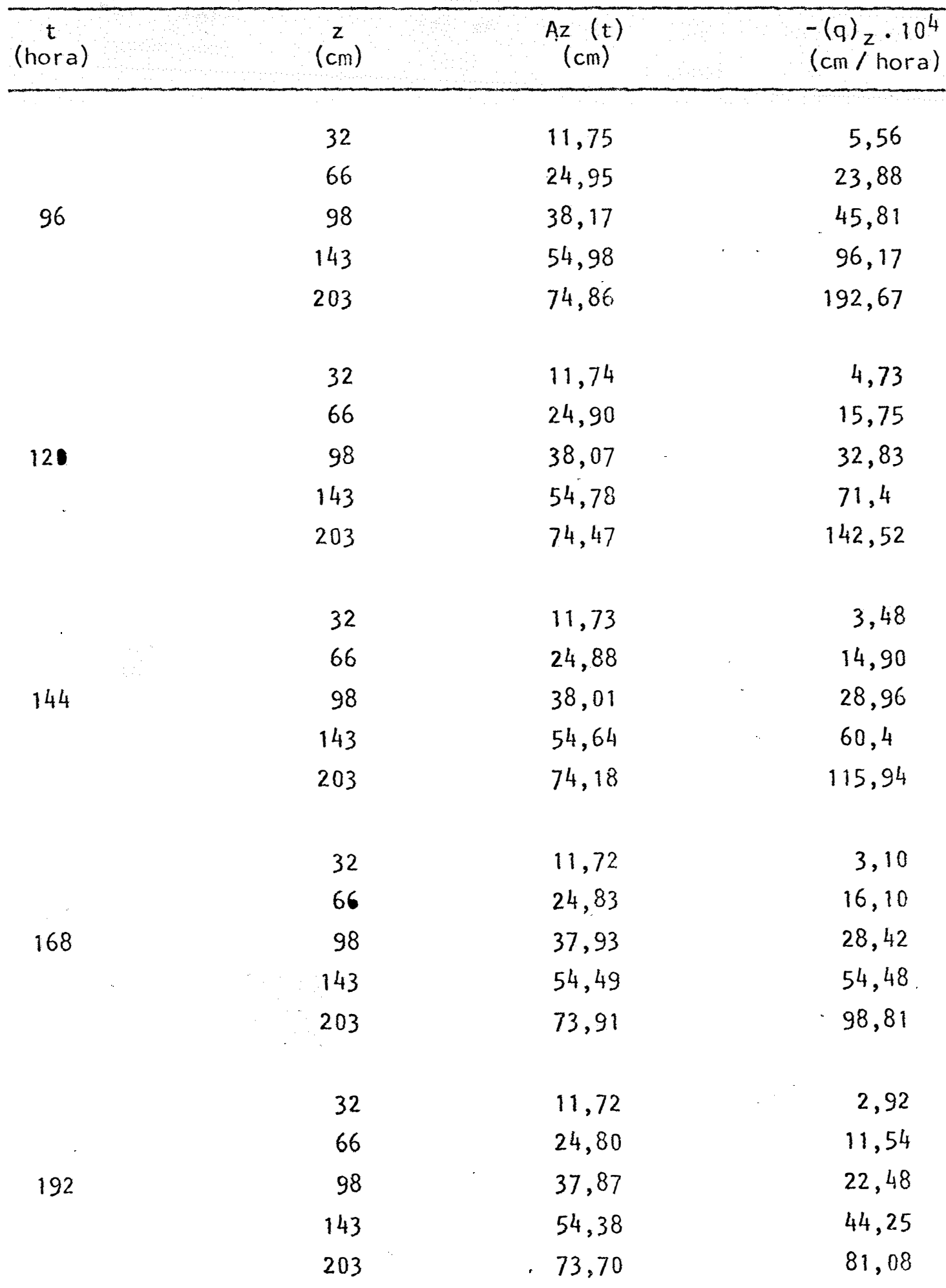

(continua) 
TABELA 8 - Cälculo dos fluxos de ägua no solo nas diversas profundidades $(z)$ e diversos tempos de redistribuição $(t)$, para o solo Terra Roxa Estruturada.

\begin{tabular}{|c|c|c|c|}
\hline $\begin{array}{c}t \\
\text { (hora) }\end{array}$ & $\begin{array}{c}z \\
(\mathrm{~cm})\end{array}$ & $\begin{array}{c}A z \quad(t) \\
(\mathrm{cm})\end{array}$ & $\begin{array}{l}-(\mathrm{q})_{\mathrm{z}} \cdot 10^{4} \\
(\mathrm{~cm} / \text { hora })\end{array}$ \\
\hline & 32 & 11,71 & 2,00 \\
\hline & 66 & 24,77 & 9,63 \\
\hline \multirow[t]{5}{*}{216} & 98 & 37,82 & 18,90 \\
\hline & 143 & 54,28 & 38,10 \\
\hline & 203 & $73, .52$ & 69,92 \\
\hline & 32 & 11,71 & 2,02 \\
\hline & 66 & 24,75 & 8,69 \\
\hline \multirow[t]{5}{*}{240} & 98 & 37,78 & 17,02 \\
\hline & 143 & 54,20 & 33,92 \\
\hline & 203 & 73,37 & 61,35 \\
\hline & 32 & 11,70 & 2,38 \\
\hline & 66 & 24,73 & 8,38 \\
\hline \multirow[t]{5}{*}{264} & 98 & 37,74 & 16,04 \\
\hline & 143 & 54,12 & 30,94 \\
\hline & 203 & 73,23 & 55,17 \\
\hline & 32 & 11,69 & 1,73 \\
\hline & 66 & 24,71 & 7,38 \\
\hline \multirow[t]{5}{*}{288} & 98 & 37,70 & 14,33 \\
\hline & 143 & 54,05 & 28,17 \\
\hline & 203 & 73,10 & 49,85 \\
\hline & 32 & 11,69 & 1,48 \\
\hline & 66 & 24,70 & 6,50 \\
\hline \multirow[t]{3}{*}{312} & 98 & 37,67 & 12,85 \\
\hline & 143 & 53,98 & 25,75 \\
\hline & 203 & 72,99 & 44,4 \\
\hline
\end{tabular}


TABELA 8 - Cálculo dos fluxos de agua no solo nas diversas profundidades ( $z$ ) e diversos tempos de redistribuição ( $t$ ), para o solo Terra Roxa Estruturada.

\begin{tabular}{|c|c|c|c|}
\hline $\begin{array}{c}\mathrm{t} \\
\text { (hora) }\end{array}$ & $\begin{array}{l}\mathrm{z} \\
(\mathrm{cm})\end{array}$ & $\begin{array}{c}\mathrm{Az}(\mathrm{t}) \\
(\mathrm{cm})\end{array}$ & $\begin{array}{l}(\mathrm{q})=10^{4} \\
(\mathrm{~cm} / \text { hora })\end{array}$ \\
\hline \multirow{5}{*}{336} & 32 & 11,69 & 1,44 \\
\hline & 66 & 24,68 & 6,06 \\
\hline & 98 & 37,64 & 11,73 \\
\hline & 143 & 53,92 & 23,15 \\
\hline & 203 & 72,89 & 39,94 \\
\hline \multirow{5}{*}{360} & 32 & 11,69 & 1,44 \\
\hline & 66 & 24,67 & 5,77 \\
\hline & 98 & 37,62 & 11,40 \\
\hline & 143 & 53,87 & 21,88 \\
\hline & 203 & 72,80 & 37,83 \\
\hline \multirow{5}{*}{384} & 32 & 11,68 & 1,48 \\
\hline & 66 & 24,65 & 5,85 \\
\hline & 98 & 37,59 & 11,21 \\
\hline & $\cdot 143$ & 53,82 & 21,17 \\
\hline & 203 & 72,71 & 35,21 \\
\hline \multirow{5}{*}{408} & 32 & 11,68 & 1,10 \\
\hline & 66 & 24,64 & 5,06 \\
\hline & 98 & 37,56 & 9,71 \\
\hline & 143 & 53,77 & 18,29 \\
\hline & 203 & 72,63 & 31,23 \\
\hline \multirow{5}{*}{432} & 32 & 11,68 & 1,17 \\
\hline & 66 & 24,63 & 4,46 \\
\hline & 98 & 37,54 & 8,77 \\
\hline & 143 & 53,73 & . $\quad 17,38$ \\
\hline & 203 & 72,56 & 29,67 \\
\hline
\end{tabular}


TABELA 8 - Cálculo dos fluxos de água no solo nas diversas profundidades $(z)$ e diversos tempos de redistribuição $(t)$, para o solo Terra Roxa Estruturada.

\begin{tabular}{|c|c|c|c|}
\hline $\begin{array}{c}t \\
\text { (hora) }\end{array}$ & $\begin{array}{l}z \\
(\mathrm{~cm})\end{array}$ & $\begin{array}{c}\mathrm{Az}(\mathrm{t}) \\
(\mathrm{cm})\end{array}$ & $\begin{array}{l}-(\mathrm{q})_{2} \cdot 10^{4} \\
(\mathrm{~cm} / \text { hora })\end{array}$ \\
\hline & 32 & 11,67 & 1,19 \\
\hline & 66 & 24,62 & 4,25 \\
\hline \multirow[t]{5}{*}{456} & 98 & 37,52 & 8,31 \\
\hline & 143 & 53,69 & 16,79 \\
\hline & 203 & 72,49 & 27,81 \\
\hline & 32 & 11,67 & 0,81 \\
\hline & 66 & 24,61 & 3,81 \\
\hline \multirow[t]{5}{*}{480} & 98 & 37,50 & 7,85 \\
\hline & 143 & 53,65 & 14,98 \\
\hline & 203 & 72,42 & 25,29 \\
\hline & 32 & 11,67 & 1,19 \\
\hline & 66 & 24,60 & 4,48 \\
\hline \multirow[t]{5}{*}{504} & 98 & 37,48 & 8,48 \\
\hline & 143 & 53,62 & 15,17 \\
\hline & 203 & 72,36 & 25,40 \\
\hline & 32 & 11,66 & 1,21 \\
\hline & 66 & 24,59 & 4,5 \\
\hline \multirow[t]{5}{*}{528} & 98 & 37,46 & 8,15 \\
\hline & 143 & 53,58 & 14,69 \\
\hline & 203 & 72,30 & 23,77 \\
\hline & 32 & 11,66 & 0,54 \\
\hline & 66 & 24,58 & 3,19 \\
\hline \multirow[t]{3}{*}{552} & 98 & 37,44 & 6,48 \\
\hline & 143 & 53,55 & 13,08 \\
\hline & 203 & 72,25 & 21,60 \\
\hline
\end{tabular}


TABELA 8 - Cälculo dos fluxos de ägua no solo nas diversas profundidades $(z)$ e diversos tempos de redistribuição $(t)$, para o solo Terra Roxa Estruturada.

\begin{tabular}{|c|c|c|c|}
\hline (hora) & $\begin{array}{c}z \\
(\mathrm{~cm})\end{array}$ & $\begin{array}{l}A z(t) \\
(\mathrm{cm})\end{array}$ & $\begin{array}{l}-(q)_{z} \cdot 10^{4} \\
(\mathrm{~cm} / \text { hora })\end{array}$ \\
\hline \multirow{5}{*}{576} & 32 & 11,66 & 0,90 \\
\hline & 66 & 24,57 & 3,54 \\
\hline & 98 & 37,43 & 6,83 \\
\hline & 143 & 53,52 & 13,02 \\
\hline & 203 & . 72,20 & 20,94 \\
\hline \multirow{5}{*}{600} & 32 & 11,66 & 1,17 \\
\hline & 66 & 24,56 & 3,81 \\
\hline & 98 & 37,41 & 7,13 \\
\hline & 143 & 53,48 & 12,77 \\
\hline & 203 & 72,15 & 19,96 \\
\hline \multirow{5}{*}{624} & 32 & 11,66 & 0,81 \\
\hline & 66 & 24,55 & 2,85 \\
\hline & 98 & 37,39 & 6,19 \\
\hline & 143 & 53,45 & 11,83 \\
\hline & 203 & 72,10 & 19,00 \\
\hline \multirow{5}{*}{648} & 32 & 11,65 & 0,58 \\
\hline & 66 & 24,55 & 2,98 \\
\hline & 98 & 37,38 & 6,02 \\
\hline & 143 & 53,43 & 11,25 \\
\hline & 203 & 72,06 & 18,31 \\
\hline
\end{tabular}


TABELA 9 - Cấlculo das funções $D_{g}(\theta), K(\theta), D_{m}(\theta), D_{z}(\theta), K_{H}(\theta)$ e $D_{m H}(\theta)$, para as profundidades $(z)$ de $32,66,98,143 \mathrm{e} 203 \mathrm{~cm}$, do solo Terra Roxa Estruturada.

\begin{tabular}{|c|c|c|c|c|c|c|c|}
\hline $\begin{array}{c}z \\
(\mathrm{~cm})\end{array}$ & $\begin{array}{l}-(\mathrm{q})_{z} \cdot 10^{4} \\
(\mathrm{~cm} / \mathrm{h}\end{array}$ & $\begin{array}{c}\partial \theta / \partial z \cdot 10^{4} \\
\left(\mathrm{~cm}^{-1}\right)\end{array}$ & $\begin{array}{c}\mathrm{D}_{\mathrm{g}_{2}} 10 \\
\left(\mathrm{~cm}^{2} / \mathrm{h}\right)\end{array}$ & $\begin{array}{r}-\mathrm{d} \psi_{\mathrm{m}} / \mathrm{d} \theta \\
\left(\mathrm{cmH}_{2} \mathrm{O}\right) \\
\end{array}$ & $\begin{array}{l}\mathrm{dz} / \mathrm{d} \theta \\
(\mathrm{cm})\end{array}$ & $\begin{array}{l}\mathrm{K} \cdot 10^{4} \\
(\mathrm{~cm} / \mathrm{h})\end{array}$ & $\begin{array}{c}\mathrm{D}_{\mathrm{m}_{2}}{ }^{20} \\
\left(\mathrm{~cm}^{2} / \mathrm{h}\right)\end{array}$ \\
\hline 32 & $\begin{array}{l}67,42 \\
38,42 \\
26,75 \\
22,25 \\
18,75 \\
14,08 \\
11,75 \\
11,05 \\
7,23 \\
5,56 \\
4,73 \\
3,48 \\
3,1 \\
2,92 \\
2 \\
2,02 \\
2,38 \\
1,73 \\
1,48 \\
1,44 \\
1,44 \\
1,48 \\
1,1 \\
1,17 \\
1,19 \\
0,81 \\
1,19 \\
1,21 \\
0,54 \\
0,9 \\
1,17 \\
0,81 \\
0,58\end{array}$ & $\begin{array}{l}29,76 \\
28,29 \\
27,41 \\
26,82 \\
26,41 \\
26 \\
25,71 \\
25,41 \\
24,53 \\
23,94 \\
23,53 \\
23,76 \\
22,88 \\
22,65 \\
22,41 \\
22,18 \\
22,06 \\
21,88 \\
21,71 \\
21,65 \\
21,47 \\
21,41 \\
21,24 \\
21,12 \\
21,06 \\
21 \\
20,88 \\
20,82 \\
20,71 \\
20,65 \\
20,59 \\
20,53 \\
20,47\end{array}$ & $\begin{array}{l}-22,65 \\
-13,58 \\
-9,76 \\
-8,29 \\
-7,1 \\
-5,42 \\
-4,57 \\
-4,35 \\
-2,95 \\
-2,32 \\
-2,01 \\
-1,46 \\
-1,36 \\
-1,29 \\
-0,89 \\
-0,91 \\
-1,08 \\
-0,79 \\
-0,68 \\
-0,66 \\
-0,67 \\
-0,69 \\
-0,52 \\
-0,55 \\
-0,56 \\
-0,39 \\
-0,57 \\
-0,58 \\
-0,26 \\
-0,43 \\
-0,57 \\
-0,4 \\
-0,28\end{array}$ & $\begin{array}{c}1504,4 \\
1731,6 \\
2286 \\
3226 \\
2574 \\
2476,7 \\
3293,9 \\
3521,2 \\
4645,9 \\
5461,5 \\
6690,3 \\
5970,1 \\
11948,1 \\
9230,8 \\
10036,4 \\
8209,1 \\
8610 \\
7122,5 \\
7502,8 \\
\infty \\
\infty \\
6012,1 \\
6303,3 \\
\infty \\
\infty \\
\infty \\
5014,3 \\
5200 \\
\infty \\
\infty \\
\infty \\
\infty \\
4600\end{array}$ & $\begin{array}{l}336 \\
353,4 \\
364,8 \\
372,8 \\
378,6 \\
384,6 \\
389 \\
393,5 \\
407,7 \\
417,7 \\
425 \\
420,8 \\
437 \\
441,6 \\
446,2 \\
450,9 \\
453,3 \\
457 \\
460,7 \\
462 \\
465,8 \\
467 \\
470,9 \\
473,5 \\
474,9 \\
476 \\
478,9 \\
480,2 \\
483 \\
484,3 \\
485,7 \\
487,1 \\
488,5\end{array}$ & $\begin{array}{c}19,38 \\
9,85 \\
5,08 \\
2,01 \\
3,23 \\
2,59 \\
1,57 \\
1,39 \\
0,7 \\
0,46 \\
0,32 \\
0,26 \\
0,12 \\
0,15 \\
0,09 \\
0,12 \\
0,13 \\
0,12 \\
0,1 \\
? \\
? \\
0,12 \\
0,09 \\
? \\
? \\
? \\
0,13 \\
0,12 \\
? \\
? \\
? \\
? \\
0,07\end{array}$ & $\begin{array}{c}-29,16 \\
-17,06 \\
-11,61 \\
-9,38 \\
-8,32 \\
-6,41 \\
-5,18 \\
-4,9 \\
-3,23 \\
-2,52 \\
-2,15 \\
-1,58 \\
-1,41 \\
-1,35 \\
-0,93 \\
-0,96 \\
-1,14 \\
-0,84 \\
-0,73 \\
? \\
? \\
-0,75 \\
-0,56 \\
? \\
? \\
? \\
-0,63 \\
-0,64 \\
? \\
? \\
? \\
? \\
-0,32\end{array}$ \\
\hline
\end{tabular}


TABELA 9 - Cälculo das funções $D_{g}(\theta), K(\theta), D_{m}(\theta), D_{z}(\Theta), K_{H}(\Theta)$ e $D_{m H}(\theta)$, para as profundidades $(z)$ de $32,66,98,143$ e $203 \mathrm{~cm}$, do solo Terra Roxa Estruturada.

\begin{tabular}{|c|c|c|c|c|c|c|c|}
\hline $\begin{array}{c}z \\
(\mathrm{~cm})\end{array}$ & $\begin{array}{c}D_{z} \cdot 10 \\
\left(\mathrm{~cm}^{2} / \mathrm{h}\right)\end{array}$ & $\begin{array}{c}\partial \psi_{\mathrm{m}} / \partial z \\
\left(\mathrm{cmH}_{2} 0 / \mathrm{cm}\right)\end{array}$ & $\begin{array}{c}\partial \psi_{h} / \partial z \\
\left(\mathrm{cmH}_{2} \mathrm{O} / \mathrm{cm}\right)\end{array}$ & $\begin{array}{l}K_{H} \cdot 10^{4} \\
(\mathrm{~cm} / \mathrm{h})\end{array}$ & $\begin{array}{l}D_{m H_{i}} 10 \\
\left(\mathrm{~cm}^{2} / \mathrm{h}\right)\end{array}$ & $\begin{array}{c}\psi_{m} \\
\left(\mathrm{cmH}_{2} 0\right)\end{array}$ & $\left(\mathrm{cm}^{3} / \mathrm{cm}^{3}\right)$ \\
\hline 32 & $\begin{array}{l}6,51 \\
3,48 \\
1,85 \\
1,08 \\
1,22 \\
1 \\
0,61 \\
0,55 \\
0,28 \\
0,19 \\
0,14 \\
0,11 \\
0,05 \\
0,06 \\
0,04 \\
0,05 \\
0,06 \\
0,05 \\
0,04 \\
? \\
? \\
0,06 \\
0,04 \\
? \\
? \\
? \\
0,06 \\
0,06 \\
? \\
? \\
? \\
? \\
0,03\end{array}$ & $\begin{array}{l}0,03 \\
0,03 \\
0,04 \\
0,05 \\
0,05 \\
0,06 \\
0,06 \\
0,06 \\
0,07 \\
0,08 \\
0,09 \\
0,1 \\
0,11 \\
0,11 \\
0,12 \\
0,13 \\
0,13 \\
0,14 \\
0,14 \\
0,14 \\
0,15 \\
0,15 \\
0,16 \\
0,16 \\
0,16 \\
0,17 \\
0,17 \\
0,18 \\
0,18 \\
0,18 \\
0,18 \\
0,19 \\
0,19\end{array}$ & $\begin{array}{l}1,03 \\
1,03 \\
1,04 \\
1,05 \\
1,05 \\
1,06 \\
1,06 \\
1,06 \\
1,07 \\
1,08 \\
1,09 \\
1,1 \\
1,11 \\
1,11 \\
1,12 \\
1,13 \\
1,13 \\
1,14 \\
1,14 \\
1,14 \\
1,15 \\
1,15 \\
1,16 \\
1,16 \\
1,16 \\
1,17 \\
1,17 \\
1,18 \\
1,18 \\
1,18 \\
1,18 \\
1,19 \\
1,19\end{array}$ & $\begin{array}{l}-65,68 \\
-37,13 \\
-25,69 \\
-21,26 \\
-17,84 \\
-13,34 \\
-11,09 \\
-10,4 \\
-6,73 \\
-5,13 \\
-4,33 \\
-3,16 \\
-2,8 \\
-2,62 \\
-1,79 \\
-1,8 \\
-2,1 \\
-1,52 \\
-1,3 \\
-1,26 \\
-1,25 \\
-1,28 \\
-1,95 \\
-1,01 \\
-1,02 \\
-0,7 \\
-1,01 \\
-1,03 \\
-0,46 \\
-0,76 \\
-0,98 \\
-1,0,68 \\
-0,49\end{array}$ & $\begin{array}{c}98,81 \\
64,29 \\
58,73 \\
68,59 \\
45,91 \\
33,03 \\
36,53 \\
36,6 \\
31,25 \\
28,01 \\
28,95 \\
18,87 \\
33,5 \\
24,18 \\
17,92 \\
14,74 \\
18,09 \\
10,84 \\
9,74 \\
? \\
? \\
7,71 \\
6,02 \\
? \\
? \\
? \\
5,08 \\
5,35 \\
? \\
? \\
? \\
? \\
2,25\end{array}$ & $\begin{array}{l}3,42 \\
4,27 \\
4,89 \\
5,39 \\
5,82 \\
6,2 \\
6,54 \\
6,86 \\
7,92 \\
8,76 \\
9,48 \\
10,11 \\
10,68 \\
11,2 \\
11,68 \\
12,12 \\
12,54 \\
12,94 \\
13,31 \\
13,67 \\
14,01 \\
14,34 \\
14,65 \\
14,95 \\
15,24 \\
15,52 \\
15,8 \\
16,06 \\
16,32 \\
16,57 \\
16,81 \\
17,05 \\
17,28\end{array}$ & $\begin{array}{l}0,3308 \\
0,3302 \\
0,3299 \\
0,3297 \\
0,3296 \\
0,3294 \\
0,3293 \\
0,3292 \\
0,329 \\
0,3288 \\
0,3287 \\
0,3286 \\
0,3285 \\
0,3285 \\
0,3284 \\
0,3284 \\
0,3283 \\
0,3283 \\
0,3282 \\
0,3282 \\
0,3282 \\
0,3282 \\
0,3281 \\
0,3281 \\
0,3281 \\
0,3281 \\
0,3281 \\
0,328 \\
0,328 \\
0,328 \\
0,328 \\
0,328 \\
0,328\end{array}$ \\
\hline
\end{tabular}


TABELA 9 - Cálculo das funções $D_{g}(\theta), K(\theta), D_{m}(\theta), D_{z}(\theta), K_{H}(\theta)$ e $D_{m H}(\theta)$, para as profundidades (z) de $32,66,98,143, \mathrm{e} 203 \mathrm{~cm}$, do solo Terra Roxa Estruturada.

\begin{tabular}{|c|c|c|c|c|c|c|c|}
\hline $\begin{array}{c}z \\
(\mathrm{~cm})\end{array}$ & $\begin{array}{c}-(\mathrm{q})_{\mathrm{z}} \cdot 10^{4} \\
(\mathrm{~cm} / \mathrm{h})\end{array}$ & $\begin{array}{c}\partial \theta / \partial z \cdot 10^{4} \\
\left(\mathrm{~cm}^{-1}\right)\end{array}$ & $\begin{array}{c}\mathrm{D}_{\mathrm{g}} \cdot 10 \\
\left(\mathrm{~cm}^{2} / \mathrm{h}\right)\end{array}$ & $\begin{array}{l}-d \psi_{m} / d \theta \\
\left(\mathrm{cmH}_{2} 0\right) \\
\end{array}$ & $\begin{array}{l}d z / d \theta \\
(\mathrm{cm})\end{array}$ & $\begin{array}{l}\mathrm{K} \cdot 10^{4} \\
(\mathrm{~cm} / \mathrm{h})\end{array}$ & $\begin{array}{c}\mathrm{D}_{\mathrm{m}} \cdot 10 \\
\left(\mathrm{~cm}^{2} / \mathrm{h}\right)\end{array}$ \\
\hline 66 & $\begin{array}{r}347,08 \\
184,75 \\
124,08 \\
95,58 \\
78,83 \\
63,42 \\
53 \\
49,03 \\
32,5 \\
23,88 \\
15,75 \\
14,9 \\
16,1 \\
11,54 \\
9,63 \\
8,69 \\
8,38 \\
7,38 \\
6,5 \\
6,06 \\
5,77 \\
5,85 \\
5,06 \\
4,46 \\
4,25 \\
3,81 \\
4,48 \\
4,5 \\
3,19 \\
3,54 \\
3,81 \\
2,85 \\
2,98\end{array}$ & $\begin{array}{l}1,59 \\
2,29 \\
2,65 \\
2,94 \\
3,18 \\
3,35 \\
3,47 \\
3,59 \\
4 \\
4,18 \\
4,35 \\
4,47 \\
4,59 \\
4,65 \\
4,71 \\
4,82 \\
4,88 \\
4,88 \\
4,94 \\
5 \\
5,06 \\
5,06 \\
5,12 \\
5,12 \\
5,18 \\
5,18 \\
5,24 \\
5,24 \\
5,29 \\
5,29 \\
5,35 \\
5,35 \\
5,35\end{array}$ & $\begin{array}{r}-2185,39 \\
-805,33 \\
-468,75 \\
-324,98 \\
-248,18 \\
-189,14 \\
-152,71 \\
-\quad 136,65 \\
-\quad 81,25 \\
-\quad 57,17 \\
-\quad 36,18 \\
-\quad 33,32 \\
-\quad 35,1 \\
-\quad 24,84 \\
-\quad 20,45 \\
-\quad 18,01 \\
-\quad 17,15 \\
-\quad 15,11 \\
-\quad 13,15 \\
-\quad 12,12 \\
-\quad 11,41 \\
-\quad 11,57 \\
-\quad 9,89 \\
-\quad 8,71 \\
-\quad 8,21 \\
-\quad 7,37 \\
-\quad 8,56 \\
-\quad 8,6 \\
-\quad 6,02 \\
-\quad 6,69 \\
-\quad 7,12 \\
-\quad 5,33 \\
-\quad 5,57\end{array}$ & $\begin{array}{l}343,5 \\
368,4 \\
409,3 \\
443,1 \\
479,3 \\
531,1 \\
581,3 \\
608,9 \\
707,4 \\
804,4 \\
862,4 \\
944,7 \\
1028,9 \\
1103,2 \\
1222,6 \\
1257,5 \\
1318 \\
1399,1 \\
1349,1 \\
1481,3 \\
1390,7 \\
1360,9 \\
1854,4 \\
1771,6 \\
1431,8 \\
1667,6 \\
2024,4 \\
1974,4 \\
1924,4 \\
1874,3 \\
1824,3 \\
1774,3 \\
1750\end{array}$ & $\begin{array}{l}6296,4 \\
4359 \\
3777,7 \\
3400 \\
3148,1 \\
2982,5 \\
2881,3 \\
2786,9 \\
2500 \\
2394,3 \\
2297,3 \\
2236,8 \\
2179,5 \\
2151,9 \\
2125 \\
2073,2 \\
2048,2 \\
2048,2 \\
2023,8 \\
2000 \\
1976,8 \\
1976,8 \\
1954 \\
1954 \\
1931,8 \\
1931,8 \\
1910,1 \\
1910,1 \\
1888,9 \\
1888,9 \\
1868,1 \\
1868,1 \\
1868,1\end{array}$ & $\begin{array}{r}-367,11 \\
-201,81 \\
-139,16 \\
-109,91 \\
-92,99 \\
-77,15 \\
-66,39 \\
-62,74 \\
-45,32 \\
-35,95 \\
-25,22 \\
-25,79 \\
-30,5 \\
-23,68 \\
-22,67 \\
-22,08 \\
-23,49 \\
-23,27 \\
-19,5 \\
-23,37 \\
-19,47 \\
-18,79 \\
-99,26 \\
-47,75 \\
-16,42 \\
-27,87 \\
74,87 \\
133,77 \\
169,81 \\
-459,41 \\
-162,49 \\
-56,81 \\
-47,11\end{array}$ & $\begin{array}{r}126,11 \\
74,35 \\
56,96 \\
48,7 \\
44,57 \\
40,97 \\
38,59 \\
38,2 \\
32,06 \\
28,92 \\
21,75 \\
24,36 \\
31,39 \\
26,13 \\
27,71 \\
27,76 \\
30,96 \\
32,56 \\
26,3 \\
34,62 \\
27,07 \\
25,57 \\
184,06 \\
84,59 \\
23,51 \\
46,48 \\
-151,57 \\
-264,11 \\
-326,78 \\
861,1 \\
296,44 \\
100,81 \\
82,44\end{array}$ \\
\hline
\end{tabular}


TABELA 9 - Cälculo das funções $D_{g}(\Theta), K(\Theta), D_{m}(\Theta), D_{z}(\Theta), K_{H}(\theta)$ e $D_{m H}(\theta)$, para as profundidades $(z)$ de $32,66,98,143$ e $203 \mathrm{~cm}$, do solo Terra Roxa Estruturada.

\begin{tabular}{|c|c|c|c|c|c|c|c|}
\hline $\begin{array}{c}z \\
(\mathrm{~cm})\end{array}$ & $\begin{array}{c}D_{z} \cdot 10 \\
\left(\mathrm{~cm}^{2} / \mathrm{h}\right)\end{array}$ & $\begin{array}{c}\partial \psi_{\mathrm{m}} / \partial z \\
\left(\mathrm{cmH}_{2} \mathrm{O} / \mathrm{cm}\right)\end{array}$ & $\begin{array}{c}\partial \psi_{h} / \partial z \\
\left(\mathrm{cmH}_{2} \mathrm{O} / \mathrm{cm}\right) \\
\end{array}$ & $\begin{array}{l}\mathrm{K}_{\mathrm{H}} \cdot 10^{4} \\
(\mathrm{~cm} / \mathrm{h})\end{array}$ & $\begin{array}{l}D_{\mathrm{mH}} \cdot 10 \\
\left(\mathrm{~cm}^{2} / \mathrm{h}\right)\end{array}$ & $\begin{array}{c}\psi_{\mathrm{m}} \\
\left(\mathrm{cmH}_{2} \mathrm{O}\right)\end{array}$ & $\left(\mathrm{cm}^{3} / \mathrm{cm}^{3}\right)$ \\
\hline 66 & $\begin{array}{l}-2311,5 \\
-\quad 879,68 \\
-\quad 525,71 \\
-\quad 373,68 \\
-292,74 \\
-\quad 230,11 \\
-\quad 191,31 \\
-\quad 174,86 \\
-113,31 \\
-\quad 86,09 \\
-\quad 57,93 \\
-\quad 57,68 \\
-\quad 66,49 \\
-\quad 50,97 \\
-\quad 48,17 \\
-\quad 45,78 \\
-\quad 48,12 \\
-\quad 47,67 \\
-\quad 39,46 \\
-\quad 46,75 \\
-\quad 38,48 \\
-\quad 37,15 \\
-\quad 193,96 \\
-\quad 93,3 \\
-\quad 31,72 \\
-\quad 53,84 \\
143,01 \\
255,51 \\
-\quad 320,76 \\
-\quad 367,79 \\
-106,56 \\
-\quad 88\end{array}$ & $\begin{array}{l}-0,01 \\
0 \\
0 \\
0,01 \\
0,01 \\
0,01 \\
0,02 \\
0,02 \\
0,03 \\
0,04 \\
0,05 \\
0,06 \\
0,07 \\
0,08 \\
0,08 \\
0,09 \\
0,1 \\
0,1 \\
0,11 \\
0,11 \\
0,12 \\
0,13 \\
0,13 \\
0,14 \\
0,14 \\
0,15 \\
0,15 \\
0,16 \\
0,16 \\
0,17 \\
0,17 \\
0,18 \\
0,18\end{array}$ & $\begin{array}{l}0,99 \\
1 \\
1 \\
1,01 \\
1,01 \\
1,01 \\
1,02 \\
1,02 \\
1,03 \\
1,04 \\
1,05 \\
1,06 \\
1,07 \\
1,08 \\
1,08 \\
1,09 \\
1,1 \\
1,1 \\
1,11 \\
1,11 \\
1,12 \\
1,13 \\
1,13 \\
1,14 \\
1,14 \\
1,15 \\
1,15 \\
1,16 \\
1,16 \\
1,17 \\
1,17 \\
1,18 \\
1,18\end{array}$ & $\begin{array}{l}-349,34 \\
-185,19 \\
-123,86 \\
-95,02 \\
-78,1 \\
-62,64 \\
-\quad 52,17 \\
-48,13 \\
-31,54 \\
-22,94 \\
-\quad 15 \\
-14,07 \\
-15,09 \\
-10,73 \\
-\quad 8,89 \\
-\quad 7,97 \\
-\quad 7,64 \\
-\quad 6,69 \\
-\quad 5,86 \\
-\quad 5,44 \\
-\quad 5,15 \\
-\quad 5,19 \\
-\quad 4,47 \\
-\quad 3,92 \\
-\quad 3,72 \\
-\quad 3,32 \\
-\quad 3,88 \\
-\quad 3,88 \\
-\quad 2,74 \\
-\quad 3,03 \\
-\quad 3,25 \\
-\quad 2,42 \\
-\quad 2,52\end{array}$ & $\begin{array}{l}120 \\
68,26 \\
50,7 \\
42,07 \\
37,43 \\
33,27 \\
30,33 \\
29,31 \\
22,31 \\
18,46 \\
12,94 \\
13,29 \\
15,53 \\
11,84 \\
10,87 \\
10,03 \\
10,07 \\
9,36 \\
7,91 \\
8,06 \\
7,16 \\
7,07 \\
8,29 \\
6,94 \\
5,32 \\
5,53 \\
7,86 \\
7,66 \\
5,27 \\
5,68 \\
5,93 \\
4,3 \\
4,41\end{array}$ & $\begin{array}{l}3,56 \\
4,59 \\
5,37 \\
6,01 \\
6,56 \\
7,06 \\
7,51 \\
7,93 \\
9,34 \\
10,5 \\
11,5 \\
12,39 \\
13,19 \\
13,93 \\
14,62 \\
15,27 \\
15,88 \\
16,45 \\
17 \\
17,53 \\
18,03 \\
18,51 \\
18,98 \\
19,43 \\
19,87 \\
20,29 \\
20,7 \\
21,1 \\
21,49 \\
21,87 \\
22,24 \\
22,6 \\
22,95\end{array}$ & $\begin{array}{l}0,4312 \\
0,4282 \\
0,4262 \\
0,4247 \\
0,4235 \\
0,4225 \\
0,4217 \\
0,421 \\
0,4188 \\
0,4173 \\
0,4161 \\
0,4151 \\
0,4143 \\
0,4136 \\
0,413 \\
0,4125 \\
0,412 \\
0,4116 \\
0,4112 \\
0,4108 \\
0,4105 \\
0,4101 \\
0,4098 \\
0,4096 \\
0,4093 \\
0,409 \\
0,4088 \\
0,4086 \\
0,4084 \\
0,4082 \\
0,408 \\
0,4078 \\
0,4076\end{array}$ \\
\hline
\end{tabular}

(continua) 
TABELA 9 - Cálculo das funções $D_{g}(\theta), K(\theta), D_{m}(\theta), D_{z}(\theta), K_{H}(\theta)$ e $D_{m H}(\theta)$, para as profundidades $(z)$ de $32,66,98,143$ e $203 \mathrm{~cm}$, do solo Terra Roxa Estruturada.

\begin{tabular}{|c|c|c|c|c|c|c|c|}
\hline $\begin{array}{c}\mathbf{z} \\
(\mathrm{cm})\end{array}$ & $\begin{array}{c}-(q)_{z} \cdot 10^{4} \\
(\mathrm{~cm} / \mathrm{h})\end{array}$ & $\begin{array}{c}\partial \Theta / \partial z \cdot 10^{4} \\
\left(\mathrm{~cm}^{-1}\right)\end{array}$ & $\begin{array}{c}D_{.} \cdot 10 \\
\left(\mathrm{~cm}_{2} / \mathrm{h}\right)\end{array}$ & $\begin{array}{l}-d \psi_{m} / d \Theta \\
\left(\mathrm{cmH}_{2} \mathrm{O}\right)\end{array}$ & $\begin{array}{l}\mathrm{d} z / d \theta \\
(\mathrm{cm})\end{array}$ & $\begin{array}{l}K .10^{4} \\
(\mathrm{~cm} / \mathrm{h})\end{array}$ & $\begin{array}{c}D_{m}=10 \\
\left(\mathrm{~cm}^{2} / \mathrm{h}\right)\end{array}$ \\
\hline 98 & $\begin{array}{l}601,75 \\
335,58 \\
230,83 \\
177,17 \\
145,67 \\
119,5 \\
101 \\
91,99 \\
62,15 \\
45,81 \\
32,83 \\
28,96 \\
28,42 \\
22,48 \\
18,9 \\
17,02 \\
16,04 \\
14,33 \\
12,85 \\
11,73 \\
11,4 \\
11,21 \\
9,71 \\
8,77 \\
8,31 \\
7,85 \\
8,48 \\
8,15 \\
6,48 \\
6,83 \\
7,13 \\
6,19 \\
6,02\end{array}$ & $\begin{array}{l}-3,33 \\
-4,53 \\
-5,27 \\
-5,73 \\
-6,13 \\
-6,4 \\
-6,67 \\
-6,87 \\
-7,4 \\
-7,73 \\
-8 \\
-8,13 \\
-8,33 \\
-8,4 \\
-8,47 \\
-8,53 \\
-8,6 \\
-8,67 \\
-8,73 \\
-8,8 \\
-8,87 \\
-8,87 \\
-8,93 \\
-8,93 \\
-9 \\
-9,07 \\
-9 \\
-9,07 \\
-9,07 \\
-9,13 \\
-9,13 \\
-9,13 \\
-9,13\end{array}$ & $\begin{array}{c}1805,27 \\
740,26 \\
438,29 \\
309,01 \\
237,5 \\
186,72 \\
151,5 \\
133,97 \\
83,98 \\
59,24 \\
11,04 \\
35,6 \\
34,1 \\
26,76 \\
22,32 \\
19,95 \\
18,65 \\
16,54 \\
14,72 \\
13,33 \\
12,85 \\
12,64 \\
10,87 \\
9,82 \\
9,24 \\
8,66 \\
9,42 \\
8,98 \\
7,15 \\
7,48 \\
7,8 \\
6,77 \\
6,59\end{array}$ & $\begin{array}{l}510,9 \\
522 \\
574,7 \\
605,2 \\
648,8 \\
705,3 \\
722,1 \\
744,1 \\
870,5 \\
975 \\
1046 \\
1136,7 \\
1200 \\
1276,1 \\
1384,5 \\
1366 \\
1382,8 \\
1512 \\
1548,6 \\
1614,8 \\
1688,9 \\
1628,9 \\
1741 \\
1874,3 \\
1824,3 \\
1760,9 \\
1712,3 \\
1910,4 \\
2132,3 \\
2083,1 \\
2049,7 \\
1980,8 \\
1933,3\end{array}$ & $\begin{array}{l}-3000 \\
-2205,9 \\
-1898,7 \\
-1744,2 \\
-1630,4 \\
-1562,5 \\
-1500 \\
-1456,3 \\
-1351,4 \\
-1293,1 \\
-1250 \\
-1229,5 \\
-1200 \\
-1190,5 \\
-1181,1 \\
-1171,9 \\
-1162,8 \\
-1153,8 \\
-1145 \\
-1136,4 \\
-1127,8 \\
-1127,8 \\
-1119,4 \\
-1119,4 \\
-1111,1 \\
-1102,9 \\
-1111,1 \\
-1102,9 \\
-1102,9 \\
-1094,9 \\
-1094,9 \\
-1094,9 \\
-1094,9\end{array}$ & $\begin{array}{l}-514,18 \\
-271,37 \\
-177,2 \\
-131,53 \\
-104,2 \\
-\quad 82,34 \\
-68,18 \\
-60,88 \\
-37,8 \\
-26,12 \\
-17,87 \\
-15,05 \\
-14,21 \\
-10,85 \\
-\quad 8,7 \\
-\quad 7,86 \\
-\quad 7,33 \\
-6,2 \\
-\quad 5,46 \\
-\quad 4,84 \\
-4,56 \\
-\quad 4,59 \\
-\quad 3,8 \\
-\quad 3,28 \\
-\quad 3,15 \\
-\quad 3,02 \\
-\quad 3,34 \\
-\quad 2,98 \\
-2,21 \\
-\quad 2,35 \\
-\quad 2,48 \\
-\quad 2,2 \\
-\quad 2,18\end{array}$ & $\begin{array}{c}262,72 \\
141,65 \\
101,83 \\
79,6 \\
67,61 \\
58,07 \\
49,23 \\
45,3 \\
32,9 \\
25,47 \\
18,7 \\
17,1 \\
17,05 \\
13,84 \\
12,04 \\
10,74 \\
10,13 \\
9,38 \\
8,46 \\
7,82 \\
7,71 \\
7,47 \\
6,61 \\
6,15 \\
5,74 \\
5,33 \\
5,71 \\
5,7 \\
4,71 \\
4,9 \\
5,08 \\
4,36 \\
4,21\end{array}$ \\
\hline
\end{tabular}


TABELA 9 - Cálculo das funções $D_{g}(\theta), K(\theta), D_{m}(\theta), D_{z}(\theta), K_{H}(\theta)$ e $D_{m H}(\theta)$, para as profundidades $(z)$ de $32,66,98,143$ e $203 \mathrm{~cm}$, do solo Terra Roxa Estruturada.

\begin{tabular}{|c|c|c|c|c|c|c|c|}
\hline $\begin{array}{c}z \\
(\mathrm{~cm})\end{array}$ & $\begin{array}{c}D_{z} \cdot 10 \\
\left(\mathrm{~cm}^{2} / \mathrm{h}\right)\end{array}$ & $\begin{array}{c}\partial \psi_{\mathrm{m}} / \partial z \\
\left(\mathrm{cmH}_{2} \mathrm{O} / \mathrm{cm}\right) \\
\end{array}$ & $\begin{array}{c}\partial \psi_{h} / \partial z \\
\left(\mathrm{cmH}_{2} \mathrm{O} / \mathrm{cm}\right)\end{array}$ & $\begin{array}{l}k_{H} \cdot 10^{4} \\
(\mathrm{~cm} / \mathrm{h})\end{array}$ & $\begin{array}{l}D_{\mathrm{mH}} \cdot 10 \\
\left(\mathrm{~cm}^{2} / \mathrm{h}\right)\end{array}$ & $\begin{array}{c}\psi_{\mathrm{m}} \\
\left(\mathrm{cmH}_{2} 0\right)\end{array}$ & $\left(\mathrm{cm}^{3} / \mathrm{cm}^{3}\right)$ \\
\hline 98 & $\begin{array}{c}1542,55 \\
598,61 \\
336,46 \\
229,41 \\
169,89 \\
128,65 \\
102,27 \\
88,66 \\
51,08 \\
33,77 \\
22,34 \\
18,5 \\
17,05 \\
12,92 \\
10,27 \\
9,21 \\
8,52 \\
7,16 \\
6,26 \\
5,51 \\
5,15 \\
5,17 \\
4,25 \\
3,67 \\
3,5 \\
3,34 \\
3,71 \\
3,29 \\
2,44 \\
2,58 \\
2,72 \\
2,41 \\
2,38\end{array}$ & $\begin{array}{l}0,31 \\
0,38 \\
0,43 \\
0,47 \\
0,5 \\
0,53 \\
0,56 \\
0,58 \\
0,66 \\
0,73 \\
0,78 \\
0,83 \\
0,87 \\
0,91 \\
0,94 \\
0,98 \\
1,01 \\
1,03 \\
1,06 \\
1,09 \\
1,11 \\
1,13 \\
1,16 \\
1,18 \\
1,2 \\
1,22 \\
1,24 \\
1,26 \\
1,27 \\
1,29 \\
1,31 \\
1,32 \\
1,34\end{array}$ & $\begin{array}{l}1,31 \\
1,38 \\
1,43 \\
1,47 \\
1,5 \\
1,53 \\
1,56 \\
1,58 \\
1,66 \\
1,73 \\
1,78 \\
1,83 \\
1,87 \\
1,91 \\
1,94 \\
1,98 \\
2,01 \\
2,03 \\
2,06 \\
2,09 \\
2,11 \\
2,13 \\
2,16 \\
2,18 \\
2,2 \\
2,22 \\
2,24 \\
2,26 \\
2,27 \\
2,29 \\
2,31 \\
2,32 \\
2,34\end{array}$ & $\begin{array}{l}-459,35 \\
-243,29 \\
-161,5 \\
-120,58 \\
-96,9 \\
-77,97 \\
-64,74 \\
-\quad 58,08 \\
-37,33 \\
-26,51 \\
-18,42 \\
-15,83 \\
-15,19 \\
-11,77 \\
-\quad 9,72 \\
-\quad 8,61 \\
-\quad 8 \\
-\quad 7,04 \\
-\quad 6,24 \\
-\quad 5,62 \\
-\quad 5,4 \\
-\quad 5,25 \\
-\quad 4,5 \\
-\quad 4,03 \\
-\quad 3,78 \\
-\quad 3,54 \\
-\quad 3,79 \\
-\quad 3,61 \\
-\quad 2,85 \\
-\quad 2,98 \\
-\quad 3,09 \\
-\quad 2,66 \\
-\quad 2,57\end{array}$ & $\begin{array}{c}234,7 \\
126,99 \\
92,81 \\
72,97 \\
62,87 \\
54,99 \\
46,75 \\
43,21 \\
32,5 \\
25,85 \\
19,27 \\
17,99 \\
18,23 \\
15,02 \\
13,46 \\
11,76 \\
11,06 \\
10,65 \\
9,66 \\
9,07 \\
9,12 \\
8,55 \\
7,84 \\
7,55 \\
6,9 \\
6,24 \\
6,49 \\
6,9 \\
6,08 \\
6,21 \\
6,33 \\
5,27 \\
4,97\end{array}$ & $\begin{array}{l}8,58 \\
10,72 \\
12,29 \\
13,56 \\
14,65 \\
15,62 \\
16,48 \\
17,28 \\
19,94 \\
22,08 \\
23,91 \\
25,52 \\
26,96 \\
28,28 \\
29,5 \\
30,63 \\
31,69 \\
32,7 \\
33,65 \\
34,56 \\
35,42 \\
36,25 \\
37,05 \\
37,81 \\
38,55 \\
39,27 \\
39,96 \\
40,64 \\
41,29 \\
41,92 \\
42,54 \\
43,15 \\
43,73\end{array}$ & $\begin{array}{l}0,4254 \\
0,4182 \\
0,4161 \\
0,4143 \\
0,4129 \\
0,4117 \\
0,4106 \\
0,4073 \\
0,405 \\
0,4032 \\
0,4017 \\
0,4005 \\
0,3994 \\
0,3985 \\
0,3977 \\
0,3969 \\
0,3962 \\
0,3956 \\
0,395 \\
0,3945 \\
0,394 \\
0,3935 \\
0,3931 \\
0,3927 \\
0,3923 \\
0,3919 \\
0,3915 \\
0,3912 \\
0,3909 \\
0,3906 \\
0,3903 \\
0,39\end{array}$ \\
\hline
\end{tabular}

(continua) 
TABELA 9 - Cálculo das funções $D_{g}(\theta), K(\theta), D_{m}(\theta), D_{z}(\theta), K_{H}(\theta)$ e $D_{m H}(\theta)$, para as profundidades $(z)$ de $32,66,98,143$ e $203 \mathrm{~cm}$, do solo Terra Roxa Estruturada.

\begin{tabular}{|c|c|c|c|c|c|c|c|}
\hline $\begin{array}{l}z \\
(\mathrm{~cm})\end{array}$ & $\begin{array}{c}-(q)_{z} \cdot 10^{4} \\
(\mathrm{~cm} / \mathrm{h})\end{array}$ & $\begin{array}{c}\partial \theta / \partial z \cdot 10^{4} \\
\left(\mathrm{~cm}^{-1}\right)\end{array}$ & $\begin{array}{c}D_{g} \cdot 10 \\
\left(\mathrm{~cm}^{2} / \mathrm{h}\right)\end{array}$ & $\begin{array}{l}-\mathrm{d} \psi_{\mathrm{m}} / \mathrm{d} \theta \\
\left(\mathrm{cmH}_{2} \mathrm{O}\right) \\
\end{array}$ & $\begin{array}{l}\mathrm{dz} / \mathrm{d} \theta \\
(\mathrm{cm}) \\
\end{array}$ & $\begin{array}{l}k .104 \\
(\mathrm{~cm} / \mathrm{h})\end{array}$ & $\begin{array}{c}D_{\mathrm{m}} \cdot 10 \\
\left(\mathrm{~cm}^{2} / \mathrm{h}\right)\end{array}$ \\
\hline 143 & $\begin{array}{l}1363,58 \\
796,5 \\
542,08 \\
408,5 \\
328,67 \\
270,42 \\
227,75 \\
200,99 \\
133,83 \\
96,17 \\
71,4 \\
60,4 \\
54,48 \\
44,25 \\
38,1 \\
33,92 \\
30,94 \\
28,17 \\
25,75 \\
23,15 \\
21,88 \\
21,17 \\
18,29 \\
17,38 \\
16,79 \\
14,98 \\
15,17 \\
14,69 \\
13,08 \\
13,02 \\
12,77 \\
11,83 \\
11,25\end{array}$ & $\begin{array}{l}-4,8 \\
-6,13 \\
-7,1 \\
-7,77 \\
-8,27 \\
-8,63 \\
-8,9 \\
-9,13 \\
-9,7 \\
-10 \\
-10,17 \\
-10,27 \\
-10,33 \\
-10,37 \\
-10,4 \\
-10,43 \\
-10,47 \\
-10,47 \\
-10,47 \\
-10,43 \\
-10,47 \\
-10,43 \\
-10,43 \\
-10,43 \\
-10,4 \\
-10,4 \\
-10,37 \\
-10,4 \\
-10,37 \\
-10,37 \\
-10,33 \\
-10,33 \\
-10,3\end{array}$ & $\begin{array}{l}2840,8 \\
1298,65 \\
763,5 \\
525,96 \\
397,56 \\
313,23 \\
255,9 \\
220,06 \\
137,97 \\
96,17 \\
70,23 \\
58,83 \\
52,72 \\
42,68 \\
36,64 \\
32,51 \\
29,56 \\
26,91 \\
24,6 \\
22,18 \\
20,9 \\
20,29 \\
17,53 \\
16,65 \\
16,15 \\
14,4 \\
14,63 \\
14,12 \\
12,62 \\
12,56 \\
12,36 \\
11,45 \\
10,92\end{array}$ & $\begin{array}{l}854,1 \\
798,5 \\
867,2 \\
948,4 \\
1028,5 \\
1106,6 \\
1193,5 \\
1274,7 \\
1546,8 \\
1794,1 \\
1997,8 \\
2244,1 \\
2424,3 \\
2619,2 \\
2809,4 \\
2854,9 \\
3121,9 \\
3268,9 \\
3307 \\
3617,6 \\
3712,9 \\
3885 \\
4066 \\
3907,5 \\
4193,8 \\
4522,5 \\
4372,4 \\
4850,1 \\
4648,9 \\
4546,8 \\
5131,6 \\
4998,2 \\
4864,8\end{array}$ & $\begin{array}{l}-1083,3 \\
-1630,4 \\
-1408,5 \\
-1287,5 \\
-1209,7 \\
-1158,3 \\
-1123,6 \\
-1094,9 \\
-1030,9 \\
-1000 \\
-983,6 \\
-974 \\
-967,7 \\
-964,6 \\
-961,5 \\
-958,5 \\
-955,4 \\
-955,4 \\
-955,4 \\
-958,5 \\
-955,4 \\
-958,5 \\
-958,5 \\
-958,5 \\
-961,5 \\
-961,5 \\
-964,6 \\
-961,5 \\
-964,6 \\
-964,6 \\
-967,7 \\
-967,7 \\
-970,9\end{array}$ & $\begin{array}{l}-967,09 \\
-534,66 \\
-335,51 \\
-235,23 \\
-177,64 \\
-138,3 \\
-110,44 \\
-92,87 \\
-53,53 \\
-34,42 \\
-23,55 \\
-18,28 \\
-15,54 \\
-11,91 \\
-\quad 9,72 \\
-\quad 8,52 \\
-7,25 \\
-\quad 6,37 \\
-\quad 5,77 \\
-4,85 \\
-\quad 4,48 \\
-\quad 4,19 \\
-\quad 3,49 \\
-\quad 3,42 \\
-\quad 3,13 \\
-\quad 2,63 \\
-\quad 2,74 \\
-\quad 2,43 \\
-\quad 2,25 \\
-\quad 2,28 \\
-2,03 \\
-\quad 1,92 \\
1,87\end{array}$ & $\begin{array}{c}826,03 \\
426,92 \\
290,96 \\
223,1 \\
182,7 \\
153,03 \\
131,81 \\
118,38 \\
82,79 \\
61,75 \\
47,06 \\
41,02 \\
37,68 \\
31,2 \\
27,3 \\
24,34 \\
22,63 \\
20,82 \\
19,09 \\
17,54 \\
16,62 \\
16,27 \\
14,19 \\
13,37 \\
13,13 \\
11,88 \\
11,99 \\
11,79 \\
10,45 \\
10,36 \\
10,4 \\
9,59 \\
9,11\end{array}$ \\
\hline
\end{tabular}


TABELLA 9 - Cālculo das funções $D_{g}(\theta), K(\theta), D_{m}(\theta), D_{z}(\theta), K_{H}(\theta)$ e $D_{m H}(\theta)$, para as profundidades $(z)$ de $32,66,98,143$ e $203 \mathrm{~cm}$, do solo Terra Roxa Estruturada.

\begin{tabular}{|c|c|c|c|c|c|c|c|}
\hline & $\begin{array}{c}D z \cdot 10 \\
\left(\mathrm{~cm}^{2} / \mathrm{h}\right)\end{array}$ & $\begin{array}{c}\partial \psi_{\mathrm{m}} / \partial z \\
\left(\mathrm{cmH}_{2} 0 / \mathrm{cm}\right)\end{array}$ & $\begin{array}{c}\partial \psi_{h} / \partial z \\
\left(\mathrm{cmH}_{2} \mathrm{O} / \mathrm{cm}\right)\end{array}$ & $\begin{array}{l}K_{H} \cdot 10^{4 /} \\
(\mathrm{cm} / \mathrm{h})\end{array}$ & $\begin{array}{l}D_{m H} \cdot 10 \\
\left(\mathrm{~cm}^{2} / \mathrm{h}\right)\end{array}$ & $\begin{array}{c}\psi_{\mathrm{m}} \\
\left(\mathrm{cmH}_{2} 0\right)\end{array}$ & $\begin{array}{c}\theta \\
\left(\mathrm{cm}^{3} / \mathrm{cm}^{3}\right)\end{array}$ \\
\hline 143 & $\begin{array}{c}2014,77 \\
871,73 \\
472,54 \\
302,87 \\
214,88 \\
160,19 \\
124,09 \\
101,68 \\
55,18 \\
34,42 \\
23,17 \\
17,81 \\
15,04 \\
11,49 \\
9,34 \\
8,17 \\
6,93 \\
6,09 \\
5,51 \\
4,65 \\
4,28 \\
4,01 \\
3,34 \\
3,28 \\
3,01 \\
2,53 \\
2,64 \\
2,34 \\
2,17 \\
2,2 \\
1,96 \\
1,86 \\
1,82\end{array}$ & $\begin{array}{l}1,17 \\
1,33 \\
1,44 \\
1,51 \\
1,58 \\
1,63 \\
1,68 \\
1,72 \\
1,84 \\
1,93 \\
2 \\
2,06 \\
2,11 \\
2,15 \\
2,19 \\
2,22 \\
2,25 \\
2,27 \\
2,3 \\
2,32 \\
2,34 \\
2,35 \\
2,37 \\
2,39 \\
2,4 \\
2,41 \\
2,43 \\
2,44 \\
2,45 \\
2,46 \\
2,47 \\
2,48 \\
2,49\end{array}$ & $\begin{array}{l}2,17 \\
2,33 \\
2,44 \\
2,51 \\
2,58 \\
2,63 \\
2,68 \\
2,72 \\
2,84 \\
2,93 \\
3 \\
3,06 \\
3,11 \\
3,15 \\
3,19 \\
3,22 \\
3,25 \\
3,27 \\
3,3 \\
3,32 \\
3,34 \\
3,35 \\
3,37 \\
3,39 \\
3,4 \\
3,41 \\
3,43 \\
3,44 \\
3,45 \\
3,46 \\
3,47 \\
3,48 \\
3,49\end{array}$ & $\begin{array}{l}-628,19 \\
-341,7 \\
-222,53 \\
-162,43 \\
-127,46 \\
-102,74 \\
-85,06 \\
-73,94 \\
-47,07 \\
-32,78 \\
-23,77 \\
-19,73 \\
-17,52 \\
-14,05 \\
-11,96 \\
-10,54 \\
-\quad 9,53 \\
-\quad 8,61 \\
-\quad 7,81 \\
-\quad 6,98 \\
-\quad 6,56 \\
-\quad 6,31 \\
-\quad 5,43 \\
-\quad 5,13 \\
-\quad 4,94 \\
-\quad 4,39 \\
-\quad 4,43 \\
-\quad 4,27 \\
-\quad 3,79 \\
-\quad 3,76 \\
-\quad 3,68 \\
-\quad 3,4 \\
-\quad 3,23\end{array}$ & $\begin{array}{c}536,56 \\
272,84 \\
192,98 \\
154,05 \\
131,09 \\
113,69 \\
101,51 \\
94,25 \\
72,81 \\
58,82 \\
47,49 \\
44,28 \\
42,48 \\
36,79 \\
33,6 \\
30,09 \\
29,75 \\
28,13 \\
25,84 \\
25,24 \\
24,34 \\
24,51 \\
22,06 \\
20,05 \\
20,71 \\
19,84 \\
19,35 \\
20,72 \\
17,64 \\
17,12 \\
18,89 \\
17,01 \\
15,7\end{array}$ & $\begin{array}{l}41,08 \\
48,72 \\
54,08 \\
58,33 \\
61,89 \\
64,98 \\
67,73 \\
70,21 \\
78,35 \\
84,74 \\
90,06 \\
94,66 \\
98,74 \\
102,41 \\
105,77 \\
108,87 \\
111,76 \\
114,46 \\
117 \\
119,41 \\
121,69 \\
123,87 \\
125,95 \\
127,94 \\
129,86 \\
131,7 \\
133,48 \\
135,2 \\
136,86 \\
138,47 \\
140,03 \\
141,55 \\
143,03\end{array}$ & $\begin{array}{l}0,3869 \\
0,3769 \\
0,3704 \\
0,3657 \\
0,3621 \\
0,3592 \\
0,3568 \\
0,3548 \\
0,349 \\
0,3452 \\
0,3424 \\
0,3402 \\
0,3385 \\
0,337 \\
0,3358 \\
0,3347 \\
0,3337 \\
0,3329 \\
0,3321 \\
0,3314 \\
0,3308 \\
0,3302 \\
0,3297 \\
0,3292 \\
0,3287 \\
0,3283 \\
0,3279 \\
0,3275 \\
0,3272 \\
0,3268 \\
0,3265 \\
0,3262 \\
0,3259\end{array}$ \\
\hline
\end{tabular}

(continua) 
TABELA 9 - Cälculo das funções $D_{g}(\theta), K(\theta), D_{m}(\theta), D_{z}(\theta), K_{H}(\theta)$ e $D_{m H}(\theta)$, para as profundidades $(z)$ de $32,66,98,143$ e $203 \mathrm{~cm}$, do solo Terra Roxa Estruturada.

\begin{tabular}{|c|c|c|c|c|c|c|c|}
\hline $\begin{array}{c}z \\
(\mathrm{~cm})\end{array}$ & $\begin{array}{r}-(\mathrm{q})_{z} \cdot 10^{4} \\
(\mathrm{~cm} / \mathrm{h})\end{array}$ & $\begin{array}{c}\partial \theta / \partial z \cdot 10^{4} \\
\left(\mathrm{~cm}^{-1}\right)\end{array}$ & $\begin{array}{l}\mathrm{D}_{\mathrm{g}} \cdot 10 \\
\left(\mathrm{~cm}^{2} / \mathrm{h}\right)\end{array}$ & $\begin{array}{r}-d \psi_{\mathrm{m}} / \mathrm{d} \theta \\
\left(\mathrm{cmH}_{2} \mathrm{O}\right)\end{array}$ & $\begin{array}{l}\mathrm{dz} / \mathrm{d} \theta \\
(\mathrm{cm})\end{array}$ & $\begin{array}{l}\text { K. } 10^{4} \\
(\mathrm{~cm} / \mathrm{h})\end{array}$ & $\begin{array}{c}D_{m_{2}} \cdot 10 \\
\left(\mathrm{~cm}^{2} / \mathrm{h}\right)\end{array}$ \\
\hline 203 & $\begin{array}{l}2614,25 \\
1781,17 \\
1242,83 \\
931 \\
738,33 \\
601,58 \\
502,5 \\
438,18 \\
279,08 \\
192,67 \\
142,52 \\
115,94 \\
98,81 \\
81,08 \\
69,92 \\
61,35 \\
55,17 \\
49,85 \\
44,4 \\
39,94 \\
37,83 \\
35,21 \\
31,23 \\
29,67 \\
27,81 \\
25,29 \\
25,4 \\
23,77 \\
21,6 \\
20,94 \\
19,96 \\
19 \\
18,31\end{array}$ & $\begin{array}{l}2,1 \\
1,97 \\
1,9 \\
1,83 \\
1,77 \\
1,77 \\
1,73 \\
1,73 \\
1,7 \\
1,63 \\
1,6 \\
1,6 \\
1,57 \\
1,53 \\
1,53 \\
1,5 \\
1,5 \\
1,5 \\
1,5 \\
1,47 \\
1,47 \\
1,47 \\
1,43 \\
1,47 \\
1,43 \\
1,43 \\
1,43 \\
1,43 \\
1,4 \\
1,4 \\
1,4 \\
1,4 \\
1,37\end{array}$ & $\begin{array}{r}-12448,81 \\
-9056,76 \\
-\quad 6541,23 \\
-\quad 5078,27 \\
-4179,17 \\
-3405,12 \\
-2899,09 \\
-2527,98 \\
-1641,67 \\
-1179,62 \\
-\quad 890,75 \\
-\quad 724,61 \\
-\quad 630,7 \\
-\quad 528,82 \\
-455,99 \\
-\quad 409,03 \\
-\quad 367,78 \\
-\quad 332,36 \\
-\quad 295,97 \\
-\quad 272,29 \\
-\quad 257,95 \\
-\quad 240,05 \\
-\quad 217,88 \\
-\quad 202,27 \\
-\quad 194,05 \\
-\quad 176,46 \\
-177,18 \\
-\quad 165,85 \\
-154,32 \\
-\quad 149,55 \\
-\quad 142,56 \\
-\quad 135,71 \\
-\quad 133,99\end{array}$ & $\begin{array}{l}919,3 \\
782,4 \\
801,9 \\
848,3 \\
915,8 \\
972,5 \\
1041,8 \\
1122,4 \\
1327,3 \\
1555,9 \\
1751,9 \\
1906 \\
2104,8 \\
2269 \\
2348 \\
2588,1 \\
2698,5 \\
2782,8 \\
3035,8 \\
3029,3 \\
3260,1 \\
3540 \\
3389,2 \\
3507,9 \\
3647,6 \\
3854,9 \\
4076,9 \\
3938,2 \\
3818,1 \\
4133,1 \\
4497,5 \\
4373,9 \\
4889,8\end{array}$ & $\begin{array}{l}4761,9 \\
5084,7 \\
5263,2 \\
5454,6 \\
5660,3 \\
5660,3 \\
5769,3 \\
5769,3 \\
5882,4 \\
6122,6 \\
6250 \\
6250 \\
6382,8 \\
6521,9 \\
6521,9 \\
6666,7 \\
6666,7 \\
6666,7 \\
6666,7 \\
6818 \\
6818 \\
6818 \\
6976,9 \\
6818 \\
6976,9 \\
6976,9 \\
6976,9 \\
6976,9 \\
7142,9 \\
7142,9 \\
7142,9 \\
7142,9 \\
7316,9\end{array}$ & $\begin{array}{l}-3239,7 \\
-2105,09 \\
-1466,23 \\
-1102,46 \\
-880,85 \\
-726,38 \\
-613,23 \\
-\quad 544,01 \\
-360,41 \\
-258,31 \\
-198,03 \\
-166,81 \\
-147,43 \\
-124,34 \\
-109,25 \\
-100,29 \\
-\quad 92,68 \\
-\quad 85,58 \\
-\quad 81,51 \\
-\quad 71,87 \\
-\quad 72,5 \\
-\quad 73,23 \\
-\quad 60,73 \\
-\quad 61,11 \\
-\quad 58,28 \\
-\quad 56,52 \\
-\quad 61,1 \\
-\quad 54,58 \\
-\quad 46,41 \\
-\quad 49,69 \\
-\quad 53,89 \\
-\quad 49,01 \\
-\quad 55,21\end{array}$ & $\begin{array}{r}2978,32 \\
1647,08 \\
1175,76 \\
935,26 \\
806,7 \\
706,41 \\
638,85 \\
610,57 \\
478,37 \\
401,89 \\
346,93 \\
317,94 \\
310,31 \\
282,13 \\
256,51 \\
259,55 \\
250,1 \\
238,14 \\
247,46 \\
217,72 \\
236,35 \\
259,23 \\
205,83 \\
214,36 \\
212,59 \\
217,89 \\
249,08 \\
214,94 \\
177,22 \\
205,37 \\
242,37 \\
214,37 \\
269,95\end{array}$ \\
\hline
\end{tabular}


TABELA 9 - Cälculo das funções $D_{g}(\theta), K(\theta), D_{m}(\theta), D_{z}(\theta), K_{H}(\theta)$ e $D_{m H}(\theta)$, para as profundidades $(z)$ de $32,66,98,143$ e $203 \mathrm{~cm}$, do solo Terra Roxa Estruturada.

\begin{tabular}{|c|c|c|c|c|c|c|c|}
\hline & $\begin{array}{c}D_{z} \cdot 10 \\
\left(\mathrm{~cm}^{2} / \mathrm{h}\right)\end{array}$ & $\begin{array}{c}\partial \psi_{\mathrm{m}} / \partial z \\
\left(\mathrm{cmH}_{2} \mathrm{O} / \mathrm{cm}\right) \\
\end{array}$ & $\begin{array}{c}\partial \psi_{h} / \partial z \\
\left(\mathrm{cmH}_{2} \mathrm{O} / \mathrm{cm}\right) \\
\end{array}$ & $\begin{array}{l}\mathrm{K}_{\mathrm{H}} \cdot 10^{\mathrm{m} / 4} \\
(\mathrm{~cm} / \mathrm{h})\end{array}$ & $\begin{array}{l}D_{m H} \cdot 10 \\
\left(\mathrm{~cm}^{2} / \mathrm{h}\right)\end{array}$ & $\begin{array}{c}\psi_{\mathrm{m}} \\
\left(\mathrm{cmH}_{2} \mathrm{O}\right) \\
\end{array}$ & $\begin{array}{c}\Theta \\
\left(\mathrm{cm}^{3} / \mathrm{cm}^{3}\right)\end{array}$ \\
\hline 203 & $\begin{array}{l}-15427,13 \\
-10703,85 \\
-7716,99 \\
-6013,53 \\
-4985,87 \\
-4111,53 \\
-3537,94 \\
-3138,56 \\
-2120,04 \\
-1581,5 \\
-1237,69 \\
-1042,55 \\
-\quad 941,02 \\
-\quad 810,94 \\
-\quad 712,5 \\
-\quad 668,58 \\
-\quad 617,88 \\
-\quad 570,5 \\
-\quad 543,43 \\
-\quad 490,02 \\
-\quad 494,3 \\
-\quad 499,28 \\
-\quad 423,71 \\
-\quad 416,63 \\
-\quad 406,64 \\
-\quad 394,34 \\
-\quad 426,27 \\
-\quad 380,78 \\
-\quad 331,53 \\
-\quad 354,93 \\
-\quad 384,93 \\
-\quad 350,09 \\
-\quad 403,94\end{array}$ & $\begin{array}{l}-0,25 \\
-0,27 \\
-0,28 \\
-0,29 \\
-0,29 \\
-0,3 \\
-0,3 \\
-0,3 \\
-0,31 \\
-0,31 \\
-0,31 \\
-0,31 \\
-0,3 \\
-0,3 \\
-0,3 \\
-0,3 \\
-0,29 \\
-0,29 \\
-0,29 \\
-0,28 \\
-0,28 \\
-0,28 \\
-0,27 \\
-0,27 \\
-0,27 \\
-0,26 \\
-0,26 \\
-0,26 \\
-0,25 \\
-0,25 \\
-0,25 \\
-0,24 \\
-0,24\end{array}$ & $\begin{array}{l}0,75 \\
0,73 \\
0,72 \\
0,71 \\
0,71 \\
0,7 \\
0,7 \\
0,7 \\
0,69 \\
0,69 \\
0,69 \\
0,69 \\
0,7 \\
0,7 \\
0,7 \\
0,7 \\
0,71 \\
0,71 \\
0,71 \\
0,72 \\
0,72 \\
0,72 \\
0,73 \\
0,73 \\
0,73 \\
0,74 \\
0,74 \\
0,74 \\
0,75 \\
0,75 \\
0,75 \\
0,76 \\
0,76\end{array}$ & $\begin{array}{l}-3491,87 \\
-2442,18 \\
-1729,36 \\
-1308,2 \\
-1044,81 \\
-855,74 \\
-717,52 \\
-627,76 \\
-402,33 \\
-278,29 \\
-205,66 \\
-166,98 \\
-141,84 \\
-116 \\
-\quad 99,64 \\
-\quad 87,07 \\
-\quad 77,92 \\
-\quad 70,15 \\
-\quad 62,27 \\
-\quad 55,65 \\
-\quad 52,5 \\
-\quad 48,63 \\
-\quad 42,94 \\
-\quad 40,6 \\
-\quad 37,89 \\
-\quad 34,3 \\
-\quad 34,3 \\
-\quad 31,95 \\
-\quad 28,91 \\
-\quad 27,9 \\
-\quad 26,48 \\
-\quad 25,1 \\
-\quad 24,1\end{array}$ & $\begin{array}{l}3210,15 \\
1910,83 \\
1386,76 \\
1109,79 \\
956,86 \\
832,21 \\
747,49 \\
704,57 \\
534,02 \\
432,97 \\
360,3 \\
318,26 \\
298,54 \\
263,2 \\
233,96 \\
225,34 \\
210,27 \\
195,22 \\
189,03 \\
168,58 \\
171,15 \\
172,15 \\
145,52 \\
142,43 \\
138,21 \\
132,23 \\
139,85 \\
125,82 \\
110,38 \\
115,33 \\
119,1 \\
109,78 \\
117,82\end{array}$ & $\begin{array}{l}45,75 \\
54,46 \\
60,59 \\
65,45 \\
69,54 \\
73,09 \\
76,24 \\
79,1 \\
88,48 \\
95,85 \\
102 \\
107,33 \\
112,06 \\
116,32 \\
120,22 \\
123,82 \\
127,17 \\
130,31 \\
133,27 \\
136,07 \\
138,73 \\
141,26 \\
143,69 \\
146,01 \\
148,24 \\
150,39 \\
152,47 \\
154,47 \\
156,41 \\
158,29 \\
160,12 \\
161,89 \\
163,62\end{array}$ & $\begin{array}{l}0,3846 \\
0,3736 \\
0,3657 \\
0,3598 \\
0,3551 \\
0,3514 \\
0,3482 \\
0,3456 \\
0,3378 \\
0,3327 \\
0,329 \\
0,3261 \\
0,3237 \\
0,3218 \\
0,3201 \\
0,3186 \\
0,3174 \\
0,3162 \\
0,3152 \\
0,3143 \\
0,3134 \\
0,3127 \\
0,312 \\
0,3113 \\
0,3107 \\
0,3101 \\
0,3096 \\
0,3091 \\
0,3086 \\
0,3081 \\
0,3077 \\
0,3073 \\
0,3069\end{array}$ \\
\hline
\end{tabular}




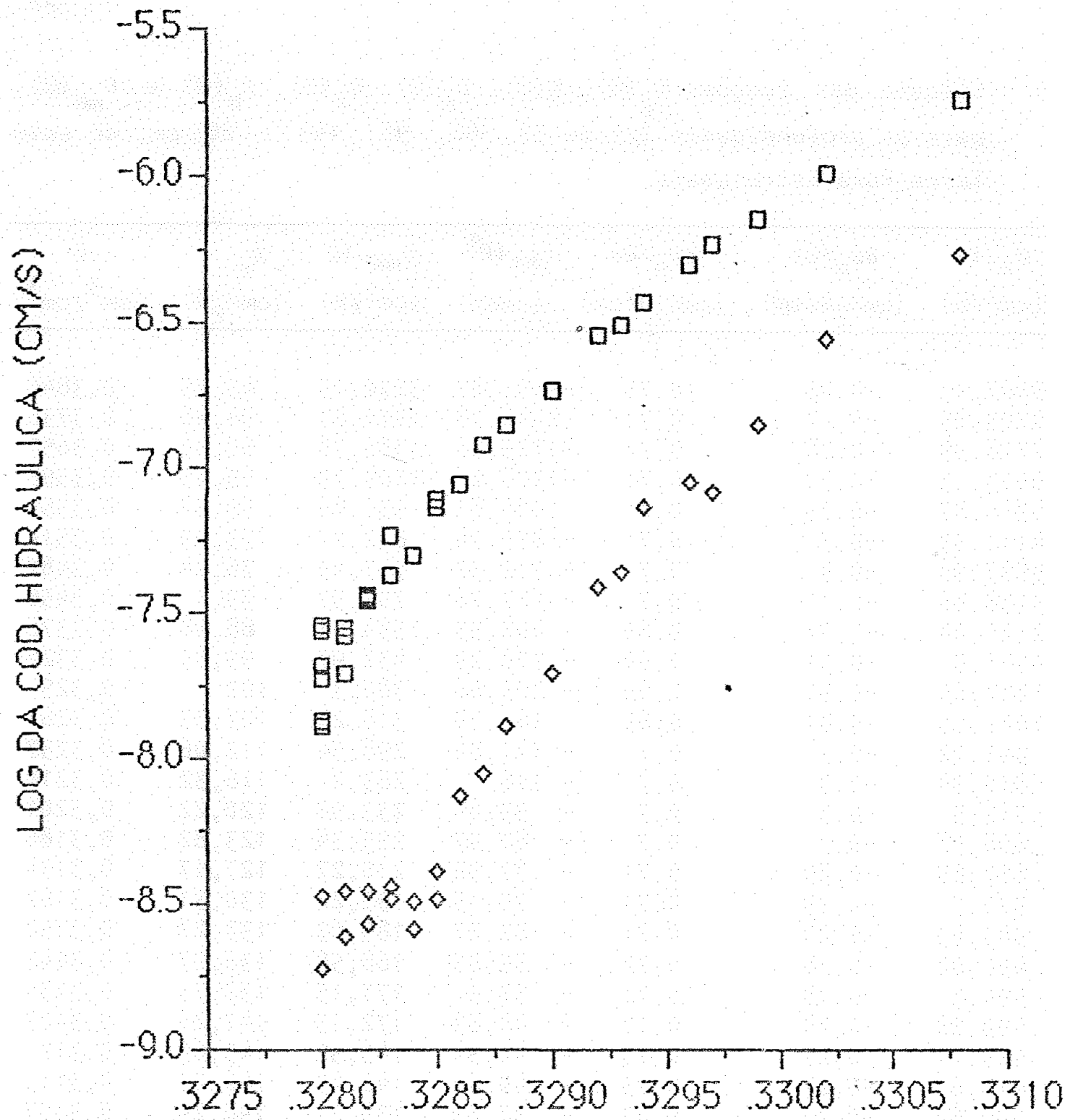

UMIDADE (CMB/CM3)

FIGURA 55 - Condutividade hidráulica em função da umidade, segundo a teoria proposta $(\diamond)$; e HILLEL et ali $i(1972)$, ( $(\square)$, para a profundidade de $32 \mathrm{~cm}$ do solo Terra Roxa Estruturada. 


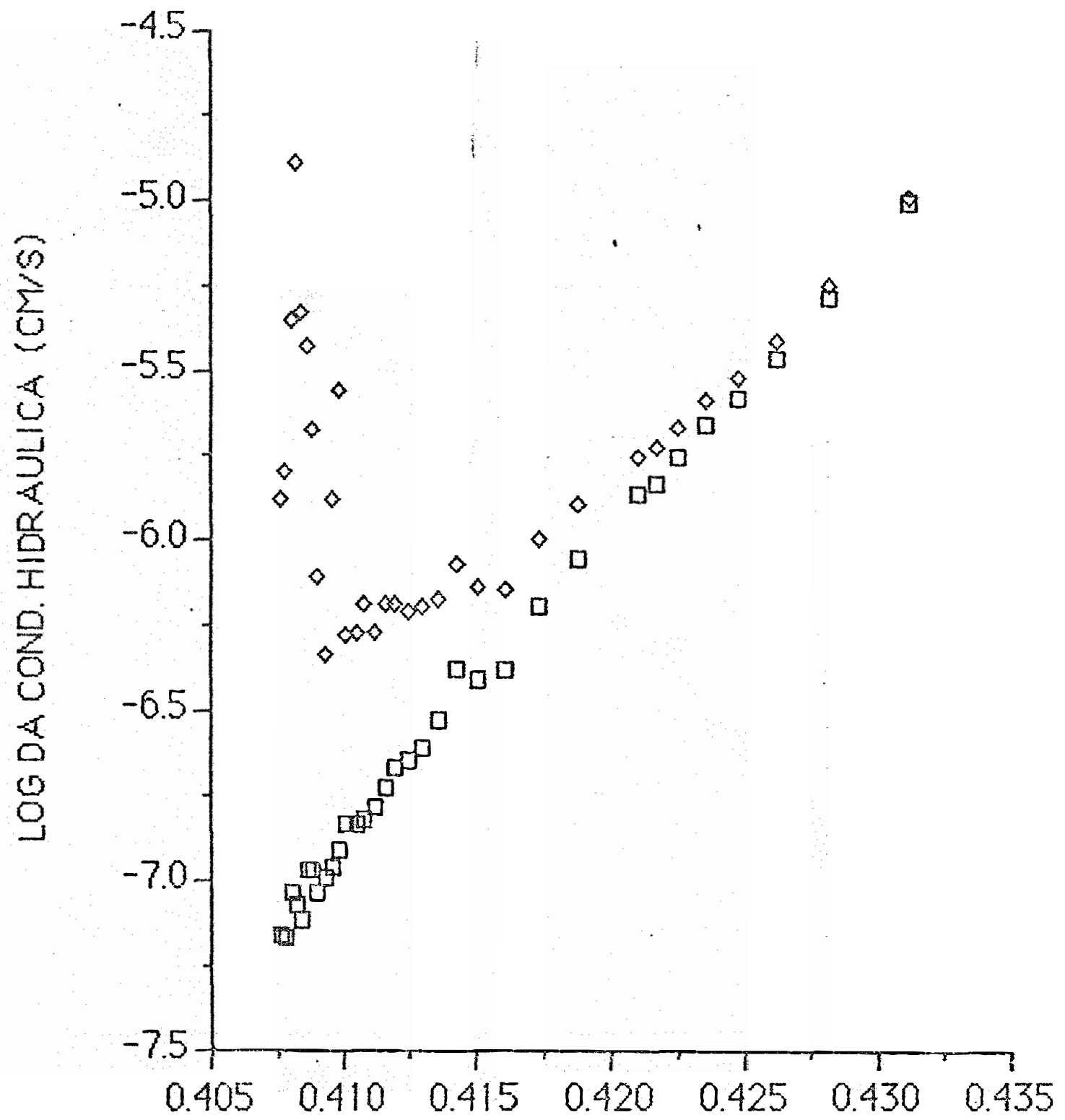

UMIDADE (CM3/CMB)

FIGURA 56 - Condutividade hidrāulica em função da umidade, segundo a teoria proposta $(\diamond)$; e HILLEL et alii (1972), ( $\square$ ), para a profundidade de $66 \mathrm{~cm}$ do solo Terra Roxa Estruturada. 


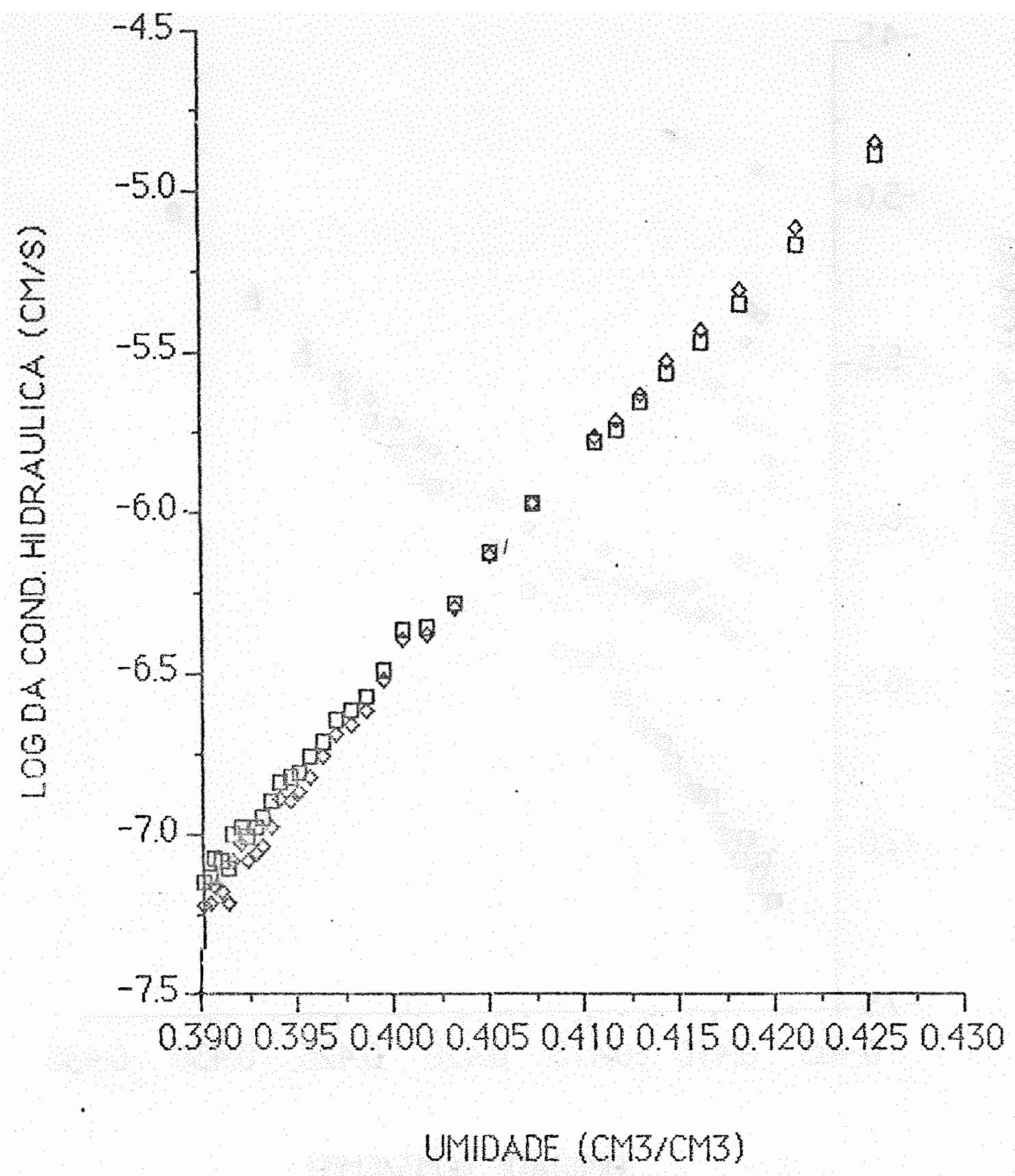

FIGURA 57 - Condutividade hidráulica em função da umidade, segundo a teoria proposta $(\diamond)$; e HILLEL et alii $(1972)$, ( $\square)$, para a profundidade de $98 \mathrm{~cm}$ do solo Terra Roxa Estruturada. 


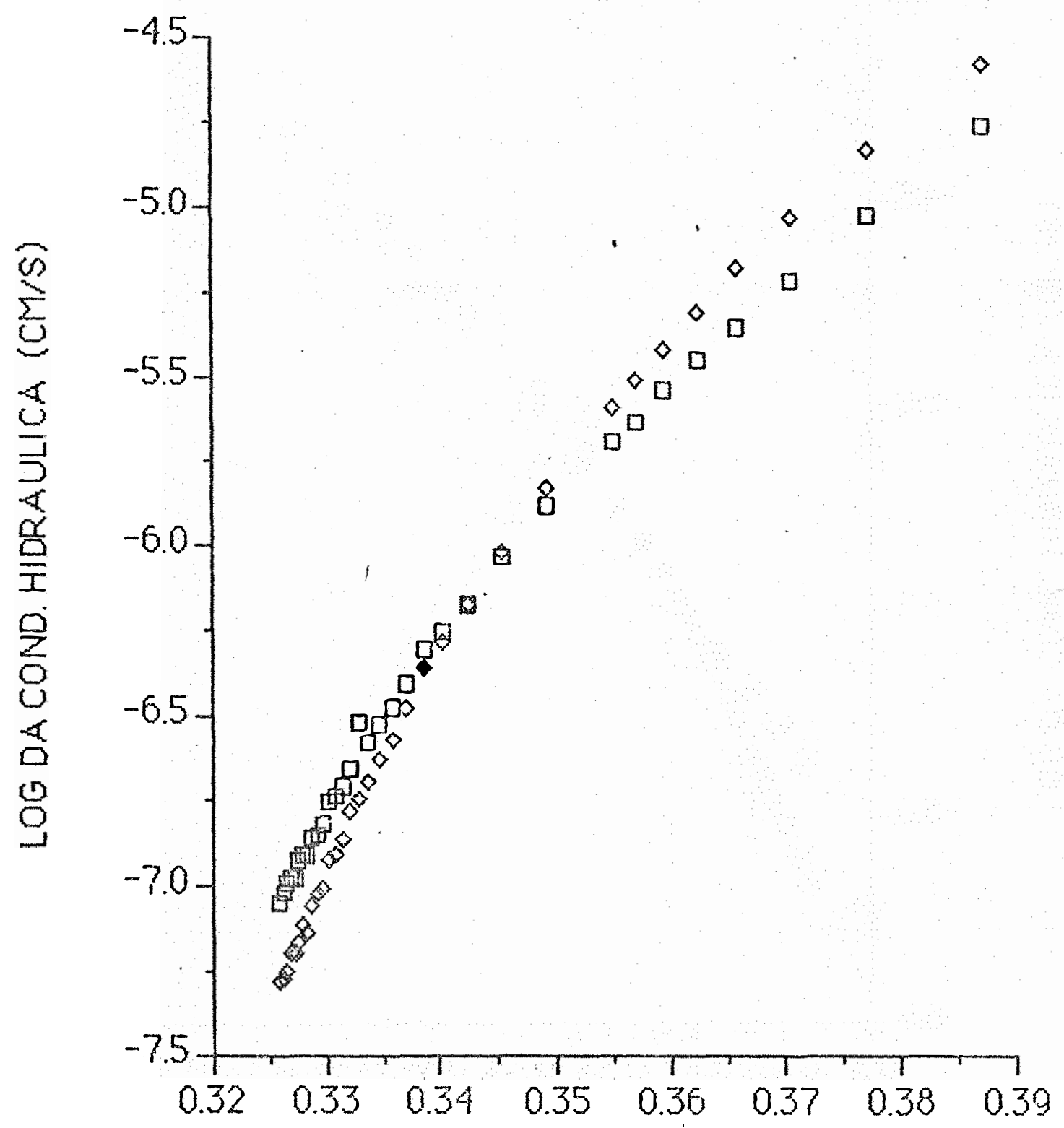

UMIDADE (CM3/CM3)

FIGURA 58 - Condutividade hidräulica em função da umidade, segundo a teoria proposta $(\diamond)$; eHILLEL et alii (1972), ( $\square)$, para a profundidade de $143 \mathrm{~cm}$ do solo Terra Roxa Estruturada. 


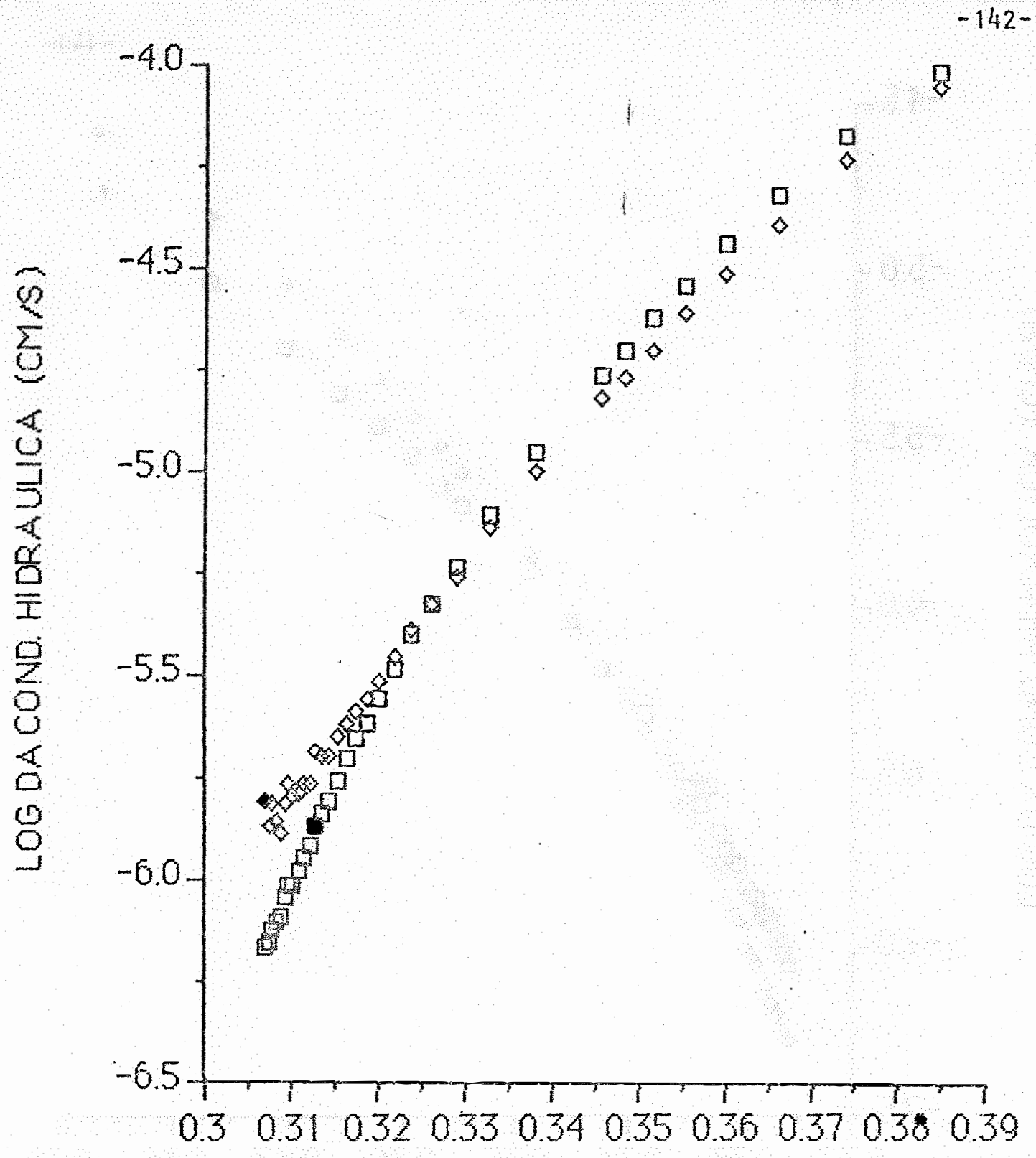

UMIDADE (CM3/CM3)

FIGURA 59 - Condutividade hidrāulica em função da umidade, segundo a teor ia proposta ( $\diamond)$; e HILLEL et alii (1972), ( $\square)$, para a profundidade de $203 \mathrm{~cm}$ do solo Terra Roxa Estruturada. 


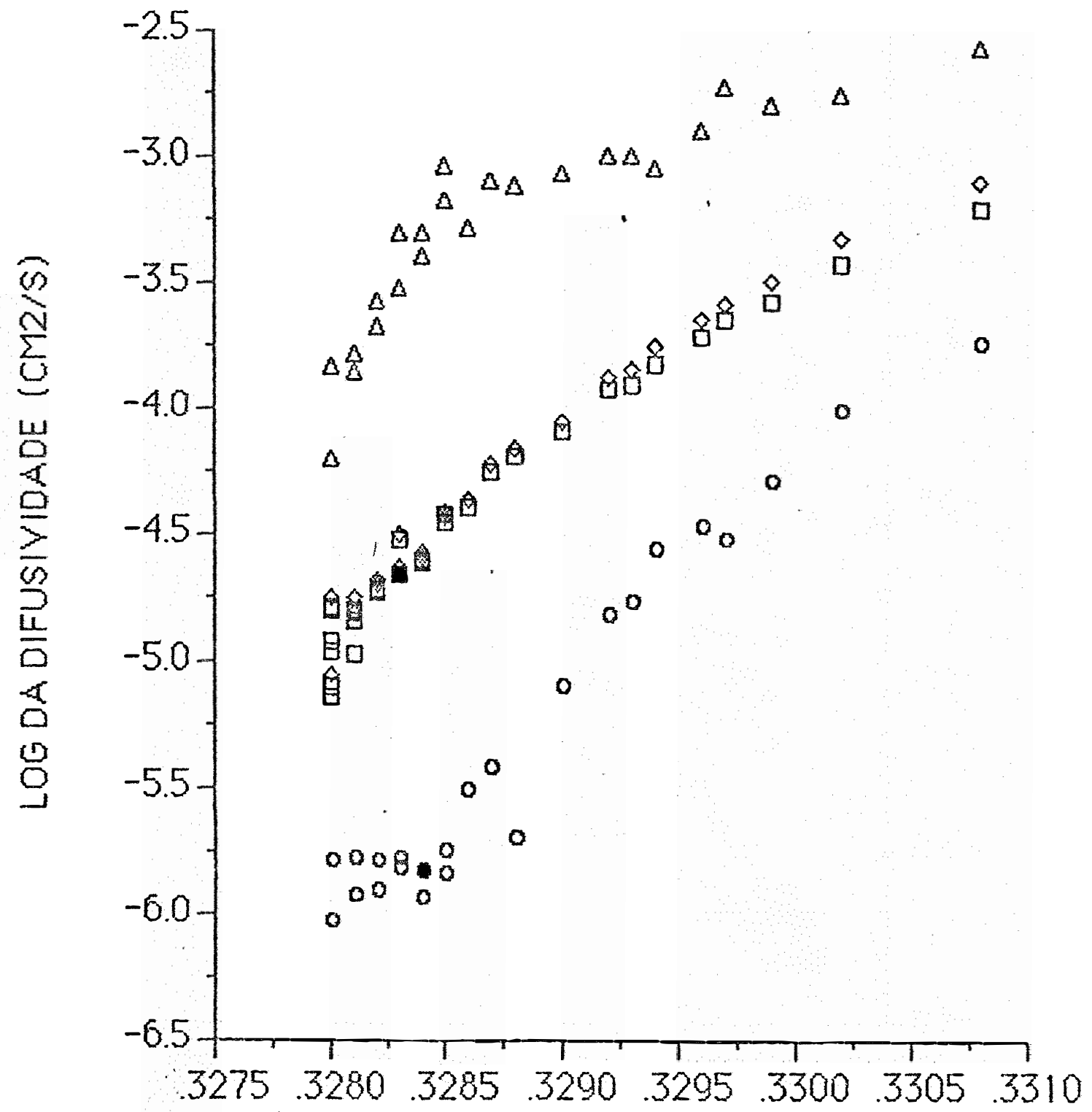

\section{UMIDADE (CMB/CM3)}

FIGURA 60 - Difusividade hidräulica em função da umidade, segundo a teoria proposta: global (口), gravitacional (o), e ma tricial ( $\diamond)$; e segundo HILLELet alii (1972), $(\Delta)$, pa ra a profundidade de $32 \mathrm{~cm}$ do solo Terra Roxa Estrutura da. 


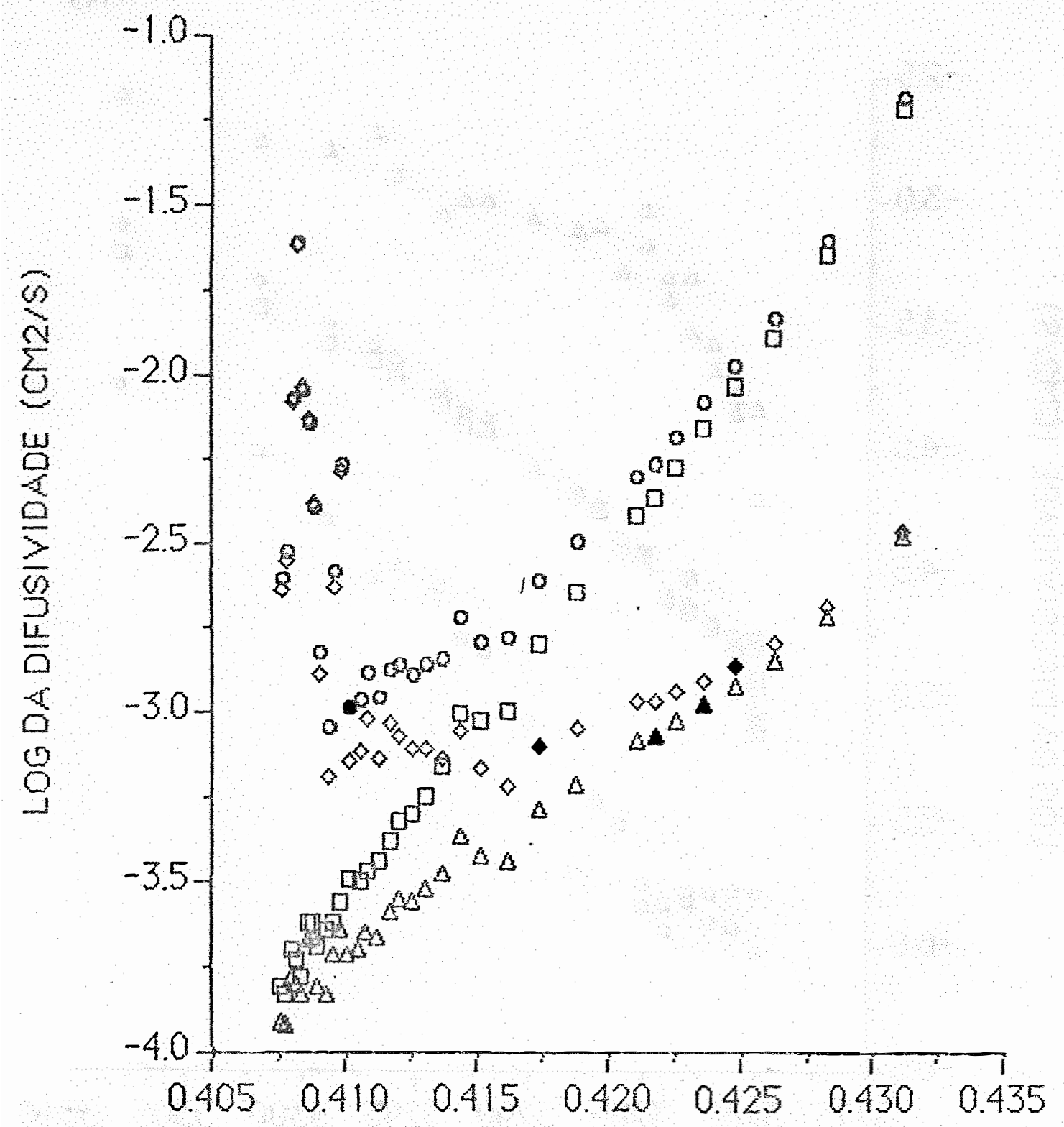

UMIDADE $(\mathrm{CMB} / \mathrm{CM})$

FIgURA 61 - Difusividade hidráulica em função da umidade, segundo a teoria proposta: global ( $($ ) , gravitacional (O), e ma tricial $(\diamond)$; e segundo HILLEL et alii (1972), $(\Delta)$, pa ra a profundidade de $66 \mathrm{~cm}$ do solo Terra Roxa Estrutura da. 


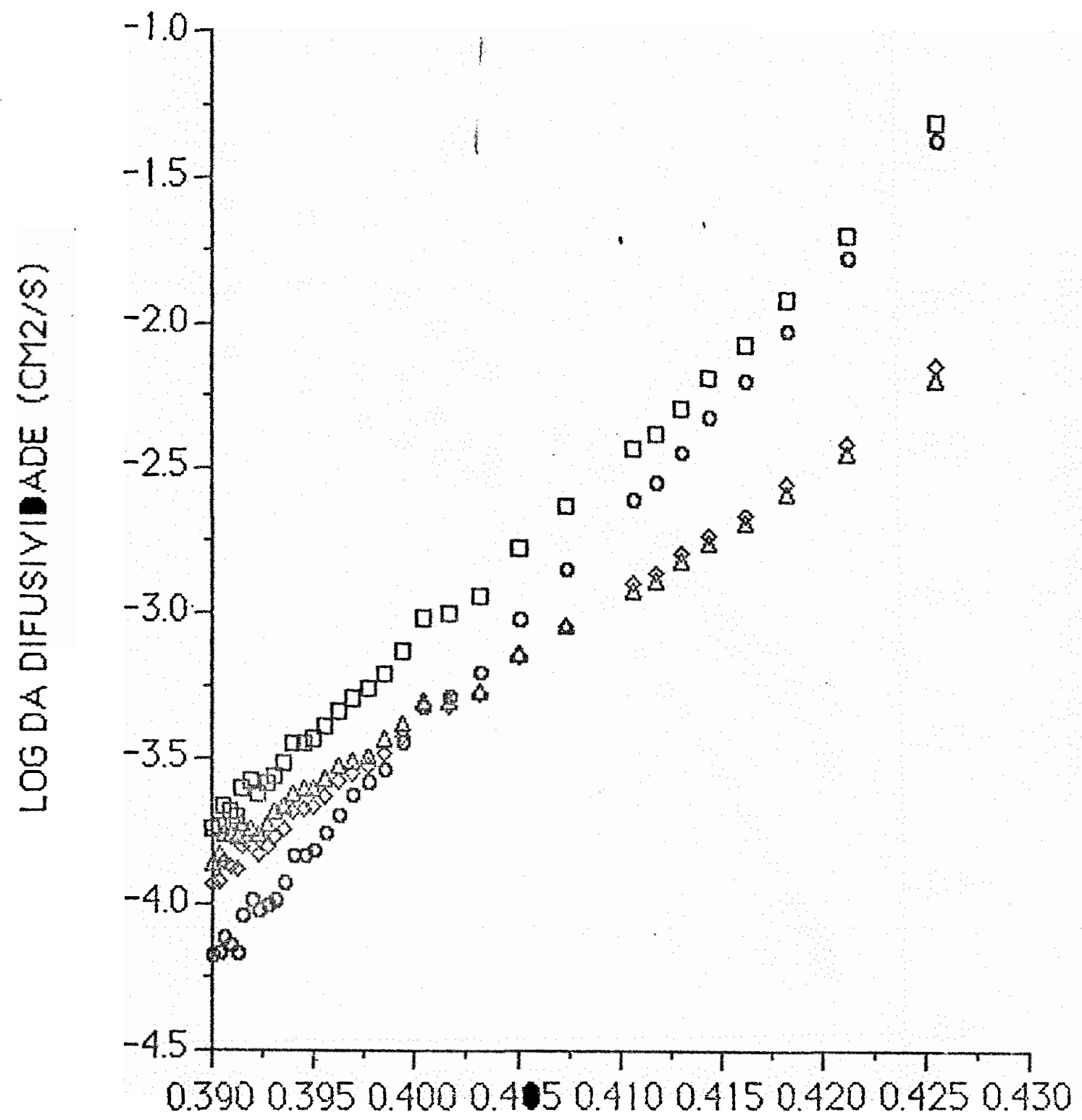

UMIDADE (CMZ/CM3)

FIGURA 62 - Difusividade hidrāulica em função da umidade, segundo a teoria proposta: global (口), gravitacional (O), e ma tricial $(\diamond)$; e segundo HILLEL et alii (1972), $(\Delta)$, pa ra a profundidade de $98 \mathrm{~cm}$ do solo Terra Roxa Estrutura da. 


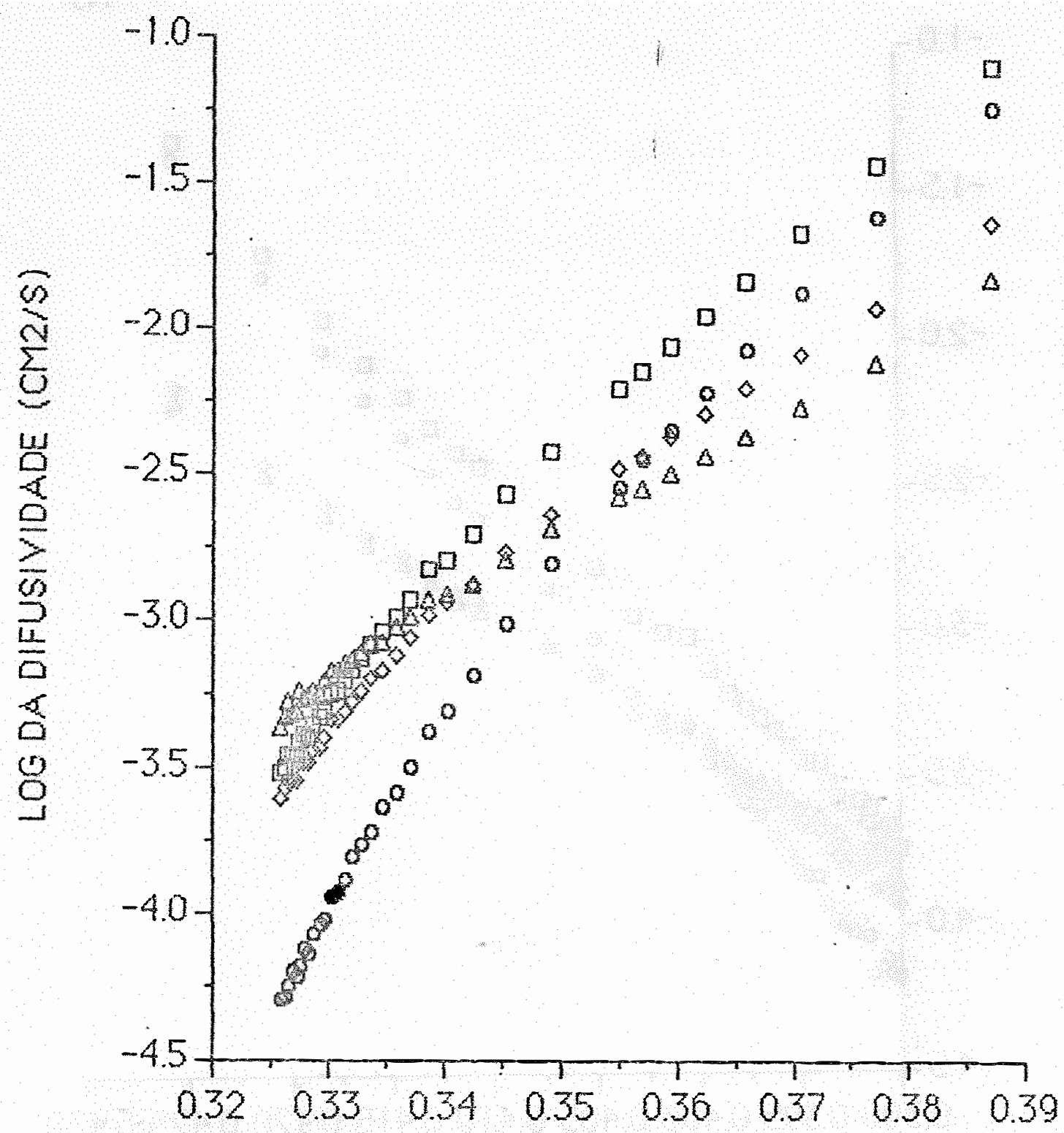

UMIDADE $(\mathrm{CM} / \mathrm{CM})$

FIGURA 63 - Difusividade hidrāulica em função da umidade, segundo a teoria proposta: global (口), gravitacional (O), e ma tricial $:(\diamond)$; e segundo HILLEL et alii (1972), $(\Delta)$, pa ra a profundidade de $143 \mathrm{~cm}$ do solo Terra Roxa Estrutu rada. 


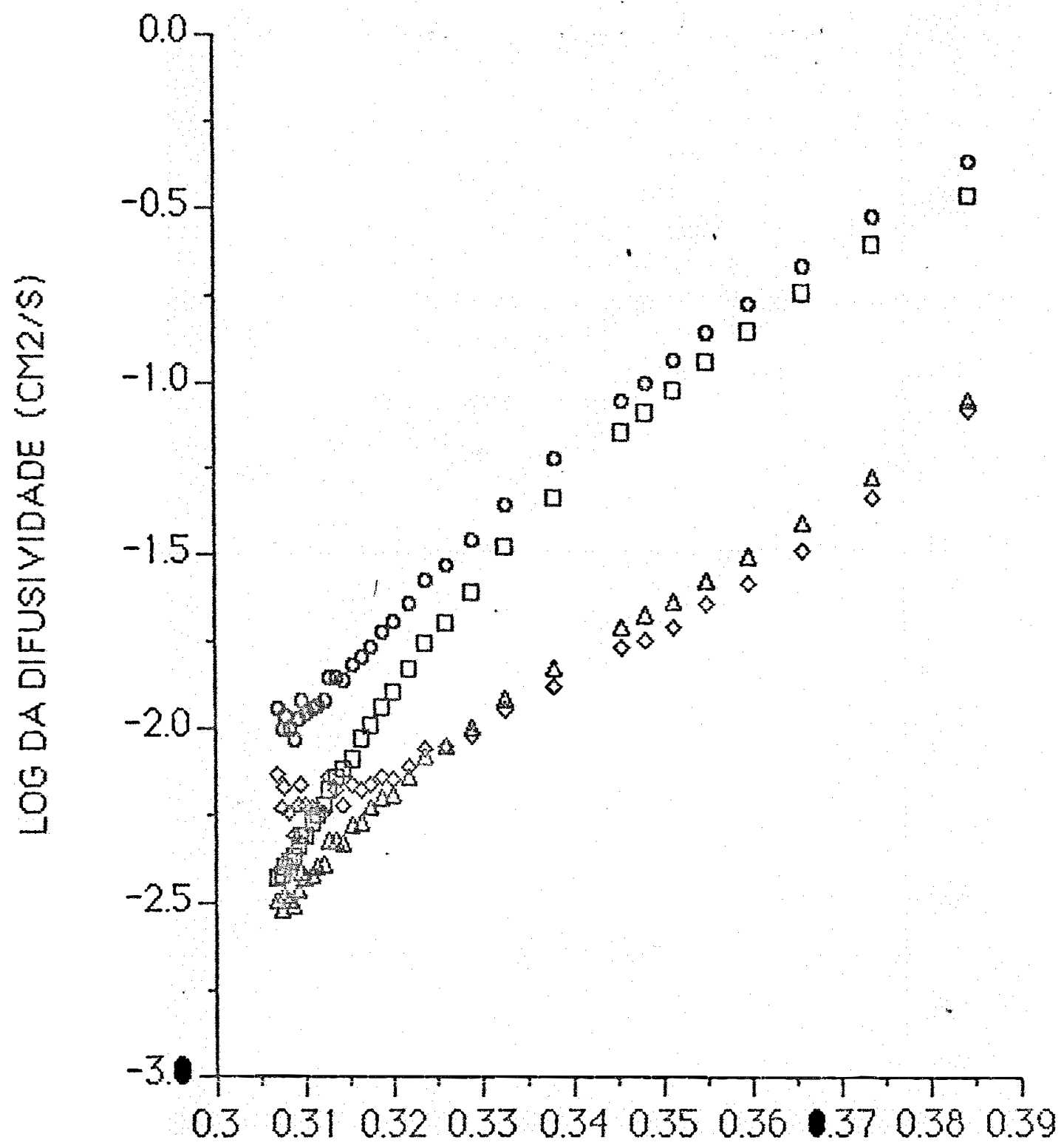

UMIDADE (CM3/CM3)

FIGURA 64 - Difusividade hidrāulica em função da umidade, segundo a teoriaproposta: global ( $\square$ ), gravitacional (o), e ma tricial ( $\diamond)$; e segundo HILLEL et alii (1972), $(\Delta)$, pa ra a profundidade de $203 \mathrm{~cm}$ do solo Terra Roxa Estrutu rada. 


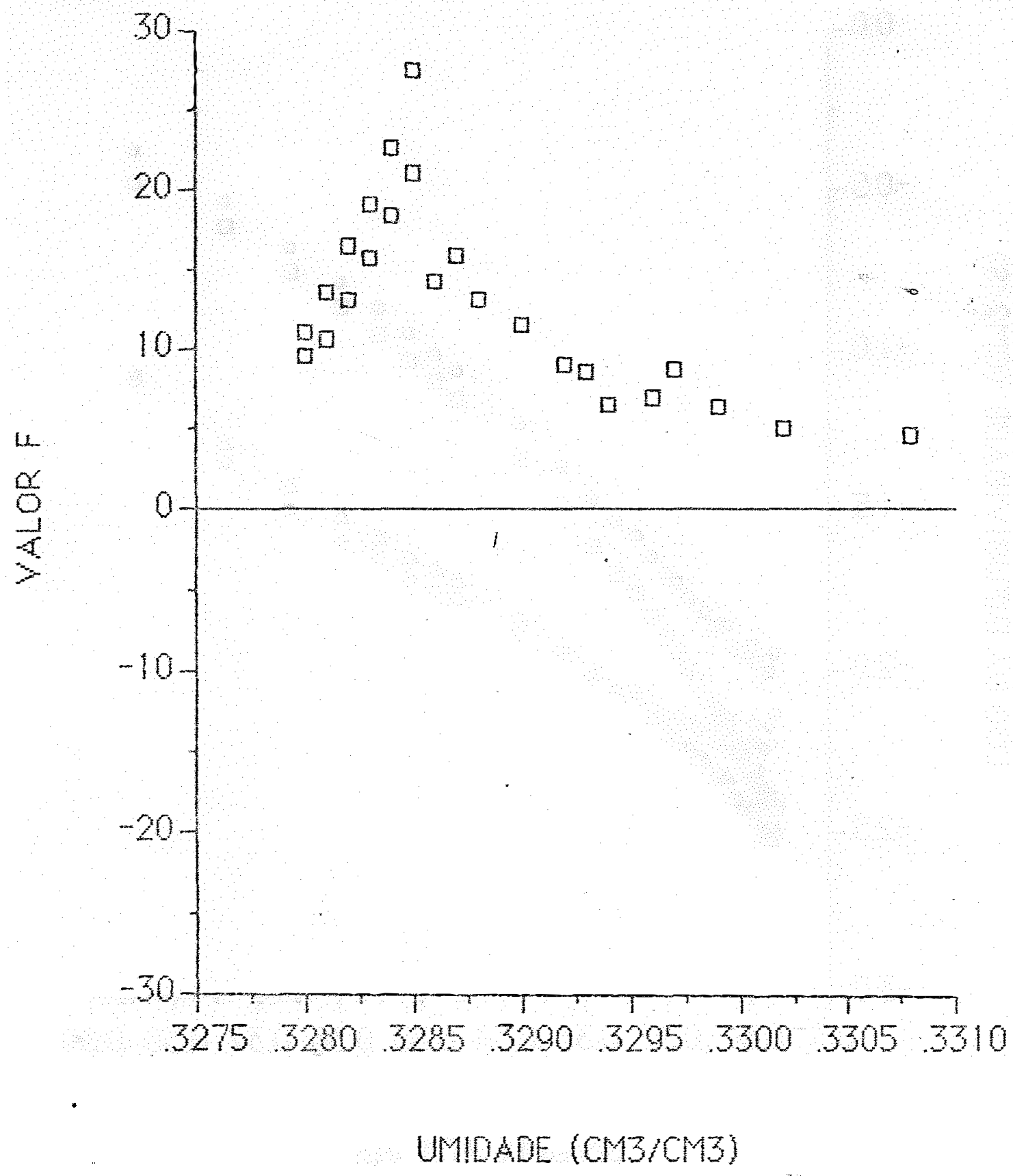

FIGURA 65 - Valor F (Equação 41) em função da umidade para a camada $15-49 \mathrm{~cm}$ do solo Terra Roxa Estruturada. 


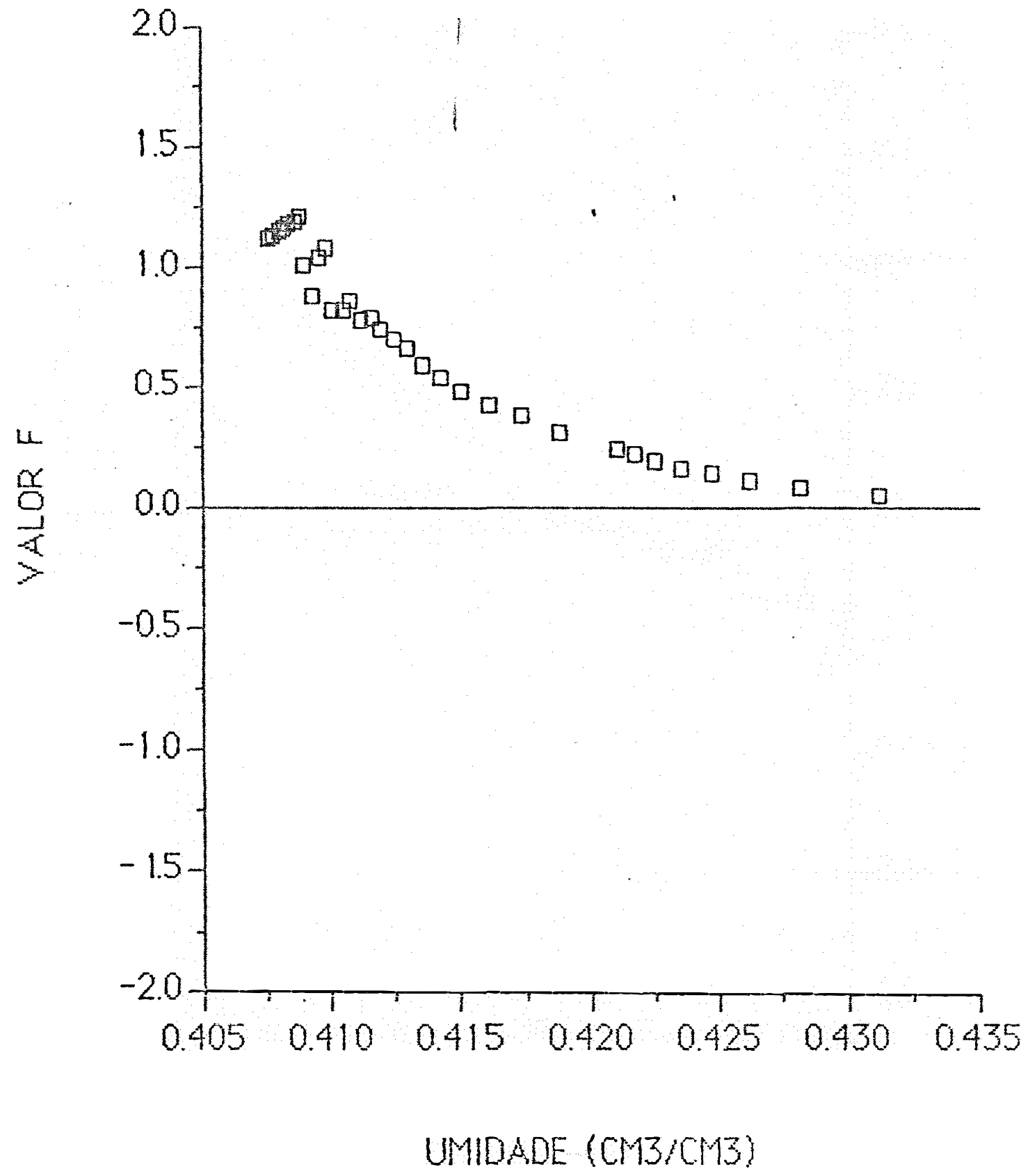

FIGURA 66 - Valor Fं (Equação 41) em função da umidade para a camada 49-83 cm do s-lo Terra Roxa Estruturada. 


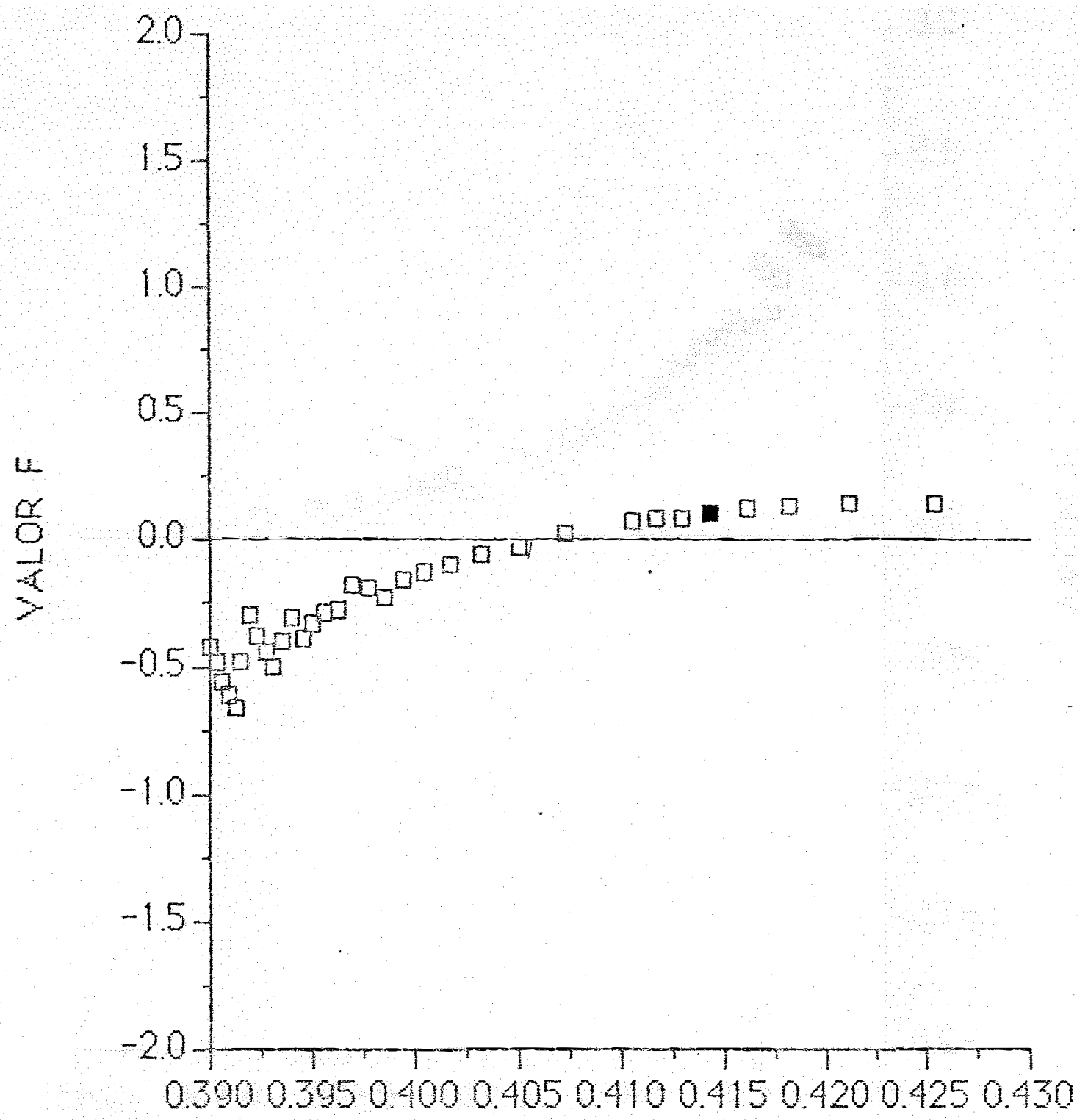

UMIDADE (CMB/CM3)

- FIGURA 67 - Valor F (Equação 41) em função da umidade para a camada $83-113 \mathrm{~cm}$ do solo Terra Roxa Estruturada. 


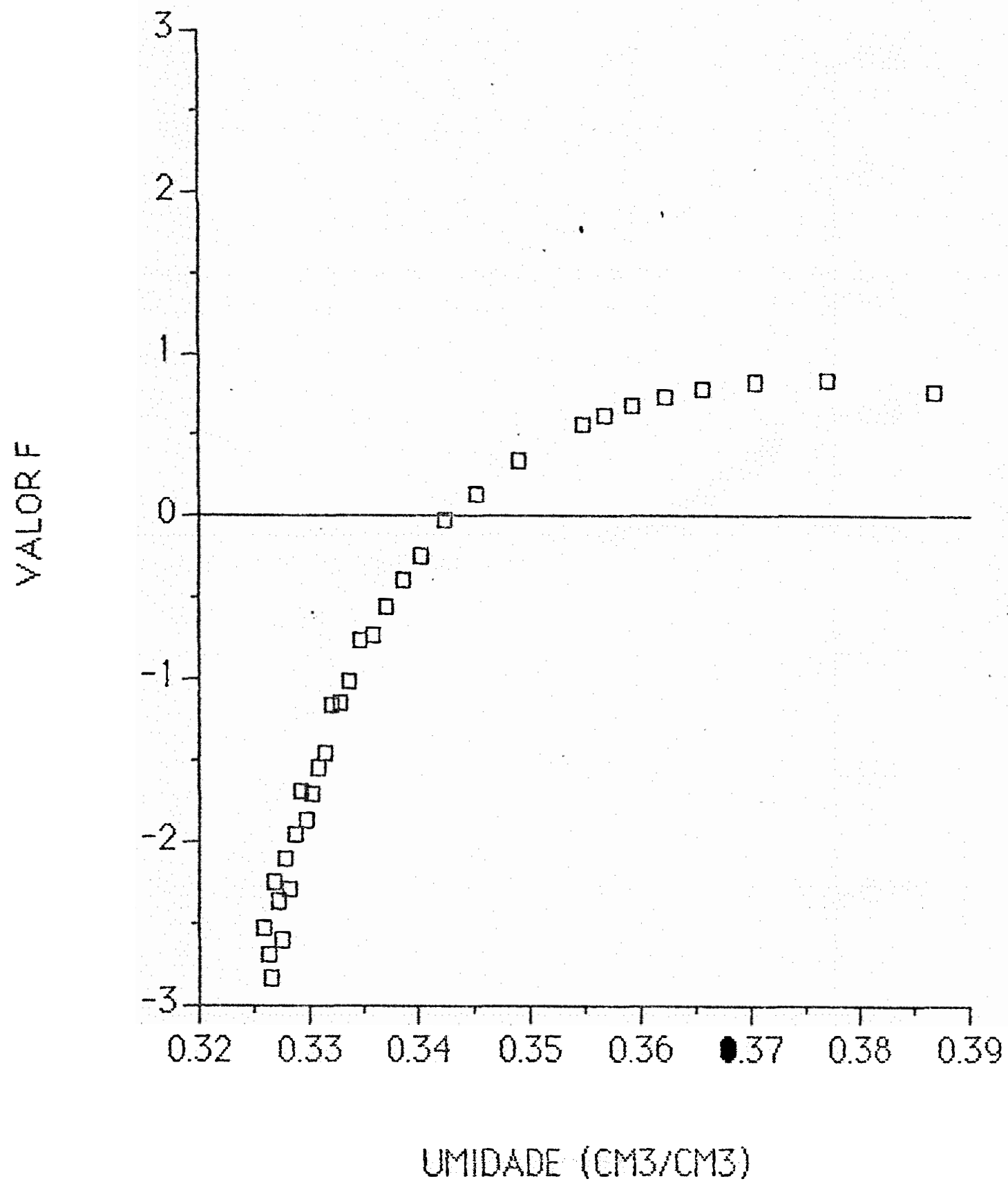

FIGURA 68 - Valor F (Equação 41) em função da umidade para a camada $113-173 \mathrm{~cm}$ do solo Terra Roxa Estruturada. 


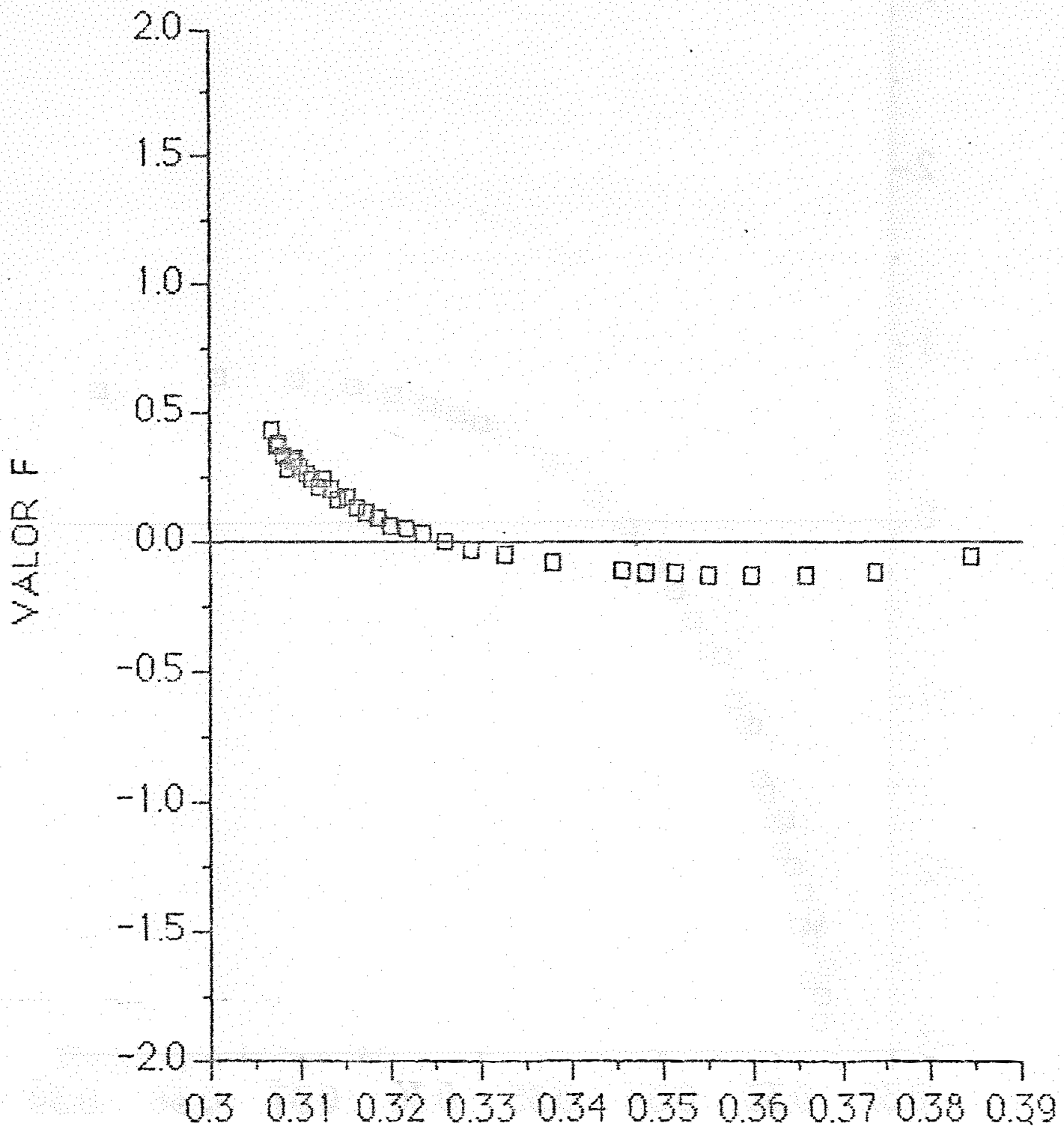

UMDADE (CMB/CMB)

FIGURA 69 - Valor $F$ (Equação 41) em função da umi dade para a camada $173-233 \mathrm{~cm}$ do solo Terra Roxa Estruturada. 


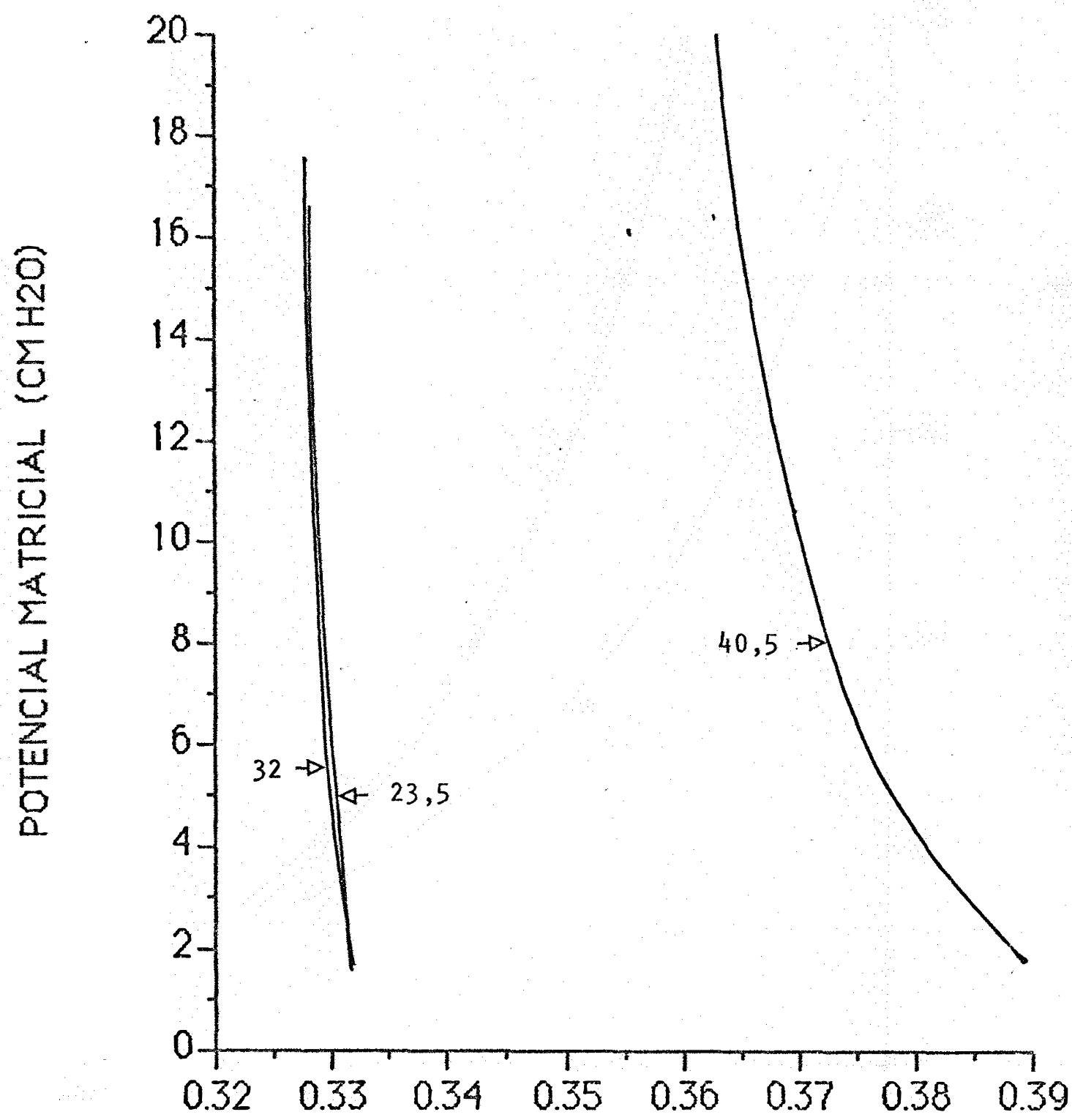

UMIDADE (CM3/CM3)

FIGURA 70 - Familia de curvas características da camada $15-49 \mathrm{~cm}$ do solo Terra Roxa Estruturada. Os nümeros das curvas re ferem-se às suas respectivas profundidades. 


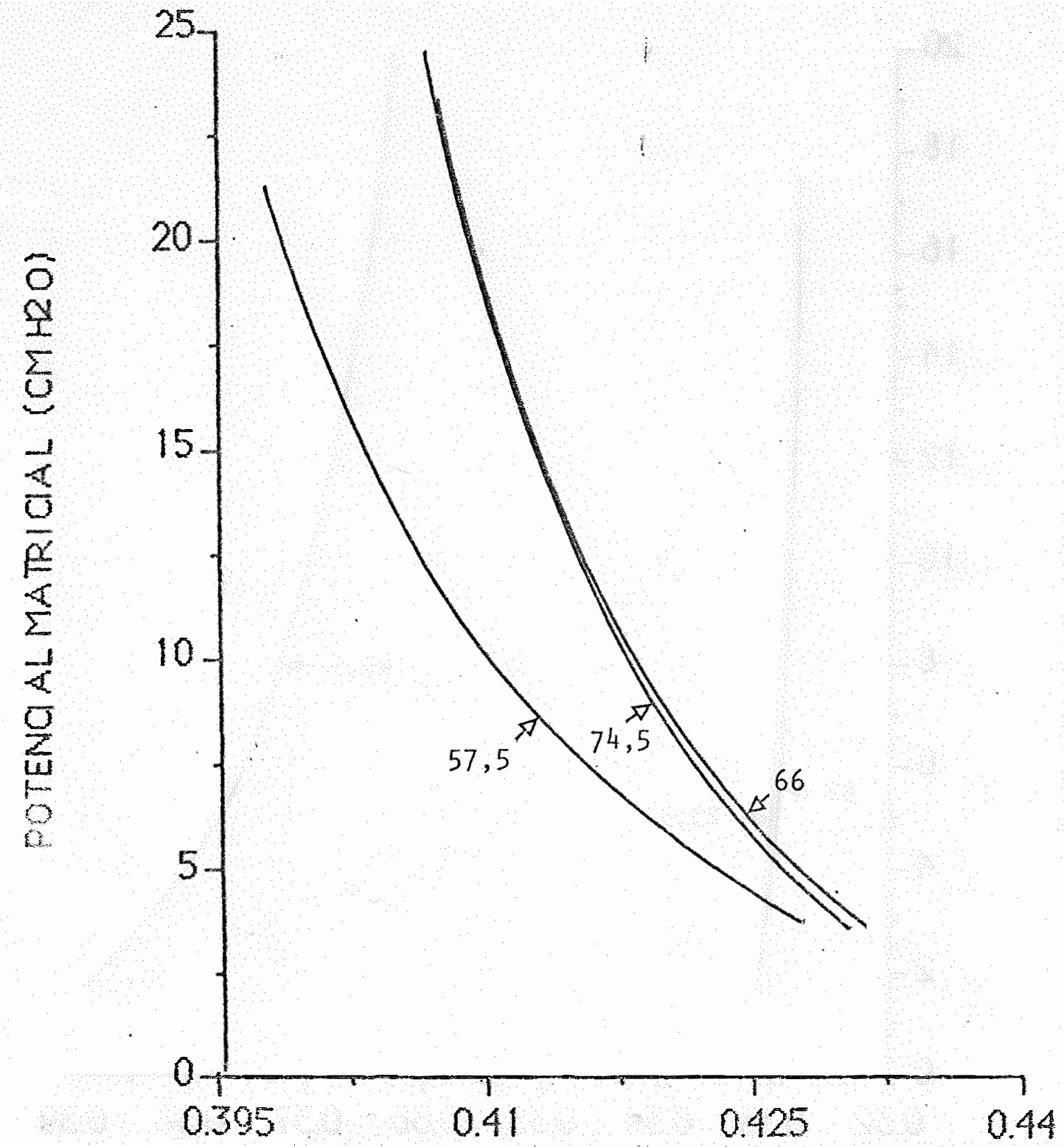

UMIDADE (CMB/CMB)

FIGURA 71 - Familia de curvas características da camada $49-83 \mathrm{~cm}$ do solo Terra Roxa Estruturada. Os nümeros das curvas re ferem-se às suas respectivas profundidades. 


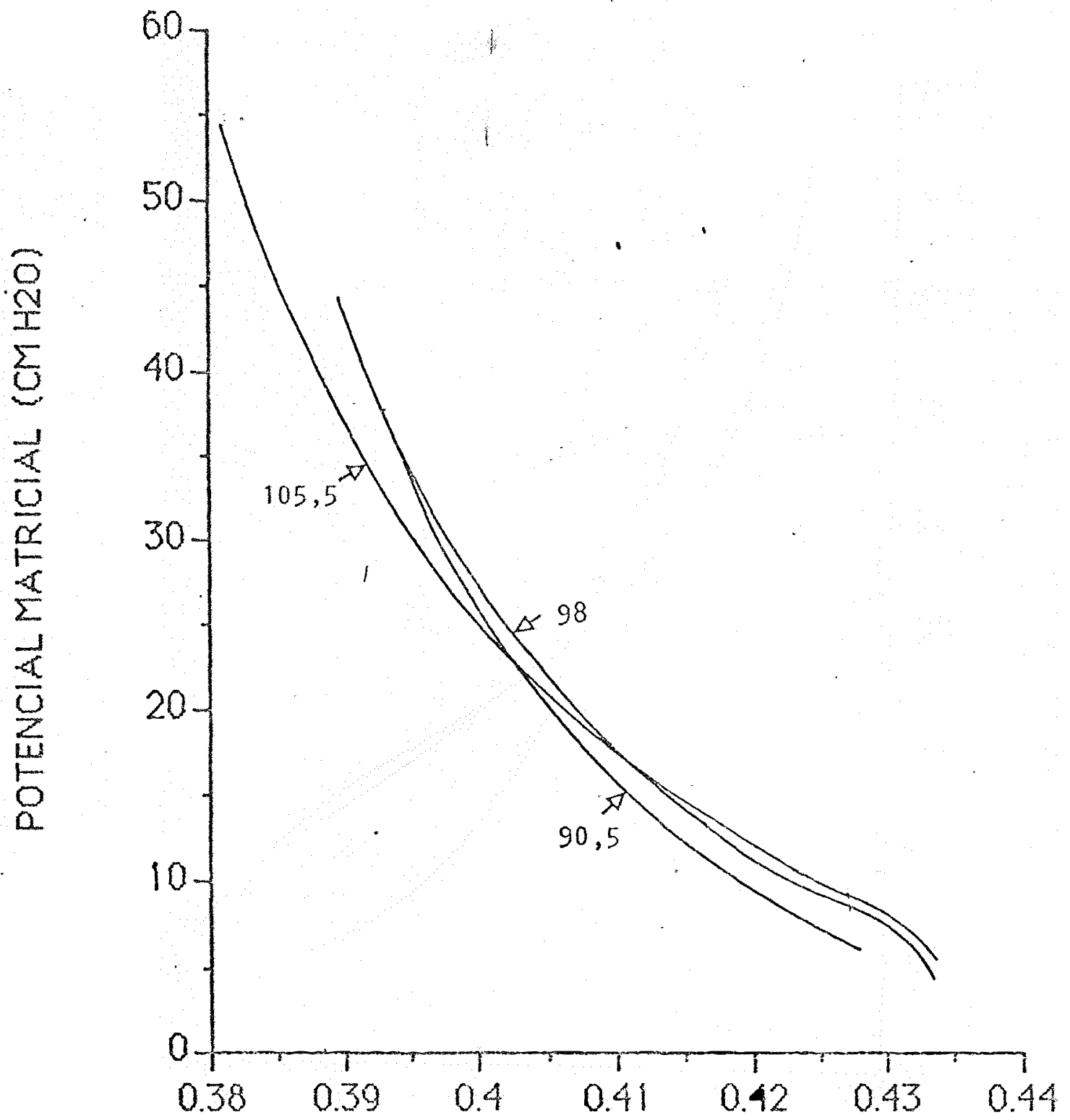

UMIDADE $(C M B, C M 3)$

FIGURA 72. - Familia de curvas características da camada 83-113 cm do solo Terra Roxa Estruturada. Os nümeros das curvas, re ferem-se às suas respectivas profundidades. 


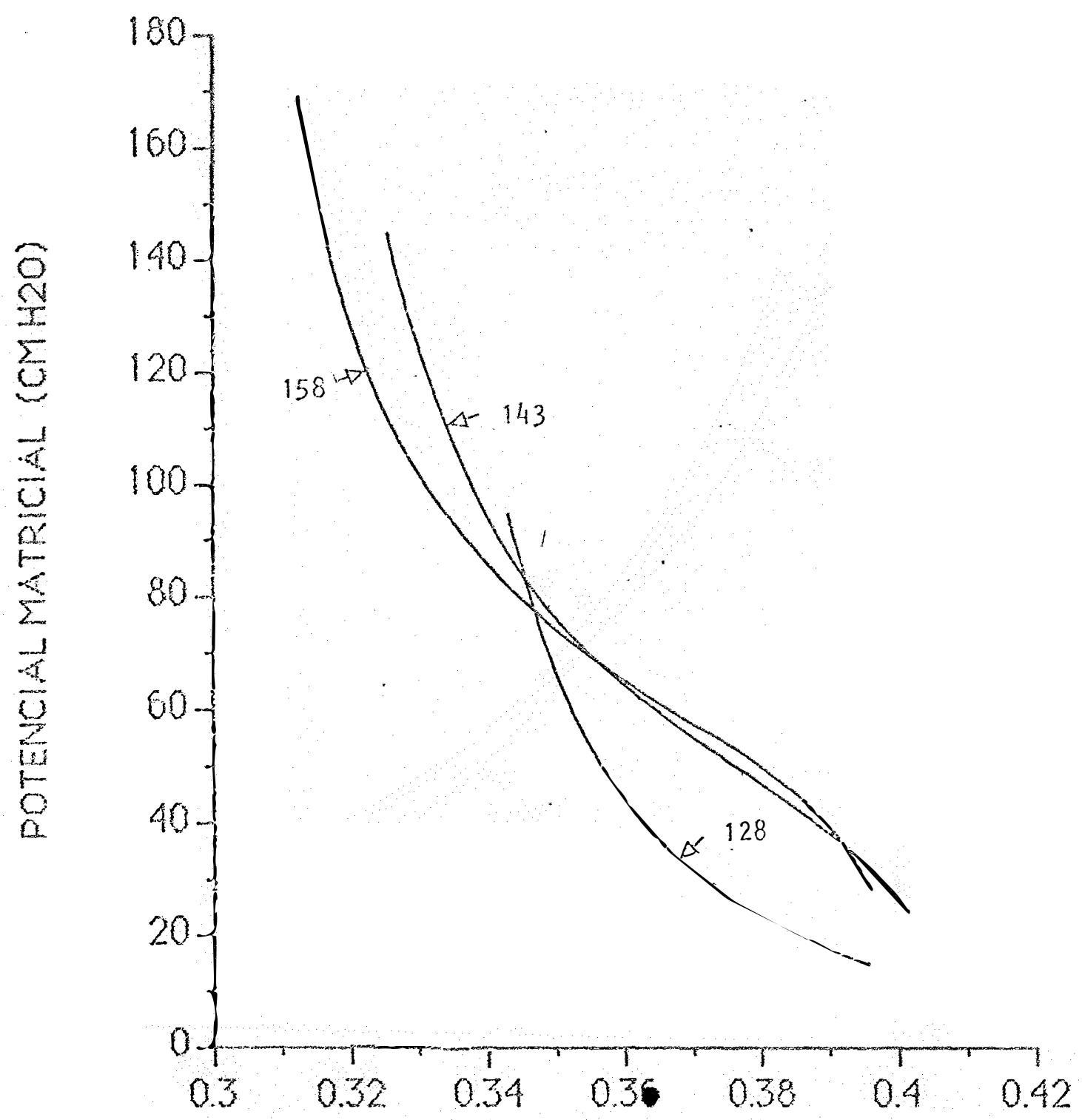

UMDADE $(\mathrm{CMB} / \mathrm{CMB})$

FIgura 73 - Familia de curvas características da camada $113-173 \mathrm{~cm}$ do solo Terra Røa Estruturada. Os números das curvas, refe rem-se às suas respectivas profundidades. 


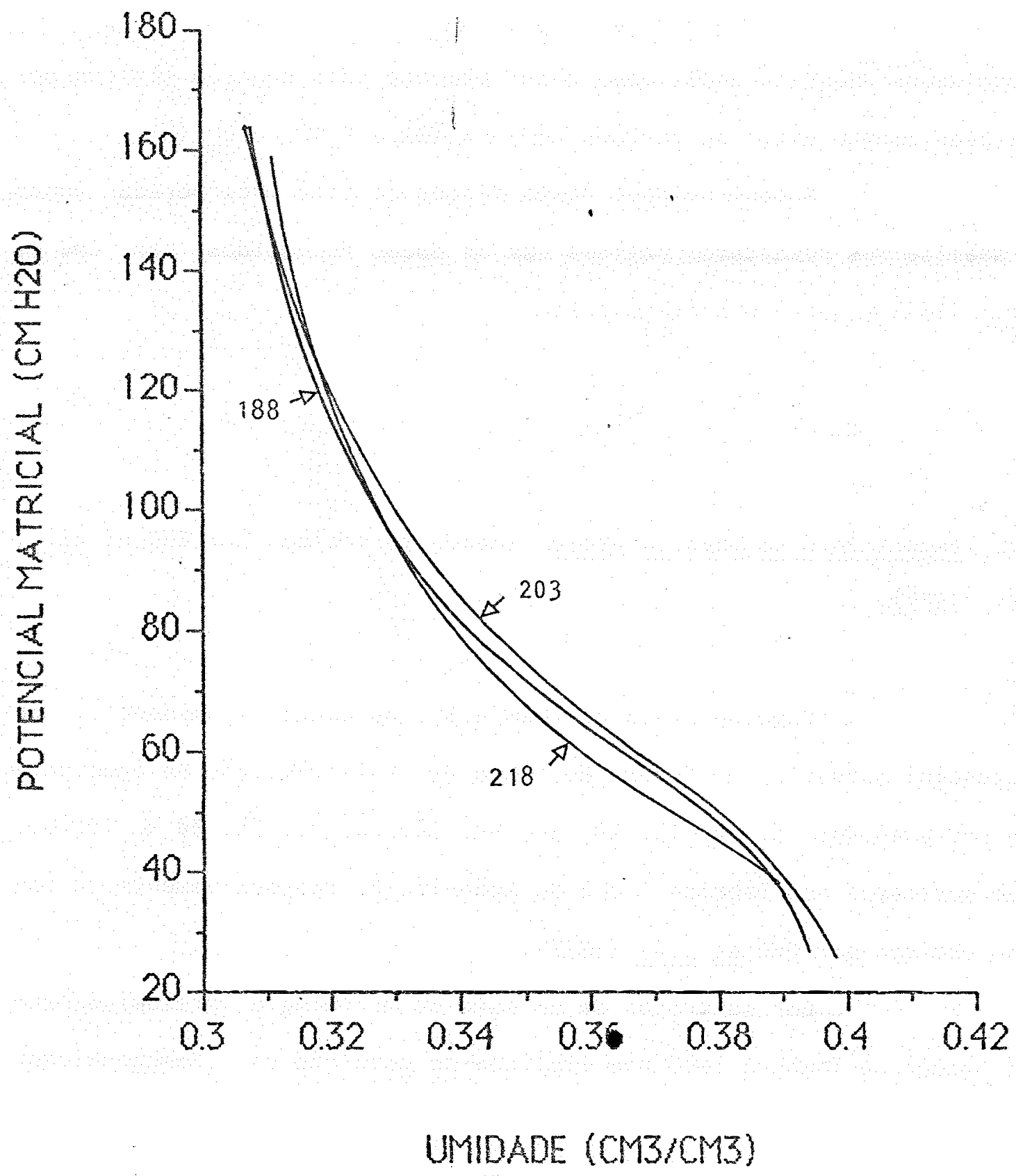

FIGURA 74 - Familia de curvas características da camada 173-233 cm do solo Terra Roxa Estruturäda. Os nümeros das curvas, refe rem-se às suas respectivas profundidades. 
conclusões daquelas analisadas anteriormente pela equação (41), ou pelo afastamento entre as funções $K(\theta)$ e $K_{H}(\theta)$, e $D_{m}(\theta)$ e $D_{m H}(\theta)$.

A continuidade desta discussão está incorporada junto à análise dos resultados obtidos com os dados fornecidos por CHO et alii (1977), que è o próximo passo.

\subsection{Experimento em duna de areia. (dados fornecidos por CHO et alii,} 1977)

Como descrito no item 4.3., os dados de umidade e de potencial matricial em função do tempo de redistribuição da água para as profundidades $5,10,15,20,30,40,50,60,70,80,90$ e $100 \mathrm{~cm}$, são mostrados nas Tabelas 1 e 2 do Apêndice $B$, respectivamente, e foram obtidos por CHO et alii (1977).

Por se tratar de um solo de morfologia presumivelmente homogênea (embora isso não implique na condição de homogeneidade hidrāulica, como discutido anteriormente), o método proposto no item 3.3. foi aplicado para as profundidades de $10,15,20,30,40,50,60$, 70,80 e $90 \mathrm{~cm}$. Para isso, foram consideradas hipoteticamente, as seguintes camadas hidraulicamente homogêneas: 5-15, 10-20, 15-30, $20-$ $40, \quad 30-50, \quad 40-60, \quad 50-70, \quad 60-80, \quad 70-90$ e $80-100 \mathrm{~cm}$.

Uma vez que o número de dados nas Tabelas 1 e 2 do Apêndice $B$ é suficientemente grande, não foram feitos os ajustes dos perfis de umidade e de potencial matricial em função do tempo. Dessa forma, todos os cálculos que se apresentam a seguir, foram obtidos a partir dessas duas tabelas. 
Assim, primeiramente, foram obtidos os perfis de umidade e de potencial matricial, ambos em função da profundidade e para Cäda tempo de redistribuição da ägua, trậs ladados em linguagem BASIC pela função "Spline" cübica (Apêndice A).

As Figuras 75 e 76 mostram, respectivamente, e como exemplo, os perfis de umidade e de potencial matricial para os tempos de 1 minuto e 168 apōs o término da infiltração da ägua na parcela.

Também aqui foi construído um perfil para cada tempo de ambas as tabelas, e as tangentes $\partial \Theta / \partial z$ e $\partial \psi_{m} / \partial z$, para cada profundidade, foram determinadas de seus respectivos perfis, através da função "Spline" cübica. A armazenagem de ägua em cada tempo, e nos limites de profundidade de interesse, foi obtida obedecendo à equação (40), a partir dos perfis de umidade, os quais foram integrados pela função "Spline" cúbica. Na Figura 75, até a profundidade de $100 \mathrm{~cm}$, os $31,1 \mathrm{~cm}$ de ägua inicialmente armazenados no primeiro minuto, diminuiu para $7,7 \mathrm{~cm}$ após 168 horas de drenagem e redistribuição. Essa variação, comparativamente ao mesmo período e profundidade no solo Terra Roxa Estruturada; è cerca de 11 vezes maior.

A determinação das funções $D_{g}(\Theta), K(\Theta), D_{m}(\theta), D_{z}(\Theta)$, $K_{H}(\Theta)$ e $D_{m H}(\Theta)$ também seguiu o procedimento apresentado no item 4.2.7., e todos os parämetros envolvidos encontram-se nas Tabelas 10 e 11 . Nota-se que aqui a coerência dos sinais das tangentes $\partial \Theta / \partial z$, é mantida na ampla variação de umidade, em praticamente todas as profundidades.

A terceira coluna da Tabela 10 e a quinta da Tabela 11 foram calculadas do mesmo modo daquelas para o solo Terra Roxa Estruturada, respectivamente.

A partir dos valores de $K(\Theta)$ e $K_{H}(\Theta)$ da Tabela 10, e dos valores de $D_{g}(\Theta), D_{z}(\Theta), D_{m}(\Theta)$ e $D_{m H}(\Theta)$ da mesma tabẹla, foram 
construidas as Figuras 77 a 86 e 87 a 96, respectivamente, para cada uma das profundidades, onde se nota que as funções $K(\theta)$ e $K_{H}(\theta)$, e $D_{m}(\theta)$ e $D_{m H}(\theta)$, de modo geral, se ajustam muito bem entre si, o que reforça a validade da teoria formulada nos itens 3.2 e 3.3 .

Como pode ser visto nessas figuras, os valores de condutividade hidrāulica, de modo geral, configuram pequenas inclinações com as umidades próximas da saturação, mas que aumenta rapidamente quando a umidade decresce. As funções difusividades, por outro lado, exibem inclinações muito grandes nos extremos de umidade, e somente para valores intermediārios é que elas assumem dependência exponencial com o conteūdo de àgua, resultando uma forma de "S" alongado, tal como nas respectivas curvas características que serão mostradas posteriormente.

A coerência do comportamento de natureza física das funções $D_{z}(\Theta)$ também pode ser observada com relação às funções $D_{m}(\theta)$, tendo em vista que aquelas se apresentam superiores a esta, em todas as profundidades, jā que a matriz desse solo è fundamentalmente constituida de areia ( $\cong 97 \%)$.

Os valores experimentais das funções difusividades carecem de ajustes, porquanto que seus cálculos foram realizados a partir dos dados originais de CHO et alii (1977), sem ajustes prévios.

De acordo com as Figuras 77 a 96 , as diferenças entre as funções $K(\theta)$ e $K_{H}(\theta)$, e $D_{m}(\theta)$ e $D_{m H}(\theta)$, somente ocorrem de modo apreciável para as profundidades de 15 e $20 \mathrm{~cm}$, mesmo assim para umidades acima de $0,18 \mathrm{~cm}^{3} / \mathrm{cm}^{3}$, em ambos os casos. Algumas pequenas diferenças tambēm entre esses valores são notadas nas demais profundidades, porém, numa faixa bem mais estreita de umidade, próxima da saturação. Isso mostra, com maior destaque para as profundidades de 15 
e $20 \mathrm{~cm}$, que atë mesmo os solos que exibem notoriamente uma morfologia homogênea, podem não o serem hidraulicamente, de acordo com o rigor conceitual imposto pela equação (18). Conçlusão semelhante a esta fol obtida para o solo Terra Roxa Estruturada quando se disse que - critërio morfolögico nem sempre conduz a resultados satisfatörios.

Para realçar ainda mais este fato, e pela importância que ele representa na aplicação da teoria proposta, foram calculados os valores de $F$ da equação (41) em função da umidade, para todas as camadas consideradas, a partir da Tabela 11. Esses valores se encontram graficados nas Figuras 97 a 106. Observa-se que realmente quando a umidade se aproxima da saturação, os valores de $F$ aumentam ná maioria das profundidades, particularmente a 15 e $20 \mathrm{~cm}$, o que coincide com as observações feitas anteriormente. Alëm disso, como as umidades nessas figuras são comuns para todas as prorundidades, tornando possivel as comparações entre elas, pode-se garantir que de todas as camadas assumidas nesse solo, a que mais se aproxima do conceito de homogeneidade hidräulica é a de $60-80 \mathrm{~cm}$, representada pela profundidade de $70 \mathrm{~cm}$, cujos valores de $F$ se áistribuem muito próximos de zero, na ampla variação de umidade (Figura 104). De fato, com base nos valores de $K(\Theta)$ e $K_{H}(\Theta)$ da Tabela 11 para $z=70 \mathrm{~cm}$, o erro que se cometeria atravēs da função $D_{g}(\Theta)$ na quantificação do fluxo pela teoria proposta, não seria maior do que 1,25 vezes aquele que se obteria com o mëtodo de HILLEL et alii (1972). Inversamente, para a profundidade de $15 \mathrm{~cm}$ e para valores de umidade pröximos à saturaçäo, esse erro poderia chegar a aproximadamente 30 vezes. Portanto, fica claro que a teoria proposta neste trabalho somente pode ser aplicada em meios porosos reconhecidamente homogêneos do ponto de vista hidräulico, e que seus resultados, tal como ficou demonstrado especial- 
mente nesse solo, serão tanto mais confiáveis quanto mais o meio se aproximar da condição padrão de homogeneidade hidráulica, uma vez que é para essa condição que a teoria foi desenvolvida.

As Figuras 107 a 116 mostram as familias decurvas características das camadas consideradas, obtidas a partir das Tabelas 1 e 2 do Apêndice B. Tal como ocorreu para o solo Terra Roxa Estruturada, esse critērio também aqui permite inferir razoavelmente bem as mesmas conclusões daquelas analisadas anteriormente, o que garante a sua indicação frente ao critério morfológico, como uma forma prätica, porém menos precisa do que a função $F(\theta)$ no reconhecimento de camadas hidraulicamente homogêneas. Para mostrar a menor precisão desse critério, comparativamente à equação (41), basta que se tomem como exemplo as Figuras 109 e 110. A família de curvas representada na Figura 109 para a camada $15-30 \mathrm{~cm}$, leva a crer que esta camada seja hidraulicamente mais homogênea do que a camada $20-40 \mathrm{~cm}$ da Figura 110 . No entanto, os valores das funções $F(\theta)$ nas Figuras 99 e 100 , respectivamente, bem como os valores dás funções $K(\theta), K_{H}(\theta)$, e $D(\theta)$ e $D_{m H}(\theta)$, mostram o contrário. Isso se deve, como comentado anteriormente, ao fato de que as curvas características são independentes do tempo, e, por isso, devem ser utilizados certos cuidados nesse propósito.

\subsection{Roteiro para determinação da função $D_{g}(\Theta)$}

Com base no que foi discutido nos itens 5.1. e 5.2., o seguinte roteiro para o estabelecimento da função $D_{g}(\theta)$, é sugerido para propósi tos präticos: 
(i) identificar as camadas de solo hidraulicamente homogêneas, ou proximamente homogêneas, através das curvas características obtidas para, no minimo, duas profundidades diferentes dentro de cada camada previamente estabelecida e de interesse. Lembrar que a função $D_{g}(\Theta)$ serä tanto mais confiävel quanto mais pröximas as curvas se apresentarem, por camada;

(ii) delimitar uma ärea de $5 \times 5 \mathrm{~m}$, livie de vegetação e bem nivelada;

( $i$ i i inundar com ägua atẻ atingir a condiçăo de regime de fluxo permanente;

(iv) parara aplicação de ägua, cobrir a superficie do solo com uma lona plástica e, logo a seguir, medir a umidade do solo desdea superfície até a ūltima profundidade de interesse, procedendo três leituras equidistantemente espaçadas em cada camada hidraulicamente homog̣ênea;

(v) continuar com as medidas de umidade, desse modo, durante aproximadamente 20 dias;

(vi) obter os perfis de umidade em função do tempo de redistribuição da ägua, mediante ajuste;

(vi i) montar uma tabéla (como a Tabela 6) reunindo os valores de umidade para as diversas profundidades, nos diversos tempos de redistribuição da àgua no solo;

(vi i calcular as armazenagens de ägua, os gradientes de umidade e os fluxos de āgua para as profundidades intermediārias de cada camadá, com auxîlio da função "Spline" cúbica, através do programa apresentado no Apêndice $A$; 
(ix) montar duas tabelas (tais como a Tabela 8 e as três primeiras colunas da Tabela 9), reunindo na primeira os valores de armazena gens e fluxos de água obtidos nas diversas profundidades e para cada tempo de redistribuição, e na segunda, os valores dos fluxos de água comuns a cada profundidade nos diversos tempos, com os respectivos gradientes de umidade;

-(x) dividir os fluxos da segunda tabela pelos gradiente de umidade respectivos, para obter os valores de $D_{g}$ em cada camada, conservando os sinais;

(xi) graficar os valores de $\left|D_{g}\right|$ em função da umidade obtida na profundidade intermediária de cada camada, e anotar a faixa de umidade para a qual os valores de $D_{g}$ foram positivos ou negativos, se isso ocorrer. Lembrar que, se for de interesse, a função "Spline" cúbica (Apêndice A) pode ser utilizada para interpolaçãó dos dados. 


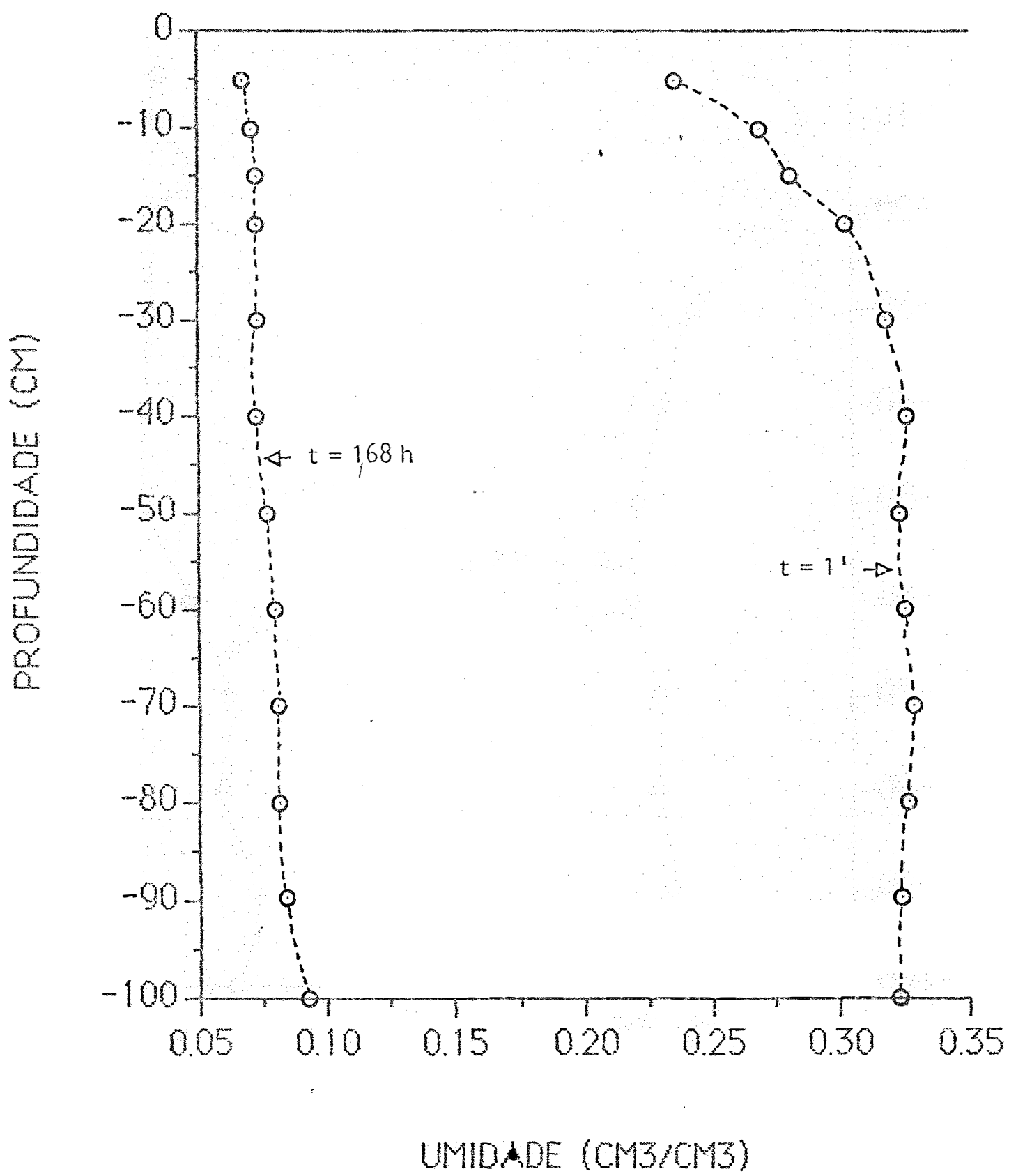

FIGURA 75 - Perfis de umidade em função da profundidade para os tempos de 1 minuto e $168 \mathrm{~h}$ de redistribuição da ägua no solo Duna de Areia. 


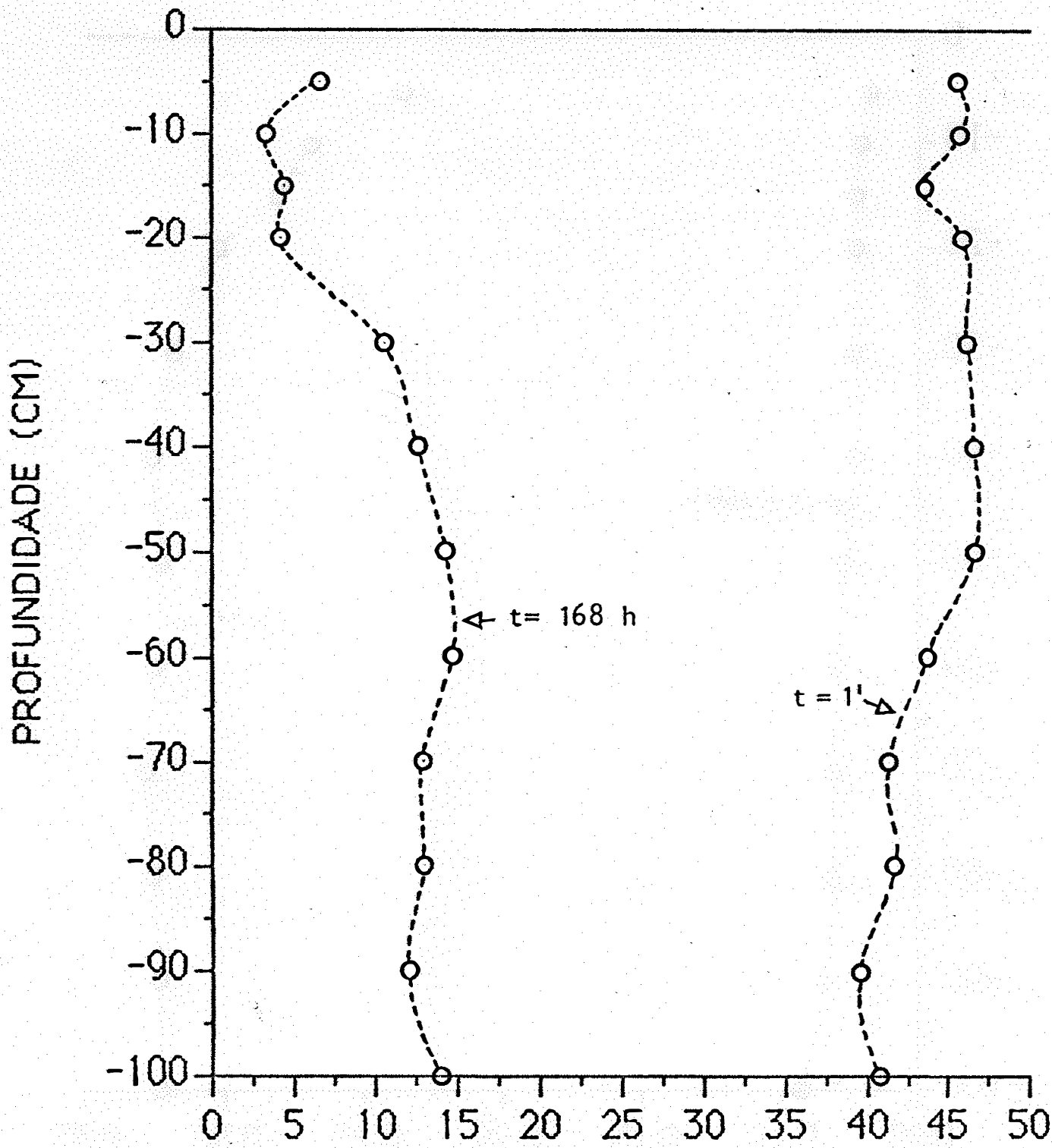

POTENCIAL MATRICIAL (CMH2O)

FIGURA 76 - Perfis de potencial matricial em função da profundidade para os tempos de 1 minuto e 168 h de redistribuição da água no solo Duna de Areia. 
TABELA 10 - Cálculo dos fluxos de àgua no solo, nas diversas profundidades ( $z$ ) e diversos tempos de redistribuição $(t)$, para - solo Duna de Areia.

\begin{tabular}{|c|c|c|c|}
\hline (hora) & $\begin{array}{c}z \\
(\mathrm{~cm})\end{array}$ & $\begin{array}{c}A z(t) \\
(\mathrm{cm})\end{array}$ & $\begin{array}{l}-(q) / 10^{2} \\
(\mathrm{~cm} / \text { hora })\end{array}$ \\
\hline 0,0333 & $\begin{array}{l}10 \\
15 \\
20 \\
30 \\
40 \\
50 \\
60 \\
70 \\
80 \\
90\end{array}$ & $\begin{array}{l}2,2 \\
3,43 \\
4,75 \\
7,73 \\
10,9 \\
14,13 \\
17,35 \\
20,62 \\
23,88 \\
27,12\end{array}$ & $\begin{array}{l}1206,37 \\
1961,85 \\
2564,41 \\
3280,89 \\
3703,87 \\
3852,07 \\
3855,01 \\
3853,51 \\
3853,81 \\
3853,51\end{array}$ \\
\hline 0,05 & $\begin{array}{l}10 \\
15 \\
20 \\
30 \\
40 \\
50 \\
60 \\
70 \\
80 \\
90\end{array}$ & $\begin{array}{l}2,05 \\
3,17 \\
4,43 \\
7,31 \\
10,39 \\
13,58 \\
16,8 \\
20,07 \\
23,33 \\
26,57\end{array}$ & $\begin{array}{l}754,79 \\
1213,17 \\
1597,6 \\
2269,16 \\
2898,8 \\
3164,67 \\
3190,12 \\
3218,86 \\
3248,5 \\
3279,94\end{array}$ \\
\hline 0,0667 & $\begin{array}{l}10 \\
15 \\
20 \\
30 \\
40 \\
50 \\
60 \\
70 \\
80 \\
90\end{array}$ & $\begin{array}{l}1,95 \\
3,01 \\
4,21 \\
6,97 \\
9,93 \\
13,07 \\
16,29 \\
19,54 \\
22,8 \\
26,03\end{array}$ & $\begin{array}{l}538,58 \\
839,2 \\
1154,34 \\
1907,39 \\
2634,2 \\
2976,45 \\
3045,4 \\
3102,75 \\
3164,02 \\
3208,35\end{array}$ \\
\hline
\end{tabular}

(continua) 
TABELA 10 - Cálculo dos fluxos de água no solo, nas diversas profundidades $(z)$ e diversos tempos de redistribuição $(t)$, para - solo Duna de Areia.

\begin{tabular}{|c|c|c|c|}
\hline (hora) & $\begin{array}{l}2 \\
(\mathrm{~cm})\end{array}$ & $\begin{array}{r}A z(t) \\
(\mathrm{cm})\end{array}$ & $\begin{array}{l}-(q)_{z} \cdot 10^{2} \\
(\mathrm{~cm} / \text { hora })\end{array}$ \\
\hline 0,0833 & $\begin{array}{l}10 \\
15 \\
20 \\
30 \\
40 \\
50 \\
60 \\
70 \\
80 \\
90\end{array}$ & $\begin{array}{l}1,87 \\
2,89 \\
4,05 \\
6,68 \\
9,51 \\
12,59 \\
15,79 \\
19,03 \\
22,28 \\
25,5\end{array}$ & $\begin{array}{l}417,1 \\
648,24 \\
920 \\
1675,05 \\
2422,5 \\
2902,73 \\
3094,67 \\
3153,26 \\
3215 \\
3246,91\end{array}$ \\
\hline 0,1167 & $\begin{array}{l}10 \\
15 \\
20 \\
30 \\
40 \\
50 \\
60 \\
70 \\
80 \\
90\end{array}$ & $\begin{array}{c}1,76 \\
2,72 \\
3,8 \\
6,19 \\
8,78 \\
11,62 \\
14,7 \\
17,92 \\
21,15 \\
24,35\end{array}$ & $\begin{array}{r}286,02 \\
453,39 \\
671,54 \\
1281,42 \\
1965,22 \\
2653,77 \\
3185,16 \\
3439,01 \\
3576,31 \\
3660,69\end{array}$ \\
\hline 0,1667 & $\begin{array}{l}10 \\
15 \\
20 \\
30 \\
40 \\
50 \\
60 \\
70 \\
80 \\
90\end{array}$ & $\begin{array}{r}1,64 \\
2,54 \\
3,52 \\
5,68 \\
7,97 \\
10,47 \\
13,17 \\
16,13 \\
19,22 \\
22,36\end{array}$ & $\begin{array}{r}192,26 \\
305,28 \\
465,84 \\
876,03 \\
1357,59 \\
1944,68 \\
2609,05 \\
3199,74 \\
3620,62 \\
3859,88\end{array}$ \\
\hline
\end{tabular}

(continua) 
TABELA 10 - Cálculo dos fluxos de ägua no solo, nas diversas profundidades (z) e diversos tempos de redistribuição (t), para o solo Duna de Areia.

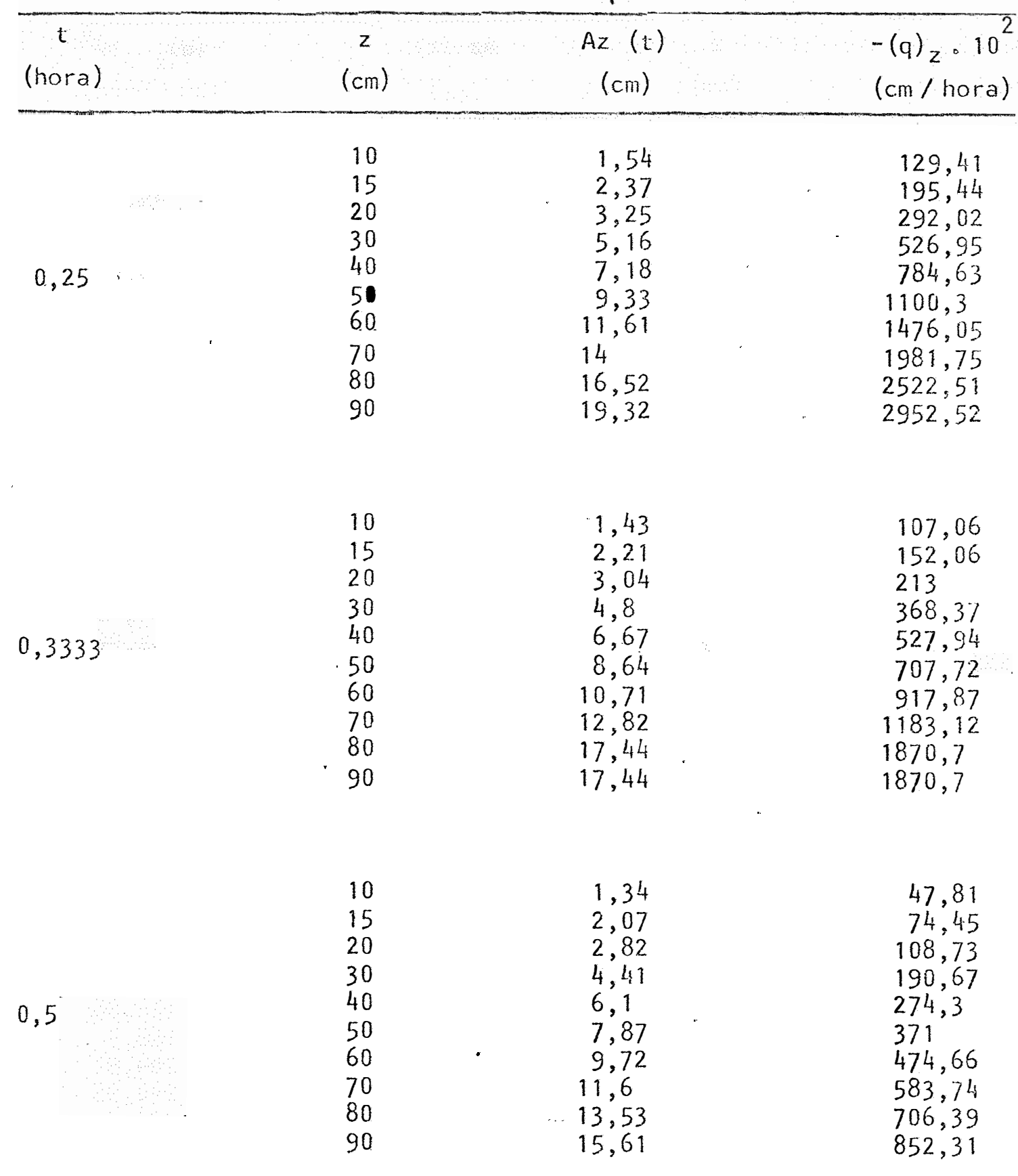

(continua) 
TABELA 10 - Cálculo dos fluxos de ägua no solo, nas diversas profundidades $(z)$ e diversos tempos de redistribuição $(t)$, para o solo Duna de Areia.

\begin{tabular}{|c|c|c|c|}
\hline (hora) & (cm) & $\begin{array}{c}A z(t) \\
(\mathrm{cm})\end{array}$ & $\begin{array}{l}-(\mathrm{g}) \text { z } 10^{2} \\
(\mathrm{~cm} / \text { hora })\end{array}$ \\
\hline 0,6667 & $\begin{array}{l}10 \\
15 \\
20 \\
30 \\
40 \\
50 \\
60 \\
70 \\
80 \\
90\end{array}$ & $\begin{array}{l}1,27 \\
1,97 \\
2,67 \\
4,16 \\
5,75 \\
7,4 \\
9,13 \\
10,88 \\
12,67 \\
14,6\end{array}$ & $\begin{array}{l}30,93 \\
49,62 \\
70,74 \\
119,82 \\
170,61 \\
229,46 \\
294,29 \\
361,97 \\
430,49 \\
506,6\end{array}$ \\
\hline 0,8333 & $\begin{array}{l}10 \\
15 \\
20 \\
30 \\
40 \\
50 \\
60 \\
70 \\
80 \\
90\end{array}$ & $\begin{array}{l}1,23 \\
1,9 \\
2,58 \\
4,01 \\
5,53 \\
7,1 \\
8,74 \\
10,4 \\
12,09 \\
13,92\end{array}$ & $\begin{array}{c}41,36 \\
54,3 \\
69,39 \\
104,46 \\
142,06 \\
182,51 \\
227,78 \\
275,92 \\
324,88 \\
383,75\end{array}$ \\
\hline 1 & $\begin{array}{l}10 \\
15 \\
20 \\
30 \\
40 \\
50 \\
60 \\
70 \\
80 \\
90\end{array}$ & $\begin{array}{r}1,13 \\
1,78 \\
2,44 \\
3,82 \\
5,28 \\
6,6 \\
8,37 \\
9,96 \\
11,58 \\
13,32\end{array}$ & $\begin{array}{l}52,97 \\
63,17 \\
75,86 \\
104,06 \\
134,88 \\
168,3 \\
204,91 \\
240,95 \\
279,5 \\
330,05\end{array}$ \\
\hline
\end{tabular}

(continua) 
TABELA 10 - Cälculo dos fluxos de água no solo, nas diversas profundidades $(z)$ e diversos tempos de redistribuição $(t)$, para o solo Duna de Areia.

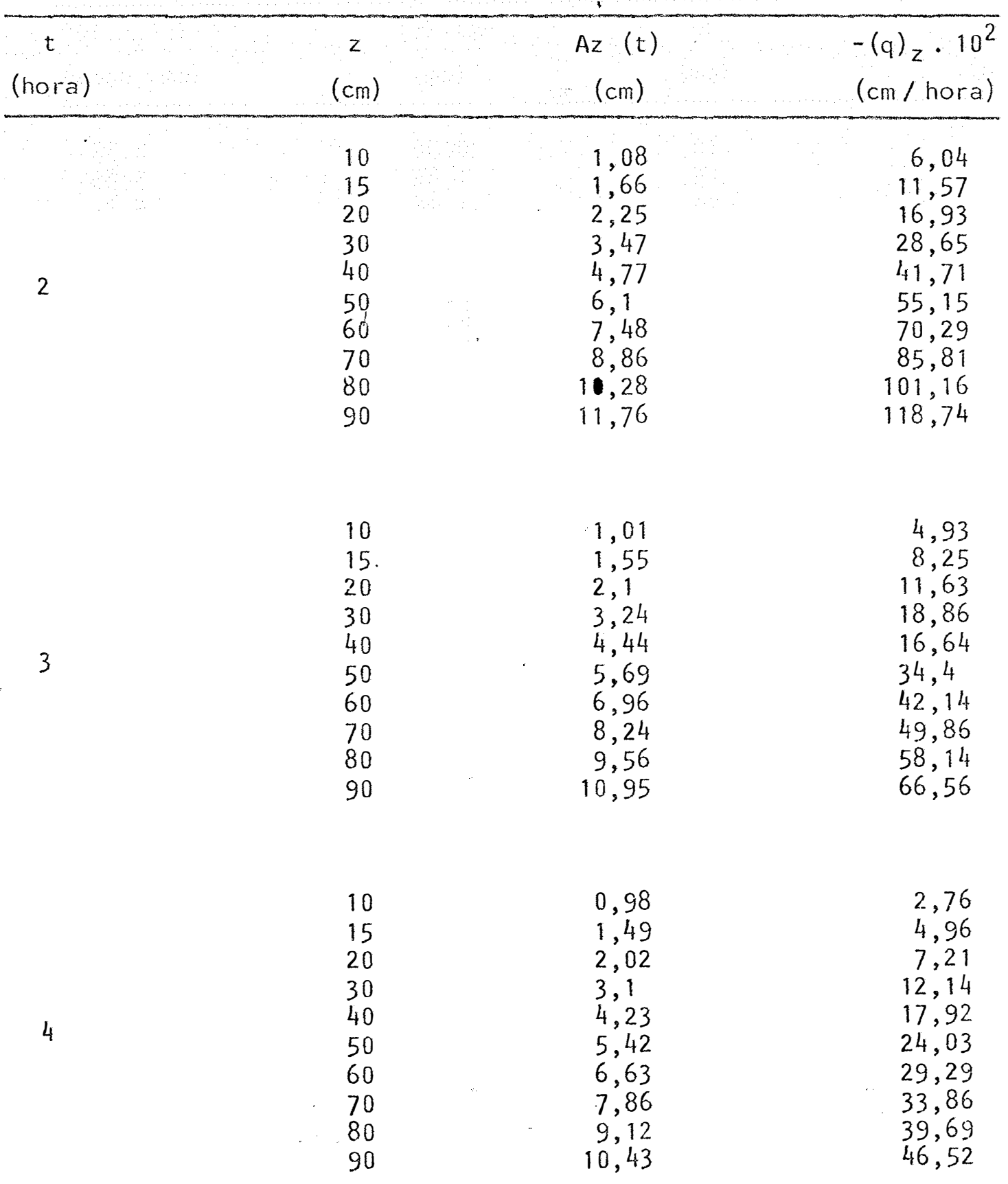

(continua) 
TABELA 10 - Cálculo dos fluxos de ägua no solo, nas diversas profundidades $(z)$ e diversos tempos de redistribuição $(t)$, para o solo Duna de Areia.

\begin{tabular}{|c|c|c|c|}
\hline $\begin{array}{c}t \\
\text { (hora) }\end{array}$ & $(\mathrm{cm})$ & $\begin{array}{c}A z \quad(t) \\
\quad(\mathrm{cm})\end{array}$ & $\begin{array}{l}-(q)_{z} \cdot 10^{2} \\
(\mathrm{~cm} / \text { hora })\end{array}$ \\
\hline 5 & $\begin{array}{l}10 \\
15 \\
20 \\
30 \\
40 \\
50 \\
60 \\
70 \\
80 \\
90\end{array}$ & $\begin{array}{c}0,96 \\
1,45 \\
1,96 \\
3 \\
4,09 \\
5,21 \\
6,38 \\
7,56 \\
8,77 \\
10,03\end{array}$ & $\begin{array}{c}2,32 \\
3,85 \\
5,2 \\
8,94 \\
13,76 \\
18,53 \\
23,28 \\
27,76 \\
32,26 \\
36,7\end{array}$ \\
\hline 6 & $\begin{array}{l}10 \\
15 \\
20 \\
30 \\
40 \\
50 \\
60 \\
70 \\
80 \\
90\end{array}$ & $\begin{array}{l}0,93 \\
1,42 \\
1,91 \\
2,92 \\
3,96 \\
5,05 \\
6,17 \\
7,31 \\
8,47 \\
9,7\end{array}$ & $\begin{array}{r}2,21 \\
3,39 \\
4,32 \\
7,58 \\
11,78 \\
15,46 \\
19,7 \\
23,88 \\
27,55 \\
-\quad 31,25\end{array}$ \\
\hline 12 & $\begin{array}{l}10 \\
15 \\
20 \\
30 \\
40 \\
50 \\
60 \\
70 \\
80 \\
90\end{array}$ & $\begin{array}{l}0,85 \\
1,29 \\
1,75 \\
2,66 \\
3,6 \\
4,55 \\
5,53 \\
6,54 \\
7,59 \\
8,69\end{array}$ & $\begin{array}{c}1,01 \\
1,59 \\
2,13 \\
3,25 \\
4,55 \\
6,06 \\
7,65 \\
9,24 \\
10,73 \\
12,26\end{array}$ \\
\hline
\end{tabular}

(continua) 
TABELA 10 - Cälculo dos fluxos de ägua no solo, nas diversas profundidades $(z)$ e diversos tempos de redistribuição $(t)$, para o solo Duna de Areia.

\begin{tabular}{|c|c|c|c|}
\hline $\begin{array}{c}t \\
\text { (hora) }\end{array}$ & $\begin{array}{c}z \\
(\mathrm{~cm})\end{array}$ & $\begin{array}{c}A z(t) \\
(\mathrm{cm})\end{array}$ & $\begin{array}{l}-(q)_{z} \cdot 10^{2} \\
(\mathrm{~cm} / \text { hora })\end{array}$ \\
\hline 18 & $\begin{array}{l}10 \\
15 \\
20 \\
30 \\
40 \\
50 \\
60 \\
70 \\
80 \\
90\end{array}$ & $\begin{array}{l}0,81 \\
1,23 \\
1,66 \\
2,53 \\
3,41 \\
4,32 \\
5,25 \\
6,2 \\
7,18 \\
8,23\end{array}$ & $\begin{array}{l}0,62 \\
0,97 \\
1,28 \\
1,9 \\
2,62 \\
3,33 \\
3,99 \\
4,79 \\
5,62 \\
6,45\end{array}$ \\
\hline 24 & $\begin{array}{l}10 \\
15 \\
20 \\
30 \\
40 \\
50 \\
60 \\
70 \\
80 \\
90\end{array}$ & $\begin{array}{l}0,78 \\
1,18 \\
1,59 \\
2,43 \\
3,28 \\
4,15 \\
5,05 \\
5,97 \\
6,91 \\
7,92\end{array}$ & $\begin{array}{l}0,49 \\
0,75 \\
0,97 \\
1,43 \\
1,96 \\
2,49 \\
2,93 \\
3,46 \\
4,06 \\
4,65\end{array}$ \\
\hline 48 & $\begin{array}{l}10 \\
15 \\
20 \\
30 \\
40 \\
50 \\
60 \\
70 \\
80 \\
90\end{array}$ & $\begin{array}{l}0,73 \\
1,1 \\
1,48 \\
2,25 \\
3,02 \\
3,82 \\
4,66 \\
5,51 \\
6,36 \\
7,31\end{array}$ & $\begin{array}{l}0,13 \\
0,2 \\
0,3 \\
0,5 \\
0,71 \\
0,91 \\
1,13 \\
1,3 \\
1,49 \\
1,76\end{array}$ \\
\hline
\end{tabular}

(continua) 
TABELA 10 - Cálculo dos fluxos de água no solo, nas diversas profundidades $(z)$ e diversos tempos de redistribuição $(t)$, para o solo Duna de Areia.

\begin{tabular}{|c|c|c|c|}
\hline $\begin{array}{c}t \\
\text { (hora) }\end{array}$ & $\begin{array}{l}z \\
(\mathrm{~cm})\end{array}$ & $\begin{array}{c}A z \quad(t) \\
(\mathrm{cm})\end{array}$ & $\begin{array}{l}-(\mathrm{q})_{z} \cdot 10^{2} \\
(\mathrm{~cm} / \mathrm{hora})\end{array}$ \\
\hline 72 & $\begin{array}{l}10 \\
15 \\
20 \\
30 \\
40 \\
50 \\
60 \\
70 \\
80 \\
90\end{array}$ & $\begin{array}{l}0,72 \\
1,08 \\
1,45 \\
2,19 \\
2,94 \\
3,71 \\
4,51 \\
5,35 \\
5,19 \\
7,07\end{array}$ & $\begin{array}{l}0,04 \\
0,06 \\
0,06 \\
0,16 \\
0,23 \\
0,33 \\
0,44 \\
0,49 \\
0,56 \\
0,7\end{array}$ \\
\hline 96 & $\begin{array}{l}10 \\
15 \\
20 \\
30 \\
40 \\
50 \\
60 \\
70 \\
80 \\
90\end{array}$ & $\begin{array}{l}0,71 \\
1,07 \\
1,43 \\
2,17 \\
2,91 \\
3,66 \\
4,45 \\
5,27 \\
6,11 \\
6,97\end{array}$ & $\begin{array}{l}0,04 \\
0,05 \\
0,06 \\
0,09 \\
0,13 \\
0,17 \\
0,21 \\
0,26 \\
0,56 \\
0,7\end{array}$ \\
\hline 120 & $\begin{array}{l}10 \\
15 \\
20 \\
30 \\
40 \\
50 \\
60 \\
70 \\
80 \\
90\end{array}$ & $\begin{array}{l}0,7 \\
1,06 \\
1,42 \\
2,15 \\
2,88 \\
3,63 \\
4,41 \\
5,22 \\
6,05 \\
6,9\end{array}$ & $\begin{array}{l}0,05 \\
0,06 \\
0,07 \\
0,1 \\
0,14 \\
0,17 \\
0,19 \\
0,23 \\
0,27 \\
0,33\end{array}$ \\
\hline 144 & $\begin{array}{l}10 \\
15 \\
20 \\
30 \\
40 \\
50 \\
60 \\
70 \\
80 \\
90\end{array}$ & $\begin{array}{l}0,69 \\
1,04 \\
1,4 \\
2,12 \\
2,84 \\
3,58 \\
4,36 \\
5,15 \\
5,98 \\
6,82\end{array}$ & $\begin{array}{l}0,04 \\
0,05 \\
0,06 \\
0,08 \\
0,1 \\
0,12 \\
0,13 \\
0,15 \\
0,19 \\
0,24\end{array}$ \\
\hline
\end{tabular}


TABELA 11 - Cälculo das funções $D_{g}(\Theta), K(\theta), D_{m}(\theta), D_{z}(\theta), K_{H}(\Theta)$ e $D_{m H}(\Theta)$, para as profundidades de $10,15,20,30,40,50,60,70,80 \mathrm{e}$ $90 \mathrm{~cm}$, do solo Duna de Areia.

\begin{tabular}{|c|c|c|c|c|c|c|c|}
\hline $\begin{array}{c}z \\
(\mathrm{~cm})\end{array}$ & $\begin{array}{l}-(q)_{z} \cdot 10^{2} \\
(\mathrm{~cm} / \mathrm{h})\end{array}$ & $\begin{array}{c}20 / 2 \mathrm{z} .10^{3} \\
\left(\mathrm{~cm}^{-1}\right)\end{array}$ & $\begin{array}{c}\mathrm{D}_{g} \\
\left(\mathrm{~cm}^{2} / \mathrm{h}\right)\end{array}$ & $\begin{array}{r}-d \psi_{m}^{\prime} / d \theta \\
\left(\mathrm{cmil}_{2} 0\right)\end{array}$ & $\begin{array}{l}d z / d \theta \\
(\mathrm{cm})\end{array}$ & $\begin{array}{l}\mathrm{K} .10^{2} \\
(\mathrm{~cm} / \mathrm{h})\end{array}$ & $\begin{array}{c}D_{m} \\
\left(\mathrm{~cm}^{2} / \mathrm{h}\right)\end{array}$ \\
\hline 10 & $\begin{array}{c}1206,37 \\
754,79 \\
538,58 \\
417,1 \\
288,02 \\
192,26 \\
129,41 \\
107,06 \\
47,81 \\
30,93 \\
41,36 \\
52,97 \\
6,04 \\
4,93 \\
2,76 \\
2,32 \\
2,21 \\
1,01 \\
0,62 \\
0,49 \\
0,13 \\
0,04 \\
0,04 \\
0,05 \\
0,04\end{array}$ & $\begin{array}{l}3,7 \\
3,2 \\
3 \\
2,9 \\
2,6 \\
2,3 \\
1,8 \\
2,1 \\
1,9 \\
1,8 \\
1,6 \\
2,5 \\
1,3 \\
1,1 \\
0,8 \\
0,6 \\
0,6 \\
0,5 \\
0,4 \\
0,4 \\
0,2 \\
0,2 \\
0,2 \\
0,4 \\
0,4\end{array}$ & $\begin{array}{l}-3260,46 \\
-2358,72 \\
-1795,27 \\
-1438,27 \\
-1107,79 \\
-\quad 835,91 \\
-\quad 718,95 \\
-\quad 509,82 \\
-251,63 \\
-\quad 171,82 \\
-258,52 \\
-211,86 \\
-\quad 46,42 \\
-\quad 44,82 \\
-\quad 34,44 \\
-\quad 38,67 \\
-\quad 36,9 \\
-\quad 20,1 \\
-\quad 15,4 \\
-\quad 12,22 \\
-\quad 6,46 \\
-\quad 2,01 \\
-\quad 2,09 \\
-\quad 1,23 \\
-\quad 0,87\end{array}$ & $\begin{array}{l}132,2 \\
186,7 \\
233,8 \\
296,3 \\
300,3 \\
268,2 \\
211,4 \\
184,5 \\
140,3 \\
133,4 \\
145,2 \\
153,7 \\
164,9 \\
220,5 \\
296,5 \\
224 \\
209,9 \\
244,7 \\
211 \\
228,6 \\
1051,4 \\
\infty \\
\infty \\
600 \\
600\end{array}$ & $\begin{array}{l}270,3 \\
312,5 \\
333,3 \\
344,8 \\
384,6 \\
434,8 \\
555,6 \\
476,2 \\
526,3 \\
555,6 \\
625 \\
400 \\
769,2 \\
909,1 \\
1250 \\
1666,7 \\
1666,7 \\
2000 \\
2500 \\
2500 \\
5000 \\
5000 \\
5000 \\
2500 \\
2500\end{array}$ & $\begin{array}{l}-2361,63 \\
-1875,03 \\
-1803,56 \\
-2963,6 \\
-1313,46 \\
-\quad 501,8 \\
-\quad 208,9 \\
-\quad 174,76 \\
-\quad 65,19 \\
-\quad 40,7 \\
-\quad 53,88 \\
-\quad 86,03 \\
-\quad 7,68 \\
-\quad 6,51 \\
-\quad 3,61 \\
-\quad 2,68 \\
-\quad 2,53 \\
-\quad 1,15 \\
-\quad 0,67 \\
-\quad 0,54 \\
-\quad 0,16 \\
\quad \infty \\
-\quad 0,06 \\
-\quad 0,05\end{array}$ & $\begin{array}{c}3122,33 \\
3500,74 \\
4216,6 \\
8781,05 \\
3944 \\
1345,83 \\
441,61 \\
322,37 \\
91,47 \\
54,3 \\
78,24 \\
132,27 \\
12,67 \\
14,35 \\
10,71 \\
6 \\
5,32 \\
2,8 \\
1,42 \\
1,23 \\
1,72 \\
\infty \\
\infty \\
0,39 \\
0,28\end{array}$ \\
\hline
\end{tabular}


TABELA 11 - Cälculo das funções $D_{g}(\theta), K(\theta), D_{m}(\theta), D_{z}(\theta), K_{H}(\theta)$, e $D_{m H}(\theta)$, para as profundidades de $10,15,20,30,40,50,60,70,80$ e $90 \mathrm{~cm}$, do solo Duna de Areia.

\begin{tabular}{|c|c|c|c|c|c|c|c|}
\hline$z$ & $\begin{array}{c}D_{z} \\
\left(\mathrm{~cm}^{2} / \mathrm{h}\right)\end{array}$ & $\begin{array}{c}\partial \psi_{\mathrm{m}} / \partial z \\
\left(\mathrm{cmH}_{2} \mathrm{O} / \mathrm{cm}\right)\end{array}$ & $\begin{array}{c}\partial \psi_{h} / \partial z \\
\left(\mathrm{cmH}_{2} 0 / \mathrm{cm}\right)\end{array}$ & $\begin{array}{l}\mathrm{K}_{\mathrm{H}} \cdot 10^{2} \\
(\mathrm{~cm} / \mathrm{h})\end{array}$ & $\begin{array}{c}D_{\mathrm{mH}} \\
\left(\mathrm{cm}^{2} / \mathrm{h}\right)\end{array}$ & $\begin{array}{c}\psi_{\mathrm{m}} \\
\left(\mathrm{cmH}_{2} \mathrm{O}\right)\end{array}$ & $\left(\mathrm{cm}^{3} / \mathrm{cm}^{3}\right)$ \\
\hline
\end{tabular}

\begin{tabular}{|c|c|c|c|c|c|c|}
\hline $\begin{array}{r}-6382,79 \\
-5859,46 \\
-6011,87 \\
-10219,32 \\
-5051,78 \\
-2181,74 \\
-1160,56 \\
-832,19 \\
-343,1 \\
-226,12 \\
-336,76 \\
-344,13 \\
-\quad 59,09 \\
-\quad 59,17 \\
-\quad 45,14 \\
-\quad 44,67 \\
-\quad 42,22 \\
-\quad 22,9 \\
-\quad 16,81 \\
-\quad 13,45 \\
-\quad 8,18 \\
\quad \infty \\
-\quad 1,62 \\
-\quad 1,15\end{array}$ & $\begin{array}{l}-0,33 \\
-0,37 \\
-0,46 \\
-0,6 \\
-0,63 \\
-0,61 \\
-0,57 \\
-0,56 \\
-0,55 \\
-0,54 \\
-0,52 \\
-0,49 \\
-0,43 \\
-0,43 \\
-0,39 \\
-0,36 \\
-0,33 \\
-0,3 \\
-0,31 \\
-0,3 \\
-0,24 \\
-0,22 \\
-0,22 \\
-0,21 \\
-0,21\end{array}$ & $\begin{array}{l}0,67 \\
0,63 \\
0,54 \\
0,4 \\
0,37 \\
0,39 \\
0,43 \\
0,44 \\
0,45 \\
0,46 \\
0,48 \\
0,51 \\
0,57 \\
0,57 \\
0,61 \\
0,64 \\
0,67 \\
0,7 \\
0,69 \\
0,7 \\
0,76 \\
0,78 \\
0,78 \\
0,79 \\
0,79\end{array}$ & $\begin{array}{l}-1800,55 \\
-1198,08 \\
-997,37 \\
-1042,75 \\
-\quad 778,44 \\
-492,97 \\
-300,96 \\
-\quad 243,32 \\
-106,25 \\
-\quad 67,23 \\
-\quad 86,17 \\
-\quad 103,85 \\
-\quad 10,59 \\
-\quad 8,65 \\
-\quad 4,52 \\
-\quad 3,62 \\
-\quad 3,3 \\
-\quad 1,44 \\
-\quad 0,89 \\
-\quad 0,7 \\
-\quad 0,17 \\
-\quad 0,05 \\
-\quad 0,05 \\
-\quad 0,06 \\
-\quad 0,04\end{array}$ & $\begin{array}{c}2380,52 \\
2236,86 \\
2331,79 \\
3089,63 \\
2337,47 \\
1322,15 \\
636,21 \\
448,84 \\
149,07 \\
69,7 \\
125,13 \\
159,67 \\
17,46 \\
19,07 \\
13,39 \\
8,12 \\
6,94 \\
3,51 \\
1,88 \\
1,6 \\
1,79 \\
\infty \\
\infty \\
0,38 \\
0,27\end{array}$ & $\begin{array}{l}6,7 \\
9,8 \\
12,1 \\
14,5 \\
18,5 \\
21,9 \\
25,2 \\
26,9 \\
28,7 \\
29,7 \\
30,4 \\
31 \\
33,2 \\
34,5 \\
36 \\
36,8 \\
37,4 \\
40,1 \\
41,5 \\
42,3 \\
43,9 \\
44,6 \\
45 \\
45,3 \\
45,6\end{array}$ & $\begin{array}{l}0,238 \\
0,219 \\
0,208 \\
0,199 \\
0,188 \\
0,175 \\
0,163 \\
0,154 \\
0,144 \\
0,136 \\
0,131 \\
0,127 \\
0,114 \\
0,106 \\
0,102 \\
0,099 \\
0,096 \\
0,086 \\
0,08 \\
0,076 \\
0,071 \\
0,071 \\
0,071 \\
0,071 \\
0,07\end{array}$ \\
\hline
\end{tabular}

(continua) 
TABELA 11 - Cälculo das funções $D_{g}(\theta), K(\theta), D_{m}(\theta), D_{z}(\theta), K_{H}(\theta)$ e $D_{m H}(\Theta)$, para as profundidades de $10,15,20,30,40,50,60,70,80 \mathrm{e}$ $90 \mathrm{~cm}$, do solo Duna de Areia.

\begin{tabular}{|c|c|c|c|c|c|c|c|}
\hline $\begin{array}{c}z \\
(\mathrm{~cm})\end{array}$ & $\begin{array}{c}-(q) z \cdot 10^{2} \\
(\mathrm{~cm} / \mathrm{h})\end{array}$ & $\begin{array}{c}\partial \theta / \partial z \cdot 10^{3} \\
\left(\mathrm{~cm}^{-1}\right)\end{array}$ & $\begin{array}{c}D_{g} \\
\left(\mathrm{~cm}^{2} / \mathrm{h}\right)\end{array}$ & $\begin{array}{r}-d \psi_{m} / d \theta \\
\left(\mathrm{cmH}_{2} 0\right)\end{array}$ & $\begin{array}{c}\mathrm{dz} / \mathrm{d} \theta \\
(\mathrm{cm})\end{array}$ & $\begin{array}{l}\text { K. } 10^{2} \\
(\mathrm{~cm} / \mathrm{h})\end{array}$ & $\begin{array}{c}D_{m} \\
\left(\mathrm{~cm}^{2} / \mathrm{h}\right)\end{array}$ \\
\hline 15 & $\begin{array}{l}1961,85 \\
1213,17 \\
839,2 \\
648,24 \\
453,39 \\
305,28 \\
195,44 \\
152,06 \\
74,45 \\
49,62 \\
54,3 \\
63,17 \\
11,57 \\
8,25 \\
4,96 \\
3,85 \\
3,39 \\
1,59 \\
0,97 \\
0,75 \\
0,2 \\
0,06 \\
0,05 \\
0,06 \\
0,05\end{array}$ & $\begin{array}{l}4,3 \\
5,1 \\
5,1 \\
4,9 \\
4,2 \\
3,3 \\
2 \\
1,5 \\
0,8 \\
0,6 \\
0,5 \\
0,4 \\
0,4 \\
0,4 \\
0,3 \\
0,3 \\
0,4 \\
0,5 \\
0,6 \\
0,7 \\
0,5 \\
0,3 \\
0,2 \\
0,2 \\
0,2\end{array}$ & $\begin{array}{l}-4562,43 \\
-2378,77 \\
-1645,48 \\
-1322,93 \\
-1079,51 \\
-\quad 925,09 \\
-977,19 \\
-1013,71 \\
-930,56 \\
-826,96 \\
-1085,9 \\
-1579,3 \\
-289,25 \\
-206,25 \\
-165,17 \\
-128,33 \\
-\quad 84,81 \\
-\quad 31,73 \\
-\quad 16,14 \\
-\quad 10,66 \\
-\quad 4,07 \\
-\quad 1,87 \\
-\quad 2,31 \\
-\quad 2,95 \\
-\quad 2,25\end{array}$ & $\begin{array}{l}144,9 \\
203,6 \\
211 \\
202,5 \\
203,4 \\
176,3 \\
132 \\
120,3 \\
124,1 \\
134,8 \\
155,6 \\
174,2 \\
156,5 \\
176 \\
253,2 \\
400 \\
462,1 \\
243 \\
229,6 \\
231,9 \\
301,3 \\
424,2 \\
1125 \\
525 \\
600\end{array}$ & $\begin{array}{l}232,6 \\
196,1 \\
196,1 \\
204,1 \\
238,1 \\
303 \\
500 \\
666,7 \\
1250 \\
1666,7 \\
2000 \\
2500 \\
2500 \\
2500 \\
3333,3 \\
3333,3 \\
2500 \\
2000 \\
1667,7 \\
1428,6 \\
2000 \\
3333,3 \\
5000 \\
5000 \\
5000\end{array}$ & $\begin{array}{r}-5204,03 \\
31473,86 \\
11058 \\
-82730,27 \\
-3115,55 \\
-\quad 729,8 \\
-265,55 \\
-\quad 185,55 \\
-\quad 82,65 \\
-\quad 53,98 \\
-\quad 58,87 \\
-\quad 67,9 \\
-\quad 12,34 \\
-\quad 8,87 \\
-\quad 5,35 \\
-\quad 4,37 \\
-\quad 4,16 \\
-\quad 1,81 \\
-\quad 1,12 \\
-\quad 0,89 \\
-\quad 0,24 \\
-\quad 0,06 \\
-\quad 0,06 \\
-\quad 0,07 \\
-\quad 0,05\end{array}$ & $\begin{array}{c}7539,97 \\
-64092,23 \\
-23327,83 \\
167514,36 \\
6338,47 \\
1286,44 \\
350,58 \\
223,28 \\
102,58 \\
72,75 \\
91,58 \\
118,27 \\
19,32 \\
15,62 \\
13,58 \\
17,5 \\
19,23 \\
4,39 \\
2,58 \\
2,07 \\
0,72 \\
0,27 \\
0,67 \\
0,35 \\
0,31\end{array}$ \\
\hline
\end{tabular}


TABELA 11 - Cálculo das funções $D_{g}(\theta), k(\theta), D_{m}(\theta), D_{z}(\theta), K_{H}(\theta)$ e $D_{m H}(\theta)$, para as profundidades de $10,15,20,30,40,50,60,70,80$ e $90 \mathrm{~cm}$, do solo Duna de Areia.

\begin{tabular}{|c|c|c|c|c|c|c|c|}
\hline $\begin{array}{c}z \\
(\mathrm{~cm})\end{array}$ & $\begin{array}{c}D_{z} \\
\left(\mathrm{~cm}^{2} / \mathrm{h}\right)\end{array}$ & $\begin{array}{c}\partial \psi_{\mathrm{m}} / \partial \mathrm{z} \\
\left(\mathrm{cmH}_{2} \mathrm{O} / \mathrm{cm}\right)\end{array}$ & $\begin{array}{c}\partial \psi_{h} / \partial z \\
\left(\mathrm{cmH}_{2} \mathrm{O} / \mathrm{cm}\right)\end{array}$ & $\begin{array}{l}\text { K. } 10^{2} \\
(\mathrm{~cm} / \mathrm{h})\end{array}$ & $\begin{array}{c}\mathrm{D}_{\mathrm{mH}} \\
\left(\mathrm{cm}^{2} / \mathrm{h}\right)\end{array}$ & $\begin{array}{c}\psi_{m} \\
\left(\mathrm{cmH}_{2} \mathrm{O}\right)\end{array}$ & $\left(\mathrm{cm}^{3} / \mathrm{cm}^{3}\right)$ \\
\hline 15 & $\begin{array}{r}-12102,4 \\
61713,45 \\
21682,35 \\
-168837,29 \\
-7417,98 \\
-2211,53 \\
-1327,77 \\
-1236,99 \\
-1033,14 \\
-899,7 \\
-1177,48 \\
-1697,57 \\
-308,57 \\
-221,87 \\
-178,75 \\
-145,83 \\
-104,04 \\
-\quad 36,12 \\
-\quad 18,72 \\
-\quad 12,73 \\
-\quad 4,79 \\
-\quad 2,14 \\
-\quad 2,98 \\
-\quad 3,29 \\
-\quad 2,56\end{array}$ & $\begin{array}{r}0,13 \\
0,13 \\
0,16 \\
0,12 \\
0,06 \\
-0,02 \\
0,03 \\
0,02 \\
-0,01 \\
-0,01 \\
0 \\
0 \\
-0,03 \\
-0,06 \\
-0,13 \\
-0,14 \\
-0,13 \\
-0,13 \\
-0,09 \\
-0,04 \\
0,04 \\
0,04 \\
0,03 \\
0,03 \\
0,02\end{array}$ & $\begin{array}{l}1,13 \\
1,13 \\
1,16 \\
1,12 \\
1,06 \\
0,98 \\
1,03 \\
1,02 \\
0,99 \\
0,99 \\
1 \\
1 \\
0,97 \\
0,94 \\
0,87 \\
0,86 \\
0,87 \\
0,87 \\
0,91 \\
0,96 \\
1,04 \\
1,04 \\
1,03 \\
1,03 \\
1,02\end{array}$ & $\begin{array}{l}-1736,15 \\
-1073,61 \\
-\quad 723,44 \\
-578,78 \\
-427,73 \\
-311,51 \\
-189,75 \\
-149,08 \\
-\quad 75,2 \\
-\quad 50,12 \\
-\quad 54,3 \\
-\quad 63,17 \\
-\quad 11,93 \\
-\quad 8,78 \\
-\quad 5,7 \\
-\quad 4,48 \\
-\quad 3,9 \\
-\quad 1,82 \\
-\quad 1,06 \\
-\quad 0,78 \\
-\quad 0,2 \\
-\quad 0,05 \\
-\quad 0,04 \\
-\quad 0,06 \\
-\quad 0,04\end{array}$ & $\begin{array}{c}2515,45 \\
2186,25 \\
1526,17 \\
1171,94 \\
870,2 \\
549,1 \\
250,5 \\
179,39 \\
93,33 \\
67,54 \\
84,46 \\
110,03 \\
18,67 \\
15,45 \\
14,42 \\
17,91 \\
18,02 \\
4,43 \\
2,44 \\
1,8 \\
0,59 \\
0,23 \\
0,51 \\
0,3 \\
0,26\end{array}$ & $\begin{array}{l}8,1 \\
11,3 \\
14,1 \\
15,7 \\
18,6 \\
21,4 \\
23,8 \\
24,9 \\
26,2 \\
27,1 \\
27,8 \\
28,5 \\
30,9 \\
32,1 \\
33,4 \\
34,6 \\
35,8 \\
38,3 \\
39,2 \\
39,9 \\
41,5 \\
42,2 \\
42,7 \\
43,1 \\
43,4\end{array}$ & $\begin{array}{l}0,249 \\
0,231 \\
0,219 \\
0,211 \\
0,197 \\
0,183 \\
0,168 \\
0,159 \\
0,148 \\
0,141 \\
0,136 \\
0,132 \\
0,118 \\
0,11 \\
0,104 \\
0,1 \\
0,098 \\
0,09 \\
0,086 \\
0,083 \\
0,076 \\
0,074 \\
0,073 \\
0,073 \\
0,072\end{array}$ \\
\hline
\end{tabular}

(continua) 
TABELA 11 - Cälculo das funções $D_{g}(\Theta), K(\theta), D_{m}(\theta), D_{z}(\theta), K_{H}(\Theta)$ e $D_{m H}(\theta)$, para as profundidades de $10,15,20,30,40,50,60,70,80$ e $90 \mathrm{~cm}$, do solo Duna de Areia.

\begin{tabular}{|c|c|c|c|c|c|c|c|}
\hline$(\mathrm{cm})$ & $\begin{array}{c}-(q) z \cdot 10^{2} \\
(\mathrm{~cm} / \mathrm{h})\end{array}$ & $\begin{array}{c}\partial \Theta / \partial z \cdot 10^{3} \\
\left(\mathrm{~cm}^{-1}\right)\end{array}$ & $\begin{array}{c}\mathrm{Dg}_{\mathrm{g}} \\
\left(\mathrm{cm}^{2} / \mathrm{h}\right)\end{array}$ & $\begin{array}{r}-\mathrm{d} \psi_{\mathrm{m}}^{\prime} / \mathrm{d} \theta \\
\left(\mathrm{cmH}_{2} 0\right)\end{array}$ & $\begin{array}{l}d z / d \theta \\
(\mathrm{cm})\end{array}$ & $\begin{array}{l}K .10^{2} \\
(\mathrm{~cm} / \mathrm{h})\end{array}$ & $\begin{array}{c}D_{m} \\
\left(\mathrm{~cm}^{2} / \mathrm{h}\right) \\
\end{array}$ \\
\hline 20 & $\begin{array}{l}2564,41 \\
1597,6 \\
1154,34 \\
920 \\
671,54 \\
465,84 \\
292,02 \\
213 \\
108,73 \\
70,74 \\
69,39 \\
75,86 \\
16,93 \\
11,63 \\
7,21 \\
5,2 \\
4,32 \\
2,13 \\
1,28 \\
0,97 \\
0,3 \\
0,09 \\
0,06 \\
0,07 \\
0,06\end{array}$ & $\begin{array}{l}5,2 \\
6,13 \\
6,2 \\
5,7 \\
4,87 \\
3,7 \\
2,47 \\
1,77 \\
0,97 \\
0,6 \\
0,43 \\
0,3 \\
0,3 \\
0,27 \\
0,33 \\
0,4 \\
0,3 \\
0,17 \\
0,07 \\
0,07 \\
0,07 \\
0,03 \\
0,03 \\
\infty \\
\infty\end{array}$ & $\begin{array}{l}-4931,56 \\
-2604,79 \\
-1861,84 \\
-1614,04 \\
-1379,87 \\
-1259,02 \\
-1183,85 \\
-1205,64 \\
-1124,77 \\
-1178,95 \\
-1601,26 \\
-2528,51 \\
-564,17 \\
-435,93 \\
-216,15 \\
-130 \\
-143,86 \\
-127,5 \\
-191,74 \\
-145,98 \\
-\quad 44,81 \\
-\quad 26,57 \\
-\quad 17,13 \\
\infty \\
\infty\end{array}$ & $\begin{array}{l}221,3 \\
255,1 \\
202,1 \\
184,4 \\
141,1 \\
129,9 \\
123,4 \\
99,2 \\
94,9 \\
116,1 \\
125,4 \\
125,4 \\
131,6 \\
142,3 \\
192,2 \\
280 \\
338,4 \\
333,3 \\
399,2 \\
396,6 \\
348,4 \\
313,4 \\
600 \\
333,3 \\
400\end{array}$ & $\begin{array}{l}192,3 \\
163 \\
161,3 \\
175,4 \\
205,5 \\
270,3 \\
405,4 \\
566 \\
1034,5 \\
1666,7 \\
2307,7 \\
3333,3 \\
3333,3 \\
3750 \\
3000 \\
2500 \\
3333,3 \\
5999,9 \\
14999,3 \\
14999,3 \\
14999,3 \\
30003 \\
30003 \\
\infty \\
\infty\end{array}$ & $\begin{array}{r}16993,45 \\
2828,51 \\
4562,77 \\
18062,65 \\
-2142,14 \\
-\quad 897,09 \\
-419,73 \\
-\quad 258,24 \\
-\quad 119,71 \\
-\quad 76,03 \\
-\quad 73,37 \\
-\quad 78,82 \\
-\quad 17,62 \\
-\quad 12,08 \\
-\quad 7,7 \\
-\quad 5,86 \\
-\quad 4,8 \\
-\quad 2,25 \\
-\quad 1,31 \\
-\quad 1 \\
-\quad 0,31 \\
-\quad 0,09 \\
-\quad 0,06 \\
\quad \infty \\
\quad \infty\end{array}$ & $\begin{array}{r}-37611,27 \\
-7216,5 \\
-9221,15 \\
-33302,89 \\
3021,78 \\
1165,55 \\
517,76 \\
256,11 \\
113,65 \\
88,3 \\
91,99 \\
98,83 \\
23,18 \\
17,19 \\
14,8 \\
16,4 \\
16,25 \\
7,5 \\
5,24 \\
3,96 \\
1,07 \\
0,28 \\
0,35 \\
\infty \\
\infty\end{array}$ \\
\hline
\end{tabular}


TABELA 11 - Cálculo das funções $D_{g}(\theta), K(\theta), D_{m}(\theta), D_{z}(\theta), K_{H}(\theta)$ e $D_{m H}(\theta)$, para as profundidades de $10,15,20,30,40,50,60,70,80$ e $90 \mathrm{~cm}$, do solo Duna de Areia.

\begin{tabular}{|c|c|c|c|c|c|c|c|}
\hline $\begin{array}{c}z \\
(\mathrm{~cm})\end{array}$ & $\begin{array}{c}\mathrm{D}_{\mathrm{Z}} \\
\left(\mathrm{cm}^{2} / \mathrm{h}\right)\end{array}$ & $\begin{array}{c}\partial \psi_{\mathrm{m}} / \partial z \\
\left(\mathrm{cmH}_{2} \mathrm{O} / \mathrm{cm}\right)\end{array}$ & $\begin{array}{c}\partial \psi_{h} / \partial z \\
\left(\mathrm{cmH}_{2} \mathrm{O} / \mathrm{cm}\right)\end{array}$ & $\begin{array}{l}K_{H} \cdot 10^{2} \\
(\mathrm{~cm} / \mathrm{h})\end{array}$ & $\begin{array}{c}\mathrm{D}_{\mathrm{mH}} \\
\left(\mathrm{cm}^{2} / \mathrm{h}\right)\end{array}$ & $\begin{array}{l}\psi_{\mathrm{m}} \\
\left(\mathrm{cmH}_{2} \mathrm{O}\right)\end{array}$ & $\left(\mathrm{cm}^{3} / \mathrm{cm}^{3}\right)$ \\
\hline 20 & $\begin{array}{r}32679,72 \\
4611,71 \\
7359,31 \\
31688,86 \\
-4401,65 \\
-2424,57 \\
-1701,61 \\
-1461,74 \\
-1238,42 \\
-1267,24 \\
-1693,25 \\
-2627,33 \\
-\quad 587,35 \\
-453,13 \\
-230,95 \\
-146,4 \\
-160,11 \\
-135 \\
-196,98 \\
-149,94 \\
-\quad 45,88 \\
-\quad 26,85 \\
-\quad 17,48\end{array}$ & $\begin{array}{l}0,16 \\
0,1 \\
0,04 \\
0,08 \\
0,1 \\
0,06 \\
0,21 \\
0,28 \\
0,31 \\
0,33 \\
0,34 \\
0,33 \\
0,26 \\
0,25 \\
0,18 \\
0,12 \\
0,04 \\
0,05 \\
0,16 \\
0,23 \\
0,33 \\
0,34 \\
0,33 \\
0,33 \\
0,33\end{array}$ & $\begin{array}{l}1,16 \\
1,1 \\
1,04 \\
1,08 \\
1,1 \\
1,06 \\
1,21 \\
1,28 \\
1,31 \\
1,33 \\
1,34 \\
1,33 \\
1,26 \\
1,25 \\
1,18 \\
1,12 \\
1,04 \\
1,05 \\
1,16 \\
1,23 \\
1,33 \\
1,34 \\
1,33 \\
1,33 \\
1,33\end{array}$ & $\begin{array}{r}-217,07 \\
-1452,37 \\
-1109,94 \\
-\quad 854,49 \\
-\quad 612,34 \\
-\quad 438,09 \\
-241,34 \\
-\quad 166,84 \\
-\quad 83 \\
-\quad 53,19 \\
-\quad 51,65 \\
-\quad 57,18 \\
-\quad 13,47 \\
-\quad 9,32 \\
-\quad 6,09 \\
-\quad 4,66 \\
-\quad 4,14 \\
-\quad 2,02 \\
-\quad 1,1 \\
-\quad 0,79 \\
-\quad 0,23 \\
-\quad 0,07 \\
-\quad 0,04 \\
-\quad 0,05 \\
-\quad 0,04\end{array}$ & $\begin{array}{l}4907 \\
3705,49 \\
2243,14 \\
1575,46 \\
863,79 \\
569,19 \\
297,7 \\
165,46 \\
78,8 \\
61,76 \\
64,76 \\
71,69 \\
17,72 \\
13,27 \\
11,7 \\
13,04 \\
14 \\
6,72 \\
4,4 \\
3,15 \\
0,78 \\
0,21 \\
0,26 \\
0,17 \\
0,17\end{array}$ & $\begin{array}{l}8 \\
11,1 \\
13,7 \\
15,7 \\
19,1 \\
21,7 \\
25,5 \\
27,1 \\
28,6 \\
29,6 \\
30,4 \\
31 \\
32,9 \\
33,9 \\
34,7 \\
35,4 \\
36,1 \\
38,8 \\
40,6 \\
41,9 \\
44,3 \\
45 \\
45,3 \\
45,6 \\
45,8\end{array}$ & $\begin{array}{l}0,281 \\
0,27 \\
0,259 \\
0,248 \\
0,23 \\
0,208 \\
0,183 \\
0,169 \\
0,152 \\
0,142 \\
0,136 \\
0,131 \\
0,118 \\
0,11 \\
0,105 \\
0,102 \\
0,1 \\
0,091 \\
0,086 \\
0,083 \\
0,076 \\
0,074 \\
0,073 \\
0,073 \\
0,072\end{array}$ \\
\hline
\end{tabular}

(continua) 
TABELA 11 - Cálculo das funções $D_{g}(\theta), K(\theta), D_{m}(\theta), D_{z}(\theta), K_{H}(\theta)$ e $D_{m H}(\theta)$, para as profundidades de $10,15,20,30,40,50,60,70,80 \mathrm{e}$ $90 \mathrm{~cm}$, do solo Duna de Areia.

\begin{tabular}{|c|c|c|c|c|c|c|c|}
\hline $\begin{array}{c}z \\
(\mathrm{~cm})\end{array}$ & $\begin{array}{c}-(q) z \cdot 10^{2} \\
(\mathrm{~cm} / \mathrm{h})\end{array}$ & $\begin{array}{c}\partial \theta / \partial z \cdot 10^{3} \\
\left(\mathrm{~cm}^{-1}\right)\end{array}$ & $\begin{array}{c}\mathrm{D}_{\mathrm{g}} \\
\left(\mathrm{cm}^{2} / \mathrm{h}\right)\end{array}$ & $\begin{array}{r}-d \psi_{m} / d O \\
\left(\mathrm{cmH}_{2} \mathrm{O}\right) \\
\end{array}$ & $\begin{array}{l}d z / d \theta \\
(\mathrm{cm})\end{array}$ & $\begin{array}{l}K .10^{2} \\
(\mathrm{~cm} / \mathrm{h})\end{array}$ & $\begin{array}{c}D_{m} \\
\left(\mathrm{~cm}^{2} / \mathrm{h}\right)\end{array}$ \\
\hline 30 & $\begin{array}{c}3280,89 \\
2269,16 \\
1907,39 \\
1675,05 \\
1281,42 \\
876,03 \\
526,95 \\
368,37 \\
190,67 \\
119,82 \\
104,46 \\
104,06 \\
28,65 \\
18,86 \\
12,14 \\
8,94 \\
7,58 \\
3,25 \\
1,9 \\
1,43 \\
0,5 \\
0,16 \\
0,09 \\
0,1 \\
0,08\end{array}$ & $\begin{array}{l}2,05 \\
2,25 \\
2,3 \\
2,35 \\
2,1 \\
1,6 \\
1,2 \\
1,1 \\
1 \\
0,95 \\
0,9 \\
0,85 \\
0,65 \\
0,6 \\
0,55 \\
0,45 \\
0,35 \\
0,2 \\
0,15 \\
0,1 \\
0,05 \\
0,05 \\
0,05 \\
\infty \\
\infty\end{array}$ & $\begin{array}{l}-16004,35 \\
-10085,16 \\
-8292,98 \\
-7127,88 \\
-6102 \\
-\quad 5474,18 \\
-4391,26 \\
-3348,79 \\
-1906,72 \\
-1261,22 \\
-1160,71 \\
-1224,21 \\
-\quad 440,77 \\
-\quad 314,25 \\
-220,73 \\
-198,67 \\
-216,61 \\
-162,54 \\
-126,72 \\
-142,59 \\
-\quad 99,38 \\
-\quad 32,5 \\
-\quad 17,71 \\
\quad \infty \\
\quad \infty\end{array}$ & $\begin{array}{l}204,4 \\
139,3 \\
114,3 \\
89,9 \\
82,7 \\
105,5 \\
110,8 \\
103,3 \\
117,2 \\
121,2 \\
105,1 \\
101,2 \\
132,2 \\
140,6 \\
134,8 \\
113,5 \\
112,3 \\
299,7 \\
317,8 \\
304 \\
347,4 \\
544 \\
692,3 \\
541 \\
1333,3\end{array}$ & $\begin{array}{l}487,8 \\
444,4 \\
434,8 \\
425,5 \\
476,2 \\
625 \\
833,3 \\
909,1 \\
1000 \\
1052,6 \\
1111,1 \\
1176,5 \\
1538,5 \\
1666,7 \\
1818,2 \\
2222,2 \\
2857,1 \\
5000 \\
6666,7 \\
10000 \\
20000 \\
20000 \\
20000 \\
\infty \\
\infty\end{array}$ & $\begin{array}{l}-5647,05 \\
-3305,35 \\
-2587,68 \\
-2123,94 \\
-1550,56 \\
-1053,94 \\
-\quad 607,74 \\
-\quad 415,6 \\
-215,98 \\
-135,41 \\
-115,37 \\
-113,85 \\
-\quad 31,34 \\
-\quad 20,59 \\
-\quad 13,11 \\
-\quad 9,42 \\
-\quad 7,89 \\
-\quad 3,46 \\
-\quad 2 \\
-\quad 1,47 \\
-\quad 0,51 \\
-\quad 0,17 \\
-\quad 0,09 \\
\infty \\
\infty\end{array}$ & $\begin{array}{c}11542,25 \\
4605,3 \\
2957,8 \\
1910,19 \\
1281,61 \\
1111,97 \\
673,25 \\
429,43 \\
253,07 \\
164,13 \\
121,2 \\
115,25 \\
41,43 \\
28,96 \\
17,67 \\
10,69 \\
8,36 \\
10,36 \\
6,34 \\
4,47 \\
1,76 \\
0,91 \\
0,63 \\
\infty \\
\infty\end{array}$ \\
\hline
\end{tabular}

(continua) 
TABELA 11 - Cálculo das funções $D_{g}(\theta), K(\theta), D_{m}(\theta), D_{z}(\theta), K_{H}(\theta)$ e $D_{m H}(\theta)$, para as profundidades de $10,15,20,30,40,50,60,70,80$ e $90 \mathrm{~cm}$, do solo Duna de Areia.

\begin{tabular}{|c|c|c|c|c|c|c|c|}
\hline & $\begin{array}{c}D_{z} \\
\left(\mathrm{~cm}^{2} / \mathrm{h}\right)\end{array}$ & $\begin{array}{c}\partial \psi_{\mathrm{m}} / \partial z \\
\left(\mathrm{cmH}_{2} \mathrm{O} / \mathrm{cm}\right) \\
\end{array}$ & $\begin{array}{c}\partial \psi_{h} / \partial z \\
\left(\mathrm{cmH}_{2} \mathrm{O} / \mathrm{cm}\right) \\
\end{array}$ & $\begin{array}{l}\mathrm{K}_{\mathrm{H}} \cdot 10^{2} \\
(\mathrm{~cm} / \mathrm{h})\end{array}$ & $\begin{array}{c}D_{\mathrm{mH}} \\
\left(\mathrm{cm}^{2} / \mathrm{h}\right)\end{array}$ & $\left(\mathrm{cmH}_{2}\right)$ & $\left(\mathrm{cm}^{3} / \mathrm{cm}^{3}\right)$ \\
\hline 30 & $\begin{array}{l}-27546,6 \\
-14690,46 \\
-11250,78 \\
-\quad 9038,06 \\
-\quad 7383,62 \\
-6587,15 \\
-\quad 5064,5 \\
-\quad 3778,22 \\
-2159,78 \\
-1425,35 \\
-1281,91 \\
-1339,46 \\
-\quad 482,2 \\
-\quad 343,21 \\
-\quad 238,4 \\
-\quad 209,36 \\
-\quad 225,47 \\
-\quad 172,9 \\
-\quad 133,06 \\
-\quad 147,06 \\
-\quad 101,13 \\
-\quad 33,41 \\
-\quad 18,34 \\
\infty \\
\infty\end{array}$ & $\begin{array}{r}0,38 \\
0,32 \\
0,28 \\
0,24 \\
0,16 \\
0,11 \\
-0,02 \\
-0,05 \\
-0,07 \\
-0,09 \\
-0,1 \\
-0,11 \\
-0,14 \\
-0,13 \\
-0,13 \\
-0,13 \\
-0,13 \\
-0,14 \\
-0,15 \\
-0,16 \\
-0,12 \\
-0,06 \\
-0,02 \\
0,01 \\
0,03\end{array}$ & $\begin{array}{l}1,38 \\
1,32 \\
1,28 \\
1,24 \\
1,16 \\
1,11 \\
0,99 \\
0,95 \\
0,93 \\
0,92 \\
0,9 \\
0,89 \\
0,86 \\
0,88 \\
0,88 \\
0,88 \\
0,88 \\
0,86 \\
0,85 \\
0,85 \\
0,88 \\
0,94 \\
0,99 \\
1,01 \\
1,03\end{array}$ & $\begin{array}{l}-1188,73 \\
-\quad 859,53 \\
-\quad 747,995 \\
-\quad 675,425 \\
-\quad 554,725 \\
-\quad 394,61 \\
-\quad 267,49 \\
-193,875 \\
-102,51 \\
-\quad 65,475 \\
-\quad 58,035 \\
-\quad 58,46 \\
-\quad 16,655 \\
-\quad 10,775 \\
-\quad 6,935 \\
-\quad 5,11 \\
-\quad 4,33 \\
-\quad 1,89 \\
-\quad 1,12 \\
-\quad 0,845 \\
-\quad 0,28 \\
-\quad 0,085 \\
-\quad 0,045 \\
-\quad 0,05 \\
-\quad 0,035\end{array}$ & $\begin{array}{l}4859,39 \\
2395,14 \\
1709,96 \\
1214,9 \\
917,02 \\
832,66 \\
592,64 \\
400,65 \\
240,23 \\
158,72 \\
121,93 \\
118,35 \\
44,03 \\
30,3 \\
18,7 \\
11,6 \\
9,73 \\
11,33 \\
7,11 \\
5,13 \\
1,95 \\
0,94 \\
0,62 \\
0,54 \\
0,99\end{array}$ & $\begin{array}{l}13,1 \\
14,9 \\
16,5 \\
18 \\
20 \\
22,4 \\
25 \\
26,6 \\
28,3 \\
29,5 \\
30,3 \\
30,8 \\
32,6 \\
34,1 \\
35 \\
35,7 \\
36,2 \\
28,4 \\
29,8 \\
40,7 \\
42,9 \\
44 \\
44,9 \\
45,5 \\
46\end{array}$ & $\begin{array}{l}0,309 \\
0,298 \\
0,285 \\
0,271 \\
0,244 \\
0,219 \\
0,197 \\
0,182 \\
0,165 \\
0,156 \\
0,149 \\
0,144 \\
0,127 \\
0,118 \\
0,111 \\
0,106 \\
0,101 \\
0,092 \\
0,088 \\
0,085 \\
0,078 \\
0,075 \\
0,074 \\
0,073 \\
0,072\end{array}$ \\
\hline
\end{tabular}

(continua) 
TABELA 11 - Cälculo das funções $D_{g}(\theta), K(\theta), D_{m}(\theta), D_{z}(\theta), K_{H}(\theta)$ e $D_{m H}(\theta)$, para as profundidades de $10,15,20,30,40,50,60,70,80$ e $90 \mathrm{~cm}$, do solo Duna de Areia.

\begin{tabular}{|c|c|c|c|c|c|c|c|}
\hline $\begin{array}{c}z \\
(\mathrm{~cm})\end{array}$ & $\begin{array}{c}-(q) z \cdot 10^{2} \\
(\mathrm{~cm} / \mathrm{h})\end{array}$ & $\begin{array}{c}\partial \theta / \partial z \cdot 10^{3} \\
\left(\mathrm{~cm}^{-1}\right)\end{array}$ & $\begin{array}{c}D_{g} \\
\left(\mathrm{~cm}^{2} / \mathrm{h}\right)\end{array}$ & $\begin{array}{r}-d \psi_{m} / d \theta \\
\left(\mathrm{cmH}_{2} 0\right) \\
\end{array}$ & $\begin{array}{l}d z / d \theta \\
(\mathrm{cm})\end{array}$ & $\begin{array}{l}K .10^{2} \\
(\mathrm{~cm} / \mathrm{h})\end{array}$ & $\begin{array}{c}D_{m} \\
\left(\mathrm{~cm}^{2} / \mathrm{h}\right)\end{array}$ \\
\hline 40 & $\begin{array}{l}3703,87 \\
2898,8 \\
2634,2 \\
2422,5 \\
1965,22 \\
1357,59 \\
784,63 \\
527,94 \\
274,3 \\
170,61 \\
142,06 \\
134,88 \\
41,71 \\
26,64 \\
17,92 \\
13,76 \\
11,78 \\
4,55 \\
2,62 \\
1,96 \\
0,71 \\
0,23 \\
0,13 \\
0,14 \\
0,1\end{array}$ & $\begin{array}{l}0,65 \\
1,15 \\
1,75 \\
2,3 \\
2,55 \\
2 \\
1,25 \\
1,05 \\
0,85 \\
0,65 \\
0,6 \\
0,55 \\
0,45 \\
0,45 \\
0,45 \\
0,4 \\
0,45 \\
0,2 \\
0,2 \\
0,2 \\
0,25 \\
0,2 \\
0,15 \\
0,2 \\
0,2\end{array}$ & $\begin{array}{l}-56982,57 \\
-25206,98 \\
-15052,6 \\
-10532,62 \\
-\quad 7706,75 \\
-6787,95 \\
-\quad 6277,07 \\
-5028 \\
-\quad 3227 \\
-2624,71 \\
-2367,67 \\
-2452,38 \\
-\quad 926,89 \\
-\quad 592 \\
-\quad 398,22 \\
-\quad 344 \\
-\quad 261,83 \\
-\quad 227,46 \\
-\quad 131,12 \\
-\quad 98,2 \\
-\quad 28,24 \\
-\quad 11,66 \\
-\quad 8,74 \\
-\quad 7,2 \\
-\quad 4,86\end{array}$ & $\begin{array}{c}378,3 \\
206,4 \\
144,8 \\
97,8 \\
61,8 \\
44,4 \\
47,9 \\
57 \\
61,3 \\
68 \\
68,7 \\
68,7 \\
100 \\
137,4 \\
136,8 \\
155,6 \\
180,1 \\
235,3 \\
284,7 \\
322 \\
628,2 \\
1039,8 \\
815,3 \\
642,4 \\
1500\end{array}$ & $\begin{array}{l}1538,5 \\
869,6 \\
571,4 \\
434,8 \\
392,2 \\
500 \\
800 \\
952,4 \\
1176,5 \\
1538,5 \\
1666,7 \\
1818,2 \\
2222,2 \\
2222,2 \\
2222,2 \\
2500 \\
2222,2 \\
5000 \\
5000 . \\
5000 \\
4000 \\
5000 \\
6666,7 \\
5000 \\
5000\end{array}$ & $\begin{array}{l}-4911,61 \\
-3801,16 \\
-3527,93 \\
-3125,86 \\
-2332,98 \\
-1489,77 \\
-\quad 834,57 \\
-\quad 561,53 \\
-289,37 \\
-\quad 178,49 \\
-148,17 \\
-140,18 \\
-\quad 43,68 \\
-\quad 28,4 \\
-\quad 19,1 \\
-\quad 14,67 \\
-\quad 12,82 \\
-\quad 4,77 \\
-\quad 2,78 \\
-\quad 2,1 \\
-\quad 0,84 \\
-\quad 0,29 \\
-\quad 0,15 \\
-\quad 0,17 \\
-\quad 0,14\end{array}$ & $\begin{array}{c}18580,7 \\
7846,6 \\
5107,03 \\
3058,05 \\
1442,21 \\
660,9 \\
399,51 \\
319,95 \\
177,3 \\
121,3 \\
101,79 \\
96,36 \\
43,68 \\
39 \\
26,12 \\
22,82 \\
23,09 \\
11,23 \\
7,92 \\
6,76 \\
5,26 \\
3,06 \\
1,22 \\
1,06 \\
2,08\end{array}$ \\
\hline
\end{tabular}

(continua) 
TABELA 11 - Cälculo das funções $D_{g}(\theta), K(\theta), D_{m}(\theta), D_{z}(\theta), K_{H}(\theta)$ e $D_{m H}(\theta)$, para as profundidades de $10,15,20,30,40,50,60,70,80$ e $90 \mathrm{~cm}$, do solo Duna de Areia.

\begin{tabular}{|c|c|c|c|c|c|c|}
\hline $\mathrm{cm}$ & $\begin{array}{c}\mathrm{D}_{Z} \\
\left(\mathrm{~cm}^{2} / \mathrm{h}\right)\end{array}$ & $\begin{array}{c}\partial \psi_{\mathrm{m}} / \partial \mathrm{z} \\
\left(\mathrm{cmH}_{2} \mathrm{O} / \mathrm{cm}\right)\end{array}$ & $\begin{array}{c}\partial \psi_{\mathrm{h}} / \partial \mathrm{z} \\
\left(\mathrm{cmH}_{2} \mathrm{O} / \mathrm{cm}\right)\end{array}$ & $\begin{array}{l}\mathrm{K}_{\mathrm{H}} \cdot 10^{2} \\
(\mathrm{~cm} / \mathrm{h})\end{array}$ & $\begin{array}{c}\mathrm{D}_{\mathrm{mH}} \\
\left(\mathrm{cm}^{2} / \mathrm{h}\right)\end{array}$ & $\left.\begin{array}{c}\psi_{\mathrm{m}} \\
\left(\mathrm{cmH}_{2} \mathrm{O}\right)\end{array}{ }^{\Theta} \mathrm{cm}^{3} / \mathrm{cm}^{3}\right)$ \\
\hline
\end{tabular}

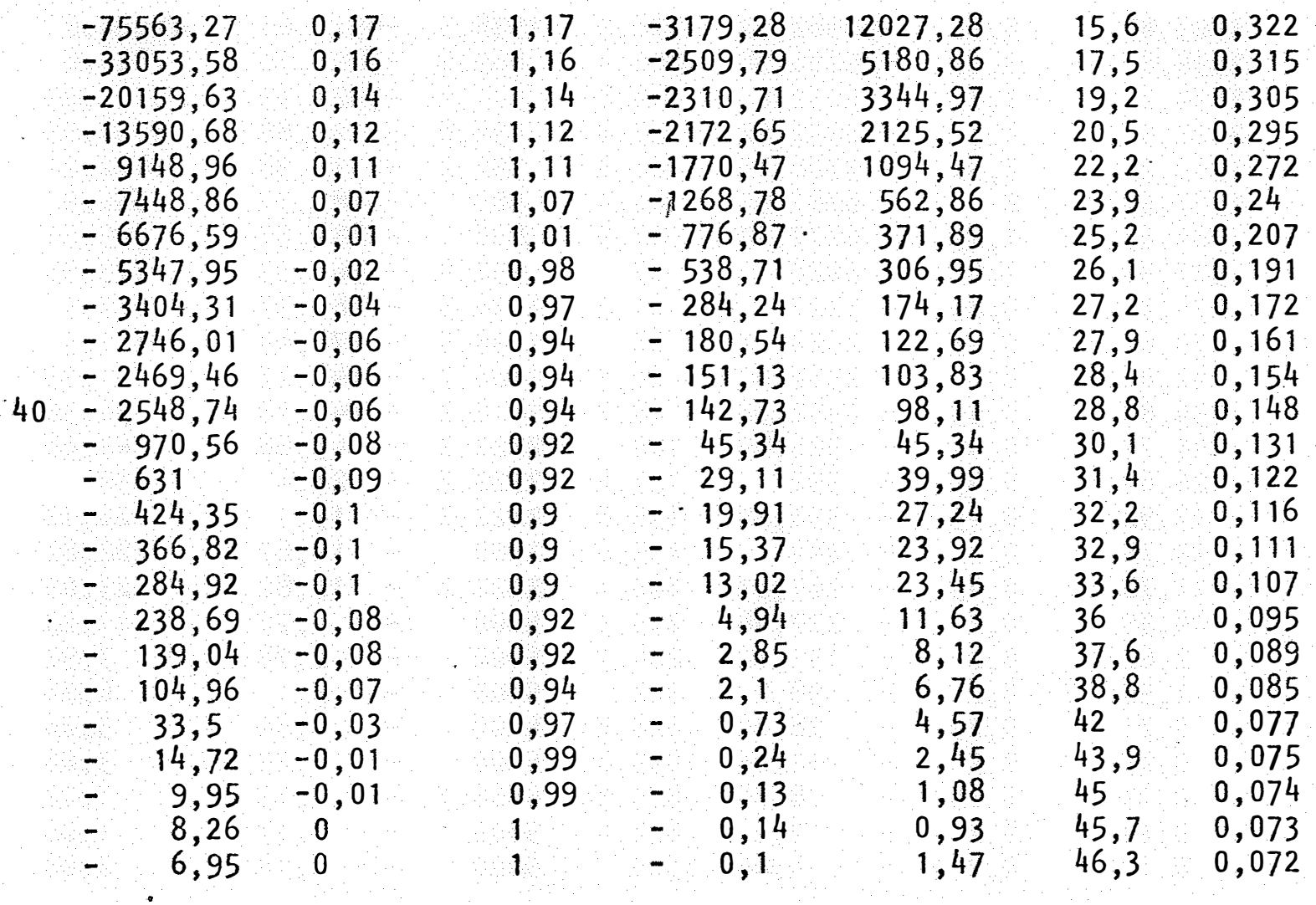

(continua) 
TABELA 11 - Cálculo das funções $D_{g}(\Theta), K(\Theta), D_{m}(\Theta), D_{z}(\Theta), K_{H}(\Theta)$ e $D_{m H}(\Theta)$, para as profundidades de $10,15,20,30,40,50,60,70,80$ e $90 \mathrm{~cm}$, do solo Duna de Areia.

\begin{tabular}{|c|c|c|c|c|c|c|c|}
\hline $\begin{array}{c}\mathrm{z} \\
(\mathrm{cm})\end{array}$ & $\begin{array}{r}-(q) z \cdot 10^{2} \\
(\mathrm{~cm} / \mathrm{h})\end{array}$ & $\begin{array}{c}\partial \Theta / \partial z \cdot 10^{3} \\
\left(\mathrm{~cm}^{-1}\right)\end{array}$ & $\begin{array}{c}D_{g} \\
\left(\mathrm{~cm}^{2} / \mathrm{h}\right) \\
\end{array}$ & $\begin{array}{r}-\mathrm{d} \psi_{\mathrm{m}} / \mathrm{d} \theta \\
\left(\mathrm{cmH}_{2} \mathrm{O}\right)\end{array}$ & $\begin{array}{l}\mathrm{dz} / \mathrm{d} \Theta \\
(\mathrm{cm})\end{array}$ & $\begin{array}{l}\mathrm{K} .10^{2} \\
(\mathrm{~cm} / \mathrm{h})\end{array}$ & $\begin{array}{c}D_{m} \\
\left(\mathrm{~cm}^{2} / \mathrm{h}\right)\end{array}$ \\
\hline 50 & $\begin{array}{l}3852,07 \\
3164,67 \\
2976,45 \\
2902,73 \\
2653,77 \\
1944,68 \\
1100,3 \\
707,72 \\
371 \\
229,46 \\
182,51 \\
168,3 \\
55,15 \\
34,4 \\
24,04 \\
18,53 \\
15,46 \\
6,06 \\
5,33 \\
2,49 \\
0,91 \\
0,33 \\
0,17 \\
0,17 \\
0,12\end{array}$ & $\begin{array}{l}0,1 \\
0,45 \\
0,9 \\
1,35 \\
2,3 \\
2 \\
1,3 \\
0,95 \\
0,8 \\
0,7 \\
0,6 \\
0,55 \\
0,35 \\
0,25 \\
0,35 \\
0,4 \\
0,35 \\
0,25 \\
0,25 \\
0,3 \\
0,35 \\
0,3 \\
0,3 \\
0,3 \\
0,35\end{array}$ & $\begin{array}{r}-385206,56 \\
-\quad 70326,02 \\
-\quad 33071,66 \\
-\quad 21501,68 \\
-11538,14 \\
-\quad 9723,4 \\
-\quad 8463,85 \\
-\quad 7449,68 \\
-\quad 4637,45 \\
-\quad 3278,05 \\
-\quad 3041,78 \\
-\quad 3059,94 \\
-\quad 1575,71 \\
-\quad 1376 \\
-\quad 686,43 \\
-\quad 463,12 \\
-\quad 441,61 \\
-\quad 242,37 \\
-\quad 133,13 \\
-\quad 83,06 \\
-\quad 26,13 \\
-\quad 10,98 \\
-\quad 5,76 \\
-\quad 5,83 \\
-\quad 3,39\end{array}$ & $\begin{array}{l}2819 \\
1419,3 \\
492,6 \\
167,8 \\
57,1 \\
40,7 \\
45,3 \\
57,7 \\
63,3 \\
73,1 \\
93,8 \\
87,3 \\
93,7 \\
99,1 \\
92,3 \\
124,7 \\
175,8 \\
260,3 \\
375,3 \\
421,3 \\
406 \\
418,6 \\
1028,6 \\
857,1 \\
812,5\end{array}$ & $\begin{array}{l}10000 \\
2222,2 \\
1111,1 \\
740,7 \\
434,8 \\
500 \\
769,2 \\
1052,6 \\
1250 \\
1428,6 \\
1666,7 \\
1818,2 \\
2857,1 \\
4000 \\
2857,1 \\
2500 \\
2857,1 \\
4000 \\
4000 \\
3333,3 \\
2857,1 \\
3333,3 \\
3333,3 \\
3333,3 \\
2857\end{array}$ & $\begin{array}{r}-5364,28 \\
-8758,69 \\
-5346,86 \\
-3753,09 \\
-3055,13 \\
-2116,81 \\
-1169,08 \\
-\quad 748,76 \\
-\quad 390,79 \\
-241,84 \\
-193,39 \\
-176,78 \\
-\quad 57,02 \\
-\quad 35,27 \\
-\quad 24,83 \\
-\quad 19,5 \\
-\quad 16,47 \\
-\quad 6,48 \\
-\quad 3,67 \\
-\quad 2,85 \\
-\quad 1,07 \\
-\quad 0,38 \\
-\quad 0,25 \\
-\quad 0,24 \\
-\quad 0,17\end{array}$ & $\begin{array}{r}151221,69 \\
124311,62 \\
26337,92 \\
6298,97 \\
1745,04 \\
860,66 \\
529,11 \\
431,98 \\
247,41 \\
176,8 \\
181,43 \\
154,29 \\
53,42 \\
34,94 \\
22,92 \\
24,3 \\
28,95 \\
16,87 \\
13,78 \\
12,02 \\
4,33 \\
1,58 \\
2,57 \\
2,02 \\
1,35\end{array}$ \\
\hline
\end{tabular}


TABELA 11 - Cálculo das funções $D_{g}(\theta), K(\theta), D_{m}(\theta), D_{z}(\theta), K_{H}(\theta)$ e $D_{m H}(\theta)$, para as profundidades de $10,15,20,30,40,50,60,70,80$ e $90 \mathrm{~cm}$, do solo Duna de Areia.

\begin{tabular}{|c|c|c|c|c|c|c|c|}
\hline $\begin{array}{r}z \\
(\mathrm{~cm})\end{array}$ & $\begin{array}{c}D_{Z} \\
\left(\mathrm{~cm}^{2} / \mathrm{h}\right)\end{array}$ & $\begin{array}{c}\partial \psi_{\mathrm{m}} / \partial z \\
\left(\mathrm{cmH}_{2} \mathrm{O} / \mathrm{cm}\right)\end{array}$ & $\begin{array}{c}\partial \psi_{h} / \partial z \\
\left(\mathrm{cmH}_{2} 0 / \mathrm{cm}\right)\end{array}$ & $\begin{array}{l}\mathrm{K}_{\mathrm{H}} \cdot 10^{2} \\
(\mathrm{~cm} / \mathrm{h})\end{array}$ & $\begin{array}{c}\mathrm{D}_{\mathrm{mH}} \\
(\mathrm{cm} 2 / \mathrm{h})\end{array}$ & $\left(\mathrm{cmH}_{2} \mathrm{O}\right)$ & $\left(\mathrm{cm}^{3} / \mathrm{cm}^{3}\right)$ \\
\hline 50 & $\begin{array}{r}-536428,25 \\
-194637,64 \\
-59409,57 \\
-27800,65 \\
-13283,18 \\
-10584,06 \\
-\quad 8992,96 \\
-\quad 7881,65 \\
-4884,85 \\
-\quad 3454,85 \\
-3223,21 \\
-3214,24 \\
-\quad 1629,14 \\
-1410,94 \\
-\quad 709,35 \\
-\quad 487,43 \\
-\quad 470,55 \\
-\quad 259,24 \\
-\quad 146,92 \\
-\quad 95,1 \\
-\quad 30,45 \\
-\quad 12,56 \\
-\quad 8,33 \\
-\quad 7,84 \\
-\quad 4,74\end{array}$ & $\begin{array}{l}0,06 \\
0,04 \\
0,02 \\
0 \\
-0,01 \\
-0,04 \\
-0,04 \\
-0,04 \\
-0,05 \\
-0,05 \\
-0,05 \\
-0,05 \\
-0,04 \\
-0,06 \\
-0,05 \\
-0,07 \\
-0,07 \\
-0,08 \\
-0,09 \\
-0,09 \\
-0,1 \\
-0,12 \\
-0,13 \\
-0,13 \\
-0,14\end{array}$ & $\begin{array}{l}1,06 \\
1,04 \\
1,02 \\
1 \\
0,99 \\
0,97 \\
0,97 \\
0,96 \\
0,96 \\
0,96 \\
0,96 \\
0,96 \\
0,96 \\
0,94 \\
0,96 \\
0,94 \\
0,93 \\
0,92 \\
0,92 \\
0,91 \\
0,9 \\
0,86 \\
0,88 \\
0,87 \\
0,86\end{array}$ & $\begin{array}{l}-3651,25 \\
-3057,65 \\
-2932,46 \\
-2902,73 \\
-2680,58 \\
-2015,21 \\
-1140,21 \\
-\quad 737,21 \\
-\quad 388,48 \\
-240,28 \\
-191,11 \\
-176,23 \\
-\quad 57,45 \\
-\quad 36,4 \\
-\quad 25,16 \\
-\quad 19,81 \\
-\quad 16,62 \\
-\quad 6,59 \\
-\quad 3,64 \\
-\quad 2,74 \\
-\quad 1,02 \\
-\quad 0,37 \\
-\quad 0,2 \\
-\quad 0,2 \\
-\quad 0,14\end{array}$ & $\begin{array}{r}102930,4 \\
43397,09 \\
1444,, 91 \\
4871,77 \\
1531,1 \\
819,35 \\
516,04 \\
425,31 \\
245,94 \\
175,66 \\
179,29 \\
153,81 \\
53,82 \\
36,06 \\
23,22 \\
24,7 \\
29,21 \\
17,14 \\
13,65 \\
11,54 \\
4,15 \\
1,56 \\
2,03 \\
1,72 \\
1,12\end{array}$ & $\begin{array}{l}16,4 \\
18 \\
19,3 \\
20,3 \\
22,2 \\
23,8 \\
25,2 \\
26,2 \\
27,6 \\
28,4 \\
29,1 \\
29,7 \\
31 \\
32,4 \\
33 \\
33,6 \\
34,3 \\
36,8 \\
38,2 \\
39,4 \\
42,3 \\
43,8 \\
44,7 \\
45,4 \\
45,9\end{array}$ & $\begin{array}{l}0,322 \\
0,321 \\
0,32 \\
0,317 \\
0,295 \\
0,259 \\
0,222 \\
0,203 \\
0,182 \\
0,169 \\
0,161 \\
0,155 \\
0,136 \\
0,127 \\
0,12 \\
0,114 \\
0,11 \\
0,096 \\
0,092 \\
0,089 \\
0,083 \\
0,079 \\
0,077 \\
0,077 \\
0,076\end{array}$ \\
\hline
\end{tabular}

(continua) 
TABELA 11 - Cálculo das funções $D_{g}(\theta), K(\theta), D_{m}(\theta), D_{z}(\theta), K_{H}(\theta)$ e $D_{m H}(\theta)$, para as profundidades de $10,15,20,30,40,50,60,70,80$ e $90 \mathrm{~cm}$, do solo Duna de Areia.

\begin{tabular}{|c|c|c|c|c|c|c|c|}
\hline $\begin{array}{c}z \\
(\mathrm{~cm})\end{array}$ & $\begin{array}{r}-(q)_{z} \cdot 10^{2} \\
(\mathrm{~cm} / \mathrm{h})\end{array}$ & $\begin{array}{c}\partial \Theta / \partial z \cdot 10^{3} \\
\left(\mathrm{~cm}^{-1}\right)\end{array}$ & $\begin{array}{c}D_{g} \\
\left(\mathrm{~cm}^{2} / \mathrm{h}\right)\end{array}$ & $\begin{array}{r}-\mathrm{d} \psi_{\mathrm{m}} / \mathrm{d} \Theta \\
\left(\mathrm{cmH}_{2} \mathrm{O}\right)\end{array}$ & $\begin{array}{l}d z / d O \\
(\mathrm{~cm})\end{array}$ & $\begin{array}{l}\text { K. } 10^{2} \\
(\mathrm{~cm} / \mathrm{h})\end{array}$ & $\left(\mathrm{cm}^{2} / \mathrm{h}\right)$ \\
\hline 60 & $\begin{array}{l}3855,01 \\
3190,12 \\
3045,4 \\
3094,67 \\
3185,16 \\
2609,05 \\
1476,05 \\
917,87 \\
474,66 \\
294,29 \\
227,78 \\
204,91 \\
70,29 \\
42,14 \\
29,19 \\
23,28 \\
19,7 \\
7,65 \\
3,99 \\
2,93 \\
1,13 \\
0,44 \\
0,21 \\
0,19 \\
0,13\end{array}$ & $\begin{array}{l}0,3 \\
0,35 \\
0,35 \\
0,45 \\
1,45 \\
2,45 \\
1,1 \\
0,5 \\
0,3 \\
0,7 \\
0,2 \\
0,2 \\
0,15 \\
0,1 \\
0,15 \\
0,2 \\
0,2 \\
0,3 \\
0,2 \\
0,15 \\
0,15 \\
0,3 \\
0,35 \\
0,3 \\
0,3\end{array}$ & $\begin{array}{r}-128500,24 \\
-\quad 91146,28 \\
-\quad 87011,57 \\
-\quad 68770,52 \\
-\quad 21966,65 \\
-\quad 10649,18 \\
-\quad 13418,64 \\
-\quad 18357,48 \\
-\quad 15821,84 \\
-\quad 4204,17 \\
-11389,25 \\
-10245,56 \\
-\quad 4686 \\
-\quad 4213,5 \\
-\quad 1946 \\
-\quad 1164 \\
-\quad 985,11 \\
-\quad 255,14 \\
-\quad 199,25 \\
-\quad 195,64 \\
-\quad 75,03 \\
-\quad 14,56 \\
-\quad 6,12 \\
-\quad 6,46 \\
-\quad 4,23\end{array}$ & $\begin{array}{c}\infty \\
2426,7 \\
1111,5 \\
600 \\
53,3 \\
29,6 \\
31,7 \\
38,8 \\
50 \\
54,8 \\
56,4 \\
59 \\
78,9 \\
133,3 \\
89,4 \\
85,7 \\
126,4 \\
201,7 \\
306,2 \\
378,6 \\
498,9 \\
747,7 \\
692,3 \\
1500 \\
\infty\end{array}$ & $\begin{array}{l}3333,3 \\
2857,1 \\
2857,1 \\
2222,2 \\
689,7 \\
408,2 \\
909,1 \\
2000 \\
3333,3 \\
1428,6 \\
5000 \\
5000 \\
6666,7 \\
10000 \\
6666,7 \\
5000 \\
5000 \\
3333,3 \\
5000 \\
6666,7 \\
6666,7 \\
3333,3 \\
2857,1 \\
3333,3 \\
3333,3\end{array}$ & $\begin{array}{r}\infty \\
-21173,37 \\
-\quad 4984,57 \\
-\quad 4939,28 \\
-\quad 3451,7 \\
-\quad 2812,81 \\
-\quad 1529,34 \\
-\quad 936,05 \\
-\quad 481,89 \\
-\quad 306,04 \\
-\quad 230,38 \\
-\quad 207,36 \\
-\quad 71,13 \\
-\quad 42,7 \\
-\quad 29,59 \\
-\quad 23,69 \\
-\quad 20,21 \\
-\quad 8,15 \\
-\quad 4,24 \\
-\quad 3,11 \\
-\quad 1,22 \\
-\quad 0,56 \\
-\quad 0,28 \\
-\quad 0,35 \\
0 \quad 0\end{array}$ & $\begin{array}{r}\infty \\
513807,08 \\
55404,69 \\
25435,67 \\
1838,18 \\
831,69 \\
484,44 \\
363,51 \\
241,15 \\
167,8 \\
130 \\
122,38 \\
56,16 \\
56,94 \\
26,47 \\
20,3 \\
25,55 \\
16,43 \\
13 \\
11,78 \\
6,07 \\
4,21 \\
1,96 \\
5,28 \\
\infty\end{array}$ \\
\hline
\end{tabular}


TABELA 11 - Cálculo das funções $D_{g}(\theta), K(\theta), D_{m}(\theta), D_{z}(\theta), K_{H}(\theta)$ e $D_{m H}(\theta)$, para as profundidades de $10,15,20,30,40,50,60,70,80$ e $90 \mathrm{~cm}$, do solo Duna de Areia.

\begin{tabular}{|c|c|c|c|c|c|c|c|}
\hline $\begin{array}{c}z \\
(\mathrm{~cm})\end{array}$ & $\begin{array}{c}\mathrm{D}_{z} \\
\left(\mathrm{~cm}^{2} / \mathrm{h}\right)\end{array}$ & $\begin{array}{c}\partial \psi_{\mathrm{m}} / \partial z \\
\left(\mathrm{cmH}_{2} \mathrm{O} / \mathrm{cm}\right)\end{array}$ & $\begin{array}{c}\partial \psi_{h} / \partial z \\
\left(\mathrm{cmH}_{2} \mathrm{O} / \mathrm{cm}\right)\end{array}$ & $\begin{array}{l}\mathrm{K}_{\mathrm{H}} \cdot 10^{2} \\
(\mathrm{~cm} / \mathrm{h})\end{array}$ & $\begin{array}{c}D_{\mathrm{mH}} \\
\left(\mathrm{cm}^{2} / \mathrm{h}\right)\end{array}$ & $\left(\mathrm{cmH}_{2} \mathrm{O}\right)$ & $\left(\mathrm{cm}^{3} / \mathrm{cm}^{3}\right)$ \\
\hline 60 & $\begin{array}{r}\infty \\
-604953,36 \\
-142416,26 \\
-94206,19 \\
-23804,83 \\
-11480,87 \\
-13903,08 \\
-18720,99 \\
-16062,98 \\
-4371,97 \\
-11519,24 \\
-10367,93 \\
-4742,16 \\
-4270,44 \\
-1972,47 \\
-1184,3 \\
-1010,66 \\
-\quad 271,57 \\
-\quad 212,25 \\
-\quad 207,42 \\
-\quad 81,1 \\
-\quad 18,77 \\
-\quad 8,08 \\
-\quad 11,74 \\
\infty\end{array}$ & $\begin{array}{r}-0,12 \\
-0,14 \\
-0,16 \\
-0,16 \\
-0,18 \\
-0,16 \\
-0,13 \\
-0,12 \\
-0,12 \\
-0,12 \\
-0,12 \\
-0,13 \\
-0,11 \\
-0,12 \\
-0,12 \\
-0,13 \\
-0,13 \\
-0,17 \\
-0,19 \\
-0,2 \\
-0,25 \\
-0,26 \\
-0,26 \\
-0,26 \\
-0,25\end{array}$ & $\begin{array}{l}0,88 \\
0,86 \\
0,85 \\
0,84 \\
0,83 \\
0,85 \\
0,88 \\
0,88 \\
0,88 \\
0,88 \\
0,88 \\
0,87 \\
0,89 \\
0,88 \\
0,88 \\
0,88 \\
0,87 \\
0,83 \\
0,82 \\
0,8 \\
0,76 \\
0,74 \\
0,75 \\
0,75 \\
0,75\end{array}$ & $\begin{array}{r}-4355,94 \\
-3709,44 \\
-3604,03 \\
-3684,13 \\
-3860,81 \\
-3087,63 \\
-1686,91 \\
-1043,04 \\
-539,38 \\
-332,53 \\
-256,85 \\
-235,53 \\
-\quad 78,98 \\
-\quad 47,88 \\
-\quad 33,17 \\
-\quad 26,61 \\
-\quad 22,78 \\
-\quad 9,22 \\
-\quad 4,89 \\
-\quad 3,67 \\
-\quad 1,49 \\
-\quad 0,59 \\
-\quad 0,29 \\
-\quad 0,26 \\
-\quad 0,17\end{array}$ & $\begin{array}{r}\infty \\
90015,79 \\
40059,66 \\
22104,81 \\
2056,05 \\
912,95 \\
534,35 \\
405,06 \\
269,92 \\
182,33 \\
146,06 \\
139 \\
62,35 \\
63,84 \\
29,67 \\
22,8 \\
28,79 \\
18,6 \\
14,97 \\
13,89 \\
7,44 \\
4,41 \\
1,99 \\
3,9 \\
\infty\end{array}$ & $\begin{array}{l}16,7 \\
18,2 \\
19,5 \\
20,5 \\
22 \\
23,2 \\
24,5 \\
25,3 \\
26,3 \\
27 \\
27,5 \\
27,9 \\
29,3 \\
30,3 \\
31,3 \\
31,6 \\
32,2 \\
34,4 \\
35,9 \\
37 \\
39,9 \\
41,6 \\
42,5 \\
43,1 \\
43,5\end{array}$ & $\begin{array}{l}0,324 \\
0,324 \\
0,323 \\
0,322 \\
0,318 \\
0,28 \\
0,233 \\
0,21 \\
0,188 \\
0,175 \\
0,166 \\
0,159 \\
0,138 \\
0,127 \\
0,123 \\
0,119 \\
0,114 \\
0,1 \\
0,094 \\
0,091 \\
0,084 \\
0,081 \\
0,08 \\
0,079 \\
0,079\end{array}$ \\
\hline
\end{tabular}

(continua) 
TABELA 11 - Cãlculo das funções $D_{g}(\theta), K(\theta), D_{m}(\theta), D_{z}(\theta), K_{H}(\theta)$ e $D_{m H}(\theta)$, para as profundidades de $10,15,20,30,40,50,60,70,80 \mathrm{e}$ $90 \mathrm{~cm}$, do solo Duna de Areia.

\begin{tabular}{|c|c|c|c|c|c|c|c|}
\hline $\begin{array}{c}z \\
(\mathrm{~cm})\end{array}$ & $\begin{array}{c}-(q) z \cdot 10^{2} \\
(\mathrm{~cm} / \mathrm{h})\end{array}$ & $\begin{array}{c}\partial \Theta / \partial z \cdot 10^{3} \\
\left(\mathrm{~cm}^{-1}\right)\end{array}$ & $\left(\begin{array}{c}\mathrm{Dg}^{2} \\
\left.\mathrm{~cm}^{2} / \mathrm{h}\right)\end{array}\right.$ & $\begin{array}{r}-\mathrm{d} \psi / \mathrm{d} \theta \\
\left(\mathrm{cmH}_{2} \mathrm{O}\right)\end{array}$ & $\begin{array}{c}d z / d \theta \\
(c m)\end{array}$ & $\begin{array}{l}\text { K. } 10^{2} \\
(\mathrm{~cm} / \mathrm{h})\end{array}$ & $\begin{array}{c}D_{m} \\
\left(\mathrm{~cm}^{2} / \mathrm{h}\right)\end{array}$ \\
\hline 70 & $\begin{array}{c}3853,51 \\
3218,86 \\
3102,75 \\
3153,26 \\
3439,01 \\
3199,74 \\
1981,75 \\
1183,12 \\
583,74 \\
361,97 \\
275,92 \\
240,95 \\
85,81 \\
49,86 \\
33,86 \\
27,76 \\
23,88 \\
9,24 \\
4,79 \\
3,46 \\
1,3 \\
0,49 \\
0,26 \\
0,23 \\
0,15\end{array}$ & $\begin{array}{l}0,05 \\
0,05 \\
0,05 \\
0,05 \\
0,15 \\
1,5 \\
1,4 \\
0,9 \\
0,5 \\
0,45 \\
0,45 \\
0,4 \\
0,35 \\
0,4 \\
0,25 \\
0,2 \\
0,25 \\
0,35 \\
0,35 \\
0,3 \\
0,25 \\
0,2 \\
0,2 \\
0,2 \\
0,15\end{array}$ & $\begin{array}{l}-770702,24 \\
-643772,46 \\
-620549,4 \\
-630652,02 \\
-229267,31 \\
-21331,58 \\
-14155,38 \\
-13145,74 \\
-\quad 11674,86 \\
-\quad 8043,83 \\
-\quad 6131,45 \\
-\quad 6023,71 \\
-\quad 2451,57 \\
-\quad 1246,37 \\
-\quad 1354,2 \\
-\quad 1388 \\
-\quad 955,05 \\
-\quad 264,02 \\
-\quad 136,74 \\
-\quad 115,25 \\
-\quad 51,86 \\
-\quad 24,7 \\
-\quad 12,8 \\
-\quad 11,28 \\
-\quad 9,87\end{array}$ & $\begin{array}{c}\infty \\
1909,1 \\
944,8 \\
861,2 \\
235,3 \\
50 \\
33,9 \\
42,3 \\
83,4 \\
63,4 \\
63,8 \\
69,5 \\
102,5 \\
105,9 \\
100 \\
111,1 \\
129,7 \\
169,1 \\
204,1 \\
250,2 \\
607,6 \\
1082 \\
798,7 \\
642,4 \\
461,5\end{array}$ & $\begin{array}{l}20000 \\
20000 \\
20000 \\
20000 \\
6566,7 \\
666,7 \\
714,3 \\
1111,1 \\
2000 \\
2222,2 \\
2222,2 \\
2500 \\
2857,1 \\
2500 \\
4000 \\
5000 \\
4000 \\
2857,1 \\
2857,1 \\
3333,3 \\
4000 \\
5000 \\
5000 \\
5000 \\
6666,7\end{array}$ & $\begin{array}{l}\infty \\
-3558,54 \\
-3256,58 \\
-3295,16 \\
-3564,83 \\
-3459,17 \\
-2080,36 \\
-1229,94 \\
-\quad 602,84 \\
-\quad 372,6 \\
-\quad 284,08 \\
-247,84 \\
-\quad 89 \\
-\quad 52,06 \\
-\quad 34,72 \\
-\quad 28,39 \\
-\quad 24,68 \\
-\quad 9,82 \\
-\quad 5,115 \\
-\quad 3,74 \\
-\quad 1,53 \\
-\quad 0,63 \\
-\quad 0,3 \\
-\quad 0,26 \\
-\quad 0,16\end{array}$ & $\begin{array}{c}\infty \\
67935,78 \\
30766,58 \\
28379,34 \\
8387,83 \\
1729,59 \\
704,33 \\
520,3 \\
382,03 \\
236,15 \\
181,32 \\
172,31 \\
91,25 \\
55,12 \\
34,72 \\
31,55 \\
32 \\
16,61 \\
10,52 \\
9,35 \\
9,29 \\
6,82 \\
2,43 \\
1,66 \\
0,73\end{array}$ \\
\hline
\end{tabular}

(continua) 
TABELA 11 - Cálculo das funções $D_{g}(\theta), K(\theta), D_{m}(\theta), D_{z}(\theta), K_{H}(\theta)$ e $D_{m H}(\theta)$, para as profundidades de $10,15,20,30,40,50,60,70,80$ e $90 \mathrm{~cm}$, do solo Duna de Areia.

\begin{tabular}{|c|c|c|c|c|c|c|c|}
\hline$(\mathrm{cm})$ & $\begin{array}{c}D_{Z} \\
\left(\mathrm{~cm}^{2} / \mathrm{h}\right)\end{array}$ & $\begin{array}{c}\partial \psi_{\mathrm{m}} / \partial z \\
\left(\mathrm{cmH}_{2} 0 / \mathrm{cm}\right)\end{array}$ & $\begin{array}{c}\partial \psi_{\mathrm{h}} / \partial \mathrm{z} \\
\left(\mathrm{cmH}_{2} \mathrm{O} / \mathrm{cm}\right)\end{array}$ & $\begin{array}{l}\mathrm{K}_{\mathrm{H}} \cdot 10^{2} \\
(\mathrm{~cm} / \mathrm{h})\end{array}$ & $\begin{array}{c}\mathrm{D}_{\mathrm{mH}} \\
\left(\mathrm{cm}^{2} / \mathrm{h}\right)\end{array}$ & $\begin{array}{c}\psi_{\mathrm{m}} \\
\left(\mathrm{cmH}_{2} 0\right)\end{array}$ & $\left(\mathrm{cm}^{3} / \mathrm{cm}^{3}\right)$ \\
\hline
\end{tabular}

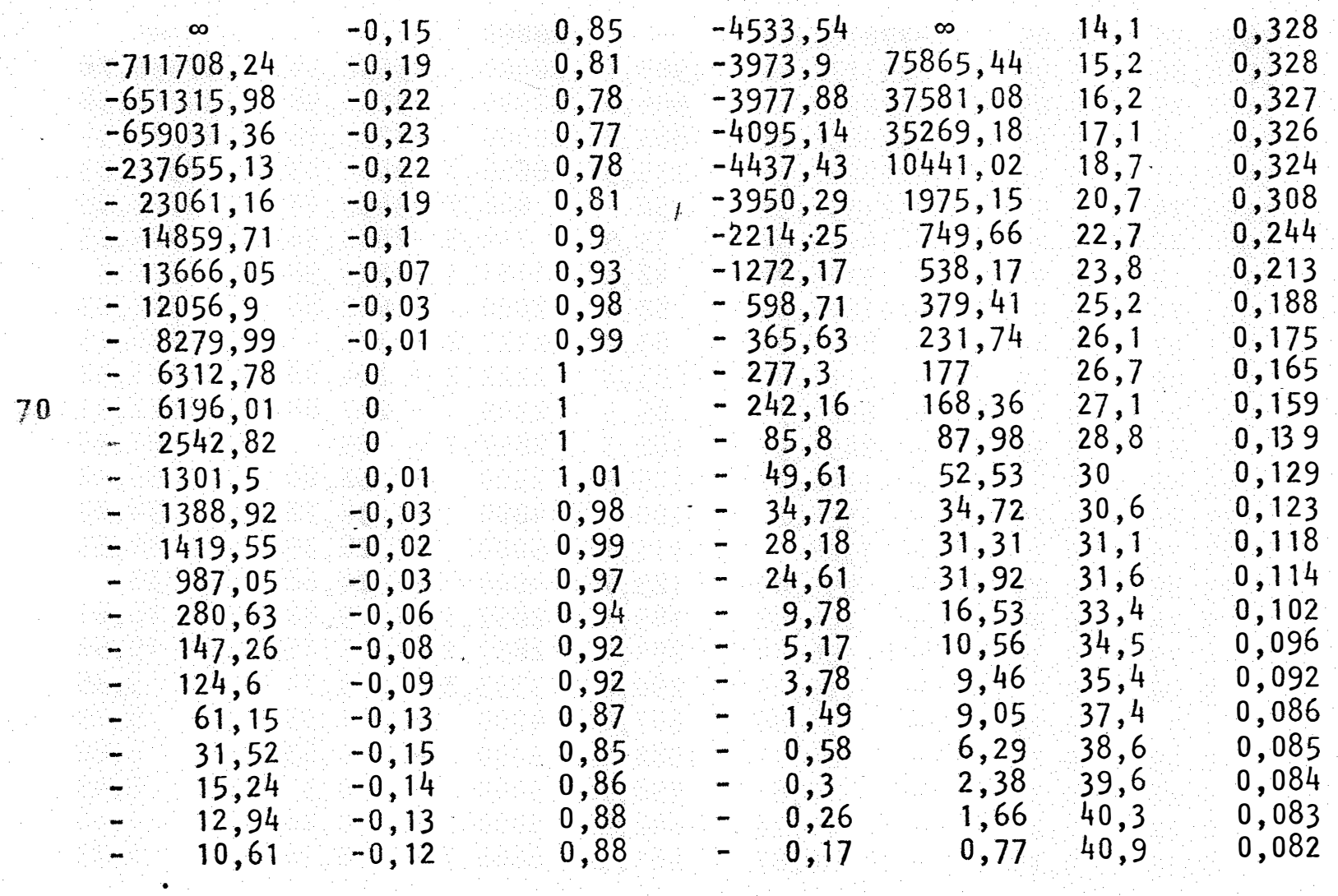

(continua) 
TABELA 11 - Cälculo das funções $D_{g}(\theta), K(\theta), D_{m}(\theta), D_{z}(\theta), K_{H}(\theta)$ e $D_{m H}(\theta)$, para as profundidades de $10,15,20,30,40,50,60,70,80 \mathrm{e}$ $90 \mathrm{~cm}$, do solo Duna de Areia.

\begin{tabular}{|c|c|c|c|c|c|c|c|}
\hline $\begin{array}{c}\mathrm{z} \\
(\mathrm{cm})\end{array}$ & $\begin{array}{c}-(\mathrm{q}) z \cdot 10^{2} \\
(\mathrm{~cm} / \mathrm{h})\end{array}$ & $\begin{array}{c}\partial \Theta / \partial z \cdot 10^{3} \\
\left(\mathrm{~cm}^{-1}\right)\end{array}$ & $\begin{array}{c}\mathrm{D}_{\mathrm{g}} \\
\left(\mathrm{cm}^{2} / \mathrm{h}\right)\end{array}$ & $\begin{array}{r}-\mathrm{d} \psi_{\mathrm{m}} / \mathrm{d} \theta \\
\left(\mathrm{cmH}_{2} \mathrm{O}\right) \\
\end{array}$ & $\begin{array}{l}d z / d \theta \\
(\mathrm{cm})\end{array}$ & $\begin{array}{l}\mathrm{K} \cdot 10^{2} \\
(\mathrm{~cm} / \mathrm{h})\end{array}$ & $\begin{array}{c}D_{m} \\
\left(\mathrm{~cm}^{2} / \mathrm{h}\right)\end{array}$ \\
\hline 80 & $\begin{array}{l}3853,81 \\
3248,5 \\
3164,02 \\
3215 \\
3576,31 \\
3620,62 \\
2522,51 \\
1494,22 \\
706,39 \\
430,49 \\
324,88 \\
279,5 \\
101,16 \\
58,14 \\
39,69 \\
32,26 \\
27,55 \\
10,73 \\
5,62 \\
4,06 \\
1,49 \\
0,56 \\
0,3 \\
0,27 \\
0,19\end{array}$ & $\begin{array}{l}-0,25 \\
-0,25 \\
-0,25 \\
-0,2 \\
-0,15 \\
0,45 \\
2,7 \\
2,15 \\
1,55 \\
1,4 \\
1,3 \\
1,1 \\
0,7 \\
0,7 \\
0,65 \\
0,65 \\
0,65 \\
0,6 \\
0,6 \\
0,6 \\
0,5 \\
0,3 \\
0,25 \\
0,2 \\
0,15\end{array}$ & $\begin{array}{l}154152,53 \\
129940,12 \\
126560,8 \\
160749,79 \\
238420,89 \\
-80458,17 \\
-\quad 9342,63 \\
-6949,85 \\
-4557,35 \\
-\quad 3074,94 \\
-2499,11 \\
-2540,86 \\
-1445,14 \\
-\quad 830,57 \\
-\quad 610,54 \\
-\quad 496,31 \\
-\quad 423,9 \\
-\quad 178,83 \\
-\quad 93,71 \\
-\quad 67,6 \\
-\quad 29,87 \\
-\quad 18,83 \\
-\quad 11,83 \\
-\quad 13,32 \\
-\quad 12,71\end{array}$ & $\begin{array}{c}1 \\
1400 \\
743,4 \\
800 \\
300,7 \\
101,2 \\
49,7 \\
51,9 \\
68,4 \\
68,4 \\
55,6 \\
53 \\
87,3 \\
65,5 \\
70,6 \\
82,8 \\
80,7 \\
164,3 \\
204,1 \\
232,2 \\
290,7 \\
525,6 \\
980,2 \\
692,3 \\
461,5\end{array}$ & $\begin{array}{r}-4000 \\
-4000 \\
-4000 \\
-5000 \\
-6666,7 \\
2222,2 \\
370,4 \\
465,1 \\
645,2 \\
714,3 \\
769,2 \\
909,1 \\
1428,6 \\
1428,6 \\
1538,5 \\
1538,5 \\
1538,5 \\
1666,7 \\
1666,7 \\
1666,7 \\
2000 \\
3333,3 \\
4000 \\
5000 \\
6666,7\end{array}$ & $\begin{array}{r}\infty \\
-2406,3 \\
-2668,17 \\
-2771,55 \\
-3421,95 \\
-3793,43 \\
-2913,68 \\
-1681,98 \\
-\quad 790,18 \\
-476,06 \\
-\quad 350,18 \\
-296,79 \\
-\quad 107,75 \\
-\quad 60,94 \\
-\quad 41,59 \\
-\quad 34,09 \\
-\quad 29,08 \\
-\quad 11,9 \\
-\quad 6,41 \\
-\quad 4,71 \\
-\quad 1,75 \\
-\quad 0,67 \\
-\quad 0,39 \\
-\quad 0,31 \\
-\quad 0,2\end{array}$ & $\begin{array}{r}\infty \\
33688,18 \\
19834,18 \\
22172,39 \\
10290,99 \\
3840,32 \\
1448,79 \\
873,3 \\
540,59 \\
325,51 \\
194,54 \\
157,22 \\
94,1 \\
39,94 \\
29,36 \\
28,22 \\
23,47 \\
19,56 \\
13,08 \\
10,94 \\
5,08 \\
3,52 \\
3,84 \\
2,14 \\
0,95\end{array}$ \\
\hline
\end{tabular}

(continua) 
TABELA 11 - Cálculo das funções $D_{g}(\theta), K(\theta), D_{m}(\theta), D_{z}(\theta), K_{H}(\theta)$ e $D_{m H}(\theta)$, para as profundidades de $10,15,20,30,40,50,60,70,80$ e $90 \mathrm{~cm}$, do solo Duna de Areia.

\begin{tabular}{|c|c|c|c|c|c|c|c|}
\hline $\begin{array}{c}z \\
(\mathrm{~cm})\end{array}$ & $\begin{array}{c}\mathrm{D}_{z} \\
\left(\mathrm{~cm}^{2} / \mathrm{h}\right)\end{array}$ & $\begin{array}{c}\partial \psi_{\mathrm{m}} / \partial z \\
\left(\mathrm{cmH}_{2} \mathrm{O} / \mathrm{cm}\right)\end{array}$ & $\begin{array}{c}\partial \psi_{h} / \partial z \\
\left(\mathrm{cmH}_{2} \mathrm{O} / \mathrm{cm}\right)\end{array}$ & $\begin{array}{l}\mathrm{K}_{\mathrm{H}} \cdot 10^{2} \\
(\mathrm{~cm} / \mathrm{h})\end{array}$ & $\begin{array}{c}D_{\mathrm{mH}} \\
\left(\mathrm{cm}^{2} / \mathrm{h}\right)\end{array}$ & $\begin{array}{c}\psi_{\mathrm{m}} \\
\left(\mathrm{cmH}_{2} \mathrm{O}\right)\end{array}$ & $\left(\mathrm{cm}^{3} / \mathrm{cm}^{3}\right)$ \\
\hline 80 & $\begin{array}{r}\infty \\
96251,94 \\
106726,65 \\
138577,4 \\
228129,89 \\
-84298,49 \\
-10791,42 \\
-\quad 7823,15 \\
-\quad 5097,93 \\
-\quad 3400,46 \\
-2693,66 \\
-2698,08 \\
-\quad 1539,25 \\
-\quad 870,51 \\
-\quad 639,9 \\
-\quad 524,52 \\
-\quad 447,36 \\
-\quad 198,4 \\
-\quad 106,79 \\
-\quad 78,54 \\
-\quad 34,95 \\
-\quad 22,35 \\
-\quad 15,67 \\
-\quad 15,46 \\
-\quad 13,65\end{array}$ & $\begin{array}{l}-0,07 \\
-0,1 \\
-0,12 \\
-0,14 \\
-0,16 \\
-0,19 \\
-0,16 \\
-0,15 \\
-0,14 \\
-0,13 \\
-0,13 \\
-0,13 \\
-0,13 \\
-0,12 \\
-0,12 \\
-0,12 \\
-0,12 \\
-0,12 \\
-0,11 \\
-0,11 \\
-0,1 \\
-0,1 \\
-0,1 \\
-0,09 \\
-0,09\end{array}$ & $\begin{array}{l}0,93 \\
0,9 \\
0,88 \\
0,86 \\
0,84 \\
0,82 \\
0,84 \\
0,85 \\
0,86 \\
0,87 \\
0,87 \\
0,87 \\
0,88 \\
0,88 \\
0,88 \\
0,88 \\
0,88 \\
0,88 \\
0,89 \\
0,89 \\
0,9 \\
0,9 \\
0,9 \\
0,91 \\
0,92\end{array}$ & $\begin{array}{l}-4143,89 \\
-3589,51 \\
-3575,16 \\
-3738,37 \\
-4257,52 \\
-4442,48 \\
-3002,99 \\
-1757,9 \\
-821,38 \\
-497,68 \\
-373,43 \\
-321,26 \\
-115,61 \\
-\quad 66,07 \\
-\quad 45,1 \\
-\quad 36,45 \\
-\quad 31,13 \\
-\quad 12,12 \\
-\quad 6,32 \\
-\quad 4,56 \\
-\quad 1,67 \\
-\quad 0,63 \\
-\quad 0,33 \\
-\quad 0,29 \\
-\quad 0,21\end{array}$ & $\begin{array}{c}\infty \\
50253,08 \\
26576,44 \\
29906,94 \\
12803,84 \\
4497,38 \\
1493,2 \\
912,72 \\
561,93 \\
340,29 \\
207,46 \\
170,18 \\
100,97 \\
43,3 \\
31,83 \\
30,17 \\
25,12 \\
19,93 \\
12,9 \\
10,58 \\
4,85 \\
3,3 \\
3,2 \\
2,03 \\
0,96\end{array}$ & $\begin{array}{l}13,7 \\
14,4 \\
15,1 \\
15,9 \\
17,5 \\
19,4 \\
22,4 \\
23,9 \\
25,8 \\
26,8 \\
27,4 \\
27,8 \\
29,3 \\
30,4 \\
30,8 \\
31,3 \\
31,6 \\
33,3 \\
34,4 \\
35,3 \\
37,3 \\
38,6 \\
39,7 \\
40,6 \\
41,2\end{array}$ & $\begin{array}{l}0,325 \\
0,325 \\
0,324 \\
0,323 \\
0,321 \\
0,31 \\
0,261 \\
0,228 \\
0,198 \\
0,184 \\
0,175 \\
0,167 \\
0,145 \\
0,135 \\
0,128 \\
0,123 \\
0,119 \\
0,107 \\
0,101 \\
0,097 \\
0,089 \\
0,085 \\
0,084 \\
0,083 \\
0,082\end{array}$ \\
\hline
\end{tabular}

(continua) 
TABELA 11 - Cãlculo das funções $D_{g}(\theta), K(\theta), D_{m}(\theta), D_{z}(\theta), K_{H}(\theta)$ e $D_{m H}(\theta)$, para as profundidades de $10,15,20,30,40,50,60,70,80$ e $90 \mathrm{~cm}$, do solo Duna de Areia.

\begin{tabular}{|c|c|c|c|c|c|c|c|}
\hline $\begin{array}{c}z \\
(\mathrm{~cm})\end{array}$ & $\begin{array}{l}(\mathrm{q})_{z} \cdot 10^{2} \\
(\mathrm{~cm} / \mathrm{h})\end{array}$ & $\begin{array}{c}\partial \theta / \partial z \cdot 10^{3} \\
\left(\mathrm{~cm}^{-1}\right)\end{array}$ & $\left(\mathrm{cm}^{2} / \mathrm{h}\right)$ & $\begin{array}{r}-\mathrm{d} \psi_{\mathrm{m}} / \mathrm{d} \theta \\
\left(\mathrm{cmH}_{2} \mathrm{O}\right) \\
\end{array}$ & $\begin{array}{l}\mathrm{dz} / \mathrm{d} \theta \\
(\mathrm{cm})\end{array}$ & $\begin{array}{l}\mathrm{k} \cdot 10^{2} \\
(\mathrm{~cm} / \mathrm{h})\end{array}$ & $\begin{array}{c}D_{m} \\
\left(\mathrm{~cm}^{2} / \mathrm{h}\right)\end{array}$ \\
\hline 90 & $\begin{array}{c}3208,35 \\
3246,91 \\
3660,69 \\
3859,88 \\
2952,52 \\
1870,7 \\
852,31 \\
506,6 \\
383,75 \\
330,05 \\
118,84 \\
66,56 \\
45,62 \\
36,7 \\
31,25 \\
12,26 \\
6,45 \\
4,65 \\
1,76 \\
0,7 \\
0,36 \\
0,33 \\
0,24\end{array}$ & $\begin{array}{l}-0,1 \\
-0,1 \\
-0,05 \\
-0,05 \\
2,45 \\
2,95 \\
2,45 \\
2,1 \\
1,9 \\
1,8 \\
1,55 \\
1,4 \\
1,3 \\
1,2 \\
1,15 \\
0,95 \\
0,9 \\
0,85 \\
0,75 \\
0,85 \\
0,75 \\
0,65 \\
0,6\end{array}$ & $\begin{array}{r}256900,75 \\
218662,67 \\
320835,35 \\
324691,14 \\
732137,76 \\
-857751,27 \\
-\quad 12051,1, \\
-\quad 6341,36 \\
-\quad 3478,81 \\
-\quad 2412,39 \\
-\quad 2019,75 \\
-\quad 1833,61 \\
-\quad 766,71 \\
-\quad 475,39 \\
-\quad 350,88 \\
-\quad 305,83 \\
-\quad 271,75 \\
-\quad 129,04 \\
-\quad 71,66 \\
-\quad 54,71 \\
-\quad 23,46 \\
-\quad 8,18 \\
-\quad 4,77 \\
-\quad 5,06 \\
-\quad 4,04\end{array}$ & $\begin{array}{c}\infty \\
1200 \\
1500 \\
4800 \\
606,7 \\
221,4 \\
41,9 \\
35,5 \\
53,4 \\
60 \\
45,2 \\
43 \\
91 \\
96 \\
100 \\
122,7 \\
127,7 \\
169,8 \\
213,6 \\
235,1 \\
261 \\
363,9 \\
451,9 \\
371,7 \\
380,2\end{array}$ & $\begin{array}{r}-6666,7 \\
-6666,7 \\
-10000 \\
-10000 \\
-20000 \\
22222,2 \\
408,2 \\
339 \\
408,2 \\
476,2 \\
526,3 \\
555,6 \\
645,2 \\
714,3 \\
769,2 \\
833,3 \\
869,6 \\
1052,6 \\
1111,1 \\
1176,5 \\
1333,3 \\
1176,5 \\
1333,3 \\
1538,5 \\
1666,7\end{array}$ & $\begin{array}{r}\infty \\
-2779,61 \\
-2789,87 \\
-2193,86 \\
-3552,9 \\
-3898,72 \\
-3290,46 \\
-2089,33 \\
-980,49 \\
-579,61 \\
-419,77 \\
-\quad 357,7 \\
-138,35 \\
-\quad 76,69 \\
-\quad 52,43 \\
-\quad 43,04 \\
-\quad 36,63 \\
-\quad 14,62 \\
-\quad 7,98 \\
-\quad 5,81 \\
-\quad 2,19 \\
-\quad 1,01 \\
-\quad 0,54 \\
-\quad 0,43 \\
-\quad 0,31\end{array}$ & $\begin{array}{r}\infty \\
33355,32 \\
41848,09 \\
105305,24 \\
21556,95 \\
8631,86 \\
1379,36 \\
741,13 \\
523,2 \\
347,65 \\
189,57 \\
153,63 \\
125,89 \\
73,85 \\
52,43 \\
52,79 \\
46,78 \\
24,82 \\
17,05 \\
13,66 \\
5,71 \\
3,66 \\
2,45 \\
1,61 \\
1,19\end{array}$ \\
\hline
\end{tabular}


TABELA 11 - Cálculo das funções $D_{g}(\theta), K(\theta), D_{m}(\theta), D_{z}(\theta), K_{H}(\theta)$ e $D_{m H}(\theta)$, para as profundidades de $10,15,20,30,40,50,60,70,80$ e $90 \mathrm{~cm}$, do solo Duna de Areia.

\begin{tabular}{|c|c|c|c|c|c|c|c|}
\hline $\begin{array}{c}z \\
(\mathrm{~cm})\end{array}$ & $\begin{array}{c}\mathrm{D}_{\mathrm{Z}} \\
\left(\mathrm{cm}^{2} / \mathrm{h}\right)\end{array}$ & $\begin{array}{c}\partial \psi_{\mathrm{m}} / \partial z \\
\left(\mathrm{cmH}_{2} \mathrm{O} / \mathrm{cm}\right)\end{array}$ & $\begin{array}{c}\partial \psi_{h} / \partial z \\
\left(\mathrm{cmH}_{2} 0 / \mathrm{cm}\right)\end{array}$ & $\begin{array}{l}K_{H} \cdot 10^{2} \\
(\mathrm{~cm} / \mathrm{h})\end{array}$ & $\begin{array}{c}D_{\mathrm{mH}} \\
\left(\mathrm{cm}^{2} / \mathrm{h}\right)\end{array}$ & $\begin{array}{c}\psi_{\mathrm{m}} \\
\left(\mathrm{cmH}_{2} \mathrm{O}\right)\end{array}$ & $\left(\mathrm{cm}^{3} / \mathrm{cm}^{3}\right)$ \\
\hline 90 & $\begin{array}{r}\infty \\
185307,35 \\
278987,26 \\
219385,9 \\
710580,81 \\
-866383,13 \\
-13430,46 \\
-7082,49 \\
-4002,01 \\
-2760,04 \\
-2209,33 \\
-1987,25 \\
-\quad 892,6 \\
-\quad 549,25 \\
-\quad 403,32 \\
-\quad 358,63 \\
-\quad 318,53 \\
-\quad 153,87 \\
-\quad 88,71 \\
-\quad 68,37 \\
-\quad 29,17 \\
-\quad 11,84 \\
-\quad 7,22 \\
-\quad 6,68 \\
-\quad 5,23\end{array}$ & $\begin{array}{l}0,03 \\
0,01 \\
0 \\
-0,03 \\
-0,07 \\
-0,01 \\
-0,13 \\
-0,1 \\
-0,04 \\
0 \\
0,02 \\
0,04 \\
0,06 \\
0,05 \\
0,06 \\
0,06 \\
0,07 \\
0,05 \\
0,04 \\
0,02 \\
-0,01 \\
-0,02 \\
-0,03 \\
-0,04 \\
-0,04\end{array}$ & $\begin{array}{l}1,03 \\
1,01 \\
1 \\
0,97 \\
0,94 \\
0,9 \\
0,88 \\
0,9 \\
0,97 \\
1 \\
1,02 \\
1,04 \\
1,06 \\
1,05 \\
1,06 \\
1,06 \\
1,07 \\
1,05 \\
1,04 \\
1,02 \\
0,99 \\
0,98 \\
0,98 \\
0,97 \\
0,97\end{array}$ & $\begin{array}{l}-3741,27 \\
-3247,47 \\
-3224,48 \\
-3347,33 \\
-3915,18 \\
-4265,06 \\
-3374,31 \\
-2076,56 \\
-\quad 863,22 \\
-\quad 506,6 \\
-376,23 \\
-\quad 318,89 \\
-112,64 \\
-\quad 63,39 \\
-\quad 43,24 \\
-\quad 34,79 \\
-\quad 29,34 \\
-\quad 11,68 \\
-\quad 6,23 \\
-\quad 4,58 \\
-\quad 1,78 \\
-\quad 0,71 \\
-\quad 0,37 \\
-\quad 0,34 \\
-\quad 0,25\end{array}$ & $\begin{array}{r}\infty \\
38969,58 \\
48367,13 \\
160671,91 \\
23755 \\
9442,94 \\
1414,5 \\
737,3 \\
471,29 \\
303,86 \\
169,91 \\
136,96 \\
102,5 \\
60,88 \\
43,24 \\
42,68 \\
37,47 \\
19,83 \\
13,31 \\
10,77 \\
4,64 \\
2,58 \\
1,66 \\
1,27 \\
0,95\end{array}$ & $\begin{array}{l}12,7 \\
13,3 \\
13,9 \\
14,3 \\
15,5 \\
17 \\
19,5 \\
20,8 \\
22,4 \\
23,4 \\
24,1 \\
24,5 \\
26,3 \\
27,6 \\
28,2 \\
28,8 \\
29,3 \\
31,1 \\
32,3 \\
33,2 \\
35,3 \\
36,6 \\
37,7 \\
38,5 \\
39,2\end{array}$ & $\begin{array}{l}0,323 \\
0,323 \\
0,322 \\
0,322 \\
0,321 \\
0,317 \\
0,298 \\
0,256 \\
0,219 \\
0,203 \\
0,191 \\
0,181 \\
0,153 \\
0,143 \\
0,136 \\
0,131 \\
0,127 \\
0,114 \\
0,108 \\
0,104 \\
0,096 \\
0,091 \\
0,089 \\
0,087 \\
0,085\end{array}$ \\
\hline
\end{tabular}




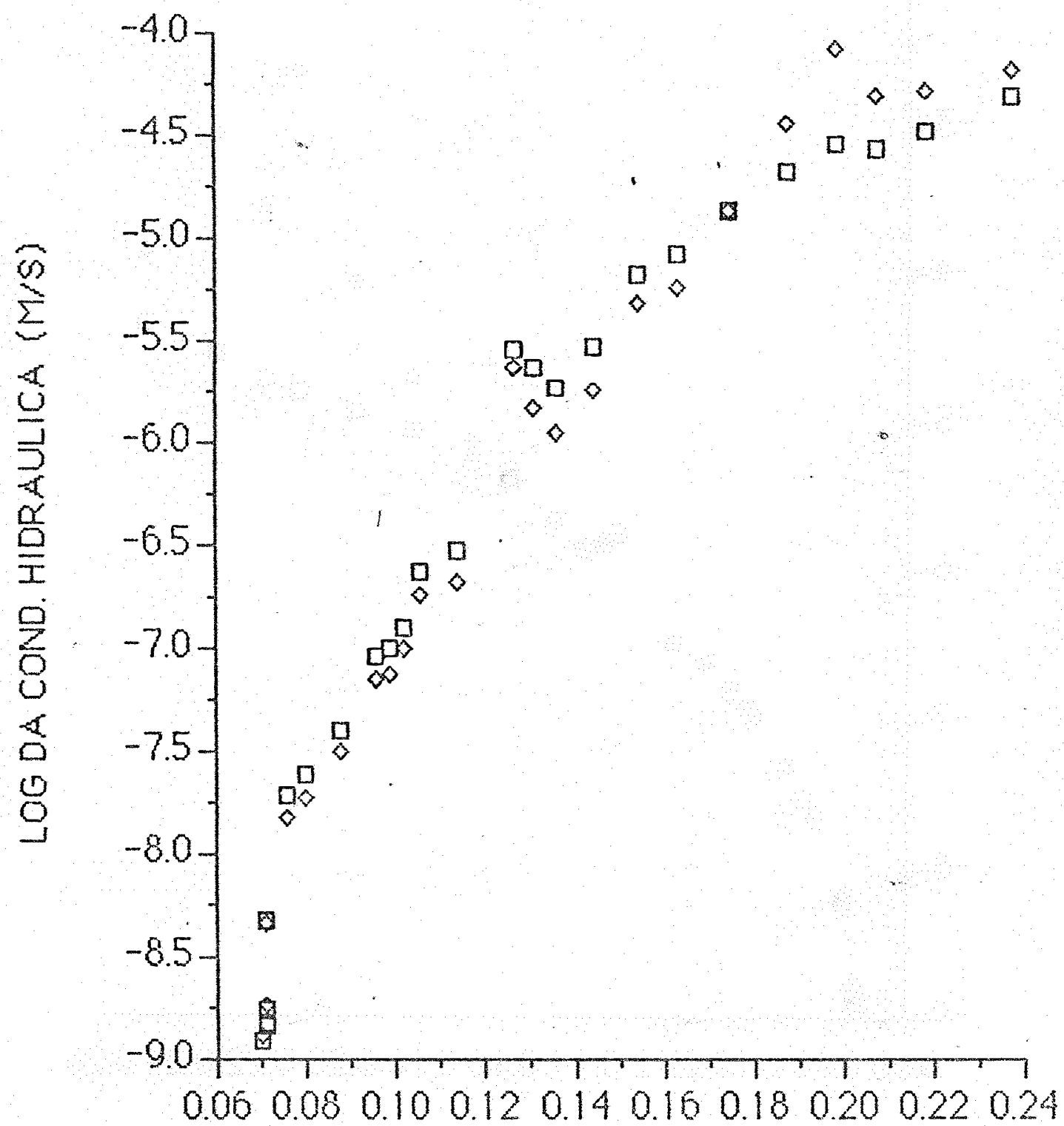

UMIDADE (CMB/CMB)

FIGURA 77 - Condutividade hidräulica em função da umidade, segundo a teoria proposta $(\diamond)$, e HILLEL etalii (1972), ( $(\square)$, pa ra a profundidade de $10 \mathrm{~cm}$ do solo Duna de Areia. 


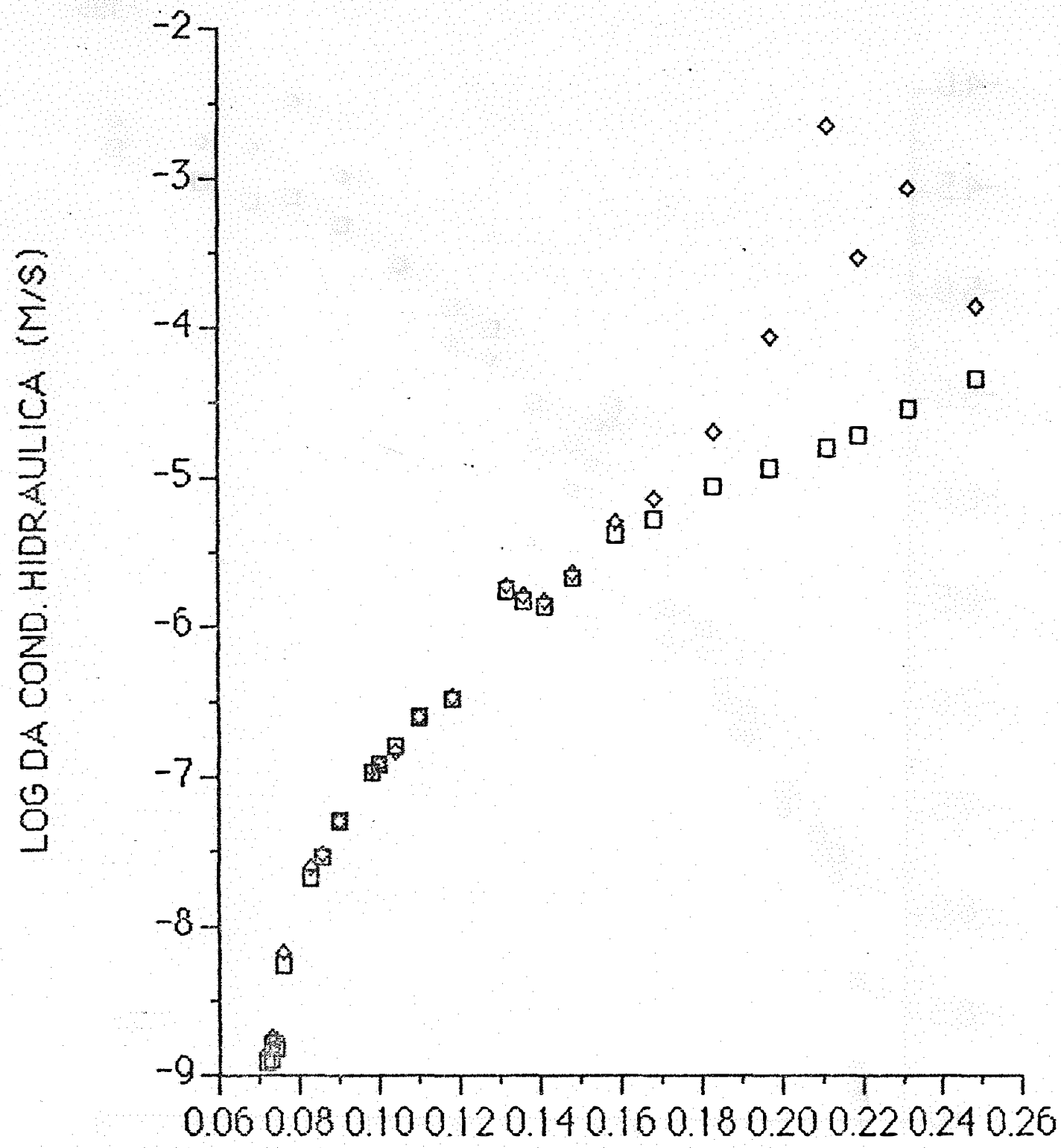

UMIDADE (CM3/CM3)

FIGURA 78 - Condutividade hidráulica em função da umidade, segundo a teoria proposta ( $)$, e HILLEL et alii (1972), (口), pa ra a profundidade de $15 \mathrm{~cm}$ do solo Duna de Areia. 


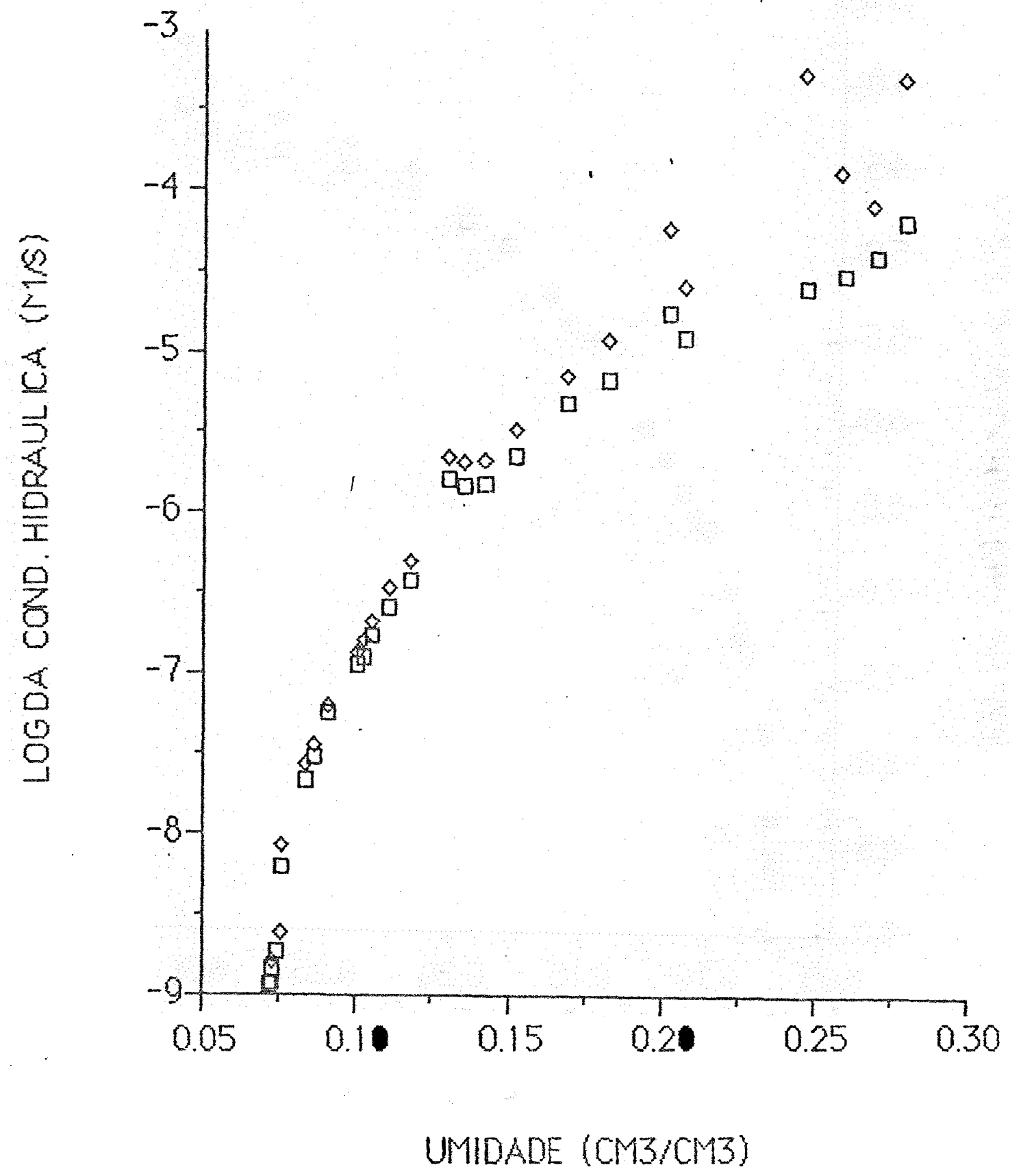

FIGURA 79 - Cundutividade hidräulica em função da umidade, segundo a teoria proposta $(\diamond)$, e HILLEL et alii (1972), ( $\square)$, pa ra a profundidade de $20 \mathrm{~cm}$ do solo Duna de Areia. 

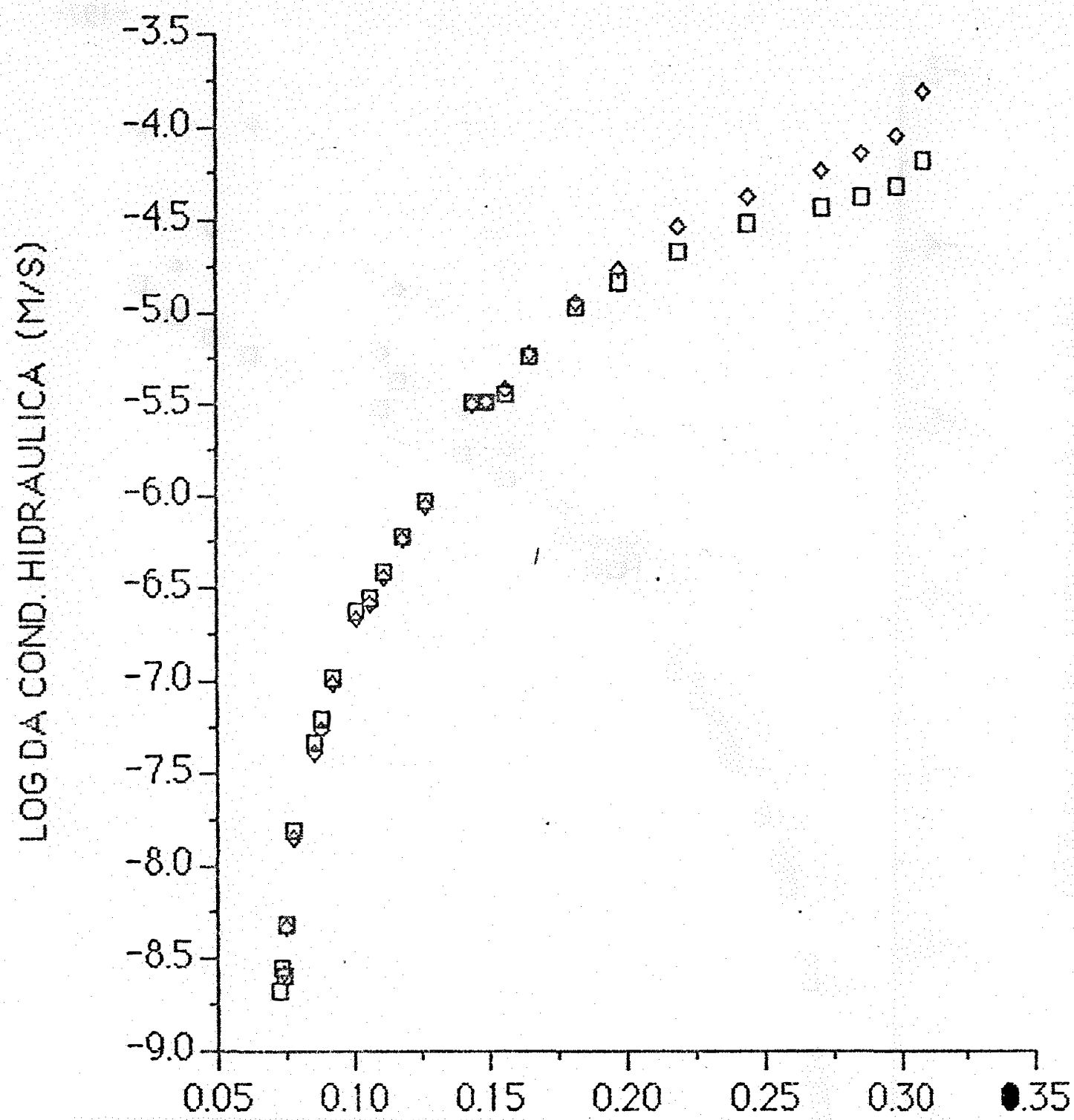

UMIDADE (CM3/CM3)

FIGURA 80 - Condutividade hidráulica em função da umidade, segundo a teoria proposta ( $\diamond)$, e HILLEL et alii (1972), (口), pa ra a profundidade de $30 \mathrm{~cm}$ do solo Duna de Areia. 


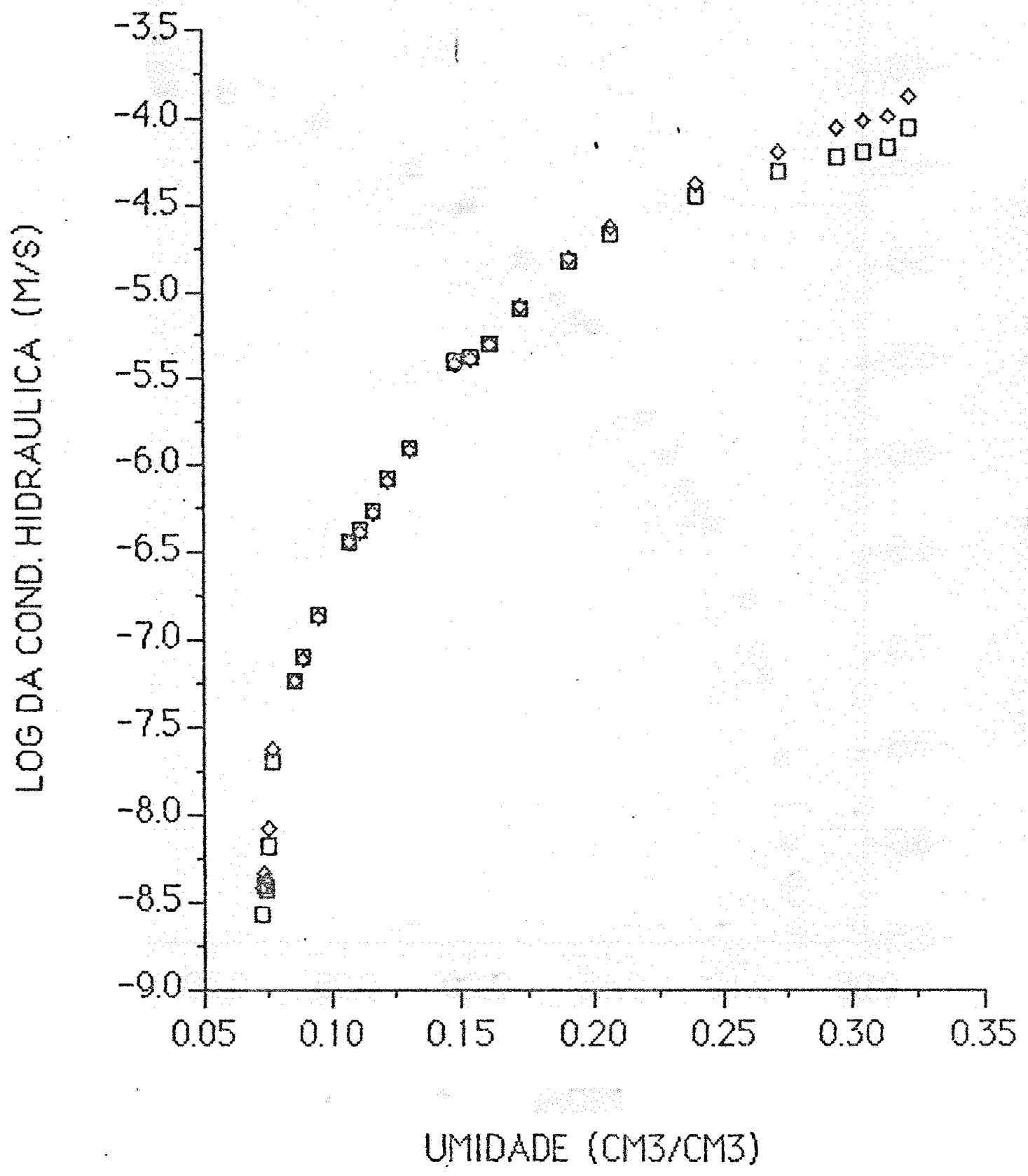

FIGURA 81 - Condutividade hidräulica em função da umidade, segundo a teoria proposta $(\diamond)$, e HILLEL et alii (1972), ( $(\square)$, para a profundidade de $40 \mathrm{~cm}$ do solo Duna de Areia. 


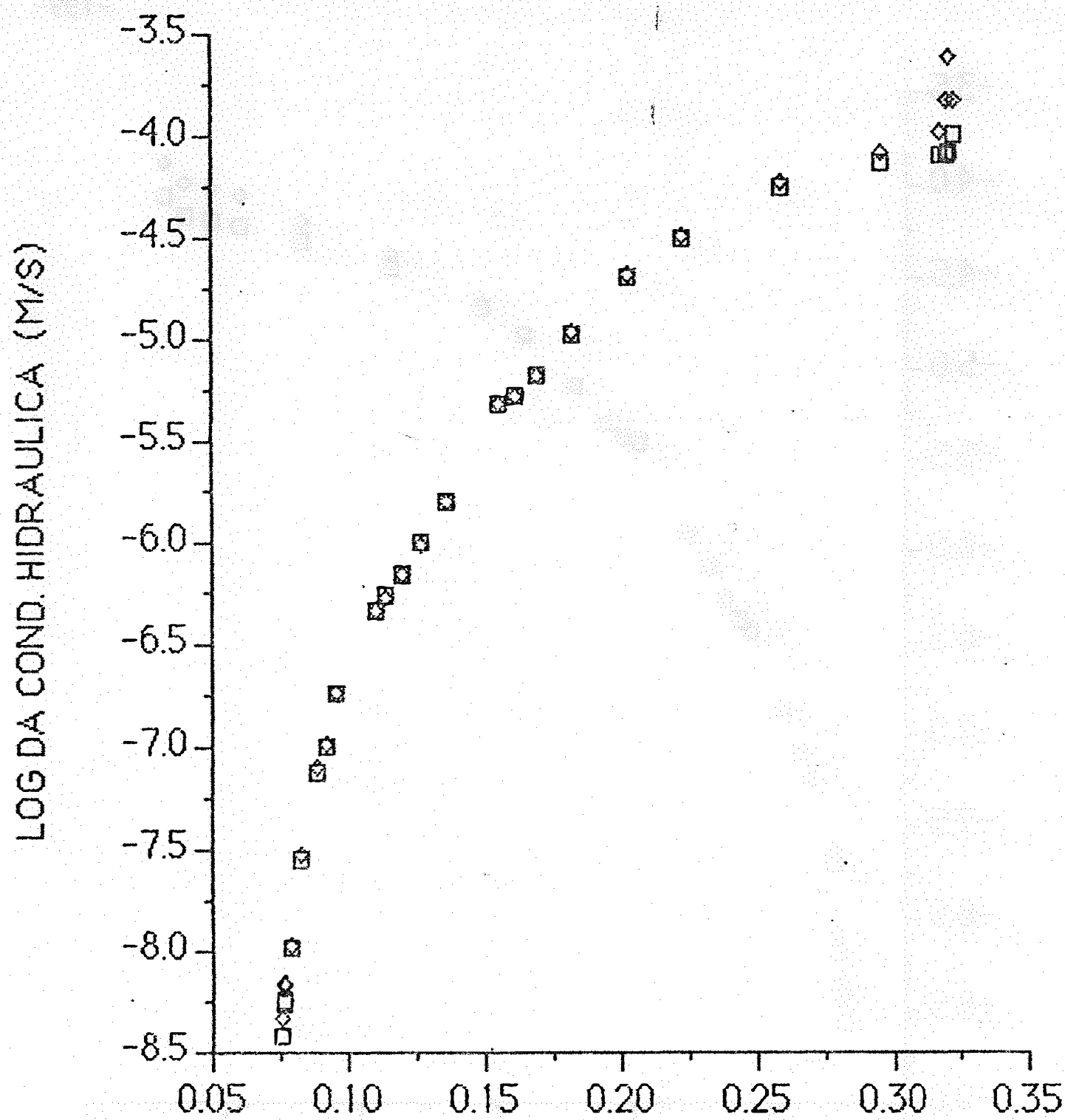

UMIDADE (CM3/CM3)

FIGURA 82 - Condutividade hidrāulica em função da umidade, segundo a teoria proposta $(\diamond)$, e HILLEL et alii (1972), (口), para a profundidade de $50 \mathrm{~cm}$ do solo Duna de Areia. 


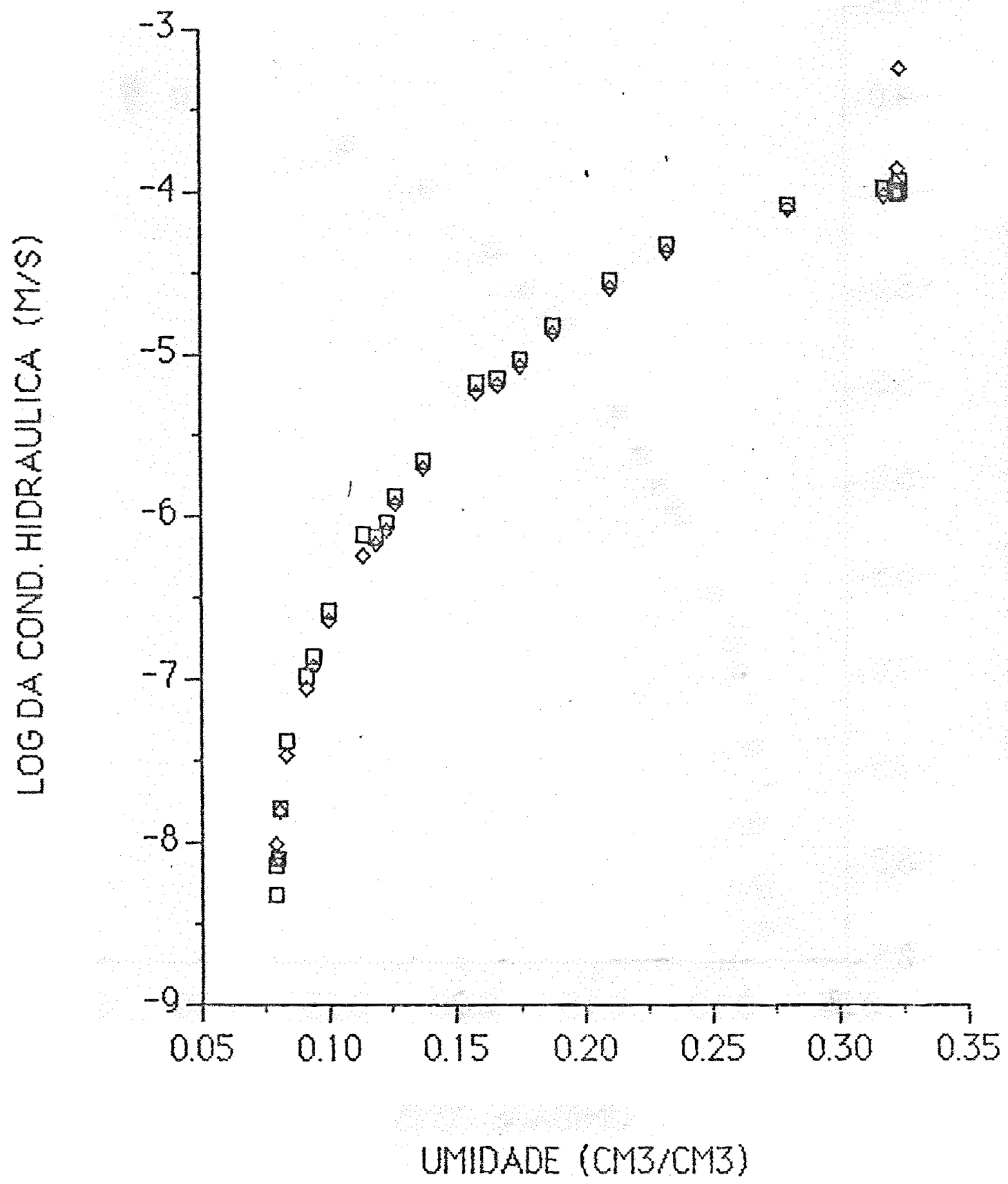

FIGURA 83 - Condutividade hidräulica em função da umidade, segundo a teoria proposta $(\diamond)$, e HILLEL et alii (1972), ( $($ ) , para a profundidade de $60 \mathrm{~cm}$ do solo Duna de Areia. 


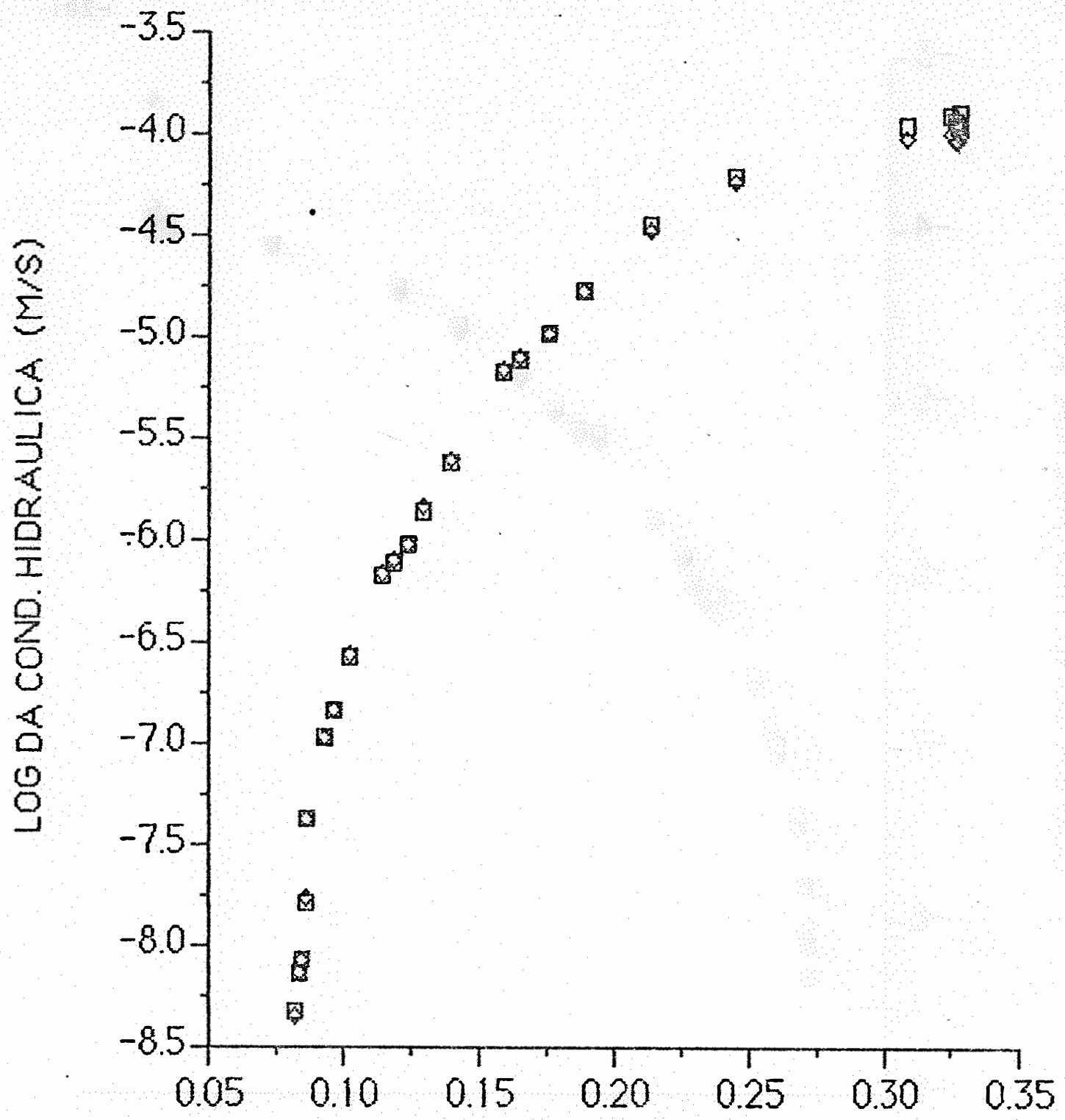

UMIDADE (CMB/CM3)

FIGURA 84 - Condutividade hidrāulica em função da umidade, segundo a teoria proposta $(\diamond)$, e HILLEL et alii (1972), (口), para a profundidade de $70 \mathrm{~cm}$ do solo Duna de Areia. 


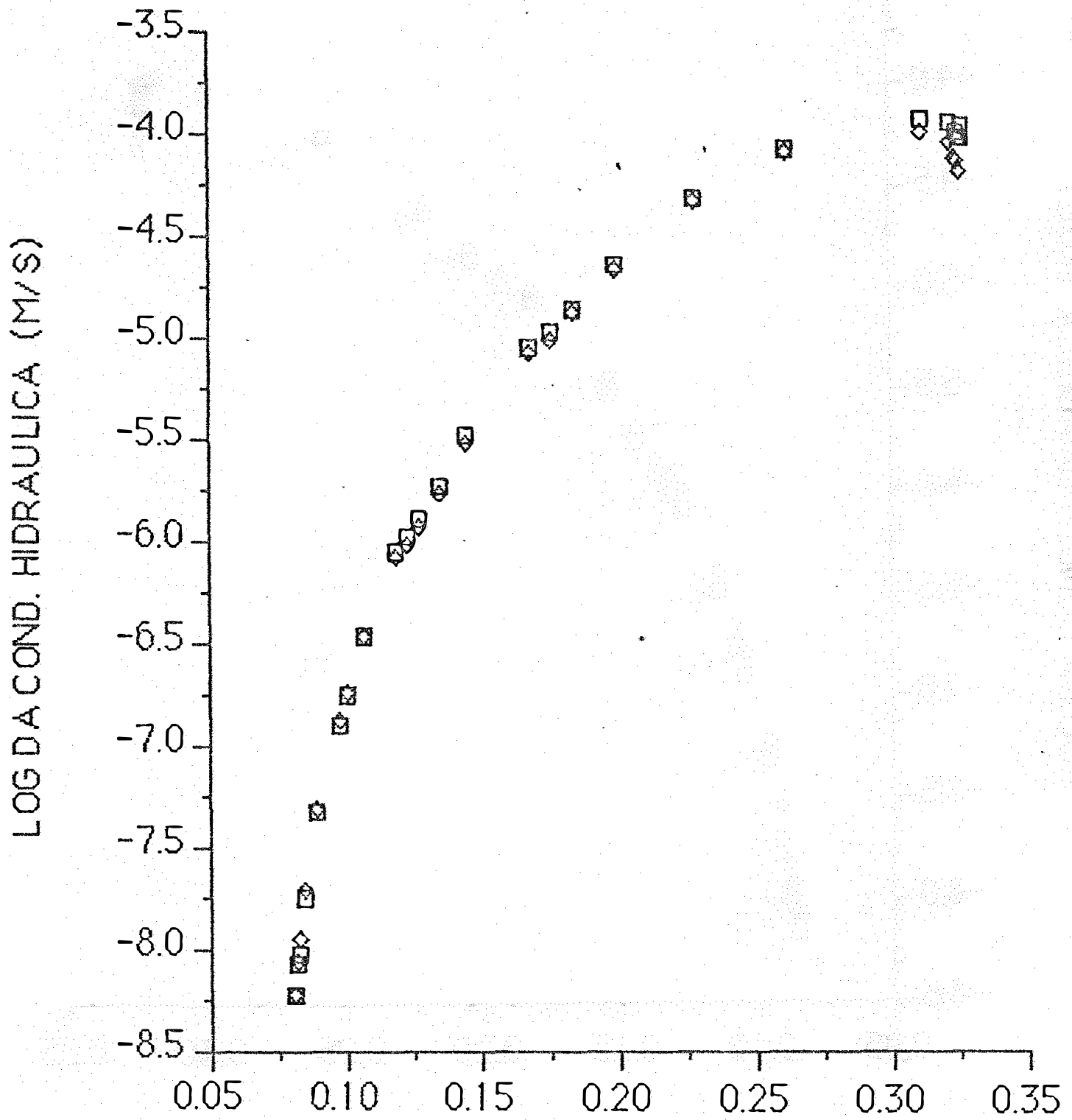

UMIDADE (CMB/CMB)

FIGURA 85 - Condutividade hidrāulica em função da umidade, segundo a teoria proposta $(\diamond)$, e HILLEL et alii (1972), ( $\square)$, para a profundidade de $80 \mathrm{~cm}$ do solo Duna de Areia. 


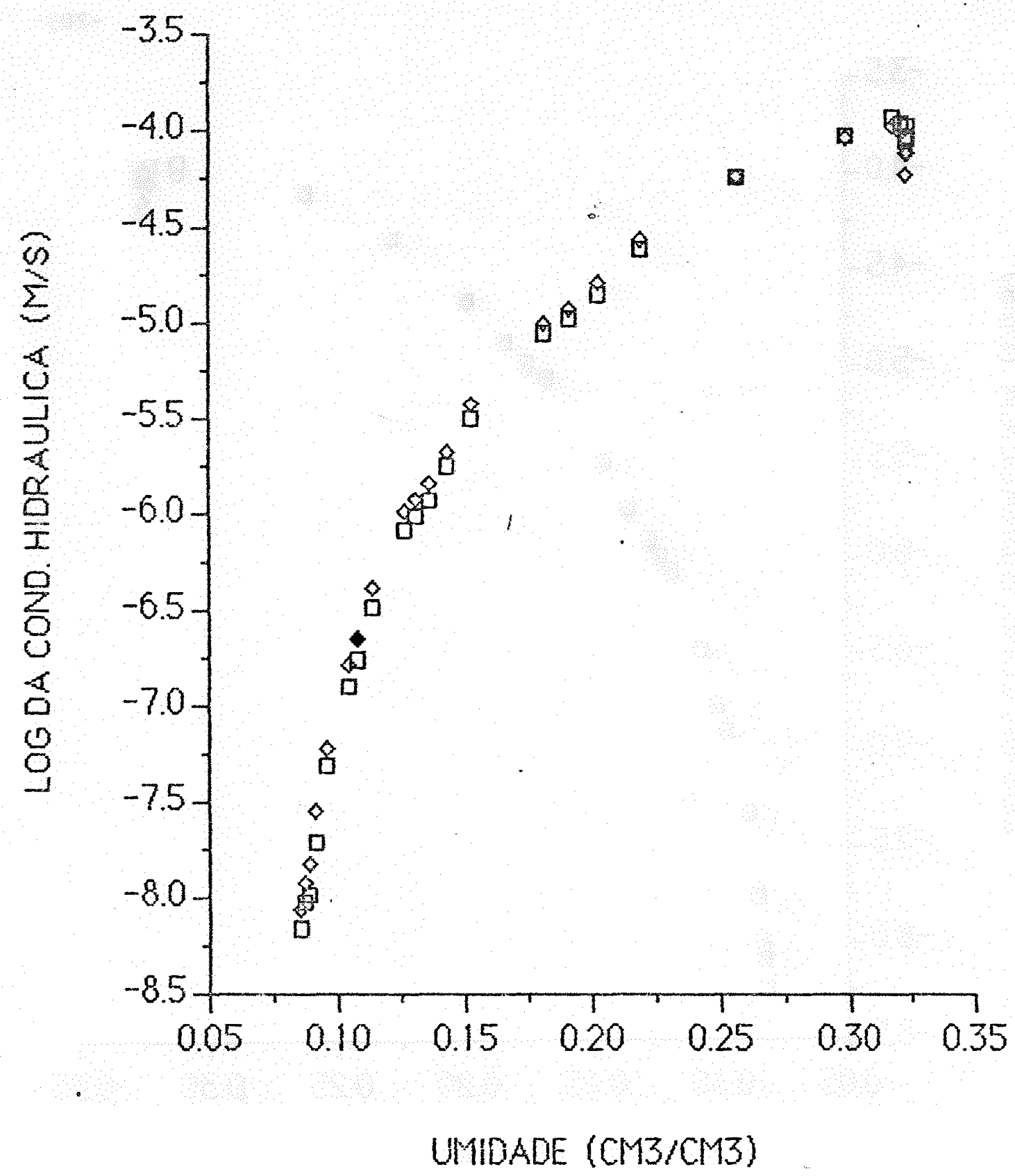

FIGURA 86 - Condutividade hidräulica em função da umidade, segundo a teoria proposta $(\diamond)$, e HILLEL et alii (1972), ( $(\square)$, para a profundidade de $90 \mathrm{~cm}$ do solo Duna de Areia. 


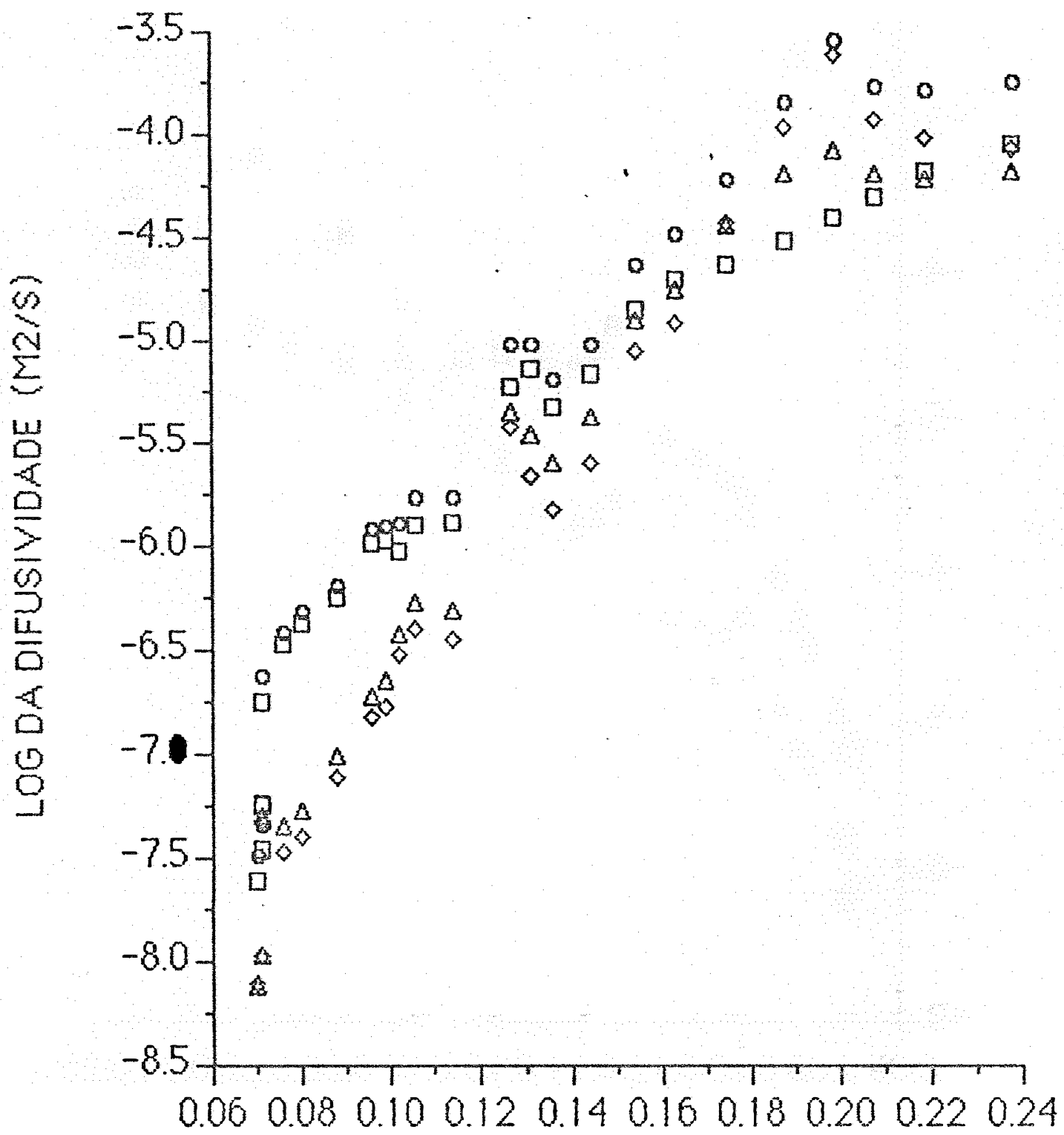

UMIDADE (CM3/CM3)

FIGURA 87 - Difusividade hidráulica em função da umidade, segundo a teoria proposta: global ( $\mathrm{D})$, gravitacional (O), e matricial $(\diamond)$; e segundo HILLEL et alii (1972), $(\Delta)$, para a profundidade de $10 \mathrm{~cm}$ do solo Duna de Areia. 


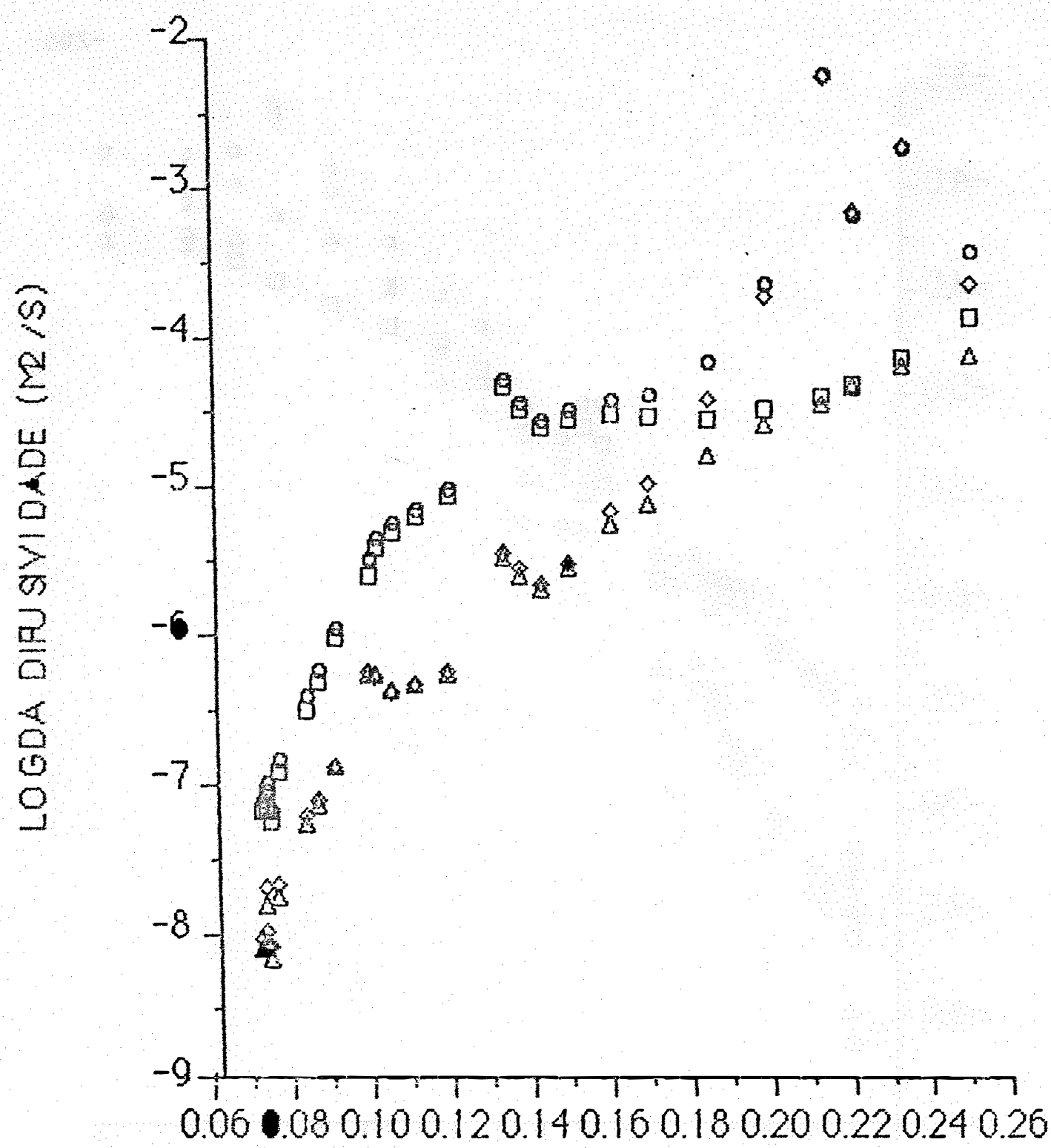

UMIDADE (CM3/CM3)

FIGURA 88 - Difusividade hidrāulica em função da umidade, segundo a teoria proposta: global (口), gravitacional (O), e matricial $(\diamond)$; e segundo HILLEL et alii (1972), ( $\Delta)$, para a profundidade de $15 \mathrm{~cm}$ do solo Duna de Areia. 


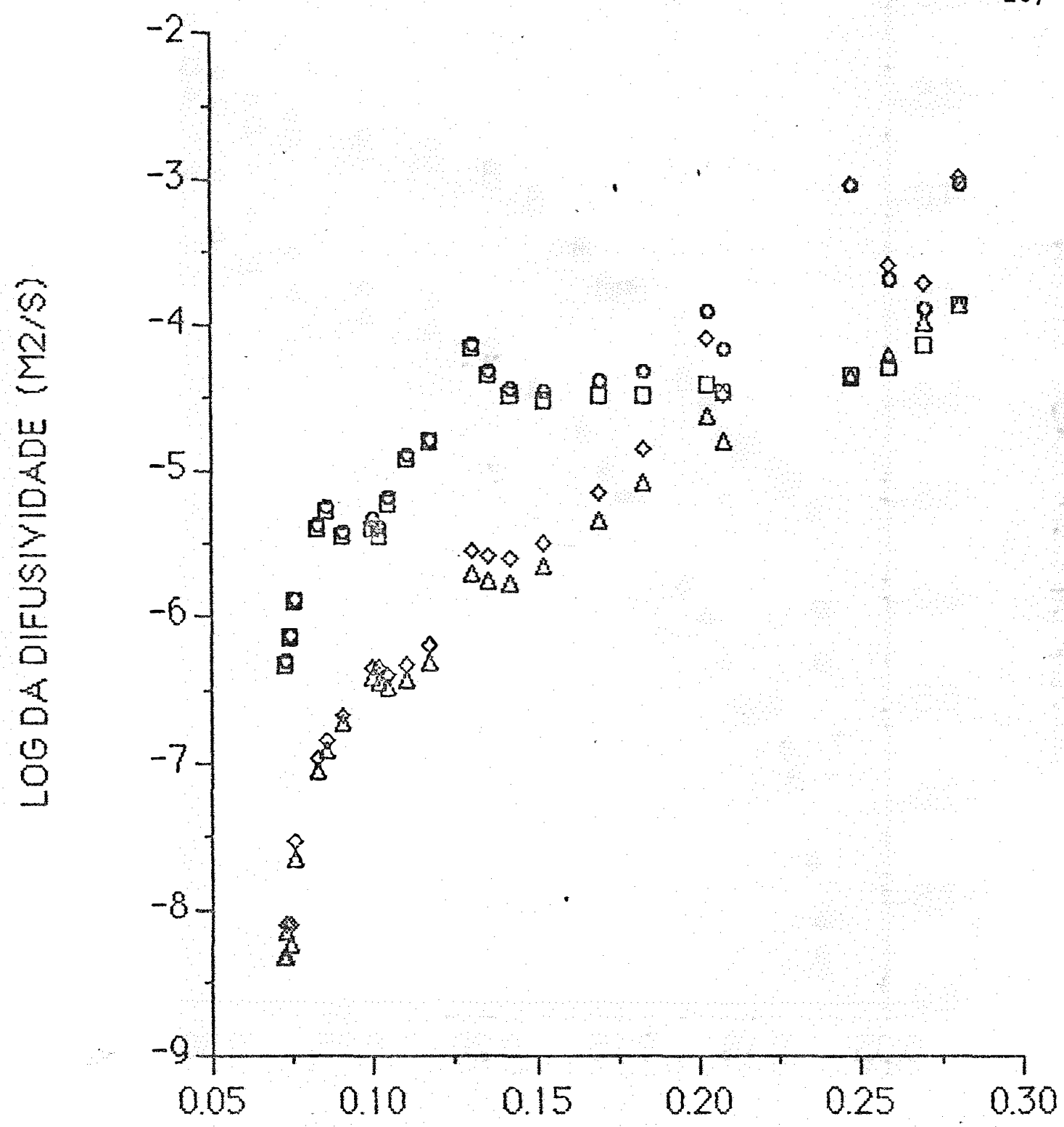

\section{UMIDADE (CM3/CMB)}

FIGURA 89 - Difusividade hidräulica em função da umidade, segundo a teoria proposta: global ( $\square$ ), gravitacional (O), e matricial $(\diamond)$; e segundo HILLEL et alii (1972), $(\Delta)$, para a profundidade de $20 \mathrm{~cm}$ do solo Duna de Areia. 


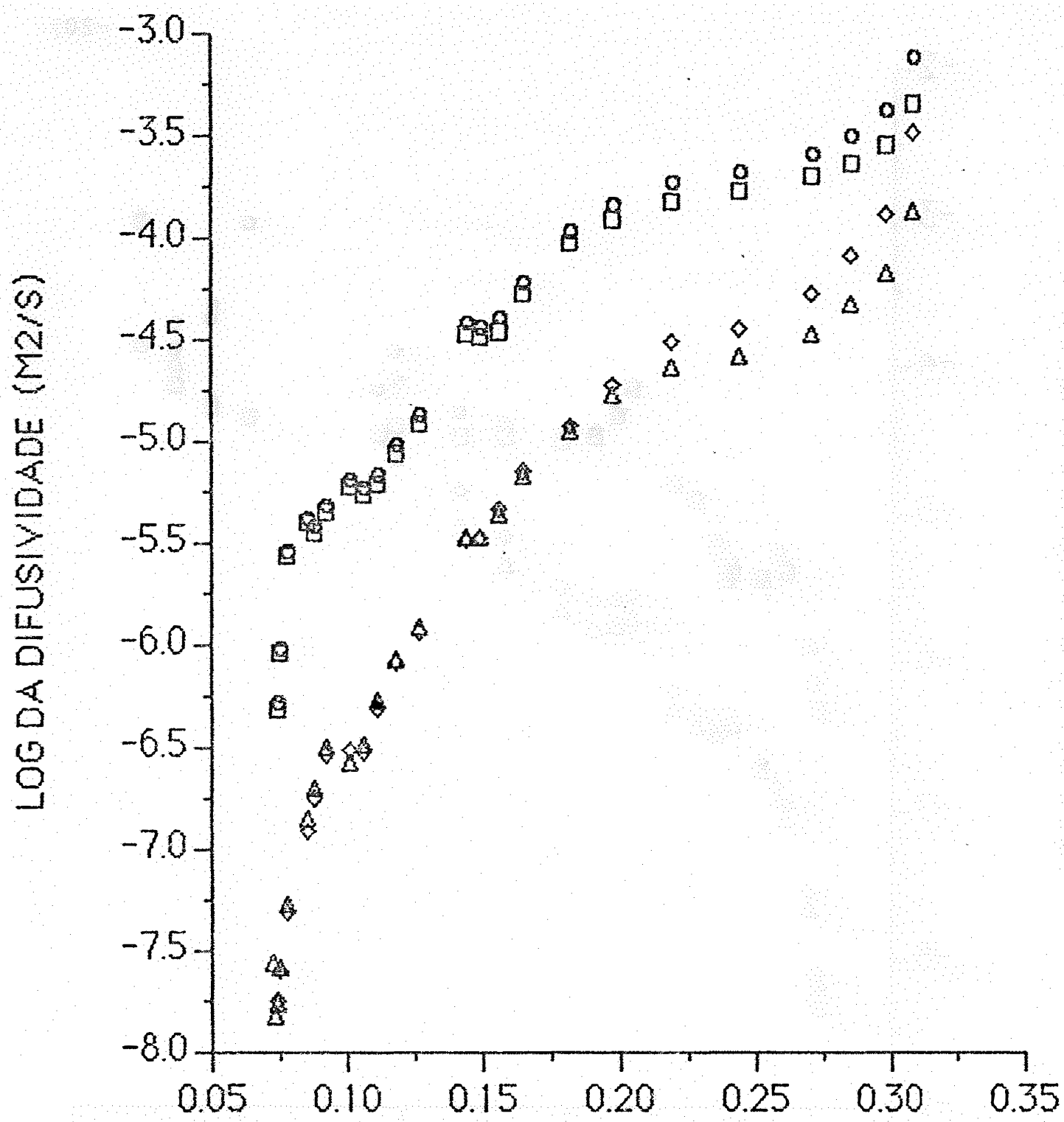

UMIDADE (CM3/CM3)

FIGURA 90 - Difusividade hidráulica em função da umidade, segundo a teoria proposta: global ( $\square$ ), gravitacional (o), e matricial $(\diamond)$; e segundo HILLEL et alii (1972), $(\Delta)$, para a profundidade de $30 \mathrm{~cm}$ do solo Duna de Areia. 


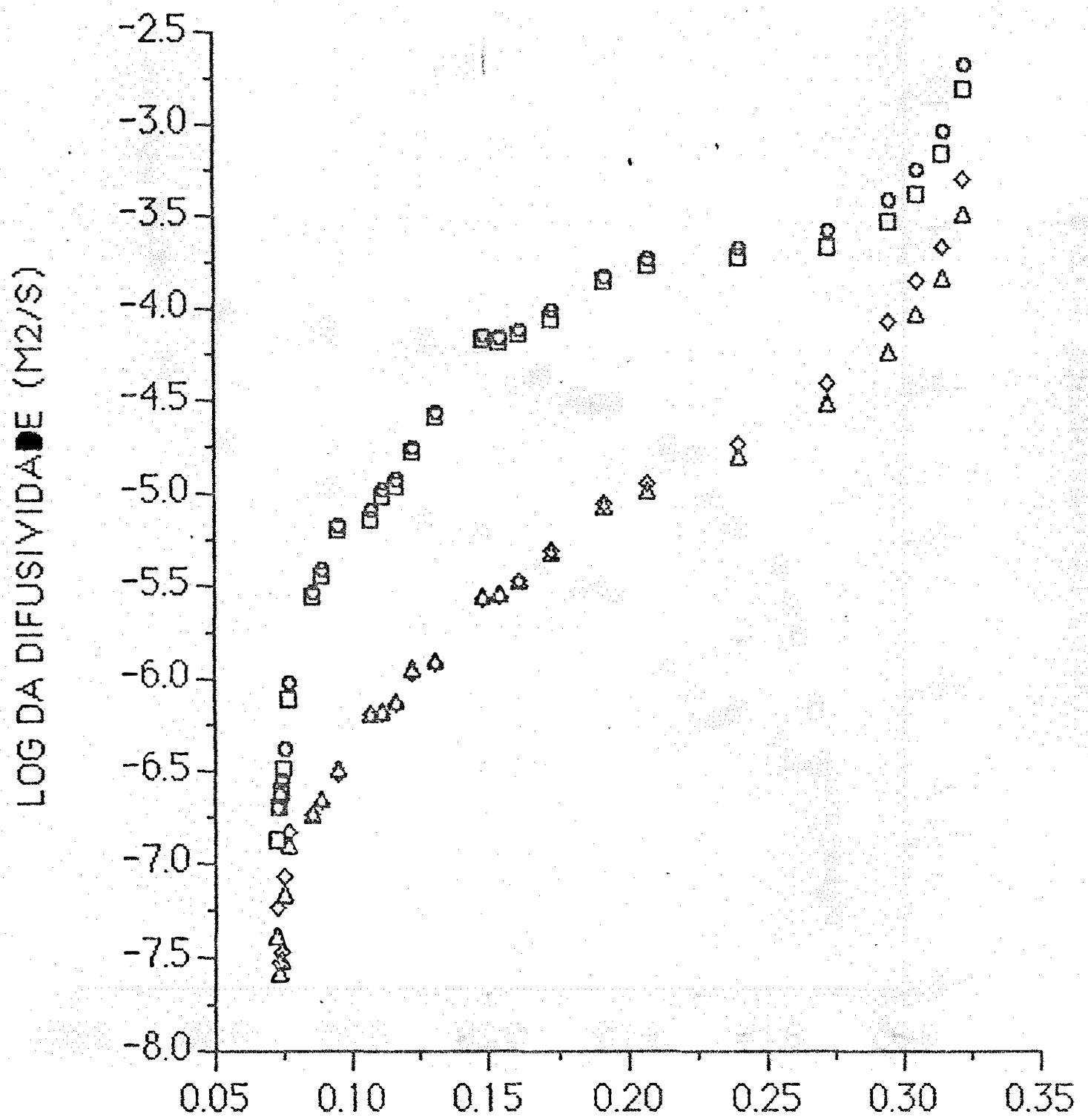

UMIDADE (CMB/CMB)

FIGURA 91 - Difusividade hidrāulica em função da umidade, segundo a teoria proposta: global (口), gravitacional (o), e matricial $(\diamond)$; e segundo HILLEL et alii $(1972),(\Delta)$, para a profundidade de $40 \mathrm{~cm}$ do solo Duna de Areia. 


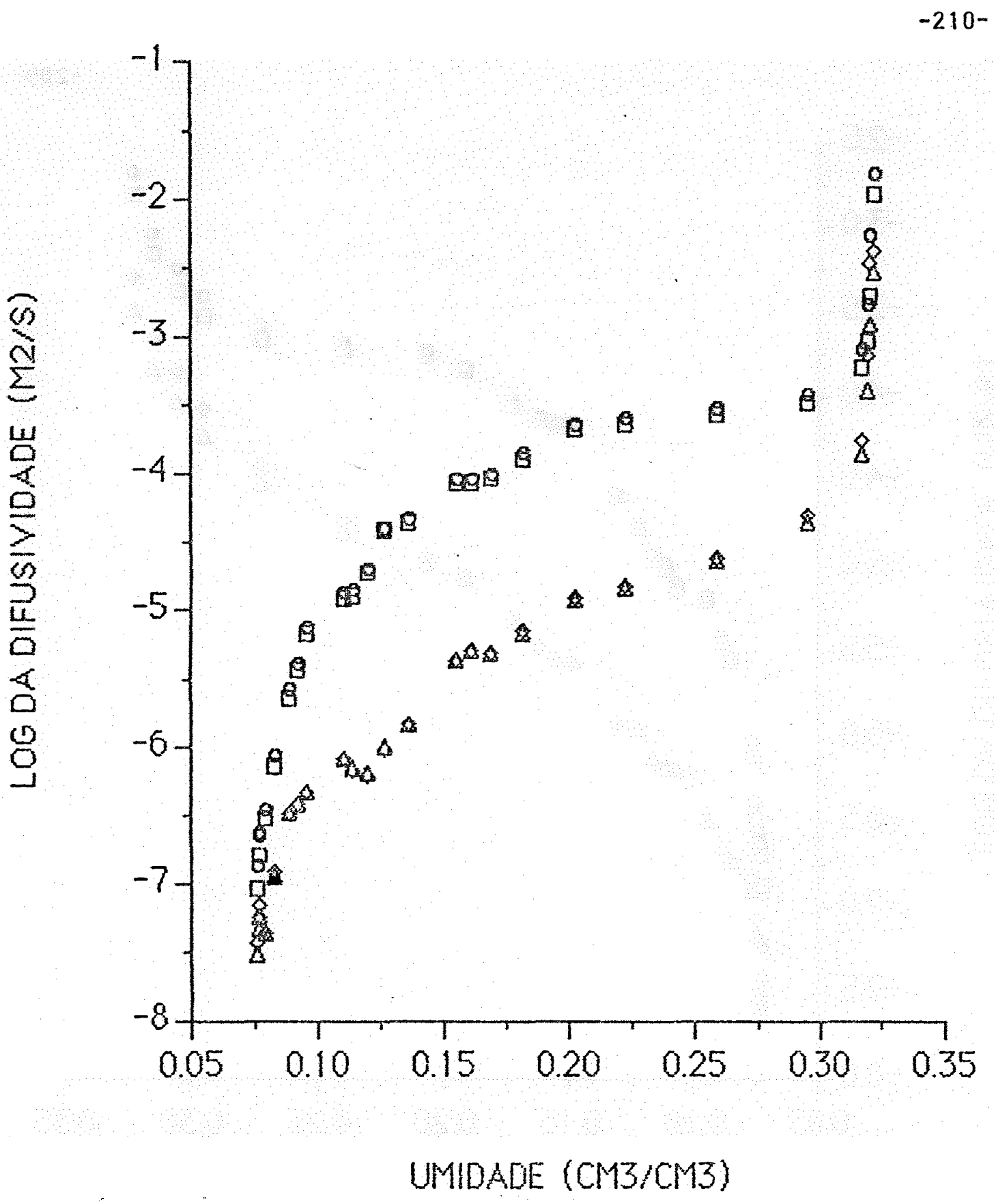

FIGURA 92 - Difusividade hidrāulica em função da umidade, segundo a teoria proposta: global ( $\square$ ), gravitacional (o), e matricial $(\diamond)$; e segundo HiLLEL et alii (1972), $(\Delta)$, para a profundidade de $50 \mathrm{~cm}$ do solo Duna de Areia. 


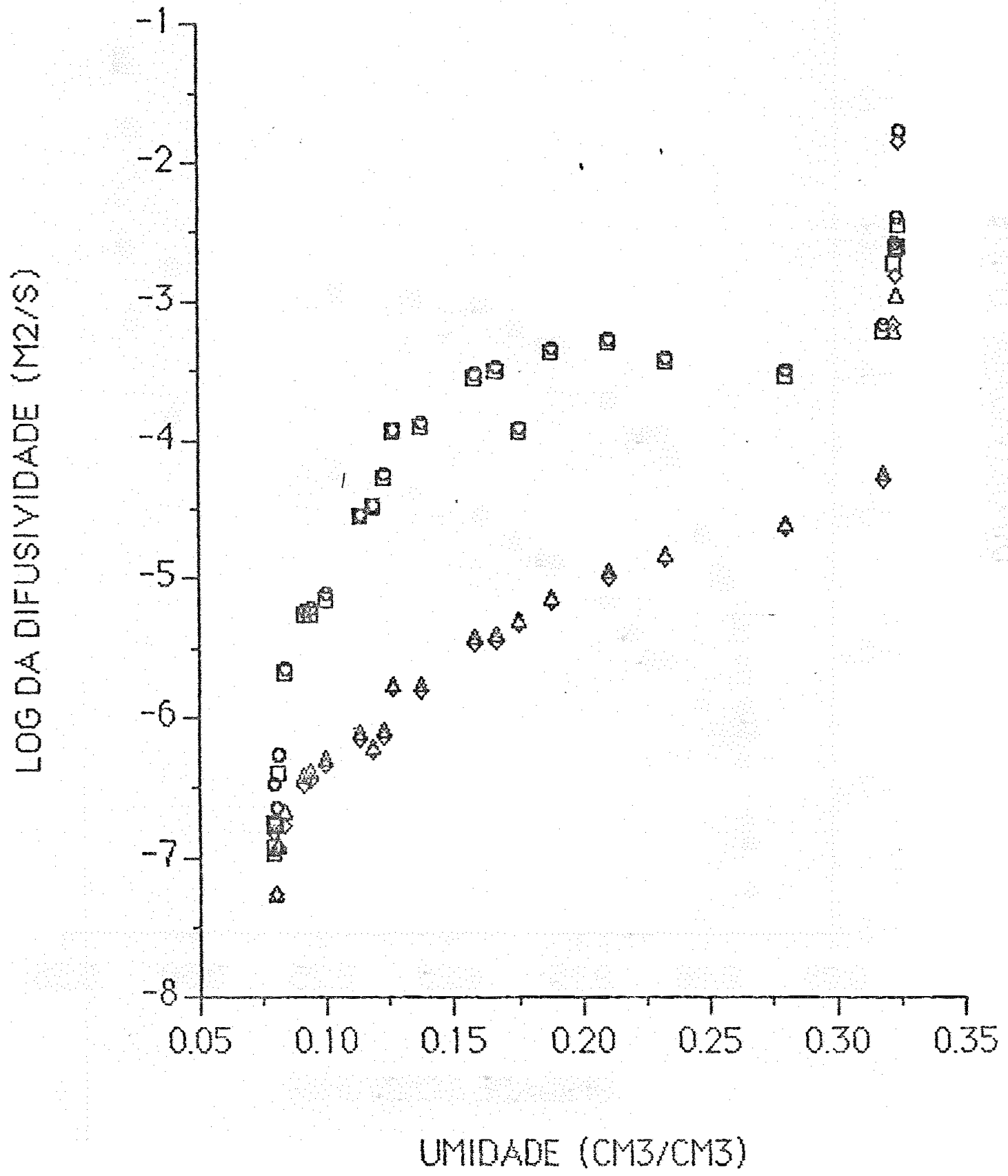

FIGURA 93 - Difusividade hidräulica em função da umidade, segundo a teoria proposta: global ( $\square$ ), gravitacional (o), e matricial $(\diamond)$; e segundo HILLEL et alii $(1972),(\Delta)$, para a profundidade de $60 \mathrm{~cm}$ do solo Duna de Areia. 


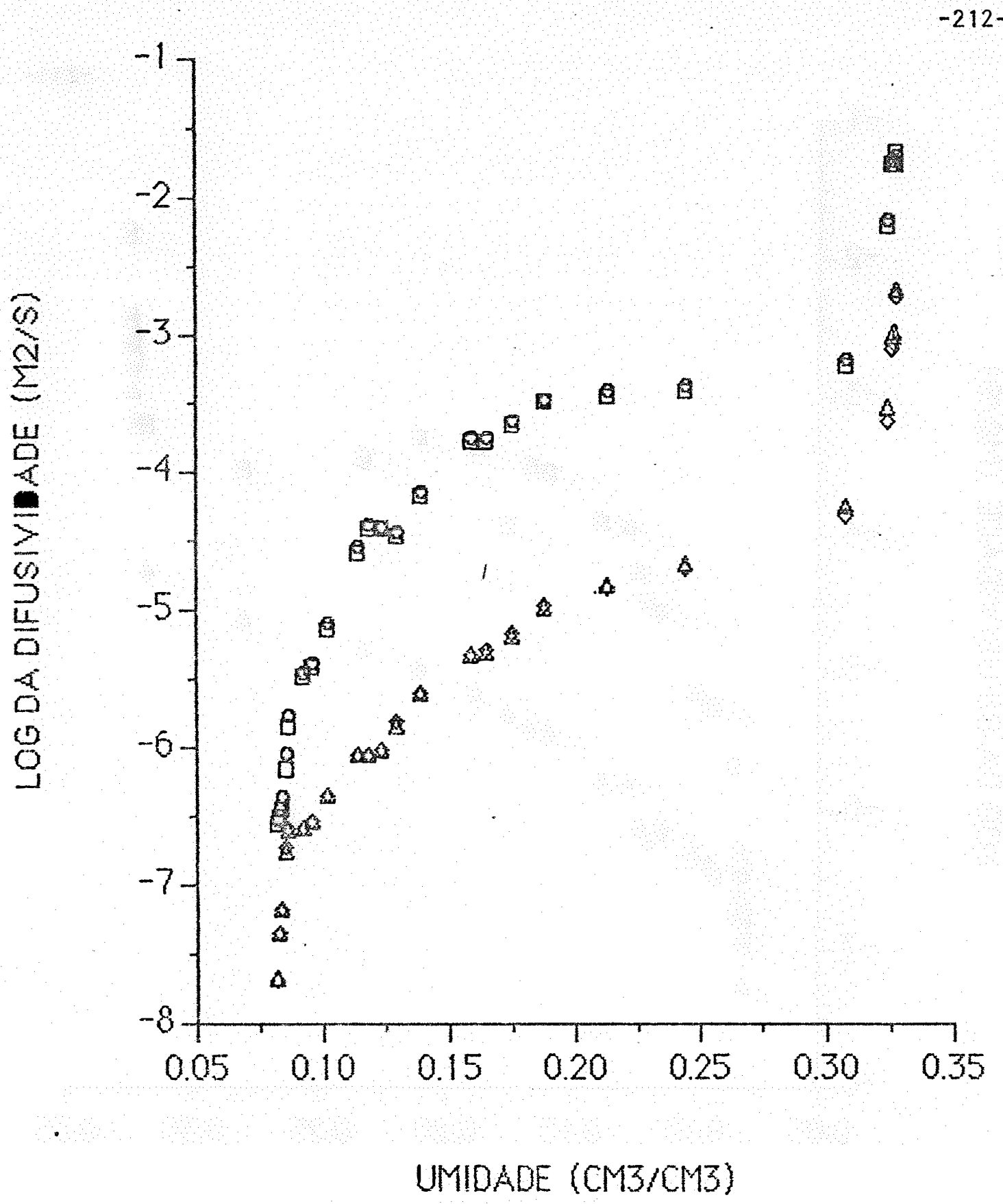

FIGURA 94 - Difusividade hidrāulica em função da umidade, segundo a teoria proposta: global ( $\square$ ), gravitacional (o), e matricial $(\diamond)$; e segundo HILLEL et alii (1972), $(\Delta)$, para a profundidade de $70 \mathrm{~cm}$ do solo Duna de Areia. 


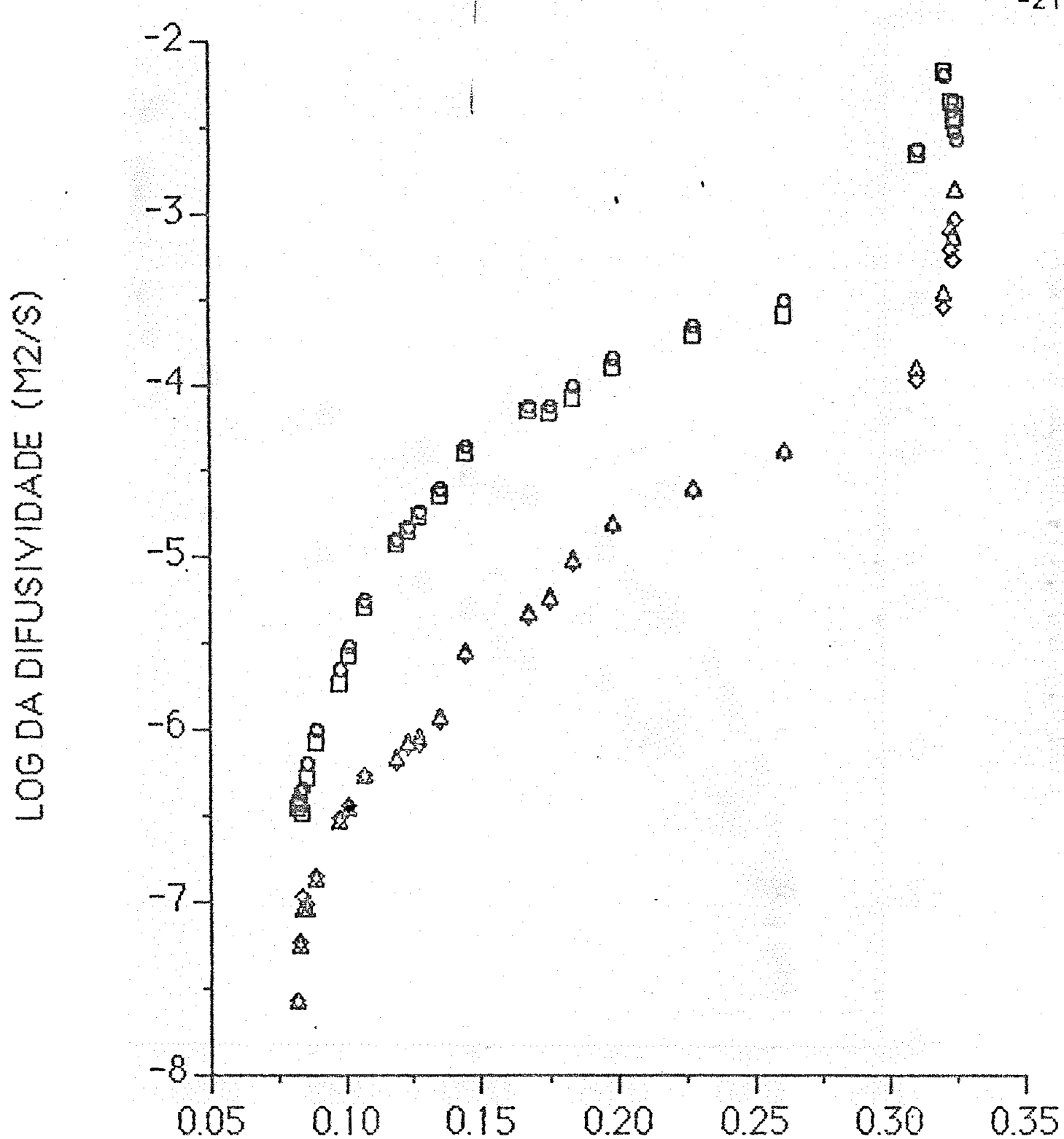

UMIDADE (CMB/CMB)

FIGURA 95 - Difusividade hidrāulica em função da umidade, segundo a teoria proposta: global ( $(0)$, gravitacional (O), e matricial $(\diamond)$; e segundo HILLEL et alii (1972), $(\Delta)$, para a profundidade de $80 \mathrm{~cm}$ do solo Duna de Areia. 


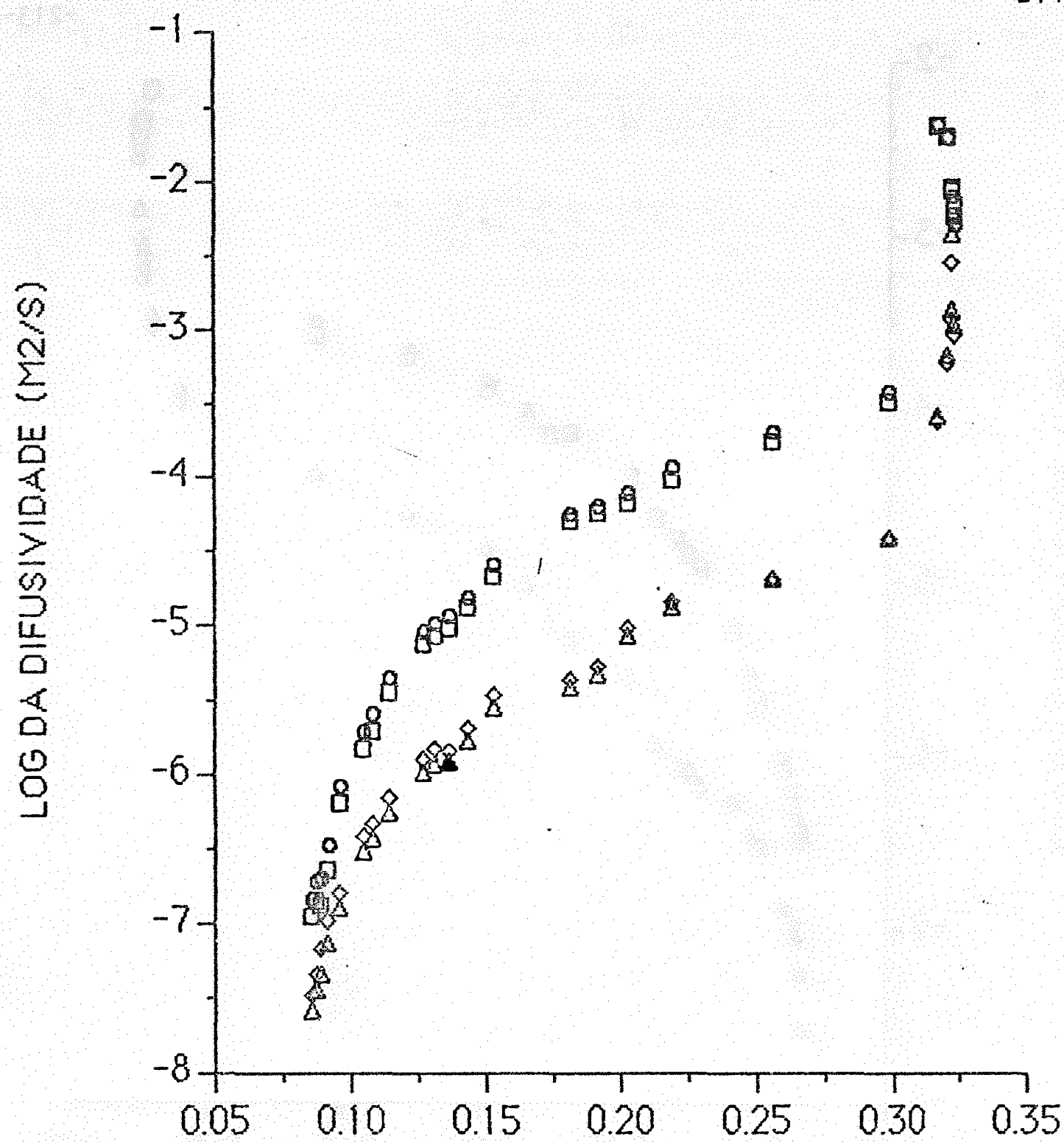

UMIDADE (CMB/CM3)

FIGURA 96 - Difusividade hidráulica em função da umidade, segundo a teoria proposta: global ( $\square$ ), gravitacional (o), e matricial ( $\diamond)$; e segundo HILLEL et alii (1972), $(\Delta)$, para a profundidade de $90 \mathrm{~cm}$ do solo Duna de Areia. 


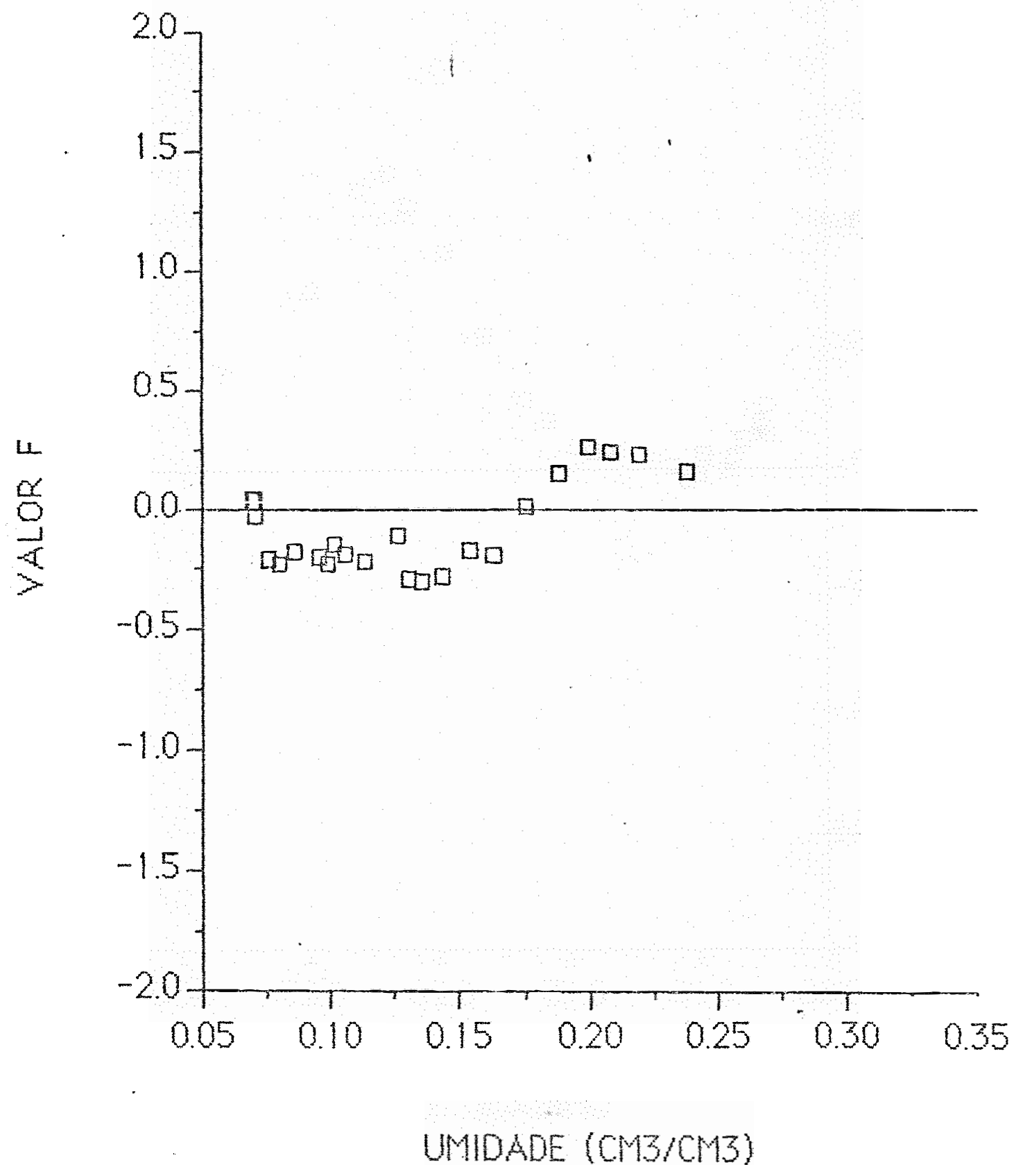

FIGURA 97 - Valor F (equação 41) em função da umidade para a camada $5-15 \mathrm{~cm}$ do solo Duna de Areia. 


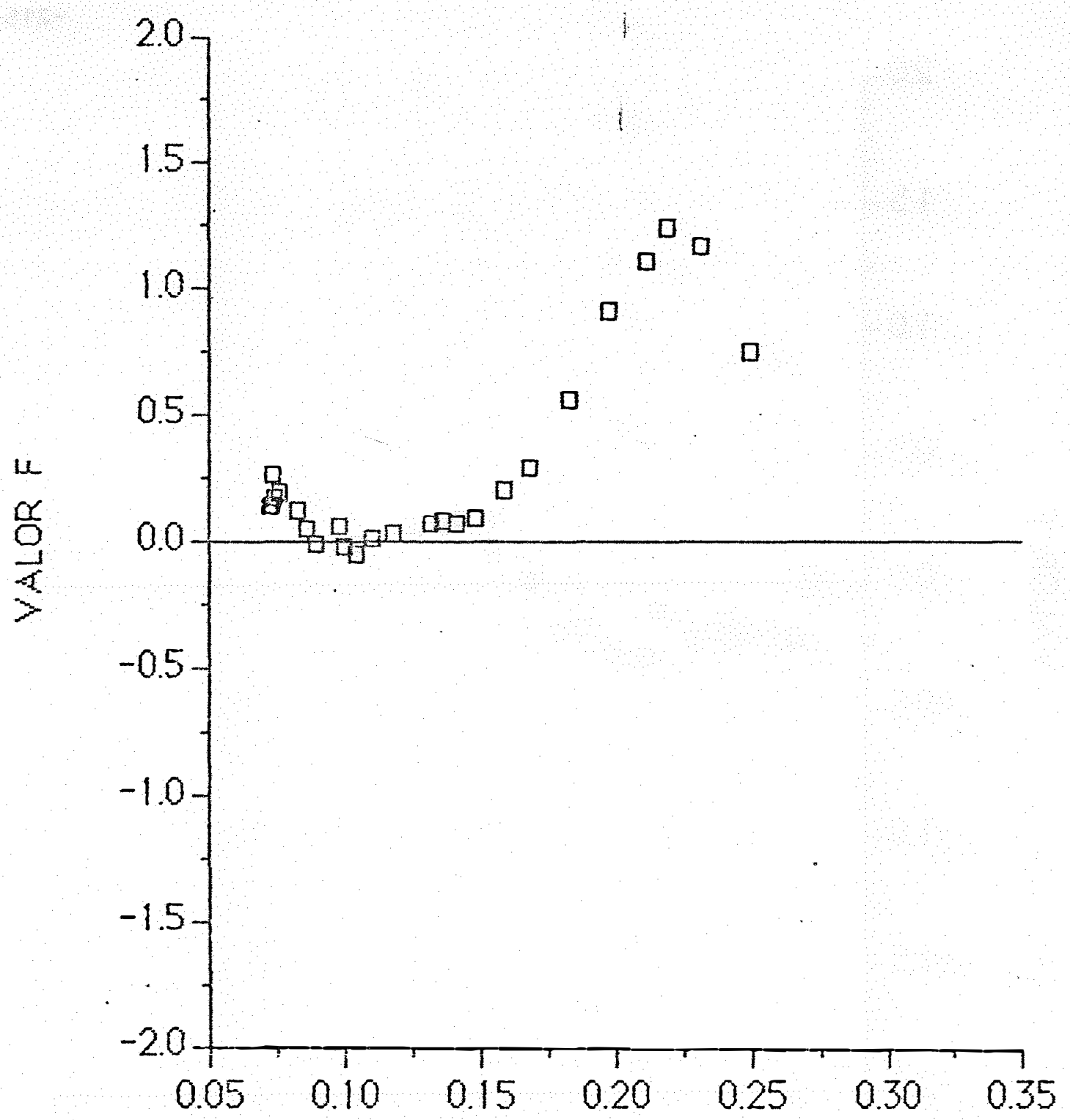

UMIDADE (CMB/CM3)

FIGURA 98 - Valor F (equação 41) em função da umidade para a camada 10-20 cm do solo Duna de Areia. 


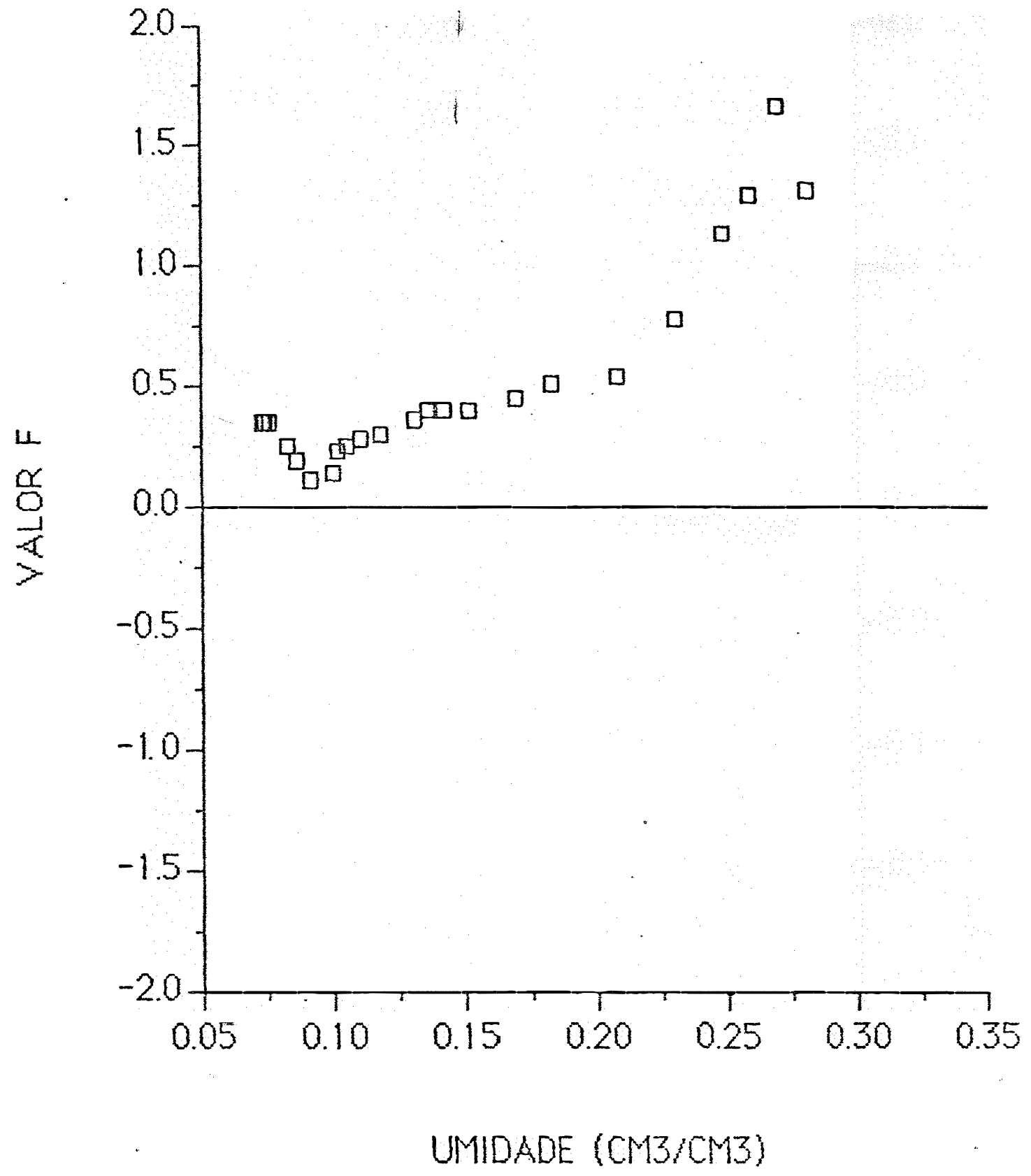

FIGURA 99 - Valor F (equação 41) em função da umidade para a camada $15-30 \mathrm{~cm}$ do solo Duna de Areia. 


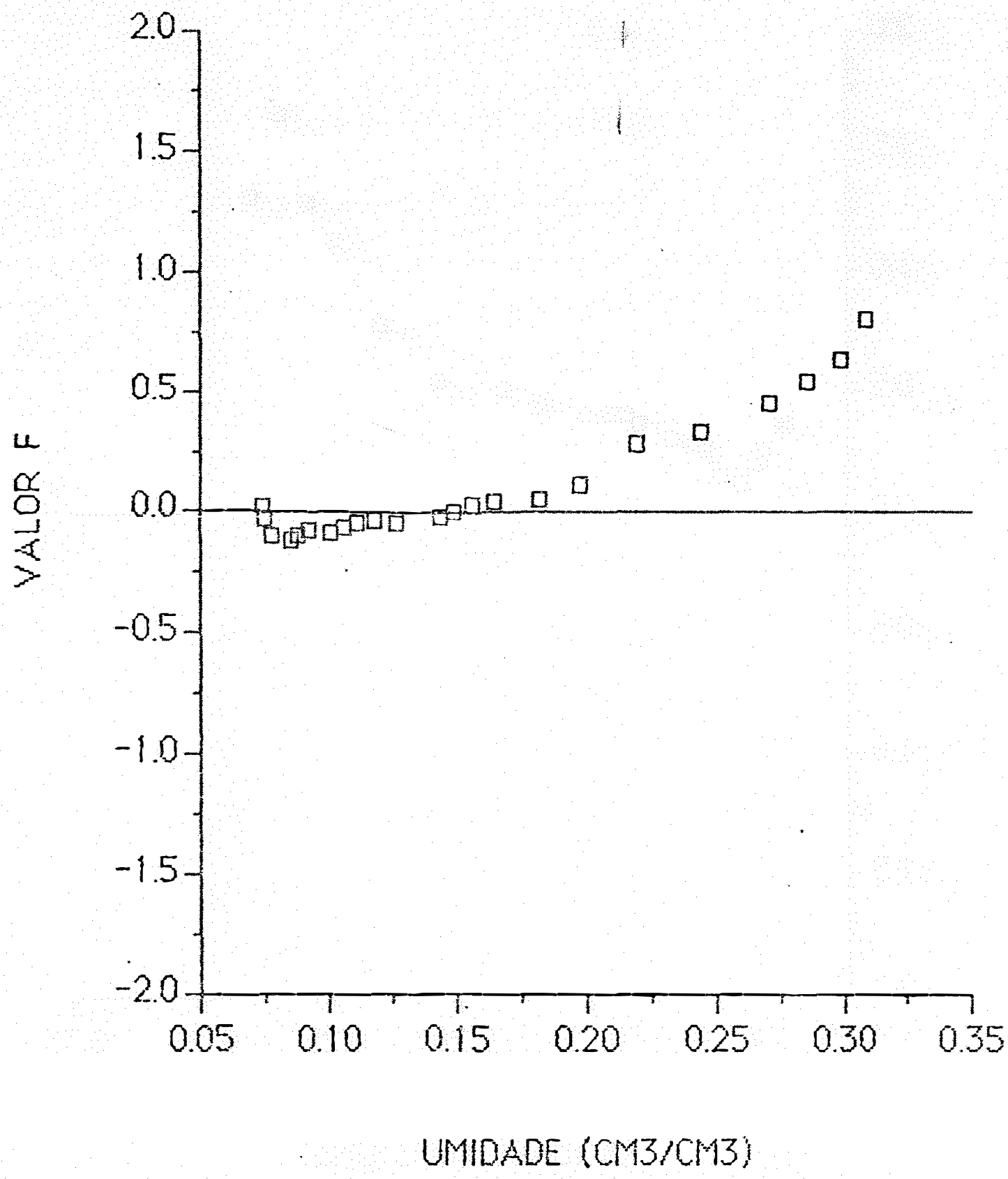

FIGURA 100 - Valor $F$ (equação 41) em função da umidade para a camada 20-40 cm do solo Duna de Areia. 


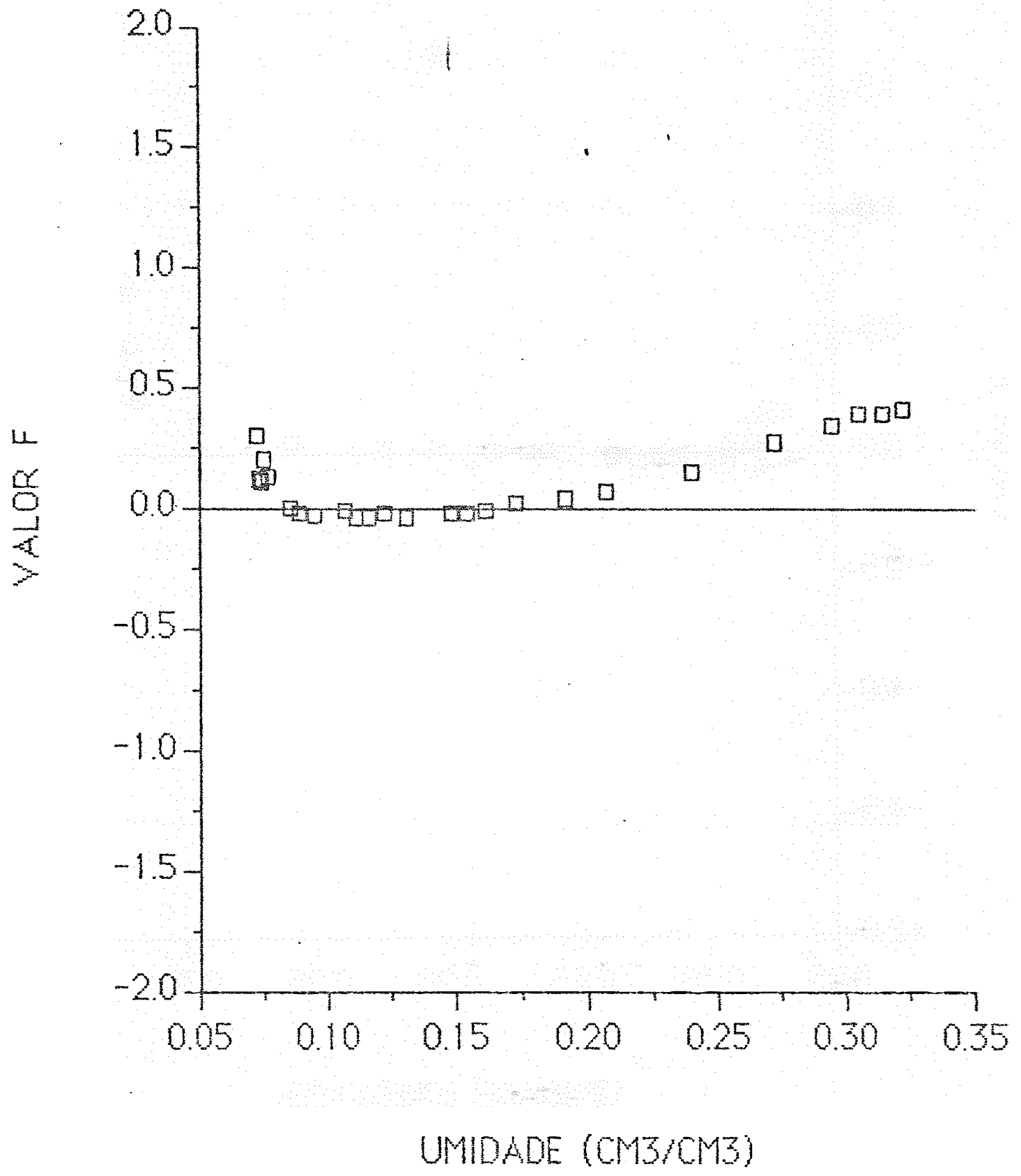

FIGURA 101 - Valor F (equação 41) em função da umidade para a camada 30-50 cm do solo Duna de Areia. 


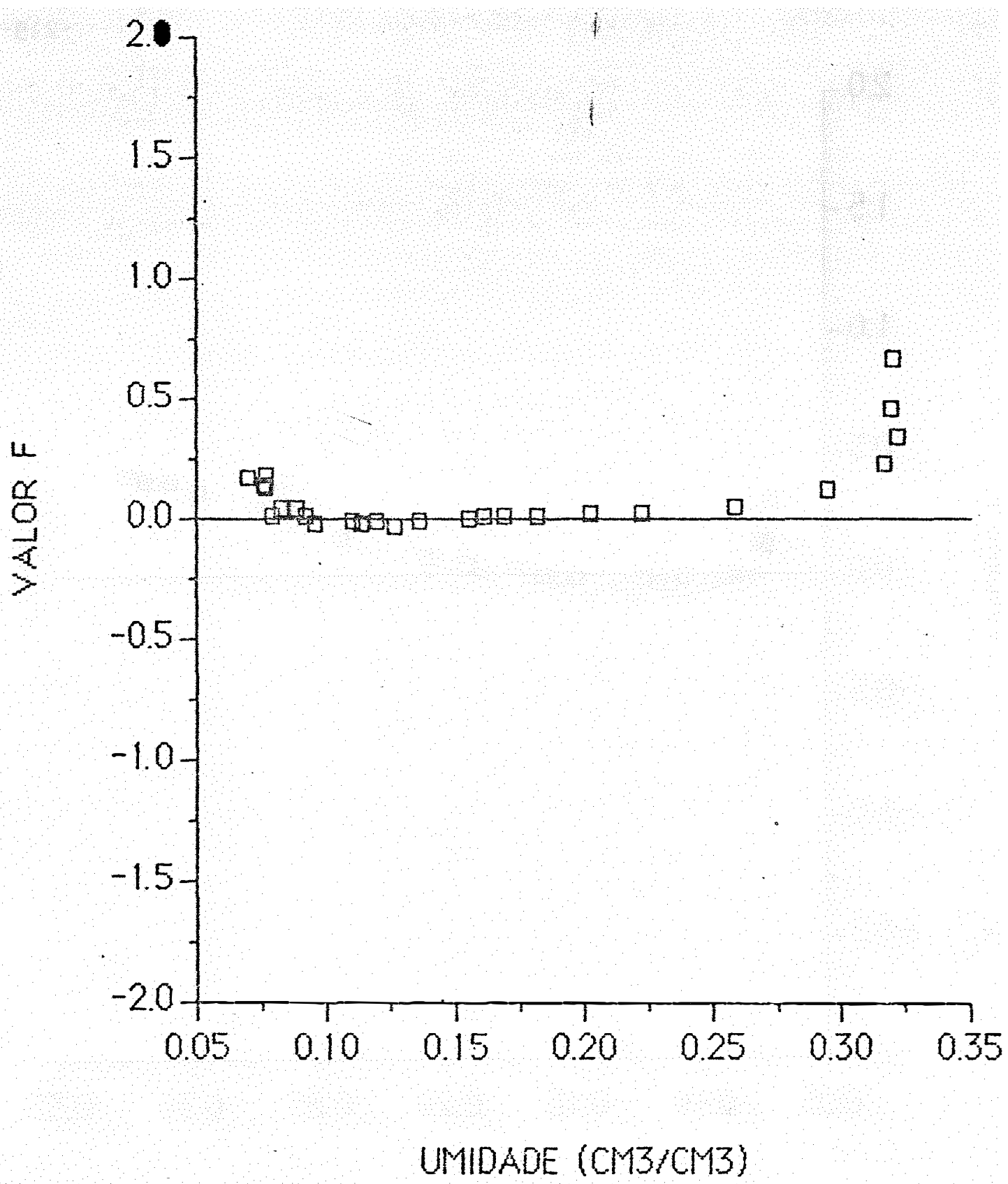

FIGURA 102 - Valor F (equação 41) em função da umidade para a camada 40-60 cm do solo Duna de Areia. 


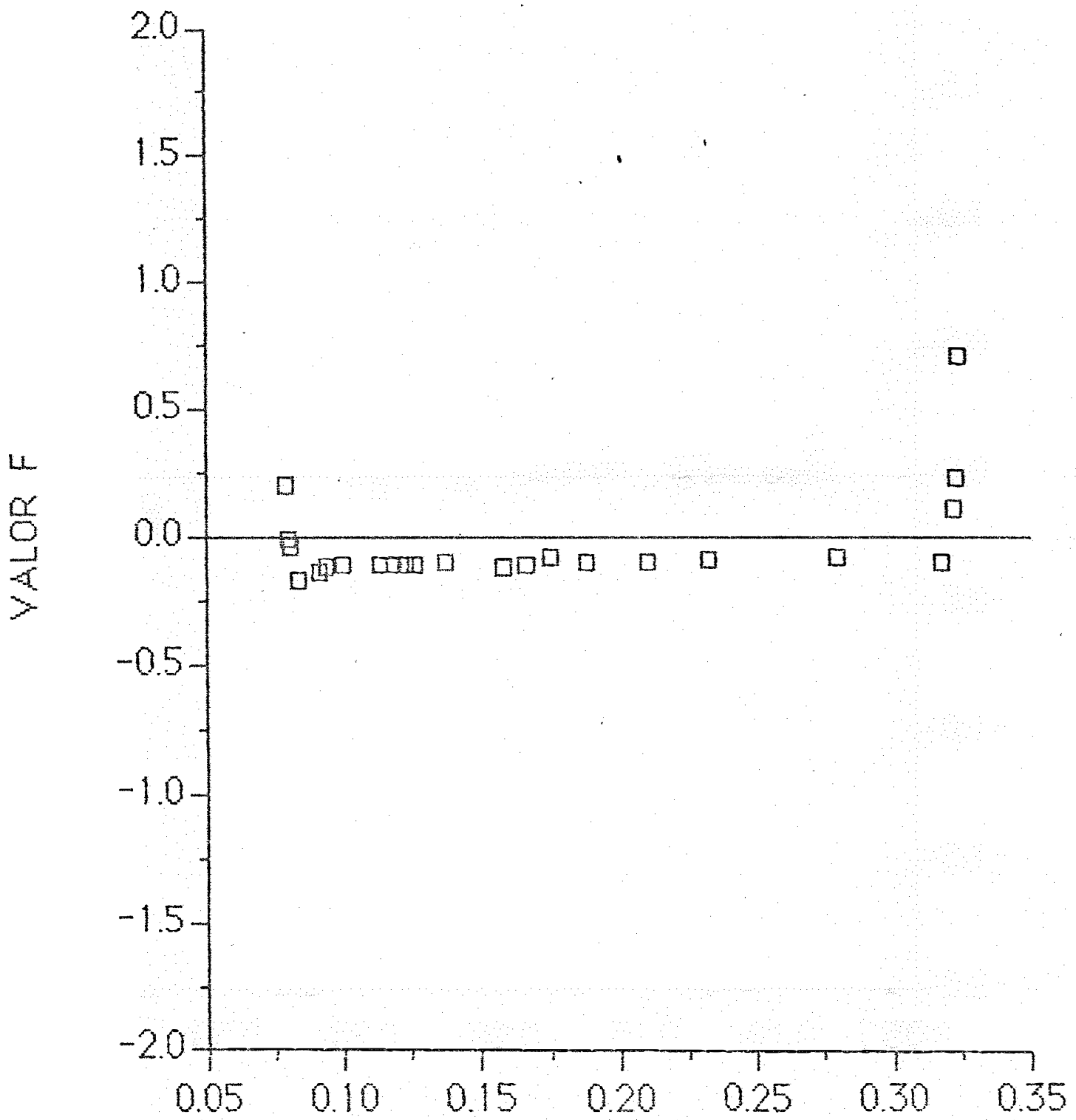

UMIDADE (CMB/CMB)

FIGURA 103 - Valor F (equação 41) em função da umidade para a camada $50-70 \mathrm{~cm}$ do solo Duna de Areia. 


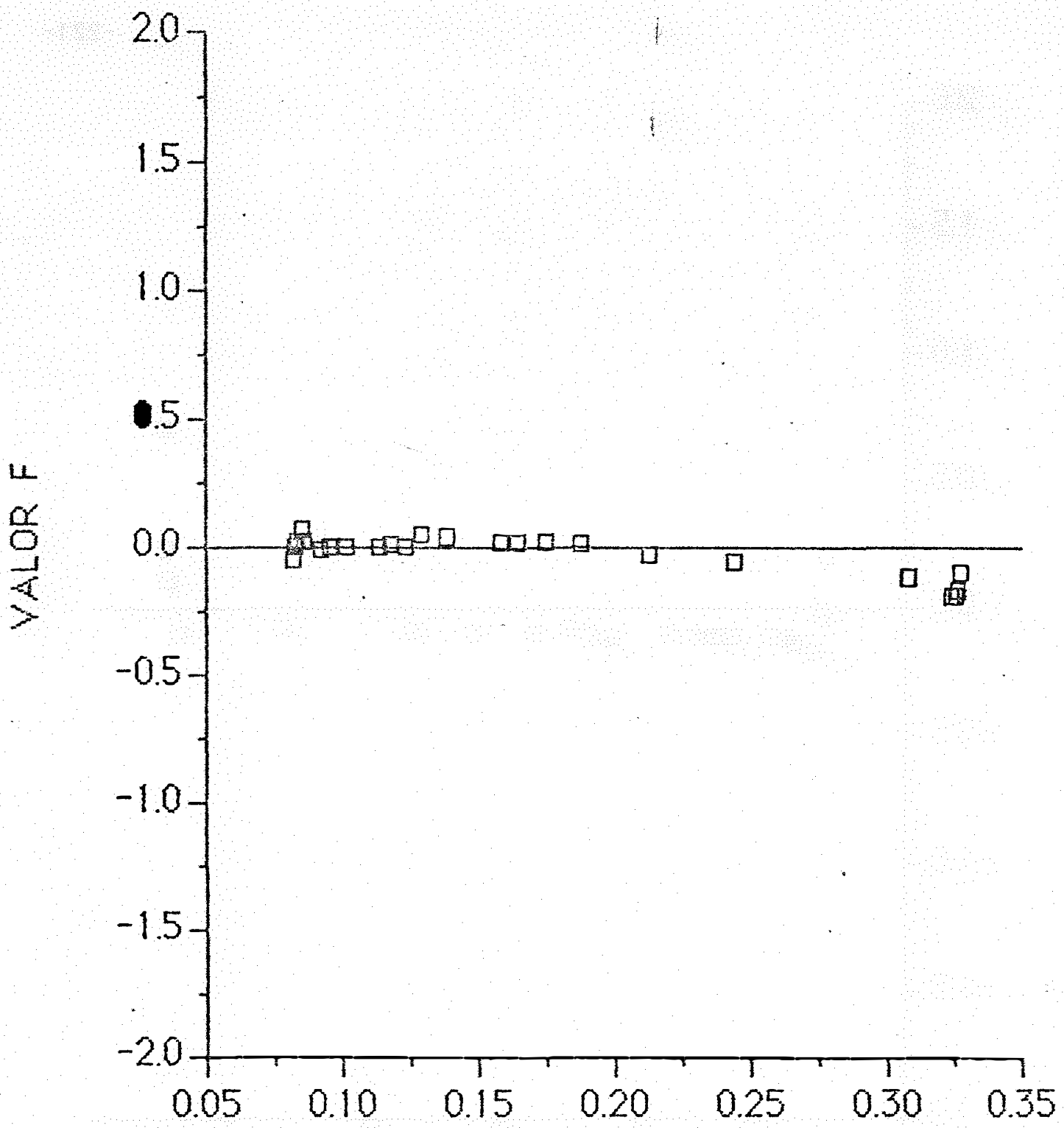

UMIDADE (CM3/CM3)

FIGURA 104 - Valor F (equação 41) em função da umidade para a camada $60-80 \mathrm{~cm}$ do solo Duna de Areia. 


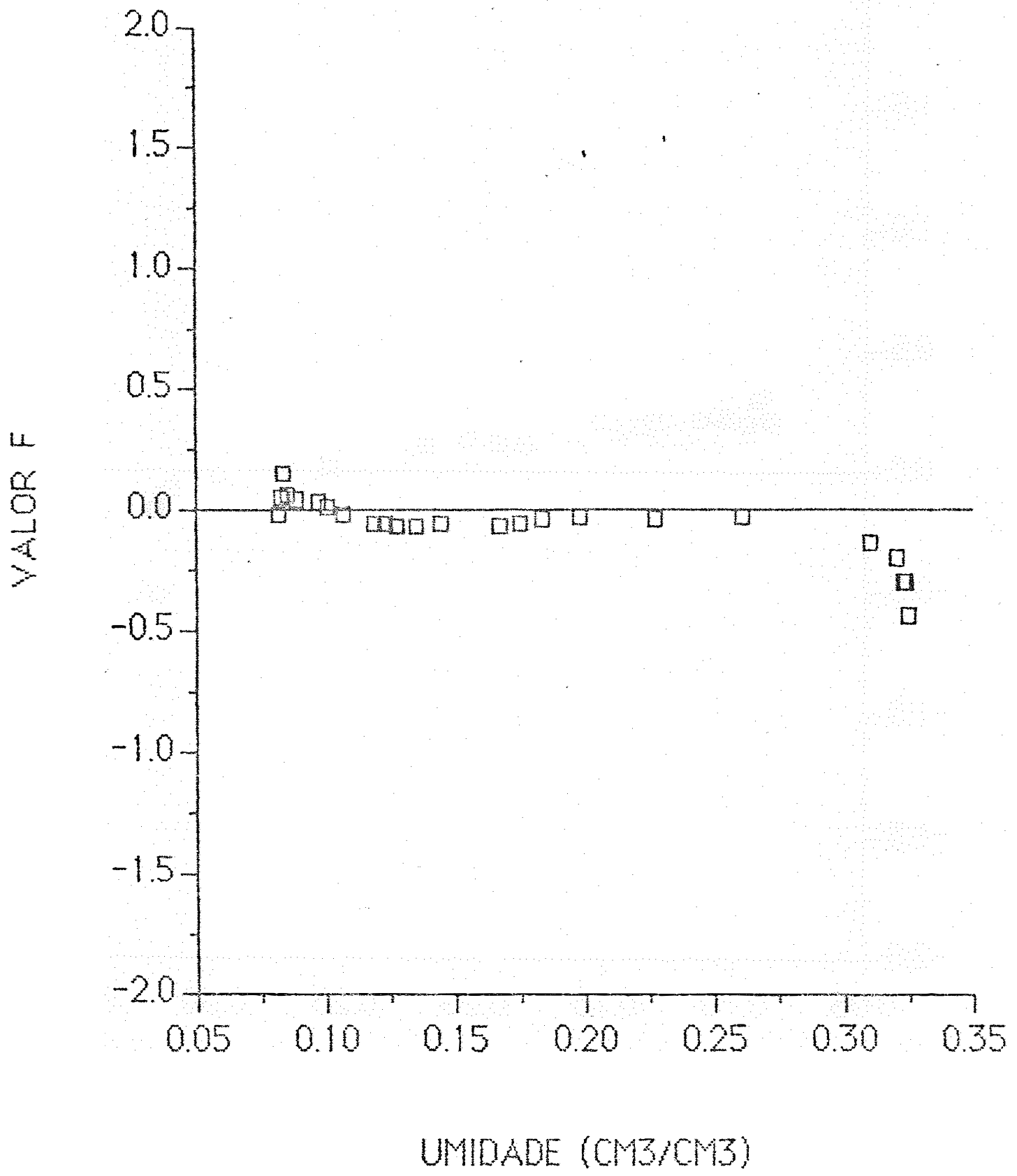

FIGURA 105 - Valor F (equação 41) em função da umidade para a camada $70-90 \mathrm{~cm}$ do solo Duna de Areia. 


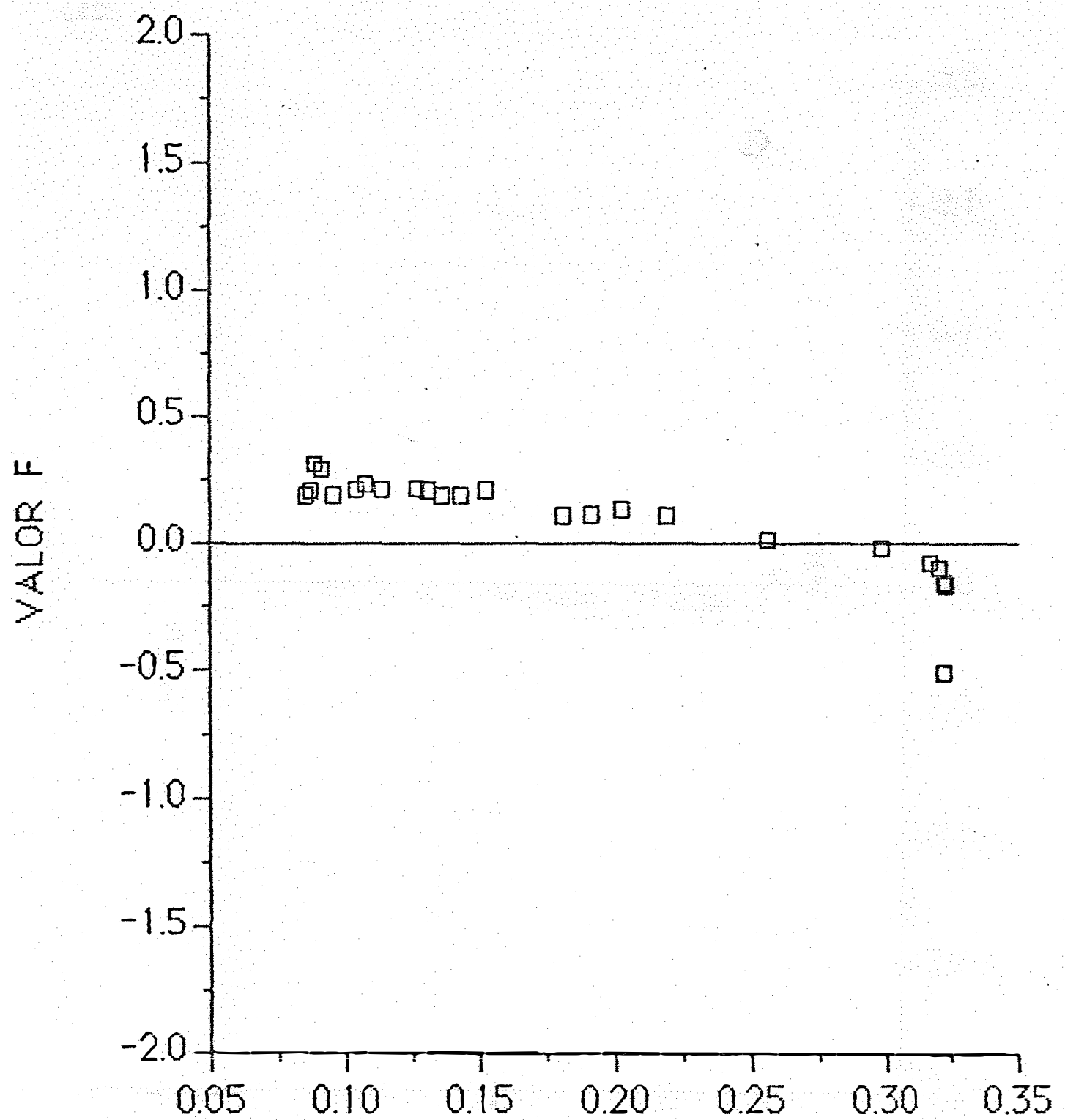

UMIDADE (CMB/CM3)

FIGURA 106 - Valor F (equação 41) em função da umidade para a camada $80-100 \mathrm{~cm}$ do solo Duna de Areia. 


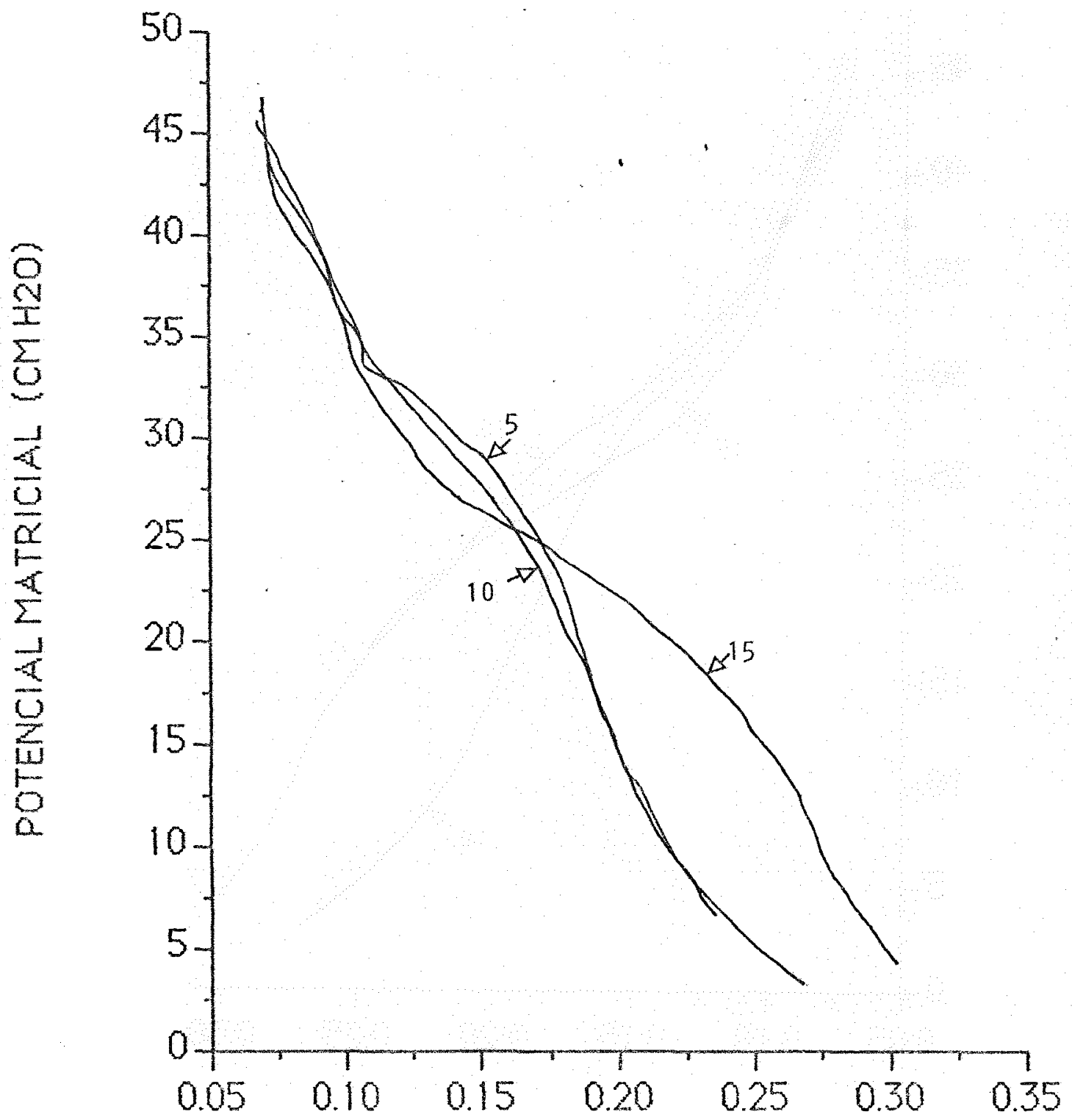

UMIDADE (CMB/CMB)

FIGURA 107 - Familia de curvas características da camada $5-15 \mathrm{~cm}$ do solo Duna de Areia. Os nümeros às curvas referem-se às suas respectivas profundidades. 


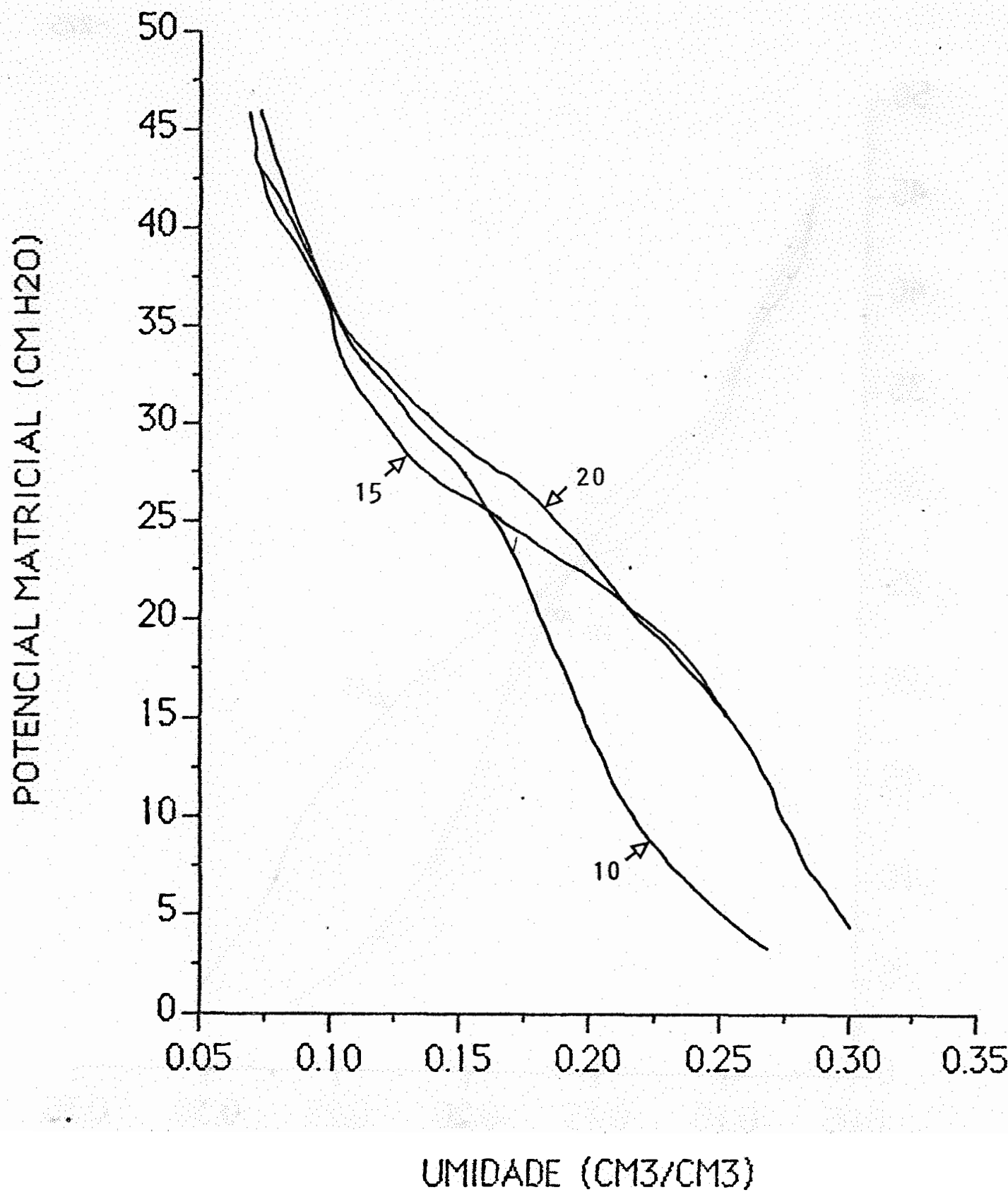

FIGURA 108 - Família de curvas características da camada $10-20 \mathrm{~cm}$ do solo Duna de Areia. Os nümeros as curvas referem-se às suas respectivas profundidades. 


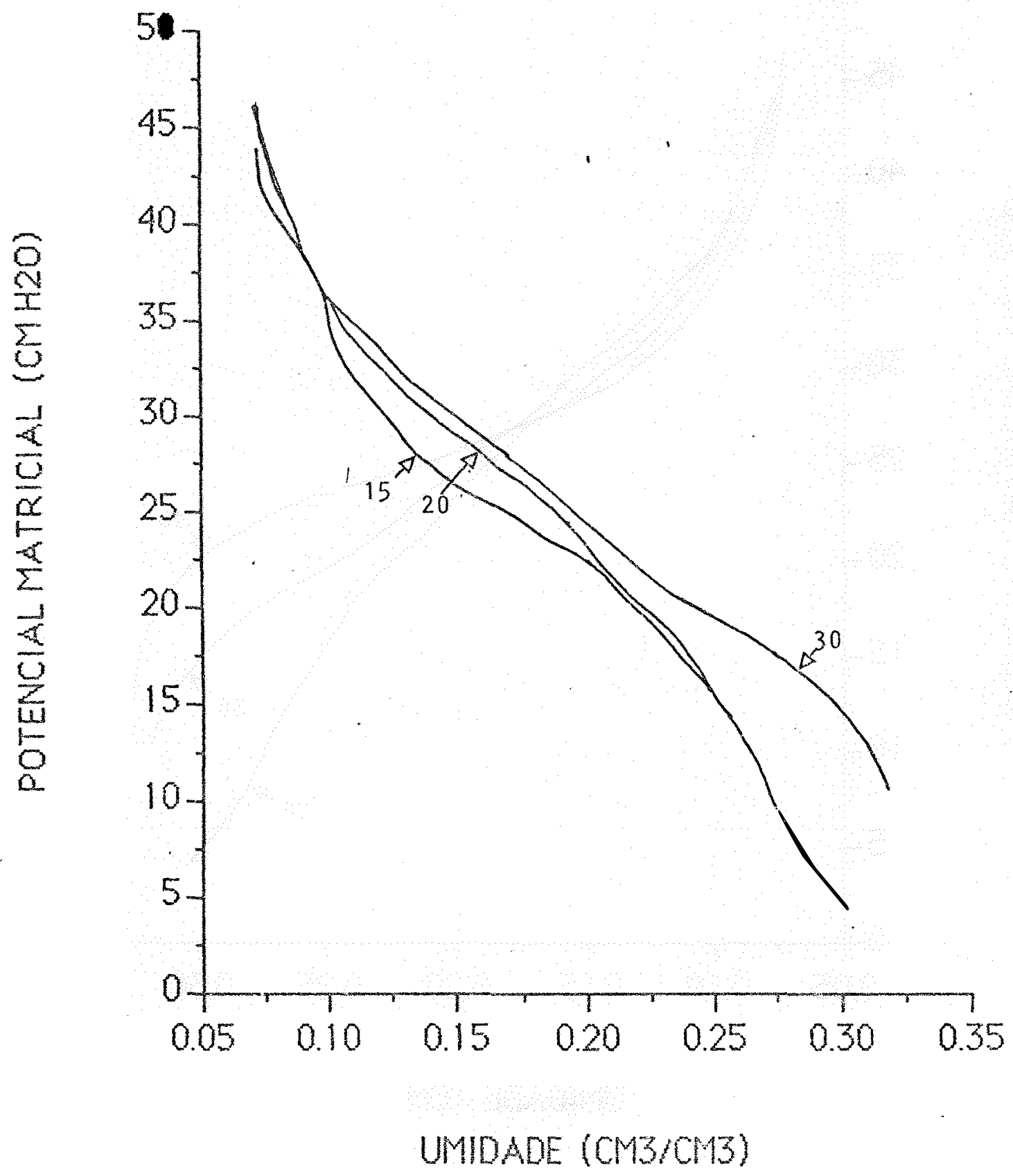

FIGURA 109 - Familia de curvas características da camada 15-30 cm do solo Duna de Areia. Os nümeros às curvas referem-se às suas respectivas profundidades. 


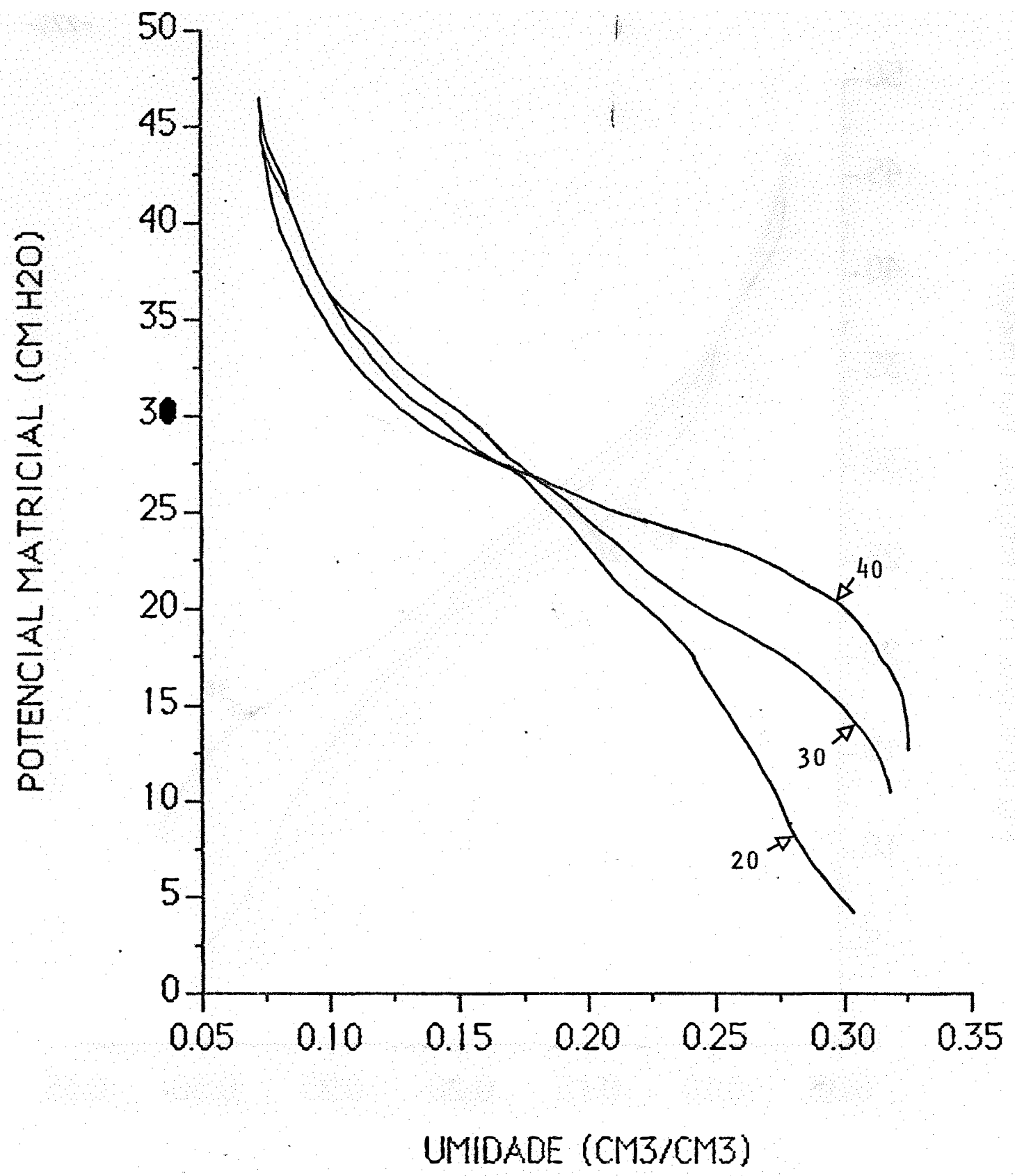

FIGURA 110 - Família de curvas características da camada $20-40 \mathrm{~cm}$ do solo Duna de Areia. Os nümeros às curvas referem-se às suas respectivas profundidades. 


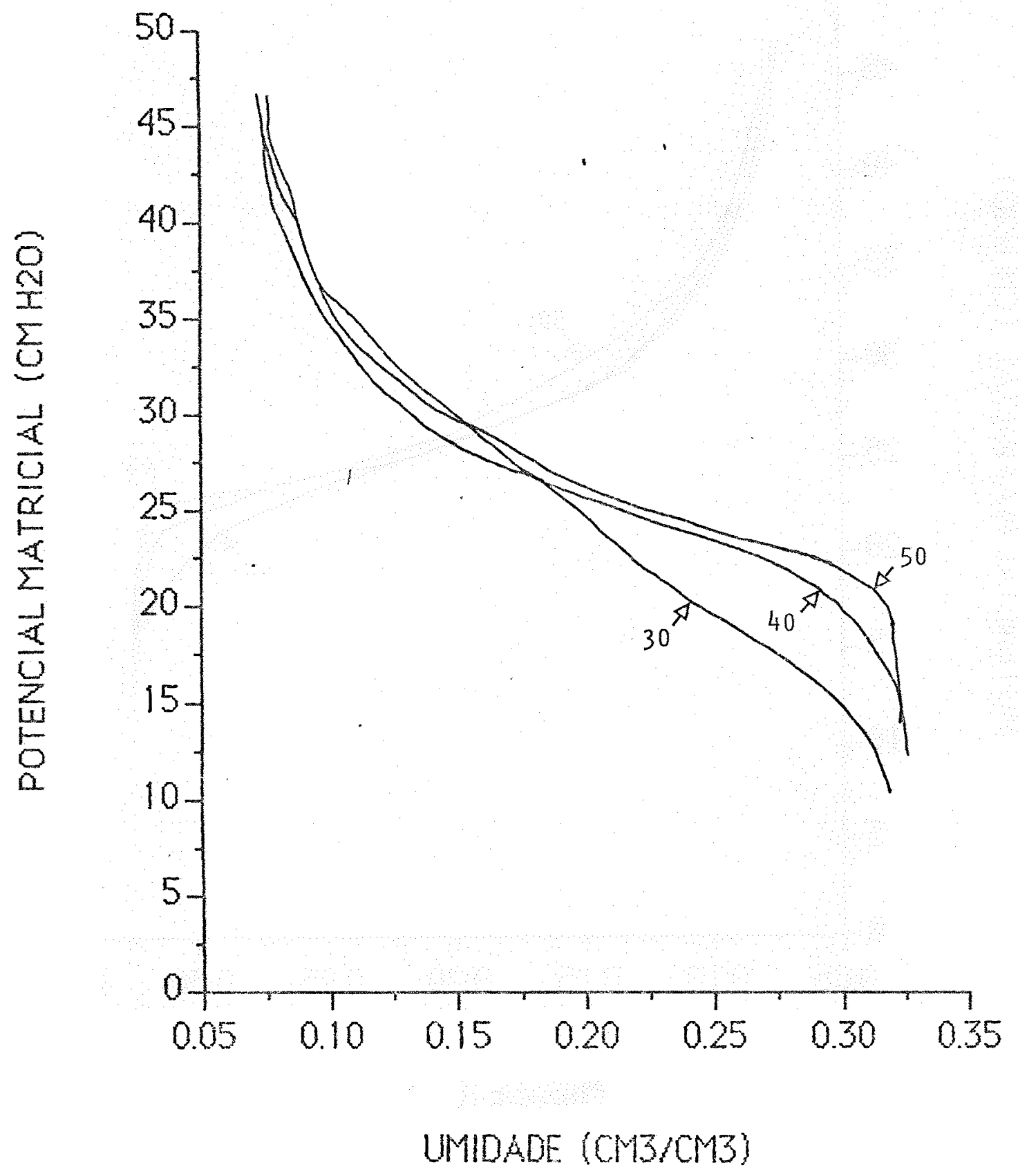

FIGURA 111 - Familia de curvas características da camada 30-50 cm do solo Duna de Areia. Os nümeros às curvas referem-se às suas respectivas profundidades. 


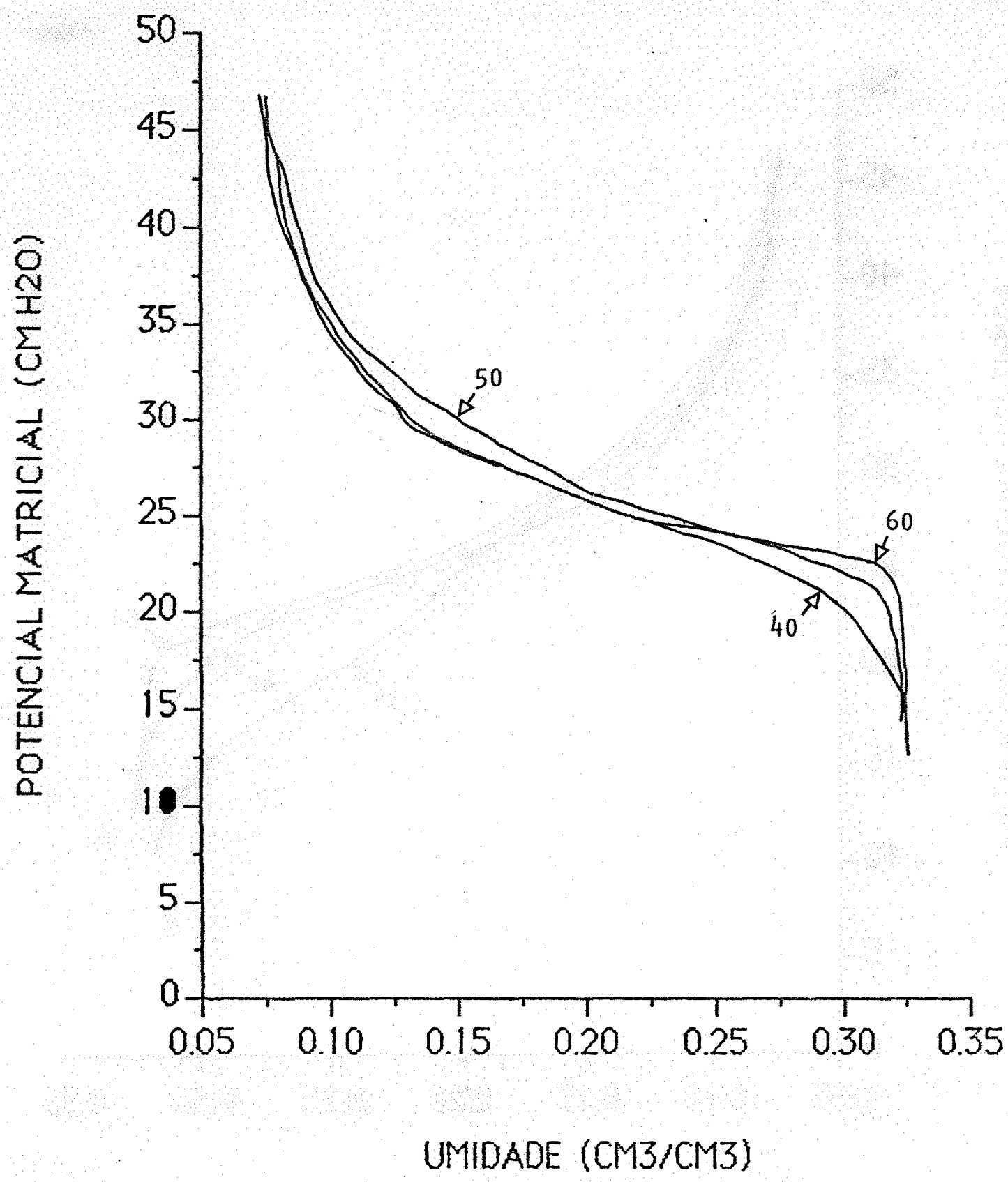

FIGURA 112 - Familia de curvas características da camada 40-60 cm do solo Duna de Areia. Os nümeros às curvas referem-se às suas respectivas profundidades. 


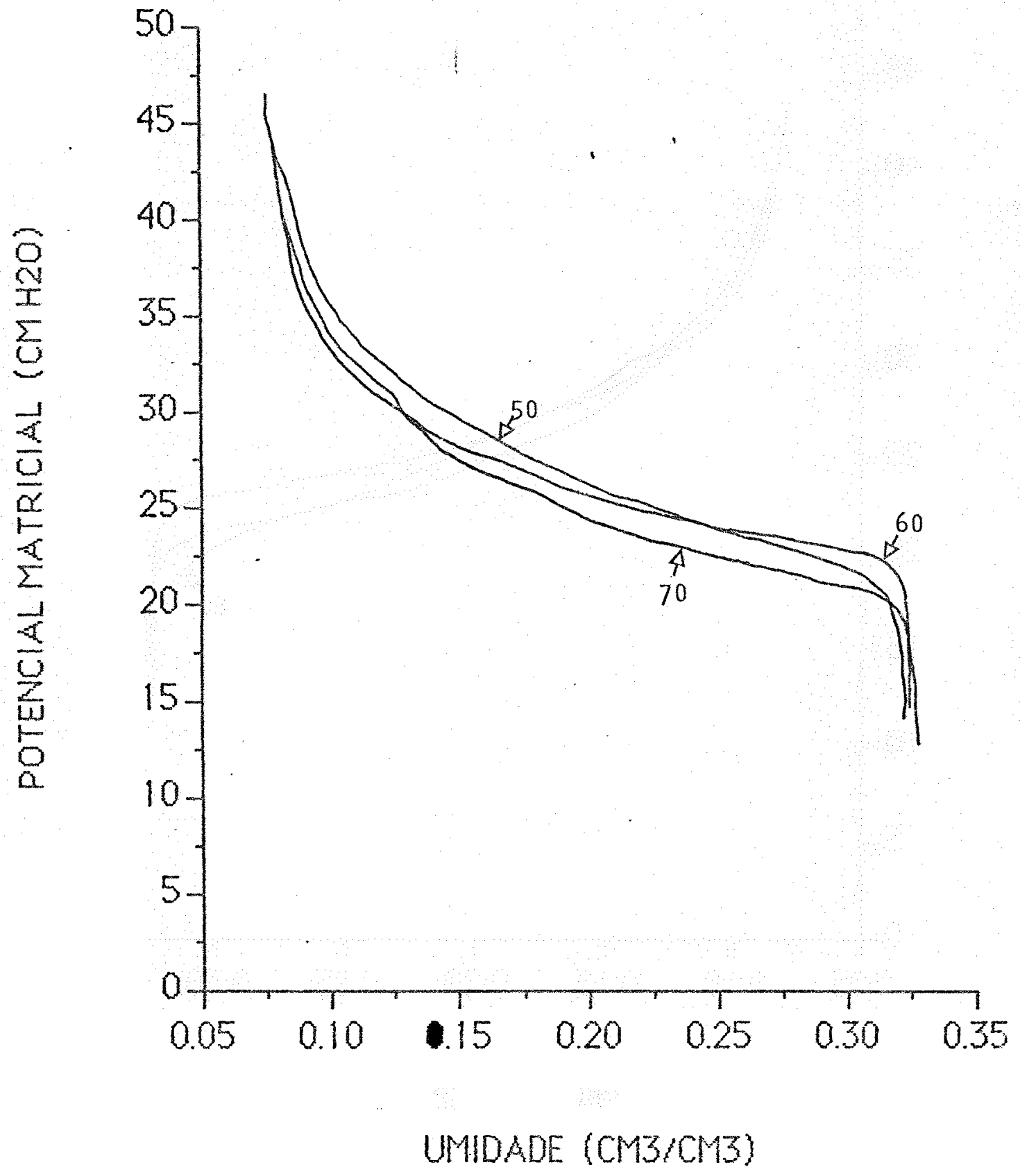

FIGURA 113 - Familia de curvas características da camada $50-70 \mathrm{~cm}$ do solo Duna de Areia. Os nümeros às curvas referem-se às suas respectivas profundidades. 


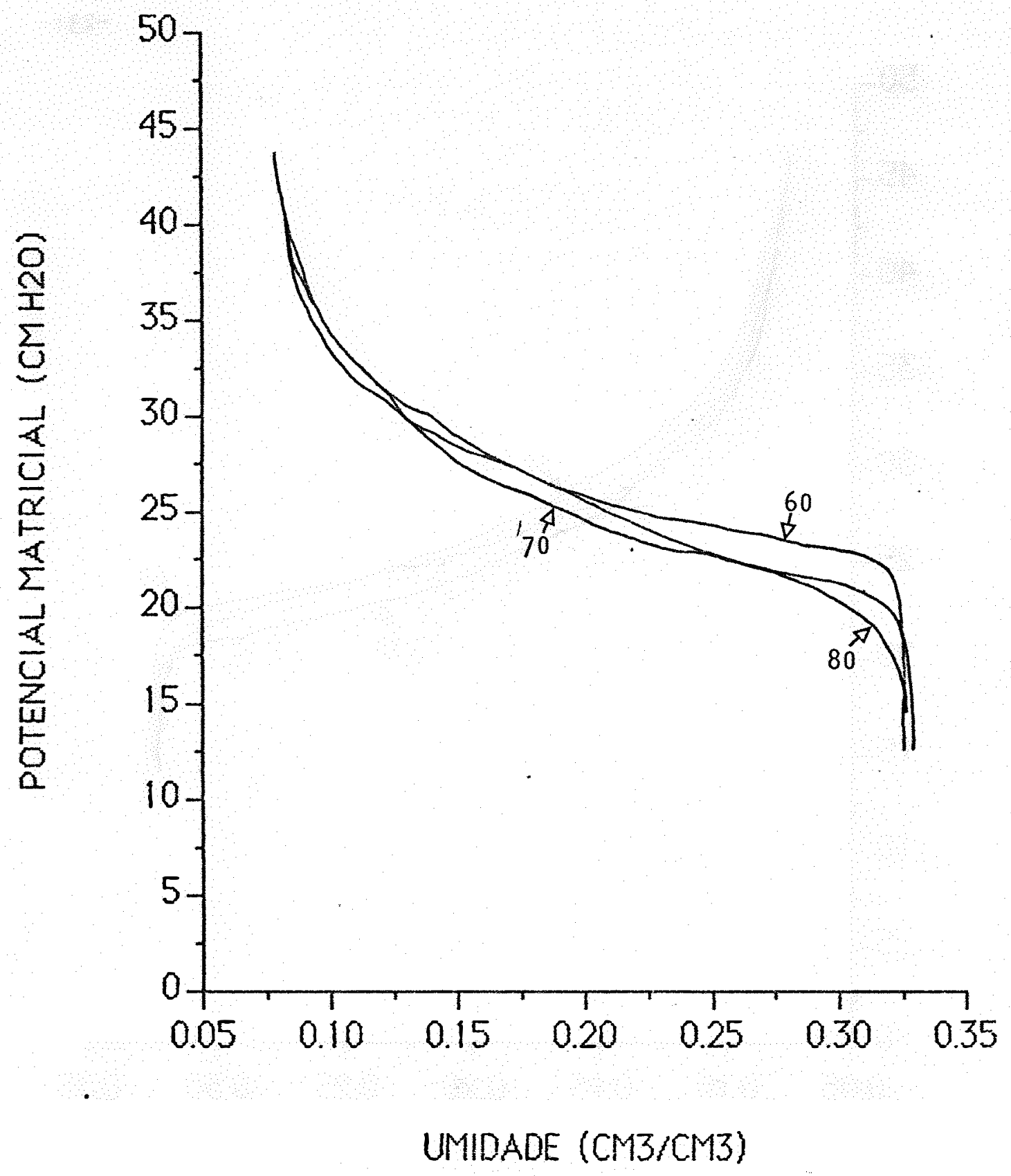

FIGURA 114 - Família de curvas caracteristicas da camada 60-80 cm do solo Duna de Areia. Os números às curvas referem-se às suas respectivas profundidades. 


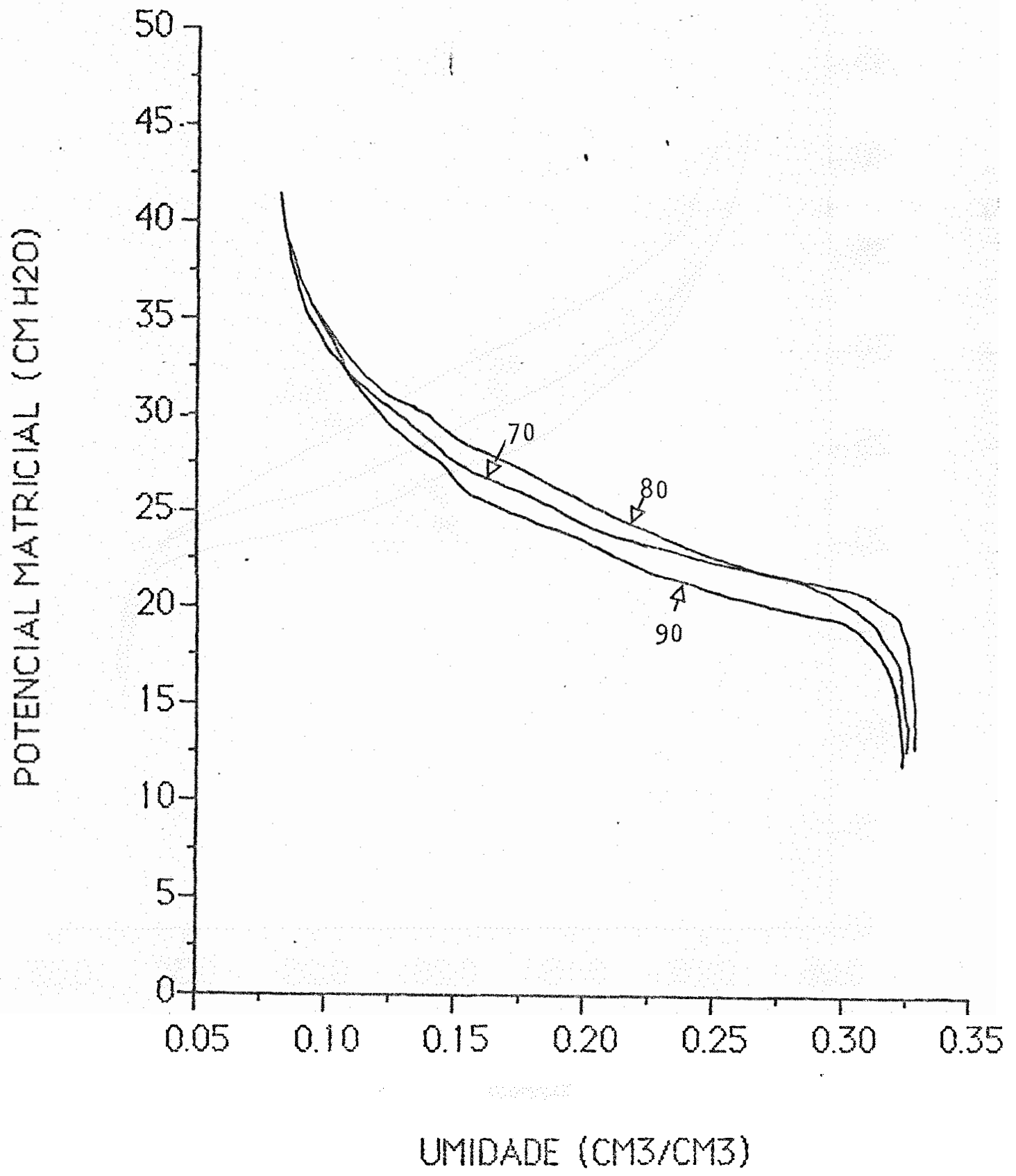

FIGURA 115 - Familia de curvas características da camada $70-90 \mathrm{~cm}$ do solo Duna de Areia. Os nümeros às curvas referem-se às suas respectivas profundidades. 


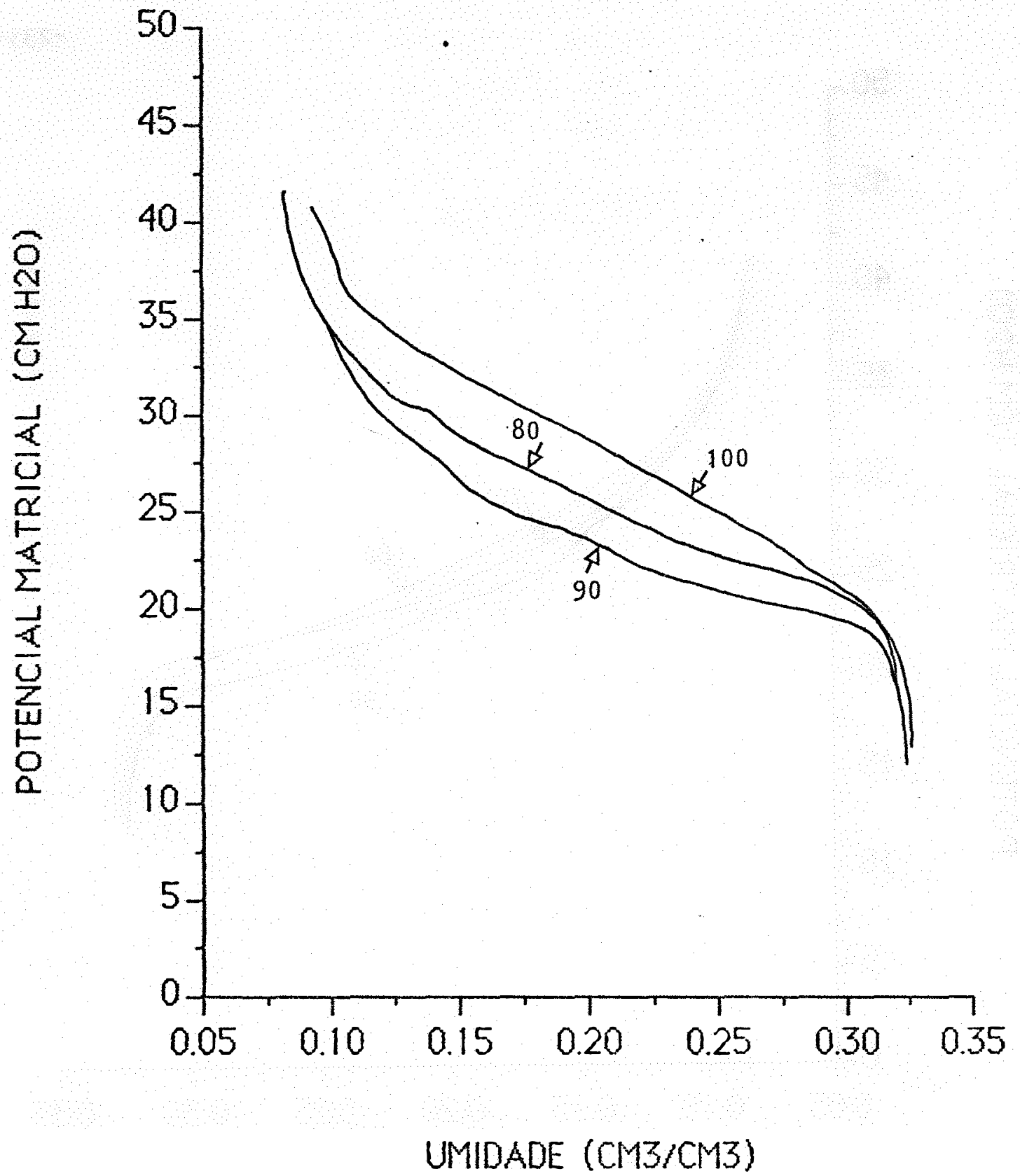

FIGURA 116 - Família de curvas características da camada 80-100 cm do solo Duna de Areia. Os números às curvas referem-se às suas respectivas profundidades. 


\section{CONCLUSÕES}

A análise dos resultados apresentados neste trabalho permitiu as seguintes conclusões:

(i). a teoria proposta (representada pelas equações (25) e (27) para a direção vertical do fluxo, pelos conceitos de difusividades hidráulicas global, gravitacional e matricial, bem como pelo método de determinação da difusividade hidráulica global em função da umidade), è vālida para meios porosos não saturados, hidraulicamente homogêneos;

(ii) a teoria pode ser aplicada também para propōsitos práticos, em meios porosos não saturados, aproximadamente homogêneos do ponto de vista hidräulico; e

(iii) dos três critērios analisados para identificação de meios porosos hidraulicamente homogêneos: a) morfolögico, b) atravēs da função $F$ (proposta neste trabalho), e (c) da família de cur.vas características, o primeiro nem sempre conduz a resultados satisfatórios, o segundo è o mais apropriado, e o terceiro é de interesse prätico, preferível ao primeiro, porèm, menos preciso que o segundo. 
7. REFERENCIAS BIBLIOGRAFICAS

BELTRAME, L. E TAYLOR, J.C. Uso da sonda de nêutrons para determinação da umidade do solo no campo, R. bras. Ci. Solo, Campinas, 4: $57-61,1980$.

BLACK, T.A.; GARDNER, W.R.; THURTELL, G.W. The prediction of evaporation, drainage and soil water storage for a bare soil. Soil Sci. Soc. Am. Proc., Madison, 33: 655-660, 1969.

BORATO, F. Basic para engenheiros e cientistas. 2a. ed., Rio de Janeiro, Livros Técricos e Científicos Editora, 1984. $120 \mathrm{p}$.

BRUCE, R.R. \& KLUTE, A. Measurement of soil moisture diffusivity. Soil Sci. Soc. Am. Proc., Madison, 20: 458-462, 1956.

BUCKINGHAM, E. Studies on the movement of soil moisture. U.S. Dept. Agr., Bur. Soils, Bul. 38: 1-61, 1907.

CAMARGO, A.; PINTO, H.S.; PEDRO JR., M.J.; ALFONSI, R.R.; ORTOLANI, A. A. Clima do Estado de São Paulo. In: SAEEP. Inst. Agronômico. Zoneamento Agrícola do Estado de São Paulo, vol. 1. 1974.

CARSLAW, H.S. \& JAEGER, J.C. Conduction of heat in solids. 2a. ed., Oxford, Clarendon Press, 1976. 510 p.

CASSEL, D.K.; WARRICK, A.W.; NIELSEN, D.R.; BIGGAR, J.W. Soil water 
diffusivity values based upon time dependent soil water content distributions. Soil Sci. Soc. Am. Proc., Madison, 32: 774-777, 1968.

CERVELLINI, A.; SALATI, E.; BARROS FERRAZ, E.S.; VILLA NOVA, N.A.; REICHARDT, K.; DECICO, A.; OMETTO, J.C.; PEDRO JR., M.J. Anälise dos dados meteorológicos de Piracicaba. Piracicaba, ESALQ/USP, Boletim Cientifico n? $36,1973.26 \mathrm{p}$.

CHILDS, E.C. E COLLIS-GEÓRGE, N. Soil geometry and soil water equilibrium. Disc.. Farada Soc. London, London, 3: 78-85, 1948.

CHILDS, E.C. \& COLLiS-GEORGE, N. The permeability of porous materials. Roy. Soc. Proc., London, 201: 392-405, 1950.

CHO, T.; NOMURA, Y.; YANO, T.; SKIKASHO, S.; INOUE, H. The use of neutron moisture meter in studies of soil water regimes. - water. management. in a sand dune area. Tottory, Faculty of Agriculture, Tottori University, 1977. $48 \mathrm{p}$.

CRANK, J. The mathematics of diffusion. London, Oxford University Press, 1975. $114 \mathrm{p}$.

DARCY, H. Les fontaines publique de la Ville de Dijon. Paris, Victor Dalmont, 1856.

DAVIDSON, J.M.; BIGGAR, J.W.; NIELSEN, D.R.; WARRICK, A.; CASSEL, D.K. Soil water diffusivity and water content distribution during outflow experiments. In: Water in the unsaturated zone. Volume 1, p. 214-223. Publ. 82, Int. Assoc. Sci. Hydrol. Proc., Wageningen, Symp., 1966.

DAVIDSON, J.M.; STONE, L.R.; NIELSEN, D.R.; LA RUE, M.E. Field 
measurement and use of soil properties. Water Res. Res., Washington, 5: $1312-1321,1969$.

DAVIS, J.C. Statistics and data analysis in Geology. New York, John Wiley, 1986. $646 \mathrm{p}$.

DOERING, E.J. Soil water diffusivity by the one-step method. Soil Sci., Baltimore, 99: $322-326,1965$.

:EHR, K.T. Application of the spline function, to soil science. Soil Sci., Baltimore, 114: 333-338, 1972.

ESTADOS UNIDOS. Soil Taxonomy: a basic system of soil classification to making and interpreting soil surveys. Washington, Agriculture Handbook n? 436, 1979. 754 p.

FLOCKER, W.J.; YAMAGUCHI, M.; NIELSEN, D.R. Capillary conductivity in soil columns. Agron. J., Madison, 60: 605-610, 1968.

GARDNER, W.R. Calculation of capillary conductivity from pressure plate outflow data. Soil Sci. Soc. Am. Proc., Madison, 20: 317$320,1956$.

GARDNER, W.R. Note on the separation and solution of diffusion type equations. Soil Sci. Soc. Am. Proc., Madison, 26: 404-405, 1962. GARDNER, W.R. Field measurements of soil water diffusivity. Soil Sci. Soc. Am. Proc., Madison, 34: 832-833, 1970.

GROHMANN, F.; BRUNINI, 0.; REICHARDT, K. Condutividade hidräulica do solo. Campinas, Instituto Agronômico. Circular no 53, 1976. 28 p.

HILLEL, D. Soil and water - physical principles and processes. 
New York; Academic Press, 1971. 288 p.

HILLEL, D.; KRENTOS, V.D.; STYLIANOU, Y. Procedure and test of an internal drainage method for measuring soil hidraulic characteristics in situ. Soil Sci., Baltimore, 114: 395-400, 1972.

HILLEL, D. E BENYAMINI, Y. Experimental comparison of infiltration and drainage methods for determining unsaturated hydraulic conductivity of a soil profile in situ. In: Isotope and radiation. techniques in soil physics and irrigation studies. Vienna, IAEA, p. 271-275, 1974 .

ISRAELSEN, 0.W. The application of hydrodynamics to irrigation and drainage problems. Hilgardia, Berkeley, 2: 479-528, 1927.

JACKSON, R.D.; VAN BAVEL, C.H.M.; REGINATO, R.J. Examination of the pressure plate outflow method for measuring capillary conductivity. Soil Sci., Baltimore, 96: 249-256, 1963.

JACKSON, R.D. Water vapor diffusion in relatively dry soil: 1 . Theoretical considerations and sorption experiments. Soil Sci. Soc. Am. Proc., Madison, 28: 172-176, 1964 a.

JACKSON, R.D. Water vapor diffusion in relatively dry soil: 11 . Desorption experiments. Soil Sci. Soc. Am. Proc., Madison, 28: $464-466,1964 b$.

KLUTE, A. The determination of the hydraulic conductivity and diffusivity of unsaturated soils. Soil Sci., Baltimore, 113: $264-276,1972$.

KUNZE, R.J. E KIRKHAM, D. Simplified accounting for membrane 
impedance in capillary conductivity determinations. Soil Sci. Soc. Am. Proc., Madison, 26: 421-426, 1962.

LIBARDI, P.L. Condutividade hidráulica do solo em condições de campo. Piracicaba, 1978. 113 p. (Doutorado, Escola Superior de Agricultura "Luiz de Queiroz" da Universidade de São Paulo).

LIBARDI, P.L. Dinâmica da água no sistema solo-planta-atmosfera. Piracicaba, 1984. 232 p. (Apostila impressa pelo CENA/USP).

LIBARDI, P.L.; REICHARDT, K.; NIELSEN, D.R.; BIGGAR, J.W. Simple field methods for estimating soil hydraulic conductivity. Soil Sci. Soc. Am. Proc., Madison, 44: 3-7, 1980.

MILLER, E.E. E ELRICK, D.E. Dynamic determination of capillary conductivity extended for non-negligible membrane impedance. Soil Sci. Soc. Am. Proc., Madison, 22: 483-486, 1958.

MONIZ, A.C. E JACKSON, M.L. Quantitative mineralogical analysis of Brazilian soils derived from basic rocks and slate. Madison, Wisc., Soil Sci. Dept., University of Wiscounsin, 1967, Report n? 212.

NIELSEN, D.R.; BIGGAR, J.W.; COREY, J.C. Application of flow theory to field situations. Soil Sci., Baltimore, 113: 254-263, 1972.

NIELSEN, D.R.; BIGGAR, J.W.; ERH, K.T. Spatial variability of field measured soil-water properties. Hilgardia, Berkeley, 42: 215-259, 1973.

NIELSEN, D.R.; DAVIDSON, J.M.; BIGGAR, J.W.; MILLER, R.J. Water movement through Panoche clay loam soil. Hilgardia, Berkeley, 42: 491-506, 1962. 
OGATA, G. E RICHARDS, L.S. Water content changes following irrigation of bare field soil that is protected from evaporation. Soil Sci. Soc. Am. Proc., Madison, 21: 355-356, 1957.

PAULETTO, E.A. Determinação da condutividade hidräulica de solos a partir da curva de retenção de ăgua. Piracicaba, 1986. 133 p. (Doutoramento, Escola Superior de Agricultura "Luiz de Queiroz" da Universidade de São Paulo).

PECK, A.J. Diffusivity determination by a new outflow method. In: Water in the unsaturated zone. Vol. 1: 191-202. Publ. no 82, Int. Assoc. Sci. Hydrol. Proc., Wageningen Symp., 1966.

PREVEdello, B.M.S.; PREVEDELLO, C.L.; LIBARDi, P.L. Simplificação analítica do método do perfil instantâneo para obtenção da condutividade hídrāulica não saturada em condições de campo. R. bras. Ci. Solo, Campinas, 5: 93-97, 1981.

RANZANI, G.; FREIRE, 0.; KINJO, T. Carta de solos do município de Piracicaba. Piracicaba, Centro de Estudos de Solos, ESALQ/USP, 1966. $85 \mathrm{p}$.

REICHARDT, K. \& LIBARDI, P.L. An analysis of soil water movement in the field. 1. Hydrological field site characterization. Piracicaba, CENA/USP. BC-021, 1974. $21 \mathrm{p}$.

REICHARDT, K. Processos de transferência no sistema solo-plantaatmosfera. 4a. edição. Campinas, Fundação Cargill, 1985. 445 p.

RICHARDS, L.A. Capillary conduction of liquids through porous medium. Physics, New York, 1: 318-333, 1931. 
RICHARDS, L.A. Trans. 7th. Intern. Congr. Soil Sci., Madison, Vol. 1, 67-69. Elsevier, Amsterdam. 1961.

RICHARDS, L.A. Physical condition of water in soil. In: BLACK, C.A., ed., Methods of soil analysis. Madison, Amer. Soc. Agron. Part 1, Agronomy, p. $128-152,1965$.

RICHARDS, L.A.; GARDNER, W.R.; OGATA, G. Physical processes determining water loss from soil. Soil Sci. Soc. Am. Proc., Madison, 20: $310-314,1956$.

RICHARDS, S.J. \& WEEKS, L.V. Capillary conductivity values from moisture yield and tension measurements on soil columns. Soil Sci. Soc. Am. Proc., Madison, 17: 206-208, 1953.

ROSE, C.W.; STERN, W.R.; DRUMOND, J.E. Determination of hydraulic conductivity as a function of depth and water content for soil in situ. Aust. J. Soil Res., Melbourne, 3: 1-9, 1965.

SAUNDERS, L.C.U.; LIBARDI, P.L.; REICHARDT, K. Condutividade hidräulica da Terra Roxa Estruturada em condições de campo. R. bras. Ci. Solo, Campinas, $\underline{2}: 164-167,1978$.

SCHOENBERG, 1.J. Contributions to the problem of approximation of equidistant data by analitic functions. Quart Appl. Math., Providence, 4: 44-99, 1946 .

SLICHTER, C.S. Theoretical investigation of the motion of ground water. U.S. Geol. Survey 19th Annual Report, Part 2, p. 295-384, 1898.

SWARTZENDRUBER, D. Soil water behavior as described by transport 
coefficients and functions. Adv. Agron., New York, 18: 327-370, 1966.

SWARTZENDRUEER, D. The flow of water in unsaturated soils. In: DE WIEST, R.J.M., ed., Flow through porous media. New York, Academic Press, cap. 6, p. 215-292, 1969.

VACHAUD, G. E THONY, J.L, Hysteresis during infiltration and redistribution in a soil column at different initial water contents. Water Res. Res., Washington, 2: 111-127, 1971.

VAN BAVEL, C.H.M.; STIRK, G.B.; BRUST, K.J. Hydraulic properties of . a clay loam soil and the field measurement of water uptaken by roots. 1. Interpretation of water content and pressure profiles. Soil Sci. Soc. Am. Proc., Madison, 32: 310-317, 1968.

VAN GENUCHTEN, M.Th. A closed-form equation for predicting the hydraulic conductivity of unsaturated soils. Soil Sci. Soc. Am. J., Madison, $44: 892-898 ; 1980$.

WALSH, J.L.; AHLBERG, J.H.; NILSON, E.N. Best approximation properties of the spline fit. J. Math. Mech., 11: 225-234, 1962.

WARRICK, A.W. E NIELSEN, O.R. Spatial variability of soil physical propertics in the field. In: HILLEL, D. Applications of soil physics. New York, Academic Press, P. 319-344, 1980.

WATSON, K.K. An instantaneous profile method for determining the hydraulic conductivity of unsaturated porous materials. Water Res. Res., Washington, 2: 709-615, 1966. 
transient flow data. Soil Sci. Soc. Am. Proc., Madison, 31: 721725,1967 .

WHISLER, F.D.; KLUTE, A.; PETERS, D.B. Soil water diffusivity from horizontal infiltration. Soil Sci. Soc. Am. Proc., Madison, 32 : $6-11,1968$

WIND, G.P. Capillary conductivity data estimated by a simple method. In: Water in the unsaturated zone, Volume 1, 181-.191. Publ. n? 82, Int. Assoc. Sci. Hydróll. Proc, Wageningen Symp., 1966.

YOUNGS, E.G. An infiltration method of measuring the hydraulic conductivity of unsaturated porous materials. Soil Sci., Baltimore, $92: 307-311,1964$. 
$-245-$

$A P E N D \mid C E$ A 
Programa em linguagem "BASIC" para o computador TK 90X, usado para calcular a armazenagem de ägua no solo (por camada e acumulada), e as tangentes nos $\mathrm{N}$ pares de pontos, a partir de um perfil de umidade que se obtëm por interpolação "SPLINE" cübica (ver item 4.2.6.), dos N pares de pontos (umidade versus profundidade).

Neste trabalho, o mesmo programa foi tambëm aplicado para obtenção das tangentes $\left(d \psi_{m} / d \theta\right),\left(\partial \psi_{m} / \partial z\right)_{t}$, e dos fluxos de água $(q)_{L}$; bastou apenas organizar as entradas dos dados $x, y$, de acordo com $o$ interesse.

1200 REM "SPL"

1201 PRINT "Programa Interpolaçao 'SPLINE COBICA' aplicada a dinamica da $\mathrm{H}_{2} \mathrm{O}$ no solo"

1202 PRINT : PRINT : PRINT

1205 REM "Este progr. computa a armazenagem de $\mathrm{H}_{2} \mathrm{O}$ (por camada e acumulada), e as tangentes nos $N$ pares de pontos, a partir de um perfil de umidade que se obtēm por interpolação spline cübica, dos $N$ pares de pontos (theta $x$ prof.)"

1210 PRINT TAB 10; "por C. L. Prevedello"

1211 PRINT : PRINT : PRINT

1391 PRINT "num. de pontos?"

1392 INPUT $n$

1393 DIM $\times(n)$

1394 DIM $y(n)$

1395 CLS

1436 PRINT "digite prof., monotonicamente"

1437 FOR $\mathrm{i}=1 \mathrm{TO} \mathrm{n}$

1438 INPUT $\times(i)$

1439 PRINT "X("; $i ; ")=$ "; $\times(i)$

1440 NEXT

1445 PRINT "digice umidade"

1447 FOR $k=1$ TO $n$ 


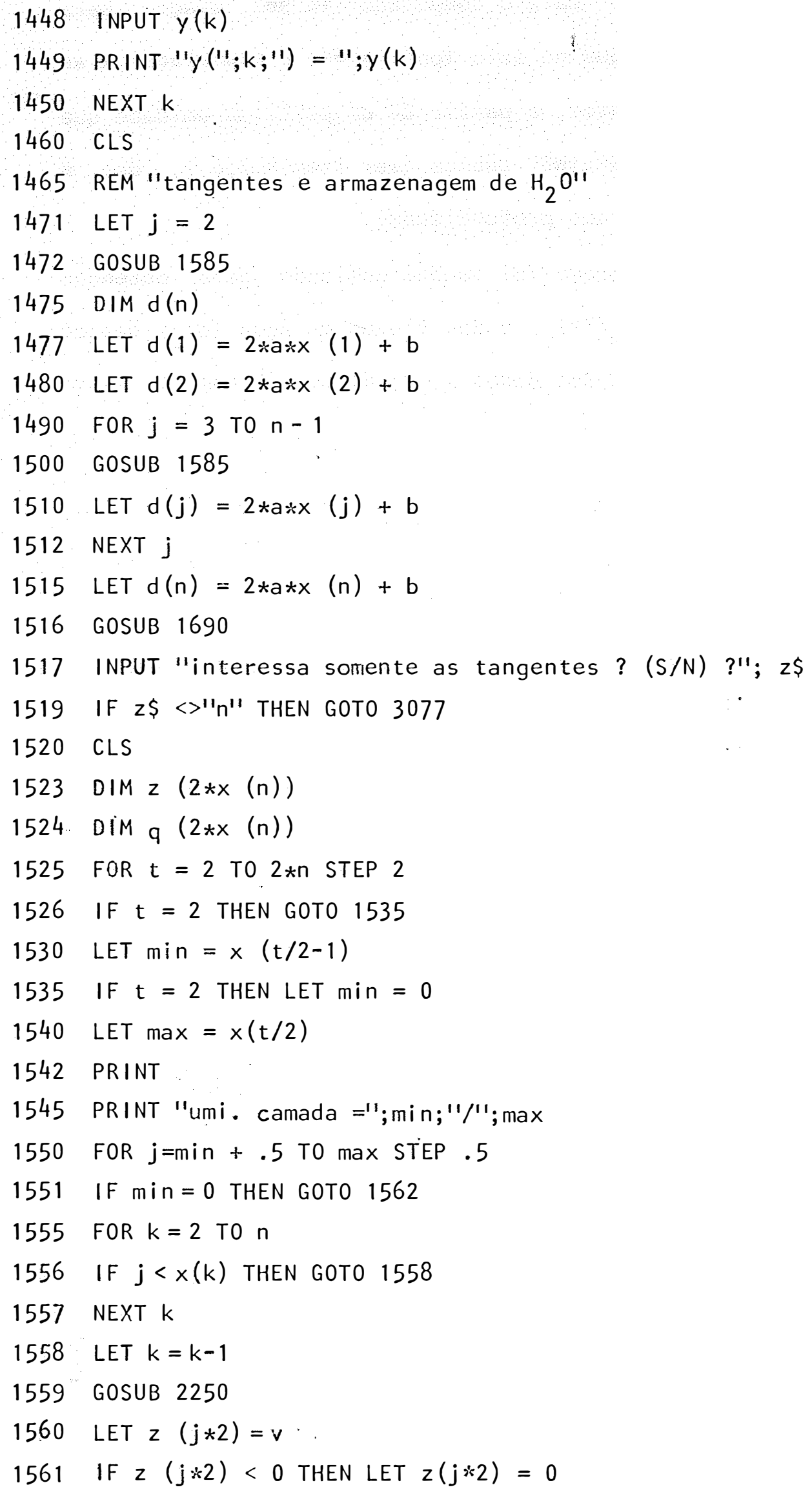


1562 IF $\mathrm{min}=0$ THEN LET $z(j * 2)=y(1)$

1574 PRINT TAB 2; "umi $(" ; j ; ")="$; TAB 20; INT $(z(j * 2) * 10000+.5) / 10000$

1575 NEXT j

1576 NEXT $t$

1577 PRINT : PRINT

1579 PRINT "cont p/ arm."

1560 STOP

1582 GOTO 3000

1583 STOP

1585 LET $a=(y(j-1)-y(j)) /(x(j-1)-x(j))$

1590 LET $a=a-(y(j)-y(j+1)) /(x(j)-x(j+1))$

1600 LET $a=a /(x(j-1)-x(j+1))$

1610 LET $b=a(y(j-1)-y(j)) /(x(j-1)-x(j))$

1620 LET $b=b-a *(x(j-1)+x(j))$

1630 RETURN

$1690 \operatorname{DIM} f(n): \operatorname{DIM} g(n): \operatorname{DIM} h(n)$

1700 FOR $j=1$ TO $n-1$

1710 LET $f(j)=d(j) *(x(j+1)-x(j))$

1720 LET $g(j)=3 * y(j+1)-d(j+1) *(x(j+1)-x(j))$

1730 LET $g(j)=g(j)-3 * y(j)-2 * f(j)$

$1740 \operatorname{LET} h(j)=y(j+1)-y(j)-f(j)-g(j)$

1750 NEXT j

1760 RETURN

2250 LET $w=(j-x(k)) /(x(k+1)-x(k))$

2260 LET $v=y(k)+f(k) * w+g(k) *_{w} *_{w}+h(k) *_{w} *_{w} * w$

2270 RETURN

2280 STOP

3000 CLS

3001 FOR $s=2$ TO $2 * n$ STEP 2

3002 IF $s=2$ THEN GOTO 3004

3003 LET $\min =x(\mathrm{~s} / 2-1)$

3004 IF $s=2$ THEN LET $\mathrm{min}=0$

3005 LET $\max =x(\mathrm{~s} / 2)$

3009 LET $e=0$

3010 FOR $i=m i n+.5$ TO $\max$ STEP .5

3020 LET $e=e+.5 * z(i * 2)$

3030 LET $\mathrm{q}(\mathrm{s} / 2)=\mathrm{e}$ 


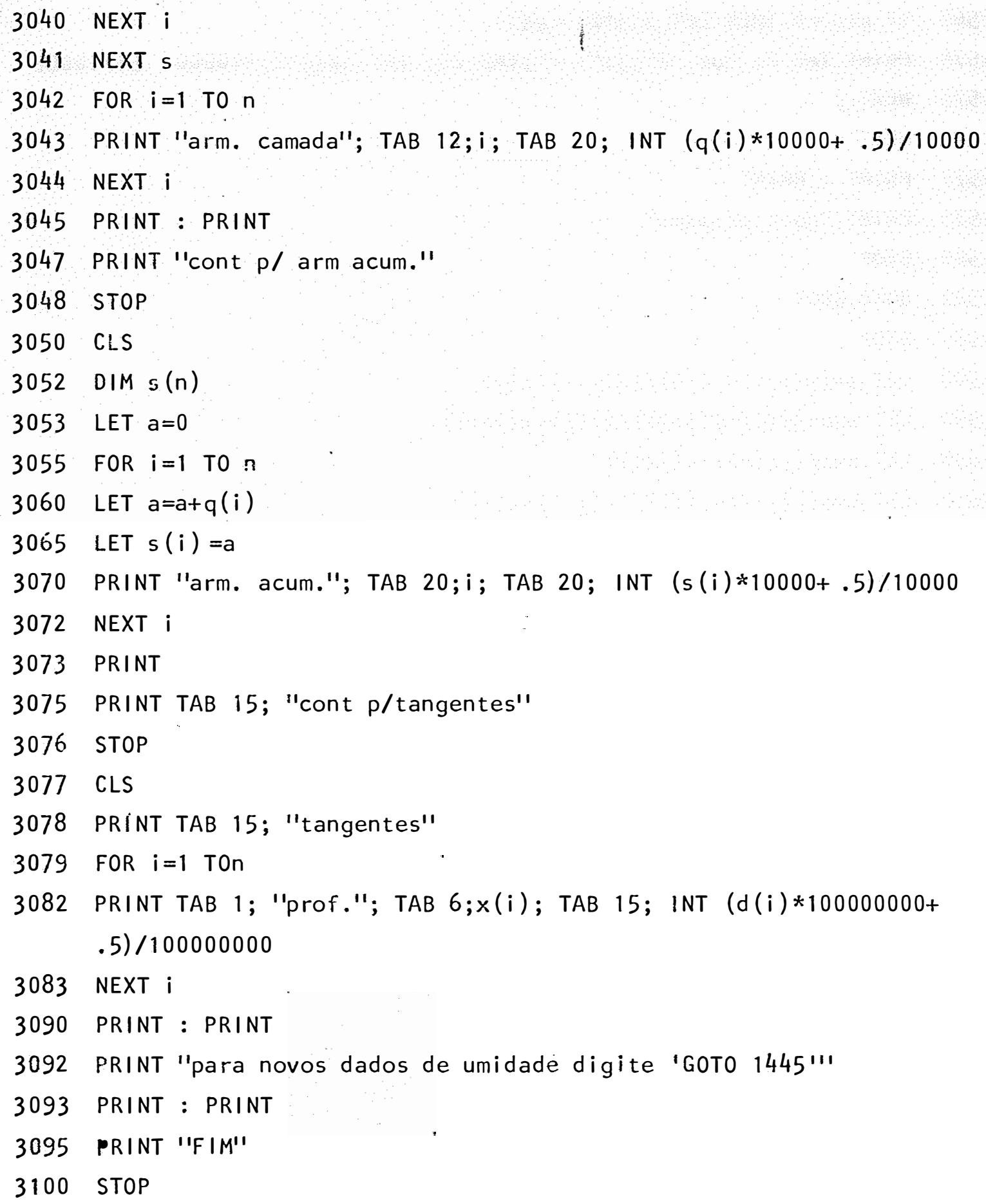


$-250-$

A PENDICE B 
Dados (fornecidos por CHO et alii, 1977) de umidade e potencial matricial, ambos em função da profundidade e do tempo (Tabelas 1 e 2, respectivamente), em experimento de redistribuição interna da ăgua em Duna de Areia, após o solo ter sido previamente saturado e prevenida a infiltração e evaporação em sua superfície. 


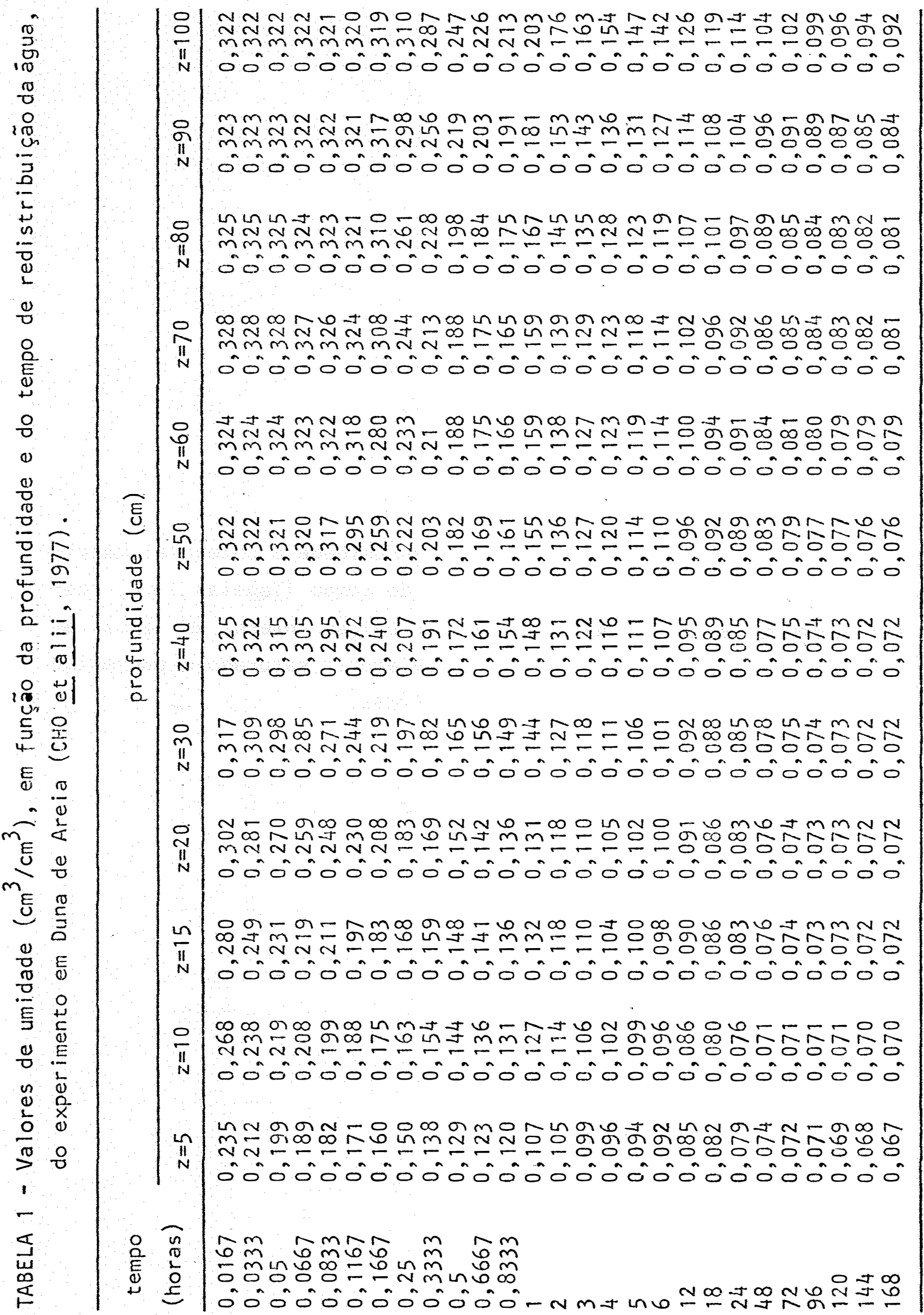




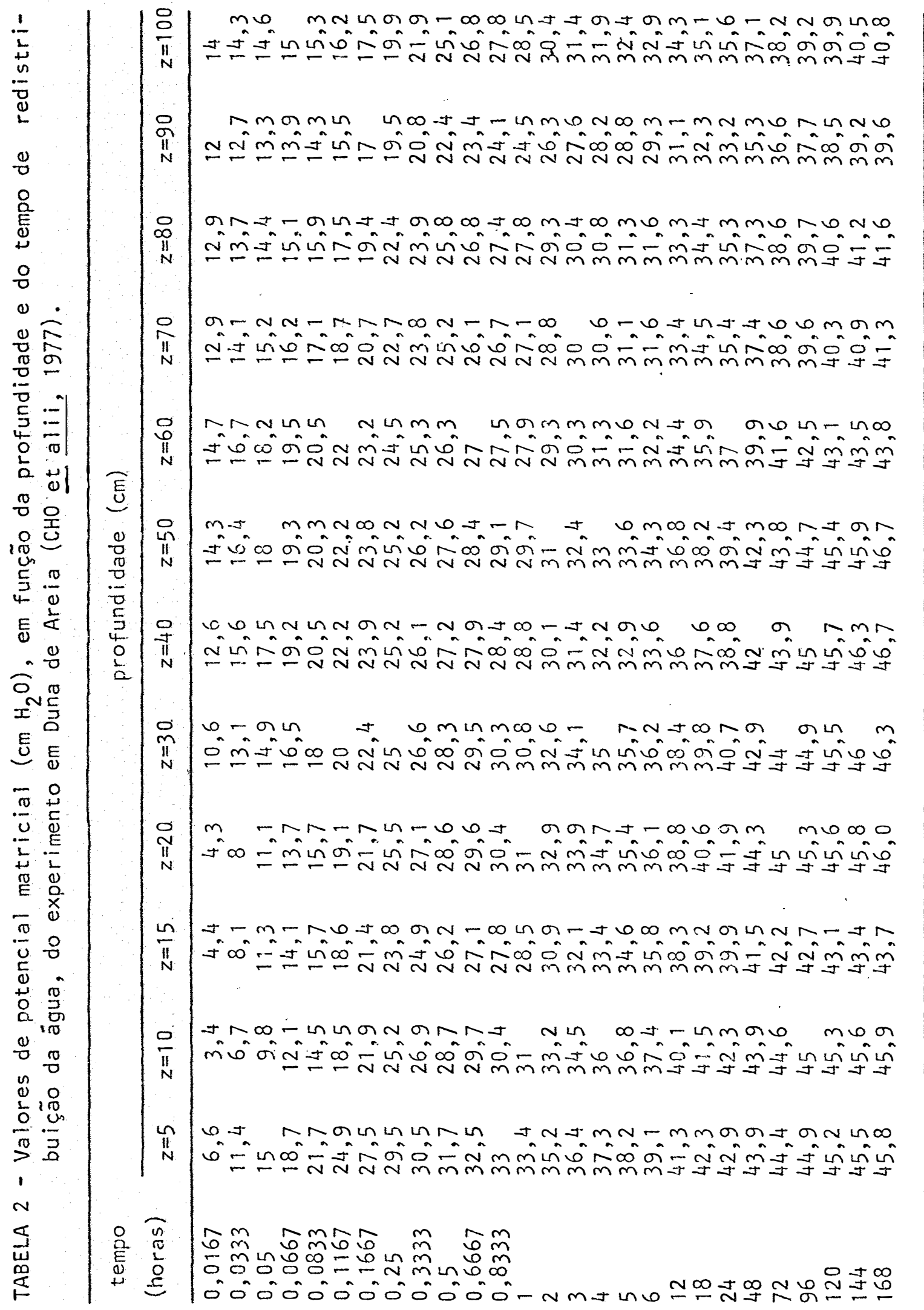


$-254-$

$$
A P E N D / C E \quad C
$$




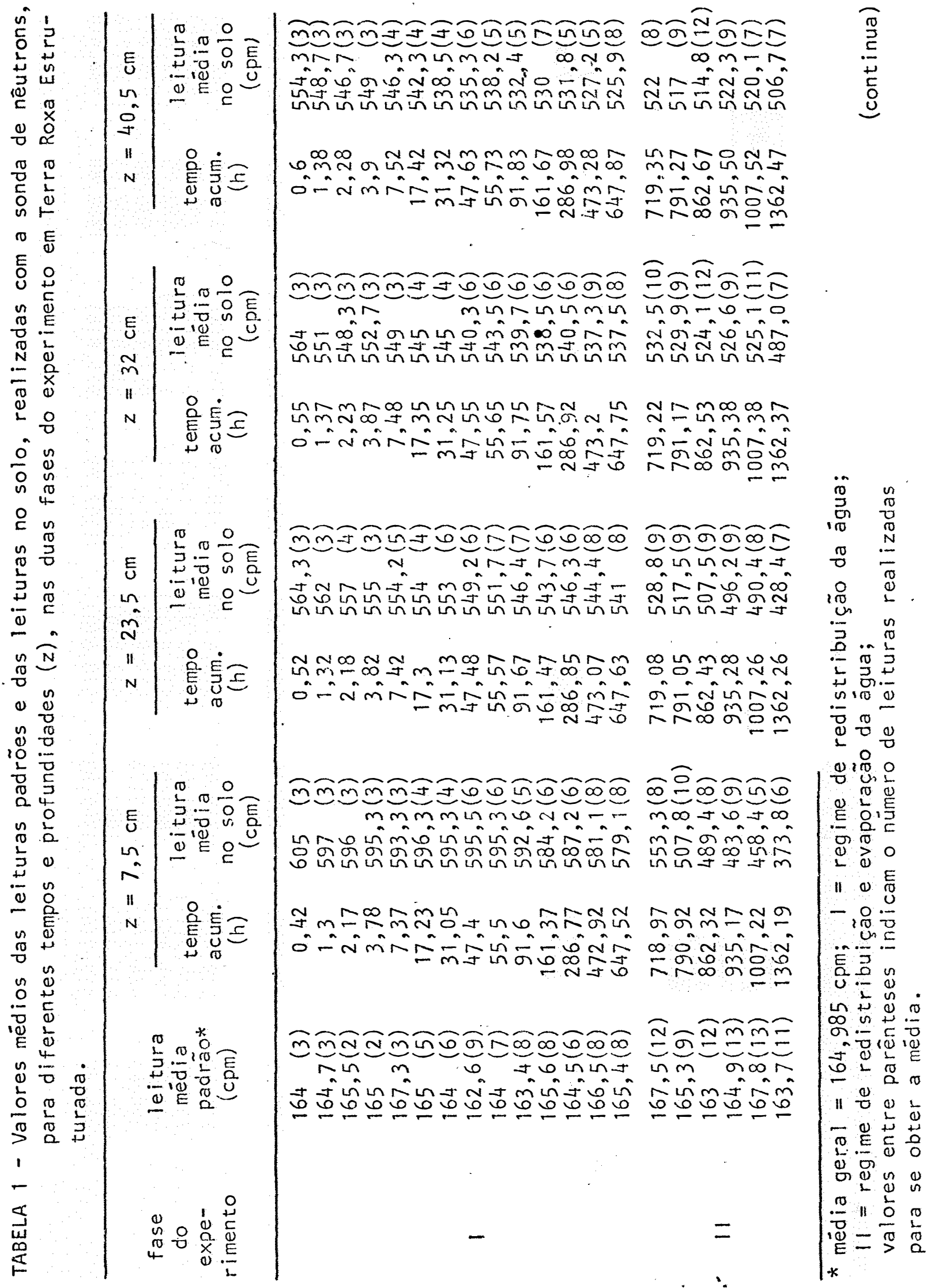




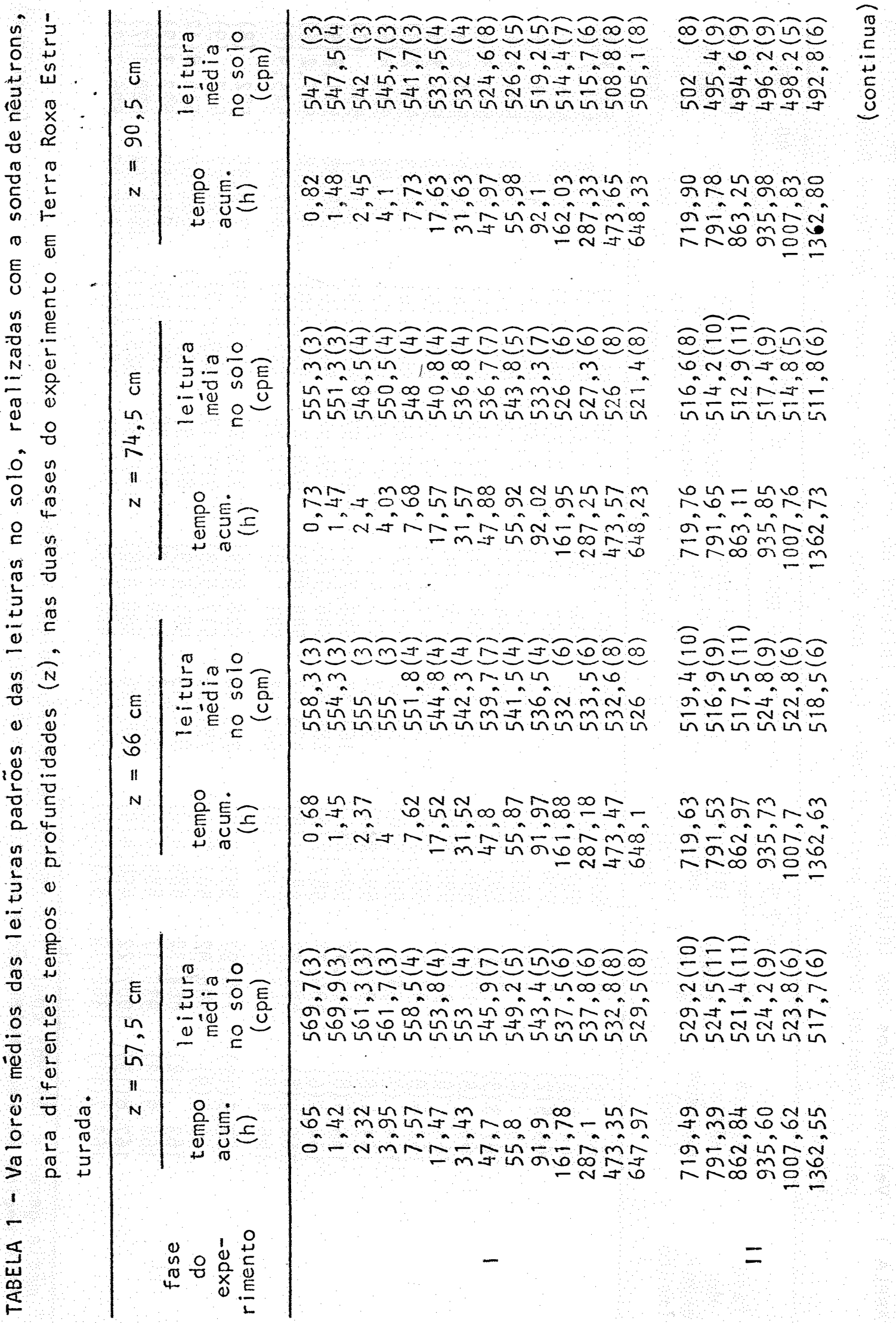




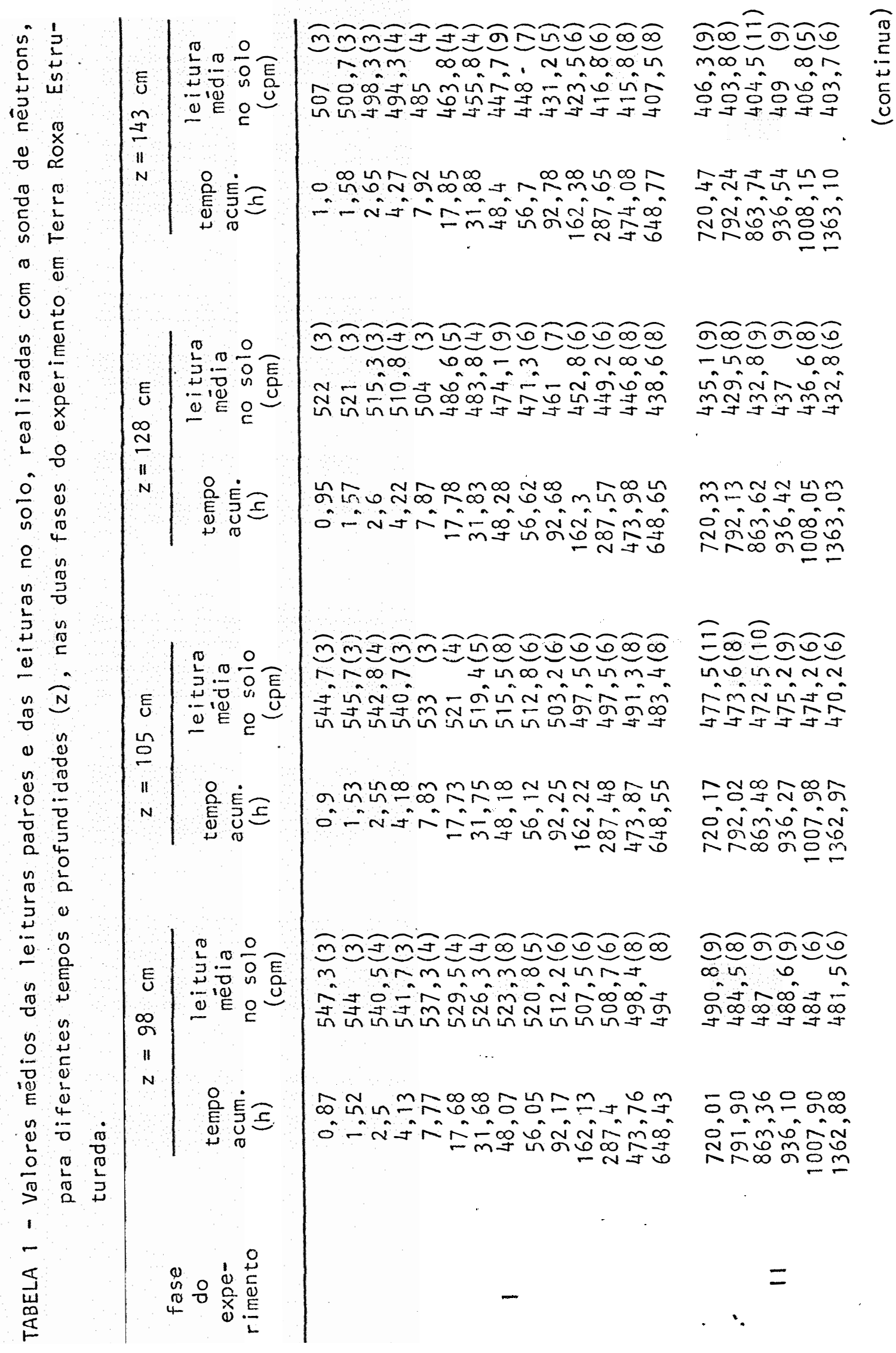




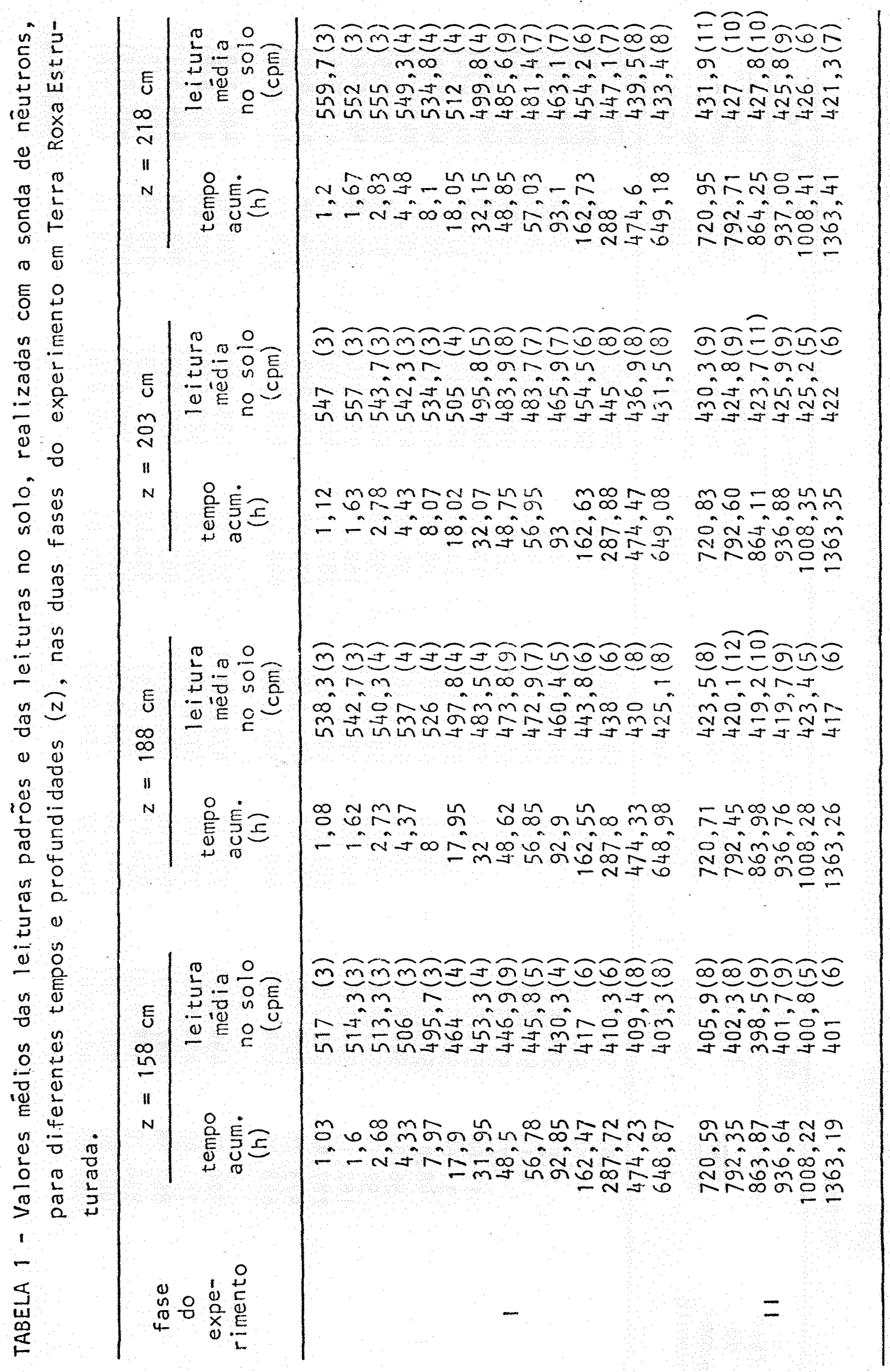




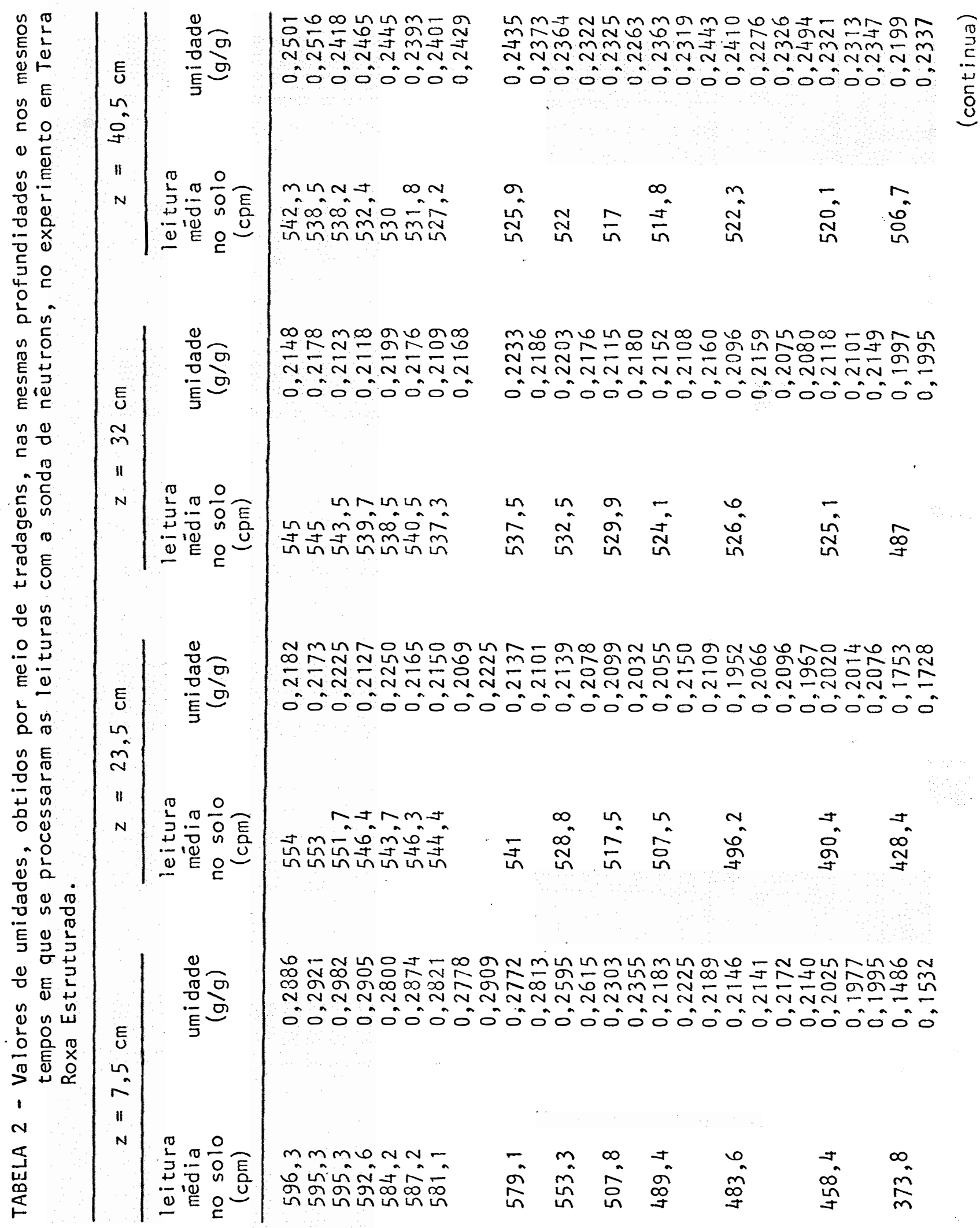




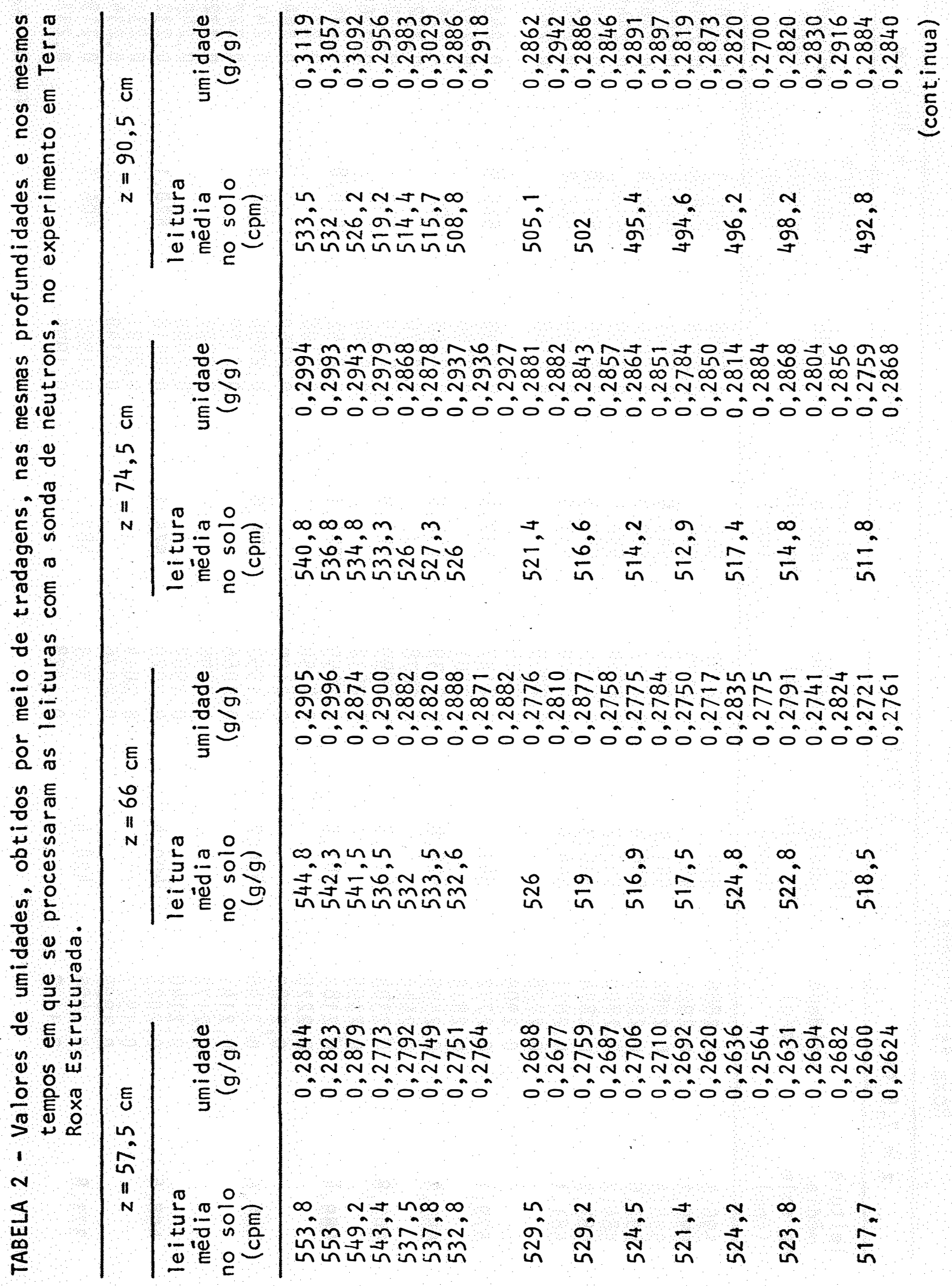




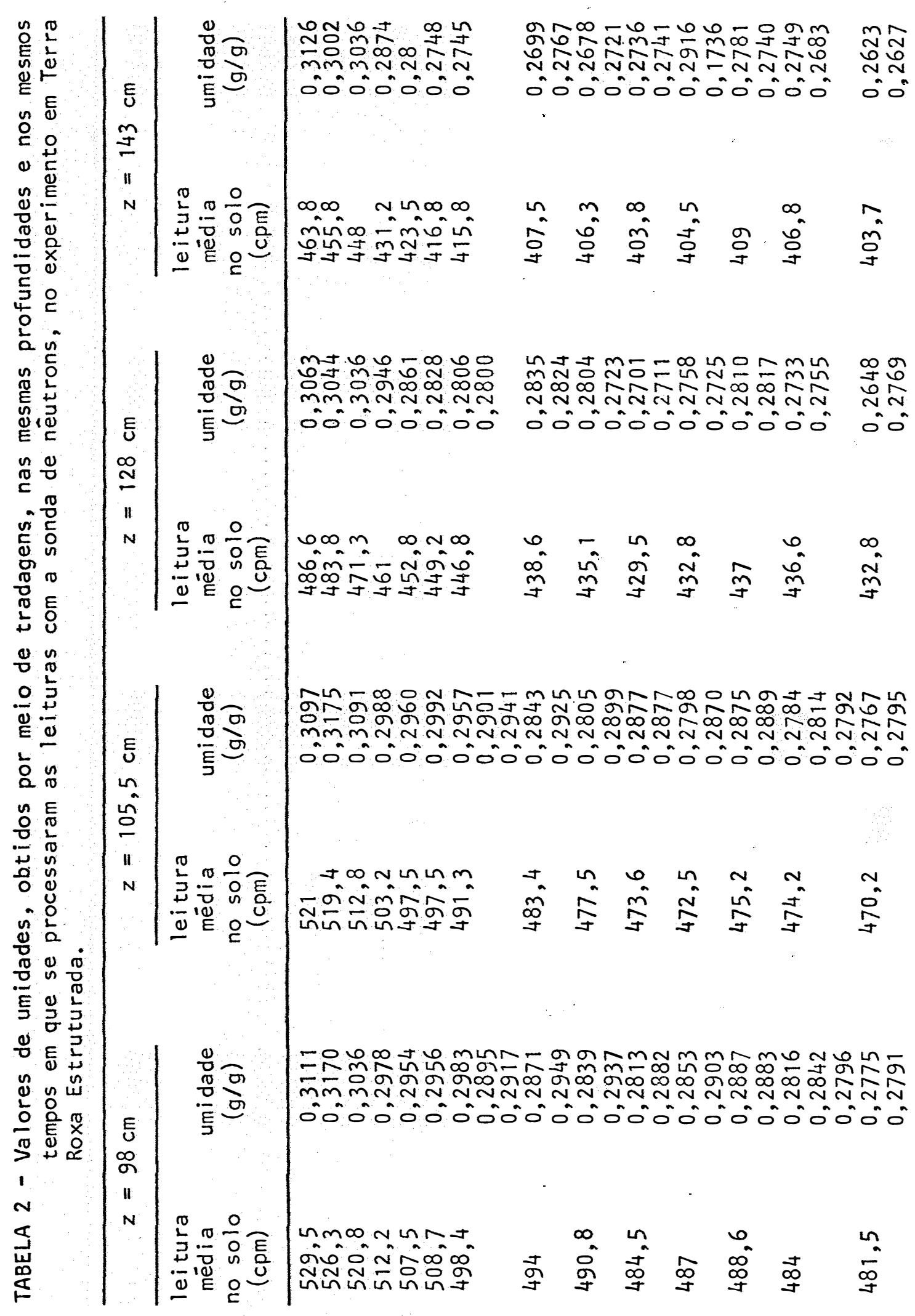




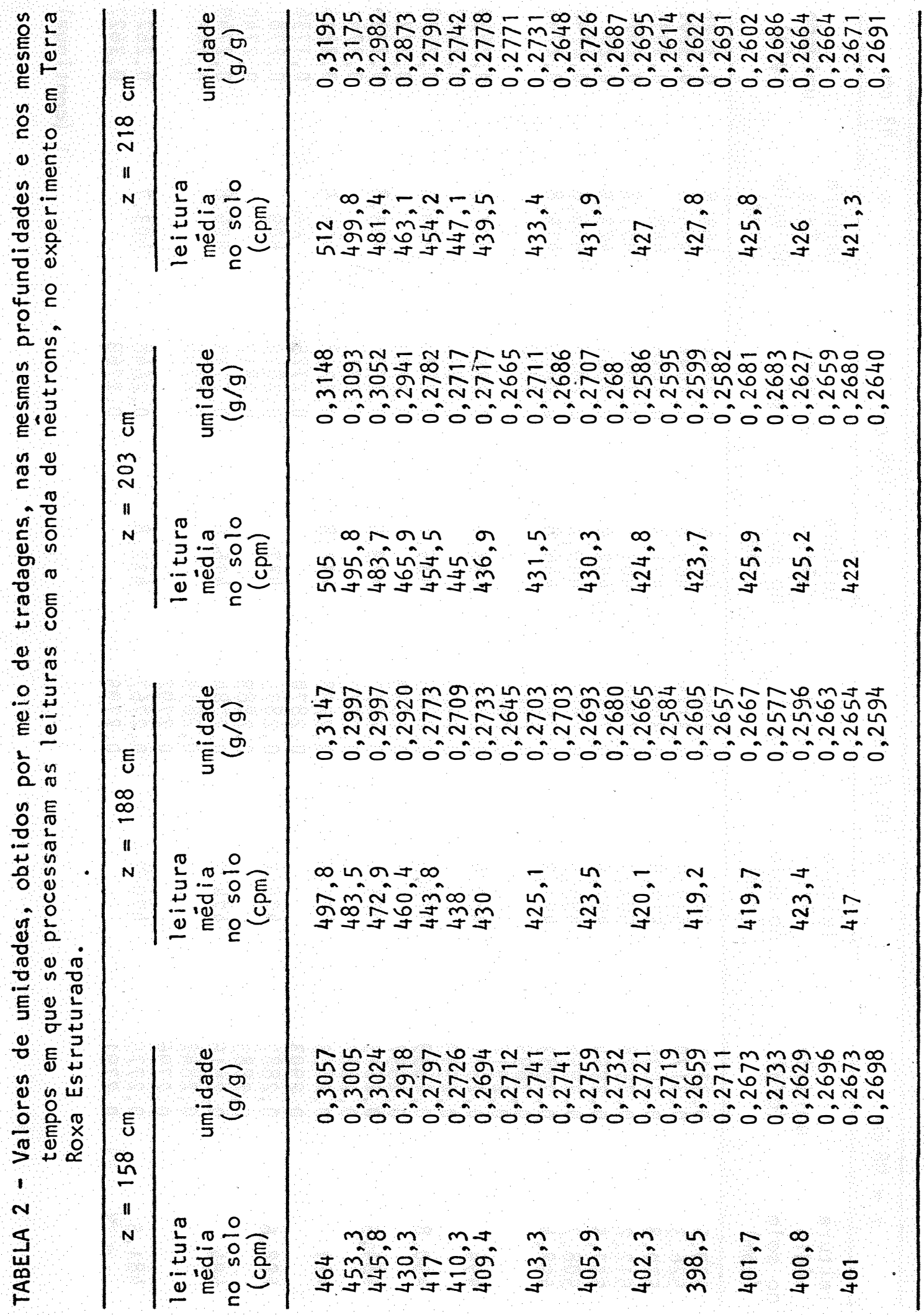




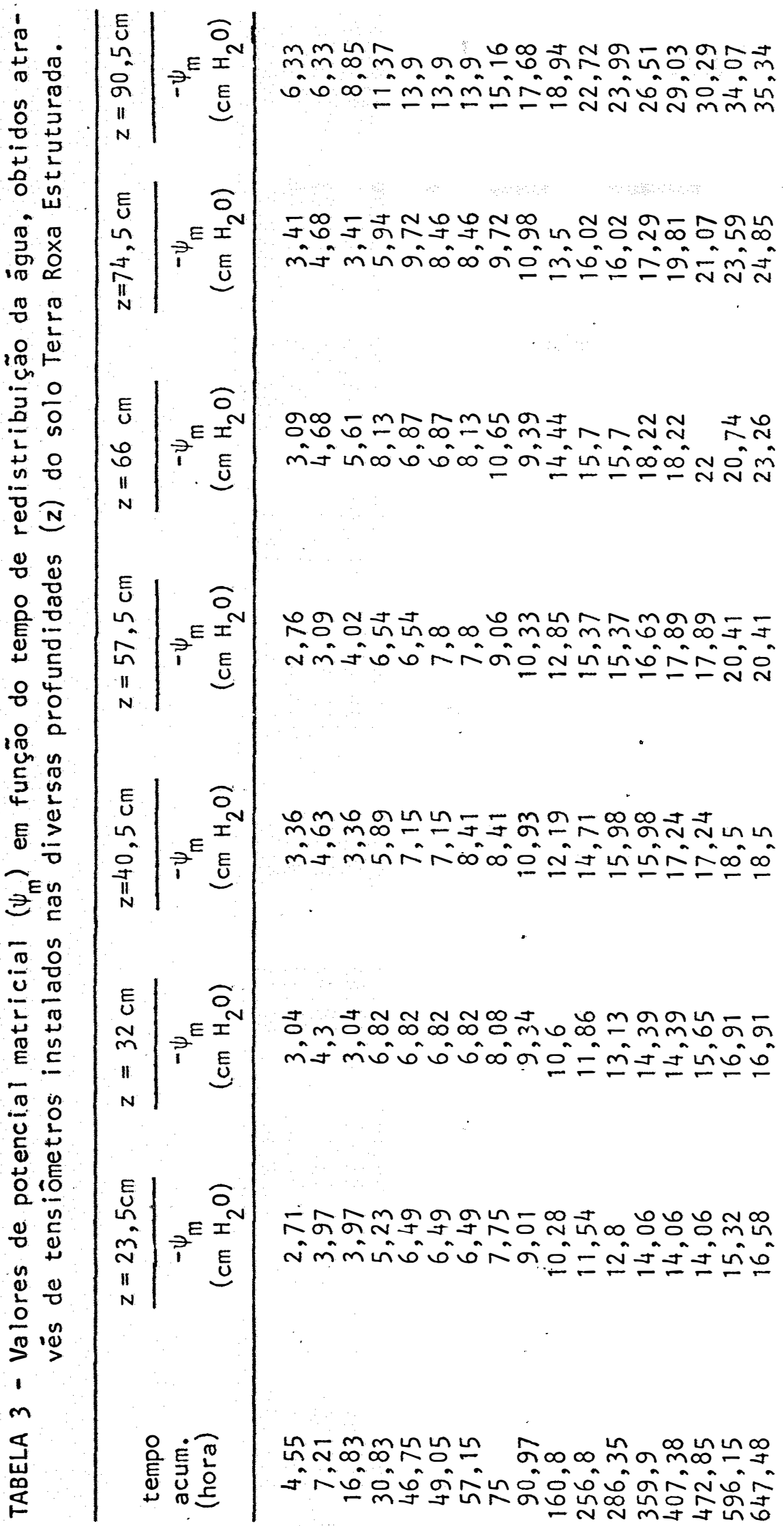




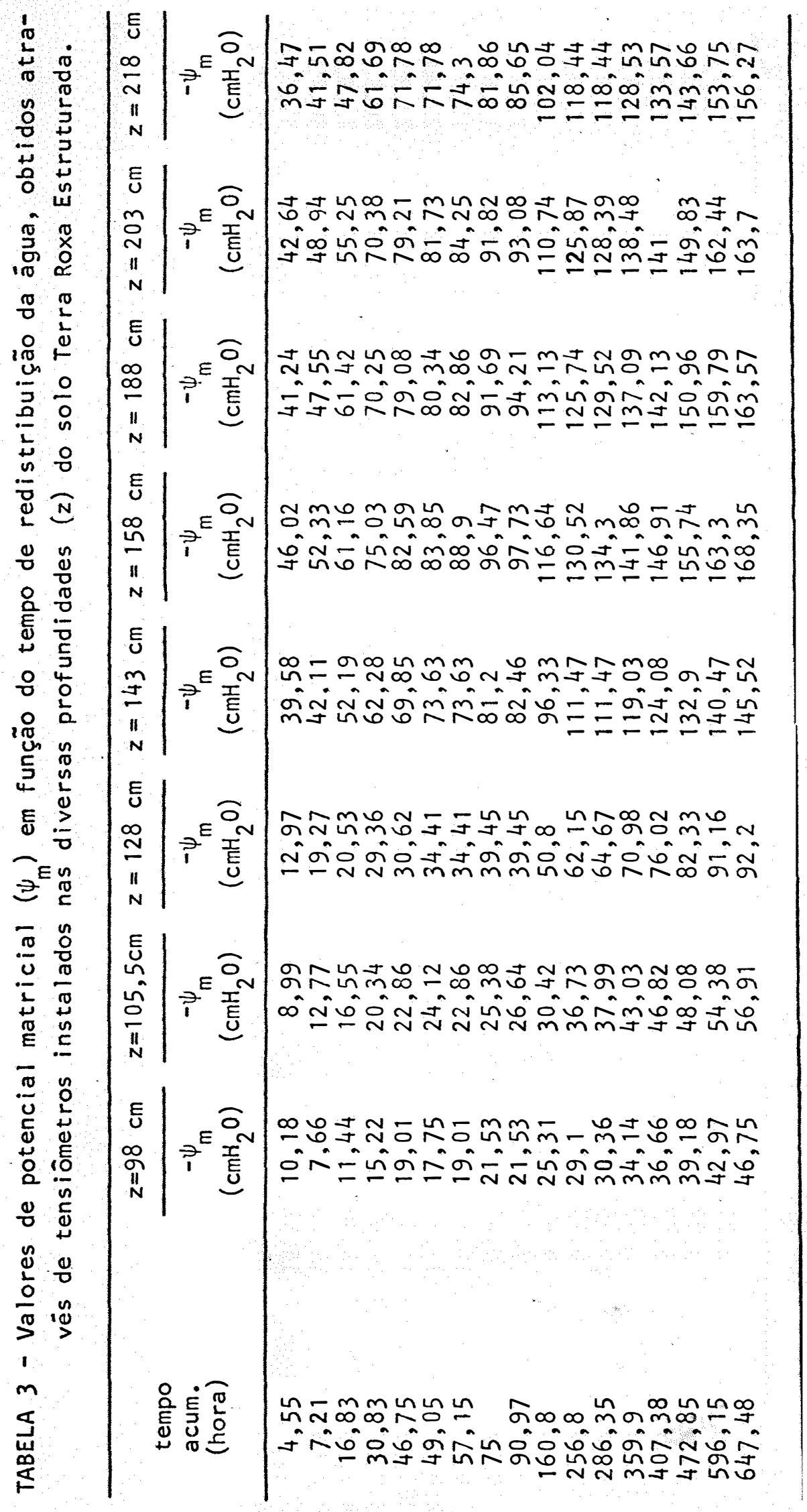

